\title{
Funktionelle Rekonstitution von Connexonen in artifizielle Membranen: Expression, Reinigung und Charakterisierung von Connexin 43
}

\author{
Dissertation \\ zur Erlangung des \\ mathematisch-naturwissenschaftlichen Doktorgrades \\ „Doctor rerum naturalium“ \\ der Georg-August-Universität Göttingen
}

vorgelegt von

Christian Carnarius

aus Magdeburg

Göttingen 2012 
Referentin: Prof. Dr. Claudia Steinem

Korreferent: Prof. Dr. Christian Griesinger

Tag der mündlichen Prüfung: $\quad$ 11.06.2012 
Meiner Frau Anika

"Imagination will often carry us to worlds that never were. But without it, we go nowhere." Carl Sagan, Cosmos (1980) ${ }^{[1]}$ 

ABSTRACT. Connexin 43 (Cx43) is the most prominent member of the connexin family in mammalian tissues. In biological lipid membranes, six connexin subunits assemble into a hemichannel (connexon). Direct communication of apposing cells is realized by two adjacent hemichannels, forming gap junction channels. Membrane channel proteins are pivotal for communication between cells. Dysfunctional ion channels are associated to diseases like osteoporosis, epilepsy, ataxia, myotonia and cardiac arrhythmia. Therefore, there is an interest in studying these channel proteins to elucidate their functional properties and determine how to manipulate their functionality. This is commonly carried out by ion channel recordings, which require invasive contacting by voltage clamp methods in cells. The alternative approach taken here was to utilize connexon-doped artificial membranes for electrical coupling of connexon-expressing cells via gap junction channels.

In this work, an expression system in Pichia pastoris to recombinantly produce and purify Cx43 as well as Cx43 fused to green fluorescent protein (Cx43-GFP) has been established. Furthermore, the expression of Cx43 and Cx43-eGFP in Dictyostelium discoideum was verified. Cx43 and Cx43-GFP hemichannels purified from $P$. pastoris were reconstituted in giant unilamellar vesicles, which was confirmed using confocal fluorescence microscopy. Their electrophysiological behavior was analyzed on the single channel level by planar patch clamping. Cx43 and Cx43-GFP both showed an ohmic behavior and a voltage-dependent open probability. Cx43 hemichannels exhibited one major mean conductance of $(224 \pm 26) \mathrm{pS}$. Additionally, a subconductance state at $(124 \pm 5) \mathrm{pS}$ was identified. In contrast, the analysis of Cx43-GFP single channels revealed 10 distinct conductance states in the range of 15 to $250 \mathrm{pS}$, with a larger open probability at low voltages compared with Cx43. These differences strongly suggest that intermolecular interactions between the GFP molecules alter the electrophysiology of the protein. Furthermore, a transfer assay based on porespanning membranes was developed to verify protein activtity. Proper function of this fluorescence-based assay was validated using the lytic peptide melittin. Finally, the formation of Cx43 gap junction channels was investigated in vitro by coupling connexon-doped GUVs to connexon-doped pore-spanning membranes. 



\section{INHALTSVERZEICHNIS}

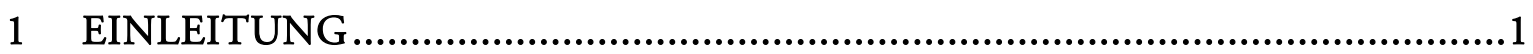

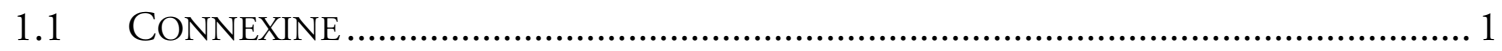

1.1.1 Connexin Halbkanal............................................................................. 1

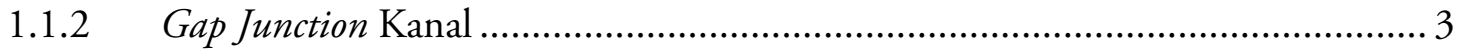

1.1.3 Laterale Organisation in Lipiddoppelschichten ........................................... 8

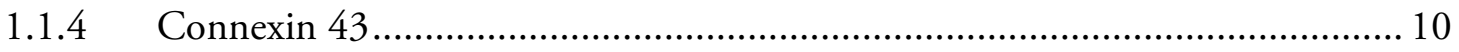

1.1.5 Regulation von Connexin Halbkanälen und Gap Junction Kanälen.................. 12

1.2 ARTIFIZIELLE MEMBRANSYSTEME ZUR UNTERSUCHUNG VON MEMBRAN-

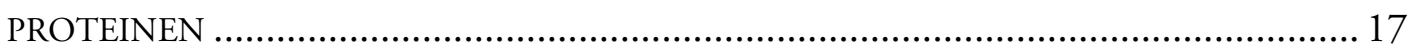

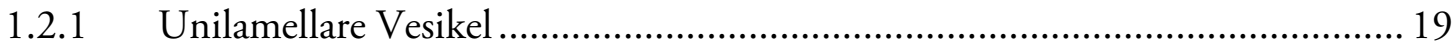

1.2.2 Porenüberspannende Membranen .............................................................. 20

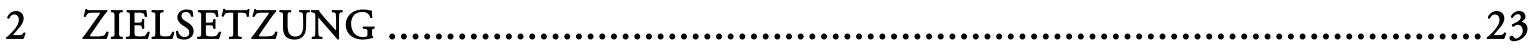

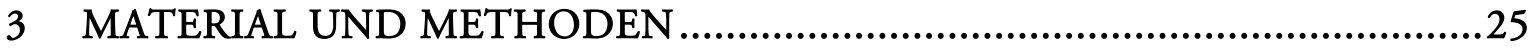

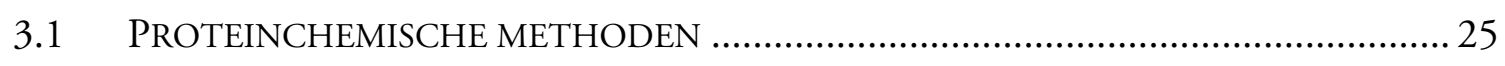

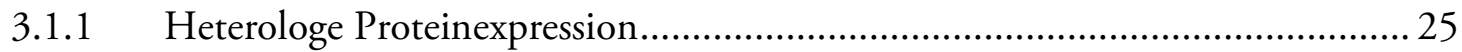

3.1.2 Zellaufschluss von Pichia pastoris ................................................................ 37

3.1.3 Immobilisierte Metallchelataffinitätschromatografie....................................... 38

3.1.4 Diskontinuierliche SDS-Polyacrylamid-Gelelektrophorese............................. 42

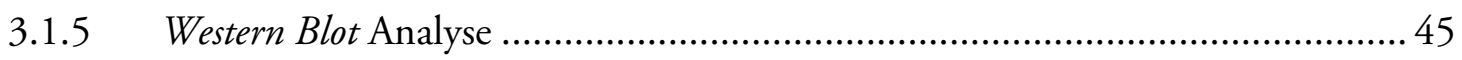

3.1.6 Bestimmung der Proteinkonzentration ...................................................... 48

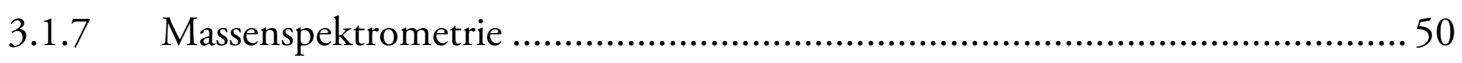

3.2 EINZELKANALMESSUNGEN MITTELS PLANAR PATCH CLAMP ............................... 54

3.2.1 Messaufbau des Planar Patch Clamp Systems ............................................... 54

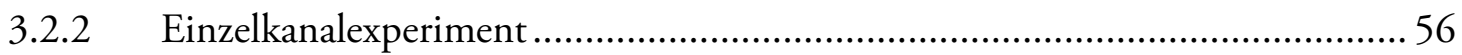

3.2.3 Auswertung von Einzelkanaldaten .......................................................... 57

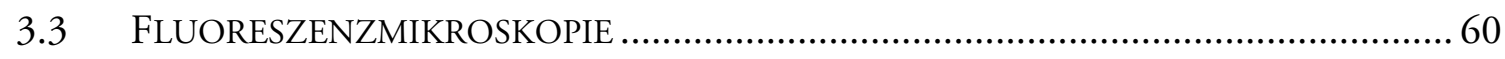

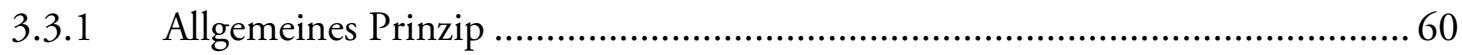

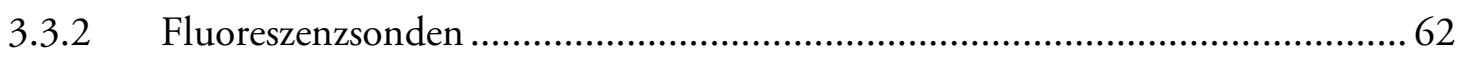

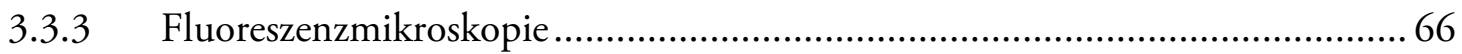

3.3.4 Fluorescence Recovery After Photobleaching...................................................... 68 


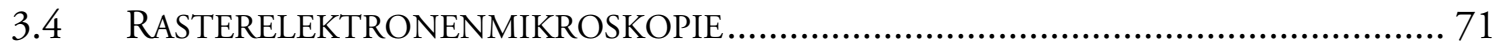

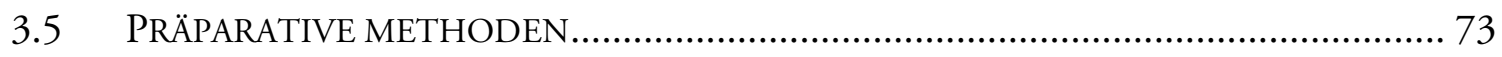

3.5.1 Präparation poröser Aluminiumoxidsubstrate …........................................... 73

3.5.2 Orthogonale Funktionalisierung der porösen Aluminiumoxidsubstrate .......... 78

3.5.3 Elektroformation von Riesenvesikeln....................................................... 81

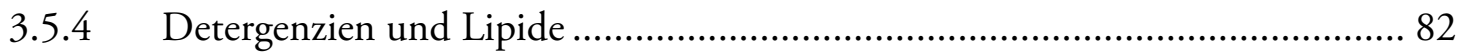

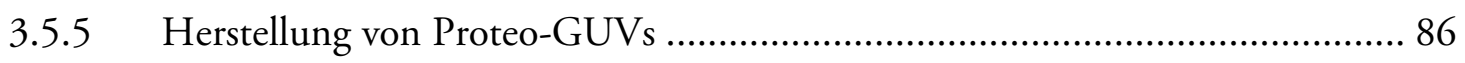

3.5.6 Präparation porenüberspannender Membranen auf orthogonal-funktionalisierten Aluminiumoxidsubstraten ........................................................ 88

3.5.7 Präparation festkörperunterstützter Membranen............................................ 90

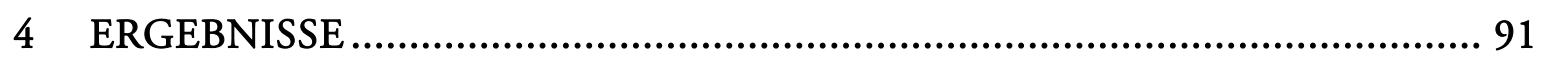

4.1 HETEROLOGE PROTEINEXPRESSION VERSCHIEDENER CONNEXIN 43-VARIANTEN 92

4.1.1 Expression und Reinigung von Cx43 und Cx43-eGFP in Dictyostelium

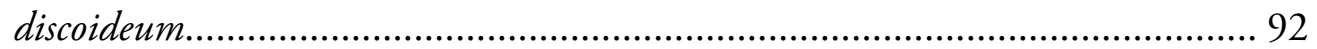

4.1.2 Expression und Reinigung von Cx43 und Cx43-GFP in Pichia pastoris........ 104

4.2 REKONSTITUTION VON CX43 UND CX43-GFP IN ARTIFIZIELLEN MEMBRANEN .... 123

4.2.1 Rekonstitution durch spontane Integration .............................................. 123

4.2.2 Bildung von proteinhaltigen Riesenvesikeln nach partieller Dehydratisierung124

4.2.3 Fusionsvermittelte Rekonstitution ............................................................ 126

4.3 ELEKTROPHYSIOLOGISCHE CHARAKTERISIERUNG VON CX43 UND CX43-GFP....... 133

4.3.1 Bestimmung der Leitfähigkeit................................................................. 136

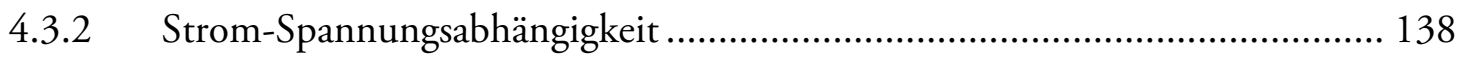

4.3.3 Bestimmung der mittleren Öffnungsdauer.............................................. 140

4.3.4 Bestimmung der Öffnungswahrscheinlichkeit............................................ 141

4.3.5 Modulation der Kanalaktivität mit Taurin................................................. 144

4.3.6 Kanalblockierung mit Lanthanchlorid ..................................................... 145

4.4 PORENÜBERSPANNENDE MEMBRANEN AUF PORÖSEM ALUMINIUMOXID ............. 146

4.4.1 Präparation von porösem Aluminiumoxid ................................................. 147

4.4.2 Orthogonale Funktionalisierung von porösem Aluminiumoxid .................... 150

4.4.3 Präparation von porenüberspannenden Membranen auf porösem Aluminium-

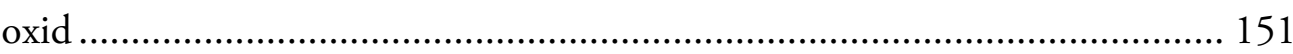


4.4.4 Verifizierung von porenüberspannenden Membranen durch die Kopplung von

Melittin-Penetration und Farbstofffreisetzung ....

4.5 NACHWEIS DER GAP JUNCTION KANALAKTIVITÄT MITTELS FLUORESZENZ-

BASIERTEN ASSAYS

4.5.1 Entwicklung eines fluoreszenzbasierten Assays zum Nachweis der Gap Junction

Kanalaktivität.

4.5.2 Untersuchung der Gap Junction Kanalaktivität durch einen Farbstofftransferassay basierend auf porenüberspannende Membranen.

5 DISKUSSION

5.1 GEWINNUNG VERSCHIEDENER CONNEXINE DURCH HETEROLOGE PROTEIN-

EXPRESSION

5.1.1 Expression von Cx43 und Cx43-eGFP in Dictyostelium discoideum............... 169

5.1.2 Expression und Reinigung von Cx43 und Cx43-GFP in Pichia pastoris ........ 173

5.2 FUNKTIONELLE REKONSTITUTION IN UNILAMELLAREN VESIKELN................... 179

5.2.1 Spontane Integration von Cx43 und Cx43-GFP zur elektrophysiologischen

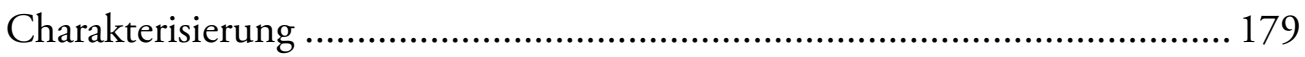

5.2.2 Einfluss des Detergens auf die Proteoliposomenbildung............................... 180

5.2.3 Proteo-GUV-Bildung nach partieller Dehydratisierung ............................... 181

5.2.4 Fusionsvermittelte Integration von Cx43 und Cx43-GFP........................... 181

5.2.5 Reproduzierbarkeit der Proteinintegration für die zweite Fermentationscharge...

5.3 EINFLUSS DER GFP-FUSION AUF DIE CX43 HALBKANALAKTIVITÄT ...................... 186

5.3.1 Leitfähigkeiten von Cx43 und Cx43-GFP ............................................. 187

5.3.2 Untersuchung der Strom-Spannungsabhängigkeit, der Öffnungswahrscheinlichkeit und der mittleren Öffnungsdauer................................................... 190

5.3.3 Chemische Regulation von Cx43 und Cx43-GFP Halbkanälen.................... 192

5.3.4 Ursachen für den Einfluss der GFP-Fusion auf die Cx43 Halbkanalaktivität 193

5.3.5 Modell für die Cx43-GFP Halbkanalaktivität ............................................. 197

5.4 PORENÜBERSPANNENDE MEMBRANEN ALS BASIS FÜR EINEN FARBSTOFFTRANSFERASSAY.

5.4.1 Präparation von artifiziellen Membranen auf porösen Aluminiumoxidsubstraten

5.4.2 Validierung der porenüberspannenden Membranen mit Melittin 202

5.4.3 Validierung der Gap Junction Kanalaktivität 
6 AUSBLICK

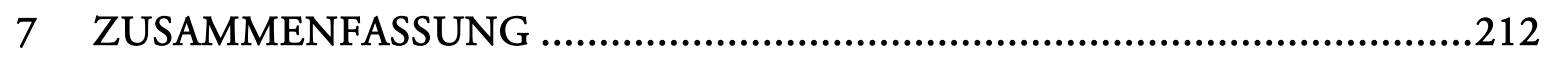

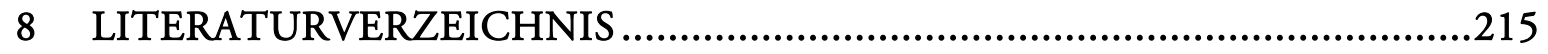

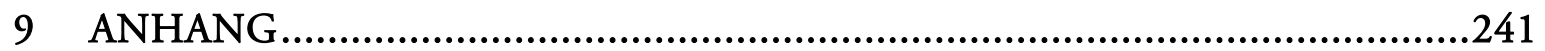

9.1 ABKÜRZUNGSVERZEICHNIS.................................................................... 241

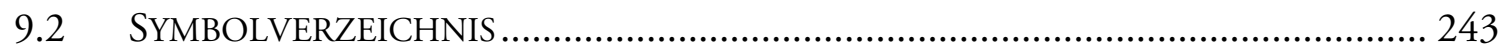

9.3 CHEMIKALIEN .................................................................................... 244

9.4 MATERIALIEN …………………………………………………………. 247

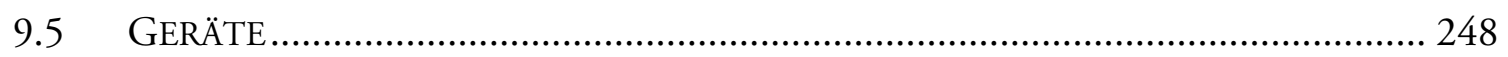

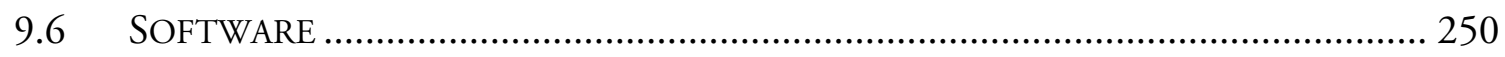

9.7 NUKLEOTIDSEQUENZEN ………………………………………............... 250

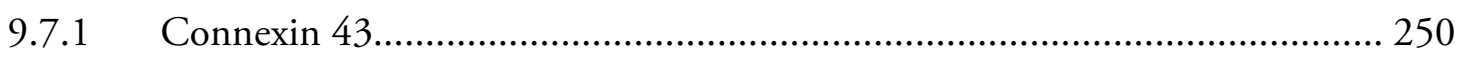

9.7.2 Connexin 43-Grün fluoreszierendes Protein ............................................... 252

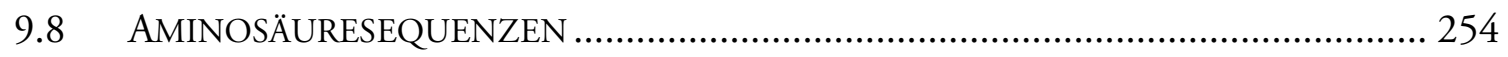

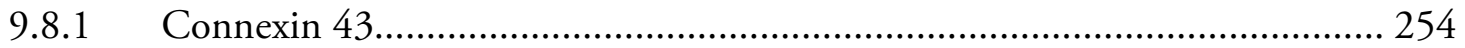

9.8.2 Connexin 43-Grün fluoreszierendes Protein ................................................. 255

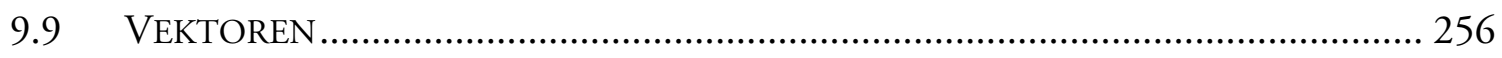




\section{Einleitung}

\subsection{Connexine}

In der Entwicklung vom ein- zum mehrzelligen Organismus sind Strukturen notwendig, welche eine direkte Kommunikation von benachbarten Zellen erlauben. Dies wird durch eine Familie intrazellulärer Kanäle (Gap Junction Kanäle) ermöglicht, welche von Connexinen und Innexinen gebildet werden und ubiquitär in Vertebraten und Invertebraten zu finden sind. ${ }^{[2,3]}$ Dadurch werden die Cytoplasmen zweier angrenzender Zellen verbunden und der Austausch von Ionen und niedermolekularen Verbindungen mit einem Molekulargewicht von bis zu $1 \mathrm{kDa}$ ermöglicht. ${ }^{[4]}$ Im humanen Genom können bislang 21 verschiedene Gene unterschieden werden, welche verschiedene Connexin-Isoformen bilden. ${ }^{[5]}$ Trotz der relativ ähnlichen Struktur besitzen diese verschiedene physiologische Funktionen. Unter anderen spielen sie eine Rolle in der Entwicklung, Differenzierung, Zellsynchronisierung, bei der neuronalen Aktivität und der Immunantwort. ${ }^{[6]}$ Jedoch werden Connexinen ebenfalls Funktionen als Halbkanal in der Plasmamembran zugeordnet. ${ }^{[7-15]}$ Mutationen in Connexin-Genen können verschiedene Krankheiten, auch Connexinopathien genannt, auslösen wie die Charcot-MarieTooth-Krankheit, die angeborene Taubheit, verschiedene Hautkrankheiten, die Linsentrübung und die Okulodentodigitale Dysplasie (ODDD). ${ }^{[16]}$ Die folgenden Kapitel beschäftigen sich mit der allgemeinen Struktur der Connexine, deren Quartärstruktur sowie ihrer Funktion und Regulation.

\subsubsection{Connexin Halbkanal}

Für die Benennung der Connexine wird am häufigsten die Nomenklatur nach Beyer et al. verwendet. ${ }^{[17]}$ Für die Bezeichnung wird Connexin $\mathrm{zu} C \mathrm{Cx}$ abgekürzt und das korrespondierende Molekulargewicht der Isoform als Suffix in kDa angehangen, das heißt das Connexin mit einem Molekulargewicht von $43 \mathrm{kDa}$ wird als $\mathrm{Cx} 43$ bezeichnet. Connexine (Protomer) besitzen eine charakteristische Sekundärstruktur. Jedes Connexin-Protomer hat vier transmembrane, eher hydrophobe $\alpha$-Helices (TM1 bis TM4), welche durch zwei extra- 
zelluläre Schleifen (E1, E2) und eine intrazelluläre Schleife (CL) miteinander verbunden sind. Außerdem sind der $C$ - und $N$-Terminus (CT, NT) ins Cytoplasma der Zellen gerichtet (Abb. 1-1). Die verschiedenen Isoformen besitzen etwa $40 \%$ Sequenzhomologie, welche vor allem die transmembranständigen Bereiche und die extrazellulären Schleifen (E1, E2) umfasst. ${ }^{[18]}$ Dagegen variieren diese in der Länge und Aminosäurezusammensetzung der intrazellulären Schleifen, sowie des $N$ - und $C$-Terminus. Charakteristisch sind sechs Cysteine (C) in E1 und E2, welche einen konstanten Abstand von $\mathrm{CX}_{6} \mathrm{CX}_{3} \mathrm{C}$ und $\mathrm{CX}_{4} \mathrm{CX}_{5} \mathrm{C}$ besitzen ( $\mathrm{X}=$ variable Aminosäure). ${ }^{[18]}$ Nur $\mathrm{Cx} 31$ besitzt in $\mathrm{E} 2$ einen Abstand von $\mathrm{CX}_{5} \mathrm{CX}_{5} \mathrm{C}$, wodurch es nicht mit anderen Connexinisoformen intrazelluläre Kanäle bilden kann. ${ }^{[19]}$ Sechs der Connexin Untereinheiten bilden einen Connexin Halbkanal (Connexon), der die Plasmamembran durchspannt. Die hydrophile Pore des Halbkanals wird dabei überwiegend durch die erste transmembrane Helix jeder Untereinheit gebildet. Diese strukturellen Elemente konnten von Maeda etal. 2009 durch Aufklärung der Quartärstruktur eines Cx26 Gap Junction Kanals mithilfe der Einkristallröntgenstrukturanalyse bestätigt werden (Kapitel 1.1.2). ${ }^{[20]}$ Ferner konnten für Cx43 ebenfalls die $\alpha$-helikalen Strukturelemente von Unger et al. durch Cryoelektronenmikroskopie visualisiert werden. ${ }^{[21]}$

Die erhöhte, extrazelluläre Calciumionenkonzentration im Vergleich zum Cytosol der Zelle ist dafür verantwortlich, dass die Connexin Halbkanäle normalerweise im geschlossenen Zustand vorliegen. Jedoch spielen für eine Reihe von Prozessen in verschiedenen Geweben auch Connexin Halbkanäle eine Rolle. ${ }^{[8,9,15,14,22]}$ Ein verändertes Membranpotential kann die Öffnung und das Schließen eines Connexin Halbkanals beeinflussen. Dies ermöglicht den Transport von Molekülen bis etwa $1 \mathrm{kDa}$. Durch die Beteiligung an verschiedenen Entwicklungsprozessen und der Signaltransduktion sind dies vor allem sekundäre Botenstoffe wie Nukleotide, Calciumionen und Inositoltrisphosphat. ${ }^{[16]}$ Auf diese Aspekte wird in Kapitel 1.1.5 näher eingegangen. 

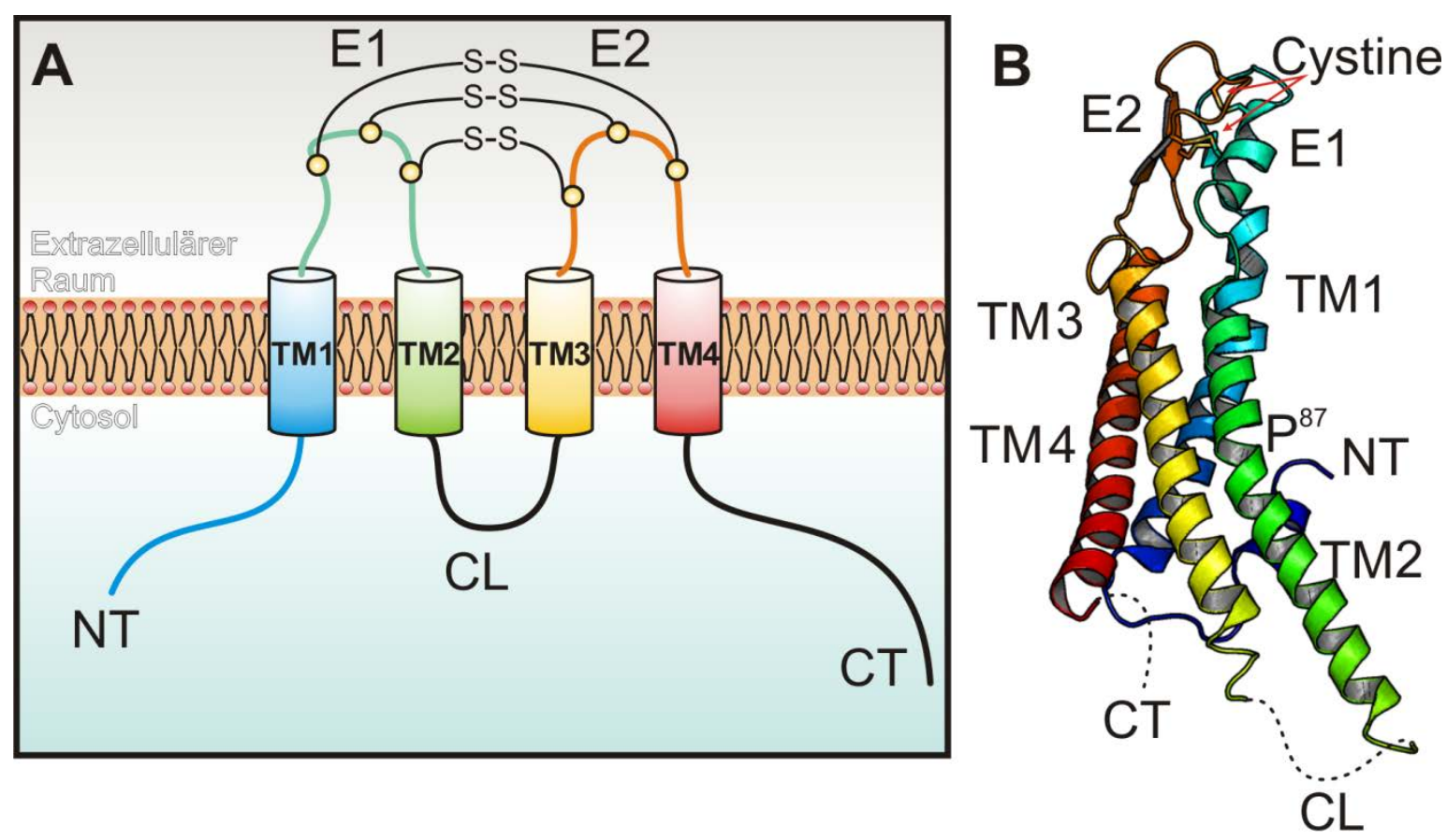

Abb. 1-1: Schematische Darstellung der Sekundärstruktur eines Connexin-Protomers $(A)$ und des korrespondierenden Bändermodells eines Cx26-Protomers $(\boldsymbol{B})$ mit den vier transmembranständigen, antiparallel verlaufenden Helices TM1 bis TM4. Diese sind über die zwei extrazellulären Schleifen (E1, E2) und die cytoplasmatische Schleife (CL) miteinander verbunden. Der $N$ - und $C$-Terminus (NT, CT) sind dem Zellinneren zugewandt (pdb-Code: 2zw3). ${ }^{[23]}$

\subsubsection{Gap J unction Kanal}

Gap Junction Kanäle werden durch die Wechselwirkung der insgesamt 24 extrazellulären Schleifen (E1, E2) von zwei Connexin Halbkanälen gebildet. ${ }^{[5]}$ Für die Kopplung von zwei Connexonen ist eine Rotation um $30^{\circ}$ gegeneinander notwendig. ${ }^{[24]}$ Die Permeabilität sowie die Öffnungscharakteristiken von Gap Junction Kanälen sind abhängig von der Connexinisoform und von posttranslationalen Modifikationen, die vor allem im Bereich der cytoplasmatischen Schleife und des $C$-Terminus zu finden sind. Jedoch hat es den Anschein, dass diese intrazellulären Kanäle relativ unselektiv in der Permeabilität für niedermolekulare Verbindungen oder Ionen sind. Connexin Halbkanäle können durch eine Isoform gebildet werden (homomeres Connexon, Abb. 1-2 I \& II) oder durch verschiedene Connexine (heteromeres Connexon, Abb. 1-2 III \& IV). Demzufolge können auch Gap Junction Kanäle durch zwei identische Connexin Halbkanäle (homotypischer Gap Junction Kanal, Abb. 1-2 I \& IV) oder durch zwei Connexone mit unterschiedlicher, homomerer oder heteromerer Zusammensetzung (heterotypischer Gap Junction Kanal, Abb. 1-2 II \& III) gebildet werden. Dies ermöglicht eine unterschiedliche Permeabilität und Selektivität des gebildeten intrazellulären 
Kanals, da jede Connexinisoform aufgrund seiner Aminosäurezusammensetzung unterschiedliche Eigenschaften besitzt. Weiter können diese durch posttranslationale Modifikation noch weiter verändert werden. ${ }^{[25]}$

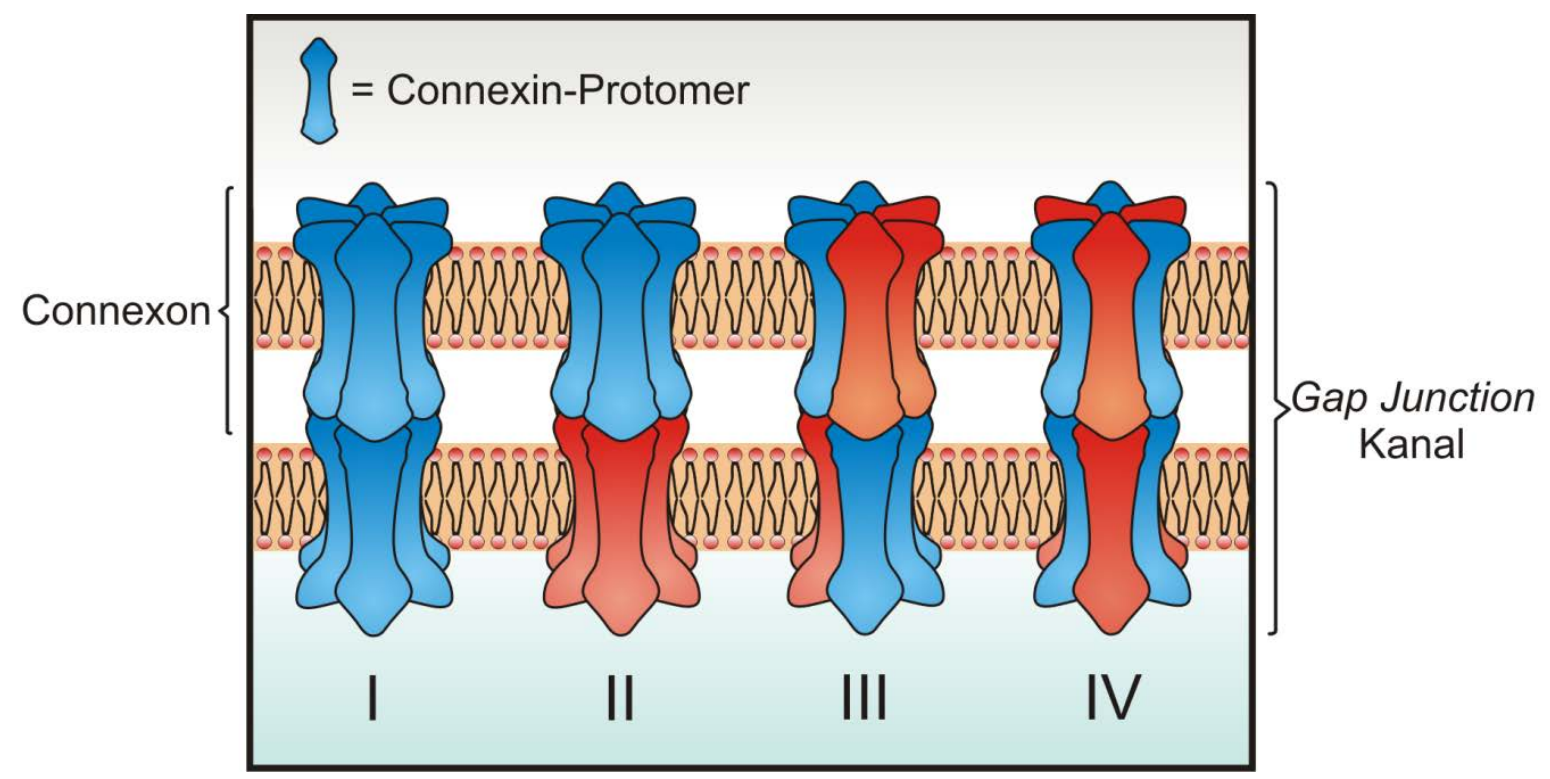

Abb. 1-2: Oligomerisierung zum Connexon und Gap Junction Kanal. I: Homotypischer Gap Junction Kanal bestehend aus zwei homomeren Connexonen. II: Heterotypischer Gap Junction Kanal zusammengesetzt aus zwei homomeren Connexonen. III: Heterotypischer Gap Junction Kanal assembliert aus zwei heteromeren Connexonen. IV: Homotypischer Gap Junction Kanal oligomerisiert aus heteromeren Connexonen.

Seit den 1980er Jahren wurde versucht die molekulare Struktur der Gap Junction Kanäle aufzuklären. Im Folgenden wird auf die Untersuchung der Struktur des Cx26 und Cx43 Gap Junction Kanals eingegangen, wodurch die allgemeine Funktion des Gap Junction Kanals besser verstanden werden kann.

\section{Cx26 Gap Junction Kanal}

Die Einkristallröntgenstrukturanalyse ermöglichte im Jahr 2009 die Aufklärung der Cx26 Gap Junction Kanalstruktur. ${ }^{[20]}$ Dadurch ist es ermöglicht worden, das elektrophysiologische Verhalten und die Regulation des Kanals in Beziehung zu dessen Struktur zu setzen. Jedoch konnten die cytoplasmatische Schleife und der $C$-Terminus nicht aufgelöst werden, was für eine hohe Flexibilität dieser Regionen spricht. Der intrazelluläre Kanal zeigt eine TsuzumiStruktur, die einer traditionellen japanischen Trommel ähnelt. Der Cx26 Halbkanal durchspannt mit einer Länge von 38 Å die Lipiddoppelschicht (Abb. 1-3 A). Dabei ragt der Halb- 
kanal um etwa $19 \AA$ aus der Lipidmembran. Die Länge dieses Bereiches varriiert zwischen den verschiedenen Connexinisoformen und nimmt mit steigendem Molekulargewicht aufgrund des $N$ - und $C$-Terminus zu. Durch die Interaktion der Connexin Halbkanäle zur Bildung eines intrazellulären Kanals wird ein Abstand von 40 Å überbrückt. Die TM1 bis TM4 bilden ein typisches Vier-Helix-Bündel im Connexin-Protomer, welches durch Dipol-DipolWechselwirkung der antiparallel verlaufenden Helices und Wasserstoff- sowie Salzbrücken stabilisiert wird (Abb. 1-1 B). Diese Kräfte stabilisieren ebenfalls die hexamere Form des Cx26 Halbkanals. Innerhalb der Connexinfamilie sind die Aminosäurereste, welche die Intra- und Interprotomerinteraktion vermitteln, konserviert. Die sechs konservierten Cysteine von E1 und E2 bilden intramolekulare Disulfidbrücken (Cystine) aus (Abb. 1-1 B). Durch die Wechselwirkung der gegenüberliegenden extrazellulären Schleifen zweier Connexone wird ein Gap Junction Kanal gebildet. Der Porendurchmesser reduziert sich ausgehend vom Cytosol zum extrazellulären Raum von $35 \AA$ auf $14 \AA$ und steigt wieder auf etwa $25 \AA$ an (Abb. 1-3 B). TM1 und TM2 flankieren mit elf positiv geladenen Aminosäuren das Poreninnere, wodurch die Pore eher für negativ geladene Moleküle passierbar ist. In diesem Zusammenhang wird deutlich, dass die Aminosäurezusammensetzung der verschiedenen Isoformen die Ladungsselektivität bzw. den Ausschluss von Molekülen mit einem bestimmten Molekulargewicht bestimmt. Außerdem zeigt die Analyse der Struktur, dass die Rolle des $N$-Terminus im Zusammenhang mit dem Öffnen und Schließen eines Kanals eine Rolle spielt, worauf in Kapitel 1.1.5 näher eingegangen wird. Allerdings weisen All-Atom Molecular Dynamics Simulationen der Cx26 Gap Junction Kanalstruktur, die auch den C-Terminus und die cytoplasmatische Schleife enthalten, nach, dass die Röntgenkristallstruktur von Maeda et al. wohlmöglich nicht den offenen Zustand darstellt. ${ }^{[25]}$ In der ursprünglichen Kristallstruktur konnte M1, K15, S17, S19, die cytoplasmatische Schleife und $\operatorname{der} C$-Terminus nicht aufgelöst werden. Die Simulation des vollständigen Gap Junction Kanals in einer POPC Lipidmembran verdeutlicht, dass M1 in der Kanalpore lokalisiert ist und sich der Porendurchmesser von $14 \AA$ auf $5 \AA$ verringert. In früheren Studien wurde nur ein geringer Einfluss des $C$-Terminus auf die Regulation von Cx26 aufgrund der Länge angenommen. Jedoch zeigen neuere Studien, dass der C-Terminus ähnlich wie für Cx43 und Cx40 nach einem Ball-and-Chain Modell für die chemische Regulation des Halbkanals sowie des Gap Junction Kanals verantwortlich ist (Kapitel 1.1.5). ${ }^{[26]}$ 
A

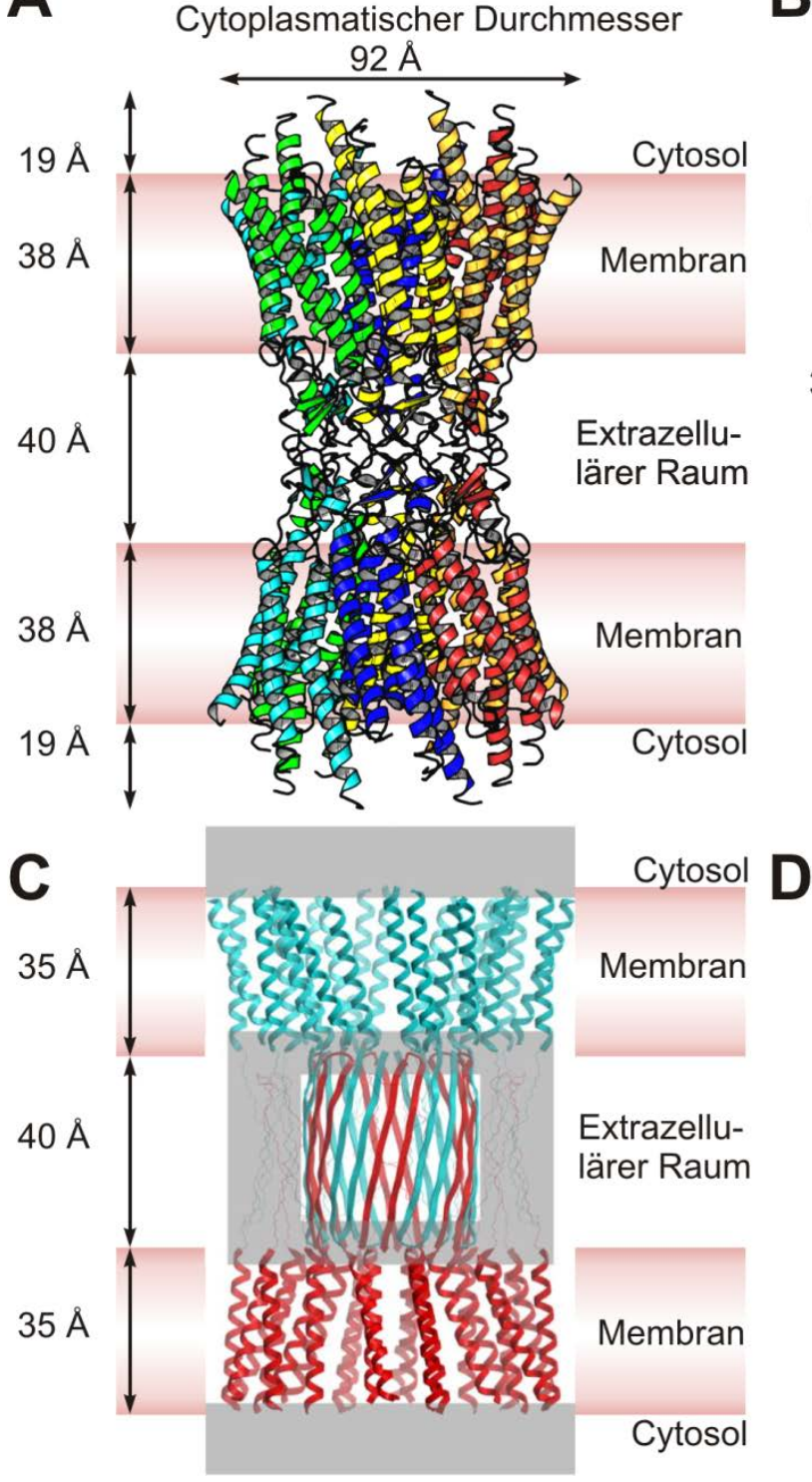

B

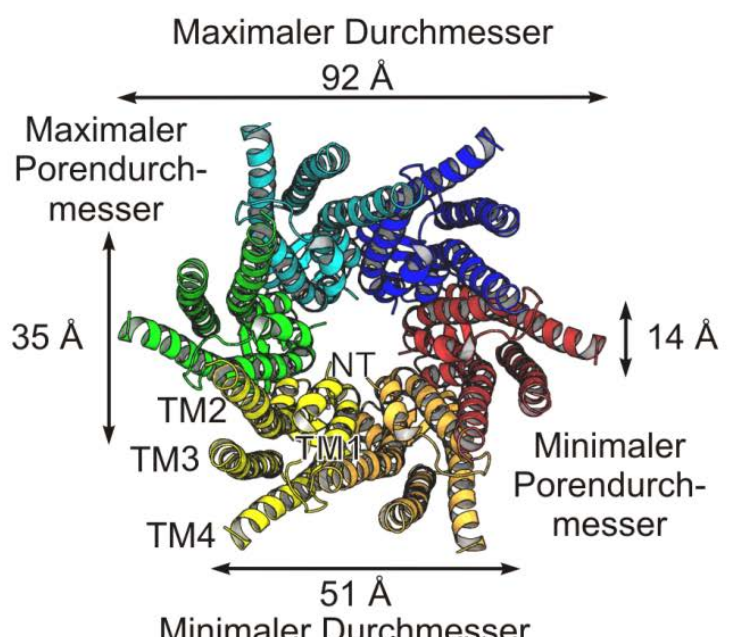

Minimaler Durchmesser

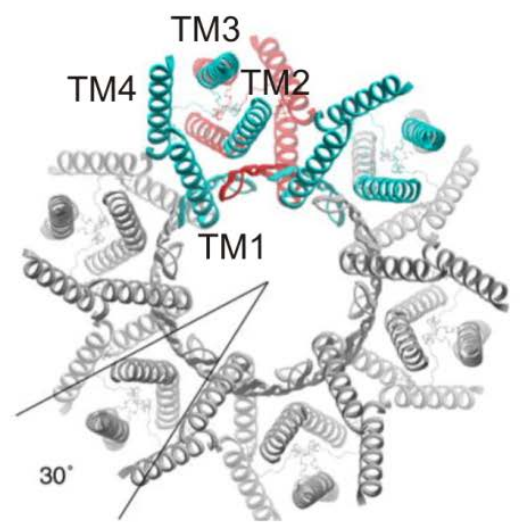

Abb. 1-3: Schematische Darstellung der molekularen Struktur des Cx26 und des Cx43 Gap Junction Kanals im Bändermodell. A, Seitenansicht des Cx26 Gap Junction Kanals basierend auf der Röntgenkristallstruktur von Maeda et al. (pdb-code: 2zw3). ${ }^{[20,23]}$ Die unterschiedlichen Kompartimente sind gekennzeichnet. Jedes Connexin-Protomer ist mit einer unterschiedlichen Farbe hervorgehoben. Die korrespondierenden Untereinheiten der gegenüberliegenden Connexone sind in der gleichen Farbe markiert. Dies verdeutlicht die Rotation des Connexons um $30^{\circ}$ gegeneinander, um einen Gap Junction Kanal zu bilden. B, Aufsicht des Cx26 Gap Junction Kanals von der extrazellulären Seite. Die Strukturelemente des Connexin-Protomers sind einzeln benannt. Außerdem sind die strukturellen Charakteristika hervorgehoben. C, Seitenansicht des Cx43 Gap Junction Kanals basierend auf der CryoEM Strukturanalyse von Unger $e$ al. und Fleishman $e t$ al. ${ }^{[21,27]}$ Die Transmembranregion zeigt $24 \alpha$-Helices, welche einen Connexin Halbkanal bilden. Die Untersuchungen der extrazellulären Schleifen führten zum Modell einer $\beta$-Fassstruktur, welche den extrazellulären Bereich durchspannt. $D$, Aufsicht des Cx43 Gap Junction Kanals von der extrazellulären Seite. Abbildung $C$ und $D$ verändert nach Yeager et al. ${ }^{[28]}$ 


\section{Cx43 Gap Junction Kanal}

Die CryoEM Untersuchung der Struktur des Cx43 Gap Junction Kanals mit einem verkürzten $C$-Terminus ergab zwei Strukturen mit einer Auflösung von 7,5 $\AA$ und 5,7 $\AA^{[21,29]}$ Die erhöhte röhrenförmige Elektronendichte wurde später den transmembranständigen $\alpha$-Helices zugeordnet, von denen 24 im Transmembranbereich eines Gap Junction Kanals zu finden sind. ${ }^{[27]}$ Die Pore hat wie beim Cx26 Gap Junction Kanal die Form eines Trichters, sie wird ausgehend vom Cytosol zum extrazellulären Raum kleiner (Abb. 1-3 D). Frühere Studien verdeutlichen, dass die Pore des Cx43 Halbkanals einen extrazellulären Eingangsdurchmesser von $-40 \AA$ hat, der sich auf $-15 \AA$ verengt und wieder auf $-25 \AA$ erweitert. ${ }^{[18]}$ Der Transmembranbereich umfasst eine Länge von etwa $35 \AA$ und der extrazelluläre Bereich umfasst wie bei einem Cx26 Gap Junction Kanal $40 \AA$ (Abb. 1-3 C). Innerhalb des Cx43 Halbkanals ist jede Untereinheit um $30^{\circ}$ zur nächstfolgenden verschoben (Abb. 1-3 D). Mit der weiteren Analyse der Struktur durch Fleishman et al. wurde basierend auf den Ergebnissen von Foote et al. vermutet, dass der extrazelluläre Bereich durch eine doppelte $\beta$-Fassstruktur ( $\beta$-Barrel) überbrückt wird (Abb. 1-3 C). Dieser wird durch die gegenüberliegenden E1 und E2 gebildet. Jedoch wurde durch die Lösung der Cx26 Gap Junction Kanalstruktur diese Vermutung widerlegt. Die Röntgenkristallstruktur des Cx26 Gap Junction Kanals ermöglichte die Aufklärung der Anordnung von TM1 bis TM4. Die Überlagerung der Strukturen von Fleishman et al., Oshima et al. (M34A Mutante von Cx26) und Maeda et al. verdeutlicht, dass die Lage und Struktur der transmembranen Helices der verschiedenen Strukturen zwischen den Connexinisoformen konserviert vorliegt (Abb. 1-4). ${ }^{[5,20,21,27,30]}$ Die Cx26 M34A Mutante hat keine physiologische Bedeutung, sie ermöglicht lediglich eine höhere Expressionsrate im Baculovirus/Insektenzellenexpressionssystem. 

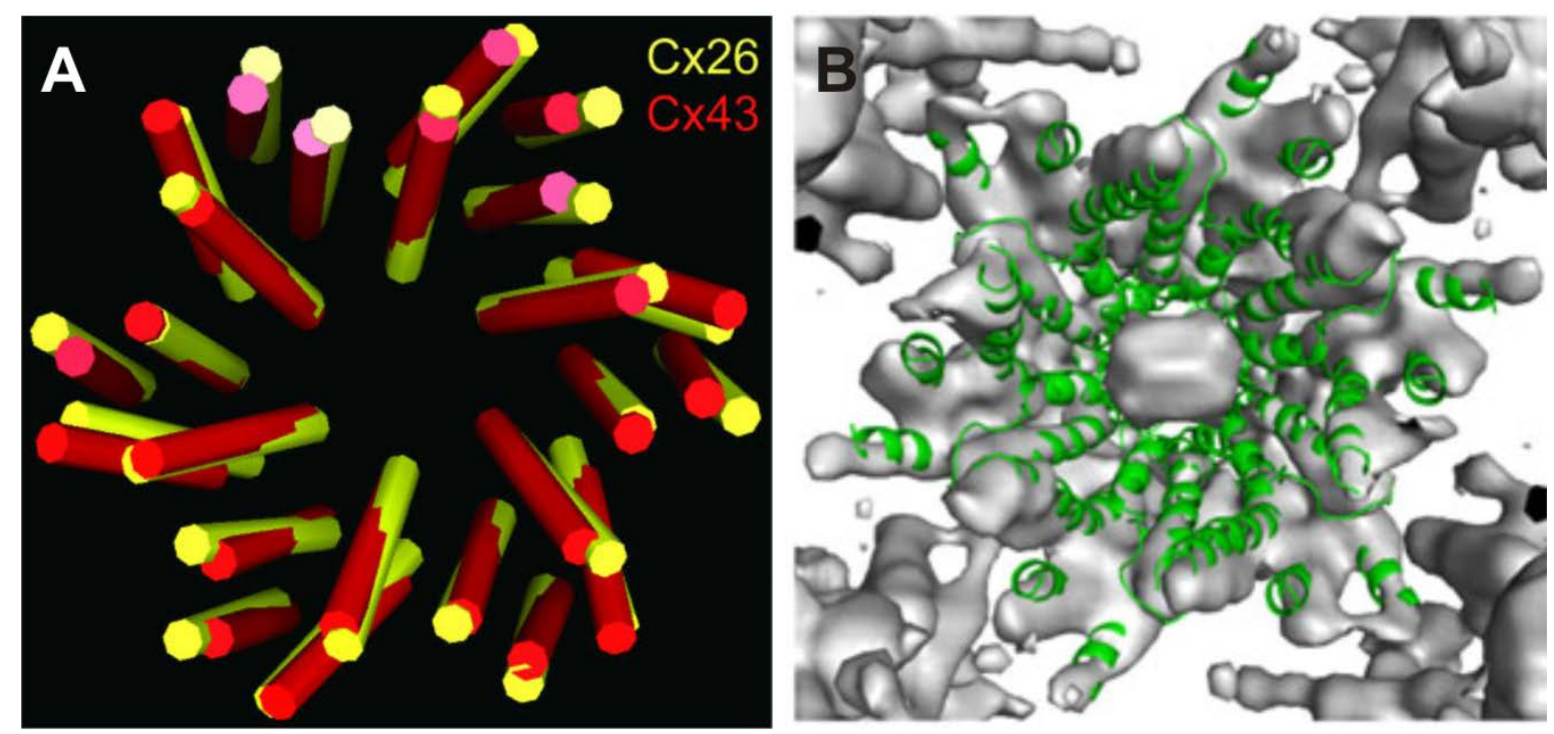

Abb. 1-4: Überlagerung der Struktur vom Wildtyp (WT)-Cx43 und WT-Cx26 sowie der Cx26 und der M34A Mutante. $A$, Überlagerung des $C$-terminal verkürzten WT-Cx43 Gap Junction Kanals mit der M34A Mutante des WT-Cx26 Gap Junction Kanals. B, Überlagerung des WT-Cx26 Gap Junction Kanals (Bändermodell: grün) mit der M34A Mutante (Oberflächendarstellung: grau). Die Anordnung der Helices ist etwas unterschiedlich, jedoch sind die Dimensionen des Kanals annähernd gleich. Die Abweichung kann möglicherweise auf die verschiedenen Kristallformen sowie die Strukturanalyse zurückgeführt werden. ${ }^{[5,27]}$

\subsubsection{Laterale Organisation in Lipiddoppelschichten}

Zwischen den Kanälen in der Plasmamembran findet eine laterale Wechselwirkung statt, welche andere Membranproteine ausschließt. Dies führt dazu, dass die notwendige Fläche für einen Zell-Zell-Kontakt minimiert wird. ${ }^{[31]}$ Die Organisationsstruktur wird als Gap Junction oder Gap Junction Plaque bezeichnet. ${ }^{[18]}$ Diese Strukturen sind dabei nicht statisch, sondern sehr mobil und es kommt fortwährend zum Wachstum und Schrumpfen der Plaques. ${ }^{[32,33]}$ Die Kräfte, welche die Bildung dieser zwei-dimensionalen Arrays ermöglichen, sind noch nicht identifiziert worden. Es wird jedoch vermutet, dass Cholesterol für diese Interaktion eine Rolle spielt. Außerdem wurde für solubilisierte Connexone und Gap Junction Kanäle beobachtet, dass diese zu höheren lateralen Aggregaten selbstassemblieren. ${ }^{[34-37]}$ Für die Isolation der Gap Junction Kanäle aus den natürlichen Quellen wurden klassische biochemische Methoden wie Dichtegradientenzentrifugation mit Saccharose und Alkaliextraktion verwendet. ${ }^{[38,39]}$ Durch die Lauge werden Lipide von den Gap Junction Plaques und Plasmamembranfragmenten, welche keine Connexone bzw. Gap Junction Kanäle enthalten, gelöst.

Die laterale Organisation in Gap Junction Plaques führt vermutlich dazu, dass das übermittelte Signal von einer benachbarten Zelle verstärkt wird. Eine intrinsische, positive Koopera- 
tivität der Kanäle könnte zu einem konzertierten Öffnen und Schließen der Kanäle führen. Bukauskas et al. korrelierten die Größe der Plaques mit der Transjunctional Voltage $V_{\mathrm{j}}$ (Kapitel 1.1.5). ${ }^{[40]}$ Dazu verwendeten sie Cx43, welches mit dem enhanced Green Fluorescent Protein (eGFP) fusioniert wurde. Die Daten lassen vermuten, dass die Gap Junction Plaques eine bestimmte Größe (>300 Gap Junction Kanäle, 3.10 $\mathrm{nm}^{2}$ ) erreichen müssen, um überhaupt funktionelle Kanäle zu enthalten. Außerdem ist nur ein kleiner Anteil der Kanäle überhaupt aktiv (5 bis $15 \%$ ).
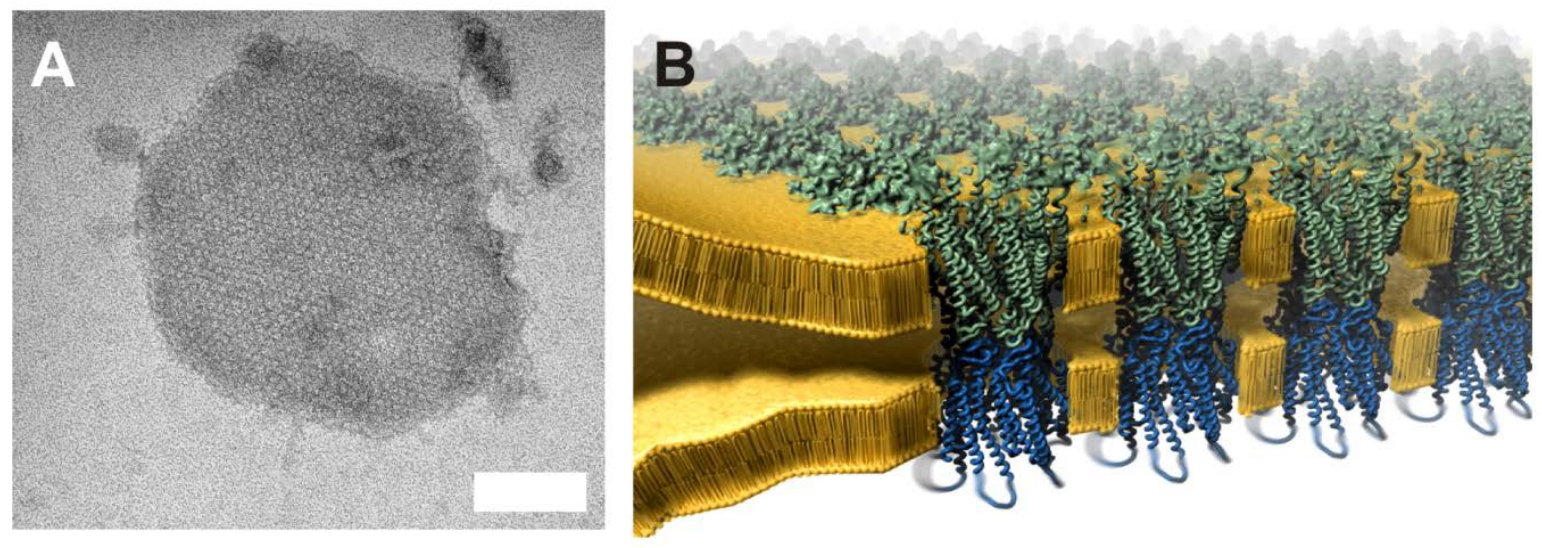

Abb. 1-5: Laterale Organisation von Gap Junction Kanälen in der Lipiddoppelschicht. A, Elektronenmikroskopische Aufnahme eines Cx26 Gap Junction Plaques, welches aus dem Baculovirus/Sf9 Expressionssystem stammt. Die runden Partikel innerhalb des Plaques haben einen Durch-

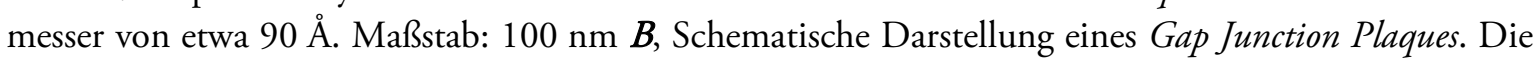
dargestellten Gap Junction Kanäle basierend auf den Strukturdaten eines Cx26 Gap Junction Kanals durchspannen zwei Lipiddoppelschichten und überbrücken einen extrazellulären Spalt von etwa $40 \AA$. Die Abbildung wurde modifiziert nach Nakagawa et al. ${ }^{[6]}$ 


\subsubsection{Connexin 43}

Die vorherrschende Isoform der Connexin-Familie ist Connexin 43 (Cx43), welches aus 382 Aminosäuren aufgebaut ist (Abb. 1-6). ${ }^{[41,42]}$ Dabei besitzt es die gleiche Struktur wie in Kapitel 1.1.1 beschrieben wurde. Aminosäuren 227 bis 382 schließen den $C$-Terminus von Cx43 $(-17 \mathrm{kDa})$ ein, welcher eine Rolle in der Interaktion mit einer Reihe von Zellkomponenten sowie in der Regulation von Cx43 (Kapitel 1.1.5) spielt. ${ }^{[43]}$ Das Vorkommen von Cx43 in wenigstens 34 verschiedenen Geweben sowie 46 Zelltypen wie Cardiomyozyten, Keratinozyten, Astrozyten, retinale Gliazellen und Osteoblasten belegt, dass Cx43 verschiedene Funktionen erfüllt. ${ }^{[41,44]}$ Beispielsweise vermittelt es den Transfer elektrischer Impulse, um die synchrone Kontraktion des Herzmuskels zu ermöglichen. ${ }^{[45]}$ Ferner ist es eine der verbreitesten Isoformen im Knochen. Hier ermöglicht es einerseits in Form von Gap Junction Kanälen den Austauch von Metaboliten zwischen den Osteozyten, welche durch die Knochenmatrix getrennt sind, und andererseits die Steuerung des Auf- und Abbaus der Knochenmatrix mithilfe von Connexin Halbkanälen. ${ }^{[46,47]}$ Mutationen bzw. Deletion im Gen gja1, welches für Cx43 codiert, sind oft letal, da es an einer Reihe von Funktionen in den Geweben beteiligt ist. Eine seltene Krankheit, welche mit Mutationen von Cx43 in Verbindung steht, ist die Occulodentodigitale Dysplasie (ODDD). Diese verursacht eine Missbildung der Augen, der Nase, der Zähne, des Herzens sowie neuronale Fehlfunktionen. ${ }^{[48]}$ Die Assemblierung von Cx43 zum Halbkanal findet im Gegensatz zu anderen Connexinen im trans-Golgi statt. Dabei beträgt die Halbwertzeit von Cx43 in der Plasmamembran $t_{1 / 2}=1$ bis 3 h. ${ }^{[18]}$ 


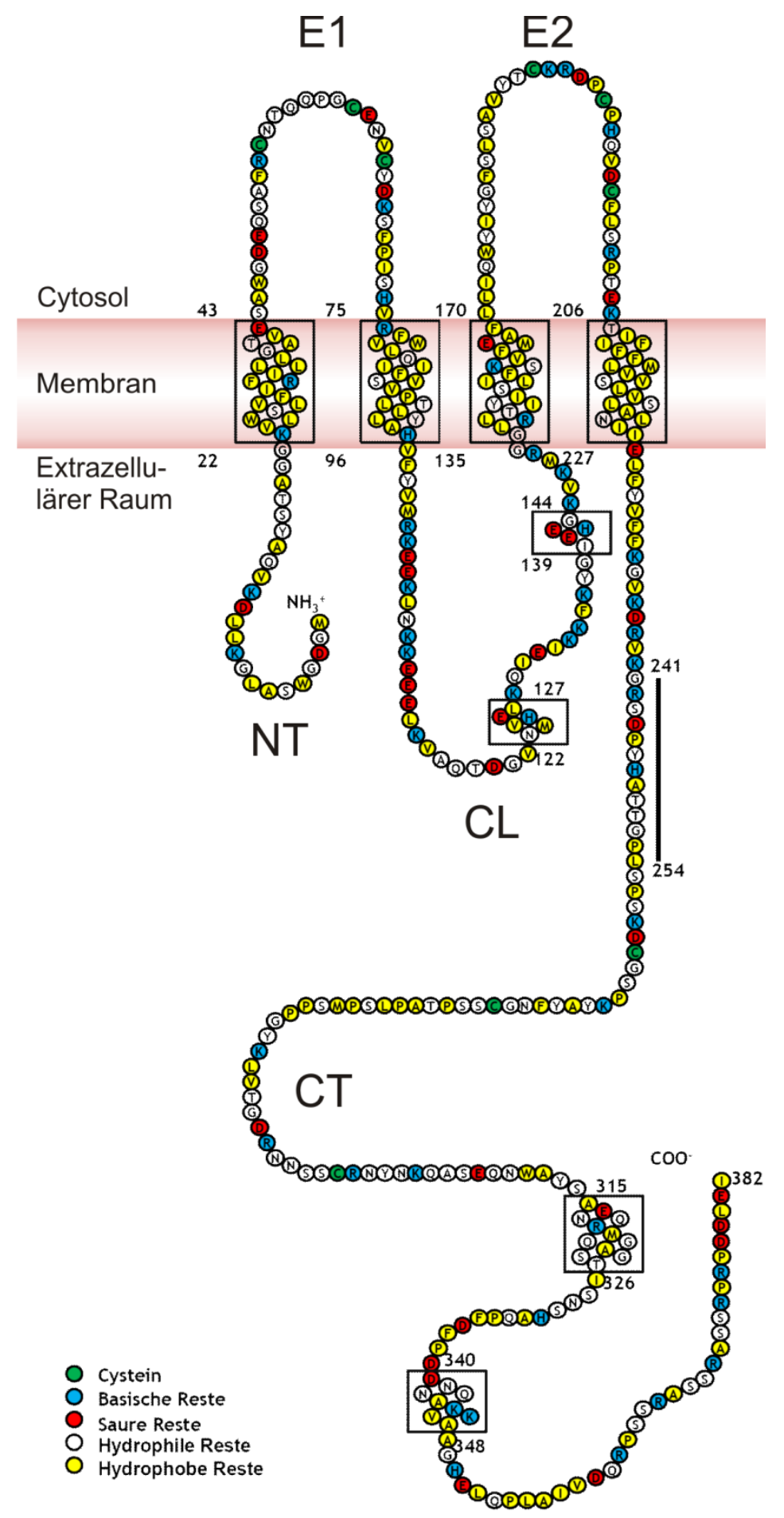

Abb. 1-6: Topologiemodell der Sekundärstruktur des Cx43 Protomers. Die Struktur basiert auf Yeager et al., Sorgen et al. und Duffy et al. Jede Untereinheit enthält vier transmembrane $\alpha$-Helices, zwei extrazelluläre Schleifen E1 und E2 sowie eine intrazelluläre Schleife (CL). Basierend auf den Strukturdaten von Sorgen et al. befinden sich am flexiblen $C$-Terminus zwei $\alpha$-Helices, welche mitverantwortlich für die pH-Sensivität sind. Daneben wurde durch Duffy et al. das Vorhandensein von zwei $\alpha$-Helices für einen Teil der cytoplasmatischen Schleife gezeigt (pH 5,8). $N$ - und $C$-Terminus (NT, CT) sind zum Cytoplasma der Zelle exponiert. Der monoklonale Antikörper connexin 43 D7 ${ }^{[49]}$ erkennt die Aminosäurereste 241 bis 254 (vertikale schwarze Linie, Kapitel 3.1.5). ${ }^{[50-52]}$ 


\title{
1.1.5 Regulation von Connexin Halbkanälen und Gap J unction Kanälen
}

\author{
Voltage Gating
}

In vivo Studien der Gap Junction Kanäle zeigen Öffnungsmechanismen, die unter anderem vom elektrischen Potential abhängig sind. ${ }^{[53]}$ Dabei haben die Transmembranspannung $V_{\mathrm{m}}$ und die Transjunctional Voltage $V_{\mathrm{j}}$ einen unterschiedlichen Einfluss. $V_{\mathrm{m}}$ ist die Potentialdifferenz zwischen dem Cytosol der Zelle und dem extrazellulären Raum. Dagegen ist $V_{\mathrm{j}}$ eine spezifische Größe von Gap Junction Kanälen und beschreibt die Potentialdifferenz zwischen zwei Zellen, welche über einen Gap Junction Kanal verbunden sind. Eine Sensitivität für $V_{\mathrm{j}}$ und $U_{\mathrm{m}}$ ist charakteristisch für Gap Junction Kanäle, welche durch Innexine gebildet werden. Im Gegensatz dazu sind die meisten auf Connexin basierenden Gap Junction Kanäle nur $V_{\mathrm{j}}$ sensitiv. ${ }^{[54]}$ Für das $V_{\mathrm{j}}$ können ebenfalls zwei Gating-Mechanismen unterschieden werden. ${ }^{[55]}$ Dies ist zum einen das Fast Gating $(<10 \mathrm{~ms})$, was durch ein unvollständiges Schließen des Kanals gekennzeichnet ist. Das unvollständige Schließen und Öffnen des Kanals könnte für das Auftreten von sogenannten Subconductance States verantwortlich sein. Zum anderen gibt es das Loop oder Slow Gating, was einen langsamen Übergang (>10 ms) von dem vollständig geschlossenen Zustand zum vollständig geöffneten Zustand darstellt. ${ }^{[5]}$ Durch die Röntgenkristallstruktur des Cx26 Gap Junction Kanals mit einer Auflösung von 3,5 A und des Cx26 Gap Junction Kanals mit der Punktmutation M34A bei einer lateralen Auflösung von $10 \AA$ (Cryoelektronenmikroskopie) konnte durch Maeda et al. und Oshima et al. (2007) das PlugGating-Model zum spannungsabhängigen Öffnen und Schließen des Kanals erweitert werden (Abb. 1-7 A). ${ }^{[5,20,30]}$ Demnach liegt der Kanal im geöffneten Zustand vor, wenn die Potentialdifferenz Null beträgt. Der geöffnete Zustand wird durch die Interaktion von M34 und W3 stabilisiert (Abb. 1-7 A). Eine veränderte Potentialdifferenz zwischen zwei Zellen zieht D2 in die Mitte der Pore, wodurch die Interaktion zwischen M34 und W3 gestört wird, und die Pore mithilfe der Interaktion von W3 des NTs der sechs Unterheiten geschlossen wird. Die M34A Mutante stellt den Cx26 Gap Junction Kanal im geschlossenen Zustand dar (Abb. 1-4 B). Anscheinend ist durch die Mutation M34A die Interaktion mit W3 gestört und die $N$-Termini der einzelnen Untereinheiten (erhöhte Elektronendichte) befinden sich in der Mitte der Pore. ${ }^{[30]}$ Jedoch ist dieser Mechanismus bis heute nur für Cx26 Gap Junction Kanäle anzunehmen, da in anderen röntgenkristallographischen Studien kein Plug in der Mitte der Pore nachgewiesen wurde. Ferner haben die Studien von Oh et al. von Cx32 Halbkanälen 
gezeigt, dass Mutationen in TM1 zu einem veränderten Voltage Gating führen. Dies deutet wie in der Struktur von Cx26 darauf hin, dass der $N$-Terminus als Spannungssensor fungiert. ${ }^{[56]}$ Ferner konnten andere Studien verdeutlichen, dass ebenfalls die Interaktion zwischen $C$-Terminus und cytoplasmatischer Schleife eine Rolle im $V_{\mathrm{j}}$-Gating spielt. ${ }^{[40,57]}$ Die Fusion von Cx32, Cx40 oder Cx43 mit eGFP oder die $C$-terminale Verkürzung führt zu einem veränderten Voltage Gating. Dies verursacht ein langsameres, vollständiges Schließen der Poren während des Loop Gatings und den Verlust des Fast Gatings. ${ }^{[58,59]}$ Erst kürzlich verdeutlichten Untersuchungen von Oshima et al. zur M34A Mutante, dass der geschlossene Zustand der M34A Mutante nicht mit dem geschlossenen Zustand des $V_{j}$ Gating übereinstimmt. ${ }^{[60]}$ Außerdem kann man von einer starken Stabilisierung des geschlossenen Zustands der M34A Mutante durch die beschriebenen Wechselwirkungen ausgehen, was nicht mit den vorgenannten Studien übereinstimmt. ${ }^{[54]}$

Weiter konnte gezeigt werden, dass die Punktmutation des konservierten P87 zu einem veränderten Voltage Gating führt (Abb. 1-1 B). Die Mutation benachbarter Reste stabilisiert die geschlossene Konformation und erst mit Applikation einer Spannung öffnet sich der Kanal. Die Konsequenz davon ist, dass der Knick in TM2, welcher durch P87 verursacht wird, wahrscheinlich verändert bzw. nicht mehr vorhanden ist. ${ }^{[61,62]}$ Jedoch zeigt die Mutation bei einigen Connexinen keine Auswirkungen. 

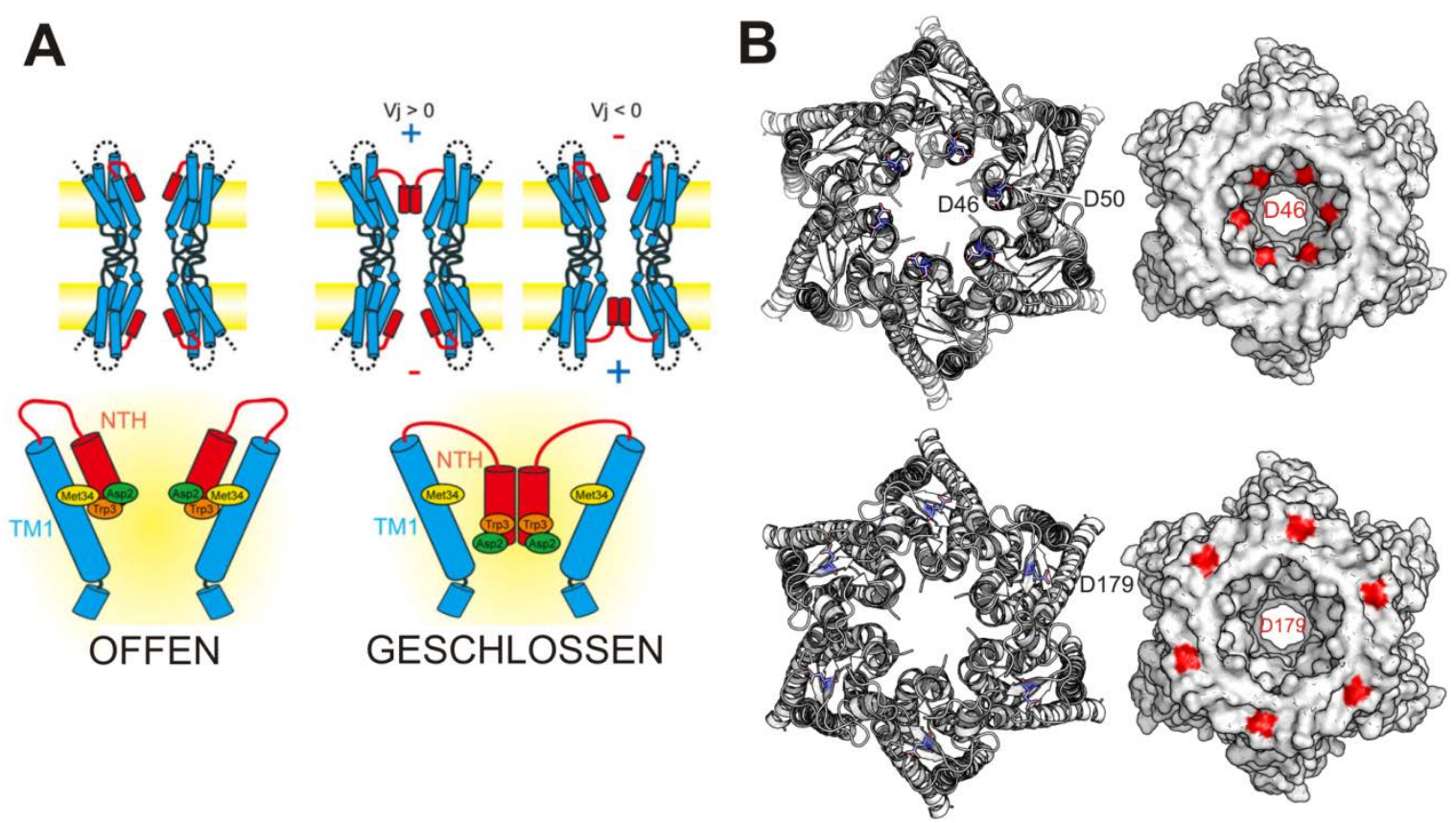

Abb. 1-7 Regulation der Connexon bzw. Gap Junction Kanalaktivität. A, Plug-Gating-Model: Modell für den Prozess des spannungsabhängigen Schließens und Öffnens eines Cx26 Gap Junction Kanals. Solange es keine Potentialdifferenz zwischen den benachbarten Zellen gibt, liegt der Kanal im geöffneten Zustand vor, d. h. der N-Terminus interagiert mit TM1 durch die Aminosäuren M34 und W3. Eine Spannungsdifferenz zwischen den Zellen führt zum Verschluss der Pore, wobei eine positive Spannung zur Bewegung des $N$-Terminus in die Pore durch D2 führt. Die Interaktion der $N$-Termini der Untereinheiten über W3 führt zum Verschluss der Pore. ${ }^{[5]} B$, Die Aminosäuren D169 und D179 (Cx32) sollen nach Gómez-Hernández et al. auf der extrazellulären Seite einen Ring aus zwölf negativgeladenen Aminosäuren bilden, welche auch hier die Selektivität des Kanals bestimmt. Diese Aminosäuren könnten potentiell für die Bindung von Calciumionen verantwortlich sein. Die schematische Darstellung des Cx26 Halbkanals in der Bänderdarstellung zeigt die Position von D179 außerhalb der Pore. D169 ist innerhalb der Connexinfamilie nicht konserviert. Maeda et al. berichten, dass am Poreneingang zwölf Aspartatreste (D46, D50) einen negativ-geladenen Ring bilden. Diese könnten eher dafür in Frage kommen, jedoch ist auch D50 nicht konserviert. D66 liegt dagegen konserviert vor, liegt aber ebenfalls außerhalb der Pore. ${ }^{[20,63]}$

\section{Chemical Gating}

Die spannungsabhängige Regulation ist außer für elektrisch erregbare Gewebe wenig relevant, da in vivo Connexin Halb- und Gap Junction Kanäle durch niedermolekulare Verbindungen und Ionen reguliert werden. ${ }^{[18]}$ Eine Senkung des intrazellulären pH-Wertes führt zum Verschluss der Gap Junction Kanäle sowie Connexin Halbkanäle und ermöglicht die pH-abhängige Regulation. ${ }^{[64]}$ Studien konnten zeigen, dass vermutlich der $C$-Terminus in diese Regulation involviert ist. Nach einem Ball-and-Chain-Modell bindet wahrscheinlich der $C$-Terminus an die cytoplasmatische Schleife des Proteins und führt so zum Verschluss der Pore. ${ }^{[51,65]}$ Dies könnte für Cx43 und Cx40 anstelle des $N$-Terminus auch als Voltage Sensor 
dienen. Daneben konnten Bevans und Harris die Regulation von Cx26 und Cx32 durch verschiedene, protonierte Aminosulfonate wie Taurin zeigen. Die Kanalaktivität kann durch den $\mathrm{pH}-$ Wert und durch protonierte Aminosulfonate reversibel moduliert werden. ${ }^{[66]}$ Taurin ist ein ubiquitäres Aminosulfonat und liegt zellulär in Konzentrationen von bis zu $50 \mathrm{mM}$ vor. Diese Erkenntnis zeigt, dass über den zellulären Taurinspiegel direkt Einfluss auf die Aktivität von Gap Junction Kanäle genommen werden kann. Jedoch gibt es bisher dafür keinen Nachweis. ${ }^{[66]}$

Das Öffnen und Schließen von Connexin Halbkanälen kann ebenfalls über die Calciumionenkonzentration gesteuert werden. Ferner wird angenommen, dass zwölf ringförmig um die Pore angeordnete negativ, geladene Aminosäuren für die Bindung des $\mathrm{Ca}^{2+}$ verantwortlich sind. ${ }^{[63]}$ Gómez-Hernández et al. schlagen die Aminosäuren D169 und D179 als potentielle $\mathrm{Ca}^{2+}$-Bindungsstelle vor (Abb. 1-7 B). Da D169 nicht innerhalb der ConnexinFamilie konserviert ist, kann D169 und D179 nur für die $\mathrm{Ca}^{2+}$-Bindung für Cx32 verantwortlich sein. Außerdem ist D179 im Cx26 Gap Junction Kanal zum Cytosol ausgerichtet und dies spricht daher nicht für die Theorie zum sterischen Verschluss der Pore. Maeda et al. identifizierten D46 und D50, welche den Poreneingang flankieren und die Selektivität des Kanals bestimmen. ${ }^{[20]}$ Diese Aminosäurepositionen sind eher für eine Calciumionenbindung denkbar. Die Bindung von Calciumionen könnte zum sterischen Verschluss der Pore führen. Untersuchungen von Cx26 mithilfe von Rasterkraftmikroskopie (Atomic Force Microscopy, AFM) zeigten, dass es nach Zugabe von $0,5 \mathrm{mM} \mathrm{Ca}^{2+} \mathrm{zu}$ einer Verkleinerung des extrazellulären Porendurchmessers von etwa $15 \AA$ auf etwa $6 \AA$ kommt, und dass dieser Prozess komplett reversibel ist. ${ }^{[67]}$ Ähnliche Ergebnisse konnten für isolierte Cx43 Halbkanäle in Anund Abwesenheit von 1,8 $\mathrm{mM} \mathrm{Ca}^{2+}$ erhalten werden. ${ }^{[68]}$ Der Porendurchmesser verringert sich von 2,5 nm auf 1,8 nm nach Zugabe. Außerdem können nicht-physiologische zweiwertige Kationen wie $\mathrm{Ba}^{2+}$ und $\mathrm{Sr}^{2+}$ verwendet werden. ${ }^{[69]}$ Als Ursache für einen verringerten Porendurchmesser ist ebenfalls eine Konformationsänderung denkbar. Desweiteren findet eine zelluläre Regulation der Connexinaktivität sowie des Auf- und Abbaus durch posttranslationale Modifikationen wie Phosphorylierungen statt. ${ }^{[70]}$ In diesem Zusammenhang wurden für Cx43 zahlreiche Serin- und Tyrosinreste am $C$-Terminus identifiziert.

Zusammenfassend lässt sich sagen, dass der $N$-Terminus als auch die cytoplasmatische Schleife von Cx43 eine Rolle für das pH-regulierte Chemical Gating spielt. ${ }^{[1,56]}$ Außerdem 
zeigt sich, dass der $C$-Terminus am pH-abhängigen Gating beteiligt ist, und dass die Aktivität von Cx43 über Phosphorylierungen am $C$-Terminus moduliert wird. ${ }^{[65,71]}$ 


\subsection{Artifizielle Membransysteme zur Untersuchung von Membran- proteinen}

In dieser Arbeit ist nach der Gewinnung von Connexinen durch heterologe Expression die Rekonstitution in artifizielle Membransysteme der nachfolgende Schritt, um ihre biophysikalischen Eigenschaften zu charakterisieren. Außerdem stellt die Rekonstitution in die Lipidmembran sicher, dass das Protein in einer Konformation vorliegt, die der Konformation in natürlichen Geweben gleicht. Im Gegensatz zum Zellsystem ist durch die Überführung in ein isoliertes System die Studie einzelner Einflussfaktoren wie posttranslationale Modifikationen oder Effektoren möglich. ${ }^{[72]}$ In diesem Kontext ist die Lipidmembran nicht nur eine Barriere, sondern ist ebenfalls Lösungsmittel für Membranproteine und beeinflusst deren Struktur und Funktion. ${ }^{[73]}$ Deshalb besteht die Schwierigkeit in artifiziellen Systemen darin, dass aus wenigstens 1.000 verschiedenen Lipiden des zellulären Systems gewählt werden muss, um Effekte wie Hydrophobic Mismatch von Lipid und Protein zu vermeiden. ${ }^{[74]}$ Phospholipide bestehen aus Sphingosin oder Glycerol, welche mit ein bzw. zwei Fettsäuren und Phosphat verestert sind. Wiederum kann die Phosphatgruppe mit verschiedenen Alkoholen verestert sein.

Für die Rekonstitution von Membranproteinen stehen eine Reihe verschiedener Systeme zur Verfügung wie Detergensmizellen, Bizellen, unilamellare Vesikel, Nanodiscs, festkörperunterstützte Membranen, freistehende Membranen und porenüberspannende Membranen (Abb. 1-8). Demnach kann je nach geplanter Applikation ein Modellmembransystem verwendet werden, welches für die jeweilige Fragestellung am besten geeignet ist. 


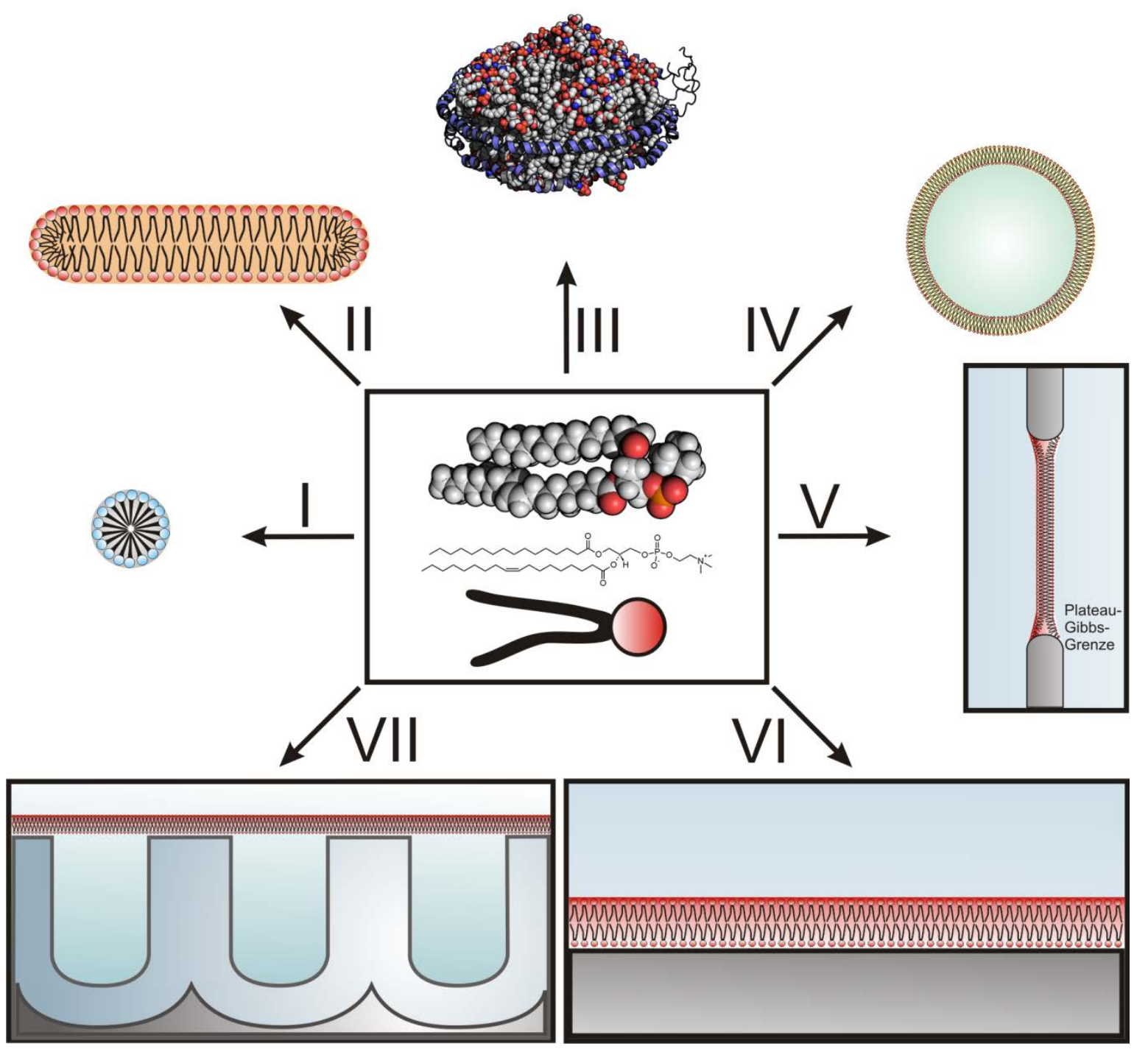

Abb. 1-8: Übersicht der etablierten Modellmembransysteme basierend auf Phospholipiden. Mitte: Kalottenmodell, Strukturformel und vereinfachte Darstellung des Lipids POPC (Kapitel 3.5.4). I: Detergensmizelle, II: Bizelle, III: Nanodisc, IV: Unilamellares Vesikel, V: Freistehende Membran (Black Lipid Membranes, BLM), VI: Festkörperunterstützte Membran (Solid Supported Membranes, SSM), VII: Porenüberspannende Membran auf geschlossenen Poren.

Detergenzien sind ähnlich wie Lipide aufgebaut und bestehen aus einer polaren Kopfgruppe und einer hydrophoben Endgruppe. Dabei können nicht-ionische, kationische und anionische Detergenzien unterschieden werden. Aufgrund ihrer konischen Struktur bilden sie einschichtige, sphärische Aggregate, die den hydrophoben Molekülabschnitt im Inneren einschließen (Abb. 1-8 I). ${ }^{[75]}$ Ferner liegen die meisten Proteine nach der Reinigung in Detergensmizellen vor, da sie durch ihre amphiphilen Eigenschaften die Lösung von Membranproteinen aus der Lipidmembran ermöglichen. Allerdings gibt es ein dynamisches Gleichgewicht zwischen Detergensmolekülen, die in der Mizelle vorliegen und Molekülen in wässriger Lösung. Dadurch kommt es zwischenzeitlich zur Exposition von hydrophoben 
Molekülbereichen des solubilisierten Proteins. Dieser Effekt kann zur Veränderung der Molekülstruktur führen. Dies ist ein weiterer Grund Membranproteine in eine naturähnliche Umgebung zu überführen. In diesem Zusammenhang haben die nicht-ionischen Detergenzien aufgrund ihrer chemischen Struktur den geringsten Einfluss auf die Proteinkonformation. ${ }^{[75]}$

Zur Studie von Rezeptoren bieten vor allem die Modellmembransysteme der Nanodiscs und Bizellen eine Möglichkeit Prozesse wie Signaltransduktion zu untersuchen. ${ }^{[76,77]}$ Bizellen können aus Mischmizellen, welche aus kurz- und langkettigen Lipiden und Detergens bestehen, durch den Entzug des Detergens entstehen und bilden ein scheibenförmiges Aggregat $(d=10$ bis $80 \mathrm{~nm}$, Abb. 1-8 II). Ähnlich wie Bizellen sind Nanodiscs aufgebaut. Hier wird der hydrophobe Anteil des scheibenförmigen Aggregates nicht durch kurzkettige Lipide umschlossen, sondern ein amphiphiles, $\alpha$-helikales Protein (Membrane Scaffold Protein, MSP) bedeckt die hydrophoben Ketten der Lipiddoppelschicht-Scheibe ( $d=10$ bis $13 \mathrm{~nm}$, Abb. 1-8 III). ${ }^{[78]}$ Der Vorteil dieser Systeme ist, dass der cytoplasmatische und der extrazelluläre Molekülabschnitt zugänglich ist und es können komplexe Prozesse wie die extrazelluläre Ligandenbindung und die Weiterleitung über den Rezeptor an intrazelluläre Komponenten untersucht werden. Für die Untersuchung von Ionenkanälen sind diese Systeme weniger geeignet, da für diese zwei voneinander getrennte Kompartimente benötigt werden. Unilamellare Vesikel sowie porenüberspannende Membranen werden diesen Anforderungen gerecht, welche dem zellulären System ähnlich sind.

\subsubsection{Unilamellare Vesikel}

Strukturell sind Vesikel relativ ähnlich zu zellulären Systemen aufgebaut. ${ }^{[79]}$ Vesikel lassen sich auf einfachem Weg durch eine Reihe von Methoden aus artifiziellen Lipiden oder Lipidextrakten herstellen. Gewöhnlich werden Phospholipide verwendet, welche in wässriger Lösung Aggregate bestehend aus einer Lipiddoppelschicht bilden und einen wässrigen Innenraum einschließen (Abb. 1-8 IV). Diese konnten durch Bangham et al. erstmals hergestellt und näher charakterisiert werden. ${ }^{[00]}$ Aufgrund der Größe können kleine unilamellare Vesikel (Small Unilamellar Vesicles, SUVs, $d=20$ bis $50 \mathrm{~nm}$ ), große unilamellare Vesikel (Large Unilamellar Vesicles, LUVs, $d=100 \mathrm{~nm}$ bis $1 \mu \mathrm{m}$ ) und riesige unilamellare Vesikel (Giant Unilamellar Vesicles, GUVs, $d>10 \mu \mathrm{m}$ ) unterschieden werden. Beim Natural Swelling werden eingetrocknete Lipidfilme in wässriger Lösung rehydratisiert. Dabei dringen Wassermoleküle zwischen die einzelnen Lipiddoppelschichten und es lösen sich einzelne 
Vesikel ab. Durch diese Methode werden überwiegend multilamellare Vesikel (MLVs) unterschiedlicher Größe erhalten. Zur Herstellung von SUVs wird der rehydratisierte Lipidfilm vorübergehend im Ultraschall inkubiert. Dies ermöglicht reproduzierbar SUVs mit ähnlicher Größe herzustellen. Bedingt durch die Größe kommt es in einem kurzen Zeitinterval zur Fusion der Vesikel, um die Membrankrümmung bzw. -spannung abzubauen. LUVs können durch Extrusion der resuspendierten Lipide durch Polycarbonatmembranen mit unterschiedlicher Porengröße (100 nm bis $1 \mu \mathrm{m})$ gewonnen werden. Zur reproduzierbaren Herstellung von GUVs, die ähnlich groß wie eukaryotische Zellen sind ${ }^{[79]}$, wird häufig die Elektroformation (Electroswelling) verwendet. ${ }^{[81]}$ Dafür werden auf einem leitenden Träger eingetrocknete Lipidfilme rehydratisiert und ein elektrisches Wechselfeld appliziert, was zur Bildung und Ablösung von GUVs führt. ${ }^{[82]}$ Im Gegensatz zu SUVs und LUVs haben GUVs den Vorteil, dass sie optischen Untersuchungsmethoden wie der Fluoreszenzmikroskopie zugänglich sind..$^{[83]}$ Zur Rekonstitution von Membranproteinen in unilamellare Vesikel können unterschiedliche Methoden verwendet werden, im Detail wird darauf in Kapitel 4.2 eingegangen.

\subsubsection{Porenüberspannende Membranen}

In dieser Arbeit wurden porenüberspannende Membranen als Basis zur Entwicklung eines fluoreszenzbasierten Biosensors verwendet. Ihre Entwicklung beruht auf zwei weiteren Modellmembransystemen, die im Folgenden kurz vorgestellt werden. Festkörperunterstützte Membranen (Solid Supported Membranes, SSMs) wurden zum ersten Mal durch Mueller et al. beschrieben (Abb. 1-8 VI). ${ }^{[84]}$ Diese können auf unterschiedliche Art präpariert werden und weisen aufgrund des Trägers vor allem eine hohe Stabilität auf. Zur Präparation der SSMs wird das Spreiten auf hydrophilen Oberflächen, auf hydrophoben oder hydrophilen Monoschichten, das Painten von Lipiden auf hydrophoben Monoschichten oder die Langmuir-Blodgett-Technik eingesetzt. ${ }^{[85-89]}$ Die direkte Interaktion der Lipide mit dem Festkörper verleiht dem System eine hohe Stabilität, jedoch beschränkt sich das Kompartiment dazwischen nur auf eine dünne Wasserschicht $(-2 \mathrm{~nm}) \cdot{ }^{[79,90,91]}$ Dies schränkt beispielsweise die Beweglichkeit rekonstituierter Membranproteine in der Lipidmembran ein. Durch die Interaktion des Proteins mit der Oberfläche könnte auch die natürliche Konformation des Proteins beeinflusst werden. ${ }^{[9]}$ Die dünne Wasserschicht kann unter anderem durch die Verwendung von Polymeren als Abstandshalter erweitert werden. Ein Modellmembransystem 
mit größerer Freiheit und Zugänglichkeit stellen freitragende Membranen wie die Black Lipid Membranes (BLMs, Abb. 1-8 V) dar. Dabei wird die Lipidmembran über eine Apertur in einer Wand, welche in einer Kunststoffkammer zwei Kompartimente trennt, mit einem Durchmesser von bis zu mehreren Millimetern hergestellt. Dadurch wird eine Zugänglichkeit zu beiden Seiten der Lipiddoppelschicht ermöglicht. Nach der Müller-Rudin-Technik wird Lipid in einem organischen Lösungsmittel mit einem Pinsel auf die Apertur getropft. ${ }^{[84]}$ Der Ausdünnprozess führt dazu, dass das Lösungsmittel zum Rand der Apertur (Plateau-GibbsGrenze) gedrängt wird und durch Selbstorganisation eine Lipiddoppelschicht ausgebildet wird. Aufgrund der Dicke der Membran von etwa $5 \mathrm{~nm}$ kommt es nach dem Ausdünnprozess zur destruktiven Interferenz und die Lipiddoppelschicht erscheint schwarz, was dem System den Namen gibt. Nachteilig ist, dass die Präparation nicht lösungsmittelfrei erfolgt und die geringe Stabilität der Lipidmembran von wenige Stunden. Die Anreicherung des Lösungsmittels in der Lipiddoppelschicht kann beispielsweise zur Beeinflussung der Struktur von integralen Membranproteinen führen. Alternativ kann die Montal-Müller-Technik zur Herstellung symmetrischer oder asymmetrischer, lösungsmittelfreier Lipidmembranen dienen. ${ }^{\left[{ }^{[2]}\right.}$

Porenüberspannende Membranen haben die Nachteile der festkörperunterstützten Membranen sowie freistehenden Membranen überwunden und vereinen deren Vorteile der Langzeitstabilität sowie die Zugänglichkeit. Diese bestehen zum einen aus einem festkörperunterstützten Bereich, auf dem die Lipidmembran verankert ist, und zum anderen aus einem freitragenden Bereich, indem die Lipiddoppelschicht die Poren überspannt. Als poröses Substrat werden hauptsächlich hochgeordnetes, poröses Aluminiumoxid sowie hochgeordnetes Silizium, welches durch Lithographie erzeugte Porenarrays enthält, verwendet. ${ }^{[93-98]}$ Jedoch können auch andere Materialien wie Polycarbonatfolien oder Glas zum Einsatz kommen. ${ }^{[99-102]}$ Der Porendurchmesser umfasst einen Bereich von wenigen Nanometern bis zu mehreren Mikrometern. Die Präparation kann auf unterschiedliche Weise erfolgen. Ähnlich wie bei festkörperunterstützten Membranen können Vesikel gespreitet werden oder wie bei freitragenden Membranen ein Lipid-Lösungsmittel-Gemisch auf einer zuvor hydrophobisierten Oberfläche aufgegeben werden. Dabei bilden Thiolipide, welche auf der aufgedampften Goldoberfläche chemisorbieren, eine hydrophobe Monolage. Die resultierenden porenüberspannenden Membranen weisen Membranwiderstände $>1 \mathrm{G} \Omega$ auf und können somit auch für Einzelkanalmessungen eingesetzt werden. ${ }^{[72,103-105]}$ Weitere Vorteile sind sowohl die mechanische Stabilität als auch die Langzeitstabilität der porenüber- 
spannenden Membransyteme. ${ }^{[106,107]}$ Desweiteren lassen sich auch die Eigenschaften einzelner Membrankomponenten sowie deren Interaktion mit peripheren und integralen Membranproteinen untersuchen. ${ }^{[108,109]}$ Außerdem ermöglichen sie durch den porösen Aufbau die gleichzeitige, fluoreszenzmikroskopische Untersuchung von mehreren hundert Einzelexperimenten. ${ }^{[110]}$ 


\section{Zielsetzung}

Die Untersuchung der Aktivität isolierter Ionenkanäle durch Einzelkanalmessungen, welche in einer Reihe von Gesellschaftskrankheiten wie Osteoporose, Epilepsie, Ataxie, Herzrhythmusstörungen und Taubheit eine Rolle spielen, erfordert noch immer die invasive Kontaktierung beider Seiten der Zellmembran. ${ }^{[11]}$ Eine Miniaturisierung und Automatisierung ist für eine schnelle Identifizierung von Wirkstoffkandidaten bedeutend. Im Rahmen eines BMBF-Projekts ist es das Ziel, ein chip-basiertes High Throughput Screening (HTS) System zur schnellen Identifizierung von Wirkstoffkandidaten aus einer Komponentenbibliothek zu entwickeln. Die Basis stellen die porenüberspannenden Membranen dar, da diese die Überführung in ein chipbasiertes System ermöglichen. Dabei sollen Zellen, welche gleichzeitig Connexone sowie einen zu untersuchenden Ionenkanal exprimieren, an eine Connexon-dotierte porenüberspannende Membran über Gap Junction Kanäle gekoppelt werden. Dies gestattet die nicht-invasive elektrische Kontaktierung eines Zellkollektivs zur schnellen Erkennung potenzieller Medikamente.

Zu diesem Zweck werden in dieser Arbeit die Organismen Pichia pastoris und Dictyostelium discoideum hinsichtlich ihrer Eignung zur heterologen Proteinexpression von Cx43 und dem Fusionsprotein aus Cx43 und dem grün fluoreszierenden Protein (Green Fluorescent Protein, GFP) bzw. enhanced GFP (eGFP) untersucht. Zur Optimierung des Reinigungsprozesses werden nach erfolgreicher Expression unterschiedliche Prozeduren getestet. Für die Bildung von Gap Junction Kanälen in einem in vitro System ist die anschließende Integration von Cx43 bzw. Cx43-GFP in artifizielle Lipidmembranen notwendig, wofür unterschiedliche Strategien verfolgt werden. Die Funktionalität der Proteine wird mithilfe des Planar Patch Clamp Systems überprüft. Weiterführend ist es das Ziel, einen fluoreszenz-basierten Transferassay unter Verwendung porenüberspannender Membranen zu etablieren. Dieser dient der Visualisierung der Gap Junction Kanalbildung durch die konfokale Laserrastermikroskopie. 


\section{Material und Methoden}

\subsection{Proteinchemische Methoden}

\subsubsection{Heterologe Proteinexpression}

\subsubsection{Heterologe Proteinexpression in Dictyostelium discoideum}

Seit der Entdeckung 1869 ist Dictyostelium discoideum (Schleimpilz) bekannt und wird als Modellorganismus für die Erforschung verschiedener biologischer Prozesse wie Signaltransduktion, „Sozialverhalten“, Chemotaxis und Zelldifferenzierung verwendet. ${ }^{[12-115]}$ Vorwiegend ernährt sich $D$. discoideum in der amöboiden, einzelligen Form von Bakterien, was auch als xenisches Wachstum der vegetativen Wachstumsphase bekannt ist. Infolge von Nahrungsmangel kommt es zur zyklischen Adenosinmonophosphat (Cyclic Adenosine Monophosphate, $c A M P)$-vermittelten Aggregation der Zellen und innerhalb von $24 \mathrm{~h}$ entwickelt sich ein Fruchtkörper (Entwicklungsphase), welcher die Sporen des momentan multizellulären Organismus enthält. Wiederum führt die Nahrungszufuhr zum Auskeimen der Sporen von D. discoideum. Die Sporen von D. discoideum sind so wie prokaryotische Sporen resistent gegen eine Reihe an widrigen Umweltbedingungen. Im Labor wird D. discoideum vorwiegend in axenischen Medien (v. a. HL5-Medium) bei $22{ }^{\circ} \mathrm{C}$ kultiviert. ${ }^{[116]}$ Axenisch bedeutet, dass der Schleimpilz in Abwesenheit von Bakterien angezogen werden kann. Eine konstante Temperatur zwischen 21 bis $23^{\circ} \mathrm{C}$ ist für den Erfolg der Kultivierung von entscheidender Bedeutung. Für die Bestimmung der Zelldichte müssen die Zellen mit einem Hämozytometer (Neubauerzählkammer) gezählt werden. Die Bestimmung der Zelldichte über die optische Dichte bei $600 \mathrm{~nm}\left(O D_{600}\right)$ kann nicht verwendet werden, da die Zellen im Gegensatz zu Escherichia coli eine heterogene Struktur (Amöbe) aufweisen. Eine Besonderheit des Schleimpilzes ist, dass extrachromosomale DNA wie Vektoren toleriert wird, was eine der wenigen Ausnahmen unter Eukaryoten darstellt. Dadurch können Proteine heterolog in D. discoideum exprimiert werden. Ferner ermöglicht die heterologe Proteinexpression post- 
translationale Modifikationen ähnlich derer höherer Eukaryoten. Nachteilig sind die langen Kultivierungszeiten und die abweichende Codon Usage. Außerdem wechselt das Glykosylierungsmuster während der Proteinexpression, wodurch ein Proteingemisch mit unterschiedlicher Funktionalität entsteht.

Für die Expression von Connexin 43 (Cx43) und dem Fusionsprotein aus Cx43 und dem enhanced Green Fluorescent Protein (Cx43-eGFP) wurden zwei D. discoideum Klone $(\mathrm{Ax} 3-\mathrm{ORF}+)$ der Arbeitsgruppe von Prof. Dr. Motomu Tanaka (Physikalische Chemie von Biosystemen, Universität Heidelberg) verwendet. Der verwendete Stamm Ax3-ORF+ wird häufig für die heterologe Proteinexpression verwendet und ermöglicht zusammen mit dem starken, konstitutiven Promoter für Actin15 (act15 in pDXA-3H, Kapitel 9.9) hohe Expressionsraten. ${ }^{[117]}$ Diesem Stamm ist es möglich auf axenischem Medium zu wachsen und die Bezeichnung ORF+ zeigt an, dass mithilfe des Gens Ddp2 ORF (genomische Lokalisation) die autonome Replikation der eingebrachten Plasmide möglich ist. ${ }^{[17]}$ Die Gene für beide Proteine sind zwischen die Restriktionsschnittstellen für HindIII und BamHI im Vektor pDXA-3H eingeführt und tragen zur Reinigung mithilfe der immobilisierten Metallchelataffinitätschromatografie (Kapitel 3.1.3) einen Oktahistidin-Tag am C-Terminus. Der Vektor pDXA-3H vermittelt eine Geneticin-Resistenz (G418). G418 wurde während der Kultivierung als Selektionsmarker zugesetzt. Die Nukleinsäure- sowie die Aminosäuresequenzen sind im Anhang zu finden (Kapitel 9.7, 9.8). Die Techniken zur Kultivierung und Stammhaltung wurden in der Arbeitsgruppe von Prof. Dr. Eberhard Bodenschatz (MPI für Dynamik und Selbstorganisation, Göttingen) erlernt und werden im Folgenden vorgestellt.

\section{Kultivierung der D. discoideum Sporen (Primärkultur)}

Zur Anzucht von D. discoideum wurden 50 bis $100 \mu \mathrm{L}$ Sporen in Sørensen-Phosphatpuffer (Cryostock) zu $10 \mathrm{~mL}$ HL5-Medium $\left(T=22^{\circ} \mathrm{C}\right.$; Formedium, Norfolk, UK) in Petrischalen (PRIMARIA Tissue Culture Dish, Falcon) pipettiert. Nach 24-stündiger Inkubation bei $22^{\circ} \mathrm{C}$ wurden $20 \mu \mathrm{g} \cdot \mathrm{mL}^{-1}$ Geneticin zugegeben und weiter inkubiert. Abhängig vom Inokulum sind die Zellen nach 3 bis $4 \mathrm{~d}$ konfluent. Da $D$. discoideum adhärent wächst, wurde die Kultur nach Erreichen der Konfluenz passagiert. 


\section{Subkultivierung von D. discoideum}

Das überstehende Medium wurde abgesaugt und die konfluenten Zellen mit $10 \mathrm{~mL}$ HL5-Medium $\left(T=22^{\circ} \mathrm{C}\right)$ von der Platte gespült. Die Zellen wurden mit einem Hämozytometer gezählt und die Zellzahl bestimmt. Dann wurden $10 \mathrm{~mL}$ HL5-Medium mit $1 \cdot 10^{5}$ bis $3 \cdot 10^{5}$ Zellen und $20 \mu \mathrm{g} \cdot \mathrm{mL}^{-1}$ Geneticin versetzt und für 3 bis $4 \mathrm{~d}$ bei $22{ }^{\circ} \mathrm{C}$ bis zum Erreichen der Konfluenz kultiviert.

\section{Schüttelkultur von D. discoideum}

Neben der Kultivierung in der Petrischale kann D. discoideum auch im Schüttelkolben kultiviert werden, um beispielsweise die Wachstumsrate der verschiedenen Klone zu bestimmen. Dafür wurden $25 \mathrm{~mL}$ HL5-Medium $\left(T=22^{\circ} \mathrm{C}\right)$ in einen $125 \mathrm{~mL}$-Erlmeyerkolben (Volumenverhältnis 1:5) gefüllt und mit $20 \mu \mathrm{g} \cdot \mathrm{mL}^{-1}$ Geneticin versetzt. Optional kann $300 \mu \mathrm{g} \cdot \mathrm{mL}^{-1}$ Streptomycin und $100 \mu \mathrm{g} \cdot \mathrm{mL}^{-1}$ Ampicillin zugesetzt werden, um ein bakterielles Wachstum zu unterdrücken. Das Medium wurde mit einem Inokulum von 50.000 Zellen $\cdot \mathrm{mL}^{-1}$ (mindestens 10.000 Zellen $\cdot \mathrm{mL}^{-1}$ ) angeimpft und bei $22^{\circ} \mathrm{C}$ und $150 \mathrm{rpm}$ (Rounds Per Minute) für 3 bis $4 \mathrm{~d}$ inkubiert. Die Zellzahl wurde wieder mithilfe des Hämozytometers bestimmt.

\section{Langzeitlagerung von D. discoideum}

Zur Langzeitlagerung von $D$. discoideum wurden zwei verschiedene Methoden verwendet. Für die eine Variante wurden Zellen von D. discoideum aus der exponentiellen Phase

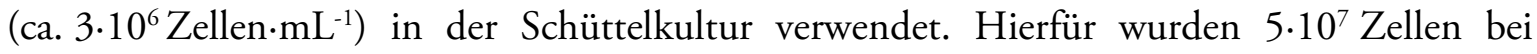
$1.500 \times g$ für 3 min zentrifugiert. Danach wurden die Zellen in $1 \mathrm{~mL}$ kaltem HL5-Medium mit $10 \%$ Dimethylsulfoxid (DMSO) resuspendiert und zunächst für 1 bis $2 \mathrm{~h}$ bei $-20{ }^{\circ} \mathrm{C}$ eingefroren. Anschließend wurden sie für 12 bis $24 \mathrm{~h}$ bei $-80^{\circ} \mathrm{C}$ weiter inkubiert und schließlich zur Lagerung in flüssigen Stickstoff überführt. Für die Kultivierung aus den Cryostocks der Zellen wurden sie schnell im Wasserbad $\left(T=37^{\circ} \mathrm{C}\right)$ aufgetaut und bei $1.500 \times g$ für $3 \mathrm{~min}$ pelletiert. Die Zellen wurden anschließend in $5 \mathrm{~mL}$ HL5-Medium $\left(T=22^{\circ} \mathrm{C}\right)$ aufgenommen und wieder zentrifugiert, um restliches DMSO zu entfernen. Anschließend wurde in $1 \mathrm{~mL}$ HL5-Medium resuspendiert und die Suspension zu $9 \mathrm{~mL}$ 
HL5-Medium (Petrischale) zugegeben. Nach 12 bis $24 \mathrm{~h}$ wurde $20 \mu \mathrm{g} \cdot \mathrm{mL}^{-1}$ Geneticin als Selektionsantibiotikum dazugegeben und die Zellen bis zur Konfluenz kultiviert.

Neben der Langzeitlagerung als Zellen konnte D. discoideum auch in Form von Sporen gelagert werden. Für die Kultivierung von Sporen wurden drei konfluente Kulturen von je 10 mL HL5-Medium (Petrischale) pro Phosphatagarplatte präpariert. Diese wurden von der Platte gespült und für $3 \mathrm{~min}$ bei $1.200 \times g$ zentrifugiert. Danach wurde der Überstand abgesaugt, die Zellen in $10 \mathrm{~mL}$ Sørensen-Phosphatpuffer ( $\mathrm{pH} 6,0 ; T=22{ }^{\circ} \mathrm{C}$ ) resuspendiert und wie zuvor zentrifugiert. Schließlich wurden die Zellen in $1 \mathrm{~mL}$ Sørensen-Phosphatpuffer resuspendiert, gleichmäßig auf die Phosphatagarplatte (Sørensen-Phosphatpuffer mit $12 \mathrm{~g} \cdot \mathrm{L}^{-1}$ Agar) getropft und durch Schwenken verteilt. Die Platte wurde zunächst für 30 min unter der Sterilbank getrocknet und bei $22^{\circ} \mathrm{C}$ inkubiert. Nach $6 \mathrm{~h}$ Inkubation wurde die Petrischale auf den Deckel gestellt. Die Sporen wurden nach $3 \mathrm{~d}$ Inkubation mit $4 \mathrm{~mL}$ Sørensen-Phosphatpuffer von der Platte gespült. Es wurden $500 \mu \mathrm{L}$ Aliquots in flüssigem Stickstoff gefroren und bei $-80^{\circ} \mathrm{C}$ gelagert.

\section{Fermentation von $D$. discoideum}

Um größere Zelldichten als in der Schüttelkultur zu erreichen, wurden mehrere Studien zur Kultivierung von D. discoideum im Bioreaktor durchgeführt. Vor der Fermentation wurden drei Schüttelkulturen wie zuvor beschrieben vorbereitet und für $3 \mathrm{~d}$ kultiviert.

5 L-Bioreaktor - Die satzweise Kultivierung (Batch-Kultivierung) von D. discoideum wurde mit dem Biostat E Typ E 5 (B. Braun, Melsungen) durchgeführt. Das Kulturgefäß Typ E 5 hat ein Gesamtvolumen von 6,4 L und es wird ein maximales Arbeitsvolumen von 5,0 L empfohlen. Es besteht aus einem Borsilikatzylinder mit Edelstahlboden sowie -deckel. Die zentrale Rührerwelle besteht aus drei 6-Blattscheibenrührern. Um den Rührer ist der Heizschlangenwärmeaustauscher zur Temperierung des Kulturgefäßes angeordnet. An der Unterseite des Fermenters ist ein Ventil zur Probenentnahme, welches über einen Dampfstrom sterilisiert wird, angebracht. Ein zentral gelegenes Begasungsrohr sorgte für zusätzliche Belüftung des Kulturmediums. Über mehrere Rückkopplungsschleifen mit verschiedenen Messsonden wurden Prozessparameter wie die Temperatur, der pH-Wert und der Sauerstoffpartialdruck $p\left(\mathrm{O}_{2}\right)$ an die Sollwerte automatisch angepasst. Das Schäumen des 
Mediums wurde durch eine Schaumsonde überwacht und gegebenenfalls über die Antischaumzugabe reguliert.

Für die Fermentation von D. discoideum wurde 2,5 L HL5-Medium im Fermenter bei $121{ }^{\circ} \mathrm{C}$ für $30 \mathrm{~min}$ autoklaviert. Die Drei-Kanal-Anstechgarnitur, der Abluftfilter, sowie die pH-Korrekturflüssigkeiten, $10 \%(v / v)$ Phosphorsäure und $2 \mathrm{M}$ Natronlauge, wurden separat autoklaviert und anschließend angeschlossen. Um eine Endkonzentration von $5 \cdot 10^{5}$ Zellen $\cdot \mathrm{mL}^{-1} \mathrm{zu}$ erreichen, wurde mithilfe eines Animpfkolbens über ein Septum die Vorkultur steril inokuliert. Anschließend wurde das Antibiotikum Geneticin $\left(20 \mu \mathrm{g} \cdot \mathrm{mL}^{-1}\right)$ steril durch ein Septum zugegeben. Proben wurden mindestens zweimal pro Tag bzw. zu jeder Überprüfung entnommen. Dabei wurde die Zellzahl mithilfe des Hämozytometers bestimmt sowie die Prozessparameter wie Rührerumdrehung, Begasungsrate, $\mathrm{pH}-$ Wert, Temperatur und Sauerstoffpartialdruck $p\left(\mathrm{O}_{2}\right)$ festgehalten. Die Fermentation wurde mit einer Rührerumdrehung von $50 \mathrm{rpm}$, einer Begasungsrate von 3,0 Slpm (Standard-Liter pro Minute) und einem $\mathrm{pH}$-Wert von 6,7 begonnen. D. discoideum kann bis zu einer Zellzahl von $5 \cdot 10^{7}$ Zellen $\cdot \mathrm{mL}^{-1}$ kultiviert werden.

HL5-Medium

(Lagerung bei $4^{\circ} \mathrm{C}$ )

$$
\begin{gathered}
14 \mathrm{~g} \cdot \mathrm{L}^{-1} \text { Pepton } \\
7 \mathrm{~g} \cdot \mathrm{L}^{-1} \text { Hefeextrakt } \\
13,5 \mathrm{~g} \cdot \mathrm{L}^{-1} \text { Glucose } \\
0,5 \mathrm{~g} \cdot \mathrm{L}^{-1} \mathrm{KH}_{2} \mathrm{PO}_{4} \\
0,5 \mathrm{~g} \cdot \mathrm{L}^{-1} \mathrm{Na}_{2} \mathrm{HPO}_{4}
\end{gathered}
$$

Sørensen-Phos-

$2 \mathrm{~g} \cdot \mathrm{L}^{-1} \mathrm{KH}_{2} \mathrm{PO}_{4}$

phatpuffer

$0,36 \mathrm{~g} \cdot \mathrm{L}^{-1} \mathrm{Na}_{2} \mathrm{HPO}_{4} \cdot 2 \mathrm{H}_{2} \mathrm{O}$

\section{Isolierung von D. discoideum Membranfragmenten}

D. discoideum wurde bis zu einer Zellzahl von etwa $2,5 \cdot 10^{7}$ Zellen $\cdot \mathrm{mL}^{-1}$ in der Schüttelkultur angezogen und anschließend bei $200 \times g$ und $4{ }^{\circ} \mathrm{C}$ für 3 min zentrifugiert. Das Pellet wurde bei $-20^{\circ} \mathrm{C}$ gelagert oder sofort verwendet. Die Isolierung der Plasmamembran mittels Dichtegradientenzentrifugation wurde von Hand et al. adaptiert. ${ }^{[38]}$ Dafür wurden etwa $1 \mathrm{~g}$ Zellfeuchtmasse in TRIS-Ethylenglycol-bis(aminoethylenether)- $N, N, N^{\prime}, N^{\prime}$-tetraessigsäure (EGTA)-Puffer mit 8,7\% $(w / v)$ Saccharose resuspendiert und einmal für $40 \mathrm{~s}$ mit Ultraschall 
(UW 2070, Bandelin electronics, Berlin) bei einer Intensität von $80 \%$ (4 cycles) aufgeschlossen. Der Aufschluss wurde mithilfe eines Lichtmikroskops kontrolliert. Anschließend wurde für die Dichtegradientenzentrifugation 1,5 mL $50 \%(w / v)$ Saccharose, $2,5 \mathrm{~mL} 27 \%$ $(w / v)$ Saccharose jeweils in TRIS-EGTA-Puffer und $1 \mathrm{~mL}$ der aufgeschlossenen Zellen aufeinandergeschichtet (sechs Gefäße) und bei $192.000 \times g$ (SW55Ti Ausschwingrotor, Beckman-Coulter, Krefeld) für $2 \mathrm{~h}$ ohne Beschleunigung und Bremse zentrifugiert. Danach wurde die milchige Interphase zwischen $27 \%$ und $50 \%$ Saccharose entnommen, vereinigt und mit $5 \mathrm{~mL}$ TRIS-EGTA-Puffer verdünnt. Die Suspension wurde bei $86.000 \times g$ für 30 min zentrifugiert (zwei Gefäße). Zur Entfernung der restlichen Saccharose wurden die Pellets in $5 \mathrm{~mL}$ TRIS-EGTA-Puffer resuspendiert und wie zuvor zentrifugiert. Schließlich wurden die zwei Pellets in jeweils $0,5 \mathrm{~mL}$ TRIS-EGTA-Puffer resuspendiert und bei $-20{ }^{\circ} \mathrm{C}$ gelagert. Die erhaltenen Crude Membranes wurden mithilfe des Western Blots zum Nachweis von Cx43 und Cx43-GFP analysiert (Kapitel 3.1.5).

TRIS-EGTA-Puffer

\author{
$5 \mathrm{mM}$ TRIS/HCl, $\mathrm{pH} 8,5$ \\ 1 mM EGTA \\ $1 \mathrm{mM}$ PMSF
}

\title{
Isolierung mittels immobilisierter Metallchelataffinitätschromatografie
}

Für die Isolierung von $\mathrm{Cx} 43$ und $\mathrm{Cx} 43-\mathrm{eGFP}$ wurde die immobilisierte Metallchelataffinitätschromatografie getestet. Auf diese Methode wird im Detail in Kapitel 3.1.3 eingegangen. Zunächst wurden $500 \mu \mathrm{L}$ der Membranfragmente, die mithilfe der Dichtegradientenzentrifugation isoliert wurden, für $6 \mathrm{~h}$ gegen $500 \mathrm{~mL} 5 \mathrm{mM}$ TRIS/HCl pH 8,5 dialysiert, um EGTA aus der Lösung zu entfernen. Zur Isolierung von Cx43 bzw. Cx43-eGFP wurden die dialysierte Suspension mit $500 \mu \mathrm{L} 10 \%(w / v) \quad n$-Octyl- $\beta$-D-glucopyranosid, 5 mM TRIS/HCl pH 8,5 versetzt und kurz mittels Vortexer geschüttelt. Nach $30 \mathrm{~s}$ Inkubation im Ultraschall (4 cycles, Intensität: $80 \%$ ) wurde die Suspension für 30 min bei Raumtemperatur inkubiert und anschließend für $1 \mathrm{~h}$ bei $17.000 \times g$ zentrifugiert. Der Überstand wurde mit $1 \mathrm{~mL}$ äquilibrierter Nickel-Nitrilotriessigsäure (Nitrilotriactetic Acid, NTA)-Agarose versetzt und über Nacht im Batch bei $4^{\circ} \mathrm{C}$ inkubiert. Am nächsten Tag wurde die Ni-NTAAgarose mit 10 Säulenvolumen $10 \mathrm{mM}$ Imidazol, $5 \mathrm{mM}$ TRIS/HCl pH 8,5 gewaschen und 
mit 2,5 Säulenvolumen 250 mM Imidazol, 5 mM TRIS/HCl pH 8,5 eluiert. Die erfolgreiche Isolierung wurde durch Western Blot Analyse überprüft (Kapitel 3.1.5).

\subsubsection{Heterologe Proteinexpression in Pichia pastoris}

In dieser Arbeit wurde das Expressionssystem der methylotrophen Hefe Pichia pastoris alternativ zu Dictyostelium discoideum erfolgreich zur Synthese von Cx43 und Cx43-GFP eingesetzt. Die Proteinexpression in Hefe ist mit mehreren Vorteilen verknüpft. Die Anzucht von Hefen ist mit der Kultivierung von prokaryotischen Expressionssystemen vergleichbar, da es im Gegensatz zur eukaryotischen Zellkultur relativ einfach und kosteneffektiv ist. Ein weiterer Vorteil ist, dass die Proteinexpression zur nativ gefalteten Proteinspezies führt und posttranslationale Modifikationen wie Glykosylierungen in einigen Fällen dem Ursprungsorganismus entsprechen. Neuerdings können durch gentechnisch modifizierte Hefen, deren $N$-Glykosylierungspfad humanisiert wurde, humane Glykoproteine produziert und therapeutisch eingesetzt werden. ${ }^{[118]}$ Auch die funktionelle Expression von Membranproteinen stellt immer noch eine Herausforderung dar, da bei Überexpression von Membranproteinen in Prokaryoten wie Escherichia coli oft fehlgefaltete Produkte im großen Überschuss entstehen. ${ }^{[119]}$ Die Einführung von Gensequenzen erfolgt durch homologe Rekombination in P. pastoris. ${ }^{[120]}$ Für die Induktion der Proteinexpression wird der Promoter der Alkoholoxidase 1 (AOX1), welcher der Zielsequenz vorgeschaltet ist und nur durch die Zugabe von Methanol aktiviert wird, verwendet. Methanol wird in speziellen Organellen (Peroxisomen) der Hefe zusammen mit Sauerstoff zu Formaldehyd und Wasserstoffperoxid metabolisiert. Da die AOX eine relativ schwache Affinität zu $\mathrm{O}_{2}$ hat, wird sie in großen Mengen, die bis zu $30 \%$ des löslichen Gesamtproteins in P. pastoris beim Wachstum mit Methanol ausmachen, exprimiert. Dadurch können mit der heterologen Proteinexpression relativ hohe Expressionsraten erreicht werden.

Klonierung von $C x 43$ und Cx43-GFP in PPICZ B

Die P. pastoris Klone, welche Cx43 und Cx43-GFP exprimieren, wurden durch die Firma Bayer Technology Services GmbH (BTS, Dr. Christoph Methfessel, Dr. Volker Möhrle) erstellt und im Rahmen einer Kooperation (BMBF 13N9110) bereitgestellt. Auf die Erstellung der beiden Klone soll im Folgenden eingegangen werden. Als Matrize für das Gen von Cx43 (Mus musculus) wurde die genomische DNA aus HeLa Zellen (Prof. Dr. Klaus Willeke), welche Cx43 exprimieren, mit dem Qiagen Tissue DNeasy Kit (Qiagen, Hilden) 
isoliert und mit den folgenden Primern mithilfe der Polymerasekettenreaktion (Polymerase Chain Reaction, PCR) amplifiziert. Die unterstrichenen Abschnitte markieren die Schnittstellen der Restriktionsenzyme.

Cx43 (Mus musculus) forward pPICZ B (EcoRI):

5’-AATAATGAATTCGAAACGATGGGTGACTGGAGCGCCTTGGGGAAGCT GCTGGA-3'

Cx43 (Mus musculus) reverse pPICZ B (XbaI):

\section{5'-ATATATTCTAGAATCTCCAGGTCATCAGGCCGAGGTCT-3`}

Nach abgeschlossener PCR wurden das Amplifikat und der Vektor pPICZ B (Invitrogen, Carlsbad, CA, USA) mit den Restriktionsenzymen EcoRI und XbaI geschnitten und in einer ligasekatalysierten Reaktion miteinander verknüpft. Dabei wurde das Konstrukt von Cx43 mit einem $C$-terminalen $c$-myc- und Hexahistidin-Tag hergestellt. Der Vektor pPICZ B vermittelt eine Zeocin ${ }^{\mathrm{TM}}$-Resistenz, die zur späteren Selektion der Klone dient. Die Nukleinsäure- und Aminosäuresequenz sowie die Plasmidkarte sind im Anhang zu finden (Kapitel 9.7, 9.8, 9.9). Der $c-m y c$-Tag ist eine kurze Peptidsequenz (EQKLISEEDL), welche vom Transkriptionsfaktor $c$-myc abstammt, und zur Affinitätsreinigung sowie häufig zur Detektion in der Western Blot Analyse verwendet wird. Die Affinitätsreinigung durch den $c$-myc-Tag wird selten angewandt, da nur über eine pH-Wert-Verschiebung in den sauren Bereich der AntigenAntikörper-Komplex aufgelöst werden kann. In dieser Arbeit wurde ein Hexahistidin-Tag zur Reinigung mithilfe der immobilisierten Metallchelataffinitätschromatografie (Kapitel 3.1.3) verwendet. Zur Herstellung des Cx43-GFP Konstrukts wurde zunächst die Sequenz des grünfluoreszierenden Proteins (GFP) mit der Punktmutation S65T aus dem Vektor pKkPGFP (W. Weichel) mit den folgenden Primern amplifiziert:

GFP forward pPICZ B-Cx43 (NheI):

5‘-ACTGGCGCTAGCCGCCACCATGAGCAAGGGCGAGGAAC-3‘

GFP reverse pPICZ B-Cx43 (XhoI-im Vektor pKkPGFP vorhanden):

5‘-TAGGGCCCTCTAGATGCATGTCG-3’ 
Nach der Reinigung des Amplifikats wurde es mit den Restriktionsenzymen NheI und XhoI geschnitten. Das Konstrukt von Cx43 im pPICZ B Vektor ohne Stoppcodon wurde mit XbaI und SalI verdaut und zusammen mit dem geschnittenen Amplifikat ligiert. Dabei entsteht ein Konstrukt ohne Hexahistidin-Tag. Damit auch das Cx43-GFP Konstrukt nach der Expression in $P$. pastoris über Metallchelataffinitätschromatographie gereinigt werden kann, wurde das erhaltene Cx43-GFP (ohne Hexahistidin-Tag) mithilfe der folgenden Primer amplifiziert:

Cx43-GFP forward pPICZ B (EcoRI):

\section{5'-AATAATGAATTCGAAACGATGGGTGACTGGAGCGCCTTGGGGAAGCT GCTGGA-3}

Cx43-GFP reverse pPICZ B (SalI):

\section{5'-CCATTCTAGACCGTCGACACCCTTGTACAGCTCGTCCATGCC-3‘}

Das Amplifikat sowie der Vektor pPICZ B wurden mit den Restriktionsenzymen EcoRI und SalI geschnitten und mithilfe einer DNA-Ligase miteinander verknüpft. Das entstandene Konstrukt mit dem Fusionsprotein Cx43-GFP besitzt $C$-terminal einen Hexahistidin-Tag.

Nach der erfolgreichen Klonierung wurde die Plasmid-DNA in Escherichia coli repliziert und isoliert. Die linearisierte DNA mit der 5'-AOX1-Region wurde in den P. pastoris Stamm X-33 transformiert. Der P. pastoris Stamm X-33 hat den Phänotyp Mut ${ }^{+}$(Methanol utilizing plus). Dadurch ist die Umsatzrate des Stammes X-33 von Methanol trotz der Integration des Gens, welches für das Zielprotein codiert, ähnlich wie die des Wildtyps. Mut ${ }^{\varsigma}$ (Methanol utilizing slow) Stämme besitzen nach Rekombination einen verlangsamten Methanolmetabolismus. Nach der Selektion der Transformanten durch Expressionstests konnte mit der Fermentation begonnen werden. Die ersten Fermentationen der Klone, die Cx43 bzw. Cx43GFP exprimieren, wurden auch durch Bayer Technology Services GmbH durchgeführt und ein Teil der Zellen wurde durch einen Hochdruckhomogenisator (French Press) aufgeschlossen. Die Fermentation der Klone sowie der Aufschluss wurden im Rahmen dieser Arbeit ein weiteres Mal durchgeführt. Darauf wird im Folgenden eingegangen. 
Erstellung von Cryostocks

Für die Stammhaltung wurden P. pastoris Cryostocks angelegt. Dafür wurden $25 \mathrm{~mL}$ autoklaviertes Yeast Pepton Dextrose (YPD)-Medium mit dem Antibiotikum Zeocin ${ }^{\mathrm{TM}}$ (Endkonzentration: $100 \mu \mathrm{g} \cdot \mathrm{mL}^{-1}$ ) versetzt und mit einer Einzelkolonie der P. pastoris Klone auf Malzagar angeimpft. Die Hefen wurden bis zum Erreichen einer optischen Dichte bei $600 \mathrm{~nm}$ $\left(O D_{600}\right)$ von etwa 12 bei $225 \mathrm{rpm}$ und $28^{\circ} \mathrm{C}$ kultiviert. Anschließend wurden die Zellen zentrifugiert und in neuem YPD-Medium mit $15 \%(w / v)$ Glycerol zu einer $O D_{600}$ von 50 resuspendiert. Die $1 \mathrm{~mL}$ Aliquots wurden in flüssigem Stickstoff schockgefroren und bei $-80{ }^{\circ} \mathrm{C}$ gelagert.

\section{Fermentation von Pichia pastoris}

Für die Fermentation von $P$. pastoris wurden vier Vorkulturen in YPD-Medium für $60 \mathrm{~h}$ bei 275 rpm und Raumtemperatur inkubiert. Das YPD-Medium wurde dafür steril mit Zellen der Cryostocks angeimpft. Für das Animpfen der Fermentationskultur sollte die $O D_{600} 2$ bis 6 betragen und das Inokulum ein Volumen zwischen 5 bis $10 \%$ des Startvolumens haben.

15 L-Bioreaktor - Die Fermentation von P.pastoris wurde mit dem Biostat E Typ ES (B. Braun, Melsungen) durchgeführt. Das Kulturgefäß Typ ES ist ein Ganzstahlgefäß aus Edelstahl mit abnehmbarem Deckel. Es hat ein Gesamtvolumen von $15 \mathrm{~L}$ und es wird ein Arbeitsvolumen von maximal $10 \mathrm{~L}$ empfohlen. Der außenliegende Doppelmantel dient als Wärmeaustauscher für eine konstante Temperatur. Zur Sauerstoffversorgung der Flüssigkultur erfolgt die Durchmischung mit einer zentralen Rührerwelle, die mit drei 6-Blattscheibenrührern ausgestattet ist, und vier Stromstörern an der Innenwand des Gefäßes. Das Begasungsrohr ist in den Deckel integriert. Die Probenentnahme erfolgt an einem Ventil am Rundboden, welches durch Dampfstrom sterilisiert wird. Die Messsonden ermöglichen die Verfolgung und Kontrolle von Prozessparametern wie Sauerstoffpartialdruck $\left(p\left(\mathrm{O}_{2}\right)\right)$, pH-Wert und Temperatur über mehrere Rückkopplungsschleifen. Außerdem ist es in der Zulaufkultivierung (Fed-Batch-Kultivierung) möglich die Nährstoffzusammensetzung des Nährmediums direkt zu beeinflussen.

Zunächst wurde nach Protokoll für den Fermenter (Biostat E, Typ ES, B. Braun, Melsungen) gearbeitet und die $\mathrm{pH}$-Elektrode geeicht. Im nächsten Schritt wurden $5 \mathrm{~L}$ 
Nährmedium eingefüllt und für $30 \mathrm{~min}$ bei $121^{\circ} \mathrm{C}$ autoklaviert. Gleichzeitig wurden die Drei-Kanal-Anstechgarnitur, der Abluftfilter und der Animpfkolben separat autoklaviert und anschließend angeschlossen. Nach dem Abkühlen des Mediums auf $30{ }^{\circ} \mathrm{C}$ wurde mit $25 \%$ iger ammoniakalischer Lösung ein pH-Wert von 5,0 eingestellt. Anschließend wurde 21,75 mL $\mathrm{PTM}_{1}$ Spurenelementlösung steril dazugegeben. Das Nährmedium wurde mit mindestens $200 \mathrm{~mL}$ Vorkultur steril über einen Animpfkolben inokuliert. Das Wachstum der Zellen bei $30{ }^{\circ} \mathrm{C}$ korreliert mit dem sinkenden Sauerstoffpartialdruck, dieser sollte $30 \%$ nicht unterschreiten. Es wurde mit einer Rührerumdrehung von $710 \mathrm{rpm}$ und einer Begasungsrate von 5 Slpm (Standard-Liter pro Minute) begonnen. Die Probenentnahme erfolgte mindestens am Ende jeder Fermentationsstufe sowie bei jeder Überprüfung. Die Überprüfungen erfolgten in regelmäßigen Abständen ( 1 bis 2 h), um den Fermentationsfortschritt festzuhalten. Dabei wurden die Prozessparameter festgehalten und gegebenenfalls angepasst. Außerdem wurde die $O D_{600}$ und die Zellfeuchtmasse kontrolliert sowie $1 \mathrm{~mL}$ Aliquots für die spätere Western Blot Analyse (Kapitel 3.1.5) entnommen und bei $-80{ }^{\circ} \mathrm{C}$ gelagert. Zur Metabolisierung von Glycerol benötigt $P$. pastoris Sauerstoff, ein steigender Sauerstoffpartialdruck zeigte nach $24 \mathrm{~h}$ an, dass das Glycerol der Nährlösung verbraucht war.

Anschließend wurde das Feeding mit $50 \%(w / v)$ Glycerol begonnen (Glycerol-Fed-Batch Phase). Bis dahin sollte eine Zellfeuchtmasse (ZFM) von 90 bis $150 \mathrm{~g} \cdot \mathrm{L}^{-1}$ erreicht werden, um in der Glycerol Fed-Batch Phase die Zelldichte auf eine ZFM von 180 bis $220 \mathrm{~g} \cdot \mathrm{L}^{-1} \mathrm{zu}$ steigern. Hierfür wurde die Glycerollösung $6 \mathrm{~h}$ zugegeben $\left(-18 \mathrm{~mL} \cdot \mathrm{h}^{-1}\right)$. Eine höhere Zelldichte erleichtert die Adaption der gesamten Kultur an den späteren Wechsel zu Methanol und bestimmt die Ausbeute an exprimiertem Protein. Hier sollte beachtet werden, dass eine Glycerolkonzentration über $4 \%$ toxisch wirkt. Nach Erreichen einer Zelldichte von mindestens $180 \mathrm{~g} \cdot \mathrm{L}^{-1}$ wurde das Glycerol-Feeding gestoppt und gewartet bis das gesamte Glycerol verbraucht war. Dies ist notwendig um den AOX1 Promotor vollständig zu induzieren. Anschließend wurde langsam mit dem Methanol-Feeding $\left(-18 \mathrm{~mL} \cdot \mathrm{h}^{-1}\right)$ begonnen (Methanol-Fed-Batch Phase). In den ersten 2 bis $3 \mathrm{~h}$ akkumuliert Methanol und wirkt toxisch auf die Zellen, deshalb sollte die Zufuhr und alle Parameter (v.a. $p \mathrm{O}_{2}$ ) überwacht werden. Die Anpassung der Kultur an Methanol kann durch das Abstellen des Feedings kontrolliert werden, denn ein schneller Anstieg des $p \mathrm{O}_{2}$-Wertes zeigt die Adaption an, da auch zur Metabolisierung von Methanol Sauerstoff benötigt wird. Die Methanolzufuhr wurde erhöht, bis ein $p \mathrm{O}_{2}$-Wert von $30 \%$ erreicht wurde (bis zu $58,5 \mathrm{~mL} \cdot \mathrm{h}^{-1}$ ). Die Induktion der Proteinsynthese mit 
Methanol sollte für etwa $24 \mathrm{~h}$ erfolgen. Schließlich wurden die Zellen bei $3.901 \times g$ und $4{ }^{\circ} \mathrm{C}$ zentrifugiert, portionsweise zu etwa $200 \mathrm{~g}$ in flüssigem Stickstoff schockgefroren und bei $-80{ }^{\circ} \mathrm{C}$ gelagert.

Nährlösung (5 L)

$$
\begin{gathered}
133,5 \mathrm{~mL} \mathrm{H}_{3} \mathrm{PO}_{4}(85 \%) \\
4,65 \mathrm{~g} \mathrm{CaSO}_{4} \\
91 \mathrm{~g} \mathrm{~K}_{2} \mathrm{SO}_{4} \\
74,5 \mathrm{~g} \mathrm{KOH}^{-} \\
200 \mathrm{~g} \mathrm{Glycerol} \\
\text { Endvolumen: } 5 \mathrm{~L}
\end{gathered}
$$

$\mathrm{PTM}_{1}$ Spurenelementlösung

$$
\begin{aligned}
& 0,6 \mathrm{~g} \mathrm{CuSO}_{4} \cdot 5 \mathrm{H}_{2} \mathrm{O} \\
& 8 \mathrm{mg} \mathrm{NaI} \\
& 0,3 \mathrm{~g} \mathrm{MnSO}_{4} \cdot \mathrm{H}_{2} \mathrm{O} \\
& 0,02 \mathrm{~g} \mathrm{Na}_{2} \mathrm{MoO}_{4} \cdot 2 \mathrm{H}_{2} \mathrm{O} \\
& 2 \mathrm{mg} \mathrm{H}_{3} \mathrm{BO}_{3} \\
& 0,05 \mathrm{~g} \mathrm{CoCl}_{2} \\
& 2 \mathrm{~g} \mathrm{ZnCl}_{2} \\
& 6,5 \mathrm{~g} \mathrm{FeSO}_{4} \cdot 7 \mathrm{H}_{2} \mathrm{O} \\
& \text { 0,02 g Biotin } \\
& 5 \mathrm{~mL} \mathrm{H}_{2} \mathrm{SO}_{4} \text { (konz.) } \\
& \text { Endvolumen: } 100 \mathrm{~mL} \\
& 500 \text { g Glycerol } \\
& 12 \mathrm{~mL} \mathrm{PTM}_{1} \text { Spurenelementlösung } \\
& 2 \text { L Methanol (100 \%) } \\
& 24 \mathrm{~mL} \mathrm{PTM}_{1} \text { Spurenelementlösung } \\
& 1 \% \text { Hefeextrakt } \\
& 2 \% \text { Pepton } \\
& 2 \% \text { Glucose (getrennt autoklavieren) }
\end{aligned}
$$$$
50 \% \text { (w/v) Glycerol }
$$$$
\text { (1 L, Feeding) }
$$$$
100 \% \text { Methanol (2 L, }
$$$$
\text { Feeding) }
$$

YPD-Medium 


\subsubsection{Zellaufschluss von Pichia pastoris}

Der Aufschluss von Hefezellen erfordert im Vergleich zu Escherichia coli hohe Kräfte, um die Zellwand zu zerstören. Die Zellhülle setzt sich aus der Plasmamembran, dem Periplasma und der Zellwand zusammen. Die Hefezellwand (100 bis $200 \mathrm{~nm}$ ) ist zum einen aus Polysacchariden wie $\beta$-Glucan, Mannan sowie Chitin aufgebaut und zum anderen spielen Glykoproteine für ihre Widerstandsfähigkeit eine Rolle. Jedoch unterscheiden sich auch die verschiedenen Hefegattungen in der Festigkeit ihrer Zellwand. In dieser Arbeit wurde zum Aufschluss von $P$. pastoris die Hochdruckdispersion verwendet und am Institut für Biochemie und Biotechnologie der Martin-Luther-Universität Halle-Wittenberg durchgeführt.

Nachdem das Wasserbad zur Kühlung des Hochdruckhomogenisators (GaulinHomogenisator, APV-Schröder GmbH, Lübeck) auf $1{ }^{\circ} \mathrm{C}$ abgekühlt war, wurden etwa 1,5 L kühles Reinstwasser in den Trichter eingefüllt und der Hochdruckhomogenisator eingeschaltet. Der Gaulin-Homogenisator wurde zunächst mit Reinstwasser gespült und der Sollwert des Wasserbades auf $-7,5^{\circ} \mathrm{C}$ reduziert. Nach dem Spülen wurde dieses gegen gekühltes Reinstwasser ausgetauscht, mehrmals Druck angelegt um Luft aus dem System zu beseitigen und gegen $50 \mathrm{mM}$ TRIS/ $\mathrm{HCl}$ pH 7,0 ausgetauscht. Nach Erreichen von etwa $-3,5^{\circ} \mathrm{C}$ wurde der Puffer gegen die Zellsuspension ausgetauscht. Hierfür wurden die gefrorenen $P$. pastoris Zellen in $1 \mathrm{~L} 50 \mathrm{mM}$ TRIS/HCl pH 7,0 mithilfe eines Dispergierers (Ultra Turrax $^{\oplus}, \mathrm{IKA}^{\oplus}$-Labortechnik, Staufen) resuspendiert. Danach wurde für $1 \mathrm{~h}$ mehrmals Druck (bis 600 bar) angelegt. Der Druck wurde jeweils solange appliziert, bis die Lösung sich erwärmt (30 bis $180 \mathrm{~s}$ ). Da bei höheren Temperaturen auch Proteasen aktiver sind und das Protein geschützt werden sollte, wurde der Druck regelmäßig wieder verringert.

Die Suspension wurde anschließend aufgefangen und bei $4.000 \times g$ für $10 \mathrm{~min}$ zentrifugiert. Da das Pellet mehrere unterschiedliche Schichten aufwies, wurden diese getrennt bei $-80^{\circ} \mathrm{C}$ gelagert. Der Überstand wurde anschließend für $1 \mathrm{~h}$ bei $16.000 \times g$ zentrifugiert. Auch hier wurden die Pellets gesammelt und bei $-80{ }^{\circ} \mathrm{C}$ gelagert. Die Lokalisation des Zielproteins wurde durch Western Blot Analyse (Kapitel 3.1.5) überprüft. 


\subsubsection{Immobilisierte Metallchelataffinitätschromatografie}

Die Isolierung von Proteinen war bis Mitte der 1990er Jahre mit zahlreichen zeitaufwendigen Reinigungsschritten verbunden. Erst durch die Einführung verschiedener Affinitätschromatografietechniken wurde die Proteinreinigung vereinfacht und beschleunigt. Zur Reinigung von Cx43 und Cx43-GFP wurde die immobilisierte Metallionenaffinitätschromatografie (Immobilized Metal Ion Affinity Chromatography, IMAC) verwendet. Porath et al. schufen die Basis für diese Art der Chromatografie. ${ }^{[121,122]}$ Dabei ist Nitrilotriessigsäure (Nitrilotriacetic Acid, NTA) an eine feste Matrix kovalent gebunden. Die immobilisierte NTA bildet Chelate mit Metallionen wie $\mathrm{Cu}^{2+}, \mathrm{Ni}^{2+}, \mathrm{Zn}^{2+}, \mathrm{Co}^{2+}, \mathrm{Fe}^{2+}$ und $\mathrm{Fe}^{3+}$. In diesem oktaedrischen Komplex werden die freien Koordinationsstellen durch Wasser besetzt und können leicht durch andere Lewis-Basen verdrängt werden. Deshalb ist es möglich, dass basische Gruppen von Proteinen mit diesen in Wechselwirkung treten. Unter anderem bindet Histidin sehr spezifisch an die Koordinationsstellen des Metalls und auf diese Weise kann ein Polyhistidin-Tag zur Reinigung eines Proteins mit dieser Methode dienen. Die Elution des Proteins erfolgt durch Zugabe eines Überschusses an Imidazol, sodass Histidin kompetitiv aus dem Ni-NTA-Komplex verdrängt wird. Eine andere Möglichkeit bietet die Erniedrigung des $\mathrm{pH}-$ Werts $(<5)$. Bei diesem $\mathrm{pH}$ liegt Histidin vollständig protoniert vor und kann dadurch nicht mehr mit dem Chelatkomplex interagieren. Alternativ kann Ethylendiamintetraessigsäure (Ethylenediaminetetraacetic Acid, EDTA) zur Elution verwendet werden, wobei Nickel im Komplex mit EDTA und das Protein eluiert werden. Unter Verwendung der IMAC können Zellextrakte effektiv von Fremdproteinen gereinigt werden. Ein Problem dieser Technik ist, dass auch auf der Proteinoberfläche von einigen Fremdproteinen, bedingt durch ihre dreidimensionale Struktur, lokal mehrere Histidine exponiert sein können und infolgedessen ähnlich stark an die Matrix binden. Zur Verbesserung der Reinheit kann deshalb mit kontinuierlichen oder diskontinuierlichen Imidazolgradienten gearbeitet werden, wodurch ein Teil der unspezifisch bzw. schwach gebundenen Proteine vor der Elution des Zielproteins entfernt werden können. In dieser Arbeit wurden zwei verschiedene Protokolle für die Reinigung von Cx43 und Cx43-GFP aus P. pastoris verwendet. Darauf soll im Folgenden eingegangen werden. 


\section{Reinigung nach Atsu}

Die Reinigung von Atsu wurde von der Arbeitsgruppe von Prof. G. Sosinsky (UCSD, San Diego, CA, USA) erfolgreich für die Reinigung von Cx26 aus Insektenzellen eingesetzt und für Cx43 übernommen. Zunächst wurden die pelletierten Membranfragmente (etwa $4 \mathrm{~g}$ ) des Aufschlusses von P. pastoris (Kapitel 3.1.2) in $10 \mathrm{~mL}$ Bicarbonatpuffer unter Rühren bei $4{ }^{\circ} \mathrm{C}$ für etwa $2 \mathrm{~h}$ resuspendiert. Zur vollständigen Resuspendierung wurde die Suspension mehrmals für einen Zyklus von 30 s und einer Intensität von $30 \%$ mithilfe von Ultraschall (UW 2070 Tip-Sonifier, Bandelin electronics, Berlin) behandelt. Anschließend wurde die Suspension in $1 \mathrm{~mL}$ Aliquots bei $-80^{\circ} \mathrm{C}$ gelagert. Pro Aliquot der resuspendierten Membranfragmente wurde $500 \mu \mathrm{L}$ dreifach-konzentrierter Solubilisierungspuffer und 1,5 $\mu \mathrm{L}$ Phenylmethylsulfonylfluorid (PMSF, 1 M) zugegeben. Zur Solubilisierung des Proteins wurde die Suspension für 2,5 h auf Eis sowie $10 \mathrm{~min}$ bei Raumtemperatur inkubiert. Anschließend wurde die Lösung für $30 \mathrm{~min}$ bei $17.000 \times g$ und $4{ }^{\circ} \mathrm{C}$ zentrifugiert, um alle unlöslichen Bestandteile abzutrennen. Zur Äquilibrierung wurde $1 \mathrm{~mL} \mathrm{Ni-NTA-Agarose} \mathrm{sukzessive} \mathrm{mit}$ dreimal $1 \mathrm{~mL}$ Waschpuffer und $1 \mathrm{~mL}$ Bindungspuffer suspendiert und zentrifugiert. Zum Schluss wurde die Affinitätsmatrix in ein $50 \mathrm{~mL}$ Greinerröhrchen überführt und mit weiteren 45 mL Bindungspuffer versetzt. Im nächsten Schritt wurde der Überstand der Zentrifugation mit solubilisiertem Protein zur äquilibrierten Ni-NTA-Agarose gegeben und über Nacht auf Eis inkubiert (Batch-Verfahren).

Am nächsten Tag wurde die Suspension bei $1.204 \times g$ für 2 min und $4{ }^{\circ} \mathrm{C}$ zentrifugiert und die Ni-NTA-Agarose in ein $2 \mathrm{~mL}$ Reaktionsgefäß überführt. Im nächsten Schritt wurde die Ni-NTA-Agarose sequentiell mit dreimal $1 \mathrm{~mL}$ Waschpuffer gespült und zentrifugiert $\left(6.200 \times g, \quad 4^{\circ} \mathrm{C}, 1 \mathrm{~min}\right)$. Anschließend wurde der Überstand entfernt und $1 \mathrm{~mL}$ Elutionspuffer zugegeben und kurz mittels Vortexer geschüttelt. Zur Elution des Proteins wurde die Ni-NTA-Agarose für $1 \mathrm{~h}$ auf Eis unter Schwenken inkubiert und hinterher bei $6.200 \times g$ und $4{ }^{\circ} \mathrm{C}$ für $1 \mathrm{~min}$ zentrifugiert. Das Eluat wurde bei $4{ }^{\circ} \mathrm{C}$ gelagert. Für die Isolierung von Cx43 wurde für den Bindungs-, Wasch- und Elutionspuffer ein pH-Wert von 7,4 und für Cx43-GFP von 8,0 verwendet, da der berechnete isoelektrische Punkt von Cx43 bei 8,6 und von Cx43-GFP bei 7,3 liegt. 
Bicarbonatpuffer

$3 \times$ Solubilisierungspuffer

Bindungspuffer

Waschpuffer

\section{Elutionspuffer}

$$
1 \mathrm{mM} \mathrm{NaHCO}_{3} \text { pH 7,4 }
$$

$9 \%(w / v) n$-Dodecyl- $\beta$-D-maltosid $3 \mathrm{M} \mathrm{NaCl}$

$0,005 \%(w / v) \mathrm{NaN}_{3}$

30 mM HEPES pH 7,4 bzw. 8,0

$0,2 \%(w / v) n$-Dodecyl- $\beta$-D-maltosid $1 \mathrm{M} \mathrm{NaCl}$

$0,005 \%(w / v) \mathrm{NaN}_{3}$

10 mM HEPES pH 7,4 bzw. 8,0

$0,2 \%(w / v) n$-Dodecyl- $\beta$-D-maltosid $1 \mathrm{M} \mathrm{NaCl}$

10 mM Imidazol

$0,005 \%(w / v) \mathrm{NaN}_{3}$

10 mM HEPES pH 7,4 bzw. 8,0

$0,2 \%(w / v) n$-Dodecyl- $\beta$-D-maltosid

$1 \mathrm{M} \mathrm{NaCl}$

1 M Imidazol

$0,005 \%(w / v) \mathrm{NaN}_{3}$

10 mM HEPES pH 7,4 bzw. 8,0 


\section{Reinigung nach Bao et al. ${ }^{[123]}$}

Die Membranfragmente von $P$. pastoris wurden für die affinitätschromatografische Reinigung von Cx43 und Cx43-GFP wie für die Reinigung nach Atsu präpariert. Zunächst wurden pro $1 \mathrm{~mL}$ Aliquot der resuspendierten Membranfragmente $5 \mu \mathrm{L} 4 \mathrm{M} \mathrm{NaOH}$ zugegeben. Danach wurde die Suspension für $60 \mathrm{~s}$ bei einer Intensität von $75 \%$ mit Ultraschall (4 cycles) behandelt und für $30 \mathrm{~min}$ und $4^{\circ} \mathrm{C}$ im Überkopfschüttler (VWR, Darmstadt) inkubiert. Anschließend wurde bei $35.000 \times g$ für $30 \mathrm{~min}$ und $4{ }^{\circ} \mathrm{C}$ zentrifugiert. Für die Solubilisierung von Cx43 oder Cx43-GFP wurde das erhaltene Pellet mit $500 \mu \mathrm{L}$ Solubilisierungspuffer versetzt und für $60 \mathrm{~s}$ bei einer Intensität von $75 \%$ im Ultraschall wie zuvor behandelt. Die Suspension wurde für $2 \mathrm{~h}$ auf Eis inkubiert. Anschließend wurde die Lösung bei $35.000 \times g$ für $40 \mathrm{~min}$ und $4^{\circ} \mathrm{C}$ zentrifugiert. Der Überstand wurde mit dem 15-fachen Volumen des Verdünnungspuffers sowie mit der sequentiell im Wasch- und Verdünnungspuffer äquilibrierten Ni-NTA-Agarose versetzt $(1 \mathrm{~mL})$ und über Nacht bei $4{ }^{\circ} \mathrm{C}$ im Überkopfschüttler inkubiert.

Am nächsten Tag wurde die Lösung abzentrifugiert $(1.204 \times g, 2 \mathrm{~min})$. Die in $2 \mathrm{~mL}$ Überstand resuspendierte Matrix wurde wiederholt zentrifugiert und anschließend sequentiell mit dreimal $1 \mathrm{~mL}$ Waschpuffer gespült. Die zentrifugierte Ni-NTA-Agarose wurde mit $1 \mathrm{~mL}$ Elutionspuffer versetzt, mittels Vortexer geschüttelt und für $1 \mathrm{~h}$ und $4^{\circ} \mathrm{C}$ im Überkopfschüttler inkubiert. Nach Zentrifugation wurde das Eluat bei $4{ }^{\circ} \mathrm{C}$ gelagert. Der $\mathrm{pH}$ Wert der verwendeten Puffer orientiert sich wie bei der Reinigung nach Atsu an den isoelektrischen Punkten von Cx43 und dem Fusionsprotein.

\section{Solubilisierungs- puffer}

Verdünnungspuffer
2,5\% $(w / v) n$-Dodecyl- $\beta$-D-maltosid

$$
2 \mathrm{M} \mathrm{NaCl}
$$

10 mM PMSF

$10 \mathrm{mM}$ DTT

10 mM Glycin pH 10,0

$0,2 \%(w / v) n$-Dodecyl- $\beta$-D-maltosid

$1 \mathrm{mM}$ PMSF

$10 \mathrm{mM} \beta$-Mercaptoethanol

100 mM HEPES pH 7,4 bzw. 8,0 


Waschpuffer $\quad \begin{gathered}0,01 \%(w / v) n \text {-Dodecyl- } \beta \text {-D-maltosid } \\ 100 \mathrm{mM} \mathrm{KCl} \\ 20 \mathrm{mM} \mathrm{Imidazol} \\ 0,1 \mathrm{mM} \text { EDTA } \\ 10 \mathrm{mM} \text { HEPES pH 7,4 bzw. 8,0 } \\ 0,01 \%(w / v) n \text {-Dodecyl- } \beta \text {-D-maltosid } \\ 100 \mathrm{mM} \mathrm{KCl} \\ 1 \mathrm{M} \mathrm{Imidazol} \\ 0,1 \mathrm{mM} \text { EDTA } \\ 10 \mathrm{mM} \mathrm{HEPES} \mathrm{pH} \mathrm{7,4} \mathrm{bzw.} \mathrm{8,0}\end{gathered}$

\subsubsection{Diskontinuierliche SDS-Polyacrylamid-Gelelektrophorese}

Die diskontinuierliche Sodiumdodecylsulfat-Polyacrylamidgelelektrophorese (SDS-PAGE) beruht auf dem System nach Laemmli und dient der elektrophoretischen Auftrennung von Proteingemischen entsprechend ihres Molekulargewichts. ${ }^{[124]}$ Im Idealfall erhalten die denaturierten Proteine durch das anionische Detergens SDS der Masse proportionale negative Ladung und werden während der Elektrophorese nur nach ihrem Molekulargewicht getrennt (ca. 1,4 g SDS/1 g Protein). Zusätzlich führt die Verwendung von Dithiotreitol (DTT) oder $\beta$-Mercaptoethanol zur Reduzierung von Disulfidbrücken, sodass die Proteinstruktur komplett entfaltet wird. Zur elektrophoretischen Trennung der Proteine ist eine poröse Matrix erforderlich. Zu diesem Zweck wurden Polyacrylamidgele verwendet. Die poröse Struktur der Gele bedingt bei der elektrophoretischen Trennung von Molekülen eine unterschiedliche Wanderungsgeschwindigkeit, die abhängig von der Masse des Moleküls ist. Zur Herstellung dieser porösen Matrices wird ein Gemisch aus Acrylamid/Bisacrylamid mithilfe des Polymerisationsinitiators Ammoniumperoxodisulfat (APS) und des Polymerisationskatalysators $N, N, N^{\prime}, N^{\prime}$-Tetramethylethylendiamin (TEMED) miteinander vernetzt. Die Konzentration von Acrylamid/Bisacrylamid und der Radikalstarter bestimmen den Vernetzungsgrad der Matrix. Da es beim Eintritt in eine engporige Gelmatrix zur Proteinaggregation kommen kann, wird hier die diskontinuierliche Gelelektrophorese verwendet. Die Verwendung eines weitporigen Sammelgels erleichtert den Eintritt in die Gelmatrix. Durch das Puffersystem aus TRIS-Chlorid/TRIS-Glycin kommt es nach Anlegen einer Spannung im 
Sammelgel zu einer Aufkonzentrierung der Proteine entsprechend ihrer elektrophoretischen Mobilität zwischen dem Leition Chlorid und dem Folgeion Glycin. Erst im engporigen Trenngel findet die eigentliche Trennung der Proteine gemäß Molekulargewicht statt. ${ }^{[125]}$

Zunächst wurde zwischen die Glasplatten des vertikalen Gelelektrophoresesystems (PerfectBlue $^{\text {m }}$ Vertikale Doppelgelsysteme, PEQLAB Biotechnologie GmbH, Erlangen) das 12,5 \%ige Trenngel ( $4 \mathrm{~mL}$ Stammlösung, $40 \mu \mathrm{L} 10 \%(w / v)$ APS, $2 \mu \mathrm{L}$ TEMED) gegossen und mit Reinstwasser oder Isopropanol überschichtet. Nach 45 min wurde das Sammelgel (2 mL Stammlösung, $20 \mu \mathrm{L} 10 \%(w / v)$ APS, $2 \mu \mathrm{L}$ TEMED) auf das Trenngel gegossen und mit einem Kamm die Probentaschen erzeugt. Die Proben wurden 1:1 mit zweifachem Probenpuffer versetzt und für $10 \mathrm{~min}$ bei $80^{\circ} \mathrm{C}$ im Thermomixer erhitzt. Anschließend wurden die Probentaschen gefüllt und die Elektrophorese bei $15 \mathrm{~mA}$ pro Gel und $150 \mathrm{~W}$ für etwa 1,5 h durchgeführt. Mithilfe des Massenstandards (Low Molecular Weight Calibration Kit for SDS Electrophoresis, GE Healthcare, München und SigmaMarker, Wide Range, SigmaAldrich, Taufkirchen) wurden die Molekulargewichte der getrennten Proteine bestimmt.

Trenngel-Stammlösung

SammelgelStammlösung

$2 \mathrm{x}$ Probenpuffer

Laufpuffer

Massenstandard

(Low Molecular
$258 \mathrm{mM}$ TRIS/HCl pH 6,8

12,5 \% Acrylamid-Bisacrylamid-Stammlösung (37,5:1, 30 \%) $0,1 \%(w / v)$ SDS

$127 \mathrm{mM}$ TRIS/HCl pH 8,8

$5,2 \%(w / v)$ Acrylamid-Bisacrylamid-Stammlösung $0,1 \%(v / v)$ SDS

$125 \mathrm{mM}$ TRIS/HCl pH 6,8

$100 \mathrm{mM}$ DTT

$20 \%(v / v)$ Glycerol

$2 \%(w / v)$ SDS

$0,02 \%(w / v)$ Bromphenolblau

$25 \mathrm{mM}$ TRIS

192 mM Glycin

$0,1 \%(w / v)$ SDS

$97 \mathrm{kDa}$ Phosphorylase b 


Weight) $\begin{aligned} & 66 \mathrm{kDa} \text { Rinderserumalbumin } \\ & 45 \mathrm{kDa} \text { Ovalbumin } \\ & 30 \mathrm{kDa} \text { Katalase } \\ & 20,1 \mathrm{kDa} \text { Trypsininhibitor } \\ & 14,4 \mathrm{kDa} \alpha \text {-Lactalbumin } \\ & 205 \mathrm{kDa} \text { Myosin } \\ & 116 \mathrm{kDa} \beta \text {-Galaktosidase } \\ & 97 \mathrm{kDa} \text { Phosphorylase b } \\ & \text { Massenstandard } \\ & \text { (Wide Range) } \\ & 64 \mathrm{kDa} \text { Fructose-6-phosphatkinase } \\ & 55 \mathrm{kDa} \text { Albumin } \\ & 45 \mathrm{kDa} \text { Ovalbumin } \\ & 36 \mathrm{kDa} \text { Glycerin-3-phosphatdehydrogenase } \\ & 29 \mathrm{kDa} \text { Katalase } \\ & 24 \mathrm{kDa} \text { Trypsinogen } \\ & 20 \mathrm{kDa} \text { Trypsininhibitor } \\ & 14,2 \mathrm{kDa} \alpha \text {-Lactalbumin } \\ & 6,5 \mathrm{kDa} \text { Aprotinin }\end{aligned}$

\section{Coomassiefärbung}

Nach der Elektrophorese wurde das Gel für 10 min in Reinstwasser geschwenkt. Danach wurde das Gel mit der Coomassie-Färbung nach Dyballa und Metzger versetzt und über Nacht inkubiert. ${ }^{[126]}$ Diese Färbung beruht auf den Arbeiten von Kang et al. und Candiano et al. und besitzt im Gegensatz zur konventionellen Coomassie-Färbung die Sensitivität der Silberfärbung. ${ }^{[127,128]}$ Eine Entfärbung der Gele war bei dieser Methode nicht notwendig. Anschließend wurde das Gel mithilfe der DOC-PRINT VX2 (Vilber Lourmat, Eberhardzell) dokumentiert. 


$$
\begin{array}{r}
10 \%(w / v) \text { Ethanol }(96 \%) \\
2 \%(v / v) \mathrm{H}_{3} \mathrm{PO}_{4}(100 \%)
\end{array}
$$

\subsubsection{Western Blot Analyse}

Für den spezifischen Nachweis der Isolierung von Cx43 und Cx43-GFP wurde die Western Blot Analyse genutzt. Zu diesem Zweck wurde das elektrophoretisch getrennte Protein mittels Elektrophorese auf eine hydrophobe Membran transferiert (Blotting). ${ }^{[129,130]}$ Die Zeit des Transfers muss für jede Probe optimiert werden, da Faktoren wie das Molekulargewicht, der isoelektrische Punkt und die Porengröße des Gels das Ergebnis bzw. die Transfereffizienz beeinflussen. Nach der Übertragung werden die Proteinbanden reversibel mit Ponceau S angefärbt, um den Massenstandard zu markieren. Zum spezifischen Nachweis des Zielproteins wird meist ein monoklonaler Antikörper, der gegen eine kurze Sequenz des Zielproteins gerichtet ist, als primärer Antikörper verwendet. In dieser Arbeit wurde das Immunglobulin connexin 43 D-7 verwendet. Dieser ist gegen das Antigen, bestehend aus den Aminosäuren 241 bis 254 des $C$-Terminus von Cx43 (Abb. 1-6), gerichtet. Im nächsten Schritt erkennt der sekundäre Antikörper einen Teil der konstanten Region des ersten Antikörpers. Der zweite Antikörper ist entweder an die Meerrettichperoxidase (Horseradish Peroxidase, HRP) oder alkalische Phosphatase gekoppelt. Letztere ermöglicht die Visualisierung des erkannten Zielproteins direkt auf der Membran. Der Einsatz der Meerrettichperoxidase zeichnet sich durch eine zehnmal höhere Sensitivität als die alkalische Phosphatase aus. Das Enzym katalysiert die Oxidation von Luminol (3-Aminophthalsäurehydrazid) durch Wasserstoffperoxid, wobei es zu einer Chemilumineszenzreaktion kommt. Aufgrund des polyklonalen, sekundären Antikörpers und der Chemilumineszenzreaktion wird das Signal amplifiziert. Dies kann mithilfe eines fotografischen Films visualisiert werden. Der Einsatz von Tween 20 als nichtionisches Detergens verbessert die Spezifität, da dadurch unspezifisch gebundener Antikörper von der Membran entfernt wird.

In dieser Arbeit wurde das Semidry Blotting Verfahren verwendet. Es hat den Vorteil gegenüber dem Tank Blotting, dass es durch Erreichen eines homogenen elektrischen Feldes und höheren Feldstärken einen effizienten Proteintransfer in kurzer Zeit gewährleistet. ${ }^{[125]}$ Zunächst wurden für die Prozedur vier Filterpapierstreifen (Whatman Paper), und eine Nitrozellulosemembran in Gelgröße und das Gel in Transferpuffer für bis zu 30 min äquilibriert. Der Transferpuffer dient dazu, den Gehalt an Salz und Detergenzien aus der Gelelektro- 
phorese zu senken. Nach der Äquilibrierung wurde die Blotting-Apparatur (Trans-Blot ${ }^{\oplus}$ SD Semi-Dry Electrophoretic Transfer Cell, Bio-Rad Laboratories GmbH, München) nach Abb. 3-1 aufgebaut und für $45 \mathrm{~min}$ bei $15 \mathrm{~V}$ und $180 \mathrm{~mA}\left(3 \mathrm{~mA}\right.$ pro $\left.\mathrm{cm}^{2}\right)$ pro Gel durchgeführt. Danach wurden die übertragenen Proteine mit Ponceau S-Lösung für etwa 2 min gefärbt, mit Reinstwasser etwas entfärbt und die Banden des Massenstandards (Kapitel 3.1.4) mit Kugelschreiber markiert. Zur Maskierung freier Bindungsstellen auf der Nitrozellulose wurde die Membran mit einer Suspension aus 5\%(w/v) Magermilchpulver in Tris Buffered Tween (TBT)-Puffer für mindestens eine Stunde inkubiert.

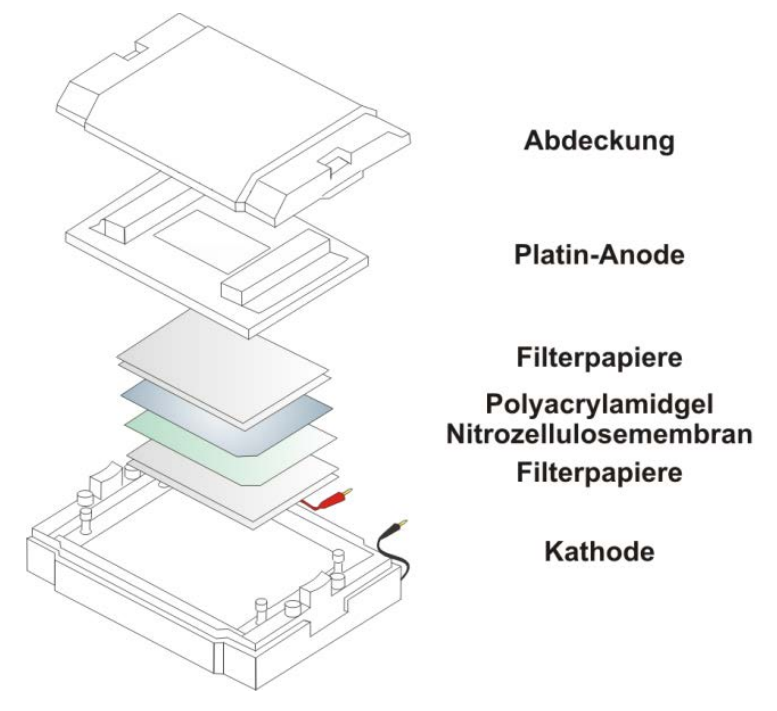

Abb. 3-1: Schematische Darstellung des Aufbaus der Western Blot Apparatur. Im Semidry Blotting Verfahren werden zwei Filterpapiere, die Nitrozellulosemembran, das Polyacrylamidgel und wieder zwei Filterpapiere von der Kathode zur Anode blasenfrei übereinander gestapelt und die Platinelektrode (Anode) drückt durch eine Feder den Stapel zusammen, damit entstehende Gase während der Elektrophorese den Stapel nicht auseinander drücken. Die Abbildung wurde nach [131] angefertigt.

Die Inkubation mit dem primären Antikörper wurde unter Schwenken für $1 \mathrm{~h}$ bei Raumtemperatur durchgeführt. Danach wurde dreimal für jeweils $10 \mathrm{~min}$ mit TBT-Puffer gewaschen. Im Anschluss wurde die Membran mit dem sekundären Antikörper für $1 \mathrm{~h}$ bei $4{ }^{\circ} \mathrm{C}$ inkubiert und nochmals dreimal für 20 min mit TBT-Puffer gespült. Die Antikörper wurden in Tab. 3-1 angegebenen Verdünnungen in 5\%(w/v) Magermilch/TBT-Puffer verwendet. 
Tab. 3-1: Eingesetzte Verdünnungen der primären und sekundären Antikörper.

\begin{tabular}{|c|c|c|}
\hline Antikörper & Bezugsquelle & Verdünnung \\
\hline $\begin{array}{c}\text { connexin 43 D-7 monoklonaler } \\
\text { IgG } ; \text { (primärer Antikörper) }\end{array}$ & $\begin{array}{c}\text { Santa Cruz Biotechnology, Inc., Santa } \\
\text { Cruz }\end{array}$ & $1: 400$ \\
\hline $\begin{array}{c}\text { goat anti-mouse IgG-HRP; } \\
\text { (sekundärer Antikörper) }\end{array}$ & Santa Cruz Biotechnology, Inc., Santa & $1: 2.000$ \\
\hline $\begin{array}{c}\text { Penta-Histidin Antikörper; } \\
\text { (primärer Antikörper) }\end{array}$ & Qruz & \\
\hline
\end{tabular}

Für die Visualisierung der Chemilumineszenzreaktion wurden alle weiteren Schritte in der Dunkelkammer durchgeführt. Es wurden jeweils $1 \mathrm{~mL}$ Enhanced Chemiluminescence (ECL)Lösung 1 und 2 gemischt und die Membran für etwa 1 bis 2 min benetzt. Anschließend wurde die Membran in eine Klarsichtfolie eingelegt, in die Belichtungskassette gelegt und ein zugeschnittener Detektionsfilm für $30 \mathrm{~s}$ bis $2 \mathrm{~h}$ (je nach Intensität) aufgelegt. Zur Entwicklung des Detektionsfilms wurde der Film für 5 bis 10 min in Entwickler geschwenkt, mit Wasser gewaschen und für 5 bis 10 min in Fixierlösung gelegt. Schließlich wurde der Film mit Wasser gespült und getrocknet.

Transferpuffer

Ponceau S-Lösung

TBT-Puffer

ECL 1
$150 \mathrm{mM}$ Glycin

$20 \mathrm{mM}$ TRIS

$$
\begin{aligned}
& 0,05 \%(w / v) \text { SDS } \\
& 20 \%(v / v) \text { Methanol }
\end{aligned}
$$

$$
\begin{aligned}
& 0,2 \%(w / v) \text { Ponceau S } \\
& 3 \%(v / v) \text { Trifluoressigsäure }
\end{aligned}
$$

$150 \mathrm{mM} \mathrm{NaCl}$

10 mM TRIS/HCl pH 7,4

$$
0,2 \%(v / v) \text { Tween } 20
$$

100 mM TRIS/HCl pH 8,8

$$
\begin{aligned}
& \text { 2,5 mM Luminol } \\
& \text { 0,4 mM Coumarinsäure }
\end{aligned}
$$


$0,02 \%(v / v) \mathrm{H}_{2} \mathrm{O}_{2}(30 \%)$

\subsubsection{Bestimmung der Proteinkonzentration}

Aufgrund der spektroskopischen Eigenschaften der Proteinstruktur kann die Konzentration von Proteinen mithilfe der UV/Vis-Spektroskopie ermittelt werden. Dieses Phänomen beruht auf der Aufnahme von elektromagnetischer Strahlung durch ein Molekül und wird im Kapitel 3.3 ausführlich behandelt. Photometrisch kann zum einen die Absorption der Peptidbindung bei $205 \mathrm{~nm}$ und zum anderen die der aromatischen Aminosäuren, wie Phenylalanin, Tyrosin und Tryptophan, bei $280 \mathrm{~nm}$ zur Konzentrationsbestimmung genutzt werden. Die Absorption der aromatischen Aminosäuren ist im Vergleich zur Absorption der Peptidbindung weitaus höher und wird normalerweise zur Proteinkonzentrationsbestimmung genutzt.

Die Proteinkonzentration wurde anhand der Absorption bei $280 \mathrm{~nm}\left(A_{280}\right)$ durch ein Spektrophotometer bestimmt. Dafür wurde eine Quarzküvette von $1 \mathrm{~cm}$ Schichtdicke für die Messung benutzt. Die lineare Abhängigkeit zwischen Absorption und Konzentration einer Substanz wird durch das Lambert-Beersche Gesetz beschrieben.

$$
A=\log \frac{I_{0}}{I}=\varepsilon \cdot c \cdot d
$$

$A$ beschreibt die Absorption, $I_{0}$ und $I$ ist die Intensität des eingestrahlten und austretenden Lichtes, $\varepsilon$ der molare Absorptionskoeffizient des Proteins, $c$ die Konzentration des Proteins (in mol. $\mathrm{L}^{-1}$ ) und $d$ die Schichtdicke (in $\mathrm{cm}$ ). Bei einer Schichtdicke von $1 \mathrm{~cm}$ wird $A$ auch als Optische Dichte $(O D)$ bezeichnet. Die lineare Abhängigkeit von Absorption und Konzentration gilt nur für verdünnte Lösungen mit einer Absorption $\leq 1$. Die Berechnung der molaren Absorptionskoeffizienten für eine Wellenlänge von $280 \mathrm{~nm}$ wurde mithilfe des ProtParam Tool's durchgeführt und basiert auf den Annahmen von Gill et al. ${ }^{[132,133]}$ Hier werden sowohl die aromatischen Aminosäuren als auch Disulfidbrücken berücksichtigt. Für Cx43 und Cx43-GFP aus P.pastoris konnte ein molarer Absorptionskoeffizient von $57.340 \mathrm{M}^{-1} \cdot \mathrm{cm}^{-1}$ und $79.355 \mathrm{M}^{-1} \cdot \mathrm{cm}^{-1}$ berechnet werden. Außerdem wurde alternativ die Konzentration des Fusionsproteins über die Absorption des Chromophors von GFP bei 
$489 \mathrm{~nm}$ bestimmt. Hierfür wurde ein molarer Absorptionskoeffizient von $58.000 \mathrm{M}^{-1} \cdot \mathrm{cm}^{-1}$ nach Patterson et al. verwendet. ${ }^{[134]}$

Die Bestimmung der Absorption bei $280 \mathrm{~nm}$ und $489 \mathrm{~nm}$ sowie die Aufnahme von Absorptionsspektren im Bereich von $240 \mathrm{~nm}$ bis $600 \mathrm{~nm}$ wurden an einem Einstrahlphotometer durchgeführt. Der prinzipielle Aufbau eines Einstrahlphotometers ist in Abb. 3-2 gezeigt. Bei einem Einstrahlphotometer wird das eingestrahlte Licht einer Halogenlampe nach Passage der Eintrittsblende und der Strahlaufweitung durch einen Hohlspiegel zunächst auf ein dispergierendes Element geleitet und spektral aufgetrennt. Durch Drehung des Prismas oder des optischen Gitters (Monochromator) werden alle spektralen Bereiche durchlaufen. Über einen zweiten Konkavspiegel wird es auf die Austrittsblende fokussiert und über einen letzten Spiegel im Winkel von $90^{\circ}$ zum Probenvolumen geführt. Nach der Probenpassage gelangt das austretende Licht zum Detektor (Photomultiplier). Ein Nachteil dieser Methode ist, dass Referenz und Probe einzeln gemessen werden müssen, was mit den modernen Zweistrahlphotometern vermieden wird. In der Arbeit wurde das Varian Cary 50 verwendet. Das Photometer ist mit einer Xenonlampe (190 bis $1.100 \mathrm{~nm}$ ) ausgestattet und die Datenanalyse konnte mithilfe des Computerprogramms Cary Win UV Software durchgeführt werden.

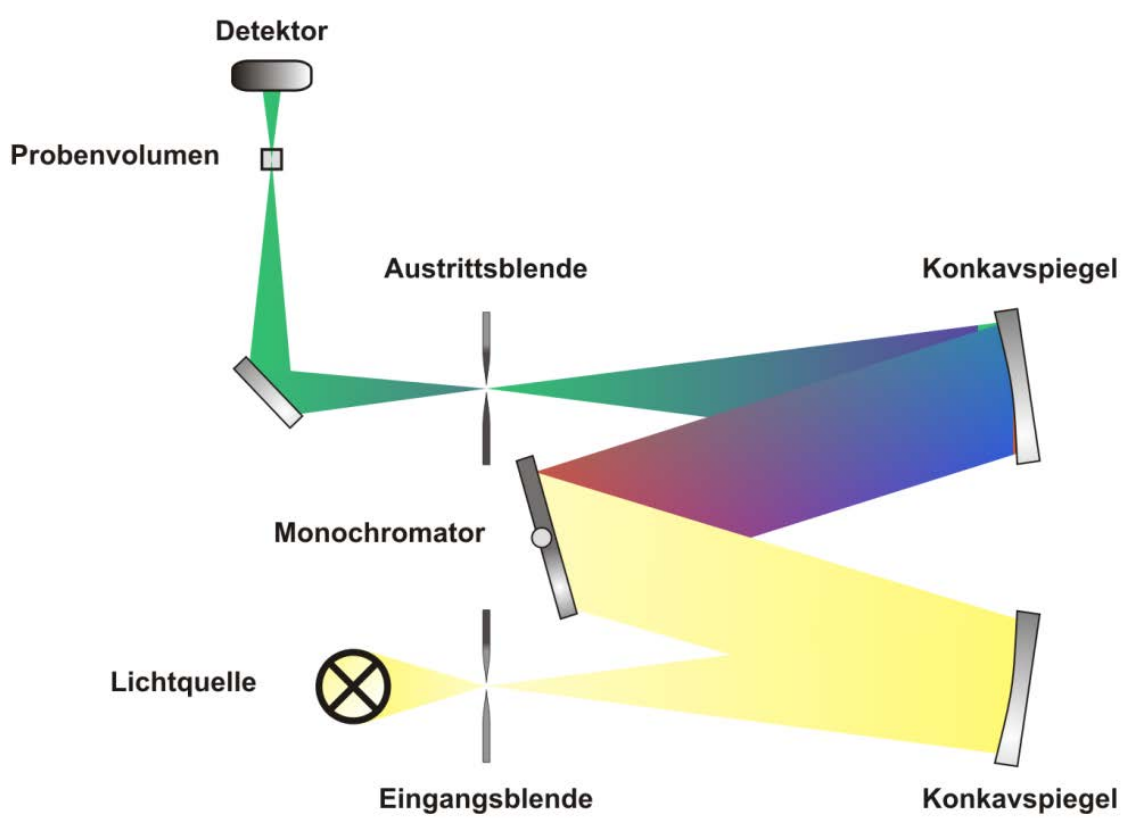

Abb. 3-2: Schematischer Aufbau eines Einstrahlphotometers nach ${ }^{[135]}$. 


\subsubsection{Massenspektrometrie}

In dieser Arbeit diente die Massenspektrometrie zur Identifizierung der Proteine Cx43 und Cx43-GFP aus P. pastoris. Die Massenspektrometrie ermöglicht die Bestimmung des Masse zu Ladungsverhältnisses $(\mathrm{m} / \mathrm{z})$ im Hochvakuum. Durch eine Ionenquelle wird der Analyt in die Gasphase überführt und in Richtung des Massenanalysators beschleunigt. Der Massenanalysator trennt die erzeugten Ionen bezüglich ihres Masse zu Ladungsverhältnisses $(\mathrm{m} / \mathrm{z})$. Der darauffolgende Detektor erfasst die Ionen und liefert das Massenspektrum. Zur Ionisation wurde in dieser Arbeit die Elektrosprayionisation (ESI) genutzt. Die Ionisation der Probe findet bereits in Lösung durch Anlegen einer Spannung an die Metallkapillare unter Atmosphärendruck statt, wodurch es zur Trennung von positiv und negativ geladenen Ionen kommt (Abb. 3-3). Die Ionen bewegen sich entsprechend ihrer Ladung von der Anode zur Kathode (Massenspektrometer), dabei treten sie aus dem Flüssigkeitskonus (Taylor-Konus) an der Spitze der Kapillare als kleine Flüssigkeitstropfen mit einem Durchmesser von wenigen Mikrometern aus und die Verdampfung von Lösungsmittel bedingt ein kontinuierliches Schrumpfen. Die Größenabnahme bei gleichbleibender Ladung führt bei Erreichen des Rayleigh-Limits zur Coulomb-Explosion und dem Zerfall in immer kleinere Tropfen (wenige $\mathrm{nm}$ ), bis schließlich ein geladenes Molekül völlig desolvatisiert ist und zum Massenspektrometer transferiert wird. Diese Methode ist für die Analyse von Proteinen besonders geeignet, da hier Verbindungen mit einer hohen molekularen Masse in die Gasphase überführt werden können und es während der Ionisierung kaum zur Fragmentierung der Ionen kommt. ${ }^{[125]}$ 


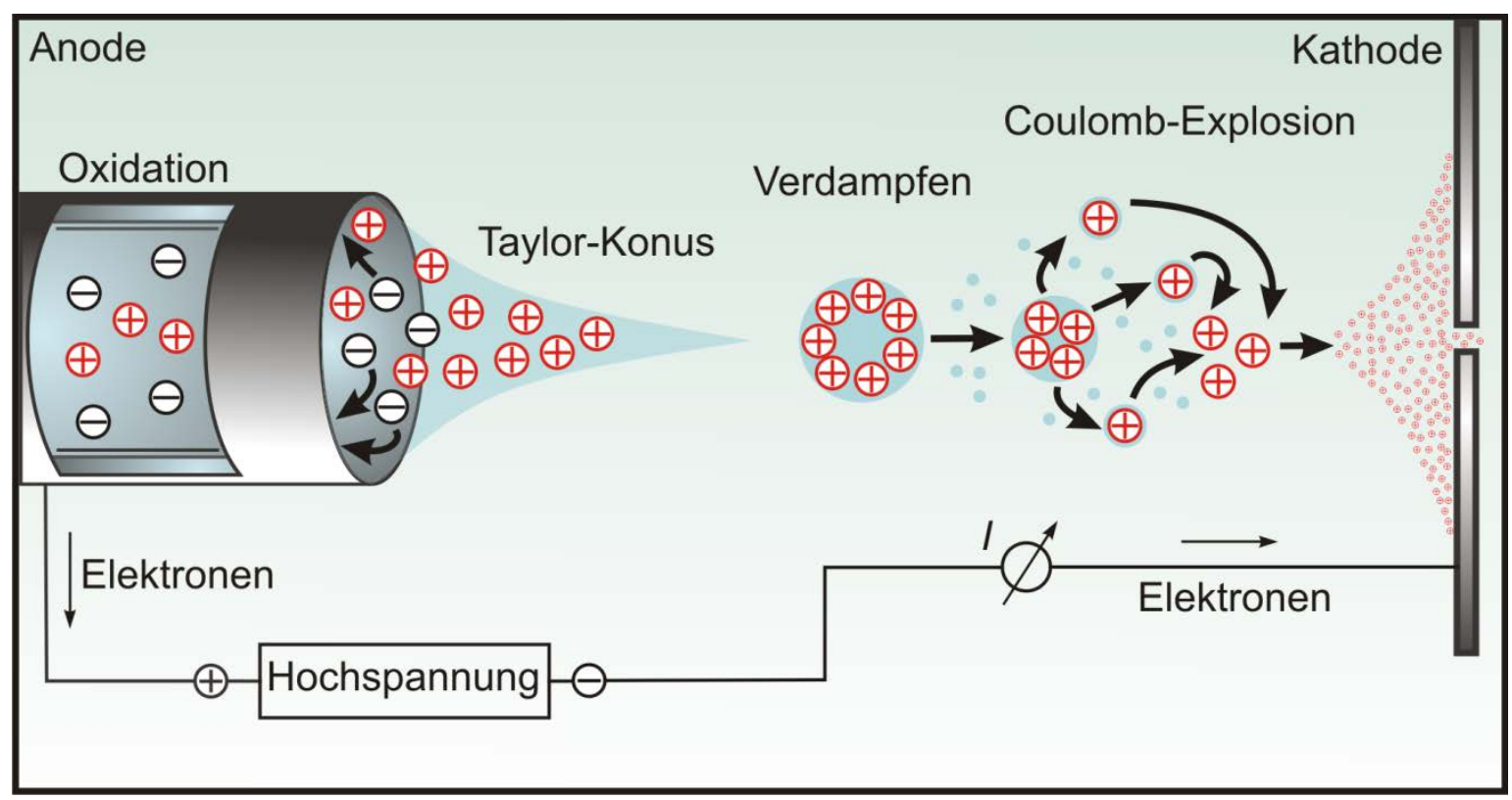

Abb. 3-3: Schematische Darstellung der mikroskopischen Prozesse, die bei der Elektrosprayionisierung stattfinden. Die Abbildung wurde nach Lottspeich et al. angefertigt. ${ }^{[125]}$

Für die Analyse werden die Proteine in definierte Fragmente mithilfe von proteolytischen Enzymen (Proteasen) geschnitten. Der Verdau von Cx43 und Cx43-GFP wurde mithilfe von Trypsin im Gel nach Shevchenko et al. durchgeführt (In Gel Verdau), da es häufig für die Fragmentierung von Proteinen verwendet wird und es reproduzierbare Ergebnisse liefert. ${ }^{[136]}$ Trypsin spaltet spezifisch auf der Carboxylseite der Aminosäuren Lysin und Arginin. ${ }^{[137]}$

Für den Verdau wurde das jeweilige Proteingemisch elektrophoretisch mithilfe der SDS-PAGE aufgetrennt (Kapitel 3.1.4). Danach wurden die entsprechenden Banden, welche mithilfe der Western Blot Analyse identifiziert wurden (Kapitel 3.1.5), ausgeschnitten und in 3 bis 5 Teile geschnitten. Die Gelstücke wurden mit mindestens $30 \mu \mathrm{L}$ Acetonitril überschichtet und für 10 min bei Raumtemperatur (RT) inkubiert. Nach dem Trocknen im Vakuumkonzentrator (Concentrator 5301, Eppendorf, Hamburg) bei $45^{\circ} \mathrm{C}$ wurden die enthaltenen Cystine mit $150 \mu \mathrm{L} 10 \mathrm{mM}$ Dithiothreitol (in $100 \mathrm{mM} \mathrm{NaHCO}$ ) für $1 \mathrm{~h}$ bei $56^{\circ} \mathrm{C}$ unter Schütteln reduziert. Nach Entfernen des Überstandes wurde die Probe zur Alkylierung der reduzierten Cysteine mit $55 \mathrm{mM}$ Iodacetamid (in $100 \mathrm{mM} \mathrm{NaHCO}$ ) für 45 min bei RT im Dunkeln inkubiert. Zum Waschen der Gelstücke wurden diese nach Entfernen der Iodacetamidlösung mit $150 \mu \mathrm{L} 100 \mathrm{mM} \mathrm{NaHCO}$ für 10 min bei RT inkubiert. Anschließend folgte ein Waschen mit $150 \mu \mathrm{L}$ Acetonitril für $10 \mathrm{~min}$ bei RT. Die beiden Waschschritte wurden noch einmal sukzessive wiederholt und die Gelstücke nach Entfernen des Acetonitrils im Vakuumkonzentrator für $10 \mathrm{~min}$ bei $45^{\circ} \mathrm{C}$ getrocknet. 
Anschließend wurden die getrockneten Gelstücke mit $30 \mu \mathrm{L}$ Trypsinlösung (20 $\mu \mathrm{g}$ Trypsin in $64 \mu \mathrm{L}$ Promega Resuspension Buffer und $1.216 \mu \mathrm{L} 50 \mathrm{mM} \mathrm{NaHCO}_{3}$ ) versetzt und für 45 min auf Eis inkubiert. Nach der Inkubation wurde der verbliebene Puffer entfernt und mit mindestens $30 \mu \mathrm{L} 50 \mathrm{mM} \mathrm{NaHCO}_{3}$ über Nacht bei $37^{\circ} \mathrm{C}$ unter Schütteln inkubiert. Der Überstand enthielt die tryptischen Peptide und wurde nach Zentrifugation bei $17.000 \times g$ in ein neues Reaktionsgefäß überführt. Für das Herauslösen weiterer tryptischer Peptide wurden die Gelstücke mit $30 \mu \mathrm{L} 20 \mathrm{mM} \mathrm{NaHCO} 3$ für 10 min bei RT inkubiert. Der Überstand wurde nach Zentrifugation wieder gesammelt und im nächsten Schritt dreimal sukzessive mit $30 \mu \mathrm{L}$ $50 \%(v / v)$ Acetonitril/5\% $\%(v / v) \mathrm{HCOOH}$ für 20 min inkubiert. Der Überstand wurde 4,5 h bei $45^{\circ} \mathrm{C}$ im Vakuumkonzentrator eingetrocknet und bis zur Messung bei $4{ }^{\circ} \mathrm{C}$ gelagert.

Die Messungen wurden von Oliver Valerius (Institut für Mikrobiologie und Genetik, Universität Göttingen) mittels LC/MS2 durchgeführt. Zur Analyse wurden die tryptischen Peptide erst auf eine präparative $\mu$-Precolumn ${ }^{\mathrm{TM}}$ (P/N 160454, Dionex, Idstein) aufgetragen und zur weitere Auftrennung auf eine nano-HPLC-MS mit einer analytischen Kapillarsäule (P/N 160321, Dionex) unter Verwendung des UltiMate 3000 HPLC System (Dionex) übertragen. Anschließend wurden die Peptide über Elektrosprayionisation unter Verwendung des PicoTip ${ }^{\mathrm{TM}}$ Emitter bei einer Spannung von $1,5 \mathrm{kV}$ direkt zum LCQ Deca XP Massenspektrometer transferiert. Während des Gradienten der Flüssigchromatografie wurden durch das Massenspektrometer in mehreren Zyklen MS Scans in einem Massenbereich von 300 bis 1.400 Da erfasst. Danach folgten vier datenabhängige, kollisionsinduzierte MS/MS Spektren der vier intensivsten Ionen. Die Daten wurden im Centroide Mode erfasst und über 2.000 MS/MS Spektren wurden während eines LC/MS-Scans in einer Xcalibur raw-Datei gesammelt. Die Peakliste für die TurboSEQUEST Analyse wurde mit Extract-ms des Bioworks-Browser 3.3.1 Package erstellt. Die MS/MS Spektren mit einem Gesamtionenstrom $>10^{5}$ wurden für die Korrelationsanalyse im Abgleich mit den Einträgen der Proteindatenbank verwendet und gegen eine nicht redundante NCBI Datenbank abgefragt. Die folgenden Parameter wurden für die Suche genutzt: (1) Toleranz der Ionenmasse der berechneten Ionen: weniger als 1,4 atomare Masseneinheiten (AME), (2) Toleranz der Ionenmasse der Fragmente: weniger als 1,0 AME, (3) bis zu drei fehlende Spaltungen des Trypsinverdau sind erlaubt, und (4) feststehende Cysteinmodifikation durch Iodacetamid zum S-Carboxyamidomethylcystein (plus 57,05 AME) und variable Modifikation von Methionin durch Oxidation (plus 15,99 AME). Identifizierte Peptide mussten folgende Kriterien erfüllen: (1) Cross-Correlation 
Score (Xcorr) über 2,0, 2,5, 3,0 für Peptide der Ladung 1, 2 und 3, (2) $\Delta \mathrm{Cn}$ der besten Übereinstimmungen der identifizierten Peptide von mindestens 0,4, und (3) Primary Score (Sp) von mindestens 600. Für die Proteinidentifikation müssen mindestens zwei Peptide diese Kriterien erfüllen. Außerdem wurde der Vollständigkeitsgrad der b- und y-Ionenserie für jedes TurboSEQUEST Ergebnis manuell für jedes identifizierte Protein überprüft. 


\subsection{Einzelkanalmessungen mittels Planar Patch Clamp}

In dieser Arbeit wurde zur Analyse der Aktivität der Proteine, Cx43 und Cx43-GFP, die Planar Patch Clamp Technik genutzt (Abb. 4-21). Erste Arbeiten zum Verhalten von Ionenkanälen gehen auf Cole und Hodgkin \& Huxley zurück. ${ }^{[138,139]}$ Mit der Patch Clamp Technik, entwickelt durch Neher und Sackman, konnten erstmals Ionenströme einzelner Kanäle aufgezeichnet werden, wodurch eine Charakterisierung der Leitfähigkeit und des kinetischen Verhaltens dieser ermöglicht wurde. Dabei wird ein Stück (Patch) der Zellmembran durch Ansaugen mit einer Mikropipette elektrisch isoliert und durch das Anlegen einer Transmembranspannung können Ionenströme gemessen werden. Diese Methode wurde durch Schmidt et al. zu einem planaren System weiterentwickelt. ${ }^{[140]}$

Für die Messungen wurden zunächst Proteo-GUVs hergestellt und auf einen Glaschip über einer Apertur, mit 2 bis $3 \mu \mathrm{m}$ Durchmesser, gespreitet (Abb. 4-21). Die gebildete Membran sollte für elektrophysiologische Messungen einen Widerstand im Gigaohm-Bereich besitzen, da die gemessenen Ionenströme im Picoampere-Bereich liegen und der Membranwiderstand $R_{\mathrm{m}}$ direkt das Signal-Rausch-Verhältnis beeinflusst. Nach Anlegen einer konstanten Transmembranspannung $U_{\mathrm{m}}$ wird ein Ionenfluss über die Ionenkanäle induziert, dieser resultiert in einer Stromantwort (Transmembranstrom $I_{\mathrm{m}}$ ). Durch den Ionenfluss kommt es zu einer erhöhten Leitfähigkeit $G$ der Membran. Um die angelegte Transmembranspannung auf einem konstanten Niveau zu halten, muss der Kompensationsstrom erhöht werden (Negative Rückkopplungsschleife). Dieser Zusammenhang kann mithilfe des ohmschen Gesetzes beschrieben werden:

$$
R_{\mathrm{m}}=\frac{U_{\mathrm{m}}}{I_{\mathrm{m}}}=\frac{1}{G}
$$

\subsubsection{Messaufbau des Planar Patch Clamp Systems}

Die elektrophysiologische Charakterisierung wurde am Port-a-Patch ${ }^{\oplus}$ der Firma Nanion Technologies GmbH durchgeführt. Die Messanordnung ist in Abb. 3-4 dargestellt. Im Wesentlichen besteht Sie aus einem elektrischen Vorverstärker und den Messelektroden, welche von einem Faradaykäfig umschlossen sind, und einer Ansaugvorrichtung. Mithilfe der Ansaugvorrichtung können definiert Drücke im Millibar-Bereich appliziert werden. Das 
Prinzip der Regelung der Transmembranspannung entspricht generell der Voltage Clamp Technik. Über den Signalgenerator wird die Transmembranspannung $U_{\mathrm{m}, \text { Soll }}$ an den Hauptverstärker weitergegeben und ein definiertes Membranpotential $V_{\mathrm{m}}$ appliziert. Die Anpassung der tatsächlichen Transmembranspannung $U_{\mathrm{m}}$ an den Sollwert findet durch eine kapazitive Rückkopplungsschleife zwischen Vorverstärker, Hauptverstärker und Signalgenerator über einen Kompensationsstrom statt. Kommt es durch den Ionenfluss zu einer veränderten $U_{\mathrm{m}}$ wird das applizierte Membranpotential $U_{\mathrm{m} \text {, soll }}$ angepasst. Die Differenz wird über den A/D-Wandler digitalisiert und zeitabhängig als Stromantwort aufgezeichnet.

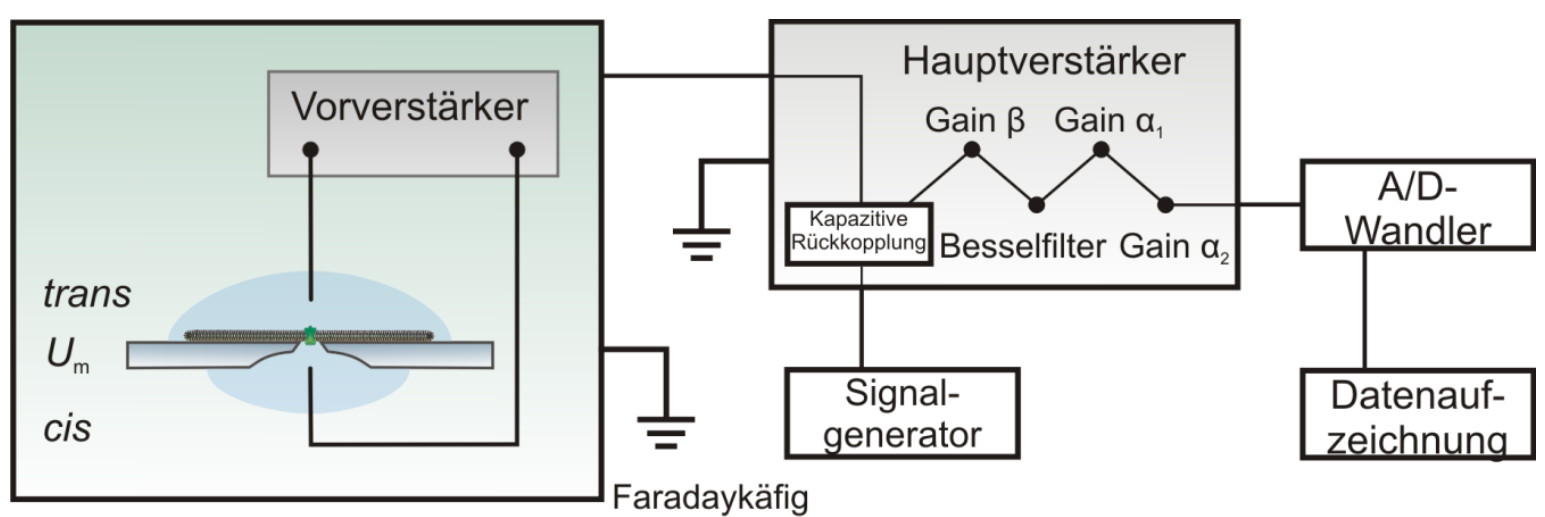

Abb. 3-4: Schematischer Aufbau eines Planar Patch Clamp Experiments. Die Silber/SilberchloridElektroden kontaktieren das trans- und cis-Kompartiment und verbinden es mit dem Vorverstärker. Im Hauptverstärker ist neben den Verstärkern $\alpha_{1}, \alpha_{2}$ und $\beta$ auch die kapazitive Rückkopplung integriert. Wiederum wird das Signal vom A/D-Wandler verstärkt und gefiltert. Die Abbildung wurde nach O. M. Schütte angefertigt. ${ }^{[141]}$ 


\subsubsection{Einzelkanalexperiment}

Um ein konstantes Elektrodenpotential zu gewährleisten, wurden die verwendeten Elektroden regelmäßig chloridiert. Dafür wurden die Silber/Silberchlorid-Elektroden mit Schmirgelpapier von Rückständen befreit und anschließend in $12 \%$ Natriumhypochloridlösung für 30 min inkubiert. Danach wurden sie mit Reinstwasser gewaschen und in Messpuffer (200 mM KCl, 2 mM EDTA, 10 mM HEPES pH 7,4) äquilibriert.

Für die Messungen wurden Proteo-GUVs nach Kapitel 3.5.5 in $1 \mathrm{M}$ Sorbitol-Lösung hergestellt. Die Aufzeichnungen erfolgten am Port-a-Patch ${ }^{\oplus}$ bei $20^{\circ} \mathrm{C}$. Zunächst wurden $6 \mu \mathrm{L}$ Messpuffer auf die Unterseite des Chips pipettiert, der Chip auf die Messapparatur geschraubt und der Faradaykäfig aufgesteckt. Anschließend wurden ebenfalls $6 \mu \mathrm{L}$ Messpuffer in die Mitte des Chips auf die Oberseite gegeben und die Arbeitselektrode in das obere Volumen getaucht. Durch Messung des Widerstandes konnte die korrekte Kontaktierung bestätigt werden (Abb. 4-21). Zum oberen Kompartiment wurden $6 \mu \mathrm{L}$ Proteo-GUVs gegeben und das Spreiten durch Anlegen eines negativen Drucks im Bereich von -15 bis -40 mbar forciert. Durch die Beobachtung des resultierenden Widerstandes konnte die Bildung einer porenüberspannenden Membran über der Apertur im Glaschip verfolgt werden (Abb. 4-21). Für die Einzelkanalmessungen wurden porenüberspannende Membranen mit einem Widerstand $>1$ G $\Omega$ verwendet. Nach der Bildung des Gigaseals wurde das obere Kompartiment dreimal mit $25 \mu \mathrm{L}$ Messpuffer gespült und der Druck sukzessive gesenkt. Der Offset wurde durch Anpassung des Kompensationsstroms auf 0 pA geregelt. Die Anpassung wurde nach jeder Änderung des Membranpotentials vorgenommen. Für die Messung von Cx43 und Cx43-GFP wurde ein Spannungsbereich von $-100 \mathrm{mV}$ bis $+100 \mathrm{mV}$ betrachtet. Bei Kanalaktivität wurde die Datenaufnahme gestartet. Die Messungen wurden bei einer elektrischen Verstärkung des Signals von $\alpha=50$ durchgeführt $(\beta=1)$. Aus der Erhöhung der Signalverstärkung resultierte ein vierfach vermindertes Rauschen. Dadurch war eine Detektion auch kleiner Ströme möglich. Die Spannungsabhängigkeit der Kanäle wurde durch die Aufnahme von StromSpannungskurven untersucht. Hierfür wurde in 21 Durchläufen jede Spannung von $+100 \mathrm{mV}$ bis $-100 \mathrm{mV}$ in $10 \mathrm{mV}$ Schritten für $5 \mathrm{~s}$ angelegt und die Stromantwort aufgezeichnet. Die Daten wurden durch einen 4-Pol-Tiefpass-Besselfilter $(1 \mathrm{kHz}$, Sampling Rate: $10 \mathrm{kHz})$ gefiltert. Die Daten wurden mit dem Programm pClamp 10.2 (Molecular Devices, München) aufgezeichnet und mit dem Programm Clampfit 10.2 (Axon Instruments) ausgewertet. 


\subsubsection{Auswertung von Einzelkanaldaten}

Die Analyse der Einzelkanalereignisse umfasste die Auswertung der Leitfähigkeit, Öffnungswahrscheinlichkeit und Öffnungsdauer des Kanals. Für die Auswertung der Daten können eine Vielzahl an Methoden verwendet werden.

\section{Analyse durch Punktamplituden-Diagramme}

Eine Möglichkeit ist die Darstellung der Datenpunkte einer Messung in einem normierten Histogramm (Punktamplitudenhistogramm). Durch die Anpassung von Gauß-Verteilungen an diese Daten können Informationen über Leitfähigkeiten und Öffnungswahrscheinlichkeit gemittelt über den betrachteten Zeitraum erfasst werden. Aus der Differenz der Maxima des ermittelten Stroms kann bei bekannter $U_{\mathrm{m}}$ nach Gl. 3-2 die Leitfähigkeit $G$ bestimmt werden. Die Öffnungswahrscheinlichkeit kann aus den Integralen der Normalverteilungen ermittelt werden.

Die digitale Nachfilterung der aufgenommenen Ereignisse ist notwendig, da erst mit der Filterung mittels $500 \mathrm{~Hz}$ Gauß-Tiefpassfilter eine getrennte Basis- und Ereignislinie unterschieden werden kann. Die Anpassung von zwei Normalverteilungen an die Punktamplituden der gefilterten Daten liefert Ergebnisse für die gemittelte Leitfähigkeit und Öffnungswahrscheinlichkeit. Außerdem wird die Verarbeitung der Daten mithilfe der Treshold-Analyse und der Single Channel Search-Analyse durch die Software Clampfit 10.2 vereinfacht. Allerdings ist mit der digitalen Nachfilterung auch ein Verlust an Information verbunden. Die Filterfrequenz $f$ steht nach Walter in direktem Zusammenhang zur Minimaldauer $t_{\mathrm{R}}$ der zu analysierenden Ereignisse. ${ }^{[142]}$

$$
t_{\mathrm{R}}=\frac{0,35}{f}
$$

Daraus folgt, dass bei einer Filterung von $500 \mathrm{~Hz}$ nur Ereignisse mit einer Dauer $>700 \mu \mathrm{s}$ untersucht werden können. Dies gilt nur für ein idealisiertes Signal, da aufgrund der geringen, detektierten Ströme ein relativ hohes Signal-Rausch-Verhältnis herrscht und auch Ereignisse mit einer geringeren Öffnungsdauer auftreten könnten. 


\section{Treshold-Analyse}

Für die Analyse der Daten im Threshold-Modus müssen zunächst zwei Niveaus definiert werden. Das untere Niveau liegt auf der Basislinie, welche dem geschlossenen Zustand des Kanals entspricht (rote Linie in Abb. 3-1). Das obere Niveau ist der geöffnete Zustand des Kanals und wird etwa dreiviertel unter der ersten detektierten Ereignisstufe festgelegt (blaue Linie in Abb. 3-5). Dieses Niveau definiert einen Schwellenwert (Treshold) für die Einzelkanalanalyse und jede Stufe, welche über diesem Niveau liegt, wird als Einzelkanalereignis registriert. Im nächsten Schritt ermittelt die Software die Ereignislänge bzw. Öffnungsdauer aus dem Zeitpunkt des erreichten Schwellenwertes und dem Unterschreiten des Niveaus. Zusätzlich lässt sich der Zeitraum in dem der Kanal im geschlossenen Zustand vorliegt festhalten. Die ermittelten Öffnungs- und Schließdauern liefern die Öffnungswahrscheinlichkeit eines Kanals im betrachteten Zeitfenster. Mit dieser Methode wird ausschließlich der Zeitraum vom Öffnen und Schließen eines Kanals erfasst (globale Analyse), aber es kann keine präzise Aussage über die Ereignishöhe gemacht werden.

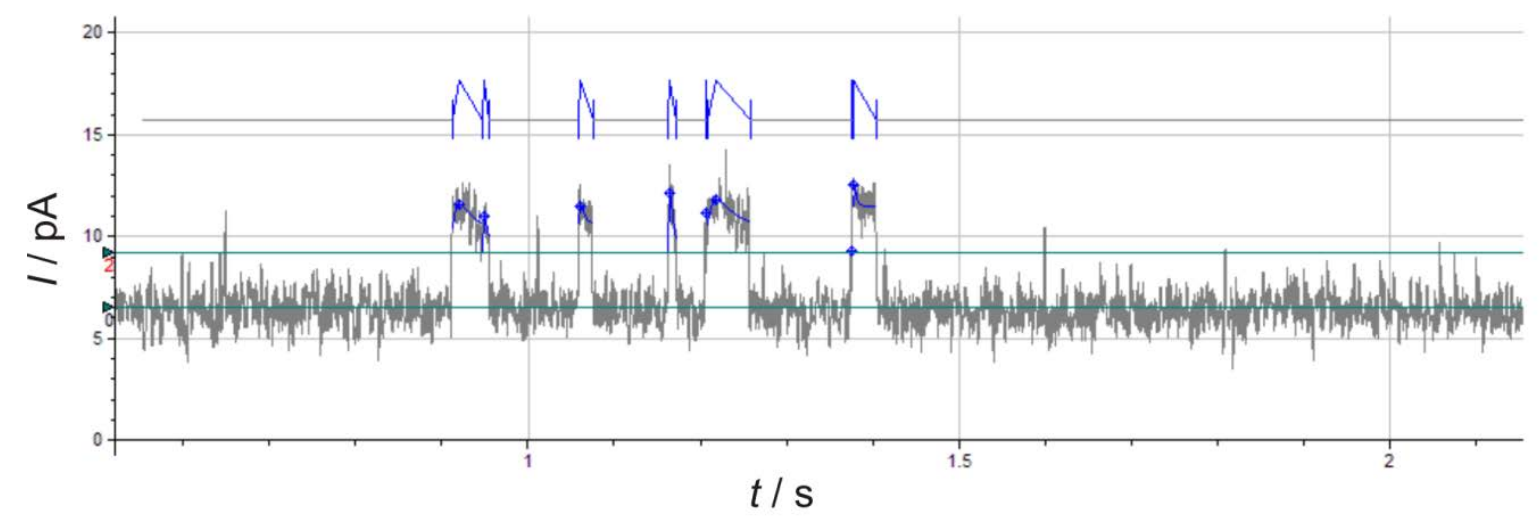

Abb. 3-5: Ausschnitt der Auswertung von Einzelkanalereignissen mittels Threshold-Analyse. Die rote Linie markiert das Niveau für die Basislinie und die blaue Linie kennzeichnet den Schwellenwert. 


\section{Single Channel Search-Analyse}

Bei dieser Analyse der Daten hinsichtlich der Ereignishöhe (Amplitude) werden ebenfalls zwei Niveaus festgelegt. Das Niveau 0 (rote Linie in Abb. 3-6) bezeichnet auch den geschlossenen Kanal und das Niveau 1 stellt den offenen Kanal dar (blaue Linie in Abb. 3-6). Durch die Festlegung der beiden Niveaus kann die Software automatisch die mittlere Höhe der Transmembranströme von Niveau 0 und 1 ermitteln. Aus der berechneten Differenz der Transmembranströme kann mit bekanntem Transmembranstrom $U_{\mathrm{m}}$ die Leitfähigkeit des Kanals für jedes Ereignis berechnet werden (lokale Analyse). Zusätzlich werden Anfangs- und Endzeit eines Einzelkanalereignisses aufgezeichnet. Aus der Differenz kann die Öffnungsdauer des Ereignisses bestimmt werden.

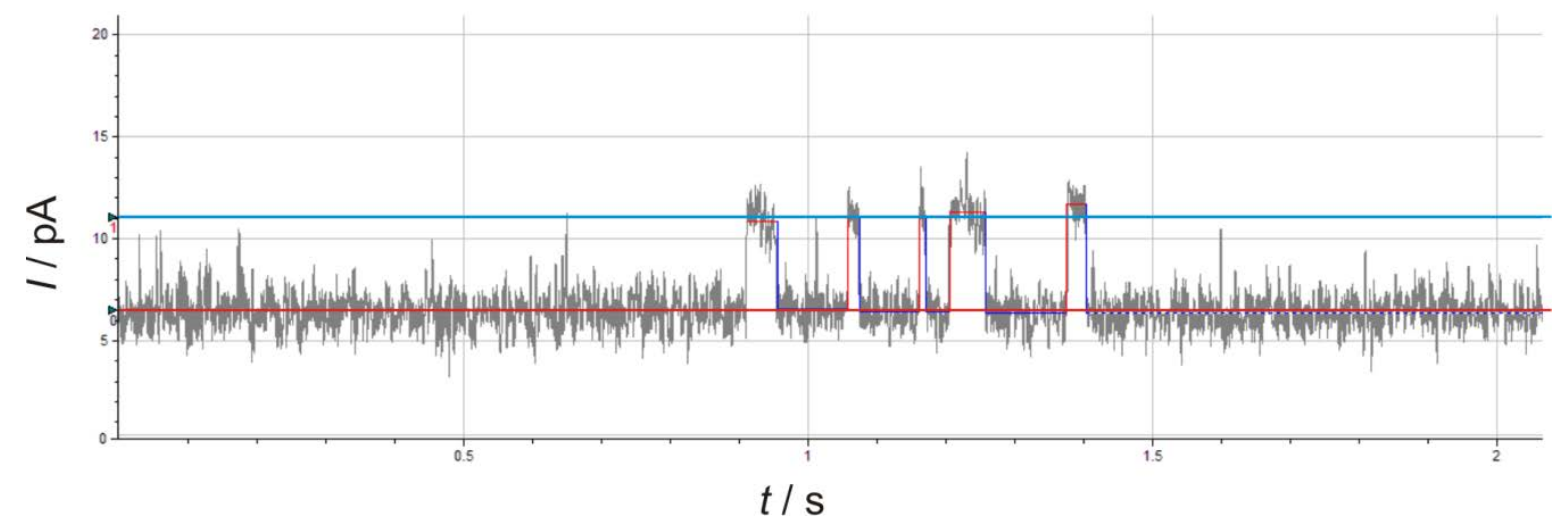

Abb. 3-6: Ausschnitt der Auswertung von Einzelkanalereignissen mittels Single Channel SearchAnalyse. Die rote Linie kennzeichnet das Niveau für den geschlossenen Kanal (0) und die blaue Linie steht für den offenen Kanal (1). 


\subsection{Fluoreszenzmikroskopie}

\subsubsection{Allgemeines Prinzip}

Im folgenden Kapitel wird auf die Grundlagen der Fluoreszenz eingegangen, da dies die Basis für die in Kapitel 4.5 behandelten Funktionsassays ist. Fluoreszenz gehört, wie die Phosphoreszenz, zur Lumineszenz und kann beschrieben werden als ein Prozess der Energieabsorption und -emission. In der Regel befinden sich alle Moleküle bei Raumtemperatur im elektronischen Singulett-Grundzustand $\left(S_{0}\right)$. Sowohl der elektronische Grundzustand als auch die angeregten Zustände $\left(S_{1}, S_{2} \ldots S_{\mathrm{n}}\right)$ können in verschiedene Schwingungsniveaus unterteilt (Schwingungszustände $v=0,1 \ldots \mathrm{n}$, Abb. 3-7) werden, die auf dem Strecken oder dem Beugen von kovalenten Bindungen beruhen. Die weitere Unterteilung in Rotationsniveaus ist für den Absorptionsprozess in wässriger Lösung nicht relevant. ${ }^{[143]}$

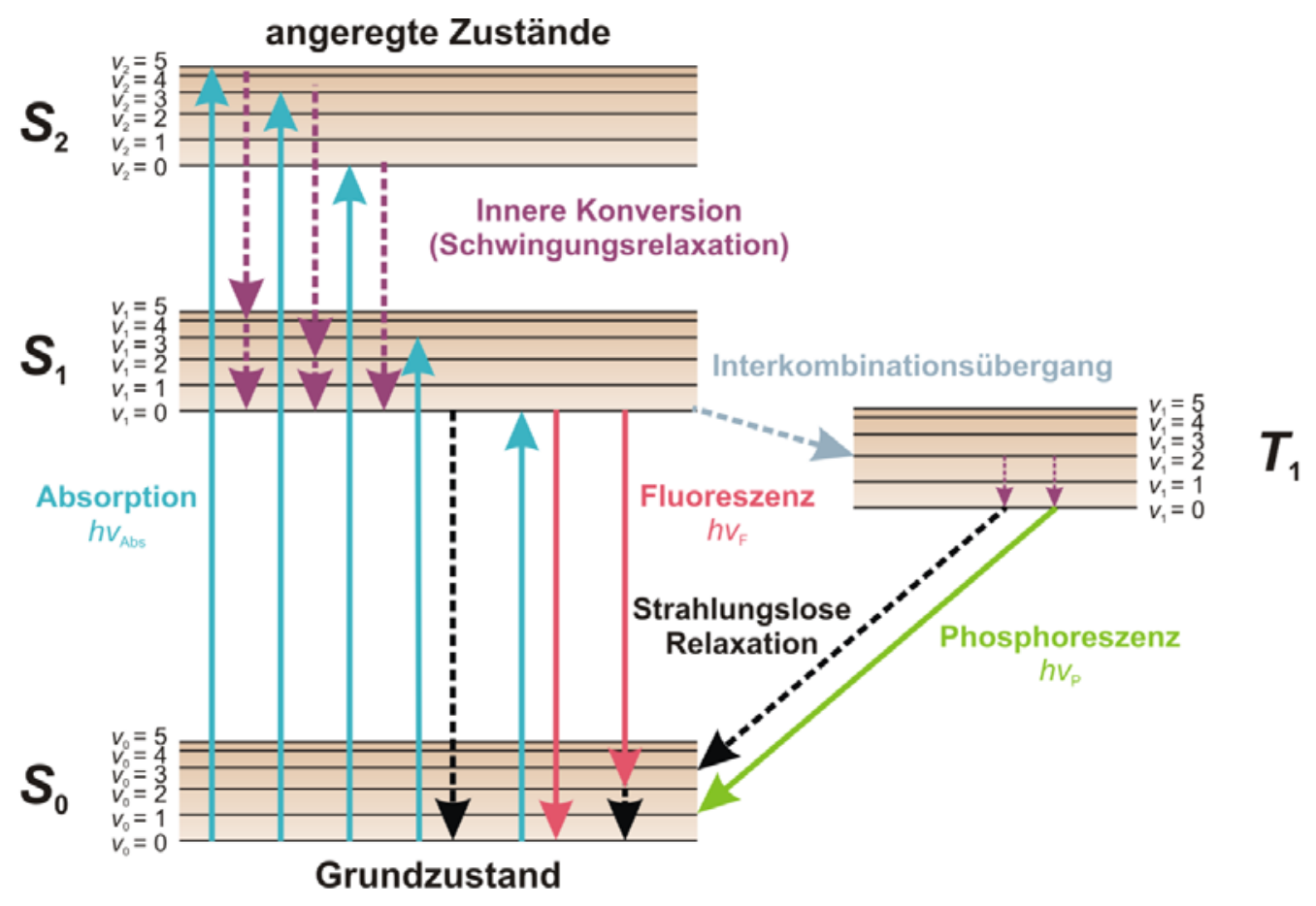

Abb. 3-7: Das Termschema (Jabłoński-Diagramm) zeigt die möglichen elektronischen Übergänge eines Moleküls nach Absorption eines Photons $\left(\tau=10^{-15} \mathrm{~s}\right)$. Prozesse wie Fluoreszenz $\left(\tau=10^{-9}\right.$ bis $10^{-7} \mathrm{~s}$ ), Phosphoreszenz $\left(\tau=10^{-3}\right.$ bis $\left.1 \mathrm{~s}\right)$ und strahlungslose Relaxation $\left(\tau=10^{-7}\right.$ bis $\left.10^{-5} \mathrm{~s}\right)$ finden immer von niedrigsten Schwingungsniveau des ersten angeregten Zustandes statt. Durch unterbrochene Linien werden strahlungslose Übergänge dargestellt. Interkombinationsübergänge sind nur durch Spinumkehr möglich und quantenmechanisch verboten. Die Schwingungszustände des Grundzustandes und der elektronisch angeregten Zustände sind durch $v_{0}, v_{1}$ bzw. $v_{2}$ von 1 bis 5 gekennzeichnet. Der Prozess der inneren Konversation erfolgt von einem höheren angeregten Schwingungsniveau auf $v_{1}=0$. 
Mit der Absorption eines Photons wird ein Elektron aus dem elektronischen, vibronischen Grundzustand $\left(S_{0}, v_{0}=0\right)$ in einen elektronisch angeregten Zustand $\left(S_{1}, S_{2}\right)$ angehoben. Nach dem Franck-Condon-Prinzip erfolgt der Übergang nur, wenn die Energie des Photons (Gl. 3-4) der Differenz zwischen dem Schwingungsniveau des Grundzustandes $v_{0}=0$ einem Schwingungsniveau des energetisch angeregten Zustandes $v_{1}, v_{2} \ldots v_{\mathrm{n}}$ entspricht und vertikal erfolgt, da sich der Kernabstand im Zeitraum des Absorptionsprozesses nicht ändert (BornOppenheimer-Approximation). Die Energie $E$ eines Lichtquants ergibt sich nach Gl. 3-4 aus dem Produkt des Planckschen Wirkungsquantums $h$ und der Frequenz $v$ eines Lichtquants.

$$
E=h \cdot v
$$

In Lösung kommt es durch innere Konversion unverzüglich im angeregten Zustand zum strahlungslosen Übergang von einem höheren zum Schwingungsniveau $v_{1}=0 \quad\left(\tau=10^{-14}\right.$ bis $10^{-11} \mathrm{~s}$ ), wodurch auch ein strahlungsloser Übergang von $S_{1}$ zu $S_{0}$ möglich ist. Der Prozess der Fluoreszenz findet ausschließlich aus dem niedrigsten Schwingungsniveau von $S_{1}$ statt. Dies erklärt auch die Verschiebung der Emission zu höheren Wellenlängen (Stokes-Verschiebung), da die emittierte Strahlung weniger energiereich ist als die absorbierte. Dieser Zusammenhang wurde erstmalig durch Georg G. Stokes beschrieben. ${ }^{[144]}$ Die Prozesse der Fluoreszenz und Phosphoreszenz unterscheiden sich in ihrer Lebensdauer. Während der Übergang von $S_{1}$ zu $S_{0}$ durch Fluoreszenz relativ schnell erfolgt (ca. $10^{-9}$ bis $10^{-7} \mathrm{~s}$ ) ist im Gegensatz dazu für die Phosphoreszenz (Übergang von Triplettzustand $T_{1} \mathrm{zu} S_{0}$ ) eine Spinumkehr (Interkombinationsübergang, Abb. 3-7) erforderlich und findet im Bereich von Millisekunden bis Sekunden statt.

Für die Untersuchung von Biomolekülen mittels Fluoreszenz kann man entweder intrinsische oder extrinsische Fluoreszenzsonden verwenden. Einerseits werden bei der Verwendung intrinsischer Fluoreszenz Gruppen genutzt, die im Molekül bereits vorhanden sind, wie beispielsweise der intrinsische Chromophor des rot-fluoreszierenden Proteins DsRed oder die Tryptophan-Fluoreszenz. Andererseits können auch Fluoreszenzsonden in Biomoleküle zusätzlich eingeführt werden. Dies erfolgt entweder durch die chemische Kopplung über den funktionellen Rest einer Aminosäure (z.B. Cys, Lys) oder durch die Expression eines Fusionsproteins, welches aus dem Zielprotein und einem fluoreszierenden Protein besteht. In der Zell- 
biologie wird dies auch als Reportergen-System eingesetzt. In dieser Arbeit wird dieses Prinzip für das Fusionsprotein Cx43-GFP genutzt.

\subsubsection{Fluoreszenzsonden}

\section{Markierung der Lipiddoppelschicht}

Für die Markierung der Lipiddoppelschichten wurden drei verschiedene Fluorophore verwendet. Perylen (peri-Dinaphthylen) hat die Summenformel $\mathrm{C}_{20} \mathrm{H}_{12}$ und besitzt eine molekulare Masse von 252,31 g. $\mathrm{mol}^{-1}$. Aufgrund seiner aromatischen Struktur löst es sich in der apolaren Phase der Lipiddoppelschicht (Abb. 3-8). Das Absorptionsmaximum liegt bei einer Wellenlänge von $400 \mathrm{~nm}$ und das Emissionsmaximum bei einer Wellenlänge von $445 \mathrm{~nm}$.

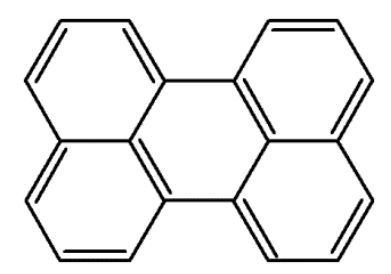

Abb. 3-8: Strukturformel von Perylen.

Der Fluoreszenzfarbstoff 2-(4,4-Difluoro-5-methyl-4-bora-3a,4a-diaza-s-diaza-indazen-3dodecanoyl)-1-hexadecanoyl-sn-glycero-3-phosphocholin (Bodipy-PC) wurde für die Verifizierung von festkörperunterstützten Membranen in FRAP-Experimenten verwendet (Kapitel 3.3.4). Das Glycerolgrundgerüst ist mit einer $\mathrm{C}_{16^{-}}$und mit einer $\mathrm{C}_{12}$-Fettsäure verestert. $\mathrm{Am}_{12}$ von Laurinsäure ist der Chromophor Boradiazaindacen positioniert. BodipyPC hat ein Molekulargewicht von $881,9 \mathrm{~g} \cdot \mathrm{mol}^{-1}$ und eine Summenformel von $\mathrm{C}_{46} \mathrm{H}_{79} \mathrm{BF}_{2} \mathrm{~N}_{3} \mathrm{O}_{8} \mathrm{P}$. Das Absorptionsmaximum ist bei einer Wellenlänge von $500 \mathrm{~nm}$ und das Emissionsmaximum liegt bei $510 \mathrm{~nm}$.

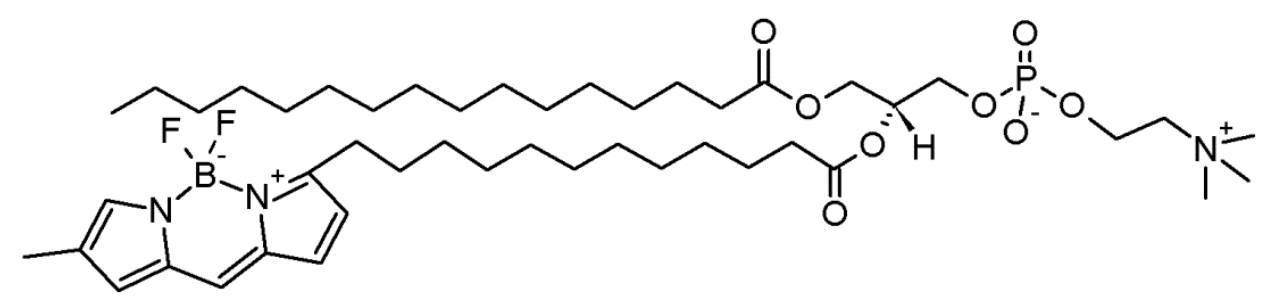

Abb. 3-9: Summenformel von 2-(4,4-Difluoro-5-methyl-4-bora-3a,4a-diaza-s-diaza-indazen-3dodecanoyl)-1-hexadecanoyl-sn-glycero-3-phosphocholin (Bodipy-PC). 
Desweiteren wurde Sulforhodamine 101 1,2-dihexyadecanoyl-sn-glycero-3-phosphoethanol-L-amin-Triethylammoniumsalz (Texas Red DHPE) verwendet (Abb. 3-10). Die Summenformel ist $\mathrm{C}_{74} \mathrm{H}_{117} \mathrm{~N}_{4} \mathrm{O}_{14} \mathrm{PS}_{2}$ und die molekulare Masse beträgt $1381,84 \mathrm{~g} \cdot \mathrm{mol}^{-1}$. Das Absorptionsmaximum von Texas Red DHPE ist bei einer Wellenlänge von $584 \mathrm{~nm}$ und das Emissionsmaximum bei einer Wellenlänge von $608 \mathrm{~nm}$ zu finden. Rhodaminderviate weisen aufgrund ihrer Struktur eine äußert hohe Photostabilität sowie eine besonders hohe Quantenausbeute auf. Das Grundgerüst entspricht 1,2-Dipalmitoyl-sn-glycero-3-phosphoethanolamin. Phosphoethanolamin ist an der Sulforhodamineinheit gebunden. Das Xanthengrundgerüst ist in der Lage zum Teil mit den Fettsäureketten der Membran zu interagieren. ${ }^{[145]}$

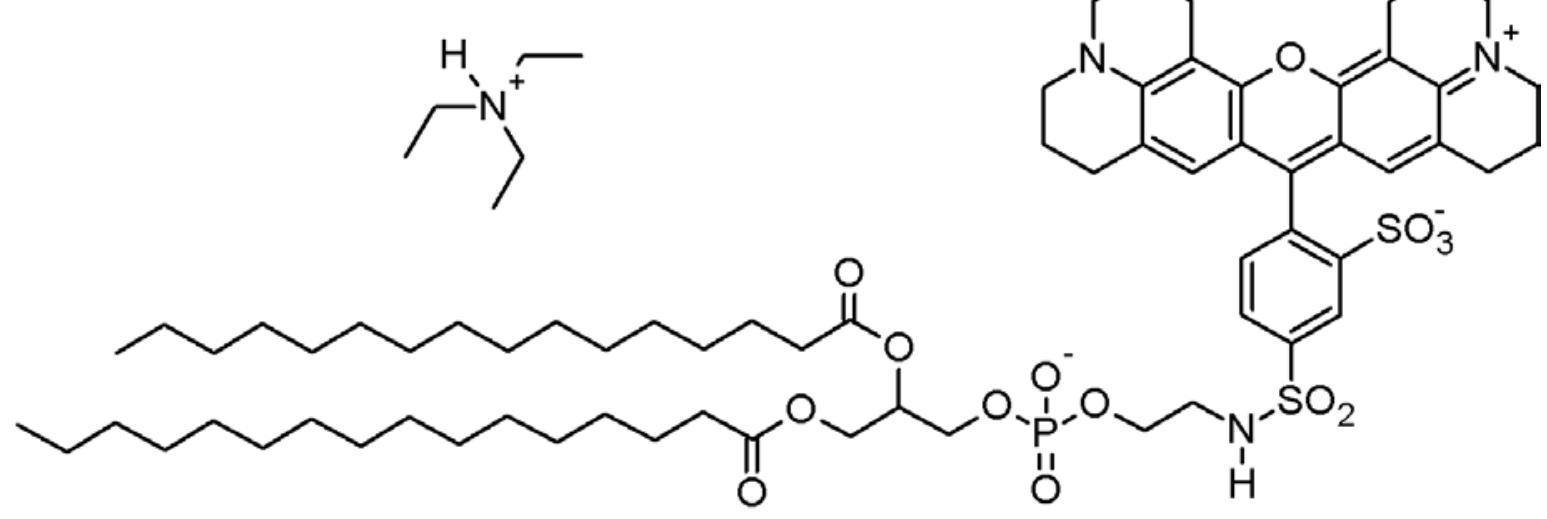

Abb. 3-10: Strukturformel von Texas Red DHPE.

\section{Markierung eines wässrigen Kompartiments}

Zur Visualisierung eines abgegrenzten wässrigen Kompartiments, beispielsweise den Inhalt eines Vesikels, wurde der wasserlösliche Fluorophor 8-Hydroxy-1,3,6-pyrentrisulfonsäuretrinatriumsalz (Pyranin) eingesetzt (Abb. 3-11). Die Summenformel ist $\mathrm{C}_{16} \mathrm{H}_{7} \mathrm{Na}_{3} \mathrm{O}_{10} \mathrm{~S}_{3}$ und es hat eine molekulare Masse von 524,39 $\mathrm{g} \cdot \mathrm{mol}^{-1}$. Aufgrund seiner Struktur weist die Absorption von Pyranin eine Abhängigkeit vom pH-Wert auf. Alle in dieser Arbeit beschriebenen Experimente, in denen Pyranin verwendet wurde, wurden bei einem pH-Wert von 7,4 durchgeführt. Das Absorptionsmaximum liegt bei einer Wellenlänge von $453 \mathrm{~nm}$ und das Emissionsmaximum bei einer Wellenlänge von $514 \mathrm{~nm}$. 
<smiles>O=S(=O)([O-])c1cc(O)c2ccc3c(S(=O)(=O)O)cc(S(=O)(=O)[O-])c4ccc1c2c43</smiles>

Abb. 3-11: Strukturformel von Pyranin.

\section{Markierung von Connexin 43}

Fluoresceinisothiocyanat (FITC, Abb. 3-12) ist als Derivat des Fluoresceins, kovalent an einen polyklonalen Antikörper gekoppelt, der aus Kaninchen stammt und Hexahistidin-Tags spezifisch erkennt. In der Arbeit wurde er zum Nachweis von rekonstituiertem Cx43 in GUVs eingesetzt (Kapitel 4.2). Das Molekulargewicht beträgt 389,4 $\mathrm{g} \cdot \mathrm{mol}^{-1}$ und die Summenformel ist $\mathrm{C}_{21} \mathrm{H}_{11} \mathrm{NO}_{5} \mathrm{~S}$. Der Succinimidester kann spezifisch an primäre Aminogruppen wie Lysinreste gekoppelt werden. FITC hat ein Absorptionsmaximum bei $495 \mathrm{~nm}$ und ein Emissionsmaximum von $521 \mathrm{~nm}$.

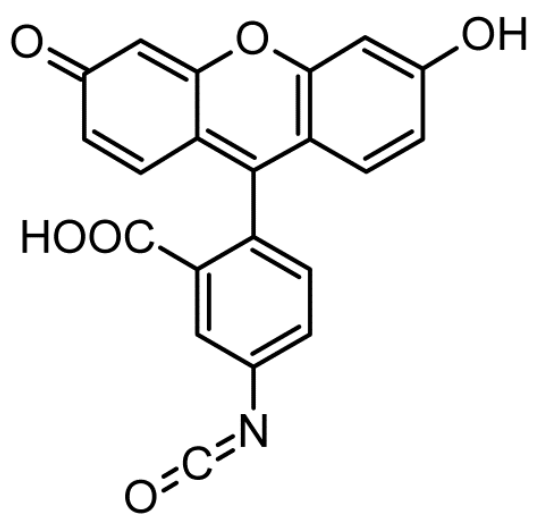

Abb. 3-12: Strukturformel von Fluoresceinisothiocyanat (FITC).

\section{Markierung von $H_{6} W G C$}

Das Peptid Hexa-L-histidyl-L-tryptophanyl-L-glycyl-L-cysteinamid, welches für den Fluoreszenz-basierten Funktionsassay zum Aktivitätsnachweis der Halb- und Gap Junction Kanäle eingesetzt wurde (Kapitel 4.5.2), war an den Fluoreszenzfarbstoff 5(6)-Carboxy- 
tetramethylrhodamin (5(6)-TAMRA) gekoppelt. Der Fluorophor besitzt ein Molekulargewicht von $430,4 \mathrm{~g} \cdot \mathrm{mol}^{-1}$ und eine Summenformel von $\mathrm{C}_{25} \mathrm{H}_{22} \mathrm{~N}_{2} \mathrm{O}_{5}$. Das Emissionsmaximum liegt bei einer Wellenlänge von $543 \mathrm{~nm}$ und das Absorptionsmaximum bei $572 \mathrm{~nm}$.

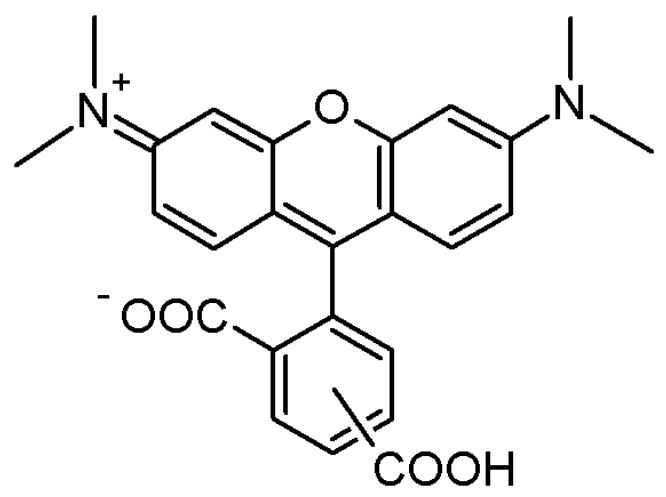

Abb. 3-13: Strukturformel von 5(6)-Carboxytetramethylrhodamin (5(6)-TAMRA).

Die Anregungswellenlänge sowie der Emissionsbereich für die verwendeten Fluoreszenzfarbstoffe sind in Tab. 3-2 zusammengefasst.

Tab. 3-2: Übersicht der verwendeten Farbstoffe mit der verwendeten Anregungswellenlänge ( $\left.\lambda_{\text {exc }}\right)$, dem Emissionsbereich $\left(\lambda_{\mathrm{em}}\right)$ sowie der eingesetzten Konzentration.

\begin{tabular}{|c|c|c|c|}
\hline Fluoreszenzsonde & $\lambda_{\mathrm{exc}}[\mathrm{nm}]$ & $\lambda_{\mathrm{em}}[\mathrm{nm}]$ & $\begin{array}{c}\text { Verwendete } \\
\text { Konzentration }\end{array}$ \\
\hline Perylen & 404 & $426-457$ & $0,5 \mathrm{~mol} \%$ \\
\hline Pyranin & 488 & $496-544$ & $0,5-10 \mathrm{mM}$ \\
\hline FITC & 488 & $492-600$ & $4 \mu \mathrm{g} \cdot \mathrm{mL}^{-1}$ \\
\hline Bodipy-PC & 488 & $490-580$ & $1 \mathrm{~mol} \%$ \\
\hline Texas Red DHPE & 594 & & $0,5 \mathrm{~mol} \%$ \\
\hline 5(6)-TAMRA & 561 & $505-690$ & $8,3 \mu \mathrm{M}$ \\
\hline
\end{tabular}




\subsubsection{Fluoreszenzmikroskopie}

Zur Überwindung der Auflösungsgrenze des menschlichen Auges wurden optische Instrumente wie das Mikroskop entwickelt. Wiederum ist die Auflösungsgrenze eines Mikroskops abhängig von den verwendeten Objektiven und kann über die Abbe Gleichung berechnet werden,

$$
d=\frac{\lambda}{2 n \cdot N A}
$$

wobei $d$ den Abstand zwischen zwei abzubildenden Punkten, $\lambda$ die Wellenlänge des Lichts, $n$ den Brechungsindex des Mediums und NA die numerische Apertur des Objektivs beschreibt. Demzufolge kann das Auflösungsvermögen erhöht werden, indem man Fluoreszenzfarbstoffe verwendet, deren Anregungswellenlänge relativ niedrig ist.

\section{Konfokale Laserrastermikroskopie}

Die konfokale Laserrastermikroskopie (Confocal Laser Scanning Microscopy, CLSM) stellt eine Verbesserung zur traditionellen Weitfeldfluoreszenzmikroskopie dar. Bei der herkömmlichen Fluoreszenzmikroskopie wird beispielsweise mithilfe einer Xenonlampe Licht eingestrahlt und die resultierende Fluoreszenz direkt beobachtet. Der Nachteil dieser Methode ist, dass die erhaltene Bildinformation nicht nur aus der betrachteten Ebene stammt. Zur Verbesserung der axialen Auflösung des herkömmlichen Mikroskops entwickelte Marvin Minsky bereits 1957 die Idee zur Einführung einer Lochblende in den Strahlengang. ${ }^{[146]}$ Der prinzipielle Aufbau eines Konfokalmikroskops ist in Abb. 3-14 schematisch gezeigt. 


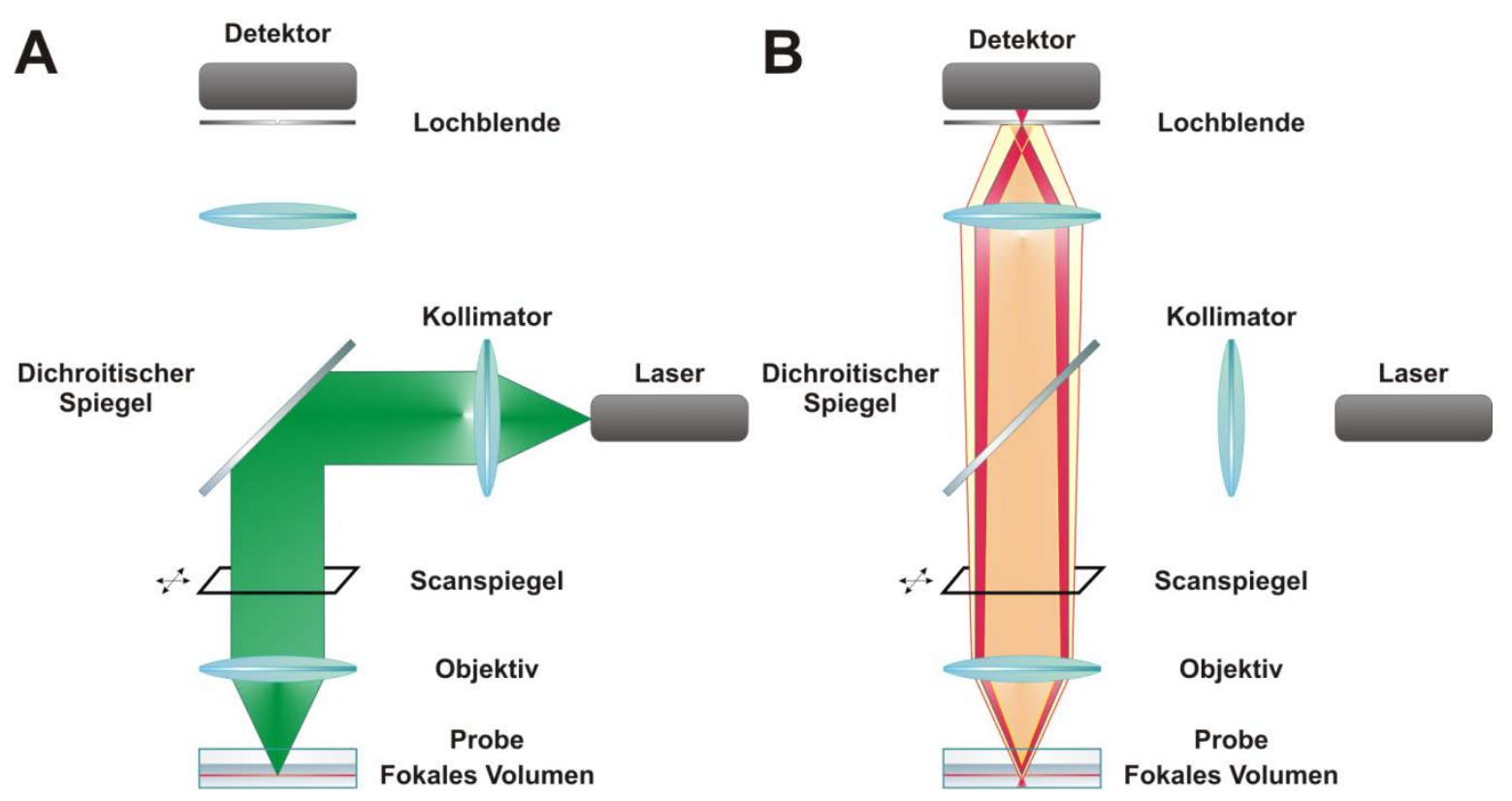

Abb. 3-14: Schematischer Aufbau eines konfokalen Laserrastermikroskops. A, Zunächst passiert das Laserlicht (grün dargestellt) den Kollimator und wird dabei aufgeweitet. Nach Einkopplung des anregenden Lichts in den Strahlengang durch den dichroitischen Spiegel wird es durch das Objektiv fokussiert. Die Probe wird in $x$ - $y$-Ebene punktförmig abgerastert. $B$, Nach Anregung passiert das emittierte, längerwellige Licht den dichroitischen Spiegel. Die Emission der Probe in rot dargestellt, ist fokal zur Lochblende und erreicht den Detektor. Das emittierte Licht in orange und gelb dargestellt, stammt aus dem Bereich oberhalb und unterhalb der Fokusebene. Da es nicht fokal zur Lochblende ist, gelangt es aus diesem Grund nicht zum Detektor.

Im Gegensatz zur Weitfeldfluoreszenzmikroskopie wird die Probe zur Bilderzeugung punktförmig durch einen Laser abgerastert. Zunächst wird das Laserlicht mithilfe des Kollimators aufgeweitet und der dichroitische Spiegel reflektiert das anregende Laserlicht in den Strahlengang, das über ein Linsensystem punktförmig fokussiert wird. Das essentielle Bauelement des konfokalen Strahlengangs ist eine Lochblende (Pinhole), die vor dem Detektor positioniert ist. Aufgrund des Aufbaus kann nur das emittierte Licht der Probe den Detektor erreichen, welches aus der Fokusebene emittiert wird bzw. fokal zur Lochblende ist. Infolgedessen wird Streulicht vermieden und dadurch die Tiefenschärfe der abgebildeten Probe erhöht. Die Größe der Lochblende bestimmt die $z$-Auflösung der fokalen Ebene. Mit der Aufnahme von optischen Schnitten entlang der $z$-Achse kann die dreidimensionale Struktur einer Probe rekonstruiert werden. Neben der Gewinnung von Informationen in drei Raumrichtungen ist auch die zeitliche Auflösung und Quantifizierung von Prozessen, die in $z$-Richtung erfolgen, möglich, beispielsweise der Transfer von Farbstoff. Für die Messung in dieser Arbeit wurde ein Lochblendendurchmesser von 1 AU (Airy Unit, AU) eingestellt. Eine Airy-Unit kann nach folgender Gleichung berechnet werden. 


$$
1 A U=\frac{1,22 \cdot \bar{\lambda}}{N A}
$$

$\bar{\lambda}$ entspricht der mittleren Wellenlänge des Lichts und $N A$ ist die numerische Apertur des Objektivs. Dadurch wird nur ein begrenzter Bereich der Probe während der Messung dem Laserlicht exponiert.

Die konfokale Laserrastermikroskopie wurde am LSM 710 der Firma Carl Zeiss Jena durchgeführt. Dafür wurde mit dem Objektiv W Plan-Apochromat 63x/1.0 M27 bei einer 63-fachen Vergrößerung gearbeitet.

\subsubsection{Fluorescence Recovery After Photobleaching}

Für den Nachweis einer kontinuierlichen, festkörperunterstützten Membran wird die Methode des Fluorescence Recovery After Photobleaching (FRAP) verwendet. Dadurch kann die Diffusionsgeschwindigkeit bzw. der Diffusionskoeffizient $D$ von fluoreszenzgekoppelten Molekülen innerhalb von Lipidmembranen durch Photobleichen bestimmt werden. In dieser Arbeit wurden für die FRAP-Experimente Bodipy-PC und Perylen verwendet (Kapitel 3.3.2). Mithilfe eines Lasers wird durch einen kurzen Puls hoher Intensität eine kreisrunde Region (Region of Interest, ROI) gebleicht. Dies führte zur irreversiblen Zerstörung der Fluorophore im ROI und im Beobachtungszeitraum $t$ wird eine Rückkehr der Fluoreszenz durch laterale Diffusion von beispielsweise Bodipy-PC in den Bleichfleck hinein und von gebleichten Molekülen aus dem Bleichfleck heraus beobachtet (Abb. 3-15). 
A

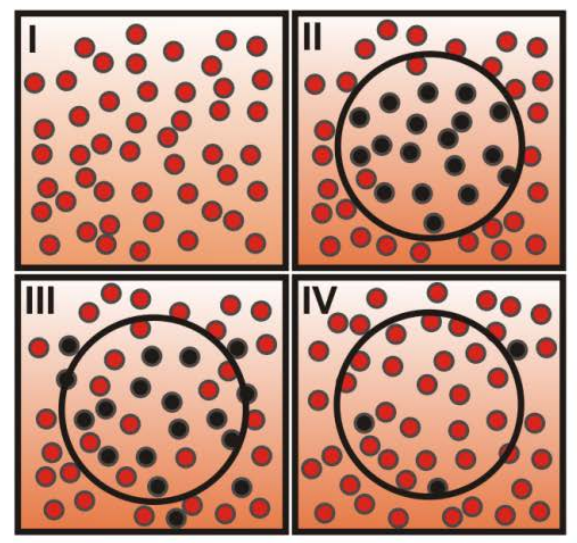

B

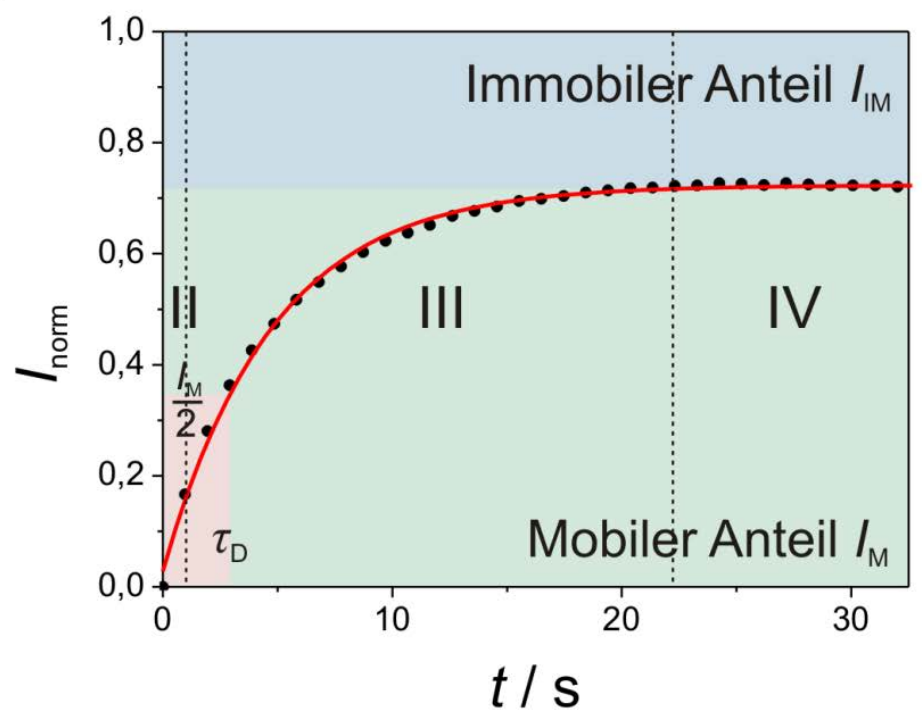

Abb. 3-15: Bestimmung des Diffusionskoeffizienten mittels FRAP. $A$, Schematische Darstellung des Photobleichens und der Rückkehr von Fluoreszenz-markierten Molekülen (rot). I: Situation vor dem Bleichen im Messfeld, II: nach Bleichpuls im Region of Interest (ROI, schwarzer Kreis), III: langsame Rückkehr der Fluoreszenz im ROI, $I V$ : maximaler Fluoreszenzrückkehr im ROI durch mobilen Anteil der Fluoreszenz-markierten Moleküle. $\boldsymbol{B}$, Normalisierter Intensitätsverlauf mit der Kurvenanpassung (rot) nach Gl. 3-7. Die Abschnitte II-IV korrespondieren mit der schematischen Darstellung in Abb. 3-15 A. $\tau_{\mathrm{D}}$-Zeit bei der die Hälfte der maximalen Fluoreszenzintensität erreicht ist.

Für die FRAP-Experimente wurde die Fluoreszenzintensität abhängig von der Zeit mithilfe des CLSMs aufgenommen. Zur Bestimmung des Diffusionskoeffizienten wurde die Zen Software (Carl Zeiss AG, Jena) verwendet. Durch die stetige Aufnahme der Fluoreszenzintensität ist der gesamte Bildausschnitt der Probe einem Bleichprozess ausgesetzt. Um diesen Prozess zu korrigieren, wurde die aufgezeichnete Intensität des Bleichflecks um die Intensität eines ROIs ähnlicher Größe außerhalb des Bleichflecks korrigiert. Zur Bestimmung des Diffusionskoeffizienten wurde eine monoexponentielle Anpassung an den Intensitätsverlauf im Bleichfleck I nach Gl. 3-7 vorgenommen.

$$
I=I_{\mathrm{F}}-I_{\mathrm{IM}} \cdot e^{\frac{-t}{T_{1}}}
$$

$I_{\mathrm{F}}$ entspricht der maximal erreichten Intensität nach dem Bleichen, $I_{\mathrm{IM}}$ beschreibt den immobilen Anteil der beobachteten Moleküle, $t$ den Beobachtungszeitraum und $T_{1}$ entspricht dem Anpassungsparameter an den Intensitätsverlauf nach Gl. 3-7. Nach Gl. 3-8 lässt sich $\tau_{\mathrm{D}}$ berechnen, was der Zeit entspricht, bei der die Hälfte der maximalen Fluoreszenzintensität erreicht ist. 


$$
\tau_{\mathrm{D}}=\ln 0,5 \cdot\left(-T_{1}\right)
$$

Mit der halbmaximalen Diffusionszeit $\tau_{\mathrm{D}}$ kann der Diffusionskoeffizient $D$ berechnet werden. Der Durchmesser des Bleichflecks wird durch $\omega$ angegeben.

$$
D=\frac{\omega^{2}}{4 \cdot \tau_{\mathrm{D}}}
$$




\subsection{Rasterelektronenmikroskopie}

In dieser Arbeit wurde die Rasterelektronenmikroskopie (Scanning Electron Microscopy, SEM) zur Charakterisierung von porösen Aluminiumoxidsubstraten verwendet. Außerdem konnte damit regelmäßig die Qualität der Präparation überprüft werden und gegebenenfalls Schritte in der Präparation angepasst bzw. verbessert werden.

Prinzipiell funktioniert das von M. v. Ardenne 1937 entwickelte Rasterelektronenmikroskop analog zu einem Lichtmikroskop, nur das statt Glaslinsen magnetische Linsen und Elektronen statt Photonen verwendet werden. Dabei rastert ein Elektronenstrahl für die Bilderzeugung einen definierten Probenabschnitt ab, wobei eine bis $\mathrm{zu}$ 800.000-fache Vergrößerung erreicht werden kann. Für die Rasterelektronenmikroskopie ist ein Hochvakuum erforderlich, damit die mittlere freie Weglänge der Elektronen nicht durch etwaige Gasmoleküle beeinflusst wird. Infolgedessen können nur Proben untersucht werden, die vakuumstabil sind. Zur Erzeugung des Elektronenstrahls werden Kathoden aus Wolfram oder Lanthanhexaborid oder Feldemissionskathoden verwendet. Durch einen Heizstrom werden Elektronen von der Kathode emittiert. Im elektrischen Feld (Beschleunigungsspannungen von bis zu $10^{5} \mathrm{~V}$ ) werden sie von der Kathode zur Anode beschleunigt. Um das Bild punktförmig abzurastern wird der Elektronenstrahl durch die Magnetspulen fokussiert und mithilfe einer Ablenkeinheit in $x-y$-Richtung bewegt. Für die Bilderzeugung können verschiedene Wechselwirkungsprodukte genutzt werden, die durch das Auftreffen der Primärelektronen entstehen (inelastische Streuung). Im Gegensatz dazu findet bei der elastischen Streuung der Primärelektronen trotz Richtungsänderung keine Energieübertragung statt. Für die Bilderzeugung werden Sekundärelektronen sowie Rückstreuelektronen (Backscattered Electrons, BSE) am häufigsten genutzt, wobei bei der Messung der Sekundärelektronen eine bessere Auflösung ermöglicht wird. Rückstreuelektronen werden nach der Wechselwirkung mit der Probe unter Energieverlust zurückgestreut $(E>50 \mathrm{eV})$ und stammen aus tieferen Schichten der Probe (Tiefeninformation). Dagegen stammen Sekundärelektronen aus der obersten Schicht der Probe (Oberflächeninformation) und entstehen während der Ionisation der Probe durch Primärelektronen $(E<50 \mathrm{eV})$. Mit der Energy Dispersive X-Ray (EDX)-Spektroskopie werden die erzeugten Röntgenstrahlen zur Aufklärung der chemischen Zusammensetzung der Probe verwendet. Bei einer geringen Schichtdicke können auch transmittierte Elektronen zur Bilderzeugung genutzt werden (Transmissionselektronenmikroskopie). ${ }^{[125]}$ 

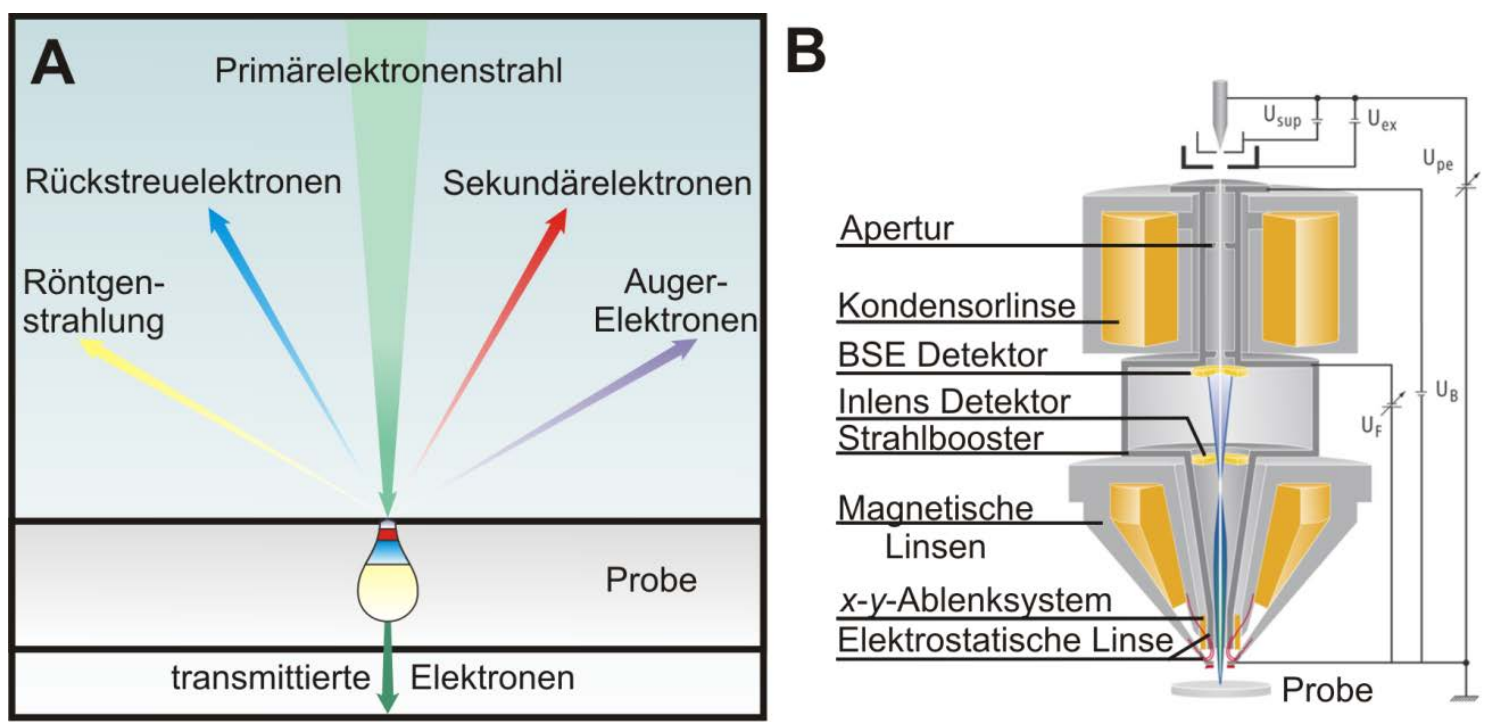

Abb. 3-16: $A$, Schematische Darstellung der Wechselwirkungsprodukte, die beim Auftreffen des Primärelektronenstrahls entstehen können. Die farbliche Kennzeichnung verdeutlicht, wo die verschiedenen Wechselwirkungsprodukte in der Anregungsbirne entstehen. $\boldsymbol{B}$, Schematischer Aufbau des Supra ${ }^{\text {TM }}$ 55VP von Carl Zeiss. Der Strahlbooster beschleunigt die Elektronen noch einmal um $8 \mathrm{kV}$, dadurch wird die Empfindlichkeit des Elektronenstrahls gegenüber magnetischen Streufeldern minimiert. Wiederum bremst die elektrostatische Linse die Elektronen um $8 \mathrm{kV}$ ab. Die Elektronen erreichen mit der eingestellten Beschleunigungsspannung die Probe. Die Sekundärelektronen werden durch den Inlens Detektor und die Rückstreuelektronen durch den BSE Detektor erfasst. ( $U_{\text {ex }}$-Extraktorspannung der 1 . Anode, $U_{\mathrm{PE}}$-Primärspannung, $U_{\mathrm{B}}$-Boosterspannung, $U_{\mathrm{F}}-$ Es BFiltering Grid-Spannung). ${ }^{[147]}$

Für die Analyse der porösen Aluminiumoxidsubstrate wurde das Supra ${ }^{\mathrm{TM}}$ 55VP (Carl Zeiss, Jena) bei einem Anodenstrom von 5 bis $10 \mathrm{kV}$ und eine Apertur von $30 \mu \mathrm{m}$ verwendet. Um Aufladungseffekte der Proben zu verhindern, wurden diese zuvor unter Hochvakuum mit einer Goldschicht von 5 bis $10 \mathrm{~nm}$ bedampft (Coating System MED020, Bal-Tec (Leica, Wetzlar)). 


\subsection{Präparative Methoden}

\subsubsection{Präparation poröser Aluminiumoxidsubstrate}

Aluminium kommt nur als Salz vor und wird industriell vor allem aus Bauxit durch Schmelzflusselektrolyse gewonnen. Bemerkenswert ist, dass sich an der Aluminiumoberfläche eine dünne Oxidschicht bildet und es dadurch vor weiterer Oxidation geschützt ist

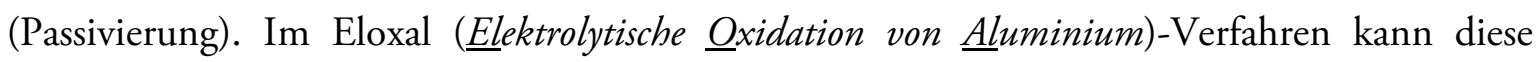
schützende Schicht durch anodische Oxidation von wenigen Nanometern bis in den Mikrometer-Bereich vergrößert werden. ${ }^{[148]}$ Die anodische Oxidation von Aluminium wird mit aziden Elektrolyten wie Oxal-, Phosphor- oder Schwefelsäure unter Gleichstrombedingungen durchgeführt. Während der Anodisierung des Aluminiums finden zwei Prozesse statt. An der Anode (Aluminium) wird Aluminium zu Al ${ }^{3+}$ oxidiert und reagiert schließlich zum Aluminiumoxid $\left(\mathrm{Al}_{2} \mathrm{O}_{3}\right.$, Gl. 3-10). Im Gegensatz dazu wird an der Kathode (Platin) $\mathrm{H}_{3} \mathrm{O}^{+}$zu Wasserstoff reduziert (Gl. 3-11). Beide Prozesse lassen sich zur Gesamtgleichung Gl. 3-12 zusammenfassen.

$$
\begin{array}{lrr}
\text { Anode: } & 2 \mathrm{Al}+9 \mathrm{H}_{2} \mathrm{O} \rightarrow \mathrm{Al}_{2} \mathrm{O}_{3}+6 \mathrm{H}_{3} \mathrm{O}^{+}+6 \mathrm{e}^{-} & \text {Gl. 3-10 } \\
\text { Kathode: } & 6 \mathrm{H}_{3} \mathrm{O}^{+}+6 \mathrm{e}^{-} \rightarrow 3 \mathrm{H}_{2}+6 \mathrm{H}_{2} \mathrm{O} & \text { Gl. 3-11 } \\
\text { Gesamtgleichung: } & 2 \mathrm{Al}+3 \mathrm{H}_{2} \mathrm{O} \rightarrow \mathrm{Al}_{2} \mathrm{O}_{3}+3 \mathrm{H}_{2} & \text { Gl. 3-12 }
\end{array}
$$

Die Oxidbildung kann mithilfe der Strom-Zeitkurve in vier Abschnitte eingeteilt werden (Abb. 3-17 C). Die Prozessabschnitte sind in Abb. 3-17 A schematisch dargestellt. In Abschnitt 1 kommt es zur Formierung einer Sperrschicht (etwa $80 \mathrm{~nm}$ ). Dieser folgt die Bildung einer porösen Struktur, welche unter bestimmten Bedingungen aus hexagonal angeordneten Zylindern besteht und mit einer Honigwabenstruktur vergleichbar ist. ${ }^{[149]}$ Während der Anodisierung gibt es zwei konkurrierende Prozesse, zum einen wird das gebildete $\mathrm{Al}_{2} \mathrm{O}_{3}$ an der Oxid-Elektrolyt-Grenzfläche aufgelöst und zum anderen wächst das $\mathrm{Al}_{2} \mathrm{O}_{3}$ an der OxidMetall-Grenzfläche. Der erste Prozess wird von der elektrischen Feldstärke beeinflusst. Der letztere wird durch den Transport von Hydroxid- und Oxid-Anionen zur Metall-OxidGrenzfläche, welche unter dem Einfluss der Säure an der Oxidschicht entstehen ${ }^{[150]}$, limitiert. Da Aluminium nicht vollkommen homogen aufgebaut ist, werden unterschiedlich starke 
Oxidschichten gebildet. Durch das elektrische Feld an der Oberfläche der Sperrschicht wird die Al-O-Bindung gedehnt, sodass das Feld $\mathrm{O}^{2-}$ in das Oxid zieht und $\mathrm{Al}^{3+}$ in die Lösung führt (Abb. 3-17 B). An den Porenböden kommt es in Bereichen mit dünnerer Oxidschicht zu einer Erhöhung der Feldstärke im Vergleich zu Bereichen mit einer dickeren Oxidschicht und aus diesem Grund auch zu einer erhöhten Auflösungsrate des Oxids (Abschnitt 2). Eine weitere Begründung für die Ausbildung einer porösen Struktur ist mechanischer Stress an der OxidMetall-Grenzfläche, da es hier zum Wachstum des Oxids kommt und gleichzeitig das schon gebildete Oxid nach oben geschoben wird. ${ }^{[151]}$ Dies bedingt abstoßende Kräfte zwischen den benachbarten Poren, die durch eine hexagonale Anordnung minimiert werden. Der erhöhte Ionenfluss beschleunigt aber auch das Oxidwachstum im Bereich der Stege (Abschnitt 3). In Abschnitt 4 kommt es zur Gleichgewichtseinstellung der beiden Prozesse von Oxidbildung und -auflösung. Das Wachstum der Poren führt zu einem Konzentrationsgradienten des Elektrolyten und dies bedingt eine leichte Stromabnahme. ${ }^{[150]}$ Die erhaltenen Substrate weisen eine Porosität von etwa $10 \%$ auf. ${ }^{[152]}$ Der Ordnungsgrad ist aufgrund der Wachstumsrichtung an der Aluminium-Oxid-Grenzfläche am höchsten und an der Oxidoberfläche am niedrigsten. Zur Erhöhung des Ordnungsgrades wird zunächst das Aluminium durch eine initiale Anodisierung vorstrukturiert, das Oxid wieder entfernt und somit die hochgeordneten Aluminiumböden freigelegt. Erst in der zweiten anodischen Oxidation wird das eigentliche, hochgeordnete Aluminiumoxidsubstrat erzeugt. 


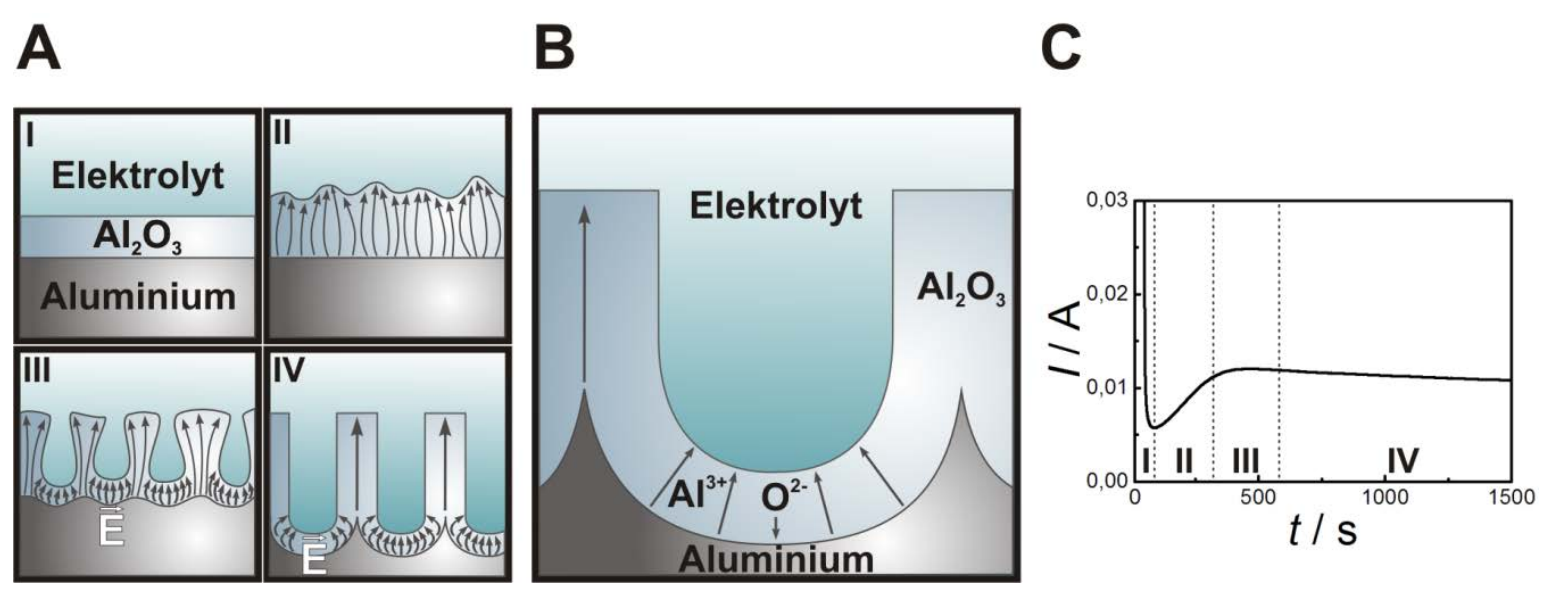

Abb. 3-17: Schematischer Verlauf der Porenbildung während der anodischen Oxidation von Aluminium. $A$, Die Oxidbildung kann in vier Abschnitte eingeteilt werden. I: Bildung eines Barriereoxids. II: Durch Schwankungen in der Feldstärke entstehen Vertiefungen. III: Bildung erster traubenförmiger Poren. IV: Porenwachstum. B, Darstellung der elektrophoretischen Mobilität der gebildeten Ionen: Aufgrund der Stromrichtung geht $\mathrm{Al}^{3+}$ zur Kathode und damit an den Porenböden in Lösung. $\mathrm{O}^{2-}$ bewegt sich zur Anode und wandert deshalb in das Oxid. C, Exemplarischer StromZeit-Verlauf der ersten $1.500 \mathrm{~s}$ der zweiten Anodisierung in $0,3 \mathrm{M}$ Oxalsäure bei $40 \mathrm{~V}$ mit den vier Abschnitten (siehe Abb. 3-17 A) der Oxidbildung. Die Abbildung wurden nach Ghicov \& Schmuki und Jessensky et al. angefertigt. ${ }^{[153,151]}$

Vor der Anodisierung wurde das Aluminium für $3 \mathrm{~h}$ bei $500{ }^{\circ} \mathrm{C}$ unter Stickstoffatmosphäre getempert, um die Homogenität und die Feinheit der Metallstruktur zu erhöhen. Durch das Tempern kommt es zur Vergrößerung der Korngrenzen.

\section{Elektrochemisches Polieren von Aluminium}

Das verwendete Aluminium (99,999\%, Goodfellow, Bad Nauheim) weist eine natürliche Oxidschicht auf. Eine nähere Untersuchung der Oberflächenrauigkeit durch Rasterelektronenmikroskopie (Kapitel 4.4.1) zeigt, dass eine Vorbehandlung der Oberfläche durch ein mechanisches oder elektrochemisches Polieren notwendig ist. Die verschiedenen Prozessabschnitte sind in Abb. 3-18 (1 bis 7) dargestellt. Die Oberflächenrauigkeit wird durch elektrochemisches Polieren vom Mikrometer- zum Nanometerbereich verringert. ${ }^{[151]}$ Für die Herstellung nanoporöser Substrate wurden quadratische Aluminiumplättchen, mit einer Kantenlänge von 1,5 cm und einer Schichtdicke von 0,5 mm, verwendet (Abb. 3-18 (1)). Die Plättchen müssen eben sein, sonst brechen die Aluminiumoxidfilme mit geringer Schichtdicke (1 bis $10 \mu \mathrm{m})$ bei der Selektiven Ablösung des Aluminiumträgers relativ leicht. Zunächst wurden diese auf der Rückseite mit Sandpapier aufgeraut und in eine Poliereinheit mit vier Aussparungen (Teflon) mit der aufgerauten Seite zwischen den Dichtringen und der Kupferplatte (Kathode) 
eingebaut. Die Heizplatte wurde auf $65^{\circ} \mathrm{C}$ vorgeheizt, die Kammer mit $25 \mathrm{~mL}$ Polierlösung, ein Gemisch aus konzentrierter Schwefelsäure, 85 \%iger Phosphorsäure und Reinstwasser im Massenverhältnis 1:1:1, aufgefüllt und der Polieraufsatz (Anode) aufgesetzt. Nach etwa fünfminütiger Äquilibrierung wurde die Poliereinheit mit einer Spannungsquelle verbunden und ein Strom von $-25 \mathrm{~V}$ appliziert. Die Polierlösung ist als starker Elektrolyt in der Lage, die gebildete Aluminiumoxidschicht aufzulösen. Nach 10 bis 15 min wurde die Polierlösung gegen neue Lösung ausgetauscht und mindestens $15 \mathrm{~min}$ weiter behandelt. Nach dem elektrochemischen Polieren ist die Beschaffenheit der Oberfläche mit der eines Spiegels vergleichbar (Abb. 3-18 (2)). Die Plättchen wurden mit Reinstwasser und absolutem Ethanol gespült und zur Entfernung von einer dünnen Aluminiumoxidschicht für etwa $1 \mathrm{~h}$ in 5 \%iger $(v / v)$ Phosphorsäure (85\%) inkubiert. Kupferrückstände auf der Rückseite wurden mithilfe von Salpetersäure entfernt.

\section{Vorstrukturierung des Aluminiums}

Zur Vorstrukturierung des elektrochemisch polierten Aluminiums wurde zunächst das Peltierelement auf $1,5^{\circ} \mathrm{C}$ vorgekühlt. Die polierten Aluminiumplättchen (4 Stück) wurden mit der aufgerauten Seite passgenau in die Ätzeinheiten (Polyvinylchlorid, PVC) eingebaut, der Kupferboden aufgelegt und mithilfe des Kupferrings festgeschraubt. Die Kammer wurde mit Reinstwasser auf ihre Dichtigkeit geprüft (etwa $10 \mathrm{~min}$ ) und anschließend zu dreiviertel mit vorgekühlter 0,3 M Oxalsäurelösung befüllt. Anschließend wurde das System für $10 \mathrm{~min}$ unter Rühren auf $1,5^{\circ} \mathrm{C}$ vorgekühlt. Danach wurde für $2 \mathrm{~h} 40 \mathrm{~min}$ bei $40 \mathrm{~V}$ anodisiert, um eine Gitterkonstante von $\lambda_{\mathrm{C}-\mathrm{C}} \approx 100 \mathrm{~nm}$ zu erreichen (Abb. 3-18 (3)). ${ }^{[149]}$

\section{Ablösen der Vorstrukturierung}

Die Aluminiumplättchen wurden nach der Anodisierung mit Reinstwasser und absolutem Ethanol gespült und zur Entfernung der Vorstrukturierung für etwa 2 bis 3 h in $5 \%$ iger $(v / v)$ Phosphorsäurelösung (85\%) inkubiert. Das Spülen mit absolutem Ethanol erlaubt den gleichmäßigen Eintritt der Phosphorsäure in die poröse Struktur und damit deren gleichmäßige Ablösung. Der Fortschritt der Oxidauflösung wurde zwischenzeitlich kontrolliert. Dazu wurde ein Plättchen mit Reinstwasser und absolutem Ethanol gespült und im Stickstoffstrom getrocknet. Solange die Oberfläche beim Trocknen im Licht opaleszent erscheint 
war noch Oxid auf der Oberfläche vorhanden. Nachdem die Vorstrukturierung vollständig entfernt worden war, erkennbar an der hochspiegelnden Oberfläche, wurden die Aluminiumscheiben wieder mit Reinstwasser gespült und im Stickstoffstrom getrocknet (Abb. 3-18 (4)).

\section{Hauptätzung}

Die zweite Anodisierung wurde analog zur Vorstrukturierung durchgeführt. Es wurde gezeigt, dass pro Stunde die Schichtdicke des gebildeten Aluminiumoxids um etwa 2,5 $\mu \mathrm{m}$ zunimmt. ${ }^{[154]}$ Um eine Schichtdicke von etwa $7 \mu \mathrm{m}$ zu erreichen, wurde für $2 \mathrm{~h} 40 \mathrm{~min}$ bei $40 \mathrm{~V}$ anodisiert. Anschließend wurden die Plättchen mit Reinstwasser und absolutem Ethanol gespült und anschließend getrocknet (Abb. 3-18 (5)).

\section{Selektive Entfernung des Aluminiumträgers}

Für das Ablösen des Aluminiums im Bereich des entstandenen Aluminiumoxids wurden die Plättchen wie in Abb. 3-18 (6) mithilfe von Spiegelklebeband auf einen Objektträger geklebt und auf einen zuvor markierten Bereich sowie an der Seite mit einem Epoxidharz (UHU plus sofort fest-2 Komponentenepoxidharzkleber, Bühl/Baden) versiegelt, sodass zum Schluss nur ein kreisrunder Ausschnitt im Bereich des Aluminiumoxids zugänglich war. Nach dem Trocknen des Harzes ( 2 bis $3 \mathrm{~h}$ ) wurde der Aluminiumausschnitt aufgeraut und zunächst in eine Kupferchloridlösung, bestehend aus $17 \mathrm{~g} \cdot \mathrm{L}^{-1} \mathrm{CuCl}_{2}$ in Reinstwasser und konzentrierter $\mathrm{HCl}$ (1:1), zur Entfernung des Aluminiums gelegt und mit einer Pasteurpipette gespült. Der Ablösevorgang verläuft nach folgender Reaktion:

$$
3 \mathrm{Cu}^{2+}+2 \mathrm{Al}+2 \mathrm{Cl}^{-}+8 \mathrm{H}_{2} \mathrm{O} \rightarrow 2 \mathrm{Al}(\mathrm{OH})_{2} \mathrm{Cl}+3 \mathrm{Cu}+4 \mathrm{H}_{3} \mathrm{O}^{+}
$$

Sobald die Aluminiumoxidschicht sichtbar wurde, wurde das Substrat in neue Kupferchloridlösung auf Eis überführt. Hier wurde weiter vorsichtig gespült, bis das Aluminium vom Oxid vollständig abgelöst war. Bei einer unregelmäßigen Entfernung des Aluminiums kommt es, sobald das Aluminiumoxid erscheint, zu einer weiteren Reaktion, welche langsamer verläuft als die Reaktion in Gl. 3-13.

$$
\mathrm{Al}_{2} \mathrm{O}_{3}+2 \mathrm{Cl}^{-}+3 \mathrm{H}_{2} \mathrm{O} \rightarrow 2 \mathrm{Al}(\mathrm{OH})_{2} \mathrm{Cl}+2 \mathrm{OH}^{-}
$$


Durch diese Reaktion wird auch die Oxidschicht angegriffen, deshalb sollte das Oxid der Kupferchloridlösung nicht zu lange ausgesetzt sein. Danach wurde es in eine Mischung aus absolutem Ethanol und Reinstwasser überführt und sukzessive mit Reinstwasser und absolutem Ethanol gereinigt. Schließlich wurde es vorsichtig im Stickstoffstrom getrocknet (von der Seite zur Mitte), damit keine Salze auf der Aluminiumoxidoberfläche zurückbleiben (Abb. 3-18 (7)).

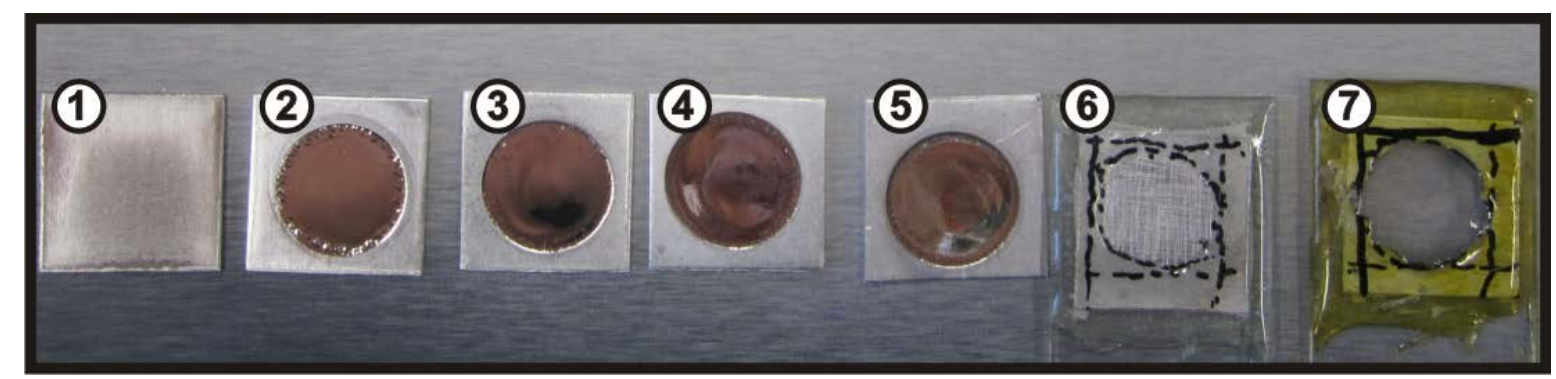

Abb. 3-18: Verschiedene Abschnitte der Herstellung der porösen Aluminiumoxidsubstrate. I: unbehandelter ausgeheizte Aluminiumrohling, II: nach elektrochemischen Polieren, III: nach 1. Anodisierung, $I V$ : nach Ablösen des $\mathrm{Al}_{2} \mathrm{O}_{3}, V$ : nach 2. Anodisierung, VI: Fixierung auf Objektträger, VII: $\mathrm{Al}_{2} \mathrm{O}_{3}$ nach Entfernen des Aluminiumträgers.

\subsubsection{Orthogonale Funktionalisierung der porösen Aluminiumoxidsub- strate}

Zur Herstellung von porenüberspannenden Membranen mussten die porösen Aluminiumoxidsubstrate zunächst funktionalisiert werden.

\section{Aufbringung der Aluminiumoxidfolie}

Zur Fixierung der porösen Aluminiumoxidfolie wurden zunächst Objektträgergläschen (Menzel Gläser, Thermo Scientific, Braunschweig) sukzessive in $2 \%(v / v)$ Hellmanexlösung und zweimal in Reinstwasser im Ultraschallbad für jeweils 15 min gereinigt. Direkt vor der Präparation wurden die Glasträger mit absolutem Ethanol gespült und anschließend auf eine Größe von $4 \times 4 \mathrm{~mm}^{2}$ zugeschnitten. Die Aluminiumoxidfolie wurde mithilfe eines optisch klaren, UV-Licht härtenden Klebers (Norland Optical Adhesive $83 \mathrm{H}$ ) fixiert. Dieser wurde im Verhältnis von etwa 1:10 $(v / v)$ in Tetrahydrofuran (THF) verdünnt und mithilfe einer Pasteurpipette aufgetragen. Darauf wurde ein Stück Aluminiumoxidfolie, mit den Porenböden 
zum Objektträger weisend, positioniert ohne dabei Luft einzuschließen. Für die Polymerisierung des Klebstoffs wurde dieser mit UV-Licht der Wellenlänge $254 \mathrm{~nm}$ und $365 \mathrm{~nm}$ für etwa 2 h gehärtet.

\section{Selektive Einstellung des Porendurchmessers}

Zur Vergrößerung des Porendurchmessers von durchschnittlich $25 \mathrm{~nm}$ auf $60 \mathrm{~nm}$ wurden die aufgeklebten Substrate für $50 \mathrm{~min}$ bei $20^{\circ} \mathrm{C}$ in $5 \%$ iger $(v / v)$ Phosphorsäure $(85 \%)$ unter Rühren inkubiert. Dabei nimmt der Porendurchmesser durchschnittlich um 0,75 nm.min ${ }^{-1}$ zu, der erzielte Porendurchmesser $d_{0}$ kann nach folgender Gleichung berechnet werden, dabei wird die Inkubationszeit mit $t_{1}$ beschrieben. ${ }^{[154]}$

$$
d_{0}=0,75 \cdot t_{\mathrm{I}}+25 \mathrm{~nm}
$$

Die Substrate wurden vor und nach der Inkubation mit Reinstwasser und absoluten Ethanol gespült. Danach wurden sie im Stickstoffstrom getrocknet.

Selektive Funktionalisierung von porösen Aluminiumoxidsubstraten (Gasphasen-Silanisierung)

Die einzelnen Schritte der Oberflächenfunktionalisierung sind in Abb. 3-19 dargestellt. Zunächst wurden die aufgeklebten Substrate durch Inkubation für $1 \mathrm{~min}$ im Sauerstoffplasma (Plasma Cleaner PDC 32 G-2, Harrick, Ithaka, NY, USA) gereinigt und die Anzahl an Hydroxylgruppen auf der Oberfläche gesteigert. Dann wurden die Substrate in einen Objektträgerkasten einsortiert und in ein Reaktionsgläschen $50 \mu \mathrm{L}$ 3-Mercaptopropyltriethoxysilan (Abb. 3-19 C) pipettiert. Der Objektträgerkasten wurde mit Vakuumklebeband (3M Electrical Tape 102087, Scotch ${ }^{\mathrm{TM}}$, St. Paul, MN, USA) verschlossen und in einen auf $135^{\circ} \mathrm{C}$ temperierten Vakuumtrockenschrank gestellt. Zunächst wurde das Gefäß für etwa 10 min äquilibriert und anschließend für $3 \mathrm{~h}$ unter kontinuierlicher Evakuierung des Trockenschranks inkubiert. 


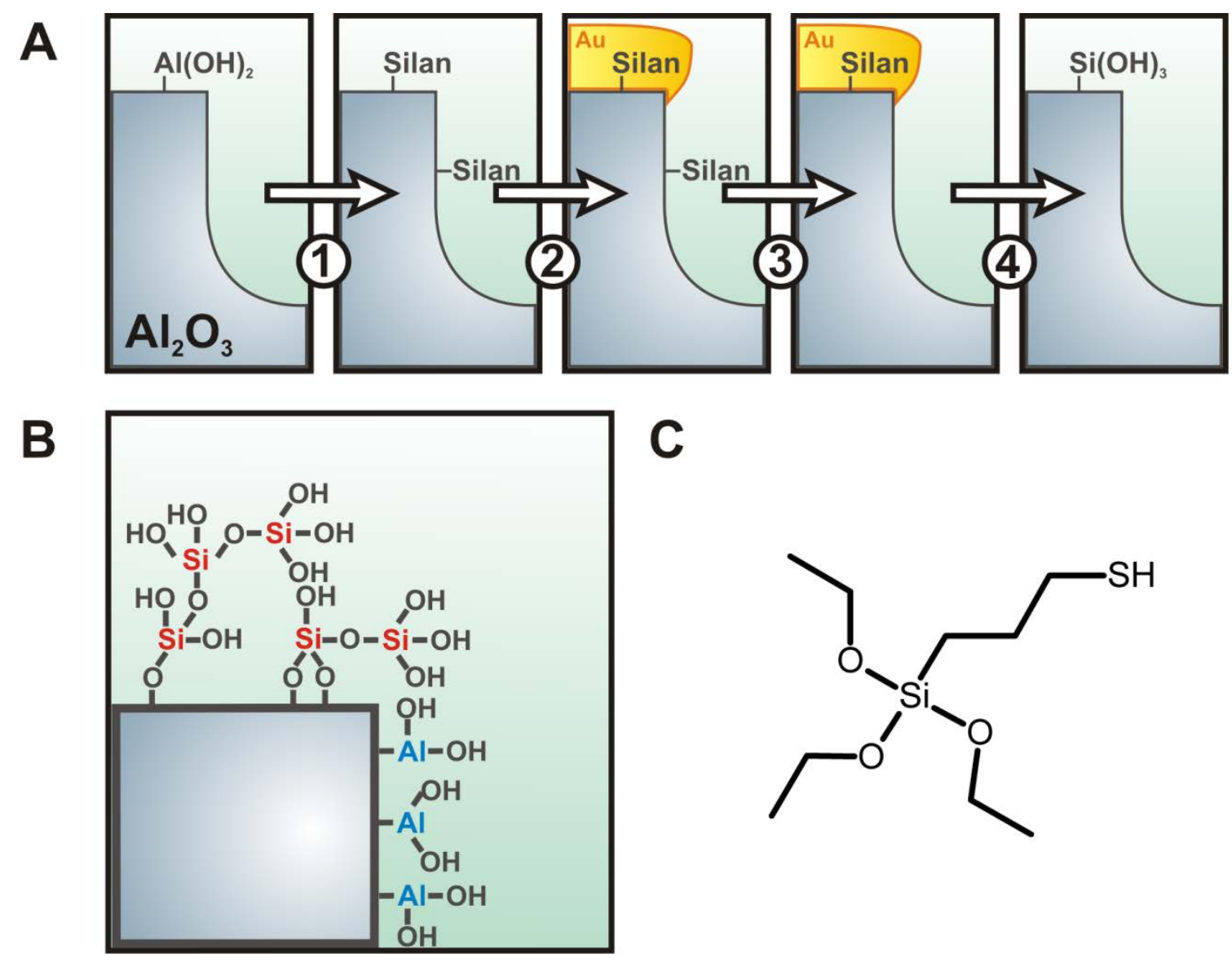

Abb. 3-19: $A$, Schematische Darstellung der orthogonalen Funktionalisierung von Aluminiumoxid: (1) Silanisierung mit 3-Mercaptopropyltriethoxysilan, (2) Evaporation von einer etwa $10 \mathrm{~nm}$ Goldschicht, (3) Entfernung der Funktionalisierung im Poreninneren durch Inkubation im $\mathrm{O}_{2}$ - und Ar-Plasma, (4) Entfernung der Goldschicht mit KI/I $\mathrm{I}_{2}$ und Hydrophilisierung durch Applikation von $\mathrm{O}_{2}$-Plasma. $\boldsymbol{B}$, Die Porenstege sind mit einer Schicht nach Entfernung der Goldschicht und Inkubation im $\mathrm{O}_{2}$-Plasma von hydrophilen Silanolgruppen funktionalisiert. Das Poreninnere besitzt nach Schritt (3) keine Funktionalisierung. C, Strukturformel von 3-Mercaptopropyltriethoxysilan. Abbildung wurde nach Lazzara et al. angefertigt. ${ }^{[155]}$

Anschließend werden etwa $10 \mathrm{~nm}$ Gold zum Schutz der Silanisierung unter Hochvakuum aufgedampft (Coating System MED020, Bal-Tec (Leica, Wetzlar)). Bedingt durch den Porendurchmesser bedeckt die kolloidale Goldschicht maßgeblich die Porenstege, wodurch das Poreninnere nicht mit Gold ausgekleidet ist. Durch eine weitere Applikation von jeweils 1 min Sauerstoff- und Argonplasma konnte selektiv die Silanisierung in den Poren wieder entfernt werden. Für das Spreiten von unilamellaren Riesenvesikeln wurde das poröse Substrat nach Entfernen des Golds mit Iod-Kaliumiodid-Lösung $\left(0,5 \%(w / v) \mathrm{KI}, 0,125 \%(w / v) \mathrm{I}_{2}\right.$ in Reinstwasser) für $1 \mathrm{~min}$ im Sauerstoffplasma inkubiert und 3-Mercaptopropyltriethoxysilan wurde zum Silanol oxidiert (Abb. 3-19 B). In Kapitel 3.5.6 wird die Präparation von poren- 
überspannenden Membranen auf den orthogonal funktionalisierten Substraten ausführlich erläutert.

\subsubsection{Elektroformation von Riesenvesikeln}

In dieser Arbeit wurden u. a. Riesenvesikel (Giant Unilamellar Vesicles, GUVs) als artifizielles Membransystem verwendet. Die Elektroformation stellt eine Methode dar, um reproduzierbar GUVs herzustellen und wurde zuerst durch Angelova und Dimitrov beschrieben. ${ }^{[81]} 1992$ erweiterte Angelova die Methode und wechselte von Gleichstrom- auf Wechselstrombedingungen, wodurch der Herstellungsprozess optimiert wurde. ${ }^{[82]}$ Im ersten Schritt werden die Lipide in geeignetem Lösungsmittel auf einen leitenden Träger (z. B. Indiumzinnoxid beschichte Objektträger) aufgebracht. Nach dem Eintrocknen sind die Lipide auf dem Träger in parallelen Schichten aus Lipidmembranen angeordnet und dadurch schon vororganisiert. Im nächsten Schritt werden die Lipidfilme durch die Zugabe von wässriger Lösung rehydratisiert und Wasser tritt auch in die Zwischenräume der einzelnen Schichten. ${ }^{[156]}$ Durch das elektrische Wechselfeld und die damit verbundene Frequenz wird eine geringe mechanische Bewegung auf die Lipidschichten übertragen. Dies führt zur Bildung und Ablösung der GUVs. ${ }^{[82]}$ Die verwendete Präparationsmethode beschränkt sich auf Pufferlösungen mit geringer Ionenstärke $\left(c_{\mathrm{NaCl}}<10 \mathrm{mM}\right)$, da bei höherer Ionenstärke eine verminderte bzw. keine Elektroformation mehr stattfindet. ${ }^{[83]}$ Die Herstellung von GUVs mit einer Ionenstärke von bis zu $250 \mathrm{mM} \mathrm{NaCl}$ wurde von Pott et al. entwickelt. ${ }^{[157]}$ Dafür werden aber Frequenzen von bis zu $500 \mathrm{~Hz}$ benötigt.

Für die Präparation der GUVs wurde zunächst $25 \mu \mathrm{L}$ Lipid $\left(c=2 \mathrm{mg} \cdot \mathrm{mL}^{-1}\right)$ in Chloroform auf Indiumzinnoxid (Indium Tin Oxide, ITO)-beschichtete Objektträger (CEC010S, Präzisions Glas \& Optik GmbH, Iserlohn) aufgetragen. Zu der Lipidlösung wurde zur fluoreszenzmikroskopischen Visualisierung durch Fluoreszenzmikroskopie verschiedene Fluoreszenzsonden zugesetzt. Die verwendeten Konzentrationen können Tab. 3-1 entnommen werden. Die ITO-Gläser wurden für mindestens $3 \mathrm{~h}$ im Vakuumtrockenschrank getrocknet, um restliches Chloroform zu entfernen. Anschließend wurden zwei ITO-Gläser mit einem Silikonabstandshalter zusammengebaut. Um die beiden Gläser zu kontaktieren wurde auf die Teflonabstandshalter jeweils ein aufgerautes Kupferklebeband geklebt. Die Kammer wurde mit 210 mM Sorbitol, 1 M Sorbitol oder 300 M Saccharose gefüllt und blasenfrei verschlossen. 
Danach wurde die Kammer an einen Frequenzgenerator (33220A, Agilent Technologies, Böblingen) angeschlossen.

Bei der GUV-Herstellung wurden abhängig von der Lipidzusammensetzung zwei Methoden verwendet. Für die Präparation von GUVs, welche sich aus DPhPC/Cholesterol zusammensetzen, wurde eine Sinusspannung von $3 \mathrm{~V}$ und $5 \mathrm{~Hz}$ für $3 \mathrm{~h}$ (Protokoll 1) appliziert.

Für andere Lipidzusammensetzungen wurde auch ein Wechselfeld für 3,5 h (Protokoll 2) angelegt. Hierfür wurde die Sinusspannung bei einer Frequenz von $12 \mathrm{~Hz}$ innerhalb von $30 \mathrm{~min}$ schrittweise von $50 \mathrm{mV}$ bis $200 \mathrm{mV}$ um $10 \mathrm{mV} \cdot \mathrm{min}^{-1}$ und anschließend von $200 \mathrm{mV}$ bis $1,6 \mathrm{mV}$ um $100 \mathrm{mV} \cdot \mathrm{min}^{-1}$ erhöht. Zum Schluss wurde die Frequenz auf $5 \mathrm{~Hz}$ reduziert und 10 min eine Rechteckspannung appliziert. Die Bildung der GUVs wurde anschließend mithilfe der Fluoreszenzmikroskopie kontrolliert.

\subsubsection{Detergenzien und Lipide}

Für die Solubilisierung von Cx43 bzw. Cx43-eGFP aus D. discoideum wurde u. a. das nichtionische Detergens $n$-Octylpolyoxyethylen ( $n \mathrm{POE}$ ) verwendet (Kapitel 4.1.1.2). Die allgemeine Strukturformel ist in Abb. 3-20 wiedergegeben. Es besitzt eine kritische Mizellenbildungskonzentration (Critical Micellar Concentration, CMC) von 6,6 mM (0,23\%). ${ }^{[37]}$

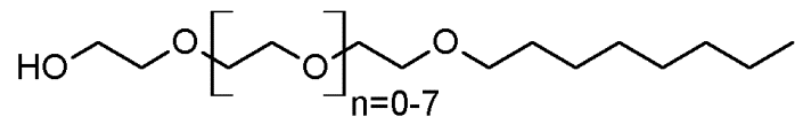

Abb. 3-20: Strukturformel von $n$-Octylpolyoxyethylen.

Für die Isolierung von Cx43 und Cx43-GFP aus P. pastoris wurde das nicht-ionische $n$-Dodecyl- $\beta$-D-maltosid (DDM, Roth, Darmstadt) verwendet (Kapitel 4.1.2.3). Es besteht aus zwei Glucopyranosen, welche durch eine 1,4- $\alpha$-glykosidische Bindung miteinander verknüpft sind (Maltose). Die Maltose bildet mit Laurylalkohol ein Acetal. Das Detergens ist in Abb. 3-21 dargestellt und hat ein Molekulargewicht von 510,6 g. $\mathrm{mol}^{-1}$ und eine Summenformel von $\mathrm{C}_{24} \mathrm{H}_{46} \mathrm{O}_{11}$. DDM hat abhängig von den experimentellen Bedingungen eine $\mathrm{CMC}$ von 0,1 bis $0,2 \mathrm{mM}(0,005-0,01 \%) .^{[158,159]}$ Das $\beta$-Anomer bildet $\mathrm{C}_{1}$ ' quasisphärische Mizellen $\left(M_{\text {Mizelle }}=50.000 \mathrm{~g} \cdot \mathrm{mol}^{-1}\right)$. Simulationen zeigten, dass etwa $10 \%$ der hydrophoben Ketten in der Mizelle solvatisiert vorliegen. ${ }^{[159]}$ Weiter sollte beachtet werden, dass DDM nicht durch Dialyse entfernt werden kann. 


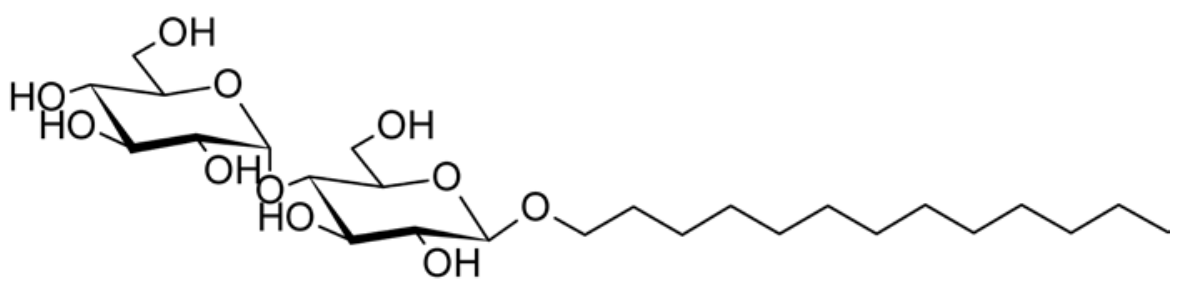

Abb. 3-21: Strukturformel von $n$-Dodecyl- $\beta$-D-maltosid (DDM).

Für die Rekonstitution von Cx43 und Cx43-GFP wurde das nicht-ionische Detergens $n$-Octyl- $\beta$-D-glucopyranosid ( $n$ OG, Roth, Darmstadt) verwendet (Kapitel 4.2), da es sich in mehreren Studien als geeignetes Detergens zur Vesikelrekonstitution von Membranproteinen bewährt hat. ${ }^{[34,37,160-163]}$ Glucose bildet über eine 1,1- $\beta$-glykosidische Bindung mit Octan-1-ol ein Halbacetal. Es bildet bei einer CMC von $25 \mathrm{mM}(0,73 \%)$ runde Mizellen und mit höheren Konzentrationen gehen sie in eine sphärische Form über $\left(25.000 \mathrm{~g} \cdot \mathrm{mol}^{-1}\right) \cdot{ }^{[164]}$ Das Molekulargewicht beträgt 292,4 $\mathrm{g} \cdot \mathrm{mol}^{-1}$ und die Summenformel ist $\mathrm{C}_{14} \mathrm{H}_{28} \mathrm{O}_{6}$. Im Gegensatz zu DDM ist es dialysierbar.

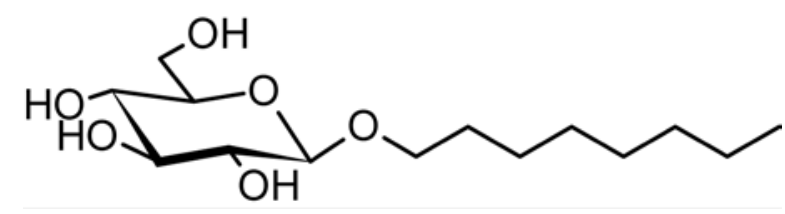

Abb. 3-22: Strukturformel von $n$-Octyl- $\beta$-D-glucopyranosid ( $n \mathrm{OG})$.

Zur Herstellung artifizieller Membranen wurden verschiedene Lipide verwendet. Diese werden im Folgenden näher beschrieben. Für die Präparation von beispielsweise Proteoliposomen zur späteren Applikation für den Fluoreszenz-basierten Funktionsassay (Kapitel 4.5) wurde das asymmetrische Phospholipid 1-Palmitoyl-2-oleoyl-sn-glycero-3-phosphocholin (POPC) verwendet (Abb. 3-23). Das Glycerolgrundgerüst ist mit Palmitinsäure sowie mit der einfachungesättigten Ölsäure (9Z) und der Kopfgruppe aus Phosphocholin verestert. POPC hat eine Phasenumwandlungstemperatur von $-2{ }^{\circ} \mathrm{C}$ und konnte deshalb problemlos bei Raumtemperatur verwendet werden. Es besitzt ein Molekulargewicht von $760,1 \mathrm{~g} \cdot \mathrm{mol}^{-1}$ und hat die Summenformel $\mathrm{C}_{42} \mathrm{H}_{82} \mathrm{NO}_{8} \mathrm{P}$. 
<smiles>[2H][C@@H](COC(=O)CCCCCCCCCCCCCCCCCCCCCCCC)COP(=O)([O-])OCC[N+](C)(C)C</smiles>

Abb. 3-23: Strukturformel von 1-Palmitoyl-2-oleoyl-sn-glycero-3-phosphocholin (POPC).

Für die Präparation der Proteo-GUVs, welche für die Einzelkanalmessungen verwendet wurden (Kapitel 4.3), wurde eine Mischung von 1,2-Diphytanoyl-sn-glycero-3-phosphocholin (DPhPC) und Cholesterol im Verhältnis 9:1 verwendet. Das Glycerolgrundgerüst ist mit Phosphocholin sowie zwei $\mathrm{C}_{16}$-Fettsäuren verestert. Die Seitenketten sind an Position 3, 7, 11 und 15 methyliert. DPhPC weist keine Phasenumwandlungstemperatur im Bereich von $-120^{\circ} \mathrm{C}$ bis $+120^{\circ} \mathrm{C}$ auf, was auf die Methylgruppen zurückzuführen ist. Das Molekulargewicht beträgt $846,3 \mathrm{~g} \cdot \mathrm{mol}^{-1}$ und die Summenformel lautet $\mathrm{C}_{48} \mathrm{H}_{96} \mathrm{NO}_{8} \mathrm{P}$.<smiles>CC(C)CCCC(C)CCCC(C)CCCC(C)CC(=O)OC[C@@H](COP(=O)([O-])OCC[N+](C)(C)C)OC(=O)CC(C)CCCC(C)CCCC(C)C</smiles>

Abb. 3-24: Strukturformel von 1,2-Diphytanoyl-sn-glycero-3-phosphocholin (DPhPC).

Cholesterol besitzt ein lipophiles Steringrundgerüst, die hydrophile Kopfgruppe bildet eine Alkoholfunktion. Das Molekulargewicht beträgt 386,7 g. $\mathrm{mol}^{-1}$ und die Summenformel ist $\mathrm{C}_{27} \mathrm{H}_{46} \mathrm{O}$. Es ist ein wichtiger Bestandteil der tierischen, zellulären Plasmamembranen und bestimmt deren Steifigkeit durch Interaktion mit den Fettsäureketten der unterschiedlichen Lipide. Außerdem ist Cholesterol Vorläufer einer Reihe von Steroidhormonen und Gallensalzen.

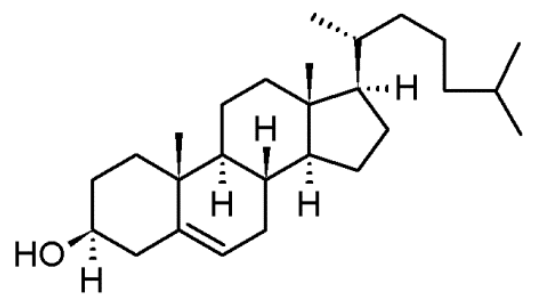

Abb. 3-25: Strukturformel des Cholesterol.

Das Phospholipid 1,2-Dipalmitoyl-sn-glycero-3-phosphoethanolamin- $N$-capronsäurebiotin-Natriumsalz (Bio-Cap-PE) wurde für den Fluoreszenz-basierten Funktionsassay zur 
Überprüfung der Halb- und GapJunction Kanalaktivität verwendet (Kapitel 4.5.2). Die Glyceroleinheit ist mit zwei Hexadekansäuren und Phosphoethanolamin verestert (Abb. 3-26). Weiter ist das Phosphoethanolamin mit Capronsäure und diese wiederum mit Biotin über jeweils eine Säureamidbindung verbunden. Bio-Cap-PE besitzt ein Molekulargewicht von $1053,4 \mathrm{~g} \cdot \mathrm{mol}^{-1}$ und eine Summenformel von $\mathrm{C}_{53} \mathrm{H}_{98} \mathrm{~N}_{4} \mathrm{O}_{11} \mathrm{PNaS}$.

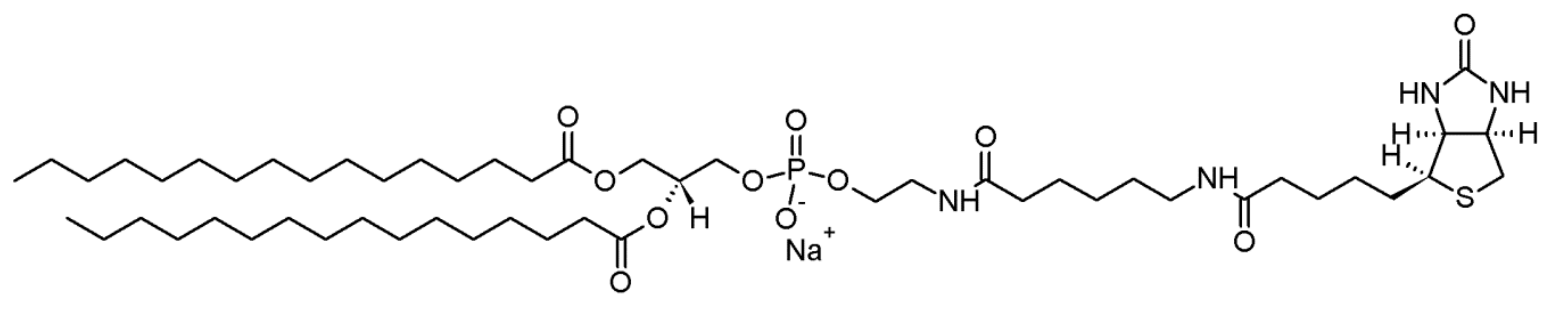

Abb. 3-26: Summenformel von 1,2-Dipalmitoyl-sn-glycero-3-phosphoethanolamin- $N$-capronsäurebiotin-Natriumsalz (Bio-Cap-PE).

Aufgrund der Maleimid-Kopfgruppe kann 1,2-Dioleoyl-sn-glycero-3-phosphoethanolamin$N$-[4-(p-maleimidomethyl)cyclohexan-carboxamid]-Natriumsalz (MCC-DOPE) durch eine Michael-Addition von Thiolgruppen z. B. von Cystein spezifisch modifiziert werden. Dadurch können gezielt Lipid-gekoppelte Funktionalitäten in artifizielle Membransysteme eingeführt werden. Im Rahmen dieser Arbeit wurde MCC-DOPE mit dem Peptid $\mathrm{H}_{6}$ WGC modifiziert und für den Fluoreszenz-basierten Funktionsassay zur Überprüfung der Halb- und Gap Junction Kanalaktivität verwendet (Kapitel 4.5.2). MCC-DOPE hat ein Molekulargewicht von 985,3 g.mol-1 und eine Summenformel von $\mathrm{C}_{53} \mathrm{H}_{90} \mathrm{~N}_{2} \mathrm{NaO}_{11} \mathrm{P}$. Es besitzt zwei ungesättigte $\mathrm{C}_{18}$-Seitenketten und als hydrophile Kopfgruppe Phosphoethanolamin, welche über ein $p$-Methylcyclohexancarboxamid mit der Maleimidfunktion verbunden ist.

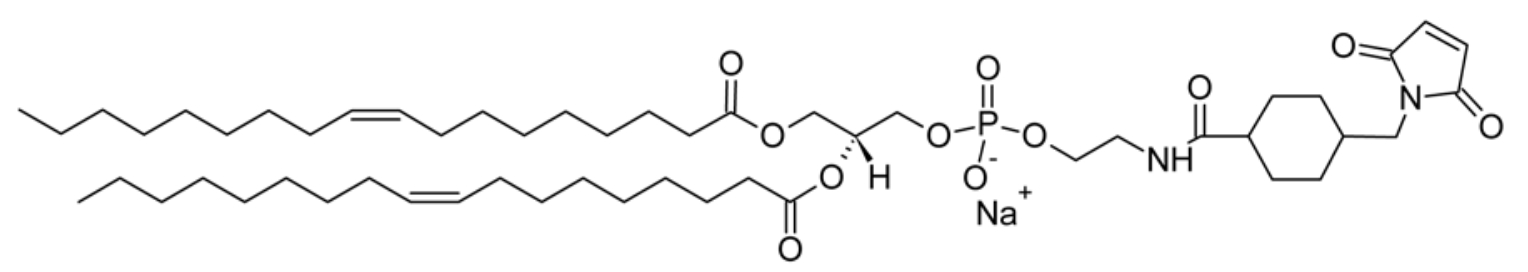

Abb. 3-27: Strukturformel von 1,2-Dioleoyl-sn-glycero-3-phosphoethanolamin- $N$-[4-( $p$-maleimidomethyl)cyclohexan-carboxamid]-Natriumsalz (MCC-DOPE).

Das 1,2-Dioleoyl-sn-glycero-3-[(N-(5-amino-1-carboxypentyl)iminodiessigsäure)succinyl] (DOGS-Ni-NTA) besteht ebenfalls aus zwei Ölsäuren, die jeweils mit dem Glycerolrückgrad verestert sind. Die dritte alkoholische Funktion des Glycerols ist mit Succinat verestert und dieses verbindet das Lipid über eine Peptidbindung mit der Nitrilotriessigsäurefunktion 
(NTA). NTA bildet einen Komplex mit zweiwertigen Metallionen wie Nickel. An diesen Komplex binden spezifisch Polyhistidine. DOGS-Ni-NTA wird in dieser Arbeit für den Fluoreszenz-basierten Funktionsassay zur Überprüfung der Halb- und Gap Junction Kanalaktivität eingesetzt (Kapitel 4.5.2).

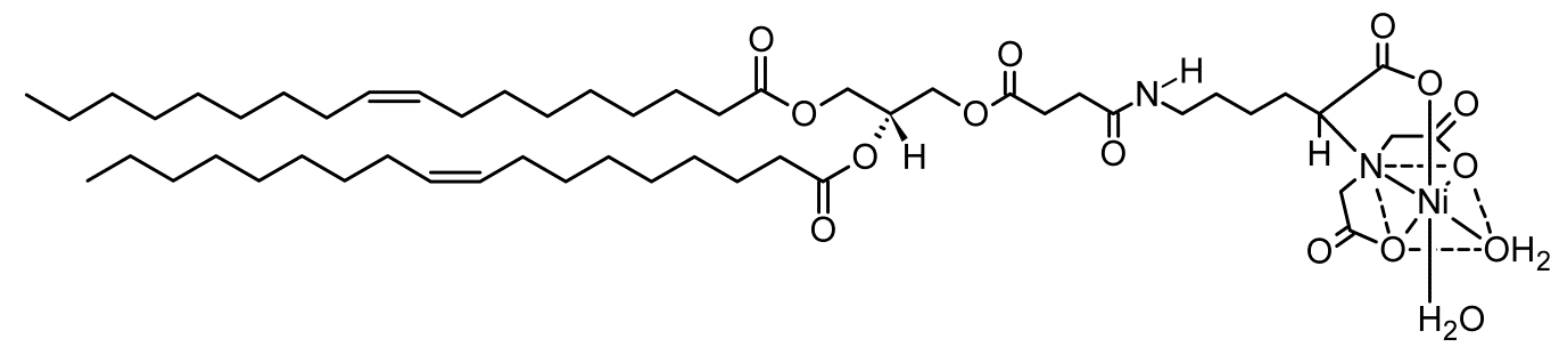

Abb. 3-28: Summenformel von 1,2-Dioleoyl-sn-glycero-3-[(N-(5-amino-1-carboxypentyl)iminodiessigsäure)succinyl] (DOGS-Ni-NTA).

\subsubsection{Herstellung von Proteo-GUVs}

Cx43 und das Fusionsprotein Cx43-GFP liegen nach der Isolierung durch Affinitätschromatografie (Kapitel 3.1.3) in Detergensmizellen vor. Mizellen sind einschichtige Aggregate von Detergenzien und/oder Lipiden, welche abhängig von der Konzentration und den experimentellen Bedingungen gebildet werden. Hier werden sie dazu verwendet, um die beiden isolierten Membranproteine in wässriger Lösung zu stabilisieren. Das Detergens ersetzt zeitlich begrenzt die Lipidmembran. Der Nachteil daran ist, dass es auch eine destabilisierende Wirkung hat, da es ein Gleichgewicht zwischen Detergensmolekülen in der Mizelle und der wässrigen Lösung gibt. Aus diesem Grund werden immer wieder hydrophobe Abschnitte des Proteins der wässrigen Lösung exponiert, was auch zur Destabilisierung des Proteins führen kann.

Für die Rekonstitution von Membranproteinen werden verschiedene Methoden genutzt, die Abwandlungen von zwei Verfahren sind. Prinzipiell werden bei der ersten Methode Detergens-destabilisierte Vesikel verwendet und das Protein in Detergens dazugegeben. Dabei kommt es zur spontanen Insertion des Proteins in die Vesikel. ${ }^{[162]}$ Für die zweite Methode werden gemischte Mizellen (Mischmizelle) aus Protein, Detergens und Lipiden verwendet. Während des Entzugs von Detergens entstehen durch Selbstorganisationprozesse spontan Proteoliposomen. ${ }^{[162]}$ Das Detergens kann durch Dialyse, Adsorption an hydrophobe Matrizes 
und Gelfiltration entzogen werden. ${ }^{[165]}$ Die zweite Methode ist für den Erhalt der Proteinaktivität zu bevorzugen, da hier das Detergens im Vergleich zur ersten Methode relativ langsam entzogen wird. Dadurch wird im besten Fall die Aggregation des Proteins vermieden.

In dieser Arbeit wurden für die Rekonstitution drei verschiedene Methoden verwendet. Für die elektrophysiologischen Studien von Cx43 und Cx43-GFP wurde u. a. die spontane Integration (erste Methode) verwendet. Dafür wurden $20 \mu \mathrm{L} 10 \mathrm{mM}$ 1,2-Diphytanoyl-snglycero-3-phospholin/Cholesterol (9:1) in Chloroform wie in Kapitel 3.5.3 beschrieben auf ITO-Gläser der Vesicle Prep Pro Station (Nanion Technology GmbH, München) gegeben und 10 min bei Raumtemperatur getrocknet. Anschließend wurde der Lipidfilm mit $250 \mu \mathrm{L}$ $1 \mathrm{M}$ Sorbitol-Lösung rehydratisiert. Die GUVs wurden bei einer Wechselspannung von $3 \mathrm{~V}$ und $5 \mathrm{~Hz}$ für $2 \mathrm{~h}$ gebildet. Zur Rekonstitution wurden die Vesikel mit $10 \mathrm{ng} \cdot \mathrm{mL}^{-1} \mathrm{Cx} 43$ (Endkonzentration) in 0,2\% $(w / v)$ DDM für 20 min inkubiert. Zur Entfernung des Detergens wurde die Lösung für $4 \mathrm{~h}$ mit $40 \mathrm{mg} \cdot \mathrm{mL}^{-1}$ BioBeads ${ }^{\mathrm{TM}}$ SM-2 Absorbent (Bio-Rad, München) inkubiert. Anschließend konnten die Proteo-GUVs für elektrophysiologische Messungen verwendet werden (Kap. 3.2).

Die zweite Methode geht auf die Arbeiten von Girard etal. und Streicher etal. zurück. ${ }^{[166,167]}$ Im ersten Schritt werden Proteo-SUVs über den Entzug von Detergens aus gemischten Mizellen hergestellt. Im zweiten Schritt werden diese auf ITO-Gläsern partiell eingetrocknet und während der Elektroformation wieder rehydratisiert. Der Entzug von Wasser durch eine gesättigte Natriumchloridlösung soll die natürliche Struktur des Proteins in der Lipidmembran bewahren (partielle Dehydratisierung). Zunächst wird Lipid in Chloroform gelöst und die Konzentration über Filmwaage bestimmt. Die Lösung wird in Reagenzgläser zu je $2 \mathrm{mg}$ aliquotiert, erst im Stickstoffstrom für $30 \mathrm{~min}$ und anschließend im Vakuum für $3 \mathrm{~h}$ getrocknet. Der Lipidfilm wurde in $2 \mathrm{mM} \mathrm{KCl,} 2 \%(w / v) n \mathrm{OG}, 1 \mathrm{mM}$ MOPS/TRIS pH 8,0 solubilisiert. Die Lösung wurde mit verschiedenen Proteinkonzentrationen versetzt, auf $1 \mathrm{~mL}$ mit $2 \mathrm{mM} \mathrm{KCl}, 1 \mathrm{mM}$ MOPS/TRIS pH 7,5 aufgefüllt und anschließend für die Ausbildung der gemischten Mizellen mit Protein für 30 min inkubiert. Auf das verwendete Lipid-ProteinVerhältnis wird näher in Kapitel 4.2. eingegangen. Danach wird das Detergens durch die Zugabe von $160 \mathrm{mg}$ BioBeads $^{\mathrm{TM}}$ SM-2 entzogen. Nach $2 \mathrm{~h}$ wurde gegen weitere $160 \mathrm{mg}$ BioBeads $^{\mathrm{TM}}$ SM-2 ausgetauscht, um restliches Detergens über Nacht zu entziehen. Danach wurde die Lösung von BioBeads ${ }^{\mathrm{TM}} \mathrm{SM}-2$ getrennt und bei $4{ }^{\circ} \mathrm{C}$ gelagert. Für die Präparation 
von GUVs wurde die Proteo-SUVs-Lösung zu $1,5 \mu \mathrm{L}$ auf die ITO-Gläser in den gekennzeichneten Bereich getropft und partiell im Exsikkator durch eine gesättigte $\mathrm{NaCl}$ Lösung getrocknet. Für die Präparation der GUVs wurde Protokoll 2 aus Kapitel 3.5.3 verwendet.

In der dritten Methode werden auch Proteo-SUVs zur Integration des Proteins in GUVs genutzt. Dieses Vorgehensweise wurde durch Martinac et al. erstmals für den mechanosensitiven Ionenkanal MscL aus Escherichia coli vorgestellt. ${ }^{[168]}$ Die Proteo-SUVs wurden ana$\log$ zur zweiten Methode präpariert. Für die Herstellung der Proteo-GUVs wurde analog zur Elektroformation in Kapitel 3.5.3 vorgegangen. Zunächst wurden die Lipidfilme auf den ITO-Gläsern eingetrocknet. Anschließend wurde zur Rehydratisierungslösung bis zu $25 \mu \mathrm{L}$ Proteo-SUVs zugegeben und die Lösung vermischt. Da Proteo-SUVs aufgrund ihrer Größe eine hohe Membrankrümmung besitzen und damit verbunden eine hohe Fusionstendenz haben, kommt es während der Elektroformation zur Fusion der Proteo-SUVs mit den entstehenden GUVs. Für die Präparation der GUVs wurde Protokoll 2 aus Kapitel 3.5.3 verwendet.

\subsubsection{Präparation porenüberspannender Membranen auf orthogonal- funktionalisierten Aluminiumoxidsubstraten}

Für die Herstellung von porenüberspannenden Membranen wurden die Substrate aus Kapitel 3.5.2 verwendet. Nach der orthogonalen Funktionalsierung ist das poröse Aluminiumoxid mit 3-Mercaptopropyltriethoxysilan beschichtet und von einer etwa $10 \mathrm{~nm}$ Goldschicht geschützt. Zuvor wurde das Substrat mit optisch klarem Kleber auf einen Objektträger mit 2,5 cm Kantenlänge fixiert und in die Messkammer eingebaut (Abb. 3-29 B). 
A

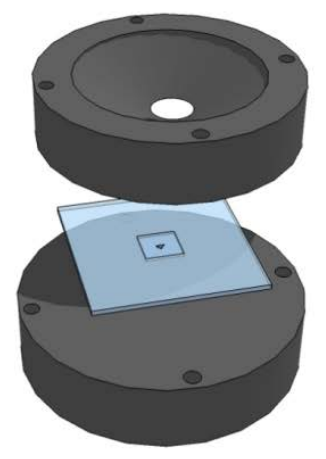

\section{Oberteil der Messkammer}

Objekträger mit fixiertem Aluminat

Unterteil der Messkammer
B

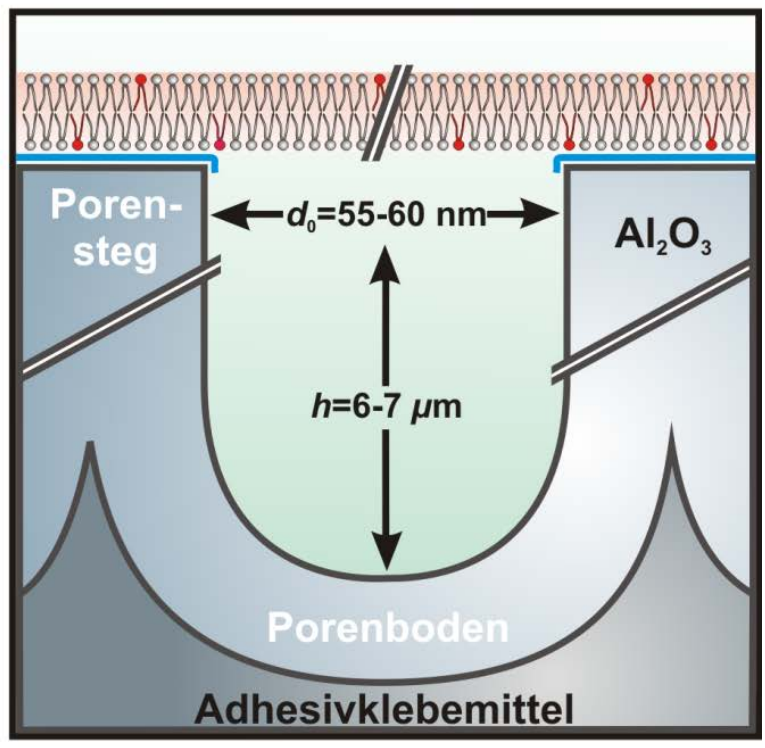

Abb. 3-29: $A$, Schematische Darstellung der Messkammer für poröse Aluminiumoxidsubstrate zur Untersuchung mit CLSM. $B$, Schematische Darstellung einer porenüberspannenden Membran mit einer hydrophilen Funktionalisierung (nicht dargestellt). Die Wechselwirkung zwischen hydrophilem Steg und Lipidmembran findet über eine Wasserschicht (blau) statt. Lipide mit einer Fluoreszenzsonde sind in rot dargestellt. Abbildung 3-11 B wurde nach Lazzara et al. angefertigt. ${ }^{[155]}$

Nachdem die Oberflächenfunktionalisierung aus dem Inneren der Poren durch Sauerstoffund Argonplasma abgelöst wurde, wurde die Goldschicht durch Iod-Kaliumiodid-Lösung $\left(0,5 \%(w / v) \mathrm{KI}, 0,125 \%(w / v) \mathrm{I}_{2}\right.$ in Reinstwasser) entfernt. Anschließend wurde das Substrat mit absoluten Ethanol gespült und im Stickstoffstrom getrocknet. Für die Bildung einer hydrophilen Oberfläche wurde das Substrat für $60 \mathrm{~s}$ im Sauerstoffplasma inkubiert. Dadurch werden die Ethoxy- und die Mercaptopropyl-Gruppen oxidiert, sodass eine hydrophile Oberflächenfunktionalisierung bestehend aus Silanolgruppen zurückbleibt. Anschließend wurde die Messkammer mit Ethanol gefüllt und gegen etwa $200 \mathrm{~mL}$ Phosphate Buffered Saline (PBS, 2,7 mM KCl, 136,9 mM NaCl, 1,5 mM $\mathrm{KH}_{2} \mathrm{PO}_{4}$ und 8,1 $\mathrm{mM} \mathrm{Na}_{2} \mathrm{HPO}_{4}$ )-Puffer ausgetauscht. Das vorherige Spülen mit Ethanol benetzt die Poren, so dass Puffer in die Poren des Substrats eindringen kann. Anschließend wurden 50-100 $\mu \mathrm{L}$ GUV-Lösung in das überstehende Puffervolumen $(V=3 \mathrm{~mL})$ getropft. Nach mindestens 15 min Inkubation wurde die Kammer dreimal mit $1 \mathrm{~mL}$ Puffer gespült, um restliche Vesikel zu entfernen. Die Qualität der porenüberspannenden Membranen wurde mithilfe der konfokalen Laserrastermikroskopie überprüft. 


\subsubsection{Präparation festkörperunterstützter Membranen}

Zur Verifizierung der Kopplung von MCC-DOPE (Kapitel 3.5.4) mit dem Peptid Hexa-Lhistidyl-L-tryptophanyl-L-glycyl-L-cysteinamid ( $\left.\mathrm{H}_{6} \mathrm{WGC}\right)$, welches an den Fluoreszenzfarbstoff 5(6)-TAMRA (Kapitel 3.3.2) gekoppelt war, wurden festkörperunterstützte Membranen präpariert. Dafür wurden Siliziumwafer (CrysTec, $d=625 \mu \mathrm{m}$, Dotierung: pTyp Bor, $R=1$ bis $20 \Omega \cdot \mathrm{cm}$, Berlin)mit einer $100 \mathrm{~nm}$ Oxidschichtdicke verwendet. Für das Spreiten wurden die Siliziumwafer zunächst mit einer Hydrophilisierungslösung behandelt. Nach Zugabe der Small Unilamellar Vesicles (SUVs) findet über Dipol-Dipol-Wechselwirkung eine Interaktion der Lipidkopfgruppen mit der hydrophilen Oberfläche statt. Die starke Membrankrümmung der verwendeten SUVs führt über die starke Wechselwirkung mit der Oberfläche zum Spreiten der SUVs.

\section{Hydrophilisieren des Siliziumwafers}

Die verwendete Siliziumwafer wurden mit einem Diamantschneider in eine Größe von $2 \mathrm{~cm} \times 0,5 \mathrm{~cm}$ zugeschnitten und mit Isopropanol und Reinstwasser gereinigt. Zum Hydrophilisieren der Siliziumwafer wurde eine Lösung aus Reinstwasser, Ammoniak (25\%) und Wasserstoffperoxid (30\%) im Verhältnis 5:1:1 (v/v) auf $75^{\circ} \mathrm{C}$ erhitzt und die Siliziumwafer für 15 bis 20 min inkubiert. Anschließend wurden diese mit Reinstwasser gespült, im Stickstoffstrom getrocknet und in eine Teflonmesszelle eingebaut. Für die Präparation von SUVs wurden $0,4 \mathrm{mg}$ Lipidfilm für $30 \mathrm{~min}$ in $0,1 \mathrm{M} \mathrm{NaCl}, 1 \mathrm{mM} \mathrm{CaCl} 2,20 \mathrm{mM}$ TRIS pH 7,4 $(V=1 \mathrm{~mL})$ quellen gelassen. Danach wurde dreimal im Abstand von 5 min für $30 \mathrm{~s}$ mithilfe des Vortexer geschüttelt und zweimal für 15 min im Ultraschallbad (4 Cycles, Intensität 75 \%) behandelt. Die SUVs-Lösung wurde mit $20 \mu \mathrm{L}$ 0,5 $\mathrm{M} \mathrm{CaCl}_{2}$ versetzt und $200 \mu \mathrm{L}$ der Lösung

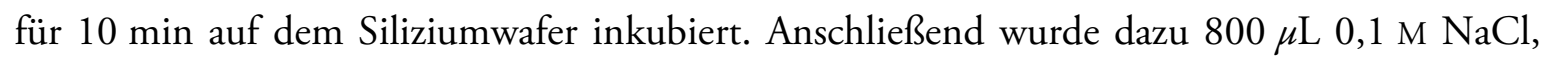
$1 \mathrm{mM} \mathrm{CaCl}_{2}, 20 \mathrm{mM}$ TRIS pH 7,4 gegeben und weiter für $1 \mathrm{~h}$ inkubiert. Abschließend wurde mit PBS-Puffer gespült. 


\section{Ergebnisse}

Ziel dieser Arbeit war es, als Teilvorhaben im Rahmen eines BMBF-Projektes ein Biosensorsystem zu entwickeln, welches grundsätzlich ermöglicht, die Funktionalität von Connexin 43 (Cx43) Gap Junction Kanälen fluoreszenzmikroskopisch nachzuweisen. Dafür wurden fünf Meilensteine definiert, die im Folgenden in den einzelnen Kapiteln behandelt werden. Zunächst wird in Kapitel 4.1 auf die Untersuchung der zwei verschiedenen Expressionssysteme, Dictyostelium discoideum und Pichia pastoris eingegangen. Diese wurden dahingehend analysiert, welches sich am besten zur Expression von Cx43 und dem Fusionsprotein aus Cx43 und dem enhanced Green Fluorescent Protein (eGFP) bzw. GFP eignet. Außerdem wird die Entwicklung einer Reinigungsstrategie für beide Proteine mittels Polyhistidin-Tag behandelt. Kapitel 4.2 beschäftigt sich mit der Herausforderung der Integration von Cx43Varianten in artifizielle Membranen, da es für die weitere Untersuchung von Cx43 und Cx43-GFP erforderlich war, die Proteine in unilamellare Riesenvesikel (Giant Unilamellar Vesicles, GUVs) zu integrieren. Weiter beschäftigt sich Kapitel 4.3 mit der elektrophysiologischen Charakterisierung von Cx43 und Cx43-GFP Halbkanälen. Dieser Schritt war essentiell, um die Funktionalität der Connexin Halbkanäle nach Rekonstitution in GUVs darzustellen. Anschließend wird in Kapitel 4.4 auf die Herstellung des porösen Aluminiumoxidsubstrates sowie die Präparation porenüberspannender Membranen auf dem porösen Substrat eingegangen. Zum Nachweis der Gap Junction Kanalaktivität war es das Ziel, einen Farbstofftransfer zwischen zwei unabhängigen Kompartimenten nach der Ausbildung von Gap Junction Kanälen zu zeigen. Deshalb wurde im nächsten Schritt der Einschluss eines wasserlöslichen Farbstoffs durch porenüberspannende Membranen getestet, um schließlich dessen Freisetzung durch ein geeignetes porenbildendes Peptid zu zeigen. Im Kapitel 4.5 wird auf die Weiterentwicklung und Anwendung des Funktionsassays zum Nachweis der Gap Junction Kanalaktivität eingegangen. 


\subsection{Heterologe Proteinexpression verschiedener Connexin 43- Varianten}

In dieser Arbeit wurden zur heterologen Proteinexpression der Schleimpilz Dictyostelium discoideum sowie die Hefe Pichia pastoris verwendet. Beide Organismen werden als Modellorganismus in der Grundlagenforschung verwendet. Dadurch sind diese Organismen umfassend genetisch charakterisiert, was unter anderem eine genetische Manipulation dieser Organismen erleichtert.

\subsubsection{Expression und Reinigung von Cx43 und Cx43-eGFP in Dictyostelium discoideum}

Der Schleimpilz Dictyostelium discoideum eignet sich nicht nur zum Studium von grundlegenden zellulären Prozessen, sondern auch zur heterologen Proteinexpression. Als einzelliger, haploider Organismus in der vegetativen Phase werden Bodenbakterien durch Phagozytose aufgenommen und metabolisiert. Dies wird als xenisches Wachstum bezeichnet und ist ein Teil des ungeschlechtlichen Lebenszyklus von D. discoideum, welcher in Abb. 4-1 A dargestellt ist. Bei Nahrungsmangel kommt es zur Anreicherung von zyklischem Adenosinmonophosphat (Cyclic Adenosine Monophosphate, cAMP) und zur chemotaktischen Aggregation der Einzelzellen zu einem multizellulären Organismus (Mound, Pseudoplasmodium). Dies stellt den Beginn der Entwicklungsphase dar. ${ }^{[169]}$ Nach etwa 24 h unter günstigen Umweltbedingungen ist ein vollständiger Fruchtkörper ausgewachsen mit einem Basalkörper zur Verankerung. ${ }^{[170]}$ Durch Differenzierung können zwei verschiedene Zelltypen unterschieden werden, die toten, stark vakuolisierten Stilzellen und keimungsfähigen Sporen. In dieser Arbeit wurden die einzellige, haploide Phase zur Proteinexpression und die Sporenzellen zur Stammhaltung verwendet. Dies wird im Folgenden näher erläutert. 


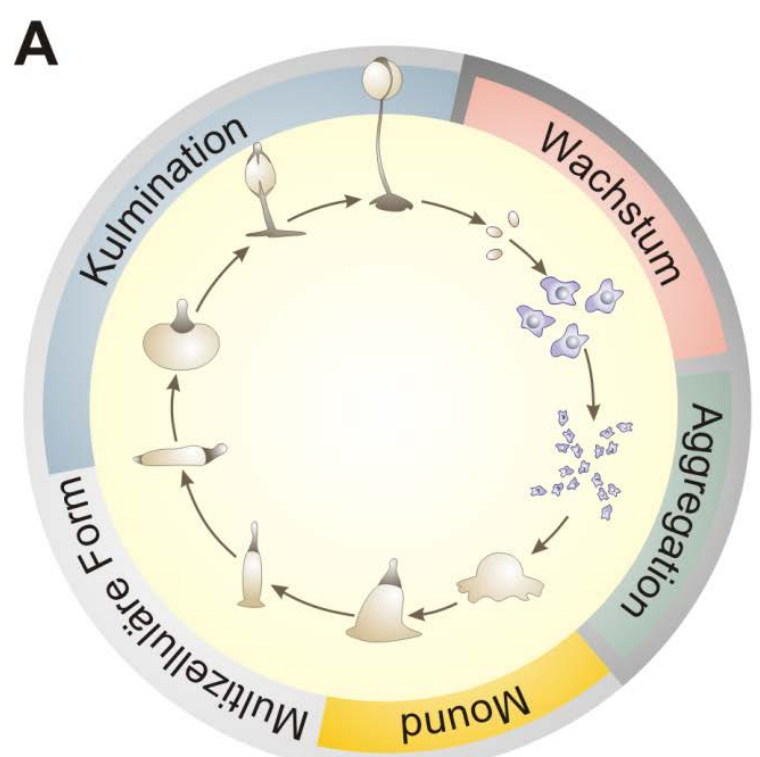

B

Abb. 4-1: $A$, Ungeschlechtlicher Lebenszyklus von D. discoideum. Mit dem Auskeimen der Sporen bildet sich die amöboide Form. Durch Nahrungsmangel kommt es zur cAMP-vermittelten Aggregation der Zellen mit einem Aggregationszentrum. Dabei entsteht ein multizellulärer Organismus, welcher zunächst als Mound (Pseudoplasmodium) bezeichnet wird. Danach kommt es zur Bildung eines Fingers, welcher auf äußere Reize wie Licht, pH, Feuchtigkeit und Temperatur reagiert, und sich darauf gerichtet bewegt. In der Kulminationsphase findet die Bildung des Fruchtkörpers mit einer Differenzierung in Stilzellen und keimfähigen Sporen statt. $\boldsymbol{B}$, Das Wachstum von Mikroorganismen lässt sich in vier Phasen einteilen. In der Latenz (lag)-Phase findet die Anpassung an neue Umweltbedingungen wie bspw. eine neue Mediumzusammensetzung statt. In der exponentiellen $(\log )$-Phase kommt es zum Wachstum der Mikroorganismen mit gleichbleibender Generationszeit. In der stationären Phase halten sich Neubildung und Absterben von Mikroorganismen die Waage. In der Absterbephase reichern sich Giftstoffe sowie Sekundärmetabolite an und es kommt zum Absterben der Mikroorganismen. Abb. 4-1 A wurde nach Lu, Fey und Shaulsky erstellt. ${ }^{[13,171,172]}$

Für die Kultivierung im Labor werden überwiegend axenische Stämme verwendet, die sich in Flüssigkultur durch Pinozytose ernähren (axenisches Wachstum). Durch diesen relativ simplen Lebenszyklus lassen sich mit der Kultivierung im Schüttelkolben oder in der Fermentation hohe Zelldichten erreichen (Kapitel 3.1.1.1). Zur heterologen Proteinexpression wird ringförmige DNA in Form von Plasmiden in D. discoideum eingeschleust, diese wird repliziert (bis zu 10 Kopien) und wie chromosomale DNA verpackt.

Zur Expression von Cx43 und dem Fusionsprotein aus Cx43 und dem enhanced Green Fluorescent Protein (eGFP) wurden jeweils die Gene in den Vektor pDXA-3H (Kapitel 9.9) zwischen den Schnittstellen HindIII und BamHI der Multiple Cloning Site eingebracht und in Escherichia coli (E. coli) amplifiziert. Als Ausgangskonstrukte wurden die HeLa Vektoren pMJ-mCx43 und pMJ-mCx43-eGFP verwendet (Arbeitsgruppe von Prof. Dr. Willecke). 
Zur Selektion von positiven Klonen in E. coli wurden die Antibiotikaresistenzen gegen Ampicillin oder Neomycin, die im Vektor pDXA-3H enthalten waren, verwendet. ${ }^{[17]}$ Anschließend wurde das isolierte Plasmid in D. discoideum Stamm Ax3-ORF+ durch Elektroporation eingebracht und die positiven Klone durch das antibiotisch wirksame Aminoglykosid Geneticin (G418) selektiert. ${ }^{[173]}$ Das bakterielle Gen Tn5 NeoR in pDXA-3H vermittelt ebenfalls eine Resistenz für Geneticin. ${ }^{[174]}$ Die Expression des Zielproteins ermöglicht der starke, konstitutive Promoter act15, wodurch das Zielprotein über den gesamten Kultivierungszeitraum exprimiert wird. Beide Proteine tragen zur Isolierung durch immobilisierte Metallchelataffinitätschromatografie einen Oktahistidin-Tag. Die beiden D. discoideum Klone wurden durch die Arbeitsgruppe von Prof. Dr. Motomu Tanaka (Physikalische Chemie von Biosystemen, Universität Heidelberg) bereitgestellt.

\subsubsection{Kultivierung von Dictyostelium discoideum}

Der axenische Stamm Ax3-ORF+ kann in komplexen Medien wie beispielsweise HL5oder LPP-Medium kultiviert werden. Für die Anzucht sollte ein Temperaturbereich von 21 bis $23{ }^{\circ} \mathrm{C}$ genutzt werden. Bei Temperaturen über $25^{\circ} \mathrm{C}$ und unter $20^{\circ} \mathrm{C}$ kommt es zum Wachstumsstillstand und folglich zur Apoptose der Zellen. Außerdem sind Prozessparameter wie der pH-Wert und die Sauerstoffversorgung entscheidende Einflussgrößen, welche das aerobe Wachstum des Schleimpilzes beeinflussen.

Zu Beginn der Arbeit wurden die Sporen der D. discoideum Klone, welche Cx43 und Cx43-eGFP exprimieren, in HL5-Medium bei $22^{\circ} \mathrm{C}$ in Petrischalen, wie in Kapitel 3.1.1.1 beschrieben, kultiviert (Primärkultur). Die Sporen benötigten gewöhnlich 12 bis $24 \mathrm{~h}$ zum Auskeimen. Erst anschließend wurde $20 \mu \mathrm{g} \cdot \mathrm{mL}^{-1}$ Geneticin als Selektionsmarker zugesetzt. Die verzögerte Zugabe ermöglicht zunächst das Auskeimen der Sporen ohne das für die Proteinsynthese der Resistenz vermitteltenden Aminoglykosid-Phosphotransferase Energie aufgewendet werden musste. ${ }^{[175]}$ Die Zellen von D. discoideum wachsen adhärent und sind nach drei bis vier Tagen in der Petrischale bis zur Konfluenz gewachsen, d. h. die gesamte Fläche der Petrischale ist mit einem Monolayer von Zellen bedeckt. Ähnlich wie bei der Kultivierung von Säugerzellen kommt es durch Erreichen der Konfluenz zum Wachstumsstillstand (beispielsweise durch Kontaktinhibition) bzw. zum Teil zum Absterben der Zellen. An diesem Punkt werden die Zellen wieder in neuem HL5-Medium verdünnt (Subkultivierung). Die Stammhaltung von D. discoideum Klonen findet gewöhnlich in Form 
von Sporen statt, da sie unempfindlicher gegen widrige Umweltbedingungen sind als die amöboiden Zellen (Kapitel 3.1.1.1). ${ }^{[17]}$ Neben der Kultivierung aus Sporen können auch Zellen des Schleimpilzes durch Zugabe von 10 \% Dimethylsulfoxid (DMSO) im gefrorenen Zustand gelagert werden (Kapitel 3.1.1.1).

Neben der Kultivierung des Schleimpilzes in der statischen Kultur (Petrischale) können die Zellen auch submers im Schüttelkolben wachsen (Schüttelkultur). Dafür wurde ebenfalls HL5-Medium verwendet und mit mindestens $1 \cdot 10^{4}$ Zellen $\cdot \mathrm{mL}^{-1}$ inokuliert. Die Anzucht wurde bei $22^{\circ} \mathrm{C}$ und $150 \mathrm{rpm}$ nach Kapitel 3.1.1.1 durchgeführt. Zur Bestimmung der Wachstumsgeschwindigkeit der D. discoideum Klone wurden zunächst Wachstumskurven aufgenommen. Dabei wurde auch der Einfluss des gelösten Sauerstoffs betrachtet und die Wachstumsgeschwindigkeit mit einem Volumenverhältnis von Medium zu Kolben von 1:5 und 1:10 bestimmt (Abb. 4-2). Das Wachstum von Mikroorganismen korreliert mit der Zunahme der Zellzahl und kann in vier Phasen unterschieden werden (Abb. 4-1 B). In der Latenzphase (lag-Phase) findet zunächst keine Zellteilung statt, da die Zellen sich erst an das neue Medium adaptieren müssen. Diese konnte für $D$. discoideum in dieser Arbeit nicht beobachtet werden, da nur eine geringe Milieuveränderung stattfand. Danach folgt die exponentielle Phase (log-Phase), in der die Generationszeit annähernd gleich ist. In der darauffolgenden stationären Phase sind die Nährstoffe verbraucht und/oder Hemmstoffe im Medium, sodass gleichermaßen Zellen absterben wie Zellen durch Zellteilung neu entstehen. Als letztes folgt die Absterbephase, in der die Reserven der Mikroorganismen aufgebraucht sind und sich teilweise auch giftige Stoffwechselprodukte anhäufen, wodurch es ebenfalls zum Absterben der Organismen kommt.

Die Abb. 4-2 zeigt die Wachstumskurven der beiden D. discoideum und den Einfluss der Gelöstsauerstoffkonzentration. Da es nur zu einer geringen Milieuveränderung kommt, können die Zellen sich relativ schnell adaptieren und es kommt zum exponentiellen Wachstum. Dadurch ist keine $\log$-Phase erkennbar. Das exponentielle Wachstum kann durch Gl. 4-1 beschrieben werden.

$$
X(t)=X\left(t_{0}\right) \cdot e^{\mu \cdot t}
$$


$X(t)$ beschreibt die Zellzahl zum Zeitpunkt $t, X\left(t_{0}\right)$ zum Zeitpunkt $t=0 \mathrm{~h}$ und $\mu$ ist die charakteristische Wachstumsrate in $\mathrm{h}^{-1}$. Durch die Bestimmung von $\mu$ kann mit Gl. 4-2 die Generationszeit (Verdopplungszeit, $t_{\mathrm{D}}$ ) bestimmt werden .

$$
t_{\mathrm{D}}=\frac{\ln (2)}{\mu}
$$

Die D. discoideum Klone, die bei einem Volumenverhältnis von Medium zu Kolben von 1:5 kultiviert wurden, haben eine geringere Generationszeit von 11,9 h für Cx43 bzw. 12,2 h für Cx43-eGFP (Abb. 4-2 A, B) als bei einem Verhältnis von 1:10. Allerdings kam es bei einem Volumenverhältnis von 1:5 schon bei einer niedrigen Zelldichte zum Absterben der Zellen. Die Wachstumskurven bei einem Volumenverhältnis von 1:10 zeigen, dass eine höhere Generationszeit für D. discoideum Cx43 mit 13,9 h bzw. Cx43-eGFP mit 16,2 h erreicht wurde (Abb. 4-2 C, D). Jedoch kam es im Fall des D. discoideum Klons, der Cx43 exprimiert, erst ab einer Zellzahl von etwa $3 \cdot 10^{7}$ Zellen $\cdot \mathrm{mL}^{-1}$ zum Absterben der Zellen. Die Zellzahl wurde durch Auszählen mit einem Hämozytometer bestimmt. 


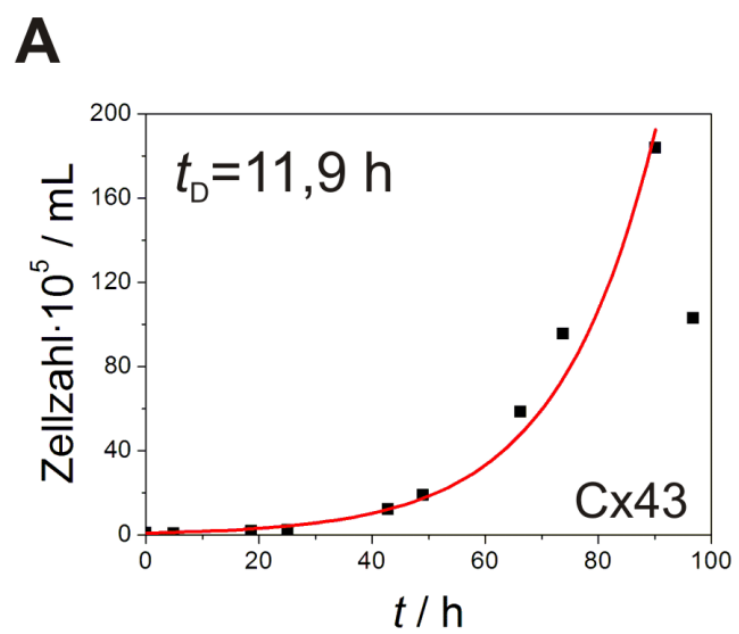

B

C
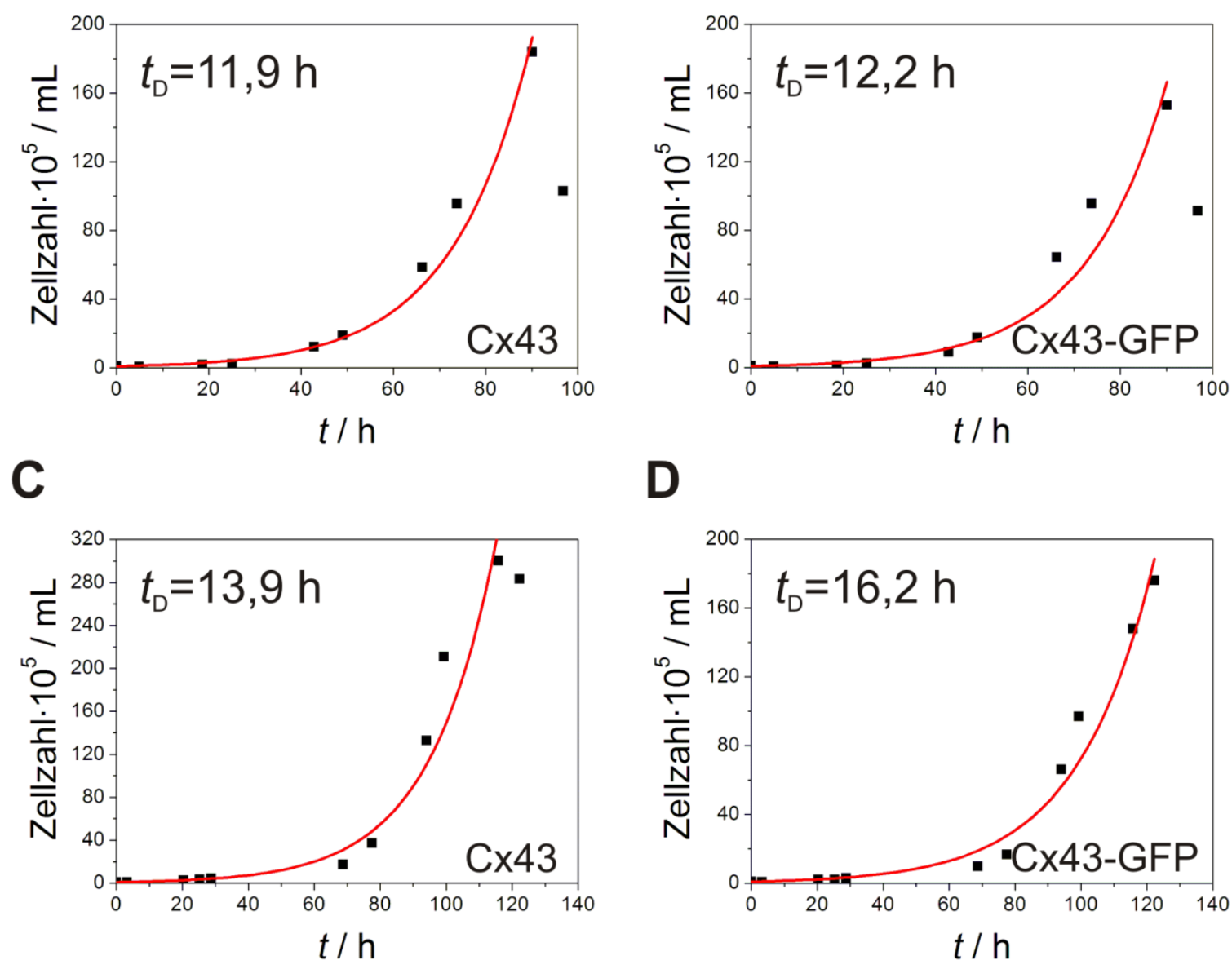

D

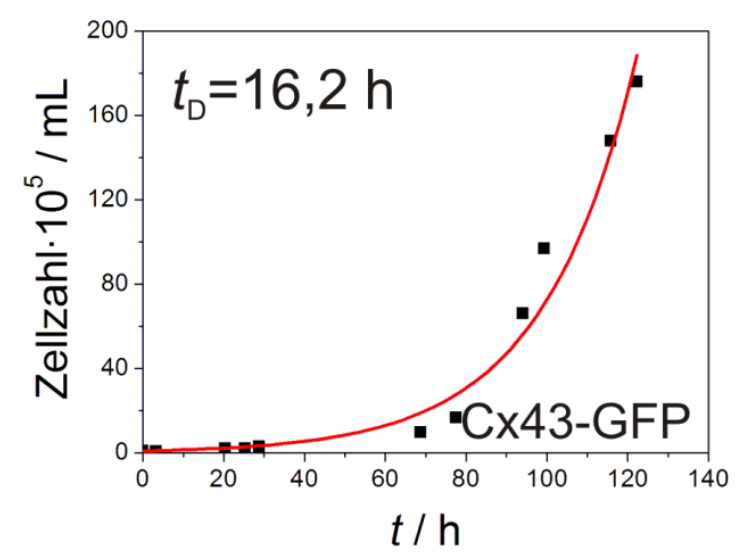

Abb. 4-2: Wachstumskurven der $D$. discoideum Klone, die Cx43 $(\boldsymbol{A}, \boldsymbol{C})$ und Cx43-eGFP $(\boldsymbol{B}, \boldsymbol{D})$ exprimieren mit einem Volumenverhältnis von Medium zu Kolben von 1:5 $(A, B)$ und 1:10 $(C, D)$. Die Kurvenanpassung wurde nach Gl. 4-1 durchgeführt mit $X\left(t_{0}\right)=1 \cdot 10^{5} \mathrm{Zellen}_{\mathrm{mL}} \mathrm{m}^{-1}$.

Zusätzlich wurde für $D$. discoideum Cx43-eGFP bei einem Volumenverhältnis von 1:10 die Fluoreszenzintensität durch Fluoreszenzmikroskopie täglich kontrolliert. Im beobachteten Zeitraum kam es zu einer Zunahme der Fluoreszenzintensität bei den D. discoideum Zellen aufgrund der Expression von GFP.

\subsubsection{Isolierung und Reinigung von Cx43 und Cx43-eGFP}

Da Dictyostelium discoideum ein relativ neuartiges Expressionssystem ist, wurden bisher noch keine heterolog exprimierten Membranproteine mithilfe der Affinitätschromatografie isoliert. Für das weitere Vorgehen musste zunächst geklärt werden, ob die beiden Proteine Cx43 und Cx43-eGFP von D. discoideum exprimiert werden. Dafür wurde die Plasmamembran durch Dichtegradientenzentrifugation nach Hand et al. isoliert, um im nächsten Schritt die Proteine durch Western Blot Analyse nachzuweisen. ${ }^{[38]}$ 
Zur Gewinnung der Biomasse wurde D. discoideum in einer Schüttelkultur bei $150 \mathrm{rpm}$ und $22^{\circ} \mathrm{C}$ mit einem Volumenverhältnis von 1:10 (Medium/Kolben) inkubiert, da hier höhere Zelldichten erreicht werden konnten (Kapitel 4.1.1.1). Nach vier Tagen wurde für D. discoideum Cx43 eine Zellzahl von $2,4 \cdot 10^{7}$ Zellen $\cdot \mathrm{mL}^{-1}$ und eine Zellfeuchtmasse von 0,77 g und für Cx43-eGFP eine Zellzahl von 2,7.10 Zellen $\cdot \mathrm{mL}^{-1}$ und eine Zellfeuchtmasse von $1,04 \mathrm{~g}$ erhalten. Die Zellen wurden für die Isolierung der Plasmamembran, in TRISEGTA-Puffer mit 8,7\% $(w / v)$ Saccharose durch Ultraschall aufgeschlossen und auf einen diskontinuierlichen Dichtegradienten aufgegeben (Kapitel 3.1.1.1). Dieser bestand aus $50 \%(w / v), 27 \%(w / v)$ Saccharose und den aufgeschlossenen Zellen (Abb. 4-3 A). Nach der Zentrifugation konnte die Plasmamembran aus der Interphase zwischen $27 \%$ und $50 \%$ Saccharose gewonnen werden.

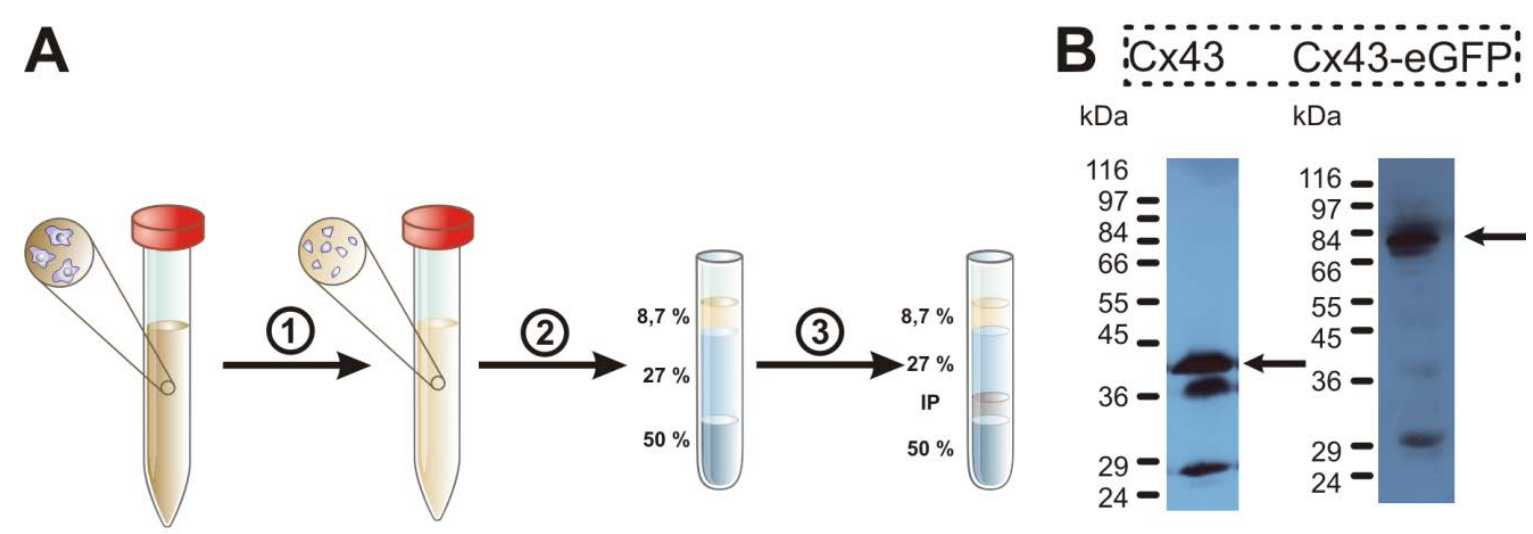

Abb. 4-3: $A$, Schematische Darstellung der Präparation von $D$. discoideum Membranfragmenten. (1) Kurze Inkubation mit Ultraschall zum Zellaufschluss. (2) Diskontinuierlicher Dichtegradient bestehend aus $50 \%(w / v)$ Saccharose, $27 \%(w / v)$ Saccharose und den aufgeschlossenen Zellen in $8,7 \%(w / v)$ Saccharose. (3) Nach der Dichtegradientenzentrifugation befindet sich zwischen 50 und $27 \%(w / v)$ Saccharose die Interphase mit D. discoideum Membranfragmenten. B, Western Blot Analyse der präparierten Membranfragmente von D. discoideum Cx43 und Cx43-eGFP. Cx43 und Cx43-eGFP sind deutlich bei $45 \mathrm{kDa}$ bzw. zwischen 64 und $84 \mathrm{kDa}$ erkennbar (Pfeil). Antikörper: connexin 43 (D-7) monoklonaler $\operatorname{IgG}_{1}$

Das Proteingemisch wurde durch diskontinuierliche Natriumdodecylsulfat-Polyacrylamid-Gelelektrophorese (SDS-PAGE, Kapitel 3.1.4) entsprechend ihres Molekulargewichts getrennt und anschließend mittels Western Blot analysiert (Kapitel 3.1.5). Zur Identifizierung von Cx43 und Cx43-eGFP wurde ein monoklonaler Antikörper verwendet, der gegen die C-terminalen Aminosäurereste 241 bis 254 von Cx43 gerichtet ist (Abb. 1-6). Der sekundäre Antikörper, welcher ein Epitop der konstanten Region des ersten Antikörpers erkennt, ist an 
die Meerrettichperoxidase gekoppelt. Abb. 4-3 B zeigt, dass sowohl Cx43 als auch Cx43-eGFP identifiziert werden konnten.

Zur Reinigung der Proteine mithilfe der immobilisierten Metallchelataffinitätschromatografie mussten die Proteine zunächst unter Verwendung von Detergenzien aus den Membranfragmenten gelöst werden. Dies ermöglicht, dass das Zielprotein via Oktahistidin-Tag an die mit Nickel-Nitrilotriessigsäure (Nickel Nitrilotriacetic Acid, Ni-NTA) funktionalisierte Affinitätsmatrix immobilisiert werden kann. Die Vorversuche wurden mit Cx43-eGFP durchgeführt, da es durch die Fluoreszenzsonde eGFP detektiert werden konnte. Zur Solubilisierung von Cx43-eGFP wurden verschiedene Konzentrationen der Detergenzien $n$-Octylpolyoxyethylen (8-POE) und $n$-Octyl- $\beta$-D-glucopyranosid ( $n \mathrm{OG}$ ) getestet. Diese sind in Kapitel 3.5.4 näher beschrieben. Frühere Studien zeigten, dass diese Detergenzien zur Solubilisierung von Cx43 geeignet sind. ${ }^{[37]}$ Kistler et al. beobachteten, dass 8-POE eine stärkere Spezifität für die Solubilisierung von Cx43 als nOG hat, da dieses auch andere Membranproteine solubilisiert. Für die Analyse wurden gleiche Mengen Membranfragmente von D. discoideum Cx43-eGFP, die mithilfe der Dichtegradientenzentrifugation gewonnen worden, mit jeweils $1 \%$ bis $4 \%(w / v)$ 8-POE und mit jeweils $2 \%$ bis $5 \%(w / v) n$ OG versetzt. Anschließend wurde die Suspension für $30 \mathrm{~s}$ mit Ultraschall behandelt und zur Solubilisierung für 30 min bei Raumtemperatur inkubiert. Nach der Zentrifugation wurde Cx43-eGFP durch Western Blot Analyse im Überstand (ÜS) bzw. Pellet (P) identifiziert. Abb. 4-4 A zeigt, dass eine niedrige Konzentration von 8-POE für die Solubilisierung von Cx43-eGFP ausreicht und höhere Konzentrationen eher einen gegenteiligen Effekt haben. Die Solubilisierung kann in beiden Untersuchungen nur indirekt verfolgt werden, da die Konzentration von Cx43-eGFP im Pellet insgesamt abnimmt, jedoch im Überstand keine Bande identifiziert werden konnte. Dies lässt sich auf eine Verdünnung des solubilisierten Proteins im Überstand zurückführen. Die Analyse der Solubilisierung mit $n$ OG zeigt, dass das Protein mit steigender Konzentration aus dem Pellet solubilisiert werden kann (Abb. 4-4 B). Der Vergleich beider Detergenzien zeigt, dass $5 \%(w / v) n$ OG geeignet ist, um Cx43-eGFP annähernd vollständig zu solubilisieren. Ferner zeigen beide Western Blot Analysen der Pelletfraktionen eine weitere Bande bei etwa $29 \mathrm{kDa}$, wobei es sich vermutlich um proteolytischen Abbau von Cx43-eGFP handelt. 


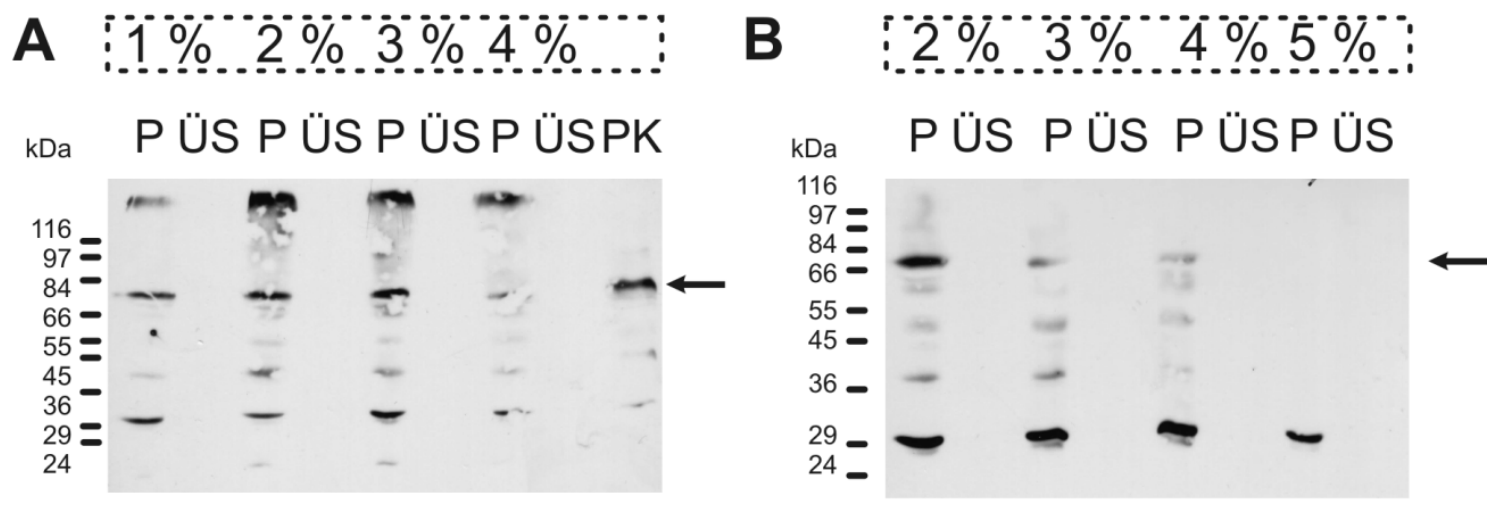

Abb. 4-4: Western Blot Analyse der Solubilisierung von Cx43-eGFP aus D. discoideum Membranfragmenten mit unterschiedlichen Konzentrationen $n$-Octylpolyoxyethylen (8-POE, $A$ ) und $n$-Octyl- $\beta$-D-glucopyranosid ( $n$ OG, $\boldsymbol{B}$ ). $1 \%$ 8-POE ist noch in der Lage zum Teil Cx43-eGFP (Pfeil) zu solubilisieren, aber mit steigender Konzentration nimmt die Fähigkeit dazu ab. Zusätzlich ist Cx43-eGFP in Membranfragmenten als Positivkontrolle (PK) aufgetragen. Mit steigender $n$ OGKonzentration nimmt die Konzentration von Cx43-eGFP (Pfeil) im Pellet (P) ab. Im Überstand (ÜS) konnte kein Cx43-eGFP identifiziert werden. Antikörper: connexin 43 D-7 monoklonaler IgG

Im nächsten Schritt wurde getestet, ob Cx43-eGFP mittels der immobilisierten Metallchelataffinitätschromatografie angereichert werden kann (Kapitel 3.1.1.1). Dafür wurden $500 \mu \mathrm{L}$ Membranfragmente der Dichtegradientenzentrifugation (eingesetzte Zellfeuchtmasse: $1,04 \mathrm{~g}, 2,7 \cdot 10^{7}$ Zellen $\cdot \mathrm{mL}^{-1}$ ) von $D$. discoideum Cx43-eGFP verwendet. Das Protein wurde durch die Zugabe von $5 \%(w / v) n$ OG wie zuvor beschrieben solubilisiert und zusammen mit der Affinitätsmatrix über Nacht im Batch, das heißt in Suspension mit der NiNTA-Agarose, bei $4{ }^{\circ} \mathrm{C}$ inkubiert. Anschließend wurde das Protein mit $250 \mathrm{~mm}$ Imidazol eluiert. Die Analyse mittels Western Blot zeigte, dass das Protein solubilisiert werden konnte. Aber die Konzentration des gereinigten Proteins reichte nicht aus, um es in der Elutionsfraktion zu detektieren. Die Konzentration an Protein korreliert mit der Biomasse. Dieser Versuch verdeutlicht, dass durch die Kultivierung von D. discoideum im Schüttelkolben nicht ausreichend Zellfeuchtmasse gewonnen werden konnte. Deshalb wurde versucht mit der Kultivierung von D. discoideum in der Fermentation ausreichend Zellfeuchtmasse zu gewinnen.

\subsubsection{Fermentationsversuche von Dictyostelium discoideum}

Die Fermentation von Mikroorganismen ermöglicht die Produktion hoher Biomassen verbunden mit hohen Produktausbeuten wie beispielsweise rekombinant hergestelltes Protein. Während der Fermentation können Prozessparameter wie der pH-Wert, die Tempe- 
ratur, die Begasungsrate, Rührergeschwindigkeit und auch die Nährstoffzufuhr überwacht und beeinflusst werden, sodass die Mikroorganismen unter optimalen Bedingungen wachsen und die Zielsubstanz produzieren können. Die Zulaufkultivierung (Fed-Batch-Kultivierung) wird zur Steigerung der Zelldichte besonders häufig eingesetzt. Hierbei wird zunächst mit einem reduzierten Kulturvolumen gestartet. Nach Erreichen der Verzögerungsphase wird durch Zulauf eines Mediumkonzentrats oder Substrat eine konstante Wachstumsgeschwindigkeit eingestellt. Auf diese Art der Fermentation wird im Kapitel 4.1.2.1 näher eingegangen.

Für D. discoideum wurde mit der satzweisen Kultivierung (Batch-Kultivierung) begonnen, um die Prozessparameter zu bestimmen, die ähnliche Generationszeiten zur entsprechenden Schüttelkultur liefern. Die Kultivierung von $D$. discoideum beschränkt sich auf drei Versuche und wurde nicht abschließend optimiert, da sich die Hefe P. pastoris zur Expression der Connexin-Varianten besser eignet (Kapitel 4.1.2). In der ersten Fermentation wurde in einem 5 L-Bioreaktor mit 2,5 L HL5-Medium mit einem pH-Wert von 6,5 begonnen und mit 5.10 Zellen $\cdot \mathrm{mL}^{-1}$ D. discoideum Cx43 (Zelldichte der Vorkultur: 2,7.10 Zellen $\cdot \mathrm{mL}^{-1}$ ) inokuliert. Es wurde mit einer Rührerumdrehung von 210 rpm und einer Begasungsrate mit Luft von 7 Slpm (Standard-Liter pro Minute) begonnen. Es wurden Parameter wie pHWert, Temperatur, Begasungsrate und Rührerumdrehung regelmäßig aufgezeichnet. Die Zelldichte wurde mit dem Hämozytometer bestimmt. Trotz Reduktion der Rührerumdrehung und Begasungsrate konnte lediglich ein geringes Wachstum beobachtet werden. Die Zellzahl schwankte zwischen $3 \cdot 10^{5}$ und $5 \cdot 10^{5}$ Zellen $\cdot \mathrm{mL}^{-1}$.

Für die folgenden Fermentationen wurde zum einen der Sauerstoffpartialdruck $p\left(\mathrm{O}_{2}\right)$ gemessen und zum anderen eine Vorkultur verwendet, bei der sich die Zellen in der exponentiellen Wachstumsphase befanden. Für die zweite Fermentation wurde HL5-Medium mit einem $\mathrm{pH}$-Wert von 6,9 verwendet und mit 5.10 Zellen $\mathrm{mL}^{-1}$ D. discoideum Cx43 (Zellzahl der Vorkultur: $1,5 \cdot 10^{7}$ Zellen $\cdot \mathrm{mL}^{-1}$ ) angeimpft. Wie in Abb. 4-5 B zu sehen ist, wurde mit einer Rührerumdrehung von $110 \mathrm{rpm}$ und einer Begasungsrate von $5 \mathrm{Slpm}$ begonnen. Nach $50 \mathrm{~h}$ war der Sauerstoffpartialdruck $p\left(\mathrm{O}_{2}\right)$ auf $90 \%$ abgefallen (Abb. 4-5 D). Um den Einfluss der Sauerstoffzufuhr auf das Wachstum zu analysieren, wurde die Rührerumdrehung auf $250 \mathrm{rpm}$ und die Begasungsrate auf 6 Slpm erhöht. Dies hatte zur Folge, dass die Zellzahl von 2,4.10 Zellen $\cdot \mathrm{mL}^{-1}$ auf 2,0 $10^{7}$ Zellen $\cdot \mathrm{mL}^{-1}$ abnahm (Abb. 4-5 A). Deshalb 
wurden diese Prozessparameter auf $50 \mathrm{rpm}$ bzw. 4 Slpm reduziert. Die Temperatur schwankte nur in einem kleinen Intervall und der $\mathrm{pH}-$ Wert nahm erst zum Schluss der Fermentation um 0,2 pH-Einheiten zu (Abb. 4-5 B). Insgesamt konnte eine Generationszeit von 24,6 h und 14,3 g Biomasse erreicht werden. Zur Verbesserung der nächsten Fermentation wurde mit einer niedrigeren Rührerumdrehung und Begasungsrate gearbeitet.

A

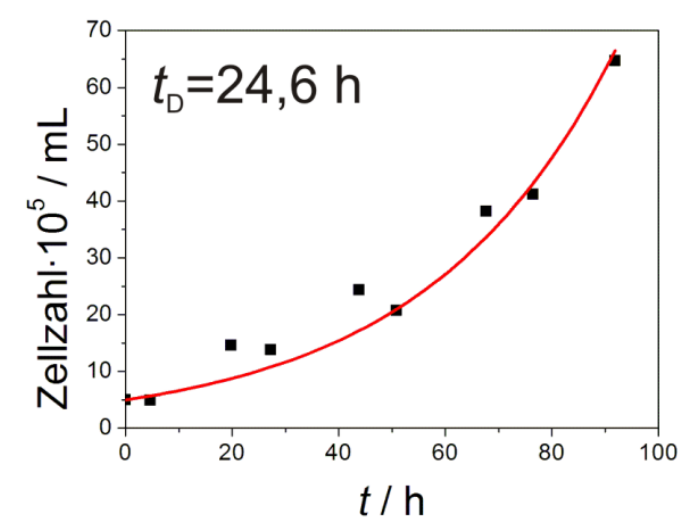

C

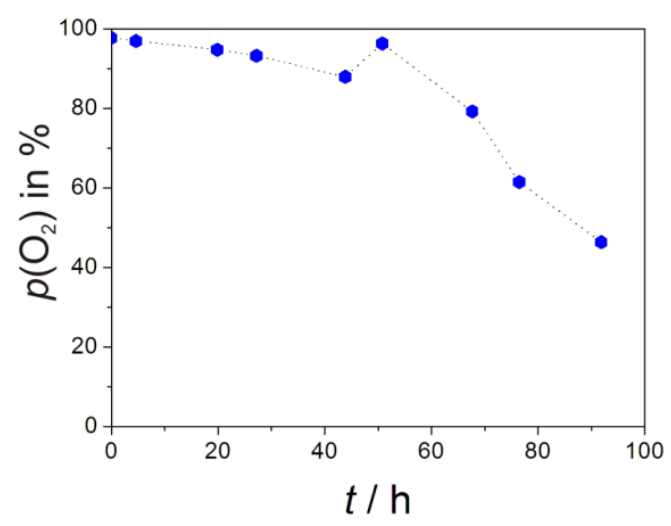

B

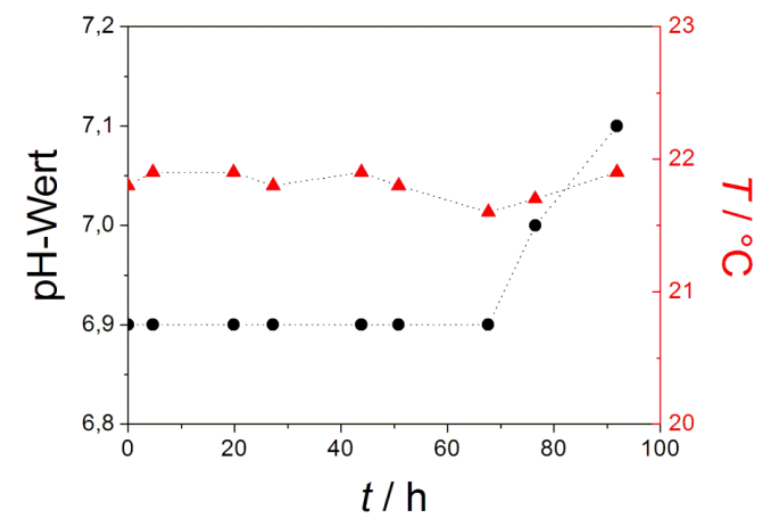

D

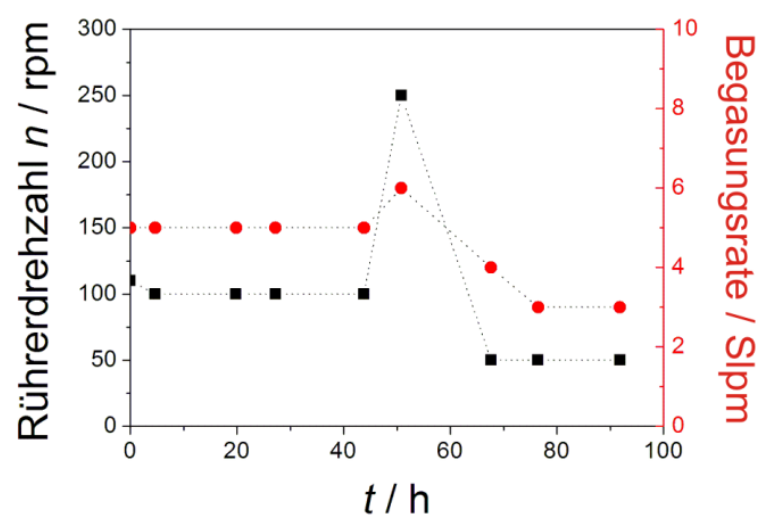

Abb. 4-5: Zweiter Fermentationsversuch von D. discoideum Cx43. A, Kurvenanpassung an die Wachstumskurve von D. discoideum (Cx43) nach Gl. 4-1 liefert eine Verdopplungszeit von 24,6 h mit $X\left(t_{0}\right)=5 \cdot 10^{5}$ Zellen. $\mathrm{mL}^{-1}$. $B$, Verlauf des $\mathrm{pH}$-Wertes und der Temperatur während der Fermentation. $C \& D$, Korrelation des Sauerstoffpartialdrucks mit Rührerdrehzahl sowie der Begasungsrate über den Zeitraum der Fermentation. $C-D$, gestrichelte Linie verdeutlicht den Verlauf der aufgezeichneten Prozessparameter.

In der dritten Fermentation von D. discoideum Cx43 wurde 2,5 L HL5-Medium (pH 6,7) mit 5.10 Zellen $\cdot \mathrm{mL}^{-1}$ (Zellzahl der Vorkultur: 1,6 $10^{7}$ Zellen $\cdot \mathrm{mL}^{-1}$ ) angeimpft und es wurde mit einer Rührerumdrehung von $50 \mathrm{rpm}$ und einer Begasungsrate von $3 \mathrm{Slpm}$ gestartet (Abb. 4-6 D). Während der Kultivierung konnte die Generationszeit von 46,8 h durch Anpassung der Prozessparameter, die die Konzentration an gelösten Sauerstoff erhöhen, nicht verringert werden. Die Fermentation musste nach 167 h beendet werden, da eine Kontami- 
nation mit Bakterien auftrat. Der Beginn mit einer niedrigen Rührerdrehzahl und einer geringeren Begasungsrate führte nicht zu einer geringeren Generationszeit.

A

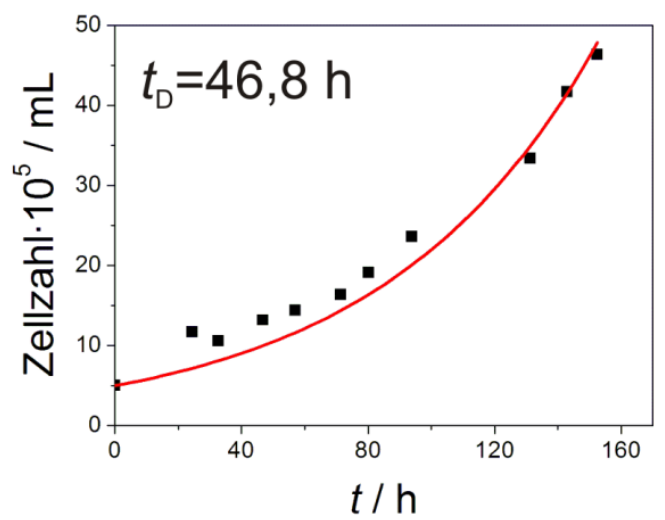

C

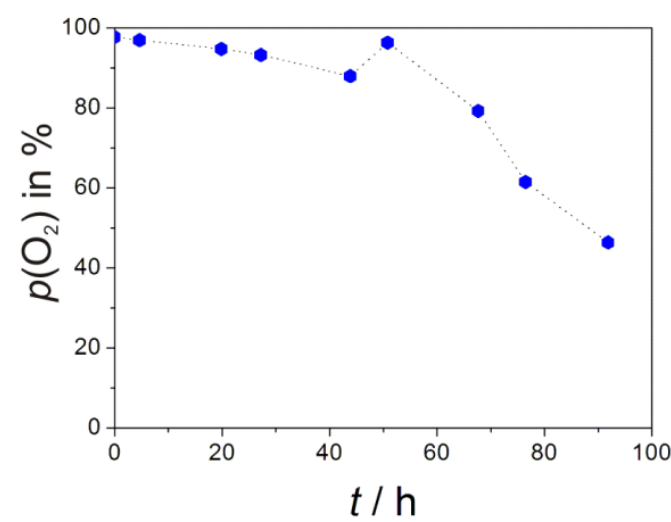

B

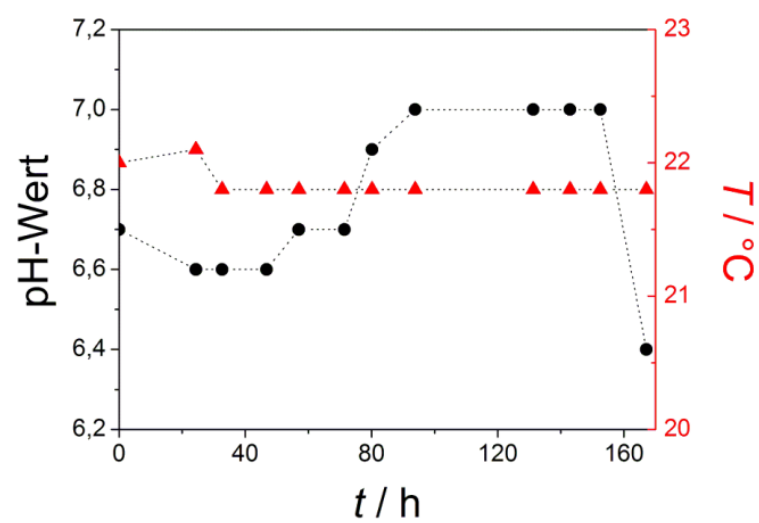

D

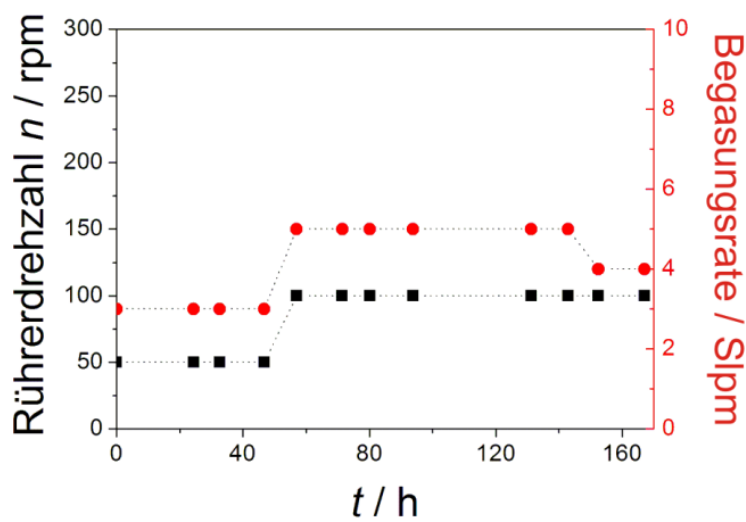

Abb. 4-6: Dritter Fermentationversuch von D. discoideum (Cx43). A, Die Wachstumskurve von D. discoideum Cx43 ergibt nach einer Kurvenanpassung nach Gl. 4-1 eine Verdopplungszeit von $46,8 \mathrm{~h}$ mit $X\left(t_{0}\right)=5 \cdot 10^{5}$ Zellen $\cdot \mathrm{mL}^{-1}$. $B$, Verlauf des $\mathrm{pH}$-Werts und der Temperatur während der Fermentation. $C \& D$, Verlauf des Sauerstoffpartialdrucks während der Fermentation in Beziehung zur Rührerdrehzahl und der Begasungsrate. $C-D$, gestrichelte Linie verdeutlicht den Verlauf der aufgezeichneten Prozessparameter. 


\subsubsection{Expression und Reinigung von Cx43 und Cx43-GFP in Pichia pastoris}

Neben D. discoideum wurde zur Expression von Connexin 43 (Cx43) und dem Fusionsprotein, bestehend aus Cx43 und dem grün fluoreszierenden Protein (GFP), ebenfalls die methylotrophe Hefe Pichia pastoris verwendet. Diese ist in der Lage Methanol als Nahrungsquelle zu nutzen. Allgemein ist es von Vorteil, dass Hefen weder Pyrogene enthalten, noch von Viren befallen werden können. Zur Kultivierung werden komplexe Medien wie Yeast Peptone Dextrose (YPD)-Medium und definierte Medien eingesetzt. Medien definierter chemischer Zusammensetzung (Kapitel 3.1.1.2) erlauben die Anzucht von P. pastoris mit einer hohen Zelldichte. Die Generationszeiten betragen für das YPD-Medium etwa $1,5 \mathrm{~h}$ und für definierte Medien etwa $3 \mathrm{~h}$. Hohe Proteinausbeuten bzw. Zellfeuchtmassen können durch die Kultivierung von P. pastoris im Bioreaktor erreicht werden, da hier verschiedene Prozessparameter direkt beeinflusst werden können. Die molekularbiologischen Arbeiten wurden durch den Kooperationspartner Dr. Christoph Methfessel und Dr. Volker Möhrle (Bayer Technology Services GmbH) übernommen. Für die Herstellung von $P$. pastoris Klonen, welche Cx43 und Cx43-GFP exprimieren, wurde das EasySelect ${ }^{\mathrm{TM}}$ Pichia Expression Kit verwendet. Dieser Prozess wird im Folgenden kurz erläutert (Kapitel 3.1.1.2). Für die Proteinexpression wurde das Gen für Cx43 (Mus musculus), welches ursprünglich aus einer HeLa Zelllinie stammt, in den Vektor pPICZ B integriert (Kapitel 9.9). Zur Expression beider Proteine wurde keine Codon-Optimierung für $P$. pastoris durchgeführt. Der Cx43-Sequenz ist dem 5'-AOX1 (Alkoholoxidase 1) Promotor vorgelagert, der die Methanolinduzierte Expression des Zielgens ermöglicht. ${ }^{[177]}$ Zusätzlich ermöglicht diese Region die spätere Integration des Plasmids in das Genom von P. pastoris durch homologe Rekombination. Diese codiert die native Transkriptionstermination- und Polyadenylierungssiganalsequenz des $A O X 1$ Gens, wodurch eine effiziente 3'-mRNA Prozessierung ermöglicht wird. Zur Herstellung des Fusionsproteins aus Cx43 und GFP wurde das Gen, welches GFP codiert, in das Plasmid mit Cx43 integriert. Das verwendete GFP besitzt eine Punktmutation des Serin 65, welches durch Threonin ersetzt wurde und dadurch die Quantenausbeute des Chromophor ansteigt. ${ }^{[178]}$

Das heterolog exprimierte Cx43 ist $C$-terminal mit dem $c$-myc Epitop fusioniert, welches in der Western Blot Analyse mithilfe eines Anti-myc Antikörpers detektiert werden kann. ${ }^{[179]}$ 
Beide Proteine besitzen einen Hexahistidin-Tag am C-Terminus. Der Affinitätstag dient zum einen der Reinigung mittels immobilisierter Metallchelataffinitätschromatografie und zum anderen zum Nachweis in der Western Blot Analyse mithilfe eines Anti-His Antikörpers (Kapitel 4.1.2.3). Die Konstrukte mit Cx43 bzw. Cx43-GFP wurden zunächst in Escherichia coli durch den pUC repliziert. Anschließend wurde jeweils der linearisierte Vektor durch Elektroformation in den P. pastoris Stamm X-33 (Genotyp: Wildtyp, Phänotyp: Mut ${ }^{+}$) eingebracht. Die Integration erfolgt durch ein Single Crossover Ereignis (homologe Rekombination) des transformierten pPICZ B (AOX1 Promotor oder Transkriptionsterminationsregion) und der homologen Region im Genom von P. pastoris. ${ }^{[180,181]}$ Dabei kann es zur Integration einer Kopie kommen. Bei 1 bis $10 \%$ der Transformanten kommt es zur Insertion von mehreren Kopien, die durch Southern Blotting identifiziert werden können. Anschließend wurden die Transformanten mittels Zeocin ${ }^{\mathrm{TM}}$-Resistenz selektiert. ${ }^{[182]} \mathrm{Nach}$ Selektion der Klone und Nachweis der Proteinexpression durch Western Blot Analyse wurden beide Klone zur Gewinnung hoher Proteinkonzentrationen durch Fermentation, ähnlich wie im Kapitel 3.1.1.2 beschrieben, kultiviert und ein Teil der P. pastoris Zellen durch Hochdruckdispersion aufgeschlossen. Die gewonnene Biomasse sowie die aufgeschlossenen Zellen (1. Fermentationscharge) wurden durch Bayer Technology Services (Leverkusen) bereitgestellt und ein Teil der in dieser Arbeit vorgestellten Ergebnisse wurde mit Cx43 und Cx43-GFP aus diesen Präparationen erstellt. Da die vorangegangenen Experimente gezeigt hatten, dass hohe Proteinkonzentrationen bzw. Biomasse mittels Fermentation von $P$. pastoris erzielt werden konnten, wurde die beiden P. pastoris Klone erneut in der Fermentation kultiviert, worauf im Folgenden eingegangen wird. 


\subsubsection{Fermentation von Pichia pastoris zur Gewinnung von Cx43 und Cx43-GFP}

Zur Realisierung hoher Zelldichten und der damit verbundenen hohen Proteinexpression wurden die beiden P.pastoris Klone Cx43 und Cx43-GFP in der Zulauffermentation (Fed-Batch-Fermentation) kultiviert (2. Fermentationscharge). Im Gegensatz zur satzweisen Kultivierung wird in der Zulaufkultivierung mit einem geringeren Volumen begonnen. Nachdem die zugesetzte Kohlenstoffquelle des Startvolumens verbraucht ist, wird ein Medium- oder Substratkonzentrat von außen zugeführt und eine definierte Wachstumsrate eingestellt. Zusätzlich kann durch kontrollierte Nährstoffzufuhr eine Substratinhibierung des Zellwachstums verhindert werden. Daneben wird durch diese Art der Fermentation die Reproduzierbarkeit verbessert bzw. das Vorhandensein inhibierender Sekundärmetabolite minimiert. Während der Fermentation können weitere Prozessparameter wie Temperatur, pH-Wert, Begasungsrate und Rührerumdrehung on-line überwacht bzw. reguliert werden.

Die erste Fermentation wurde mit $P$. pastoris Cx43-GFP durchgeführt, da hier schon aus der Fermentation von P. pastoris Cx43-GFP (Dr. Volker Möhrle, Bayer Technology Services $\mathrm{GmbH}$ ) bekannt war, dass sich die Zellen grün färben und der Erfolg direkt visualisiert werden konnte (Abb. 3-1 B). Zunächst wurden für die Fermentation von P.pastoris Cx43-GFP drei Vorkulturen in Yeast Peptone Dextrose (YPD)-Medium (200 mL) für 3 Tage bei Raumtemperatur unter Schütteln inkubiert (Kapitel 3.1.1.2). Es wurde mit $5 \mathrm{~L}$ autoklaviertem Medium im 15 L-Bioreaktor (Abb. 4-7 A), welches die Basalsalze sowie 4 \% $(w / v)$ Glycerol enthielt, begonnen (Abb. 4-8 B). Außerdem wurde dem Medium eine Mischung aus Spurenelementen $\left(\mathrm{PTM}_{1}\right)$ steril zugesetzt und anschließend mit $200 \mathrm{~mL}$ der Vorkultur mit einer Optischen Dichte (Absorption bei $600 \mathrm{~nm}$ ) von 12 inokuliert (Abschnitt 1). Die Temperatur wurde durch den außenliegenden Doppelmantel auf $30^{\circ} \mathrm{C}$ reguliert (Abb. 4-8 B). In einem Temperaturbereich zwischen 28 bis $30^{\circ} \mathrm{C}$ ist ein ideales Wachstum von P.pastoris möglich. ${ }^{[183]}$ Bei Temperaturen über $30^{\circ} \mathrm{C}$ kommt es zum Absterben der Zellen. Zu Beginn der Fermentation betrug die Rührerumdrehung 710 rpm und die Begasungsrate 5 Slpm (Standard-Liter pro Minute). Die Gelöstsauerstoffkonzentration (Dissolved Oxygen, DO) ist für aerob wachsende Zellen eine wesentliche Größe. Diese wird mit einer Messsonde über das Henry'sche Gesetz als Sauerstoffpartialdruck 
$\left(p\left(\mathrm{O}_{2}\right)=c_{\mathrm{s}} / H, c_{\mathrm{s}}=\right.$ Konzentration des gelösten $\mathrm{O}_{2}, H=$ Henry-Konstante $)$ in der Messgröße \%-Sauerstoffsättigung bestimmt.

A

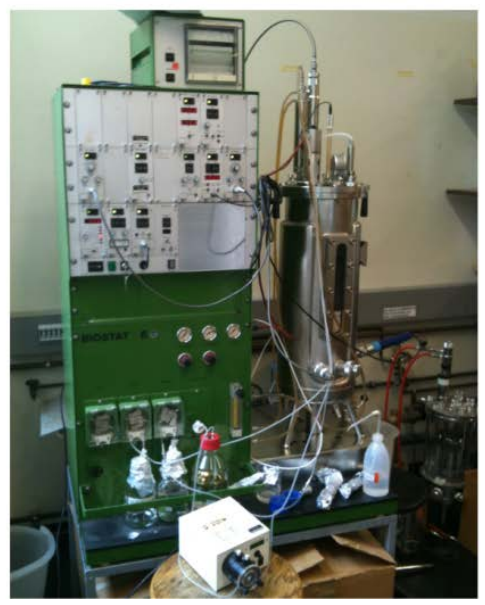

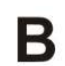

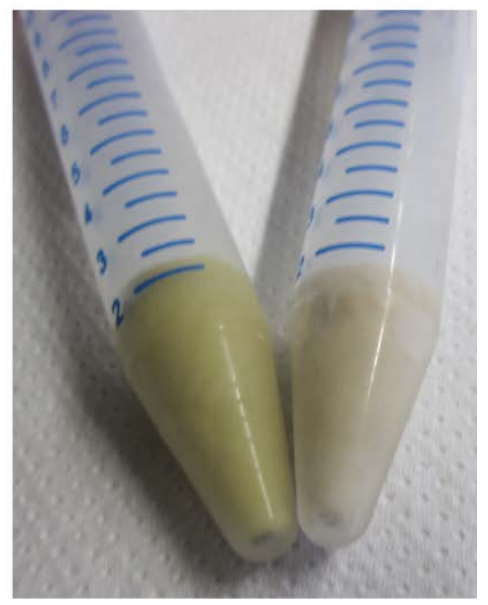

Abb. 4-7: A, 15 L-Bioreaktor Biostat E Typ ES der Firma B. Braun. B, P. pastoris Cx43-GFP Zellen vor der Induktion (rechts) und nach der Induktion (links) der Proteinexpression mit Methanol.

$\mathrm{Ab}$ einer Kultivierungszeit von $15 \mathrm{~h}$ wurde die Gelöstsauerstoffkonzentration durch Erhöhung der Rührerumdrehung und der Begasungsrate kontinuierlich angepasst (Abb. 4-8 D). Nach $19 \mathrm{~h}$ war das Glycerol des Startvolumens verbraucht, was an einer steigenden Sauerstoffkonzentration erkennbar war (Abb. 4-8 C) und es konnte eine Zellfeuchtmasse von $78 \mathrm{~g} \cdot \mathrm{L}^{-1}$ erreicht werden. Der zweite Fermentationsabschnitt dient der regulierten Erhöhung der Zelldichte. Zum einen wird dadurch die Ausbeute an heterolog, exprimiertem Protein erhöht und zum anderen wird die Anpassung der Kultur im dritten Abschnitt erleichtert. Dazu wurde ein Glycerolkonzentrat von $50 \%(w / v)$ Glycerol mit Spurenelementlösung kontinuierlich zugegeben. Die Generationszeit betrug bis zum Ende des zweiten Fermentationsabschnitts nach Gl. 4-1 $t_{\mathrm{D}}=4,2 \mathrm{~h}$. Nach Erreichen von $229 \mathrm{~g} \cdot \mathrm{L}^{-1}$ Zellfeuchtmasse $(-25 \mathrm{~h})$ wurde das Glycerol-Feeding beendet. Nach 1 h betrug die Gelöstsauerstoffkonzentration erneut $90 \%$ und es wurde mit etwa $18,5 \mathrm{~mL} \cdot \mathrm{h}^{-1}$ Methanol zugegeben (Abb. 4-8 C). Dabei wurde vor allem die Gelöstsauerstoffkonzentration kontinuierlich überprüft, da in den ersten Stunden Methanol akkumuliert und eine Konzentration $>2 \%$ toxisch wirkt. Die Anpassung der Zellen an die Metabolisierung von Methanol wurde regelmäßig durch das Abschalten des Methanol-Feedings überprüft. Nach 4,7 h war der Stoffwechsel der Kultur vollständig adaptiert und die Methanol-Feeding-Rate wurde kontinuierlich bis zu einer Gelöstsauerstoffkonzentration von $30 \%$ erhöht (bis zu 54,5 mL·h ${ }^{-1}$ ). Der 
Anstieg der Gelöstsauerstoffkonzentration ist auf eine Zugabe von Antischaum zurückzuführen, da die Zellen sensibel auf diese Polyollösung reagieren. Nach 41,5 h wurde die Fermentation beendet. Insgesamt wurde für 15,7 h mit Methanol die Proteinexpression induziert und es konnte nach der Zentrifugation eine Zellfeuchtmasse von 1,10 kg erreicht werden. Die Diskrepanz zwischen der erreichten Zellfeuchtmasse von Cx43-GFP in Abb. 4-8 A und der angegebenen Ausbeute ist darauf zurückzuführen, dass aufgrund eines technischen Defekts der Fermentationsanlage nicht das gesamte Fermentationsvolumen geerntet werden konnte.

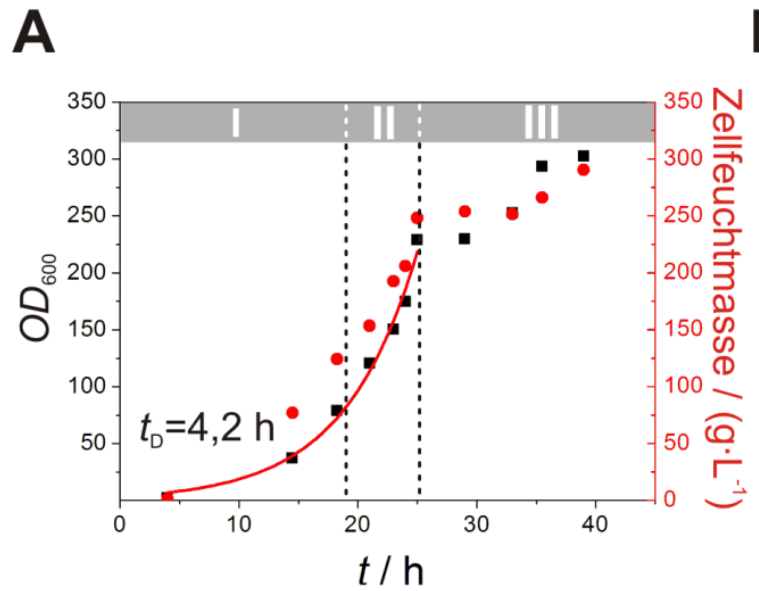

C

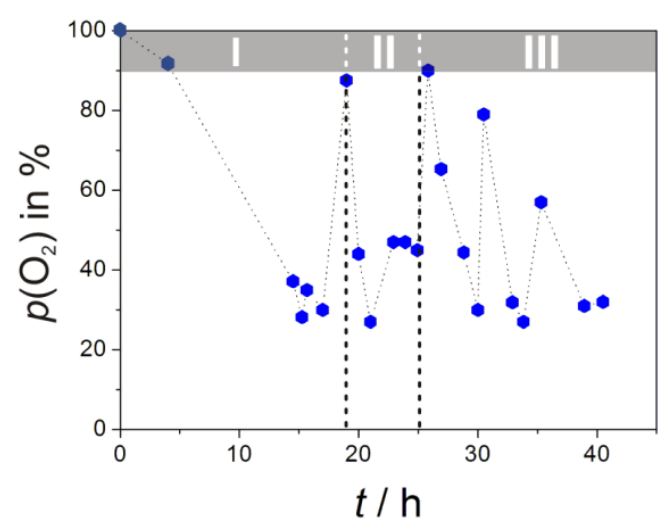

B

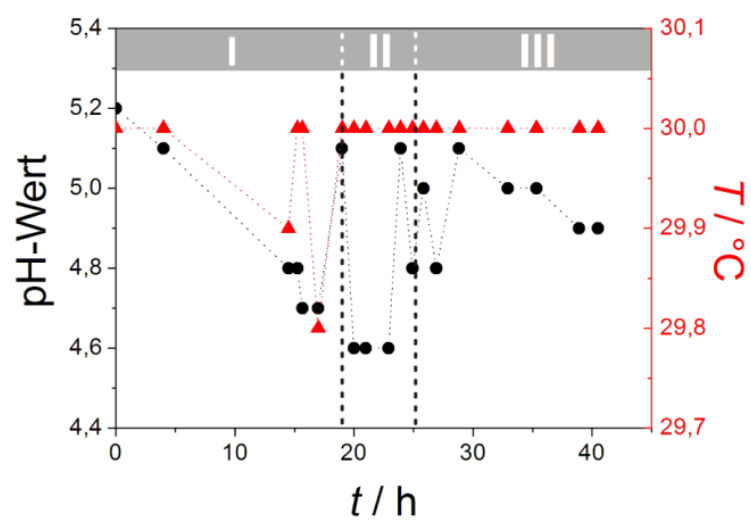

D

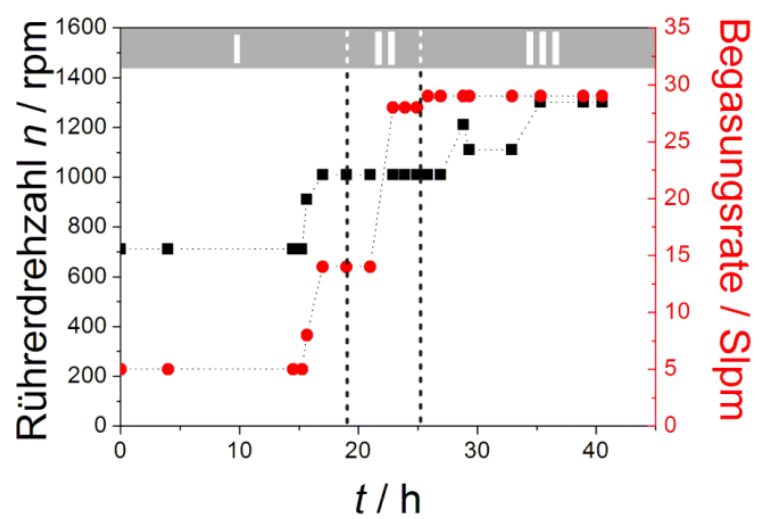

Abb. 4-8: Fermentation von P. pastoris Cx43-GFP. I: Batch-Phase, II: Glycerol-Fed-Batch-Phase, III: Methanol-Fed-Batch-Phase. A, Wachstumskurve von P. pastoris Cx43-GFP. Vergleich der Zunahme der Optischen Dichte bei $600 \mathrm{~nm}$ und Zellfeuchtmasse. Die Kurvenanpassung ergibt nach Gl. 4-1 eine Verdopplungszeit von $t_{\mathrm{D}}=4,2 \mathrm{~h}$ für die erste und zweite Fermentationsphase. $\boldsymbol{B}$, Verlauf des $\mathrm{pH}$-Wertes und der Temperatur über den Zeitraum der Fermentation. $\boldsymbol{C} \& \boldsymbol{D}$, Gegenüberstellung des zeitabhängigen Verlaufs des Sauerstoffpartialdrucks in \%-Sauerstoffsättigung und dessen Regulation über die Rührerdrehzahl und die Begasungsrate während der Fermentation. Der Anstieg des $p\left(\mathrm{O}_{2}\right)$ verdeutlicht die Übergänge zwischen den Fermentationsabschnitten. $\boldsymbol{B}$ - $\boldsymbol{D}$, gestrichelte Linie verdeutlicht den Verlauf der aufgezeichneten Parameter. 
Für die Fermentation von P.pastoris Cx43 wurden ebenfalls drei Vorkulturen mit YPD-Medium bei Raumtemperatur für drei Tage unter Schütteln inkubiert. Zur Kultivierung von $P$. pastoris Cx43 in einem $15 \mathrm{~L}$-Bioreaktor wurde $5 \mathrm{~L}$ autoklaviertes Nährmedium ( $\mathrm{pH} \mathrm{5,0)} \mathrm{mit} 200 \mathrm{~mL}$ Vorkultur mit einer Optischen Dichte bei $600 \mathrm{~nm}$ von 9 inokuliert. Für den ersten Abschnitt wurde mit einer Rührerumdrehung von 500 rpm und einer Begasungsrate von 10 Slpm begonnen, um eine Überlastung der Rührerwelle bzw. der Gleitringdichtung zu vermeiden. Nach 17,6 h Inkubation war der Sauerstoffpartialdruck auf 2,1 \% abgefallen (Abb. 4-9 C). Nach der Erhöhung der Rührerdrehzahl und der Begasungsrate stieg die Gelöstsauerstoffkonzentration wieder auf 38,7 \% an und die Kultur zeigte eine typische Wachstumsrate. Nach etwa $24 \mathrm{~h}$ war die Kohlenstoffquelle des Nährmediums metabolisiert. Dies wird durch den steigenden Sauerstoffpartialdruck verdeutlicht und es konnte mit dem Glycerol-Feeding begonnen werden (Abb. 4-9 C). Nach 6 h GlycerolFeeding konnte eine Zellfeuchtmasse von $180 \mathrm{~g} \cdot \mathrm{L}^{-1}$ erreicht werden (Abb. 4-9 A). Die Wachstumsrate betrug bei der Kultivierung mit Glycerol nach Gl. 4-1 $t_{\mathrm{D}}=3,1 \mathrm{~h}$. Bis zum Ende des Glycerol-Feedings wurden $50 \mathrm{~g} \cdot \mathrm{L}^{-1}$ weniger Zellfeuchtmasse erreicht, verglichen mit der Fermentation von P. pastoris Cx43-GFP. Dies diente dazu eine Überlastung des Bioreaktors zu vermeiden, da die höhere Zellfeuchtmasse bei der Kultivierung von P. pastoris Cx43GFP zu einer erschwerten Sauerstoffregulation führte. Nach Erreichen einer Gelöstsauerstoffkonzentration von $98 \%$ wurde mit dem Methanol-Feeding $\left(18 \mathrm{~mL} \cdot \mathrm{h}^{-1}\right)$ begonnen (Abb. 4-9 C). Zunächst kam es zu einem leichten Abfall der Zelldichte, was auf eine zu hohe Methanolkonzentration schließen lässt. Nach 4,3 h war der Metabolismus der P.pastoris Zellen vollständig adaptiert und die Feeding-Rate wurde langsam erhöht bis eine Gelöstsauerstoffkonzentration von etwa $35 \%$ erreicht wurde (bis zu $54,5 \mathrm{~mL} \cdot \mathrm{h}^{-1}$ ). Allerdings schwankte der Sauerstoffpartialdruck zwischen 25 und 45 \%. Nach 19 h Methanol-Feeding wurde die Fermentation beendet. Die Kultivierungsbedingungen in Abschnitt 1 der Fermentation, die in der ersten Fermentation verwendet wurden, sind für den ersten Abschnitt besser geeignet als die der zweiten Fermentation. Durch die niedrigere Zelldichte in der zweiten Fermentation war in diesem Bioreaktor eine einfachere Regelung möglich. Außerdem konnten sich der Metabolismus der P.pastoris Zellen schneller an das Methanol-Feeding adaptieren. Es wurde nach der Zentrifugation eine Zellfeuchtmasse von 1,24 kg erhalten. Die Diskrepanz zwischen der erreichten Zellfeuchtmasse von Cx43-GFP in Abb. 4-8 A und der angegebenen Ausbeute ist darauf zurückzuführen, dass aufgrund eines technischen Defekts der Fermentationsanlage nicht das gesamte Fermentationsvolumen geerntet werden 
konnte. Im nächsten Schritt wurden die P. pastoris Zellen zur Gewinnung der Plasmamembran durch eine geeignete Methode aufgeschlossen.

A

B
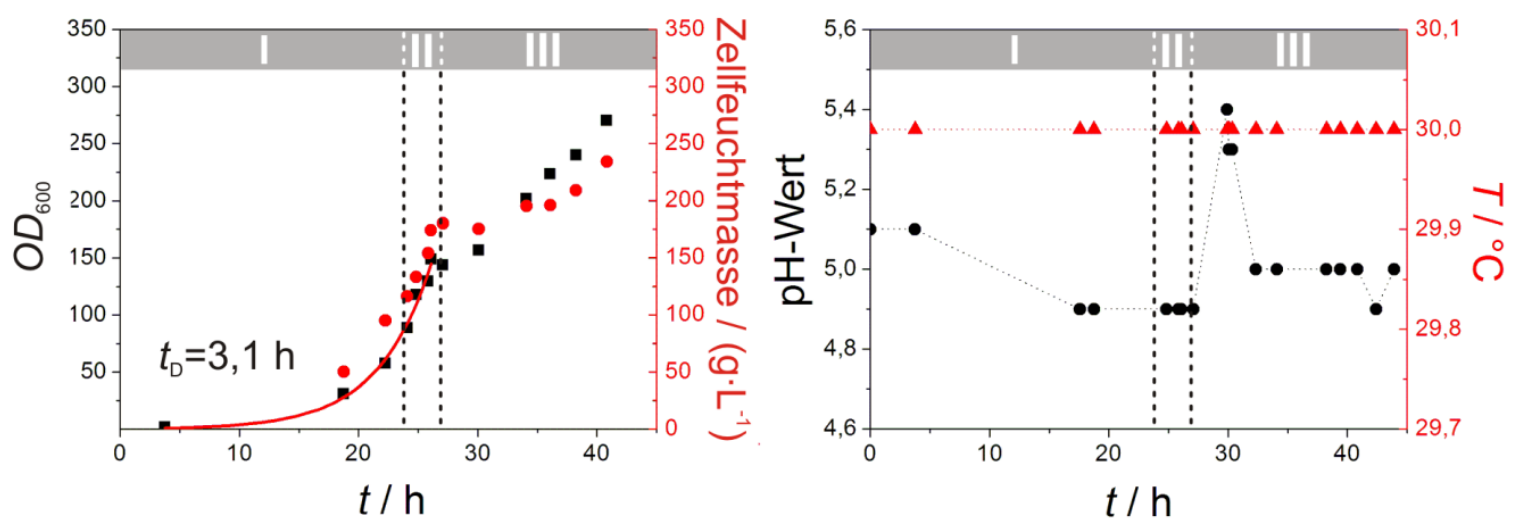

C

D
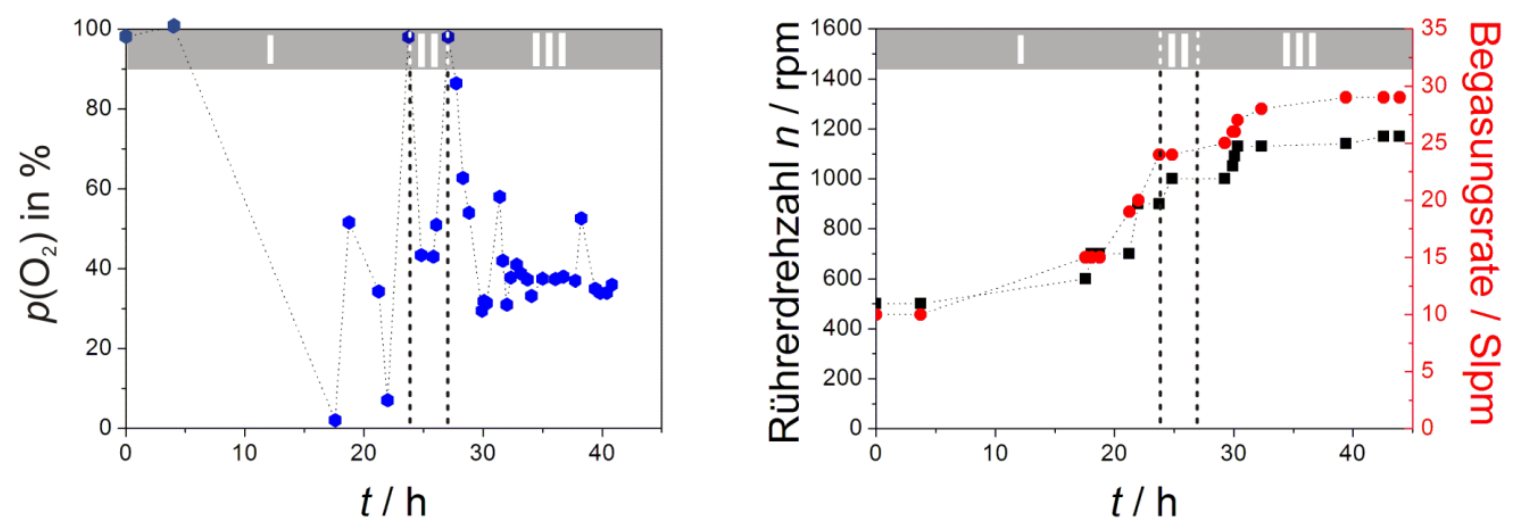

Abb. 4-9: Fermentation von P.pastoris Cx43. I: Batch-Phase, II: Glycerol-Fed-Batch-Phase, III: Methanol-Fed-Batch-Phase. $A$, Wachstumskurve von P.pastoris Cx43. Vergleich der zeitabhängigen Zunahme der Optischen Dichte bei $600 \mathrm{~nm}$ und Zellfeuchtmasse. Durch die Anpassung einer exponentiellen Zunahme kann nach Gl. 4-1 eine Generationszeit von $t_{\mathrm{D}}=3,1 \mathrm{~h}$ ermittelt werden. $\boldsymbol{B}$, Verlauf des $\mathrm{pH}$-Wertes und der Temperatur abhängig von der Zeit. $\boldsymbol{C} \& \boldsymbol{D}$, Darstellung des aufgezeichneten Sauerstoffpartialdrucks und den Einflussparametern Rührerdrehzahl und Begasungsrate. $B-D$, gestrichelte Linie verdeutlicht den Verlauf der aufgezeichneten Parameter. 


\subsubsection{Präparation von Pichia pastoris Membranfragmenten}

Aufgrund der Membranlokalisation von Cx43 und Cx43-GFP, mussten die P. pastoris Zellen für die Isolierung der Proteine aus den Membranfragmenten aufgeschlossen werden. $P$. pastoris besitzt analog zu anderen Hefestämmen eine Zellwand, welche sich aus $\beta$-Glucan, Mannan, Chitin sowie Glykoproteinen zusammensetzt. Dabei trägt ein Netzwerk aus unterschiedlich verzweigten Glucanen den Hauptteil zur Widerstandsfähigkeit der Zellwand bei. In Saccharomyces cerevisiae werden $15 \%$ des gesamten Zellenvolumens von der Zellhülle beansprucht, die sich aus Zellwand, Periplasma und Plasmamembran zusammensetzt. ${ }^{[184]}$ Aufgrund der Zusammensetzung der Zellwand werden hohe Kräfte zum Aufschluss benötigt. Zusätzlich variiert der Aufbau zwischen den verschiedenen Hefestämmen, weshalb unterschiedliche Aufschlussmethoden erforderlich sind.

Zum Aufschluss von P. pastoris wurden verschiedene Methoden getestet. Zunächst wurde mit der Waring Blender (Labormixer)-Methode und der Grinder (Ultrazentrifugalmühle)Methode gearbeitet. Beide Methoden wurden in der Arbeitsgruppe von Prof. Dr. Ficner (GZMB, Universität Göttingen) bzw. in der Arbeitsgruppe von Prof. Dr. Lührmann (MPI für biophysikalische Chemie, Göttingen) für den Aufschluss von der Hefe S. cerevisiae erfolgreich eingesetzt. Der gemeinsame Vorteil ist, dass während des Zellaufschlusses bei tiefen Temperaturen $\left(<-50^{\circ} \mathrm{C}\right)$ gearbeitet wird. Dadurch wird der Einfluss von Reibungswärme reduziert und Proteasen sind inaktiv. Bei der Waring Blender-Methode sollten die Zellen durch schnell rotierende Messer des Labormixers zerstört werden. Die Grinder-Methode beruht auf einem ähnlichen Prinzip. Die Zellen werden mit $18.000 \mathrm{rpm}$ durch ein Sieb mit einer Porengröße von 0,75 mm gepresst. Zum Zellaufschluss notwendige Scherkräfte werden durch eine rotierende Scheibe mit Messern erzeugt, die die Zellsuspension durch die Siebporen drückt. Mit der lichtmikroskopischen Analyse der Zellen vor und nach dem Aufschluss konnte beobachtet werden, dass die Scherkräfte beider Methoden nicht ausreichend waren, um die $P$. pastoris Zellen aufzuschließen.

Mittels einer dritten Methode (French Press), durchgeführt im Institut für Biochemie und Biotechnologie der MLU Halle-Wittenberg, konnten die P. pastoris Zellen aufgeschlossen werden. Beim Aufschluss mithilfe der French Press wird die Zellsuspension mit hohem Druck durch eine kleine Öffnung $(<1 \mathrm{~mm})$ gedrückt. Durch schnellen Auf- und Abbau des angelegten Drucks (600 bar) werden so starke Scherkräfte erzeugt, dass die Zellen zerstört 
werden (Kapitel 3.1.2). Die Suspension wurde zweimal bei unterschiedlichen Geschwindigkeiten zentrifugiert. Das Pellet der ersten Zentrifugation konnte in verschiedene Schichten eingeteilt werden. Aufgrund der grünen Färbung wurde das Fusionsprotein Cx43-GFP in der obersten Schicht des Pellets vermutet. Die P. pastoris Cx43 Zellen wurden auf die gleiche Weise aufgeschlossen. Die gesammelten Fraktionen der Isolierung wurden durch die Western Blot Analyse (Kapitel 3.1.5) mit einem monoklonalen Antikörper, der gegen die Cterminalen Aminosäuren 241 bis 254 von Cx43 gerichtet ist (Abb. 1-6), untersucht und die Ergebnisse sind in Abb. 4-10 dargestellt. Es wurde für die Isolierung von Cx43-GFP und Cx43 Membranfragmenten jeweils der Überstand der ersten und zweiten Zentrifugation (ÜS1, ÜS2), die zwei Schichten (S1, S2) des ersten Pellets (P1) sowie das Pellet der zweiten Zentrifugation (P2) analysiert. Cx43-GFP mit 71,3 kDa ist sowohl im Überstand und Pellet der ersten Zentrifugation (ÜS1, P1) als auch im Überstand der zweiten Zentrifugation (ÜS2) zu finden (Abb. 4-10 A). Aus der Bandenintensität der Western Blot Analyse lässt sich schlussfolgern, dass Cx43-GFP noch in höheren Konzentrationen im Überstand der zweiten Zentrifugation (ÜS2) vorlag (Abb. 4-10 A). Zur vollständigen Pelletierung der Membranfragmente, die Cx43-GFP enthalten, sind höhere Zentrifugalkräfte notwendig. Im Pellet der zweiten Zentrifugation (P2) ist ebenfalls Cx43-GFP enthalten. Jedoch konnte es aufgrund der hohen Proteinkonzentration nicht aufgetrennt werden bzw. größere Proteinaggregate konnten nicht ins Trenngel eindringen (Abb. 4-10A). Cx43 mit 45,6 kDa konnte ausschließlich in der oberen Pelletschicht der ersten Zentrifugation (P1, S1) identifiziert werden. Im Überstand der ersten sowie der zweiten Zentrifugation (ÜS1, ÜS2) ist eine zusätzliche Bande zwischen 66 und $90 \mathrm{kDa}$ zu sehen, die wahrscheinlich ein Cx43-Dimer und dessen Abbauprodukte darstellt. Trotz der Zugabe eines Proteaseinhibitorcocktails kam es teilweise zum Abbau der Proteine, was an der Lauffront zu sehen ist (Abb. 4-10). 

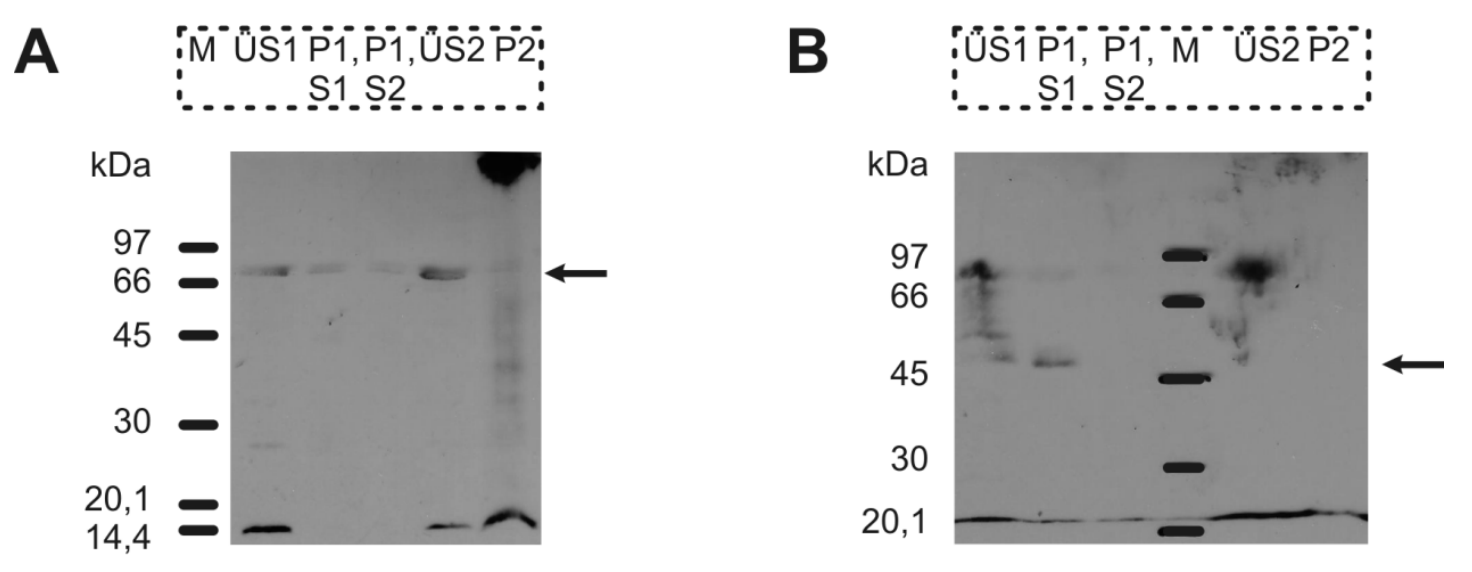

Abb. 4-10: Western Blot-Analyse des Aufschlusses von P.pastoris Cx43 und Cx43-GFP (Pfeil). $\boldsymbol{A} \& \boldsymbol{B}$, (ÜS1), Überstand der ersten Zentrifugation (P1, S1), obere Schicht des Pellets der ersten Zentrifugation (P1, S2), zweite Schicht des Pellets der ersten Zentrifugation (ÜS2), Überstand der zweiten Zentrifugation und (P2), Pellet der zweiten Zentrifugation. Antikörper: connexin 43 (D-7) monoklonaler $\operatorname{IgG}_{1}$

\subsubsection{Reinigung von Cx43 und Cx43-GFP via Affinitätschromatografie}

Beide Proteine tragen zur Reinigung mittels Affinitätschromatografie einen $C$-terminalen Hexahistidin-Tag. Dieser ist in der Lage spezifisch an Nickel-Nitrilotriessigsäure (Nickel Nitrilotriacetic Acid, Ni-NTA), die an einem Polymer wie Agarose immobilisiert ist, zu binden. Es musste zunächst untersucht werden, welches Detergens sich zur Solubilisierung von Cx43 bzw. Cx43-GFP aus den P. pastoris Membranfragmenten, eignet. Dafür wurde das Detergens $n$-Octyl- $\beta$-D-glucopyranosid ( $n \mathrm{OG}$, Kapitel 3.5.4), welches bereits gute Ergebnisse für die Solubilisierung des in $D$. discoideum exprimierten Cx43-eGFP lieferte (Kapitel 4.1.1.2), und $n$-Dodecyl- $\beta$-D-maltosid (DDM, Kapitel 3.5.4) in den Konzentrationen von 2 bis $5 \%(w / v)$ getestet. DDM gilt als geeignetes Detergens zur Solubilisierung von Connexinen. ${ }^{[185]}$ In Abb. 4-11 ist die Western Blot Analyse von Pellet (P) und Überstand (ÜS) des Solubilisierungstests nach Zentrifugation aufgetragen. Die Untersuchung verdeutlicht, dass mit steigenden Konzentrationen von $n \mathrm{OG}$ die Solubilisierungseffizienz abnimmt (Abb. 4-11 A). Dies korreliert mit der abnehmenden Bandenintensität des solubilisierten Proteins im Überstand (ÜS). Im Gegensatz dazu ist DDM mit steigenden Konzentrationen in der Lage höhere Konzentrationen an Cx43-GFP aus den Membranfragmenten zu solubilisieren, was hier an der zunehmenden Bandenintensität zu erkennen ist (Abb. 4-11 B). Durch die Ergebnisse wird ersichtlich, dass DDM höhere Konzentrationen an Cx43-GFP aus den Membranfragmenten solubilisieren kann. Außerdem wurde bereits 
durch Bao et al. erfolgreich Cx43 mit DDM aus Membranfragmenten von Insektenzellen gereinigt. ${ }^{[123]}$ Aus diesem Grunde wurde DDM zur Solubilisierung beider Proteine eingesetzt.

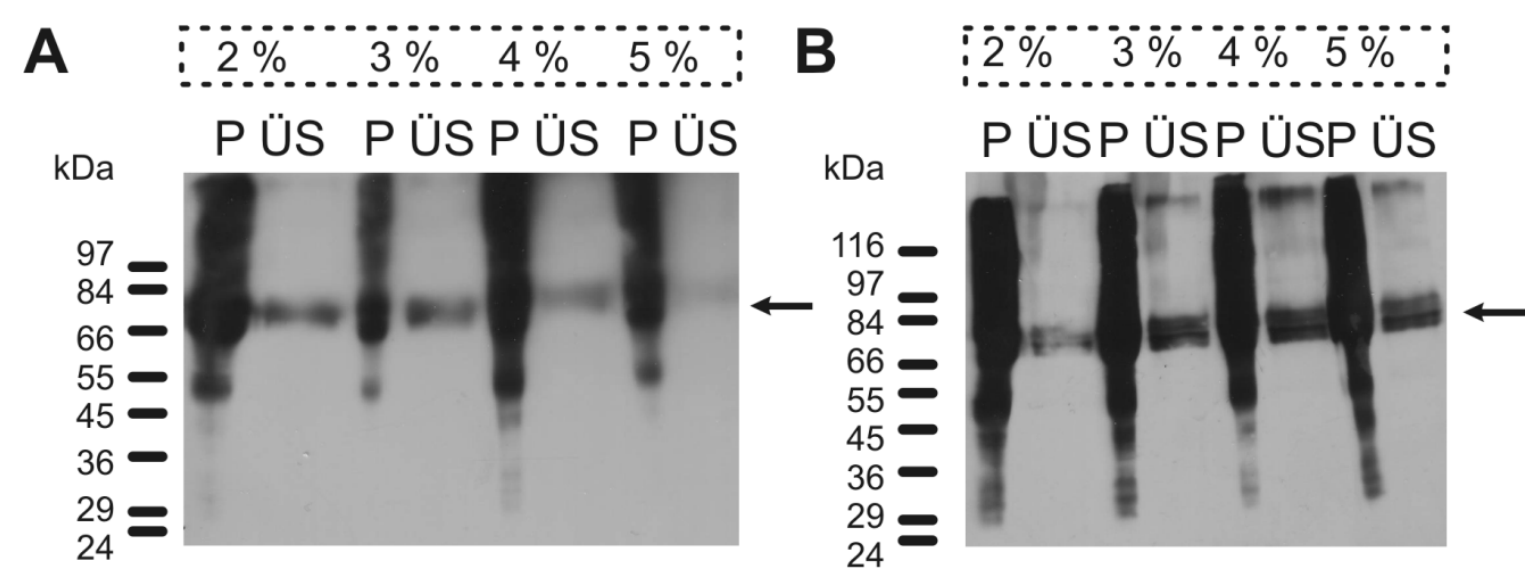

Abb. 4-11: Solubilisierungsversuche von Cx43-GFP (Pfeil) exprimiert in P.pastoris mit verschiedenen Detergenskonzentrationen. $A$, Solubilisierungstest mit $n$-Octyl- $\beta$-D-maltosid mit einer Konzentration von 2 bis $4 \%$. B, Solubilisierungstest mit $n$-Dodecyl- $\beta$-D-maltosid mit einer Konzentration von 2 bis $4 \%$. P bezeichnet das Pellet und ÜS kennzeichnet den Überstand der Zentrifugation. Antikörper: connexin 43 (D-7) monoklonaler $\operatorname{IgG}_{1}$

Innerhalb der Arbeit wurden zwei verschiedene Reinigungsstrategien verfolgt. Einerseits wurde die Affinitätsreinigung, welche bereits für die Isolierung von Cx26 aus Insektenzellmembranfragmenten erfolgreich angewendet wurde, von der Kooperationspartnerin Prof. Dr. Gina Sosinsky (UCSD, San Diego, CA, USA) übernommen. Diese Methode wird im Folgenden als Reinigung nach Atsu bezeichnet. Andererseits wurde die Reinigung nach Bao et al. angewendet. ${ }^{[123]}$

\section{Reinigung nach Atsu}

Neben Cx43 wurde parallel mit Cx26 in der Dissertation von Dr. Oliver Gaßmann (AK Steinem) gearbeitet. Die Proteinsynthese von Cx26 erfolgte im Baculovirus/Insektenzellen Expressionssystem und die Affinitätsreinigung war ebenfalls über einen Polyhistidin-Tag möglich. Das Protokoll zur Isolierung von Cx26 wurde für Cx43 adaptiert. ${ }^{[186]}$ Für die Isolierung wurden die Membranfragmente in Bicarbonatpuffer mithilfe von Ultraschall resuspendiert (Kapitel 3.1.3). In allen Schritten wurde Phenylmethylsulfonylfluorid (PMSF) zur Inhibierung von Serinproteasen verwendet. Anschließend wurde Cx43 bzw. Cx43-GFP mithilfe von $3 \%(w / v)$ DDM für $2,5 \mathrm{~h}$ bei $4{ }^{\circ} \mathrm{C}$ solubilisiert. Nach der Zentrifugation wurde der Überstand, der das solubilisierte Protein enthält, mit der Affinitätsmatrix (Ni- 
NTA-Agarose) im Batch-Verfahren über Nacht bei $4{ }^{\circ} \mathrm{C}$ inkubiert. Da die Zugänglichkeit $\operatorname{der} C$-terminalen Polyhistidin-Tags im Connexin 43 Halbkanal nicht bekannt ist, bot das Batch-Verfahren die Möglichkeit auch schlecht zugängliche Polyhistidin-Tags an die Affinitätsmatrix zu binden. Im nächsten Schritt wurde unspezifisch gebundenes Protein durch einen Waschschritt mit 20 mM Imidazol von der Ni-NTA-Agarose entfernt. Imidazol ist in der Lage, kompetitiv die Histidine aus dem Komplex mit Ni-NTA zu verdrängen. Dies wurde ebenfalls im nächsten Schritt zur Elution des Proteins mit $1 \mathrm{M}$ Imidazol genutzt. Anschließend wurden die Proben der einzelnen Schritte der Affinitätschromatografie durch SDS-PAGE entsprechend ihres Molekulargewichts aufgetrennt und die Proteine mithilfe von Coomassie angefärbt. Abb. 4-12 A und B zeigen die Analyse der einzelnen Schritte. Die SDS-PAGE Gele verdeutlichen, dass durch die drei Waschschritte unspezifisch gebundenes Protein zum Teil von der Ni-NTA-Agarose gelöst werden konnte (W1 bis W3). Aber sowohl die Elutionsfraktion (E) von Cx43 als auch die von Cx43-GFP zeigen in allen Schritten eine starke Bande zwischen 66 und $97 \mathrm{kDa}$. Aufgrund der Verunreinigungen kann beiden Proteinen keine spezifische Bande zugeordnet werden. Zur weiteren Untersuchung wurden die Proteine in der Western Blot Analyse mithilfe von spezifischen Antikörpern gegen Cx43 sowie gegen den Hexahistidin-Tag identifiziert. Abb. 4-12 C und D zeigt, dass Cx43 mit 45,6 kDa und Cx43-GFP mit 71,3 kDa jeweils in der Elutionsfraktion (E) nachgewiesen werden konnte. Außerdem sind in der Elutionsfraktion von Cx43-GFP mehrere schwache Banden im oberen und unteren Molmassenbereich zu erkennen. Es könnte sich um das Dimer des Proteins und dessen proteolytische Abbauprodukte handeln. Ferner konnte Cx43-GFP mit einer schwachen Bande ebenfalls in den beiden Überständen (ÜS1, ÜS2) des Batch-Verfahrens nachgewiesen werden. Dies ist darauf zurückzuführen, dass die Ni-NTA-Agarose überladen war und Protein nicht mehr daran binden konnte. Dagegen zeigen die drei Waschschritte (W1 bis W3), dass Cx43-GFP durch den C-terminalen Hexahistidin-Tag an der Matrix immobilisiert war. Diese Reinigung ermöglichte in dieser Arbeit eine hohe Reproduzierbarkeit und hohe Ausbeuten. 


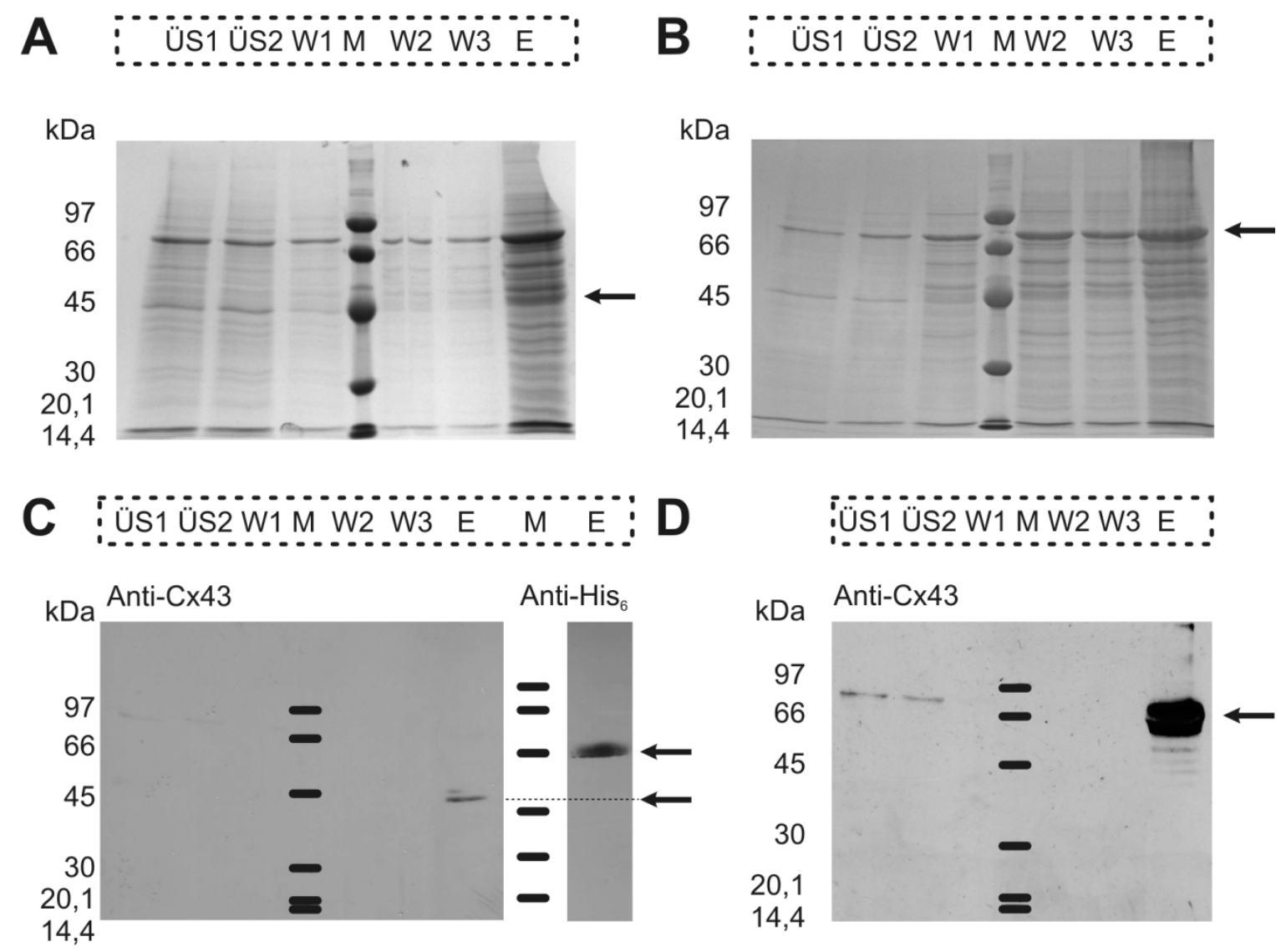

Abb. 4-12: Affinitätsreinigung von $\mathrm{Cx} 43$ und Cx43-GFP nach dem Protokoll von Atsu. Exemplarisches Coomassie gefärbtes SDS-PAGE Gel $(\boldsymbol{A})$ und Western Blot Analyse $(\boldsymbol{C})$ der Reinigung von Cx43. Durch den Immunoblot konnte spezifisch Cx43 bei etwa $45 \mathrm{kDa}$ (Pfeil) in der Elutionsfraktion mit dem monoklonalen Antikörper gegen Cx43 und dem polyklonalen Antikörper gegen den Hexahistidin-Tag nachgewiesen werden. Das Coomassie gefärbte SDS-PAGE Gel $(\boldsymbol{B})$ und die Western Blot Analyse (D) zeigen die Schritte der Reinigung von Cx43-GFP. Ebenso konnte die Untersuchung mit dem spezifischen Antikörper Cx43-GFP bei etwa $70 \mathrm{kDa}$ (Pfeil) nachgewiesen werden. ÜS1, ÜS2-Überstände Ni-NTA-Agarose, W1 bis W3-Waschschritte der Affinitätsreinigung, E-Elutionfraktion.

Nach Dialyse der Elutionsfraktion von Cx43 bzw. Cx43-GFP gegen Elutionspuffer ohne Imidazol wurde ein Absorptionsspektrum für das jeweilige Protein gemessen und durch die Absorption bei $280 \mathrm{~nm}$ konnte mit dem Lambert-Beerschen Gesetz (Gl. 3-1) die Konzentration der Proteine berechnet werden (Abb. 4-13). Allerdings wird so nur die Gesamtproteinkonzentration bestimmt, nicht die des reinen Cx43, da in der Elutionsfraktion auch Fremdprotein vorlag. Für das Fusionsprotein wurde auch die Absorption bei $489 \mathrm{~nm}$ bestimmt (Abb. 4-13 B), das Absorptionsmaximun des GFP-Chromophors. Die Verunreinigungen verfälschten den Wert für die bestimmten Konzentrationen. Zur besseren Entfernung der Fremdproteine wurde die Reinigung nach Bao et al. mit Alkaliextraktion für die Isolierung von Cx43 und Cx43-GFP getestet. $^{[123]}$ 


\section{A}

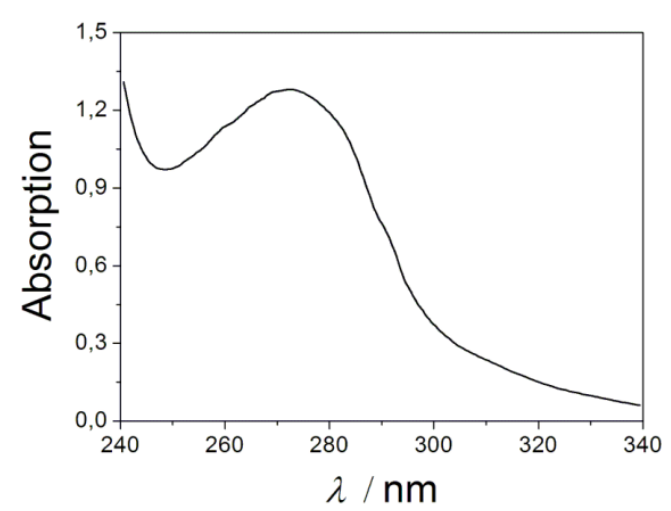

B

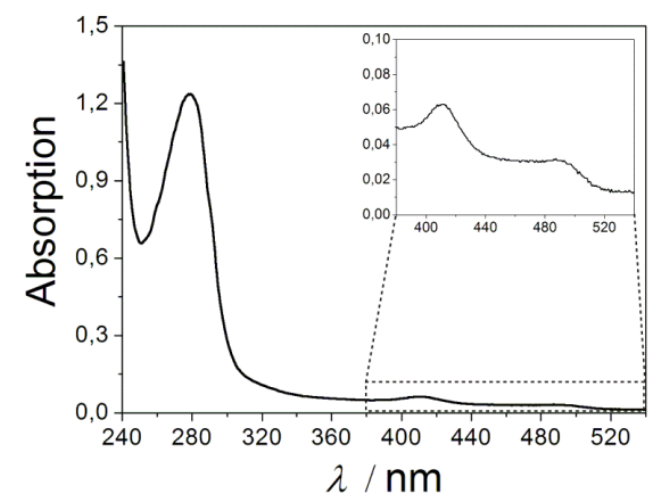

Abb. 4-13: Exemplarisches Absorptionsspektrum der dialysierten Elutionsfraktionen von $\mathrm{Cx} 43$ in $A$ und Cx43-GFP in $B$. das Absorptionsmaximum ist bei etwa $280 \mathrm{~nm}$ zu finden. Die Konzentrationen sind in Tab. 4-1 zusammengefasst. Der Bereich zwischen $380 \mathrm{~nm}$ bis $540 \mathrm{~nm}$ ist vergrößert, da in diesem Bereich GFP absorbiert.

Reinigung nach Bao et al. ${ }^{[123]}$

Die Alkaliextraktionsmethode ermöglicht die Solubilisierung von peripheren Membranproteinen und wurde bereits für die Isolierung von Gap Junction Kanälen aus ihren natürlichen Ressourcen verwendet. ${ }^{[39]}$ Zunächst wurden die Membranfragmente, wie Kapitel 3.1.3 beschrieben, in Bicarbonatpuffer resuspendiert und anschließend $20 \mathrm{mM}$ Natriumhydroxid zugesetzt. Anschließend wurden die Verunreinigungen von den Membranfragmenten durch Zentrifugation abgetrennt und im nächsten Schritt wurde Cx43 bzw. Cx43-GFP mit 2,5\%(w/v) DDM solubilisiert. Außerdem enthielt der Solubilisierungspuffer $10 \mathrm{mM}$ PMSF zur Inhibierung von Serinproteasen sowie $10 \mathrm{mM}$ DTT, 10 mM Glycin- $\mathrm{NaOH}$ (pH 10) und $2 \mathrm{M} \mathrm{NaCl}$, da sich diese Komponenten zum Aufbrechen der lateralen Organisation der Connexin Halbkanäle bewährt haben. ${ }^{[185]}$ Nach 2 h Inkubation wurde das solubilisierte Protein durch Zentrifugation von unlöslichen Bestandteilen getrennt. Im nächsten Schritt wurde der Überstand mit solubilisiertem Protein in HEPES-Puffer sowie $10 \mathrm{mM} \beta$-Mercaptoethanol verdünnt und somit die DDM Konzentration auf $0,2 \%(w / v)$ gesenkt. Ferner wurde das Batch-Verfahren in dieser Reinigungsmethode für die Immobilisierung von Cx43 und Cx43-GFP an der Ni-NTA-Agarose genutzt. Durch drei Waschschritte wurde unspezifisch gebundenes Protein von der Affinitätsmatrix entfernt und die Proteine durch 0,3 bzw. $1 \mathrm{M}$ Imidazol eluiert. Abb. 4-14 A und B zeigen die Analyse der verschiedenen Reinigungsschritte der Isolierung von Cx43 bzw. 
Cx43-GFP, welche durch SDS-PAGE analysiert wurden. Im Vergleich zur Reinigung nach Atsu wird deutlich, dass für die Isolierung von Cx43 und Cx43-GFP der Anteil an Fremdprotein drastisch reduziert werden konnte (Abb. 4-14 A, B), jedoch ging ein Teil des Cx43 ebenfalls bei der Alkaliextraktion verloren und wurde im Überstand der Zentrifugation wiedergefunden (Abb. 4-14 A, C). Die Elution mit 0,3 und $1 \mathrm{M}$ Imidazol (E1, E2) zeigt, dass das Cx43 erst bei höheren Imidazolkonzentrationen von der Ni-NTA-Agarose gelöst werden konnte. Außerdem ist ein Cx43 Dimer zwischen 66 und $97 \mathrm{kDa}$ in E1 und E2 sowie Produkte proteolytischen Abbaus sowie dessen Dimer unterhalb der Bande von Cx43 zu erkennen. Für die Reinigung von Cx43-GFP konnte ebenfalls die Kontamination mit Fremdprotein reduziert werden, jedoch wurde Cx43-GFP nicht durch die Alkaliextraktion solubilisiert. Im Gegensatz zu Cx43 konnte Cx43-GFP nicht vollständig aus dem Pellet solubilisiert werden. Der Unterschied der in Abb. 4-14 dargestellten Isolierung liegt darin, dass je $300 \mathrm{mg}$ Membranfragmente für Cx43 $1 \mathrm{~mL}$ Solubilisierungspuffer und für Cx43-GFP 0,5 mL verwendet wurden. Ferner zeigt die Analyse der Überstände 2 und 3 (Ü2-3) der Inkubation von Ni-NTA-Agarose im Batch sowie der Waschschritte der Isolierung von Cx43-GFP (W1-3), dass die Affinitätsmatrix mit Protein vollständig beladen und ein Teil des Cx43-GFP nicht mehr binden konnte. Die Elution mit 0,3 und 1 M (E1, E2) zeigt, dass Cx43-GFP mit 71,3 kDa ebenfalls erst mit höheren Imidazolkonzentrationen eluiert werden konnte. Oberhalb und unterhalb der Bande von Cx43-GFP ist wahrscheinlich ein Dimer bzw. proteolytischer Abbau zu sehen. 


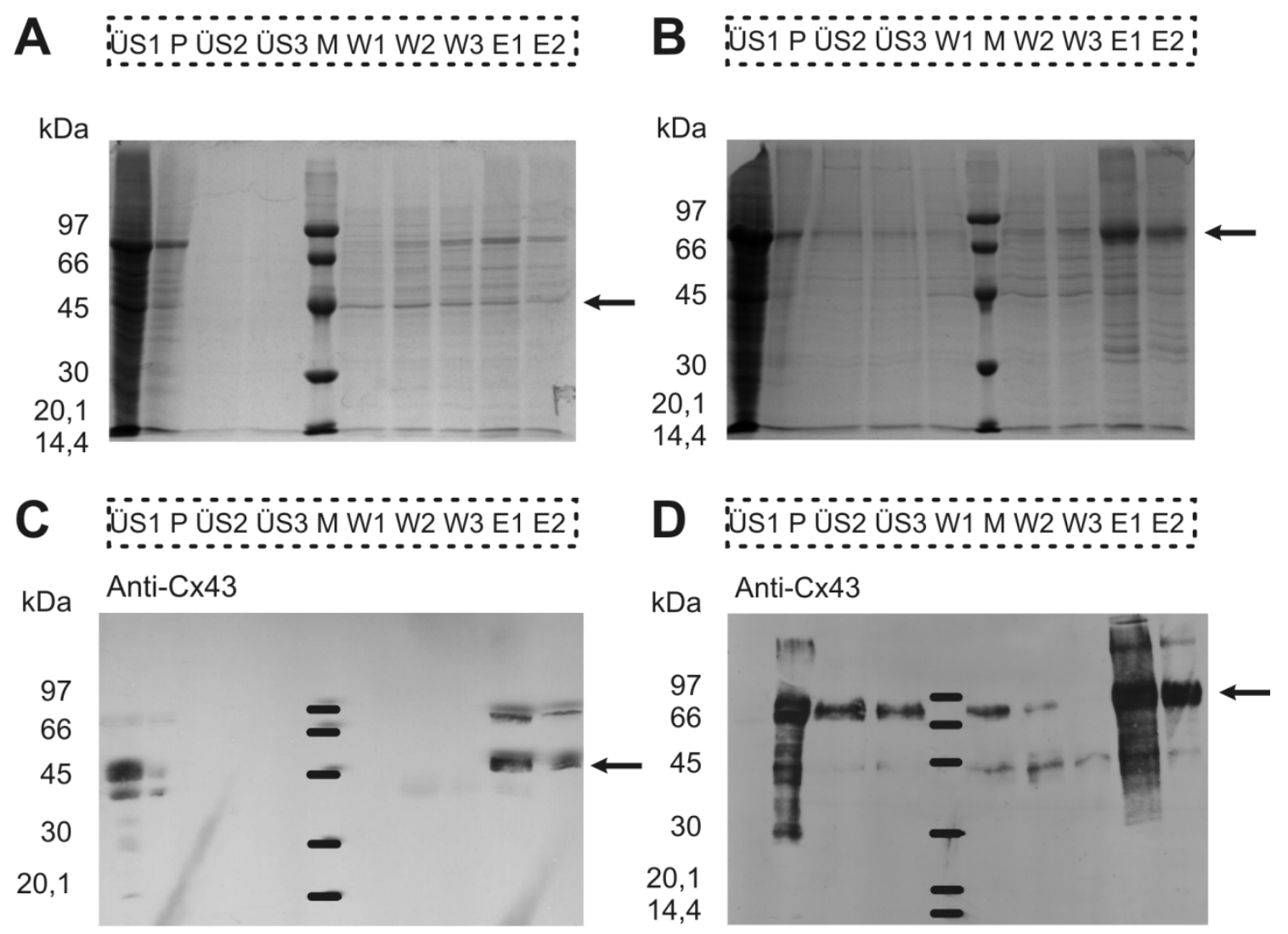

Abb. 4-14: Reinigung von Cx43 und Cx43-GFP exprimiert in P. pastoris nach Bao et al. Die einzelnen Schritte der Affinitätsreinigung von Cx43 wurden durch SDS-PAGE $(A)$ sowie Western Blot $(\boldsymbol{C})$ analysiert. Die Untersuchung mit dem spezifischen Antikörper gegen Cx43 zeigte, dass Cx43 (bei etwa $45 \mathrm{kDa}$, Pfeil) durch 0,3 bzw. $1 \mathrm{M}$ Imidazol (E1, E2) eluiert werden konnte. Auch der Überstand der Alkaliextraktion (ÜS1) enthielt Cx43. Die Analyse der Reinigung von Cx43-GFP durch ein Coomassie SDS-PAGE Gel $(\boldsymbol{B})$ und Western Blot $(\boldsymbol{D})$ zeigt, dass Cx43-GFP (bei etwa 71 $\mathrm{kDa}$, Pfeil) ebenfalls mithilfe dieser Methode gereinigt werden konnte. ÜS1-Überstand der Alkaliextraktion, P-Pellet der Solubilisierung, ÜS2, ÜS3-Überstand der Ni-NTA-Agarose, W1 bis W3-Waschschritte der Reinigung, E1, E2-Elution mit 0,3 und $1 \mathrm{M}$ Imidazol.

Nach der Dialyse der Elutionsfraktionen gegen den Elutionspuffer ohne Imidazol wurden Absorptionsspektren im Bereich von 240 bis $340 \mathrm{~nm}$ für Cx43 und im Bereich 240 bis 540 nm für Cx43-GFP aufgenommen (Abb. 4-15). Hier konnte ebenfalls mit Gl. 3-1 die Konzentration von Cx43 bzw. Cx43-GFP durch die Absorption bei $280 \mathrm{~nm}$ mit 3,6 $\mu \mathrm{M}$ für E1 und 1,6 $\mu \mathrm{M}$ für E2 bzw. 4,0 $\mu \mathrm{M}$ für E1 und 9,1 $\mu \mathrm{M}$ für E2 sowie die Konzentration von GFP durch die Absorption bei $489 \mathrm{~nm}$ mit 1,4 $\mu \mathrm{M}$ für E1 und 3,3 $\mu \mathrm{M}$ für E2 berechnet werden (Tab. 4-1). Das Spektrum von Cx43-GFP in Abb. 4-15 im Vergleich zu Abb. 4-13 zeigt, dass das Verhältnis $A_{489} \mathrm{zu} A_{280}$ die Konzentration an GFP in der Elutionsfraktion höher ist. 


\section{A}

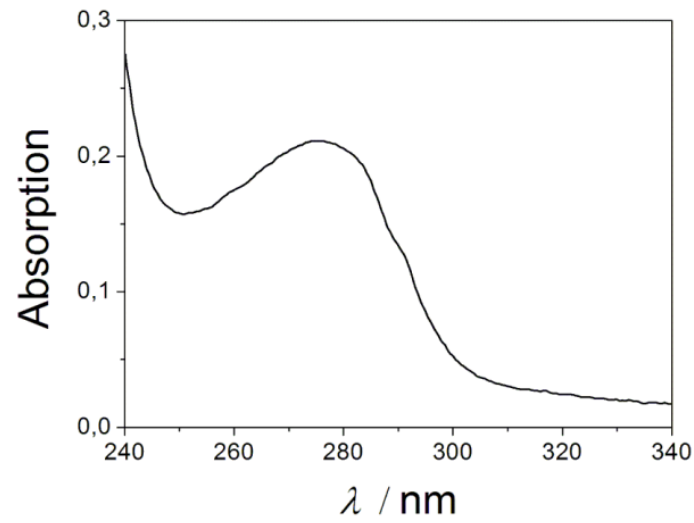

B

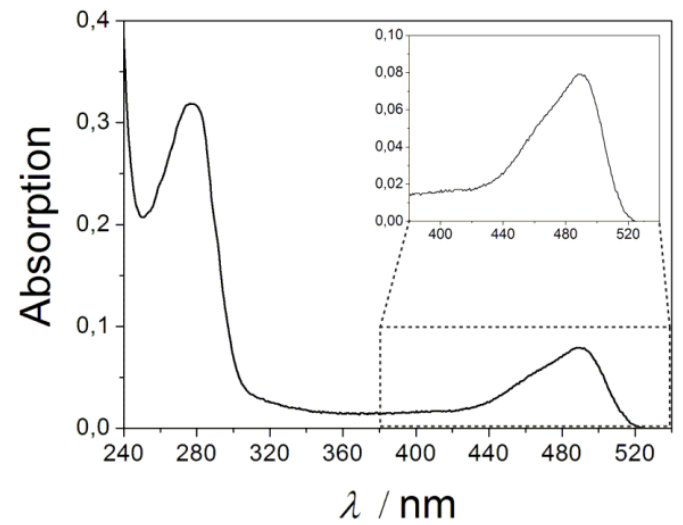

Abb. 4-15: Absorptionsspektren der dialysierten Elutionsfraktionen (E1) von Cx43 in $A$ und Cx43-GFP in $B$. Die Konzentrationen sind in Tab. 4-1 zusammengefasst. Der Bereich zwischen $380 \mathrm{~nm}$ bis $540 \mathrm{~nm}$ ist vergrößert, da in diesem Bereich GFP absorbiert.

Exemplarische Konzentrationen für Cx43 und Cx43-GFP, die durch die Reinigung nach Atsu bzw. Bao et al. für die 2. Fermentationscharge erreicht werden konnten, sind in Tab. 4-1 zusammengefasst. ${ }^{[123]}$ Zunächst scheint es, dass mit der Reinigung nach Bao et al. geringere Proteinausbeuten erreicht werden konnten. Unter Berücksichtigung der Absorption der Konzentration des GFP wird deutlich, dass die Proteinkonzentration sowie die Reinheit deutlich zunehmen. Die Proteinkonzentration wird bei der Reinigung nach Atsu durch den hohen Fremdproteinanteil verfälscht. 
Tab. 4-1: Übersicht der erzielten Konzentrationen an Cx43 und Cx43-GFP durch die Reinigung nach Atsu und nach Bao et al. bestimmt über die Absorption bei $280 \mathrm{~nm}$ bzw. $489 \mathrm{~nm}$. Für die aufgeführten Isolierungen wurden 0,6 g Membranfragmente eingesetzt, bis auf die Isolierung nach Atsu für Cx43 (1,2 g). E1 und E2 bezeichnet die Elutionsfraktion.

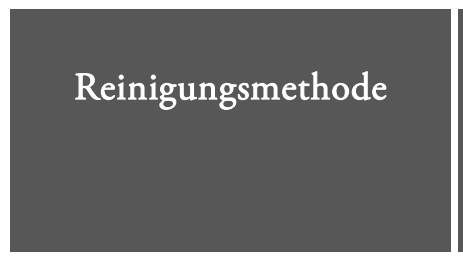

Atsu

Bao et $a^{[123]}$

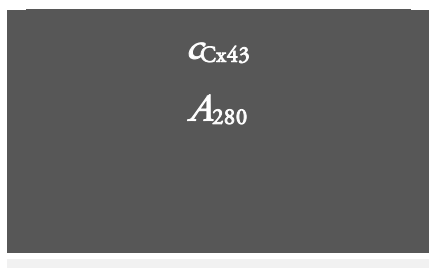

$21,0 \mu \mathrm{M}$

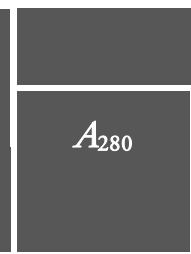

$15,5 \mu \mathrm{M}$
C.x43-GFP

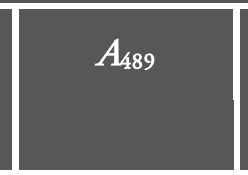

$0,5 \mu \mathrm{M}$

E1

$3: 1$

E1

E2

9,1 $\mu \mathrm{M}$

E2

$3: 1$

$3,3 \mu \mathrm{M}$
Verhältnis

$C_{\mathrm{C} \times 43} \mathrm{ZU}$ CGFP

$31: 1$

\section{4,0 $\mu \mathrm{M}$ \\ 3,6 $\mu \mathrm{M}$ \\ $1,6 \mu \mathrm{M}$ \\ $1,4 \mu \mathrm{M}$}

Tab. 4-2 gibt eine Übersicht über die erzielten Ausbeuten von Cx43 und Cx43-GFP pro Gramm Zellfeuchtmasse der P. pastoris Fermentationen. Hier wird besonders deutlich, dass die Ausbeute an Protein mit der Reinigung nach Bao et al. nicht gravierend abnimmt. Es zeigt nochmals, dass der Anteil an GFP mit dem isolierten Protein zunimmt und damit eine höhere Reinheit für Cx43-GFP erreicht werden konnte und vermutlich auch für Cx43.

Tab. 4-2: Übersicht der erzielten Ausbeute von Cx43 bzw. Cx43-GFP die pro Gramm Zellfeuchtmasse der $P$. pastoris Fermentation (2. Fermentationscharge) mit der jeweiligen Reinigungsmethode erreicht wurden.

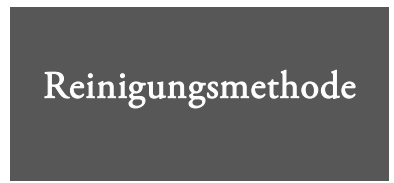

Atsu

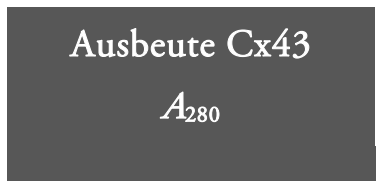

$40 \mu \mathrm{g} \cdot \mathrm{g}^{-1}$

Zellfeuchtmasse

Bao et al..$^{[123]}$
$20 \mu \mathrm{g} \cdot \mathrm{g}^{-1}$

Zellfeuchtmasse

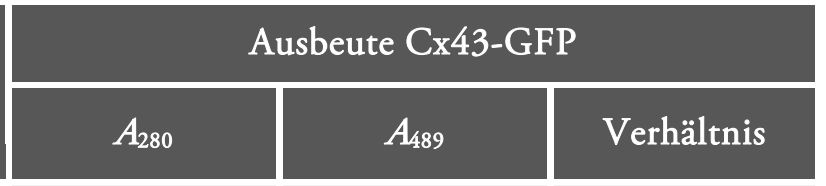

$100: 1$

Zellfeucht-

$0,8 \mu \mathrm{g} \cdot \mathrm{g}^{-1}$

Zellfeucht-

masse

$10 \mu \mathrm{g} \cdot \mathrm{g}^{-1}$

$7: 1$

Zellfeucht-

masse

Im Folgenden wird kurz erläutert, dass für die 1. Fermentationscharge (Bayer Technology Services, Leverkusen) bereits mit der Reinigung nach Bao et al. gearbeitet wurde, bei der die 
Alkaliextration nicht verwendet wurde. Außerdem wurde die Affinitätsreinigung im Säulenkörper mit Ni-NTA-Agarose bei konstanten $4{ }^{\circ} \mathrm{C}$ durchgeführt. Im Gegensatz dazu wurden für die 2. Fermentationscharge (Göttingen) die beiden beschriebenen Reinigungen verwendet. Die Prozeduren wurden nur zum Teil auf Eis durchgeführt und die Ni-NTA-Agarose lag in Suspension vor. Die Auswirkungen dieses Vorgehens werden in der Diskussion näher analysiert.

\section{1.2.4 Identifizierung von Cx43 und Cx43-GFP via Massenspektrometrie}

Für die weitere Charakterisierung der isolierten Proteine wurde die Massenspektrometrie eingesetzt. Dafür wurden Cx43 und Cx43-GFP elektrophoretisch durch SDS-PAGE aufgetrennt und die durch Western Blot Analyse identifizierten Banden ausgeschnitten. Anschließend wurde nach Shevchenko et al. ein In Gel Verdau der Proteine durchgeführt und anschließend die Peptide aus dem Gel extrahiert (Kapitel 3.1.7). ${ }^{[136]}$ Zur Überführung der Proteinionen in die Gasphase wurde die Elektrospray Ionisierung (ESI) genutzt und anschließend mittels Flüssigkeitschromatografie gekoppelt mit Massenspektrometrie (Liquid Chromatography/Mass Spectrometry, LC/MS2) analysiert. Diese massenspektrometrischen Untersuchungen wurden von Dr. Oliver Valerius (Institut für Mikrobiologie und Genetik, Universität Göttingen) durchgeführt. Mit der Analyse durch LC/MS2 konnten Cx43 sowie GFP nachgewiesen werden. In Abb. 4-12 und B sowie in Abb. 4-14 A und B ist zwischen 66 und $97 \mathrm{kDa}$ eine starke Bande zu sehen, die sowohl bei der Isolierung von Cx43 als auch bei Cx43-GFP wiederzufinden ist. Das Protein konnte mittels LC/MS2 als Alkoholoxidase aus P. pastoris identifiziert werden. Die Alkoholoxidase wurde während der Induktion der Proteinexpression mit Methanol coexprimiert und kann bis zu $30 \%$ des löslichen Gesamtproteins ausmachen. Diese setzt sich aus acht identischen Untereinheiten, mit einem Molekulargewicht von etwa $79 \mathrm{kDa}$ pro Monomer, zusammen. ${ }^{[187,188]}$ Zur Identifizierung von Cx43 wurde ebenfalls LC/MS2 durchgeführt, aber erst mit der fünffachen Konzentrierung konnte ein Cx43-Peptid nachgewiesen werden. 


\subsection{Rekonstitution von Cx43 und Cx43-GFP in artifiziellen Mem- branen}

In dieser Arbeit wurden drei verschiedene Methoden zur Rekonstitution und zwei verschiedene artifizielle Membransysteme zur Studie von Cx43 und Cx43-GFP verwendet. Diese werden im Folgenden näher vorgestellt. Die Integration in kleine unilamellare Vesikel (Small Unilamellar Vesicles, SUVs) ist intensiv untersucht und charakterisiert, aber die Rekonstitution von Membranproteinen in Riesenvesikel (Giant Unilamellar Vesicles, GUVs) für bspw. elektrophysiologische oder fluoreszenzmikroskopische Untersuchungen (Kapitel $4.3,4.5)$ stellt immer noch eine Herausforderung dar.

\subsubsection{Rekonstitution durch spontane Integration}

Zur Rekonstitution von Cx43 bzw. Cx43-GFP in GUVs wurde u. a. die direkte Integration aus der Detergensmizelle in GUVs verwendet. Diese Methode wird häufig verwendet um geringe Proteinkonzentrationen in artifizielle Membransysteme wie bspw. Vesikel oder porenüberspannende Membranen zu überführen. ${ }^{[72,189]}$ Dabei wird die Rekonstitution durch geringe Konzentrationen amphipathischer Verbindungen wie Detergenzien, Cholesterol, kurzkettige Phosphatidylcholine, Fettsäuren oder auch Lysoderivate, die eine Fettsäure weniger besitzen, unterstützt. Ein wesentlicher Vorteil dieser Methode ist, dass das Protein nach der Rekonstitution eine unidirektionale Orientierung aufweist. ${ }^{[162]}$ Für die Rekonstitution durch spontane Integration wurden zunächst GUVs durch Elektroformation hergestellt (Kapitel 3.5.3). Dafür wurde die Lipidmischung, welche sich aus den Lipiden DPhPC und Cholesterol im molaren Verhältnis 9 zu 1 zusammensetzt (Kapitel 3.5.4), auf Indiumzinnoxid (ITO)-beschichteten Objektträgern eingetrocknet. Die Kammer, bestehend aus den Objektträgern und einem Abstandshalter, wurde mit $1 \mathrm{M}$ Sorbitollösung befüllt und für zwei Stunden ein Wechselfeld zur Bildung der GUVs appliziert (Kapitel 3.5.3). Anschließend wurde die Lösung mit Proteinlösung, welche eine Endkonzentration von $10 \mathrm{ng} \cdot \mathrm{mL}^{-1}$ und $0,2 \% \mathrm{DDM}$ enthielt, versetzt und für $20 \mathrm{~min}$ inkubiert (Kapitel 3.5.5). Schließlich wurde die Lösung für vier Stunden mit hydrophoben Polystyrenkugel (BioBeads $^{\text {TM }}$ SM-2) zur Entfernung des Detergens versetzt. Zur Überprüfung der funktionellen Integration von Cx43 und Cx43-GFP wurde eine elektrophysiologische Studie mithilfe des Planar Patch Clamp Systems Port-a-Patch ${ }^{\circledast}$ (Firma Nanion Technologies 
GmbH) durchgeführt. Ein Nachteil im Vergleich zu den beiden Methoden die in Kapitel 4.2.2 und 4.2.3 behandelt werden ist, dass es durch die Zugabe der Proteinlösung zur GUV-Lösung zur plötzlichen Verdünnung des Detergens kommt. Weiterhin kommt die Konzentration des Detergens unter die kritischen Mizellenbildungskonzentration (Critical Micellar Concentration, CMC). Dies hat zur Folge, dass es neben der Integration von Membranproteinen in die Lipidmembran auch zur Aggregation von Connexonen kommt.

Hinsichtlich der Integration von Membranproteinen zur ihrer funktionellen Charakterisierung ist diese Methode besonders geeignet, da auf diesem Weg je nach gewählter Konzentration nur geringe Mengen in Vesikel integriert werden. Die elektrophysiologische Charakterisierung von Ionenkanälen erfordert zur Bestimmung der Leitfähigkeit, Öffnungsdauer sowie Öffnungswahrscheinlichkeit Einzelkanalereignisse. Die nachfolgenden Methoden sind dagegen auch zur Integration von höheren Proteinkonzentrationen geeignet.

\subsubsection{Bildung von proteinhaltigen Riesenvesikeln nach partieller Dehydratisierung}

Eine Methode zur Integration hoher Proteinkonzentrationen wurde durch Girard et al. und Streicher et al. vorgestellt. ${ }^{[166,167]}$ Grundlage für diese Methode ist die häufig verwendete und gut charakterisierte Detergens-vermittelte Rekonstitution. Üblicherweise werden zunächst gemischte, binäre Lipid-Detergens-Mizellen hergestellt. Dazu wird das solubilisierte Membranprotein gegeben, sodass sowohl binäre als auch ternäre, gemischte Mizellen vorliegen, die sowohl Protein als auch Detergens- und Lipidmoleküle enthalten. Im nächsten Schritt wird das Detergens der Lösung entzogen, dies führt in einem Selbstorganisationsprozess zur Bildung von SUVs, welche integrierte Proteine enthalten. Während der Entfernung des Detergens kommt es zur sequenziellen Aggregation der Mizellen, um die energetisch ungünstige Exposition von hydrophoben Molekülregionen zum wässrigen Medium zu minimieren. ${ }^{[190]}$ Anschließend wird die Lösung mit proteinhaltigen SUVs in $1,5 \mu \mathrm{L}$ Tropfen auf Indiumzinnoxid-beschichtete Objektträger gegeben und im Exsikkator mithilfe einer gesättigten Natriumchloridlösung partiell dehydratisiert. Nachfolgend wurde ähnlich wie zuvor die gebildete Kammer mit 0,3 M Saccharoselösung gefüllt und ein elektrisches Wechselfeld zur Bildung von proteinhaltigen Riesenvesikeln (Proteo-GUVs) durch Elektroswelling appliziert (Kapitel 3.5.5). Diese Methode wurde bereits erfolgreich für Membranproteine wie die sarkoplasmatische Retikulum $\mathrm{Ca}^{2+}$-ATPase, Bakteriorhodopsin, 
das Integrin $\alpha_{\mathrm{IIb}} \beta_{3}$ und den Kaliumkanal KvAP eingesetzt. ${ }^{[166,167,191]}$ Für die Präparation der proteinhaltigen SUVs wurde eine Proteinkonzentration von $96 \mathrm{bis} 3 \mu \mathrm{g} \cdot \mathrm{mL}^{-1}$ bei einer Lipidkonzentration von $2 \mathrm{mg} \cdot \mathrm{mL}^{-1}$ verwendet. Für die Rekonstitution wurde das Detergens $n$ OG verwendet, da es sich besonders für die Herstellung von Proteo-SUVs eignet und aufgrund einer CMC von $25 \mathrm{mM}(0,73 \%)$ relativ einfach durch Dialyse oder hydrophobe Matrizes entzogen werden kann. ${ }^{[192]}$ Außerdem fördert $n$ OG die Oligomerdissoziation und die Insertion von Proteinen als Monomer. ${ }^{[162]}$ Nach 30-minütiger Inkubation zur Bildung gemischter Mizellen wurde das Detergens mithilfe von hydrophoben Polystyrolkugeln für zwei Stunden entzogen. Das restliche Detergens wurde durch eine erneute Inkubation mit Polystyrolkugeln über Nacht adsorbiert. Abb. 4-16 zeigt exemplarisch fluoreszenzmikroskopische Aufnahmen eines unilamellaren sowie eines multilamellaren Riesenvesikels mit integriertem Cx43-GFP. Die Membranlokalisation des Cx43-GFP ist deutlich anhand der grünen Fluoreszenz zu erkennen.
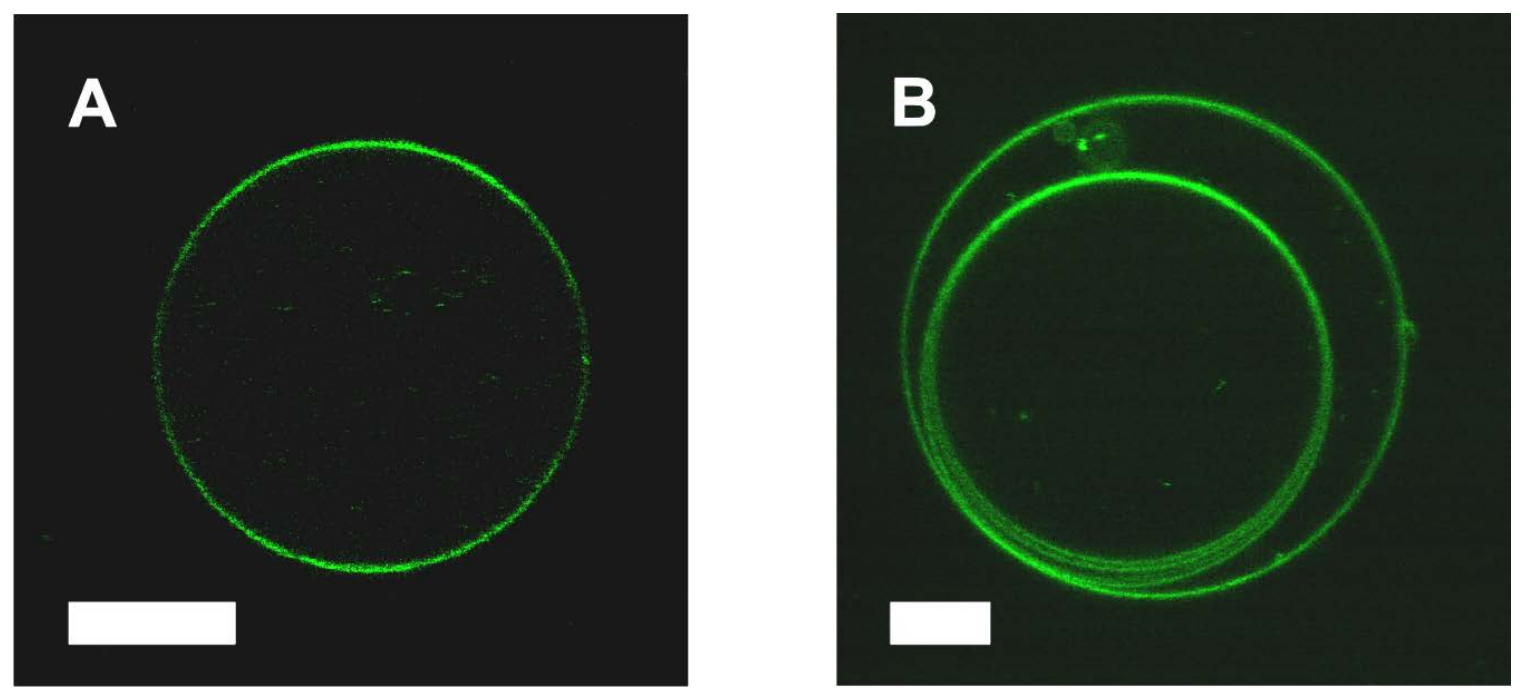

Abb. 4-16: POPC Riesenvesikel mit Cx43-GFP (grüne Fluoreszenz) aus $P$. pastoris. $A$, Proteo-GUV hergestellt durch Elektroformation (Proteo-SUVs: $96 \mu \mathrm{g} \cdot \mathrm{mL}^{-1}, 2 \mathrm{mg} \cdot \mathrm{mL}^{-1}$ POPC). B, Multilamellarer proteinhaltiger Riesenvesikel (Proteo-SUVs: $96 \mu \mathrm{g} \cdot \mathrm{mL}^{-1}, 2 \mathrm{mg} \cdot \mathrm{mL}^{-1}$ POPC). PBS-Puffer: $136,9 \mathrm{mM}$ $\mathrm{NaCl}, 2,7 \mathrm{mM} \mathrm{KCl}, 8,1 \mathrm{mM} \mathrm{Na}_{2} \mathrm{HPO}_{4}, \mathrm{pH}$ 7,4, Maßstab: $10 \mu \mathrm{m}$.

Der Nachteil dieser Methode ist, dass der Entzug von Wasser zur Aggregation der Proteine führen kann. Dieser Effekt könnte für sehr robuste Proteine wie Bakteriorhodopsin keine Rolle spielen, aber Proteine aus eukaryotischen Systemen reagieren empfindlicher auf Bedingungen, welche nicht ihrer natürlichen Umgebung entsprechen. Zusätzlich kam es während der Elektroformation sowohl zur Bildung von multilamellaren Vesikeln als auch zur Aggregation der Vesikel untereinander. Für die Bildung von porenüberspannenden Mem- 
branen werden unilamellare Riesenvesikel benötigt, da multilamellare Riesenvesikel durch die Interaktion der unterschiedlichen Lipiddoppelschichten ein abweichendes Spreitverhalten zeigen. Weiter würde auch die Aggregation der Vesikel untereinander dazu führen, dass die Vesikel nicht spreiten. Zu Beginn der Arbeit konnte Cx43-GFP erfolgreich auf diesem Weg in GUVs integriert werden. Dieses Protein stammte aus der ersten Fermentationscharge von P. pastoris Cx43-GFP. Mit der zweiten Fermentationscharge von P.pastoris Cx43-GFP konnte diese Methode nicht erfolgreich angewendet werden.

\subsubsection{Fusionsvermittelte Rekonstitution}

Als dritte Methode wurde die fusionsvermittelte Rekonstitution modifiziert nach Martinac et al. eingesetzt. ${ }^{[168]}$ Zunächst wurde auch hier das solubilisierte Cx43 bzw. Cx43-GFP mit binären Lipid-Detergens-Mizellen in $2 \mathrm{mM} \mathrm{KCl}, 1 \mathrm{mM} \mathrm{MOPS/TRIS}$, pH 8,0 versetzt, um anschließend durch die Zugabe von Polystyrolkugeln das Detergens nOG zu entziehen. Durch den Entzug des Detergens entstehen Proteo-SUVs mit einem Durchmesser von 100 bis $200 \mathrm{~nm}$. Im nächsten Schritt wurde für die Präparation der Proteo-GUVs eine Lipidstammlösung (2 bis $3 \mathrm{mg} \cdot \mathrm{mL}^{-1}$ ) auf ITO-beschichtete Objektträger eingetrocknet und wie zuvor eine Elektroformationskammer mit $0,21 \mathrm{M}$ Sorbitollösung präpariert. Zur Sorbitollösung wurden bis zu $25 \mu \mathrm{L}$ Proteo-SUV-Lösung zugegeben und die Elektroformation nach Kapitel 3.5.3 mit dem schrittweisen Spannungsanstieg durchgeführt. Während des Elektroswellings kommt es durch die hohe Fusionstendenz von SUVs zur Integration der Proteine in die Lipidmembran der entstehenden GUVs. Die hohe Fusionstendenz ist auf die starke Membrankrümmung der SUVs zurückzuführen, welche durch Vesikelfusion abgebaut wird. ${ }^{[193]}$

Die Visualisierung von Cx43 wurde mithilfe eines fluoreszenzmarkierten Antikörpers verwirklicht. Cx43 besitzt zur Affinitätsreinigung mithilfe von Ni-NTA-Agarose einen $C$-terminalen Hexahistidin-Tag (Kapitel 4.1.2.3). Dieser kann durch den polyklonalen Antikörper, welcher an den Fluoreszenzfarbstoff Fluoresceinisothiocyanat (FITC, Kapitel 3.3.2) gebunden ist, erkannt werden. Durch die spezifische Bindung des Antikörpers an den $C$-Terminus von Cx43, kann die Lokalisierung des Proteins in der Lipidmembran nachgewiesen werden. Dazu wurde die Proteo-GUV-Lösung in PBS-Puffer (136,9 mM $\left.\mathrm{NaCl}, 2,7 \mathrm{mM} \mathrm{KCl}, 8,1 \mathrm{mM} \mathrm{Na} \mathrm{HPO}_{4}, \mathrm{pH} 7,4\right)$ im Verhältnis 1 zu 6 verdünnt und anschließend für zwei Stunden mit dem Anti-Hiss-Antikörper im Verhältnis 1 zu 250 
inkubiert. Proteo-GUVs mit rekonstituiertem Cx43 sind exemplarisch in Abb. 4-17 A dargestellt. Der Nachweis von Cx43-GFP erfolgte wieder über die intrinsische Fluoreszenz des GFP-Chromophors (Abb. 4-17 B).
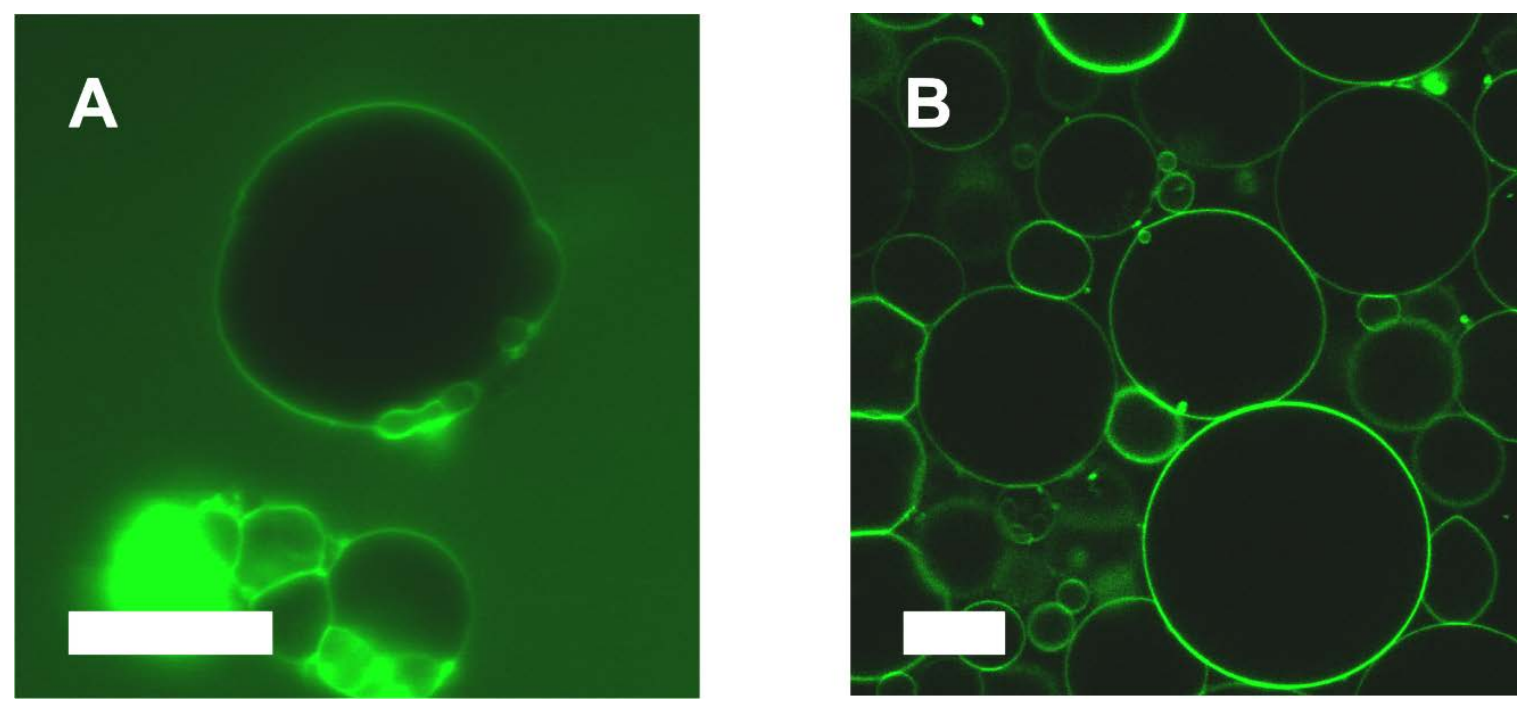

Abb. 4-17: Fusionsvermittelte Rekonstitution von Cx43 und Cx43-GFP in GUVs. Die ProteoGUVs wurden in PBS-Puffer $\left(136,9 \mathrm{mM} \mathrm{NaCl}, 2,7 \mathrm{mM} \mathrm{KCl}, 8,1 \mathrm{mM} \mathrm{Na}_{2} \mathrm{HPO}_{4}, \mathrm{pH} 7,4\right)$ verdünnt. $A$, Cx43 rekonstituiert in POPC GUVs (Proteo-SUVs: $22 \mu \mathrm{g} \cdot \mathrm{mL}^{-1} \mathrm{Cx} 43,2 \mathrm{mg} \cdot \mathrm{mL}^{-1}$ POPC). $B$, POPC GUVs mit integriertem Cx43-GFP. (Proteo-SUVs: $40 \mu \mathrm{g} \cdot \mathrm{mL}^{-1}$ Cx43-GFP, $2 \mathrm{mg} \cdot \mathrm{mL}^{-1}$ POPC). Maßstab: $20 \mu \mathrm{m}$.

Da die fusionsvermittelte Rekonstitution reproduzierbare Ergebnisse mit einheitlichen, unilamellaren Riesenvesikeln lieferte, wurden verschiedene Lipidzusammensetzungen sowie unterschiedliche Sorbitolkonzentrationen gestestet. Dafür wurden zunächst Proteo-SUVs mit Cx43-GFP mit einer Endkonzentration von $40 \mu \mathrm{g} \cdot \mathrm{mL}^{-1}$ und mit einer Lipidkonzentration von $2 \mathrm{mg} \cdot \mathrm{mL}^{-1}$ hergestellt. Es wurden zur Herstellung von GUVs Filme mit POPC sowie der Lipidzusammensetzung POPC und Cholesterol im molaren Verhältnis 8 zu 2 und DPhPC und DOPC im molaren Verhältnis $6 \mathrm{zu} 4$ auf ITO-beschichteten Objektträgern eingetrocknet. Danach wurde die Elektroformationskammer mit Rehydratisierungslösung gefüllt und mit $10 \mu \mathrm{L}$ der Proteo-SUV-Suspension versetzt. Für die POPC GUVs wurden für die Rehydratisierungslösung eine Konzentration von 0,21 und $1 \mathrm{M}$ Sorbitol getestet. Die Elektroformation wurde wie zuvor durchgeführt. Abb. 4-18 A \& B zeigt exemplarisch die Ergebnisse der Untersuchung von POPC GUVs mit integriertem Cx43-GFP, die mit unterschiedlichen Konzentrationen von Sorbitol als Rehydratisierungslösung hergestellt wurden. Mit 0,21 M Sorbitol konnten wie zuvor einheitliche GUVs erhalten werden. Ähnliche Ergebnisse lieferte ebenfalls die Elektroformation mit 1 M Sorbitol, jedoch wurden 
im Vergleich zu der niedrigeren Sorbitolkonzentration weniger Proteo-GUVs erhalten. Das Elektroswelling mit POPC und Cholesterol im Verhältnis 8 zu 2 ergab ebenfalls gute Ausbeuten mit einheitlichen GUVs, allerdings waren diese kleiner und bildeten untereinander Cluster (Abb. 4-18 C). Mit der Lipidmischung von DPhPC und DOPC konnten nur sehr geringe Ausbeuten an Proteo-GUVs erhalten werden (Abb. 4-18 D). Außerdem waren sie zum Teil multilamellar. Zusammenfassend zeigte sich, dass sich für die Integration von hohen Proteinkonzentrationen am besten die Verwendung des Lipids POPC sowie 0,21 M Sorbitol eignet. 

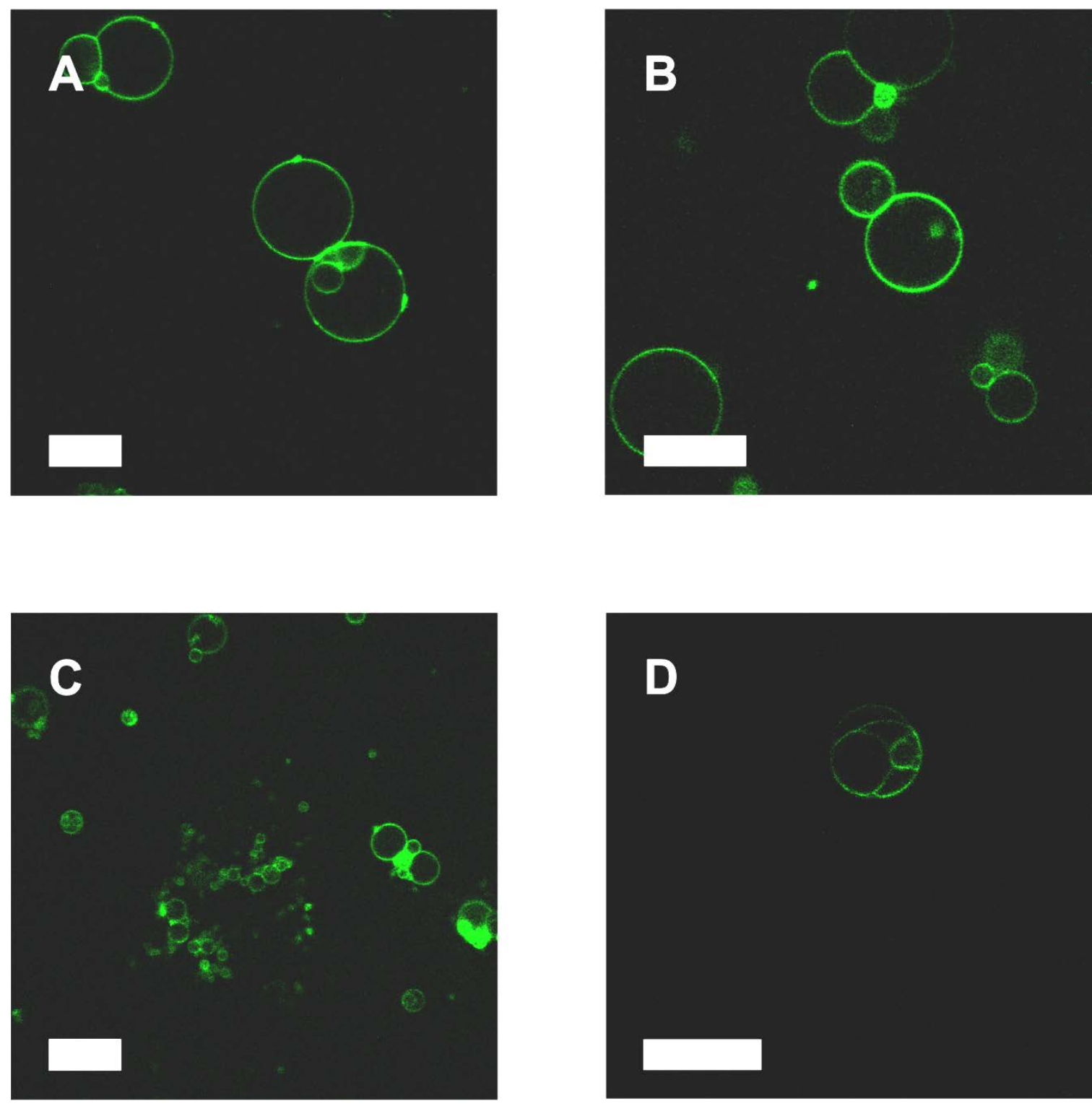

Abb. 4-18: Fluoreszenzmikroskopische Aufnahmen der Untersuchungen verschiedener Sorbitolkonzentrationen sowie Lipidzusammensetzungen für die Herstellung von GUVs mit Cx43-GFP. Für die Rekonstitution von Cx43-GFP in GUVs während der Elektroformation wurden $10 \mu \mathrm{L}$ ProteoSUVs mit einer Proteinkonzentration von $22 \mu \mathrm{g} \cdot \mathrm{mL}^{-1}\left(2 \mathrm{mg} \cdot \mathrm{mL}^{-1}\right.$ POPC) verwendet. Die fluoreszenzmikroskopischen Untersuchungen der Proteo-GUVs wurden in PBS-Puffer $\left(136,9 \mathrm{mM} \mathrm{NaCl}, 2,7 \mathrm{mM} \mathrm{KCl}, 8,1 \mathrm{mM} \mathrm{Na}_{2} \mathrm{HPO}_{4}, \mathrm{pH} 7,4\right)$ durchgeführt. $A$, POPC GUVs mit integriertem Cx43-GFP gefüllt mit $0,21 \mathrm{mM}$ Sorbitol. $\boldsymbol{B}$, POPC GUVs mit rekonstituiertem Cx43-GFP in $1 \mathrm{M}$ Sorbitol hergestellt. $C$, Cx43-GFP GUVs mit der Lipidzusammensetzung POPC und Cholesterol im molaren Verhältnis 8 zu 2 und gefüllt mit $210 \mathrm{mM}$ Sorbitol. $D$, Die dargestellten Proteo-GUVs wurden in $210 \mathrm{mM}$ Sorbitol mit den Lipiden DPhPC und DOPC im molaren Verhältnis $6 \mathrm{zu} 4$ hergestellt. Maßstab: $20 \mu \mathrm{m}$, 
Labeling von Cx43 mit Cy3 und Rekonstitution in GUVs

Neben dem indirekten Nachweis der Membranlokalisation von Cx43 mithilfe eines fluoreszenzmarkierten Antikörpers wurde Cx43 mit einem Fluoreszenzfarbstoff gekoppelt. Dies ermöglicht den direkten Nachweis von Cx43 in der Lipidmembran ähnlich wie bei Cx43-GFP. Zur Kopplung eines Fluoreszenzfarbstoffs an Cx43 wurden zwei Funktionalitäten in Betracht gezogen, Cystein und Lysin. Die Sequenz des Proteins enthält 32 Lysinund neun Cysteinreste (Abb. 1-6). Für eine spezifische Kopplung eines Fluoreszenzfarbstoffs eignet sich Cystein, da sechs von neun Cysteinresten als Cystin vorliegen. Für die Kopplung von Cx43 mit einem Fluoreszenzfarbstoff wurde das Cyanin Cy3 mit einer Maleimidgruppe verwendet. $\mathrm{Cy} 3$ zeichnet sich durch eine hohe Photostabilität aus. Die Maleimid-Funktion ermöglicht es direkt an Cysteinreste über eine Michael-Addition zu koppeln.

Damit eine möglichst hohe Kopplungsrate erreicht wird, wurde für die Kopplung von Cx43 (0,61 mg, 13,4 nmol) mit Cy3-Maleimid ein zehnfacher Überschuss des Farbstoffs eingesetzt. Nach Inkubation des Ansatzes unter Rühren über Nacht bei $4{ }^{\circ} \mathrm{C}$ wurde der freie Farbstoff von Cx43-Cy3 mithilfe einer Größenausschlusschromatografie (Size Exclusion Chromatography, SEC, Sephadex G 75) getrennt. In Abb. 4-19 A ist durch die Absorption bei $280 \mathrm{~nm}$, dem Absorptionsmaximum von Cx43, und $552 \mathrm{~nm}$, dem Absorptionsmaximum von $\mathrm{Cy} 3$, eine deutliche Trennung zwischen Cx43-Cy3, welches aufgrund des höheren Molekulargewichts zuerst eluiert, und freiem Farbstoff zu sehen. Die Auswertung der Absorption bei $280 \mathrm{~nm}$ und $552 \mathrm{~nm}\left(A_{\max }\right.$ von Cy3) ergab, dass in der Hauptfraktion 10 8,4 \% des Proteins mit Cy3 verknüpft werden konnte. Im nächsten Schritt wurde Cx43-Cy3 mit $10 \mu \mathrm{g} \cdot \mathrm{mL}^{-1}$ in SUVs wie zuvor rekonstituiert und anschließend durch Fusion in POPC GUVs integriert. Abb. 4-19 B zeigt eine fluoreszenzmikroskopische Aufnahme der POPC GUVs mit integriertem Cx43-Cy3 mit einer roten Fluoreszenz. 

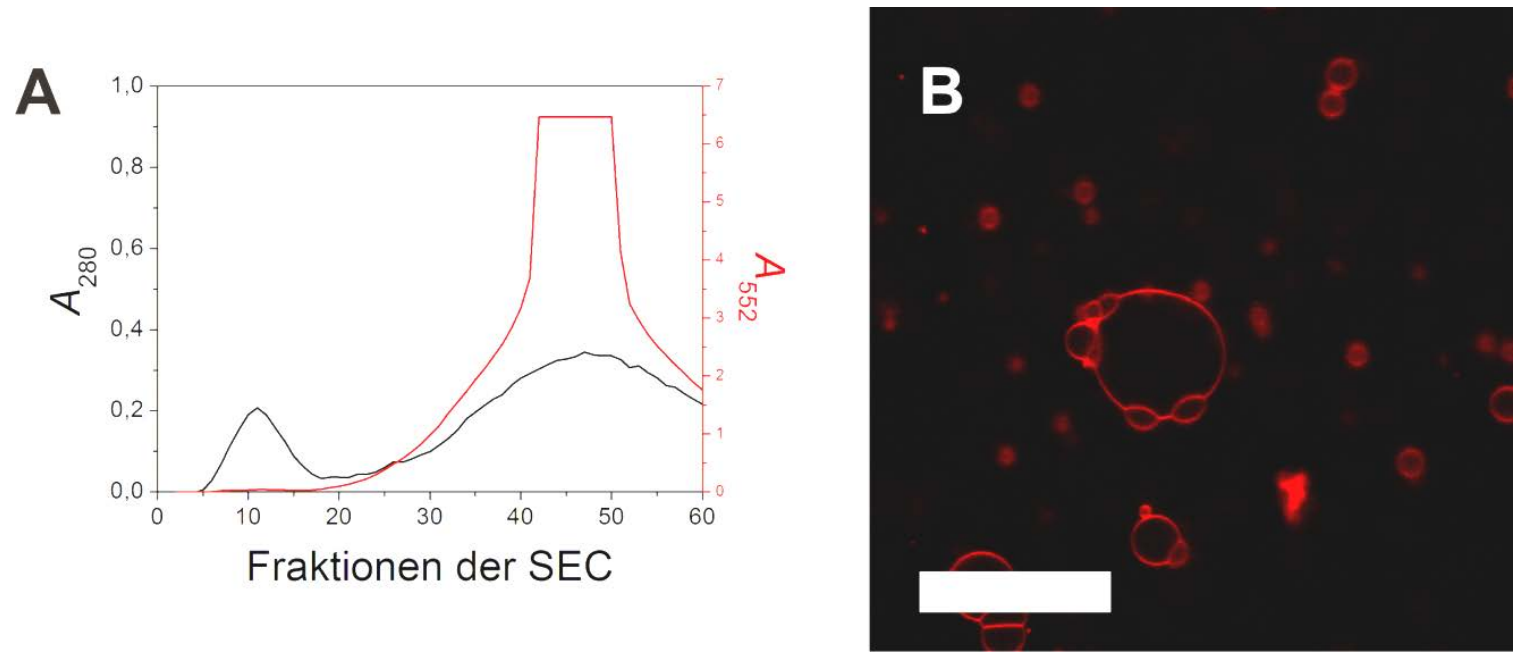

Abb. 4-19: Labeling von Cx43 (13,4 nmol) mit Cy3-Maleimid. A, Absorption der Fraktionen der Größenausschlusschromatografie bei $280 \mathrm{~nm}(-)$ und $552 \mathrm{~nm}(-)$. Die Absorptionen bei $280 \mathrm{~nm}$ und $552 \mathrm{~nm}$ zeigen, dass Cx43-Cy3 in Fraktion 7 bis 16 vom freien Farbstoff Cy3 beginnend mit Fraktion 20 getrennt werden konnte. Die Absorption bei $552 \mathrm{~nm}$ endet bei 6,5, da hier das Detektorlimit erreicht wurde. $\boldsymbol{B}$, Fluoreszenzmikroskopische Aufnahme von Cx43-Cy3 rekonstituiert in POPC GUVs. Zur Rekonstitution wurde $10 \mu \mathrm{g} \cdot \mathrm{mL}^{-1}$ Protein für die Herstellung von Proteo-SUVs $\left(2 \mathrm{mg} \cdot \mathrm{mL}^{-1}\right)$ eingesetzt. Die Herstellung der Proteo-SUVs erfolgte mit $40 \mu \mathrm{L}$ der Proteo-SUV-Lösung. Die Proteo-GUVs wurden in PBS-Puffer $(136,9 \mathrm{mM} \mathrm{NaCl}, 2,7 \mathrm{mM} \mathrm{KCl}$, $\left.8,1 \mathrm{mM} \mathrm{Na} 2 \mathrm{HPO}_{4}, \mathrm{pH} 7,4\right)$ verdünnt. Maßstab: $30 \mu \mathrm{m}$.

\section{Variierende Rekonstitutionseffizienz abhängig von der Fermentationscharge}

Die vorangegangenen Rekonstitutionsexperimente zeigen, dass Cx43 und Cx43-GFP, welches aus den Fermentationen von Bayer Technology Services (1. Fermentationscharge) stammt, in hohen Konzentrationen in SUVs und nachfolgend in GUVs rekonstituiert werden konnte. Nach erfolgreicher Etablierung der Fermentation von P. pastoris Cx43 bzw. Cx43-GFP (2. Fermentationscharge) in der vorliegenden Arbeit (Kapitel 4.1.2.1) und der Reinigung nach Atsu bzw. Bao et al. (Kapitel 4.1.2.3) wurde getestet, ob beide Proteine wie zuvor mit der vorgestellten Methode rekonstituiert werden können. ${ }^{[123]}$ Für die Integration in SUVs wurde ein Konzentrationsbereich von $130 \mathrm{ng} \cdot \mathrm{mL}^{-1}$ bis $187 \mu \mathrm{g} \cdot \mathrm{mL}^{-1}$ für Cx43-GFP analysiert. Cx43-GFP wurde aufgrund der direkten Nachweisbarkeit der GFP-Fluoreszenz für die nachfolgenden Untersuchungen genutzt. Bis auf wenige Ausnahmen konnte nach der Integration in GUVs durch konfokale Laserrastermikroskopie keine ausreichende Fluoreszenz des GFP-Chromophors detektiert werden (Abb. 4-20 A). Außerdem konnte fluoreszenzmikroskopisch in den präparierten Proteo-SUV-Lösungen häufig die Bildung von größeren Aggregaten von Protein oder Vesikeln beobachtet werden (Abb. 4-20 B). Die 
Verwendung von negativ geladenen Lipiden konnte die Aggregation nicht verhindern.

Dieses Phänomen trat während der Proteo-SUV-Präparation der 1. Fermentationscharge nicht auf. Die nachfolgenden elektrophysiologischen Studien von Cx43-GFP (2. Charge) zeigten, dass funktionales Protein in die GUVs integriert werden konnte (Kapitel 4.3). Außerdem konnten in Kooperation mit der Arbeitsgruppe von Prof. Dr. Gina Sosinsky (UCSD, CA, USA) durch Transmissionselektronenmikroskopie geringe Konzentrationen von Cx43- und Cx43-GFP-Halbkanälen in Proteo-SUVs nachgewiesen werden.
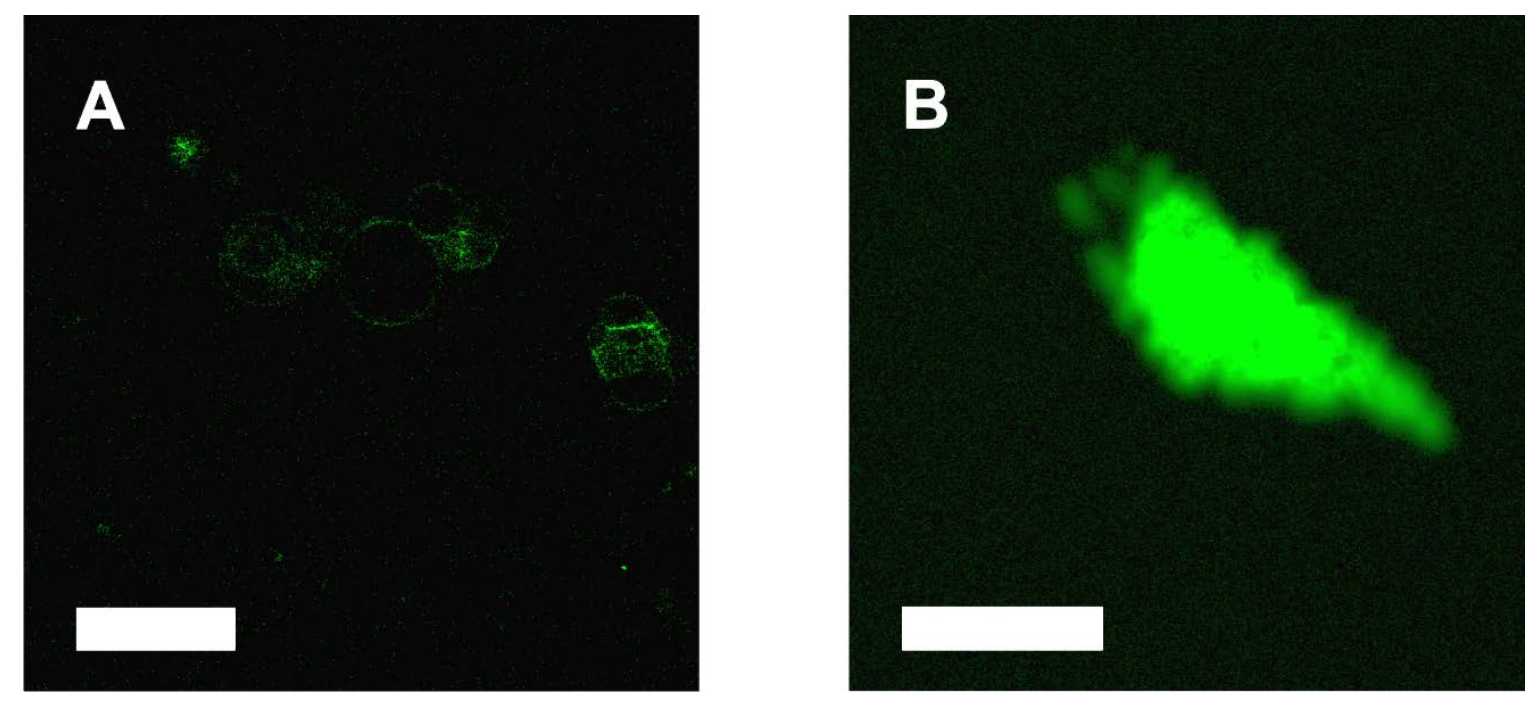

Abb. 4-20: Fluoreszenzmikroskopische Aufnahmen der Rekonstitution von Cx43-GFP in POPC GUVs und SUVs. Die Proteo-GUVs und -SUVs wurden in PBS-Puffer $(136,9 \mathrm{mM} \mathrm{NaCl}$, 2,7 mM KCl, 8,1 $\mathrm{mM} \mathrm{Na}_{2} \mathrm{HPO}_{4}$, pH 7,4) verdünnt. $A$, Die Untersuchung der Proteo-GUVs zeigte, dass es nur vereinzelt zur Integration von Protein in die Lipidmembran der GUVs kam (ProteoSUVs: $44 \mu \mathrm{g} \cdot \mathrm{mL}^{-1} \mathrm{Cx} 43-\mathrm{GFP}, 2 \mathrm{mg} \cdot \mathrm{mL}^{-1}$ POPC). $B$, Exemplarische Darstellung der Aggregate, die nach der Rekonstitution von Cx43-GFP in SUVs beobachtet werden konnten. Maßstab: $40 \mu \mathrm{m}$

Obwohl keine hohen Proteinintegrationsraten mehr erreicht wurden, zeigte die Untersuchung durch Transmissionselektronenmikroskopie, dass zumindest ein Teil des Proteins in die gebildeten SUVs integriert wurde. Daraus wurde mit den Ergebnissen der elektrophysiologischen Studien (Kapitel 4.3) geschlossen, dass ebenfalls Protein in die GUVs integriert wurde. Die gebildeten Proteo-GUVs wurden für weiterführende fluoreszenzmikroskopische Studien zur Untersuchung der Halb- und Gap Junction Kanalaktivität, welche im Kapitel 4.5 näher erläutert werden, eingesetzt. 


\subsection{Elektrophysiologische Charakterisierung von Cx43 und Cx43- GFP}

In Kapitel 4.1.2 konnte gezeigt werden, dass durch die heterologe Proteinexpression in Pichia pastoris hohe Proteinkonzentrationen erreicht und durch immobilisierte Metallchelataffinitätschromatografie isoliert werden konnten. Durch die Integration in artifizielle Membranen wurden die Proteine in eine naturähnliche Umgebung überführt und sind damit einer elektrophysiologischen Messung durch Planar Patch Clamp zugänglich. Wie Abb. 4-21 zeigt, kehrt dies die konventionelle Patch Clamp Methode um. Anstelle einer Mikropipette wird ein Borsilikatchip mit einer Apertur von 1 bis $3 \mu \mathrm{m}$ verwendet. Zunächst wurde auf beide Seiten des Glaschips $6 \mu \mathrm{L}$ Messpuffer (200 mM KCl, 2 mM EDTA, 10 mM HEPES) aufgegeben und das cis- und trans-Kompartiment elektrisch kontaktiert. Anschließend wurden zum oberen Reservoir proteinhaltige Riesenvesikel (Proteo-Giant Unilamellar Vesicles, Proteo-GUVs, siehe Kapitel 4.2) gegeben und diese mithilfe eines Unterdrucks auf dem Glaschip gespreitet. Durch das Spreiten bildet sich über der Apertur eine elektrisch-dichte Lipidmembran mit einem Membranwiderstand $R_{\mathrm{m}}>1 \mathrm{G} \Omega$.
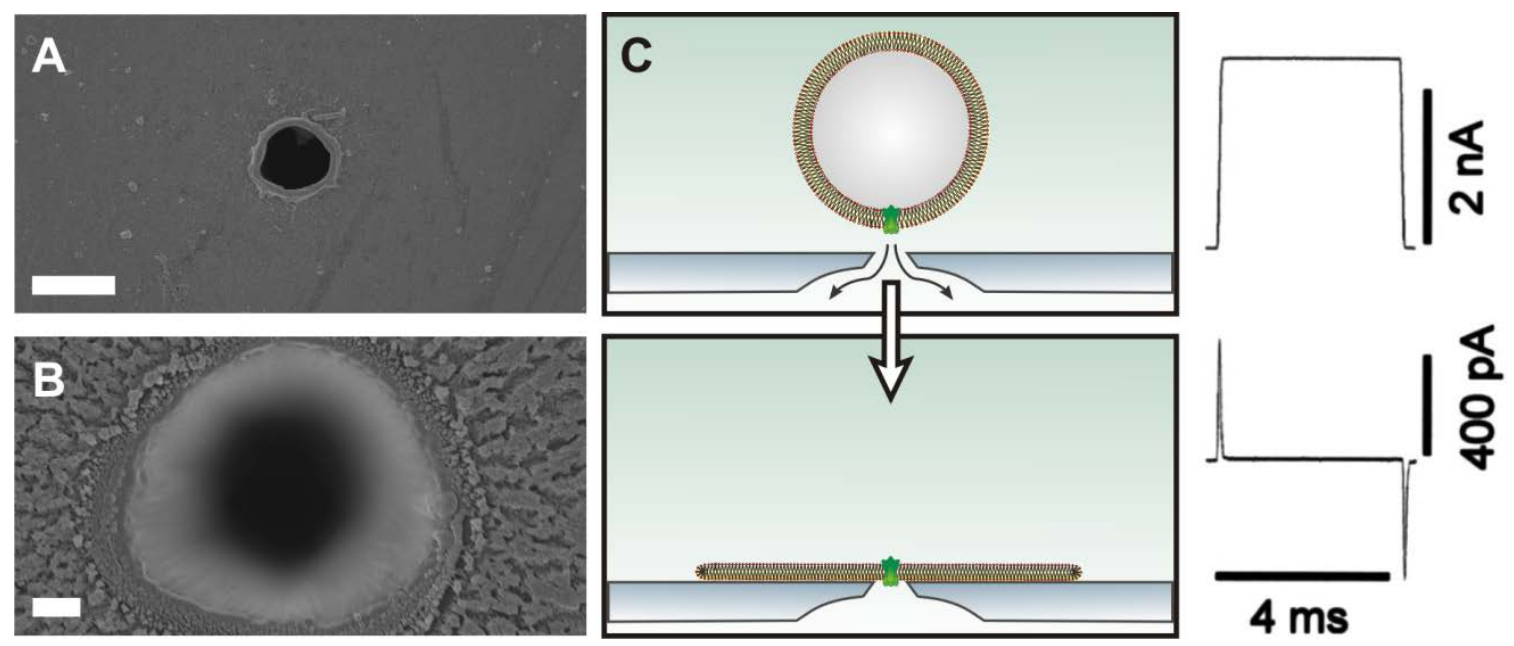

Abb. 4-21: Planar Patch Clamp System Port-a-Patch ${ }^{\circ}$ A \& B, Rasterelektronenmikroskopische Aufnahme der Oberseite bzw. Unterseite des Borsilikatchips für den Port-a-Patch (Maßstab: $3 \mu \mathrm{m}$ ). Der Durchmesser der Apertur auf der Oberseite beträgt ca. 2,5 $\mu \mathrm{m}$, auf der Unterseite ca. 7,5 $\mu \mathrm{m}$. $C$, Schematische Darstellung der Annäherung und des Spreitens eines Connexon-dotierten GUVs auf dem Borsilikatchip des Port-a-Patch ${ }^{\circ}$. Die Stromantwort nach einem $10 \mathrm{mV}$-Puls vor und nach dem Spreiten zeigt die Zunahme des Widerstandes von $4 \mathrm{M} \Omega$ auf $5 \mathrm{G} \Omega .^{[194]}$

Die elektrophysiologischen Messungen von Cx43 und Cx43-GFP aus P. pastoris wurden in Kooperation mit der Nanion Technologies GmbH durchgeführt. Ziel war es, die beiden 
Cx43-Varianten in ihrem elektrophysiologischen Verhalten zu charakterisieren und zu vergleichen. Die elektrophysiologische Charakterisierung von Cx43 wurde durch Dr. Mohamed Kreir durchgeführt. Für die Präparation der Proteo-GUVs wurde zum einen die Rekonstitution durch spontane Integration, zum anderen die fusionsvermittelte Rekonstitution verwendet (Kapitel 4.2.1, 4.2.3). Für die Rekonstitution durch spontane Integration wurde mit einer Proteinkonzentration von $10 \mathrm{ng} \cdot \mathrm{mL}^{-1}$ (Endkonzentration) gearbeitet. Die fusionsvermittelte Rekonstitution erforderte eine höhere Proteinkonzentration $\left(-40 \mu \mathrm{g} \cdot \mathrm{mL}^{-1}\right), \mathrm{da}$ nicht quantifiziert werden konnte, wie viel Protein mittels Fusion in GUVs integriert wurde. Die Kanalaktivität wurde bei konstanter Transmembranspannung zwischen $-100 \mathrm{mV}$ und $+100 \mathrm{mV}$ aufgezeichnet. Abb. 4-22 zeigt charakteristische Einzelkanalereignisse für Cx43 und Cx43-GFP. Das Öffnen und Schließen eines Kanals erfolgt durch Sprünge im Stromsignal von der Basislinie zu einem höheren Leitfähigkeitsniveau. Mithilfe von Punktamplitudendiagrammen konnte die gemittelte Leitfähigkeit $G$ nach Gl. 3-2, wie in Kapitel 3.2.3 beschrieben, berechnet werden. 
A

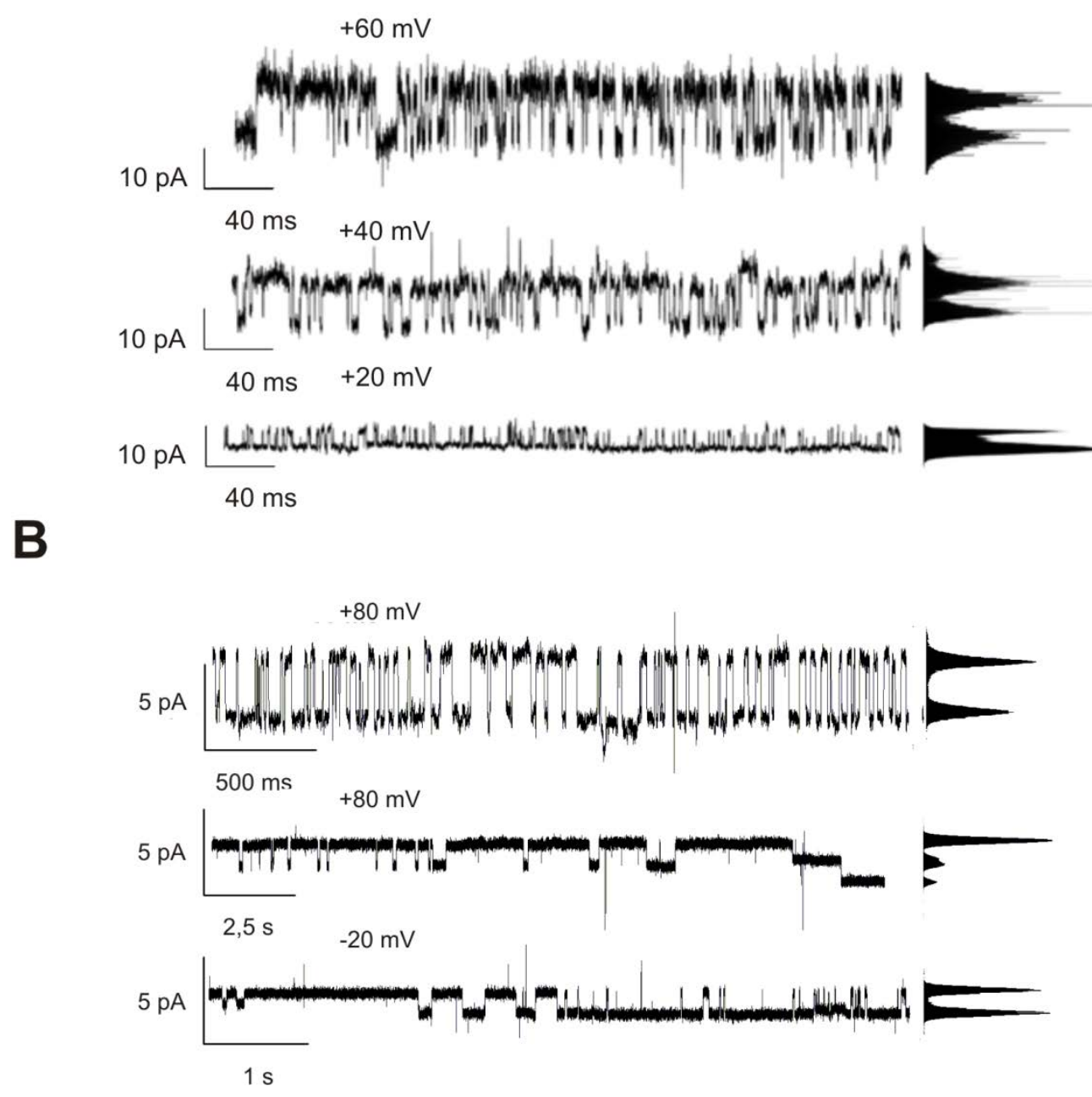

Abb. 4-22: Charakteristische Einzelkanalereignisse von Cx43 und Cx43-GFP mit Punktamplitudenhistogrammen. A, Exemplarische Planar Patch Clamp Messung von Cx43 Halbkanälen in $200 \mathrm{mM} \mathrm{KCl,} 2 \mathrm{mM}$ EDTA, $10 \mathrm{mM}$ HEPES, pH 7,0 bei den jeweils angegebenen Transmembranspannungen. Kanalöffnungen des integrierten Cx43 Halbkanals sind an dem sprunghaft ansteigenden Strom zu erkennen. Die gemittelte Leitfähigkeit beträgt $220 \mathrm{pS}$. B, Exemplarische Planar Patch Clamp Messung von Cx43-GFP Halbkanälen in $200 \mathrm{mM}, 2 \mathrm{mM}$ EDTA, $10 \mathrm{mM}$ HEPES, pH 7,4 bei $+80 \mathrm{mV}$ und $-20 \mathrm{mV}$. Die dazugehörigen Punktamplitudenhistogramme ergaben eine mittlere Leitfähigkeit $G$ von $(45 \pm 4) \mathrm{pS}$ bei $+80 \mathrm{mV},(21 \pm 1) \mathrm{pS}$ und $(13 \pm 2) \mathrm{pS}$ bei $+80 \mathrm{mV}$ sowie $59 \mathrm{pS}$ bei $-20 \mathrm{mV}$.

Während die mittlere Leitfähigkeit mit 220 pS von Cx43 bei verschiedenen Spannungen annähernd gleich ist, lässt sich für Cx43-GFP bei $+80 \mathrm{mV}$ eine Leitfähigkeit von (45 \pm 4$) \mathrm{pS}$ bzw. $(13 \pm 2) \mathrm{pS}$ und $(21 \pm 1) \mathrm{pS}$ sowie bei $-20 \mathrm{mV}$ eine mittlere Leitfähigkeit von $59 \mathrm{pS}$ unterscheiden (Abb. 4-22). Infolgedessen sollte die Leitfähigkeit bei unterschiedlichen Transmembranspannungen weiter untersucht werden. 


\subsubsection{Bestimmung der Leitfähigkeit}

Zur Bestimmung der Leitfähigkeit von Cx43 und Cx43-GFP wurden Einzelkanalereignisse bei unterschiedlichen Transmembranspannungen zwischen $-100 \mathrm{mV}$ und $+100 \mathrm{mV}$ aufgezeichnet. Die Auswertung der Daten erfolgte softwaregestützt durch die Single Channel Search-Analyse des Programms Clampfit 10.2 (Kapitel 3.2.3). Im Gegensatz zur Analyse mithilfe von Punktamplitudenhistogrammen wird nicht die mittlere Leitfähigkeit über ein bestimmtes Zeitintervall erfasst, sondern es erfolgt eine Ereignisanalyse. Dadurch wird die Leitfähigkeit jedes einzelnen Einzelkanalereignisses erfasst. Abb. 4-23 zeigt die ermittelten Leitfähigkeiten für Cx43 und Cx43-GFP.

A

B
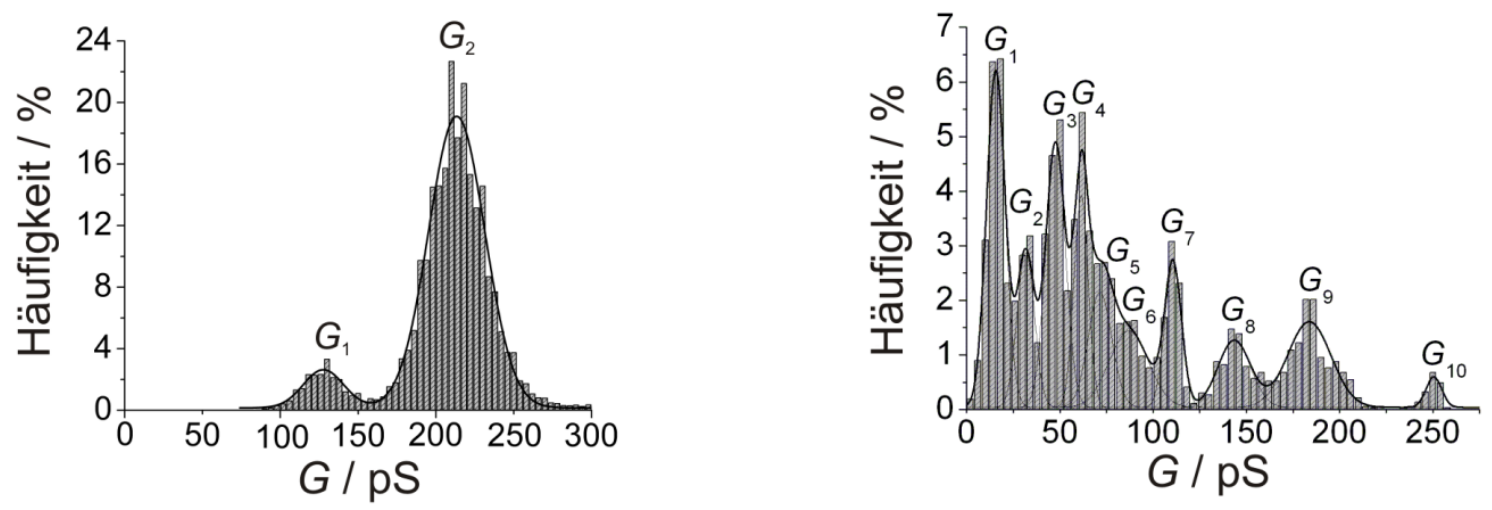

Abb. 4-23: Ereignishistogrammanalyse von Cx43 und Cx43-GFP. $A$, Ereignishistogramm aller detektierten Kanalöffnungen ( $n=1.680$ Ereignisse, Intervallbreite: $10 \mathrm{pS})$ in porenüberspannenden Membranen $\left(V_{\mathrm{m}}\right.$ zwischen -100 und $+100 \mathrm{mV}$, Puffer: $200 \mathrm{mM} \mathrm{KCl,} 2 \mathrm{mM}$ EDTA, $10 \mathrm{mM}$ HEPES, $\mathrm{pH}$ 7,0). Den Daten konnten zwei Gauß-Verteilungen angepasst werden (-). Cx43 zeigt eine Hauptleitfähigkeit von $G_{2}=(224 \pm 26) \mathrm{pS}$ und eine Nebenleitfähigkeit von $G_{1}=(124 \pm 5) \mathrm{pS}$. $B$, Ereignishistogramm von 3.676 Ereignissen (Intervalbreite: $4 \mathrm{pS}$ ) von Cx43-GFP Halbkanälen in porenüberspannenden Membranen bei einer Transmembranspannung von $+80 \mathrm{mV}$ und $-20 \mathrm{mV}$ (Puffer: $200 \mathrm{mM} \mathrm{KCl}, 2 \mathrm{mM}$ EDTA, $10 \mathrm{mM}$ HEPES, pH 7,4). Die durchgezogene Linie (一) zeigt das Ergebnis der Anpassung von zehn Gauß-Verteilungen an die Daten: $G_{1}=(15 \pm 4) \mathrm{pS}$, $G_{2}=(31 \pm 4) \mathrm{pS}, \quad G_{3}=(48 \pm 4) \mathrm{pS}, \quad G_{4}=(61 \pm 3) \mathrm{pS}, \quad G_{5}=(74 \pm 6) \mathrm{pS}, \quad G_{6}=(87 \pm 10) \mathrm{pS}$, $G_{7}=(110 \pm 4) \mathrm{pS}, G_{8}=(144 \pm 8) \mathrm{pS}, G_{9}=(184 \pm 11) \mathrm{pS}, G_{10}=(250 \pm 3) \mathrm{pS}$.

Aus den Ereignishistogrammen geht hervor, dass hier mehrere überlagerte Normalverteilungen unterschieden werden können. Durch Anpassung von normierten Gaußfunktionen nach Gl. 4-3 können verschiedene Leitfähigkeiten ermittelt werden. 


$$
f\left(G_{\mathrm{Cx}}\right)=\sum_{i=1}^{n} \frac{A_{\mathrm{i}}}{\sigma_{G_{i}} \cdot \sqrt{2 \pi}} \cdot \mathrm{e}^{\left(-\frac{\left(G_{\mathrm{Cx}}-G_{i}\right)^{2}}{2 \sigma_{G_{i}}{ }^{2}}\right)}
$$

$G_{C x}$ entspricht hierbei der experimentell bestimmten Leitfähigkeit der Einzelkanalereignisse, $G_{\mathrm{i}}$ dem Erwartungswert, $\sigma_{\mathrm{Gi}}$ der Standardabweichung der jeweiligen Leitfähigkeit, $A_{\mathrm{i}}$ der Fläche der angepassten Gaußfunktion und $n$ der Anzahl der überlagerten Gaußfunktionen.

Für die Bestimmung der Leitfähigkeit von Cx43 wurden 32 Präparationen von porenüberspannenden Membranen mit Aktivität verwendet. Die Hauptleitfähigkeit des Cx43 Halbkanals beträgt $G_{2}=(224 \pm 26) \mathrm{pS}$ (Abb. 4-23). Zusätzlich wurde eine Nebenleitfähigkeit mit $G_{1}=(124 \pm 5) \mathrm{pS}$ ermittelt. Das Ereignis-Histogramm von Cx43-GFP weicht von dem für Cx43 stark ab (Abb. 4-23). Die Analyse von 3.676 Einzelkanalereignissen zeigt verschiedene Leitfähigkeiten im Bereich von 15 bis 250 pS. Allein $70 \%$ der analysierten Einzelkanalereignisse sind im Bereich der Leitfähigkeitstufen $G_{1}=(15 \pm 4) \mathrm{pS}$ bis $G_{6}=(87 \pm 10) \mathrm{pS}$ zu finden, welche durchschnittlich jeweils um $14 \mathrm{pS}$ zunehmen. Weiter konnten Leitfähigkeiten von $G_{7}=(110 \pm 4) \mathrm{pS}, G_{8}=(145 \pm 8) \mathrm{pS}$ und $G_{9}=(184 \pm 11) \mathrm{pS}$ ermittelt werden. Ausschließlich mit der Leitfähigkeitsstufe $G_{10}=(250 \pm 3) \mathrm{pS}$ konnte die Hauptleitfähigkeit des Wildtyps mit $G_{2}=(224 \pm 26) \mathrm{pS}$ erreicht werden. Einzelkanalereignisse über 200 pS wurden mit Cx43-GFP Halbkanälen selten beobachtet, was durch die Häufigkeit der Leitfähigkeitsstufe $G_{10}$ mit $1,5 \%$ aller Einzelkanalereignisse belegt wird. Weiterhin ergab die Histogrammanalyse der Einzelkanalereignisse bei einer Transmembranspannung von $-20 \mathrm{mV}$, dass die Hauptleitfähigkeit für Cx43-GFP bei $(184 \pm 10) \mathrm{pS}$ liegt. Dagegen sind $G_{1}$ und $G_{2}$ die Hauptleitfähigkeiten bei einer Transmembranspannung von $+80 \mathrm{mV}$. 


\subsubsection{Strom-Spannungsabhängigkeit}

Die ermittelten Ereignishistogramme sind die Summe von Einzelkanalereignissen bei verschiedenen Transmembranspannungen. Verhält sich der Ionenkanal wie ein elektrischer bzw. ohmscher Widerstand, so bedeutet dies, dass der ermittelte Widerstandswert im Idealfall unabhängig von der angelegten Transmembranspannung ist. Diese Art von Ionenkanal wird auch als ohmscher Kanal bezeichnet. Zur Untersuchung des Verhaltens von Cx43 und Cx43-GFP in porenüberspannenden Membranen wurden I-V-Traces aufgenommen. Dafür wurde in 21 Schritten die Transmembranspannung in $10 \mathrm{mV}$ Schritten von $-100 \mathrm{mV}$ bis $+100 \mathrm{mV}$ erhöht. Die für jede Spannung resultierende Stromantwort wurde jeweils für $5 \mathrm{~s}$ aufgezeichnet. Für Cx43-GFP wurden elf verschiedene Präparationen von porenüberspannenden Membranen mit Aktivität verwendet. Die ermittelten Daten wurden wieder mittels Single Channel Search-Analyse ausgewertet. Die Auftragung der Transmembranspannung gegen den aufgezeichneten Transmembranstrom von Cx43 und Cx43-GFP ist in Abb. 4-24 gezeigt. Aus der Steigung lässt sich für Cx43 nach Gl. 3-2 eine mittlere Leitfähigkeit von $(228 \pm 8) \mathrm{pS}\left(G_{2}\right)$ ermitteln. Für Cx43-GFP wurde die Strom-Spannungsabhängigkeit aufgrund der zahlreichen Nebenleitfähigkeiten abhängig von der ermittelten Leitfähigkeit getrennt analysiert. Abb. 4-24 zeigt, dass für Cx43-GFP sowohl bei einer mittleren Leitfähigkeit von $(57 \pm 3) \mathrm{pS}\left(G_{4}\right)$ als auch bei $(116 \pm 3) \mathrm{pS}\left(G_{7}\right)$ eine lineare Strom-Spannungsabhängigkeit besteht. Demnach zeigen beide Varianten der Cx43 Halbkanäle ein ohmsches Verhalten. 
A

B
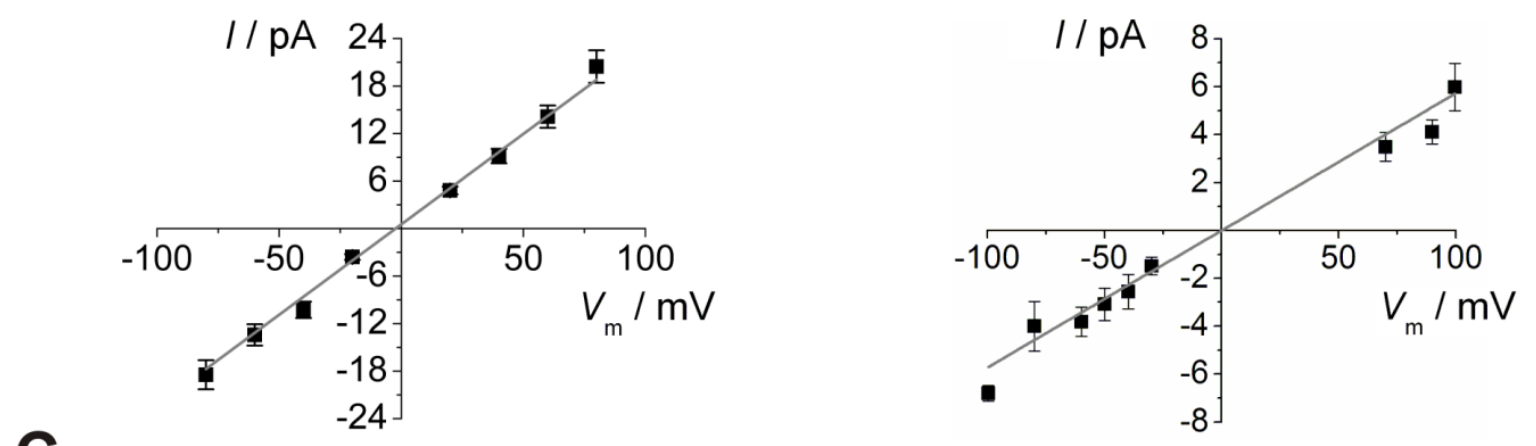

C

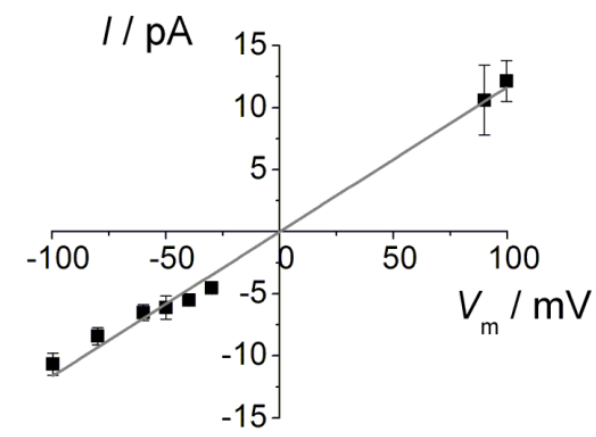

Abb. 4-24: Strom-Spannungsabhängigkeit von Cx43 und Cx43-GFP. $A$, Die Auftragung des Transmembranstroms gegen die Transmembranspannung von Cx43 Halbkanälen zeigt das Verhalten des Kanals in porenüberspannenden Membranen $(n=11.189$ Ereignisse, Puffer: $200 \mathrm{mM} \mathrm{KCl}, 2 \mathrm{mM}$ EDTA, 10 mM HEPES, pH 7,0). Die mittlere Leitfähigkeit konnte aus dem Anstieg durch lineare Regression (-) nach Gl. 3-2 zu $(228 \pm 8)$ pS bestimmt werden. $B$, Die Strom-Spannungsabhängigkeit von Cx43-GFP bestätigt ebenfalls das ohmsche Verhalten des Halbkanals in Planar Patch Clamp Messungen ( $V_{\mathrm{m}}$ zwischen -100 und $+100 \mathrm{mV}$, Puffer: $200 \mathrm{mM} \mathrm{KCl,} 2 \mathrm{mM}$ EDTA, $10 \mathrm{mM}$ HEPES, pH 7,4). Grundlage der Analyse sind 236 Ereignisse, die der ermittelten Leitfähigkeit $G_{4}$ aus Abb. 4-23 mit $(57 \pm 3) \mathrm{pS}$ entspricht. $C$, Der Leitfähigkeit mit $(116 \pm 3) \mathrm{pS}$ konnten 214 Einzelkanalereignisse von Cx43-GFP, ermittelt wie in $B$, zugeordnet werden. Dies entspricht etwa der Leitfähigkeit $G_{7}$ aus Abb. 4-23 und zeigt ebenfalls das ohmsche Verhalten von Cx43-GFP Halbkanälen. 


\title{
4.3.3 Bestimmung der mittleren Öffnungsdauer
}

Die Untersuchung der mittleren Öffnungsdauer $\tau$ ermöglicht es, neben der Leitfähigkeitsanalyse weitere Unterschiede zwischen Cx43 und Cx43-GFP Halbkanälen festzustellen. Zur Ermittlung der mittleren Öffnungsdauer wurden die Einzelkanalereignisse der I-V-Traces durch die Treshold-Analyse der Software Clampfit 10.2 analysiert. Dies ermöglicht die Bestimmung der Öffnungsdauer des Einzelkanalereignisses, d. h. die Verweildauer auf dem Stromniveau des geöffneten Kanals. Abb. 4-25 zeigt die Histogrammanalyse der Daten für Cx43 sowie Cx43-GFP.
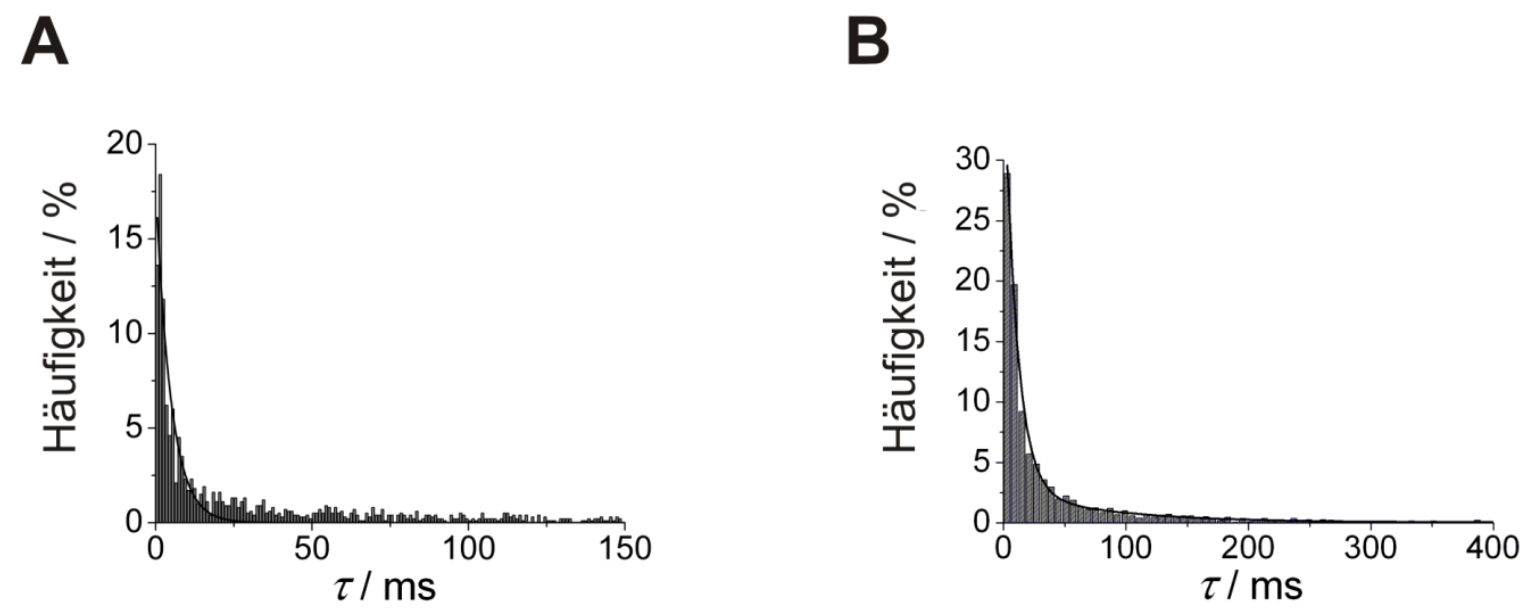

\begin{abstract}
Abb. 4-25: Histogrammanalyse zur Bestimmung der mittleren Öffnungsdauer von Cx43 und Cx43-GFP durch Anpassung einer Exponentialfunktion. A, Die Histogrammanalyse der mittleren Öffnungsdauer für Cx43 Halbkanäle ( $n=1.647$ Ereignisse, Intervalbreite: $20 \mathrm{~ms}$, Puffer: $200 \mathrm{mM}$ $\mathrm{KCl}, 2 \mathrm{mM}$ EDTA, $10 \mathrm{mM}$ HEPES, pH 7,0). Den Daten wurde eine Exponentialfunktion zweiter Ordnung angepasst (-). Daraus ließen sich mittlere Öffnungsdauern von $\tau_{1}=(15 \pm 3) \mathrm{ms}$ und $\tau_{2}=(75 \pm 5)$ ms ermitteln. $B$, Die Histogrammanalyse der mittleren Öffnungsdauer von Cx43-GFP ( $n=2.349$ Ereignisse, Intervalbreite: $20 \mathrm{~ms}$ ) wurden im Spannungsbereich von -100 bis $+100 \mathrm{mV}$ aufgenommen (Puffer: $200 \mathrm{mM} \mathrm{KCl}, 2 \mathrm{mM}$ EDTA, $10 \mathrm{mM}$ HEPES, pH 7,4). Die Anpassung erfolgte nach einer Exponentialfunktion zweiter Ordnung (-), die mittlere Öffnungsdauern von $\tau_{1}=(10 \pm 1) \mathrm{ms}$ und $\tau_{2}=(80 \pm 26) \mathrm{ms}$ liefert.
\end{abstract}


Durch die Anpassung einer Exponentialfunktion nach Gl. 4-4 wurde das Histogramm ausgewertet.

$$
f(t)=\sum_{i=1}^{n} A_{i} \cdot \mathrm{e}^{-\frac{t}{\tau_{i}}}
$$

$A_{\mathrm{i}}$ beschreibt die Amplitude der Funktion, $t$ die experimentell bestimmte Öffnungsdauer und $\tau_{\mathrm{i}}$ die mittlere Öffnungsdauer der Einzelkanalereignisse. Die Anpassung einer Exponentialfunktion liefert für Cx43 mittlere Öffnungsdauern von $\tau_{1}=(15 \pm 3) \mathrm{ms}$ und $\tau_{2}=(75 \pm 5) \mathrm{ms}$ und für Cx43-GFP mittlere Öffnungsdauern von $\tau_{1}=(10 \pm 1) \mathrm{ms}$ und $\tau_{2}=(80 \pm 26) \mathrm{ms}$. Die Ergebnisse für die Bestimmung der mittleren Öffnungsdauern für Cx43 und Cx43-GFP sind in Tab. 4-3 zusammengefasst. Die ermittelten mittleren Öffnungsdauern von Cx43 stimmen mit den mittleren Öffnungsdauern für Cx43-GFP annähernd überein.

Tab. 4-3: Mittlere Öffnungsdauern von Cx43 und Cx43-GFP, die durch die Anpassung von Exponentialfunktionen (Abb. 4-25) erhalten werden konnten.

\begin{tabular}{|c|c|}
\hline Variante & $\tau / \mathrm{ms}$ \\
\hline Cx43 & $(15 \pm 3)$ \\
& $(75 \pm 5)$ \\
\hline Cx43-GFP & $(10 \pm 1)$ \\
& $(80 \pm 26)$ \\
\hline
\end{tabular}

\subsubsection{Bestimmung der Öffnungswahrscheinlichkeit}

Die elektrophysiologische Analyse von Gap Junction Kanälen zeigt, dass sie eine von der angelegten Transmembranspannung abhängige Leitfähigkeit bzw. Öffnungswahrscheinlichkeit aufweisen. Für die Messung der Öffnungswahrscheinlichkeit $P_{\mathrm{o}}$ wurde für Cx43 mit neun verschiedenen Präparationen mit Cx43 Halbkanälen bzw. für Cx43-GFP mit elf verschiedenen Präparationen mit Cx43-GFP Halbkanälen I-V-Traces gemessen. Die Zeitintervalle für die Dauer von Öffnen und Schließen eines Kanals wurden durch die TresholdAnalyse aus den I-V-Traces bestimmt. Die Öffnungswahrscheinlichkeit $P_{\mathrm{o}}$ in \% wird nach Gl. 4-5 bestimmt. 


$$
P_{\mathrm{o}, V_{\mathrm{m}}}=\frac{\sum t_{\mathrm{o}, V_{\mathrm{m}}}}{\sum t_{\mathrm{o}, V_{\mathrm{m}}}+\sum t_{\mathrm{g}, V_{\mathrm{m}}}} \cdot 100
$$

Die Analyse erfolgt in Abhängigkeit von der Transmembranspannung, deshalb werden alle Verweildauern $t_{\mathrm{o}}$ des geöffneten und $t_{\mathrm{g}}$ des geschlossenen Zustandes des Kanals bei gleicher Transmembranspannung $V_{\mathrm{m}}$ addiert. In Abb. 4-26 ist die Öffnungswahrscheinlichkeit als Funktion der Transmembranspannung $V_{\mathrm{m}}$ aufgetragen. Die Datenanpassung in Abb. 4-26 erfolgte nach Mazet et al. und Bukauskas et al. mit einer BoltzmannVerteilung. ${ }^{[195,196]}$

$$
P_{\mathrm{o}, V_{\mathrm{m}}}=\frac{P_{\mathrm{o}, \max }-P_{\mathrm{o}, \min }}{1+e^{\left(V_{\mathrm{m}}-V_{50} / m_{50}\right)}}+P_{\mathrm{o}, \min }
$$

$P_{\mathrm{o}, \min }$ und $P_{\mathrm{o}, \max }$ stellt die minimale bzw. die maximale Öffnungswahrscheinlichkeit dar. $V_{50}$ ist die Transmembranspannung, bei der die Öffnungswahrscheinlichkeit $50 \%$ beträgt und der Anstieg $m_{50}$ entspricht. Unter der Annahme einer symmetrischen Spannungsabhängigkeit für $P_{\mathrm{o}, \max }$ und $P_{\mathrm{o}, \min }$ ergibt sich für $\mathrm{Cx} 43$ eine $P_{\mathrm{o}, \max }=55 \%$ und eine $P_{\mathrm{o}, \min }=44 \%$. Während sich für $V_{50}$ abhängig von der angelegten Transmembranspannung $51,5 \mathrm{mV}$ und $+53,1 \mathrm{mV}$ und für $\mathrm{m}_{50}=-7,4 \mathrm{mV}^{-1}$ bzw. $+4,0 \mathrm{mV}^{-1}$ ergibt. Die Anzahl der aufgezeichneten Einzelkanalereignisse für Cx43 ist für niedrige Spannungen höher, beispielsweise bei $+20 \mathrm{mV}$ mit 5.800 Einzelkanalereignissen größer als für höhere Spannungen mit 341 bei $+80 \mathrm{mV}$. 
A

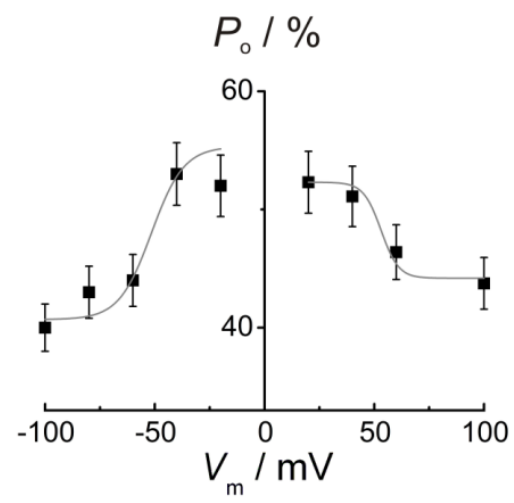

B

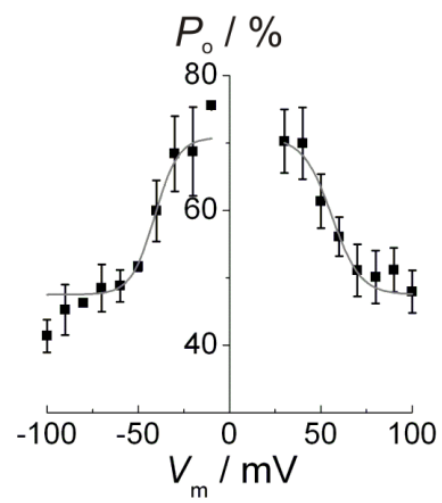

Abb. 4-26: Öffnungswahrscheinlichkeit von Cx43 und Cx43-GFP. $A$, Öffnungswahrscheinlichkeit von Cx43 Halbkanälen, die aus 32 unabhängigen Planar Patch Clamp Experimenten bestimmt werden konnten ( $n=11.189$ Ereignisse, Puffer: $200 \mathrm{mM} \mathrm{KCl,} 2 \mathrm{mM}$ EDTA, $10 \mathrm{mM}$ HEPES, pH 7,0). Die Anpassung einer Boltzmann-Verteilung (-) erfolgte nach Gl. 3-7 und ergab folgende Parameter: $P_{\mathrm{o}, \max }=55 \%, P_{\mathrm{o}, \text { min }}=44 \% ; V_{50}=-51 \mathrm{mV}, m_{50}=-7 \mathrm{mV}^{-1}$ für negative $V_{\mathrm{m}}$-Werte und $V_{50}=+53 \mathrm{mV}, m_{50}=+4 \mathrm{mV}^{-1}$ für positive $V_{\mathrm{m}}$-Werte. $\boldsymbol{B}$, Bestimmung der Öffnungswahrscheinlichkeit von Cx43-GFP aus elf unabhängigen Experimenten durch Anpassung (-) nach Gl. 3-7 ( $n=2.349$ Ereignisse, Puffer: $200 \mathrm{mM} \mathrm{KCl}, 2 \mathrm{mM}$ EDTA, $10 \mathrm{mM}$ HEPES, pH 7,4). Dabei konnten folgende Parameter bestimmt werden: $P_{\mathrm{o}, \max }=71 \%, P_{\mathrm{o}, \min }=48 \% ; V_{50}=-41 \mathrm{mV}, m_{50}=-6 \mathrm{mV}^{-1}$ für eine negative $V_{\mathrm{m}}$-Werte, $V_{50}=+56 \mathrm{mV}, m_{50}=+8 \mathrm{mV}^{-1}$ für positive $V_{\mathrm{m}}$-Werte.

Die Datenanpassung für Cx43-GFP ergibt unter Annahme einer symmetrischen Spannungsabhängigkeit für $P_{\mathrm{o}, \max }$ und $P_{\mathrm{o}, \min }$ eine maximale $P_{\mathrm{o}}$ von $71 \%$ und eine minimale $P_{\mathrm{o}}$ von $48 \%$. Dagegen ergibt sich für $V_{50}$ spannungsabhängig $-41 \mathrm{mV}$ und $+56 \mathrm{mV}$ und für $\mathrm{m}_{50}=-6,4$ und $+7,8 \mathrm{mV}^{-1}$. Für die Auftragung wurden ausschließlich Transmembranspannungen berücksichtigt, bei denen ausreichend Kanalereignisse $(\geq 15)$ aufgezeichnet wurden. Beide Auftragungen zeigen, dass die Öffnungswahrscheinlichkeit mit steigender bzw. sinkender Transmembranspannung ausgehend von $0 \mathrm{mV}$ abnimmt. Die Öffnungswahrscheinlichkeit von Cx43 ist mit $55 \%$ niedriger als die Öffnungswahrscheinlichkeit von Cx43-GFP mit $71 \%$. 


\subsubsection{Modulation der Kanalaktivität mit Taurin}

Zahlreiche Studien belegen, dass die Aktivität von Halbkanälen durch Modulation des pH-Wertes, v. a. durch Sulfonsäuren wie MOPS oder Taurin, reguliert werden kann. ${ }^{[66]}$ Zum spezifischen Nachweis der Connexin Halbkanäle wurde die Kanalaktivität durch die Zugabe von Taurin in millimolaren Konzentrationen moduliert. Die Zugabe von $10 \mathrm{mM}$ Taurin in Messpuffer führte bei einer Transmembranspannung von $+80 \mathrm{mV}$ zur Abnahme des Transmembranstroms von Cx43 Halbkanälen bis zu 0 pA (Abb. 4-27 A). In gleicher Weise fiel durch die Zugabe von $44 \mathrm{mM}$ Taurin in Messpuffer die Leitfähigkeit von $(55 \pm 4) \mathrm{pS}$ auf null ab (Abb. 4-27 B). Für Cx43-GFP konnte gezeigt werden, dass die Modulation der Einzelkanalaktivität durch die Zugabe von Taurin möglich ist.

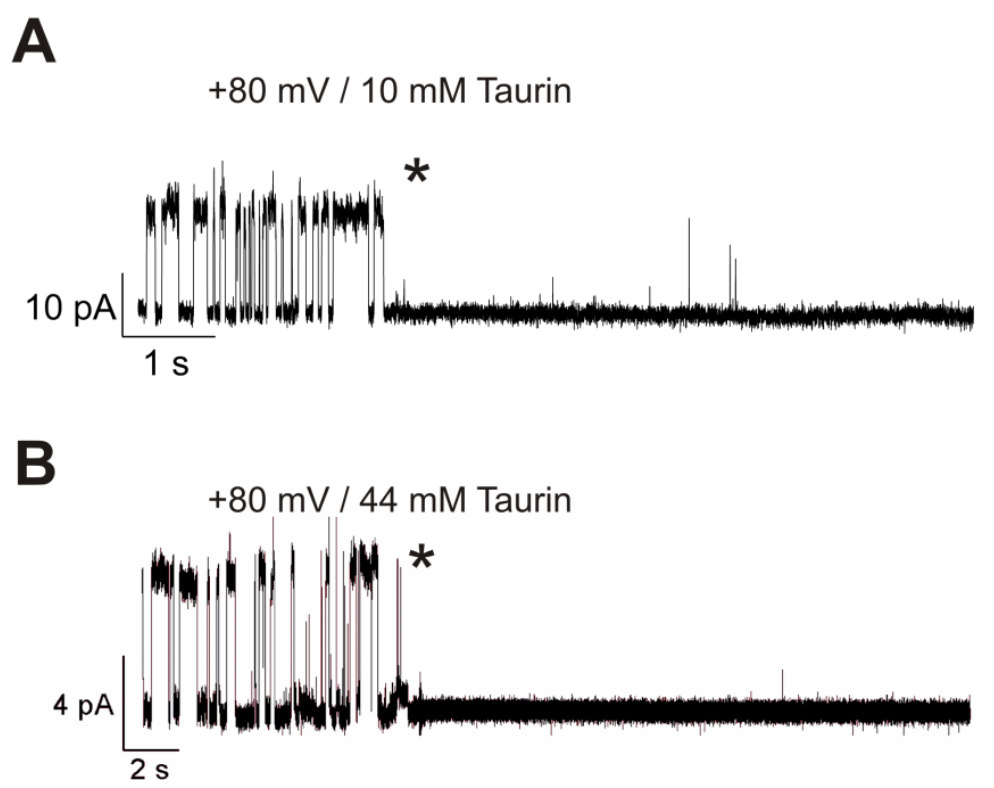

Abb. 4-27: Modulation der Aktivität von Cx43 und Cx43-GFP Halbkanälen durch die Aminosulfonsäure Taurin. A, Exemplarische Einzelkanalereignisse eines Planar Patch Clamp Experiments mit Cx43 bei $+80 \mathrm{mV}$ (Puffer: $200 \mathrm{mM} \mathrm{KCl,} 2 \mathrm{mM}$ EDTA, $10 \mathrm{mM}$ HEPES, pH 7,0). Die mittlere Leitfähigkeit $G$ konnte mittels Punktamplitudendiagramm zu $(236 \pm 8)$ pS bestimmt werden. Sofort nach der Zugabe von $10 \mathrm{mM}$ Taurin $\left(^{*}\right)$ fiel der Transmembranstrom auf null ab. $B$, Die mittlere Leitfähigkeit $G$ konnte für das gezeigte Experiment mit Cx43-GFP Halbkanälen bei $+80 \mathrm{mV}$ zu $(55 \pm 4)$ pS bestimmt werden (Puffer: $200 \mathrm{mM} \mathrm{KCl,} 2 \mathrm{mM}$ EDTA, 10 mM HEPES, pH 7,4). Die Zugabe von $44 \mathrm{mM}$ Taurin (*) führte ebenfalls zum Abfall des Transmembranstroms. 


\subsubsection{Kanalblockierung mit Lanthanchlorid}

Eine weitere Möglichkeit zur Verifizierung von Cx43-GFP Halbkanälen ist die Blockade mit Lanthanchlorid. Thompson et al. konnten zeigen, dass $\mathrm{La}^{3+}$ in der Lage ist, spezifisch Cx43 zu blockieren. ${ }^{[197]}$ Während der Messung bei einer Transmembranspannung von $80 \mathrm{mV}$ wurden $26 \mathrm{mM}$ Lanthanchlorid in Messpuffer zugegeben und der Transmembranstrom für mindestens 5 min weiter aufgezeichnet. Sofort nach Zugabe kam es zum Abfall der Leitfähigkeit wie Abb. 4-28 zeigt. Die vollständige Blockade von Cx43-GFP durch 26 mM Lanthanchlorid konnte in 8 von 10 Messungen beobachtet werden.

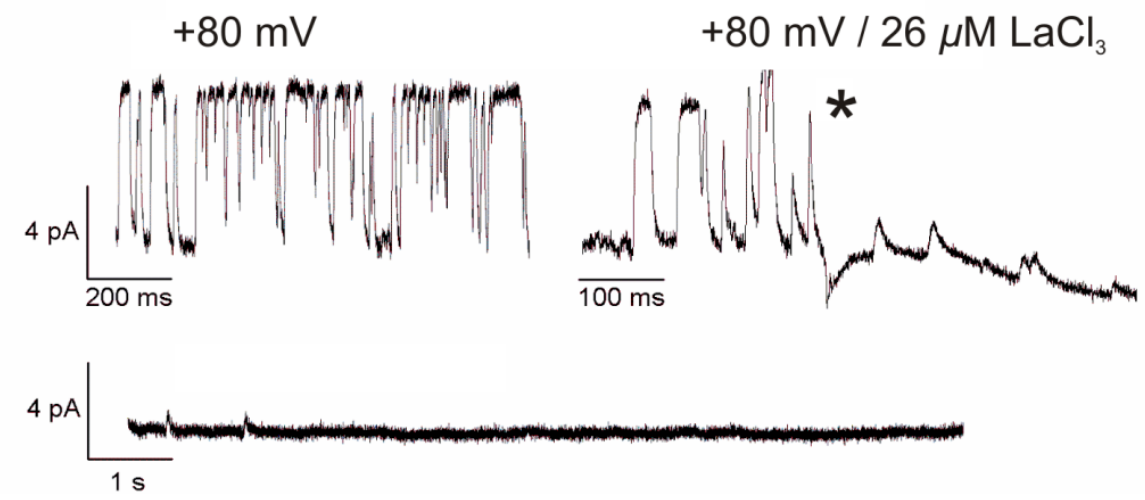

Abb. 4-28: Blockierung des Cx43-GFP Halbkanals mit Lanthanchlorid in einem exemplarischen Planar Patch Clamp Experiment (Puffer: 200 mM KCl, 2 mM EDTA, 10 mM HEPES, pH 7,4). Die mittlere Leitfähigkeit $G$ lässt sich für die gezeigte Einzelkanalmessung von Cx43-GFP Halbkanälen bei $+80 \mathrm{mV}$ mithilfe von Punktamplitudenhistogrammen zu $(63 \pm 3) \mathrm{pS}$ bestimmen. Die Zugabe von $26 \mu \mathrm{M}$ Lanthanchlorid $(*)$ führt zur vollständigen Blockade der Halbkanalaktivität. Es konnte in einem Zeitintervall von 5 min nach Zugabe keine weitere Halbkanalaktivität beobachtet werden. 


\subsection{Porenüberspannende Membranen auf porösem Aluminiumoxid}

Nach der erfolgreichen elektrophysiologischen Charakterisierung von Cx43 sowie Cx43-GFP wurde die Entwicklung eines fluoreszenzbasierten Funktionsassays zum optischen Nachweis der Halb- und Gap Junction Kanalaktivität begonnen. Die Entwicklung dieses Biosensorsystems zur Visualisierung der Proteinfunktionalität wird im Folgenden dargestellt. Die Basis für diese Präparation bieten die porenüberspannenden Membranen, die durch unterschiedliche Methoden präpariert werden können. Zunächst wurden zur Präparation porenüberspannender Membranen poröse Substrate der Firma fluxxion (Eindhoven, Niederlande) aus Siliziumnitrid verwendet. Diese haben einen Grundkörper aus Silizium, auf dem eine Siliziumnitridfolie mit mehreren porösen Arrays aufgebracht ist (Abb. 4-29 A). Die Substrate stehen mit einem Porendurchmesser $d_{0}$ von 0,45 bis $2 \mu \mathrm{m}$ zur Verfügung und die Poren sind beidseitig offen (Abb. 4-29 A, Vergrößerung). Zur Präparation der porenüberspannenden Membranen wurde zunächst das Siliziumsubstrat mit 2,5 nm Titan und $30 \mathrm{~nm}$ Gold besputtert und anschließend in Propanol mit 0,5 mM Cholesterylpolyethylenoxythiol (CPEO3) über Nacht bei $4{ }^{\circ} \mathrm{C}$ inkubiert. $\mathrm{CPEO} 3$ chemisorbiert an die Goldoberfläche und bildet eine unvollständige Monolage auf der Goldoberfläche. Während der Inkubation in $n$-Propanol, mit einer niedrigeren Dielektrizitätskonstante als Wasser, ist der Cholesterylrest des $\mathrm{CPEO} 3$ parallel zur Oberfläche ausgerichtet und bedingt so eine unvollständige Belegung. Erst nach der Überführung in eine elektrolythaltige Lösung mit hoher Dielektrizitätskonstante richten sich die Cholesterylreste auf. ${ }^{[198-200]}$ Nach Überführung des Substrats in PBS-Puffer wurden zur Bildung von porenüberspannenden Membranen proteinhaltige, unilamellare Riesenvesikel (Proteo-Giant Unilamellar Vesicles, ProteoGUVs) zugegeben. Die Monolage aus CPEO3-Molekülen, welche in die Lipidmembran insertieren, ermöglicht das Spreiten der GUVs auf der Substratoberfläche. Abb. 4-29 B zeigt porenüberspannende Membranen auf einem porösen Substrat mit einem Porendurchmesser von 1,2 $\mu \mathrm{m}$. Die grüne Fluoreszenz zeigt Cx43-GFP rekonstituiert in porenüberspannenden Membranen. In Blau ist die Reflexion des eingestrahlten Laserlichts $\left(\lambda_{\text {exc }}=405 \mathrm{~nm}\right)$ auf der Goldoberfläche des Substrats zu sehen. Auf den Porenrädern ist keine Fluoreszenz zu sehen, da es zur Fluoreszenzlösung (Quenching) aufgrund der Nähe der Fluorophormoleküle zur 
Goldoberfläche kommt. Da kein lipidgekoppelter Fluorophor verwendet wurde, kann keine Aussage über das Vorhandensein der Membran über den dunklen Poren getroffen werden.
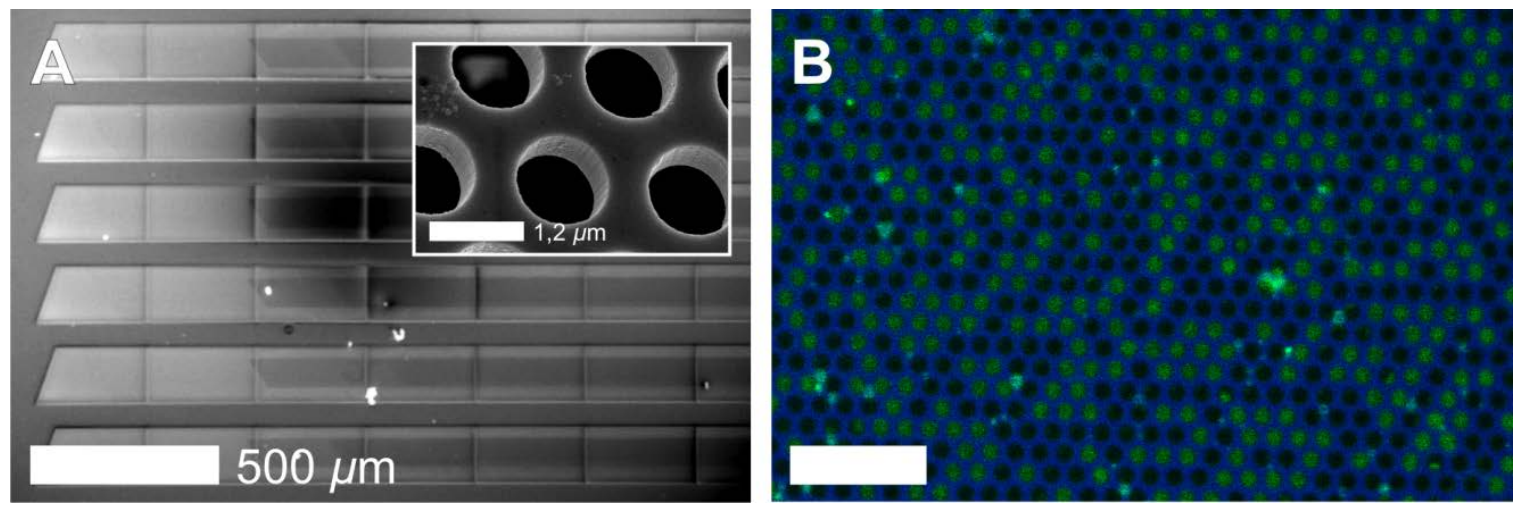

Abb. 4-29: Porenüberspannende Membranen auf porösen Siliziumsubstraten. $A$, Rasterelektronenmikroskopische Aufnahme der Siliziumsubstrate mit einem Porendurchmesser von 1,2 $\mu \mathrm{m}$ (Vergrößerung). $B$, Fluoreszenzmikroskopische Aufnahme porenüberspannender POPC Membranen mit Cx43-GFP (grün) auf goldbeschichteten, CPEO3-funktionalisierten Siliziumsubstraten. Die Reflexion des eingestrahlten Laserlichts auf der Substratoberfläche ist in Blau dargestellt. Maßstab: $10 \mu \mathrm{m}$

Für einen fluoreszenzbasierten Assay kann zum Nachweis der Gap Junction Kanalaktivität der Transfer von einem wasserlöslichen Farbstoff zwischen zwei voneinander unabhängigen Kompartimenten dienen. Dafür wurden poröse Substrate mit geschlossenen Poren benötigt, welche durch die Bildung porenüberspannender Membranen abgeschlossene Kompartimente bilden und für den Funktionsassay einen wasserlöslichen Fluorophor einschließen. Im Gegensatz zu Siliziumdioxid musste das Substrat optisch transparent sein, da es das Ziel war, gleichzeitig die Fluoreszenz des ein- bzw. ausgeschlossenen Farbstoffs und des lipidgekoppelten Fluorophors fluoreszenzmikroskopisch nachzuweisen. Diese optischen und geometrischen Eigenschaften vereinen die porösen Aluminiumoxidsubstrate mit einer Schichtdicke von bis zu $10 \mu \mathrm{m}$ und einen einstellbaren Porendurchmesser von $d_{0}=60 \mathrm{~nm}$.

\subsubsection{Präparation von porösem Aluminiumoxid}

Zunächst wird auf die Fabrikation der porösen Aluminiumoxidsubstrate eingegangen. Es wurden regelmäßige, poröse Strukturen verwendet. Nach der Funktionalisierung der Porenstege mit Silanolgruppen, dient es als hydrophiles Substrat zur Herstellung porenüberspannender Membranen. Die Präparation der Aluminiumoxidsubstrate durch anodische Oxidation von Aluminium umfasst sieben Schritte, die in Kapitel 3.5.1 ausführlich beschrieben wurden. Zur Optimierung des Fabrikationsprozesses und Verbesserung der Substratstruktur 
wurden die Substrate regelmäßig mittels Rasterelektronenmikroskopie (Scanning Electron Microscopy, SEM, Kapitel 3.4) analysiert. Dazu wurde aufgrund der schlechten Leitfähigkeit von Aluminiumoxid eine kolloidale Goldschicht von etwa $10 \mathrm{~nm}$ aufgedampft.

Zunächst wurde durch Tempern des Aluminiums auf $500{ }^{\circ} \mathrm{C}$ die Feinheit und Homogenität des Metalls erhöht. Abb. 4-30 A bis C zeigt, dass die Rauigkeit der Aluminiumoberfläche durch den Walzprozess relativ hoch ist. Für die Herstellung eines porösen Substrats, mit einer hochgeordneten Struktur im Nanometerbereich, wurde die Metalloberfläche elektrochemisch mit einem Gemisch aus Schwefelsäure, Phosphorsäure und Reinstwasser poliert. Das Ergebnis dieses Prozesses ist in Abb. 4-30 D bis E abgebildet und verdeutlicht, dass durch das elektrochemische Polieren die Oberflächenrauigkeit bedeutend reduziert werden konnte.
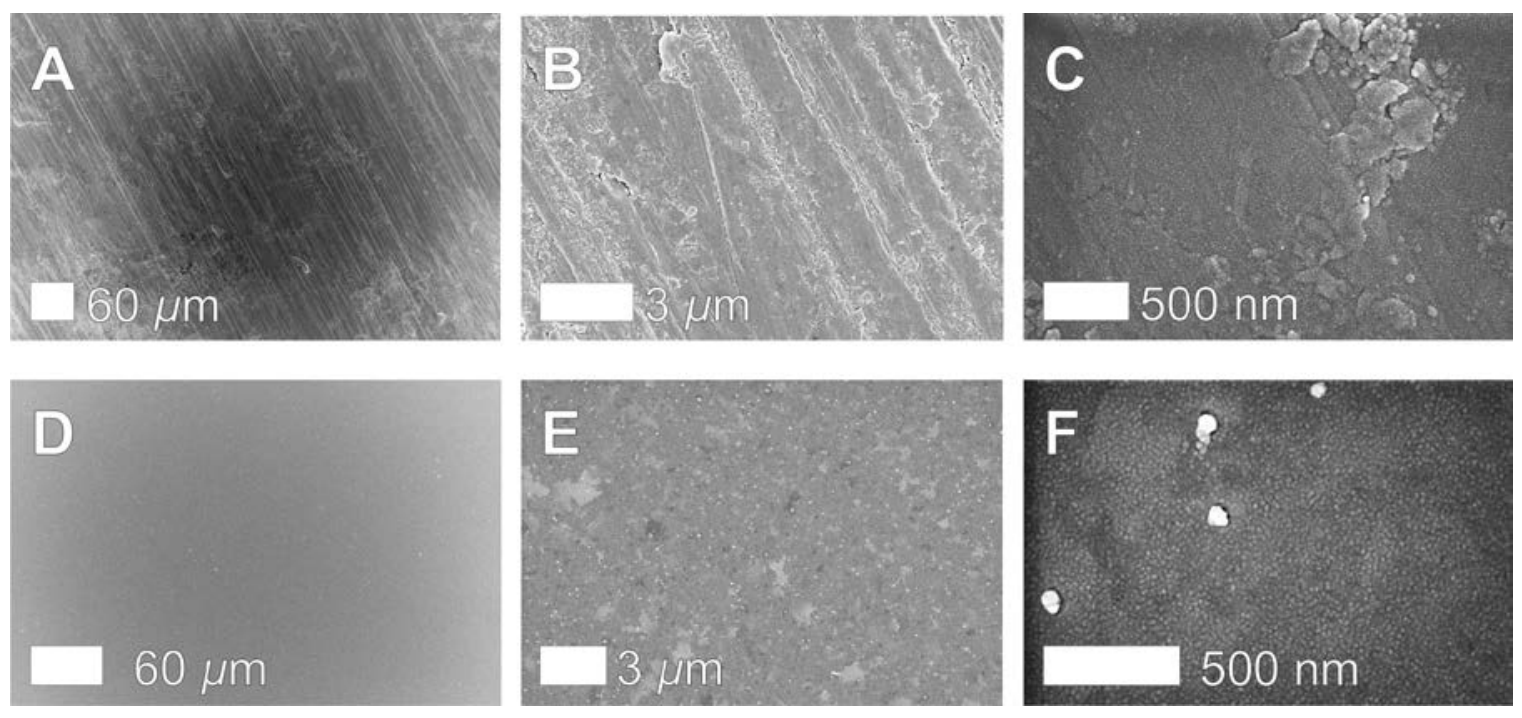

Abb. 4-30: Optimierung der Oberflächenrauigkeit der Aluminiumoberfläche. $A$ - $C$, SEM-Aufnahme der unbehandelten Aluminiumoberfläche in unterschiedlichen Vergrößerungen. $D F$, SEM-Aufnahme der elektrochemisch polierten Oberfläche des Aluminiums bei entsprechenden Vergrößerungen.

Zur Fertigung einer hochgeordneten porösen Aluminiumoxidstruktur wurden zwei anodische Oxidationen durchgeführt. Die erste Anodisierung des polierten Aluminiums von 160 Minuten dient der Vorstrukturierung der Metalloberfläche. Das Wachstum des Aluminiumoxids findet an der Metall-Oxid-Grenzfläche statt, dadurch befindet sich die geordneteste Porenstruktur an den Aluminiumoxidböden und die ungeordneteste Struktur an der Porenoberfläche (Abb. 4-31 A). Während der ersten anodischen Oxidation entstehen durch das Porenwachstum Vertiefungen in der Metalloberfläche, deren Ordnungsgrad über den 
Zeitraum der ersten Anodisierung zunimmt. Im nächsten Schritt wurde das Aluminiumoxid durch $5 \%(v / v)$ Phosphorsäure wieder entfernt und damit die hochgeordnete Aluminiumoberfläche freigelegt (Abb. 4-31 B). Diese Vertiefungen bildeten eine wesentliche Basis zur Herstellung hochgeordneter poröser Aluminiumoxidsubstrate (Abb. 4-31 C). Die Porosität des Substrats beträgt etwa $10 \%$. ${ }^{[152]}$
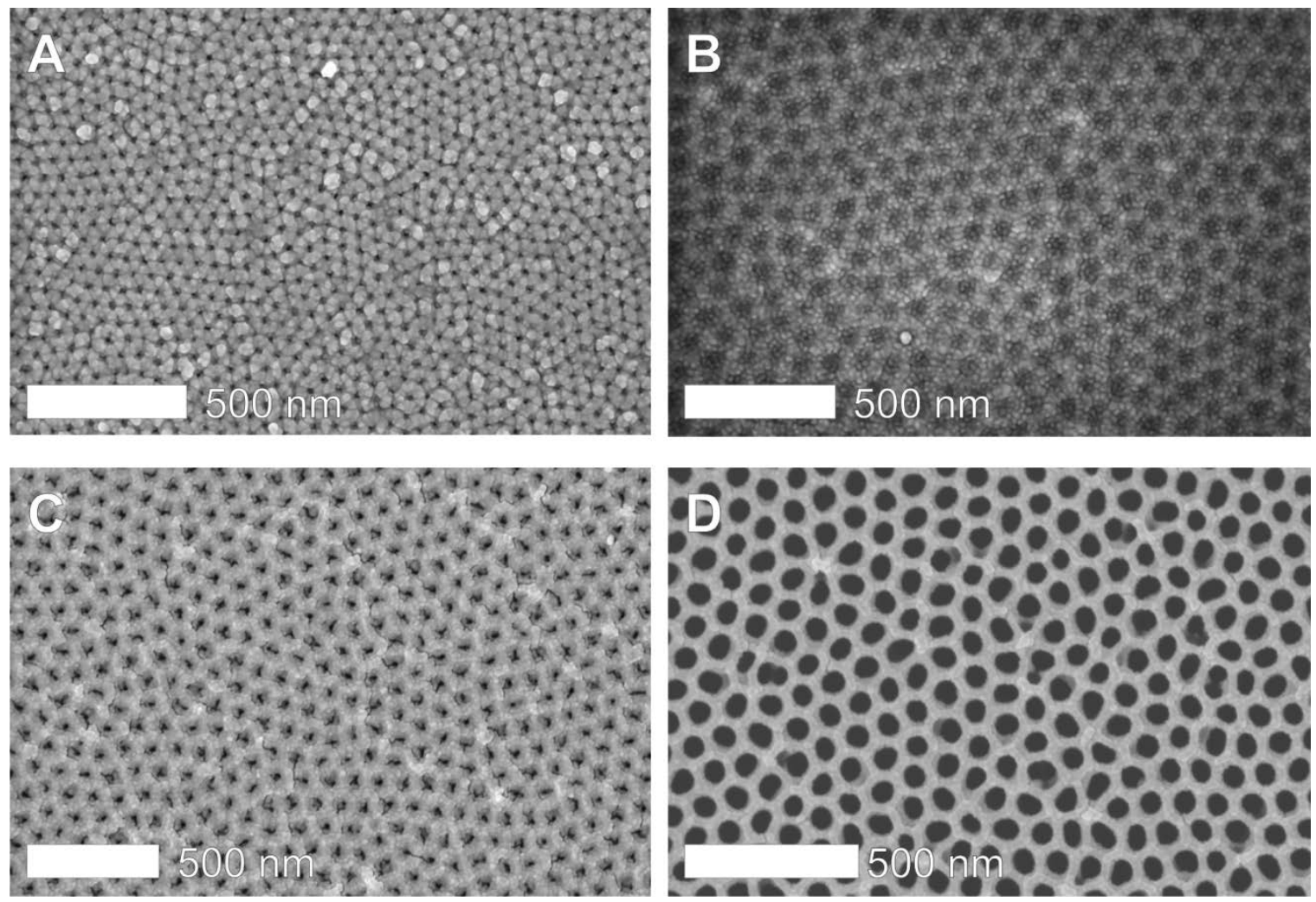

Abb. 4-31: Darstellung der Fabrikationsstufen zur Herstellung hochgeordneter poröser Aluminiumoxidsubstrate. $A$, SEM-Aufnahme des porösen Aluminiumoxidsubstrats der ersten Anodisierung. $B$, Vorstrukturierung des Aluminiums nach Entfernung des Aluminiumoxids mit fünfprozentiger Phosphorsäure. $C$, Zweite Anodisierung des Aluminiums zur Herstellung von hochgeordnetem porösen Aluminiumoxid mit einem Porendurchmesser von $d_{0} \approx 25 \mathrm{~nm}$. $D$, SEMAufnahme nach Vergrößerung des Porendurchmessers auf $d_{0} \approx 60 \mathrm{~nm}$.

Durch die Anodisierung bei einer Spannung von $40 \mathrm{~V}$ in $0,3 \mathrm{M}$ Oxalsäure wurde ein Porendurchmesser von $d_{0} \approx 25 \mathrm{~nm}$ bzw. eine Gitterkonstante von $\lambda_{\text {C-C }} \approx 100 \mathrm{~nm}$ (Abb. 4-32 A) mit einer Substratdicke von etwa $7 \mu \mathrm{m}$ erreicht (Abb. 4-32 B). Durch Inkubation der Aluminiumoxidsubstrate in $5 \%(v / v)$ Phosphorsäure kann ein Porendurchmesser nach Gl. 3-15 von bis zu 70 nm eingestellt werden (Abb. 4-32 C). Für die nachfolgenden Experimente wurden poröse Substrate mit einem Porendurchmesser von $d_{0} \approx 60 \mathrm{~nm}$ verwendet. 

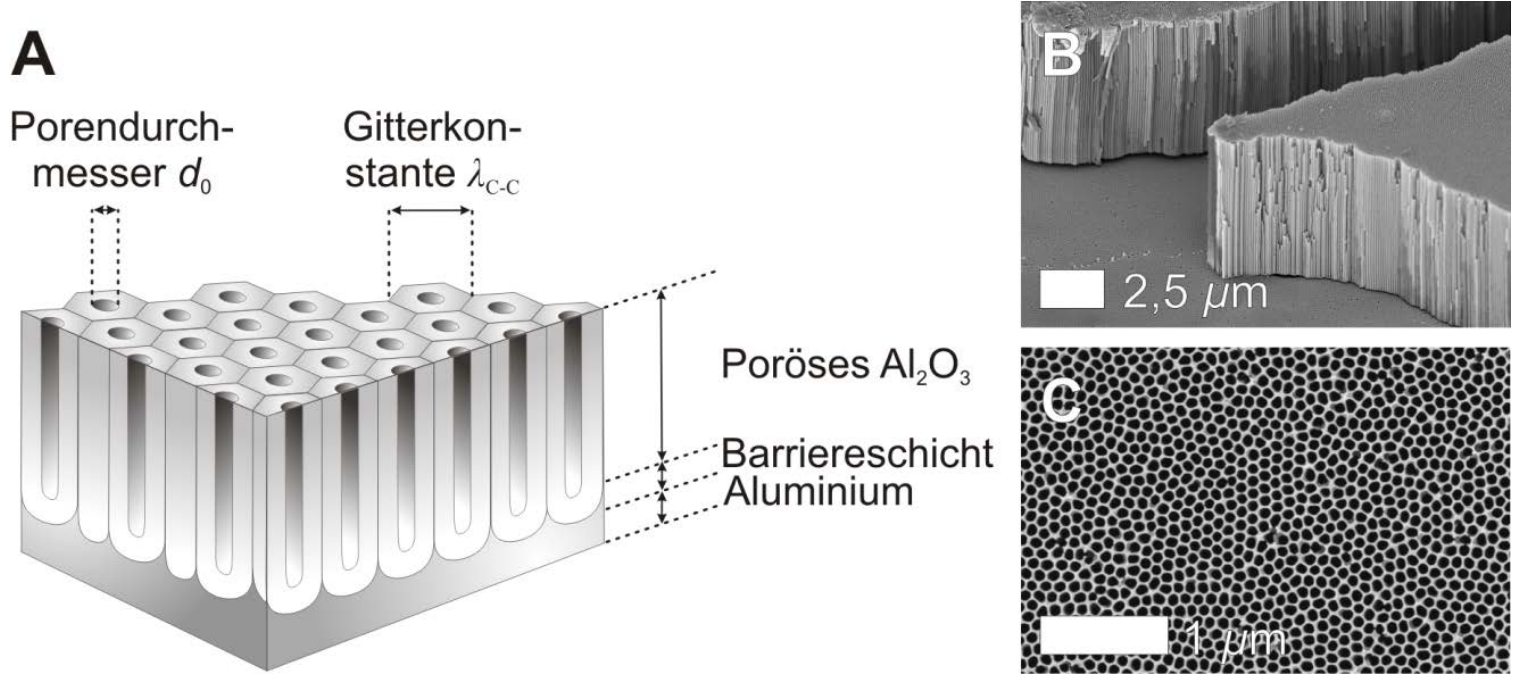

Abb. 4-32: $A$, Schematische Darstellung des porösen Aluminiumoxids, welches durch anodische Oxidation von Aluminium gewonnen wird. B, SEM-Aufnahme des Aluminiumoxidsubstrates in der Seitenansicht. Dies verdeutlicht die parallele Anordnung der zylindrischen Poren. $C$, Maximal geweiteter Porendurchmesser der hergestellten Aluminiumoxidsubstrate von $d_{0} \approx 70 \mathrm{~nm}$.

\subsubsection{Orthogonale Funktionalisierung von porösem Aluminiumoxid}

Die physikalischen Eigenschaften von porösem Aluminiumoxid erfordern eine Funktionalisierung der Oberfläche, denn die erhöhte Porosität von 25-30 \% nach der Einstellung des Porendurchmessers (Kapitel 3.5.2) bedingt nur eine geringe Adhäsion der Vesikel an die Oberfläche, wodurch die Vesikel nicht aufreißen. Im Vergleich dazu führt die starke Adhäsionsenergie zwischen Vesikeln und der hydrophilen Siliziumdioxidschicht einer Waferoberfläche zu deren Aufreißen. Nur mit wenigen Methoden wie dem Bubble Collapse oder der Applikation von Vesikeln unter Durchfluss ist es gelungen, direkt Membranen auf Aluminiumoxid zu generieren. ${ }^{[98,201]}$ Zur Erhöhung der Hydrophilie der Substrate ist eine chemische Funktionalisierung notwendig. In dieser Arbeit wurde dazu 3-Mercaptotriethoxypropylsilan (3-MPS) verwendet (Abb. 3-19 C). Nach der Vergrößerung des Porendurchmessers wurden die Substrate mit Sauerstoffplasma gereinigt, um die Anzahl der Hydroxylgruppen auf der Oberfläche zu erhöhen. In Abb. 3-19 A sind die einzelnen Schritte der $\mathrm{Al}_{2} \mathrm{O}_{3}$-Funktionalisierung schematisch dargestellt. Nachfolgend wurden die Substrate mit 3-MPS in der Gasphase silanisiert. Zum Schutz der Funktionalisierung wurde eine Goldschicht von etwa $10 \mathrm{~nm}$ auf das Substrat aufgedampft. Durch die Struktur des Substrates sind nur die Porenstege mit einer Goldschicht bedeckt, jedoch nicht das Innere der Poren. Durch die Applikation von Argon- und Sauerstoffplasma (60s) wurde die Funktionalisierung im Poreninneren entfernt. ${ }^{[202]}$ Die Goldschicht schützt die Funktionalisierung mit 
3-MPS auf den Porenstegen vor der Ablösung durch das Plasma. Diese Substrate können für das Spreiten von GUVs weiterverwendet werden.

\subsubsection{Präparation von porenüberspannenden Membranen auf porösem Aluminiumoxid}

Die Goldschicht wurde durch Iod-Kaliumiodidlösung entfernt. Anschließend führte die Inkubation im Sauerstoffplasma zur Oxidation des 3-MPS bis zum Silanol. Auf diese aktivierte, hydrophile Substratoberfläche können im nächsten Schritt POPC-haltige GUVs dotiert mit 0,5 mol\% Texas Red DHPE (Kapitel 3.3.2) gespreitet werden. Die GUVs sind mit 0,3 M Saccharose gefüllt. Dadurch sinken diese in PBS-Puffer mit niedrigerer Dichte auf die Substratoberfläche und es kommt zur starken Interaktion mit der hydrophilen Oberfläche. Die Dipol-Dipol-Wechselwirkung der Lipidkopfgruppen mit dem hydrophilen Substrat sowie die dadurch bedingte Deformation des Vesikels führen zum Aufreißen der GUVs und der Bildung von porenüberspannenden Membranen. Das Spreiten der GUVs führt fast zur vollständigen Belegung des porösen Substrats mit Membran (Abb. 4-33 A). Der Spreitvorgang fand innerhalb von Sekunden statt. Dabei konnten zwei verschiedene Arten von Membranpatches gefunden werden. Diese hatten abhängig vom Spreitmechanismus entweder eine eher runde Form oder eine herz- bis tropfenförmige Struktur (Abb. 4-33). Lazzara et al. konnten zeigen, dass die Mobilität der porenüberspannenden Membran (0,1 mol\% Bodipy DHPE) durch Fluorescence Recovery After Photobleaching (FRAP, Kapitel 3.3.4) zu $(4 \pm 1) \mu \mathrm{m}^{2} \cdot \mathrm{s}^{-1}$ mit einem immobilen Anteil von $5 \%$ bestimmt werden konnte. ${ }^{[155]}$ Dies veranschaulicht, dass die Lipidmembranen auf den porösen Aluminiumoxidsubstraten eine defektfreie, kontinuierliche Membran über dem überspannten Bereich bildeten und nicht innerhalb der Poren zu finden ist. Allerdings ist in Abb. 4-33 zu sehen, dass es zwischen den einzelnen Membranpatches keine Verbindung gab, sondern es eher zu einer Art „Auffaltung“ kam. Ein Selfhealing Effect, wie es beim Spreiten von Vesikeln auf bspw. Siliziumdioxid zu beobachten ist, trat nicht auf. ${ }^{[1,90]}$ 

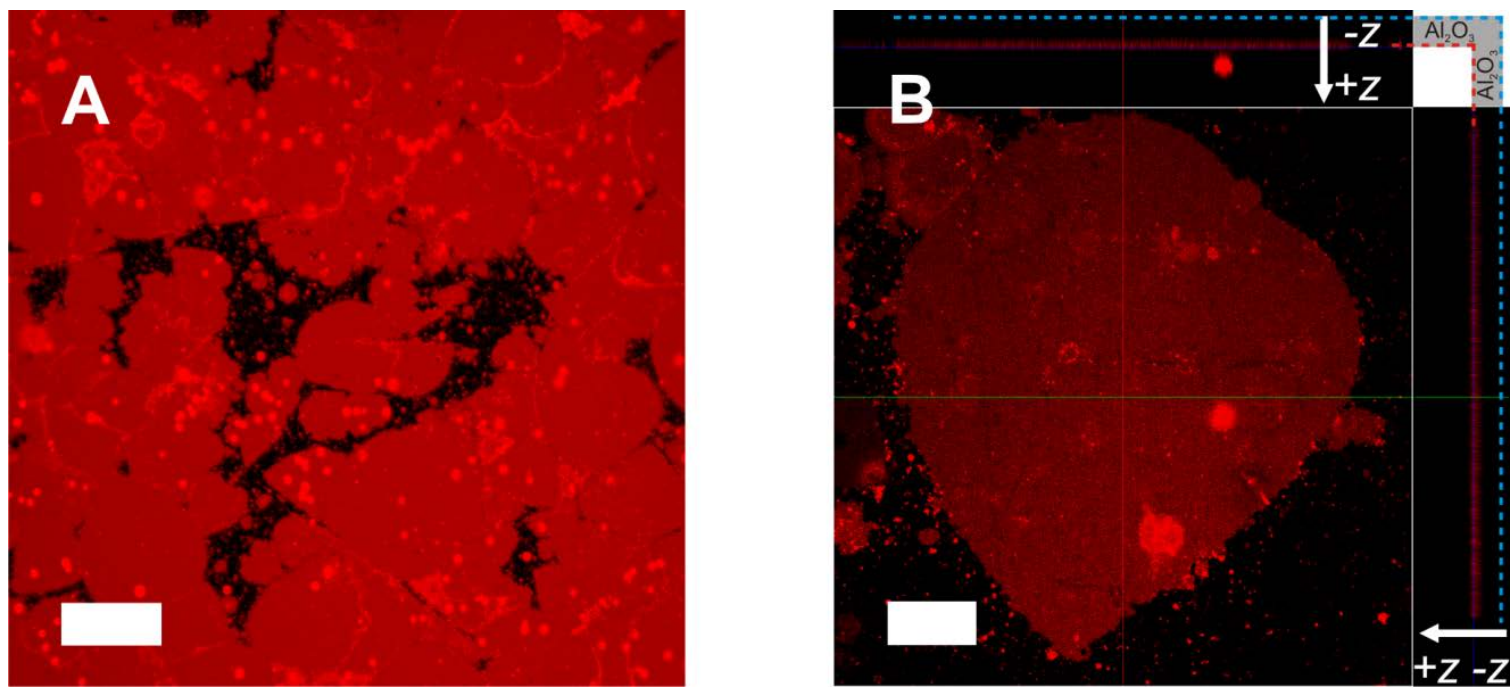

Abb. 4-33: Bildung von porenüberspannenden POPC Membranen (0,5 mol\% Texas Red DHPE) auf porösen Aluminiumoxidsubstraten $\left(d_{0} \approx 60 \mathrm{~nm}, h \approx 7 \mu \mathrm{m}\right) . A$, Exemplarische Fluoreszenzaufnahme eines Substrates mit fast vollständiger Belegung durch porenüberspannende Membranen (rot). B, Die konfokalmikroskopische Aufnahme zeigt den $z$-stack eines Membranpatches (rot) auf porösen Aluminiumoxidsubstraten. Die blaue gestrichelte Linie markiert den Boden des Substrats und die rote gestrichelte Linie kennzeichnet die Porenöffnungen. Das zentrale Bild stellt eine $z$-Ebene dar. Die $z$-Schnitte erfolgen entlang der roten Linie für die rechte Abbildung und entlang der grünen Linie für die obere Linie. Maßstab: $20 \mu \mathrm{m}$

\section{Einschluss von Pyranin in Aluminiumoxidporen durch porenüberspannende Membranen}

In einem fluoreszenzbasierten Funtionsassay zum Nachweis der Gap Junction Kanalaktivität sollte der Farbstofftransfer zur Validierung der Kanalfunktion dienen. Dafür war der Einschluss eines wasserlöslichen Farbstoffs in die Poren des Aluminiumoxidsubstrats durch eine Lipidmembran notwendig. Gleichzeitig konnte abermals die Defektfreiheit und Kontinuität der porenüberspannenden Membran überprüft werden. Jede Pore hat bei einem Porendurchmesser von $d_{0}=60 \mathrm{~nm}$ und einer Substratdicke von $7 \mu \mathrm{m}$, ein Volumen von etwa 20 aL. Für den Einschluss wurde das Substrat wie zuvor beschrieben präpariert und nach Applikation des Sauerstoffplasmas, $10 \mathrm{mM}$ des wasserlöslichen Farbstoffs Pyranin in PBS-Puffer zugegeben. Im nächsten Schritt wurden wieder POPC-haltige GUVs dotiert mit 0,5 mol\% Texas Red DHPE zugegeben und für etwa 15 Minuten inkubiert. Schließlich wurde der nicht-eingeschlossene Farbstoff sowie nicht gespreitete GUVs durch Spülen mit PBS-Puffer wieder entfernt. 

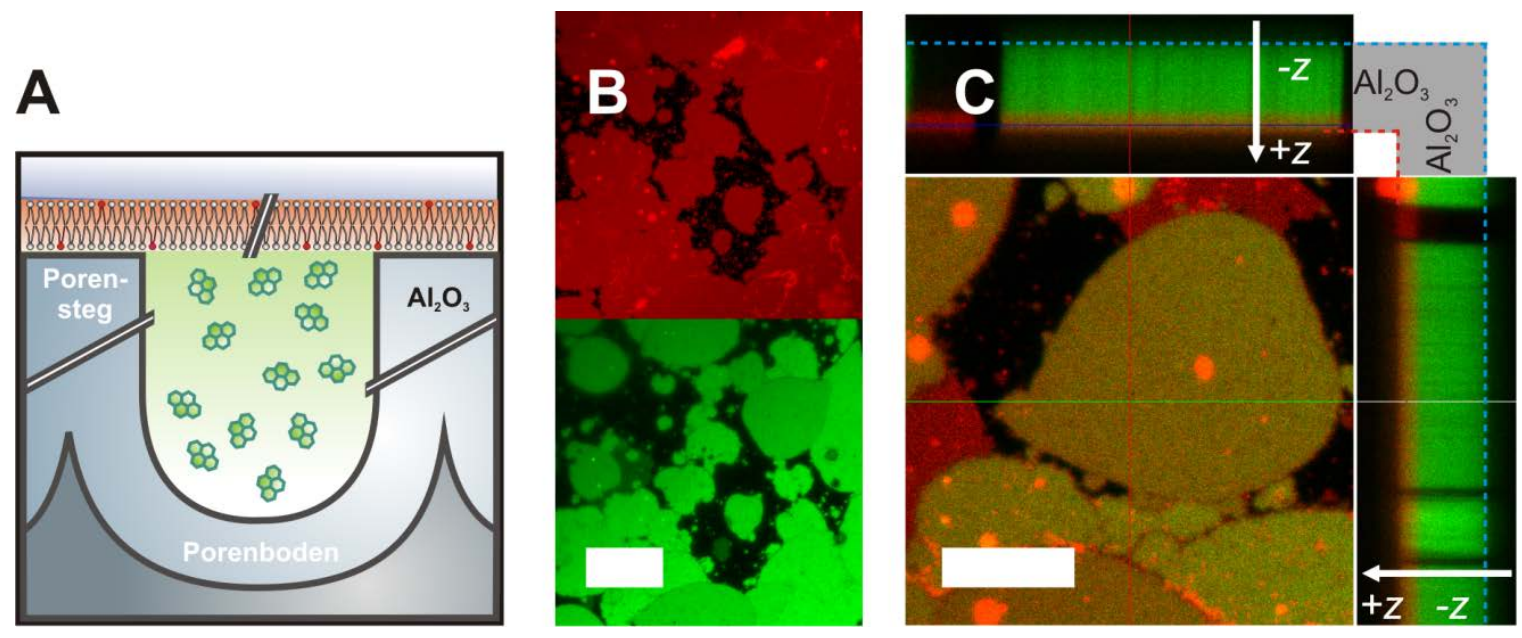

Abb. 4-34: Einschluss des wasserlöslichen Farbstoff Pyranins in die Poren des Aluminiumoxidsubstrates durch porenüberspannende POPC Membranen (0,5 mol\% Texas Red DHPE). $A$, Schematische Darstellung des Einschlusses von Pyranin durch porenüberspannende Membranen. $B$, Aufsicht eines präparierten Substrates mit der porenüberspannenden Membran (rot) mit eingeschlossenem Farbstoff (grün). Maßstab: $20 \mu \mathrm{m} C$, Die konfokalmikroskopische Aufnahme zeigt einen $z$-stack des eingeschlossenen Pyranins (grün) mit porenüberspannender Membran (rot). Die blaue gestrichelte Linie markiert die Porenböden und die rote gestrichelte Linie kennzeichnet die Porenöffnungen. Das zentrale Bild stellt eine $z$-Ebene dar. Die $z$-Schnitte erfolgen entlang der roten Linie für die rechte Abbildung und entlang der grünen Linie für die obere Linie. Maßstab: $10 \mu \mathrm{m}$

Abb. 4-34 verdeutlicht, dass die Lipidmembran an den Rändern benachbarter Membranpatches nicht porenüberspannend ist, da der Fluorophor dort nicht eingeschlossen werden konnte. Die präparierten Membranen konnten den Farbstoff für wenigstens $48 \mathrm{~h}$ einschließen. Weiter konnte gezeigt werden, dass jede einzelne Pore ein unabhängiges Kompartiment darstellt. Zu diesem Zweck wurde Pyranin in einem definierten Bereich gebleicht (Abb. 4-35 A). Die Auftragung des Intensitätsverlaufs im Bleichfleck in Abhängigkeit von der Zeit zeigt, dass es nur zu einem geringen Anstieg der Fluoreszenzintensität kam. Dieser resultiert vermutlich daher, dass Fluorophor in $z$-Richtung außerhalb der fokalen Ebene in die betrachtete Ebene des Bleichflecks diffundiert. 

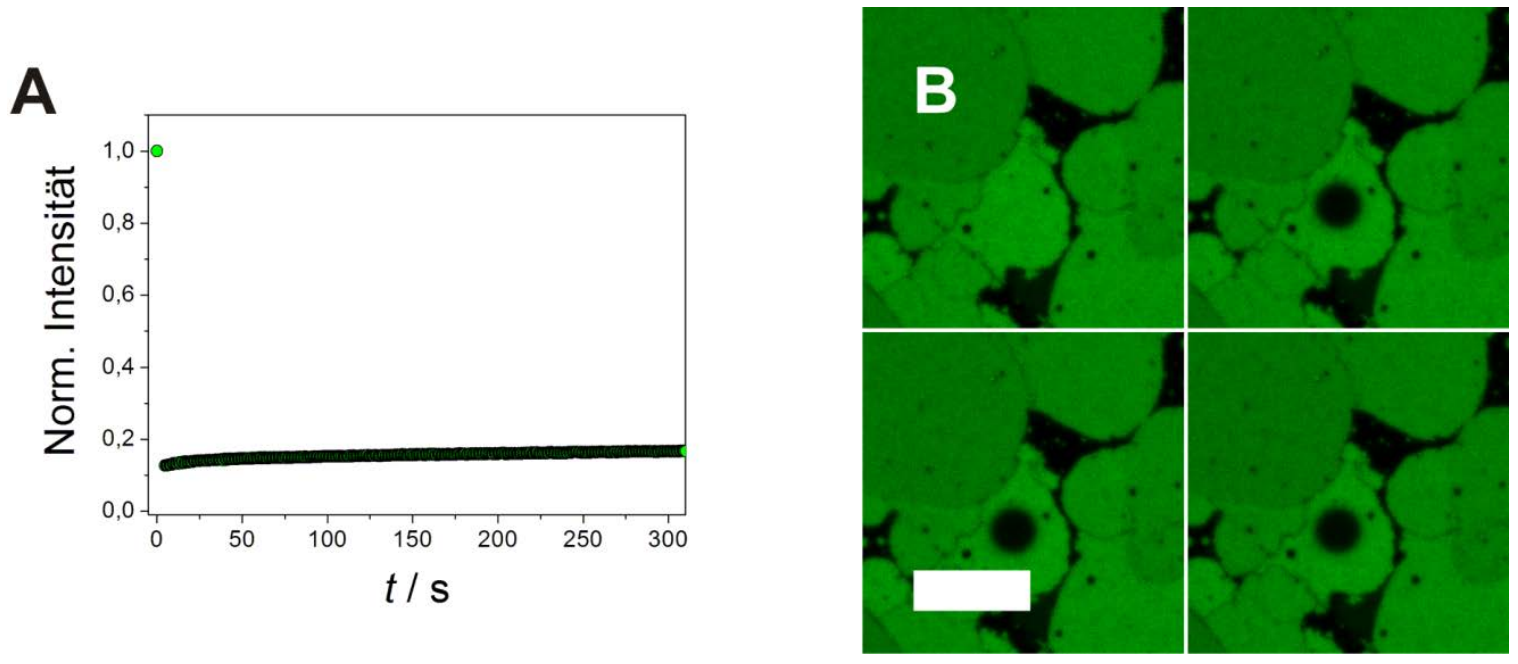

Abb. 4-35: Rückkehr der Fluoreszenz nach Bleichen des eingeschlossenen Pyranins innerhalb der Poren. Der weiße Kreis markiert die Region des Bleichflecks (Region of Interest, ROI) zum Zeitpunkt $t=0$. $A$, Die korrespondierenden fluoreszenzmikroskopischen Aufnahmen zu $B$, zu den Zeitpunkten $t=0,75,150$ und $300 \mathrm{~s}$. Maßstab: $20 \mu \mathrm{m}$ B, Zeitlicher Verlauf der Fluoreszenzintensität nach Bleichen von Pyranin bei $t=5 \mathrm{~s}$.

\subsubsection{Verifizierung von porenüberspannenden Membranen durch die Kopplung von Melittin-Penetration und Farbstofffreisetzung}

Der Aktivitätsnachweis von Connexin Halbkanälen durch einen fluoreszenzbasierten Assay kann über die Freisetzung eines eingeschlossenen Fluorophors, die Aktivität von Gap Junction Kanäle über den Farbstofftransfer zwischen zwei abgeschlossenen Kompartimenten erfolgen. Im nächsten Schritt wurde für die kontrollierte Freisetzung des durch porenüberspannende Membranen eingeschlossenen Farbstoffs Pyranin untersucht. Dafür wurde das lytische Peptid Melittin verwendet. Abb. 4-36 A zeigt schematisch die Farbstofffreisetzung durch die lytische Aktivität von Melittin. Der Einschluss des Fluoreszenzfarbstoffs Pyranin erfolgte wie in Kapitel 4.4.3 beschrieben. Dazu wurde zunächst ein Konzentrationsbereich von 0,07 bis 12,6 $\mu \mathrm{M}$ von Melittin untersucht. Das Peptid wurde in PBS-Puffer gelöst zur Probe hinzugegeben, gemischt und die Intensitätsänderung von Pyranin mittels konfokaler Laserrastermikroskopie zeitabhängig aufgezeichnet. Abb. 4-36 A veranschaulicht das Substrat mit eingeschlossenem Fluorophor vor der Melittinzugabe. Nach 1-minütiger Inkubation der porenüberspannenden POPC-haltigen Membran (0,5 mol\% Texas Red DHPE) mit 2,1 $\mu \mathrm{M}$ Melittin wurde durch die Intensitätsabnahme von Pyranin deutlich, dass durch die Penetration Fluorophor in detektierbaren Mengen freigesetzt werden konnte (Abb. 4-36 C). Zusätzlich wird Lipid durch Melittin solubilisiert, was ebenfalls an 
der Intensitätsabnahme zu sehen ist. Ferner ist es möglich, dass Pyranin zum Teil elektrostatisch mit den Aluminiumoxidsubstraten interagiert und deshalb nicht vollständig aus den Poren freigesetzt wurde. An den Randbereichen der Lipidmembranpatches scheint die Lipiddoppelschicht in mehreren Schichten gestapelt zu sein, so dass es nicht oder nur erschwert zur Freisetzung des Farbstoffs kommt (Abb. 4-36 C).
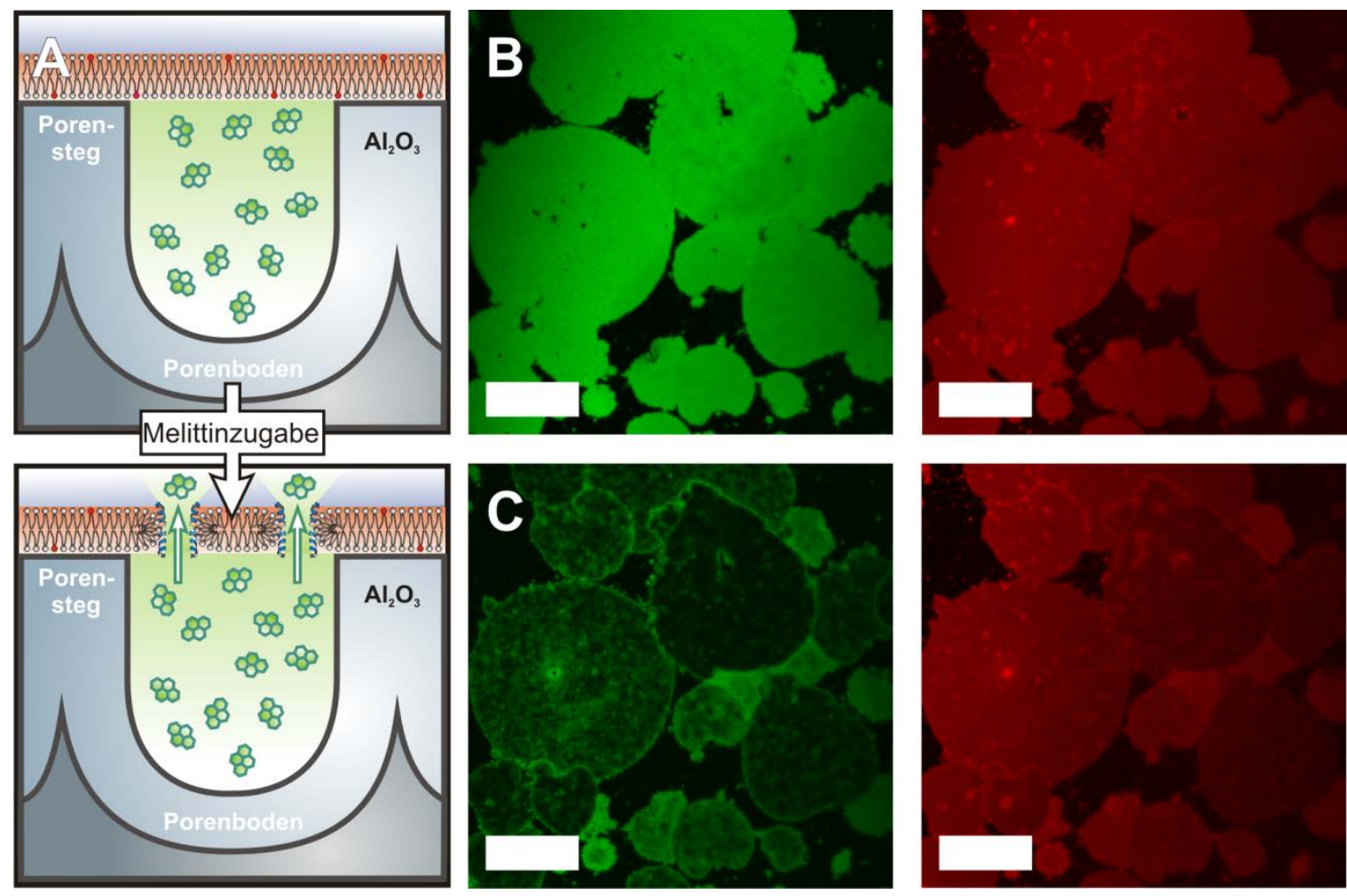

Abb. 4-36: Penetration von porenüberspannenden Membranen auf Aluminiumoxidsubstraten und Freisetzung des zuvor eingeschlossenen Fluorophors. $A$, Schematische Darstellung von porenüberspannenden Membranen, welche Pyranin einschließen. Nach Zugabe von Pyranin kommt es zur Freisetzung des Farbstoffs. $\boldsymbol{B}$, Aluminiumoxidsubstrate mit eingeschlossenem Fluorophor (grün) durch porenüberspannende POPC Membranen mit 0,5 mol\% Texas Red DHPE (rot). $C$, Die fluoreszenzmikroskopische Aufnahme zeigt, dass bei Zugabe von 2,1 $\mu \mathrm{M}$ Melittin nach 1 min der Farbstoff fast vollständig aus den Poren freigesetzt wurde. Sowohl die Intensität von Pyranin (grün) als auch von Texas Red DHPE (rot) nimmt ab und wurde zur Abbildung verstärkt. PBS-Puffer: $136,9 \mathrm{mM} \mathrm{NaCl}, 2,7 \mathrm{mM} \mathrm{KCl}, 8,1 \mathrm{mM} \mathrm{Na}_{2} \mathrm{HPO}_{4}, \mathrm{pH} 7,4, \mathrm{Maßstab}: 20 \mu \mathrm{m}$.

Die ersten Untersuchungen mit unterschiedlichen Konzentrationen an Melittin zeigten, dass es eine Konzentrationsabhängigkeit für die Geschwindigkeit des Penetrationsprozesses gab. Zur Untersuchung dieser Abhängigkeit wurden im ersten Schritt porenüberspannende Membranen, welche aus POPC bzw. DPhPC/Cholesterol im Verhältnis 9 zu 1 bestanden, präpariert und anschließend Pyranin zum PBS-Puffer zugegeben. Dadurch wurde der Farbstoff aus den Poren, die unterhalb der porenüberspannenden Membranen lokalisiert sind, 
ausgeschlossen. Die Vorversuche zeigten, dass sich für dieses System Melittinkonzentrationen $<2,1 \mu \mathrm{M}$ für kinetische Untersuchungen eignen. Zur Membranpenetration wurde Melittin in den Konzentrationen 0,18, 0,35, 0,7 und 1,4 $\mu \mathrm{M}$ zugegeben und unter Rühren die Intensitätszunahme des Bereiches unterhalb des porenüberspannenden Bereichs zeitabhängig aufgezeichnet. Abb. 4-37 A und B zeigt exemplarisch die Penetration von porenüberspannenden POPC Membranen mit 0,35 $\mu \mathrm{M}$ Melittin. Nach Melittinzugabe ist eine deutliche Intensitätszunahme unterhalb der Lipidmembranen zu erkennen. Außerdem ist nach 53 Minuten ebenfalls der Eintritt von Lipidmaterial in die Poren zu erkennen. Der Vergleich der Penetrationsgeschwindigkeit von POPC und DPhPC/Cholesterol Lipidmembranen mit unterschiedlichen Melittinkonzentrationen in Abb. 4-37 C und D zeigt, dass DPhPC/Cholesterol bei gleicher Melittinkonzentration langsamer permeabilisiert werden als POPC Lipidmembranen. Durch die lineare Regression der zeitabhängigen Intensitätsverläufe bei unterschiedlichen Melittinkonzentrationen nach Gl. 4-7 konnten die Geschwindigkeitskonstanten ermittelt werden.

$$
I=I_{0}+k \cdot t
$$

Diese sind zum Vergleich abhängig von der eingesetzten Melittinkonzentration in Abb. 4-37 E aufgetragen. Bei einer Melittinkonzentration von $0,18 \mu \mathrm{M}$ konnte für DPhPC/Cholesterol Lipidmembranen im Zeitfenster von 53 min kein Farbstoffeintritt visualisiert werden. 

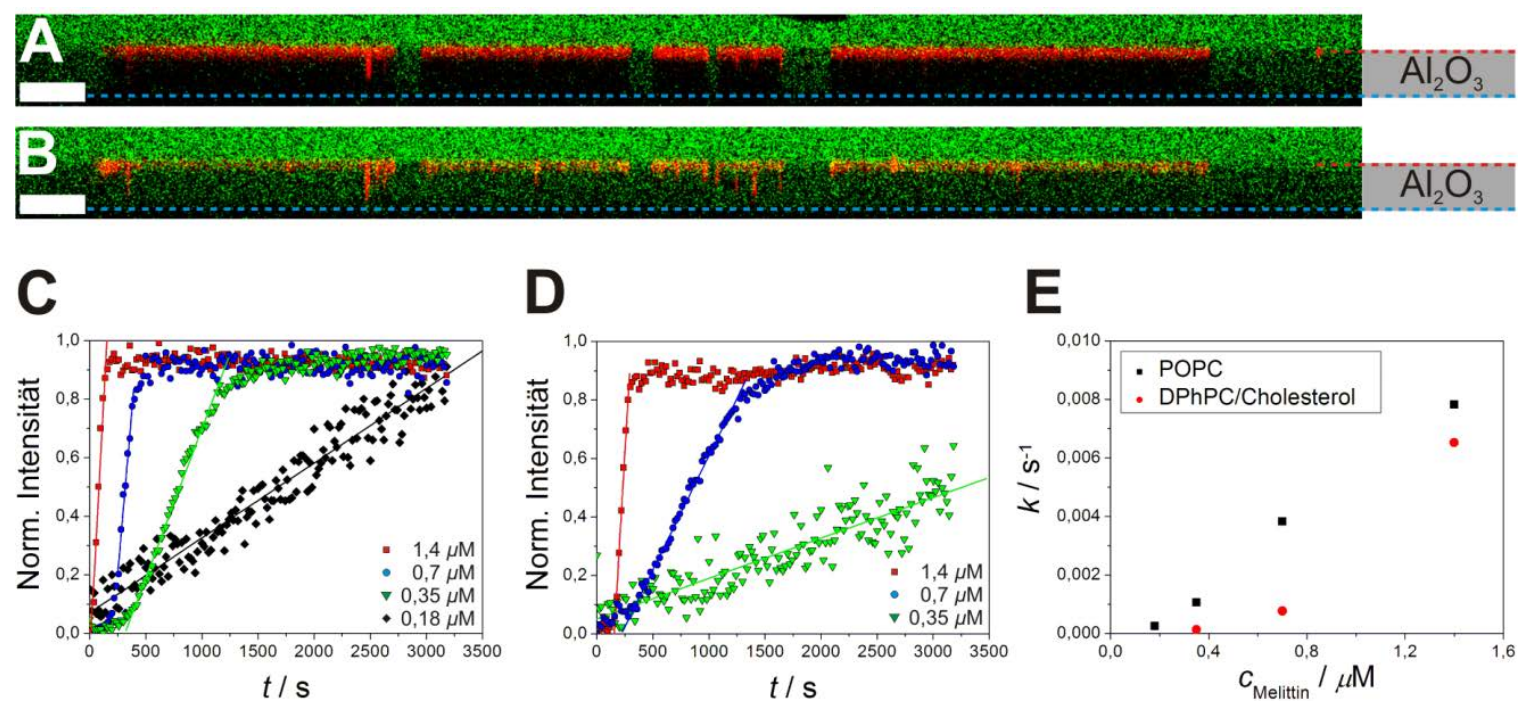

Abb. 4-37: Penetration von porenüberspannenden Membranen mit unterschiedlichen MelittinKonzentrationen. $A$, Porenüberspannende POPC Membranen mit 0,5 mol\% Texas Red DHPE auf porösen Aluminiumoxidsubstraten vor Melittinzugabe zum Zeitpunkt $t=0 \mathrm{~s}$. Die blaue gestrichelte Linie markiert die Porenböden und die rote gestrichelte Linie kennzeichnet die Porenöffnung. PBSPuffer: $\quad 136,9 \mathrm{mM} \quad \mathrm{NaCl}, \quad 2,7 \mathrm{mM} \quad \mathrm{KCl}, \quad 8,1 \mathrm{mM} \quad \mathrm{Na}_{2} \mathrm{HPO}_{4}, \quad \mathrm{pH} 7,4, \quad$ Maßstab: $10 \mu \mathrm{m}$. $B$, Porenüberspannende POPC Membranen nach 53 min Inkubation mit 0,35 $\mu$ M Melittin. $C$ und $D$, Zunahme der Intensität unterhalb von porenüberspannenden POPC und DPhPC/Cholesterol (9:1) Membranen bei den Melittinkonzentrationen 0,18, 0,35, 0,7 und 1,4 $\mu \mathrm{M}$ abhängig von der Zeit. Die durchgezogene Linie zeigt die lineare Regression nach Gl. 4-7. E, Vergleich der ermittelten Geschwindigkeitskonstanten für porenüberspannende POPC und DPhPC/Cholesterol (9:1) Membranen abhängig von der eingesetzten Melittinkonzentration.

Die Ergebnisse der Untersuchungen von porenüberspannenden Membranen, die einen Fluoreszenzfarbstoff einschließen, zeigen, dass der Fluoreszenzfarbstoff Pyranin gezielt mithilfe von Melittin aus den Poren freigesetzt werden kann. Im nächsten Schritt soll nun die Gap Junction Kanalaktivität mithilfe eines fluoreszenzbasierten Assays untersucht werden.

Dieser wird im folgenden Abschnitt näher erläutert. 


\subsection{Nachweis der Gap J unction Kanalaktivität mittels fluores- zenzbasierten Assays}

\subsubsection{Entwicklung eines fluoreszenzbasierten Assays zum Nachweis der Gap J unction Kanalaktivität}

Seit Beginn der Arbeit wurden unterschiedliche, fluoreszenzbasierte Assays konzipiert, um die Gap Junction Kanalaktivität nachzuweisen. Das gemeinsame Prinzip besteht darin, einen Transfer zwischen zwei unterschiedlichen, geschlossenen Kompartimenten zu visualisieren. Niedermolekulare Verbindungen bis zu einem Molekulargewicht von $1 \mathrm{kDa}$ können den Gap Junction Kanal passieren. ${ }^{[16]} \mathrm{Zu}$ Beginn der Arbeit wurden für den Transferassay zwei unterschiedliche, unilamellare Riesenvesikelpopulationen (Giant Unilamellar Vesicles, GUVs) präpariert. Zur Herstellung der ersten Vesikelfraktion, die mit einem wasserlöslichen Fluoreszenzfarbstoff gefüllt war, lag während der Elektroformation der POPC-haltigen GUVs (Kapitel 3.5.3) Carboxyfluorescein in einer Konzentration von $1 \mathrm{mM}$ vor. Durch Verdünnung der GUVs in TRIS-Puffer wurde das Carboxyfluorescein außerhalb der GUVs soweit verdünnt, dass die gefüllten GUVs durch konfokale Laserrastermikroskopie visualisiert werden konnten. Die ersten Untersuchungen zeigten, dass der niedermolekulare Fluorophore Carboxyfluorescein $\left(M=376 \mathrm{~g} \cdot \mathrm{mol}^{-1}\right)$ nicht in der Lage war, den Halbkanal zu passieren. Dies konnte ebenfalls von Gaßmann für den Connexin 26 (Cx26) Halbkanal und Kaneda et al. für den Cx43 Halbkanal gezeigt werden. ${ }^{[186,203]}$ Die zweite POPC-haltige Vesikelpopulation wurde mit dem lipidgekoppelten Farbstoff Texas Red (Kapitel 3.3.2) markiert. Für die Integration von Cx43 bzw. Cx43-GFP aus P. pastoris (1. Fermentationscharge, Kapitel 4.1.2) in unilamellare GUVs wurde die fusionsvermittelte Rekonstitution genutzt (Kapitel 4.2.3). Das Prinzip des Transferassays ist in Abb. 4-38 dargestellt. Wenn es zur Ausbildung von GapJunction Kanälen zwischen den unterschiedlichen Vesikelpopulationen kommt, müssten Vesikelpaarungen von Carboxyfluorescein gefüllten GUVs mit Texas Red DHPE dotierten GUVs zu finden sein, die eine identische Fluoreszenzintensität von Carboxyfluorescein aufweisen. Mithilfe der Fluoreszenzmikroskopie konnten allerdings nur wenige Paarungen identifiziert werden. Zur Überprüfung des kanalvermittelten Farbstofftransfers wurde der Vesikelinhalt der Texas Red DHPE dotierten GUVs durch einen Laserpuls hoher Intensität gebleicht. Dadurch konnte überprüft werden, 
ob der Farbstoff durch die Bildung von Gap Junction Kanälen übertragen wurde oder durch Membrandefekte in den benachbarten GUV gelangt. Abb. 4-38 B und C zeigt zwei Ereignisse, die für diesen fluoreszenzbasierten Assay charakteristisch waren. Abb. 4-38 B veranschaulicht, dass in beiden GUVs Farbstoff in unterschiedlicher Konzentration eingeschlossen war. Jedoch wird durch das Bleichen des Vesikelinhalts von GUV (b) ersichtlich, dass der Farbstoff wahrscheinlich aus dem umgebenden Medium stammte und nicht über einen Transfer von GUV (a), da die Intensität im GUV (b) nur wieder das Niveau der Hintergrundfluoreszenz erreichte. Dagegen veranschaulicht die Vesikelpaarung in Abb. 4-38 C einen Transfer von Carboxyfluorescein in beide Richtungen, unabhängig davon, welcher Vesikelinhalt gebleicht wurde. Allerdings sind beide Vesikel mit Texas Red DHPE dotiert. Dies deutet daraufhin, dass es zur Hemifusion zwischen den gepaarten Vesikeln kam. Der Transfer könnte über Gap Junction Kanäle stattgefunden haben, aber auch der Transfer über Membrandefekte, die durch die Annäherung bzw. Hemifusion von zwei Lipidmembranen entstehen können, konnte nicht ausgeschlossen werden. 

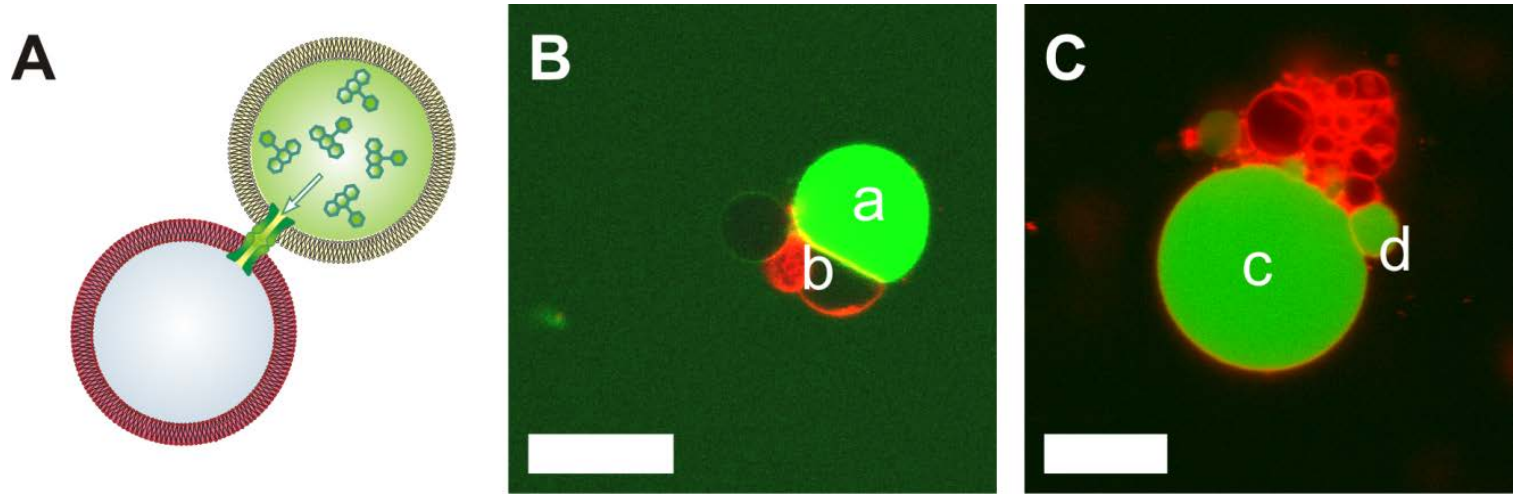

Abb. 4-38: Farbstofftransferassay zum Nachweis der Gap Junction Kanalaktivität. $A$, Schematische Darstellung der Gap Junction Kanalbildung zwischen der Vesikelfraktion, welche mit Carboxyfluorescein gefüllt ist, und der Texas Red DHPE dotierten Vesikelfraktion. Der Farbstoffaustausch findet durch den GapJunction Kanal bis zum Intensitätsausgleich statt. $\boldsymbol{B}$, Fluoreszenzmikroskopische Aufnahme einer Vesikelpaarung von Texas Red DHPE und Cx43 dotiertem GUV (a) mit einem Cx43-GFP dotierten GUV (b), der mit Carboxyfluorescein gefüllt ist. Durch das Bleichen des Vesikelinhalts von GUV (b) konnte keine Verbindung durch Gap Junction Kanäle nachgewiesen werden. $C$, Darstellung einer Kopplung zwischen zwei Texas Red DHPE und Cx43 bzw. Cx43-GFP dotierten GUVs. Durch das Bleichen der Carboxyfluorescein-Fluoreszenz von GUV (c) und (d) konnte ein Transfer zwischen den Vesikeln in beide Richtungen beobachtet werden. Proteo-SUVs: $22 \mu \mathrm{g} \cdot \mathrm{mL}^{-1}, 107 \mu \mathrm{g} \cdot \mathrm{mL}^{-1} \mathrm{Cx} 43-\mathrm{GFP}, 2 \mathrm{mg} \cdot \mathrm{mL}^{-1}$ POPC; Puffer: $100 \mathrm{mM} \mathrm{KCl}, 10 \mathrm{mM}$ TRIS, pH 7,4; Maßstab: $20 \mu \mathrm{m}$.

Die Untersuchung der Gap Junction Kanalaktivität mit diesem fluoreszenzbasierten Assay zeigte, dass aufgrund der geringen Anzahl an Paarungen nur wenige Transferereignisse beobachtet werden konnten. Um die Anzahl der Ereignisse zu erhöhen, wurde als Basis für einen weiteren fluoreszenzbasierten Assay ein molekulares Erkennungssystem verwendet. Dies besteht aus der lipidgekoppelten Nitrilotriessigsäure in Komplex mit Nickel (Nitrilotriacetic Acid, Ni-NTA) und aus dem Lipid DOPE mit einer Maleimidgruppe (MCCDOPE, Kapitel 3.5.4). ${ }^{[204]}$ Diese Maleimidgruppe kann in einer Michael-Addition mit der C-terminalen Thiolgruppe des Nonapeptids $\mathrm{H}_{6}$ WGC reagieren (Abb. 4-39 A, Kapitel 3.5.4).

A

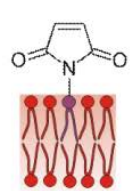

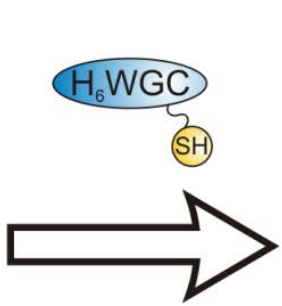
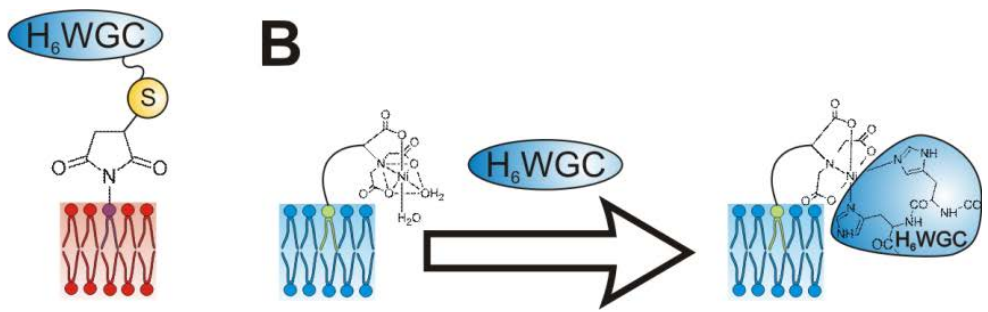

Abb. 4-39: Schematische Darstellung der Komplexbildung von DOGS-Ni-NTA mit dem Nonapeptid $\mathrm{H}_{6} \mathrm{WGC}(\boldsymbol{A})$ und der Kopplung der Maleimidgruppe des MCC-DOPE mit der Thiolgruppe des $C$-terminalen Cysteins von $\mathrm{H}_{6} \mathrm{WGC}(\boldsymbol{B})$. Die Abbildung wurde nach Stephanie Voß angefertigt. ${ }^{[205]}$ 
Durch die spezifische Interaktion des Hexahistidins mit dem Ni-NTA-Komplex wird der Abstand zwischen zwei gegenüberliegenden Membranen bis auf etwa $3 \mathrm{~nm}$ verringert (Abb. 4-39 B). Einleitend wurde bereits erwähnt, dass es durch die Bildung von Gap Junction Kanälen zwischen den Plasmamembranen von zwei benachbarten Zellen zu einer Abstandsverringerung des Extrazellularraums (Gap) zwischen den Zellen von etwa $20 \mathrm{~nm}$ auf 3 bis $4 \mathrm{~nm}$ kommt. Die Reduktion des Membranabstandes zwischen den Vesikeln könnte die Gap Junction Kanalbildung begünstigen.

Die Entwicklung eines fluoreszenz-basierten Funktionsassays, basierend aus planaren, porenüberspannenden Membranen, konnte nach der Validierung mit Melittin in Kapitel 4.4 zum Nachweis der Gap Junction Kanalaktivität eingesetzt werden. Abb. 4-40 zeigt den schematischen Aufbau dieses Funktionsassays. Im ersten Schritt werden porenüberspannende Membranen mit Cx43 bzw. Cx43-GFP dotierten POPC-haltigen GUVs wie in Kapitel 4.4 beschrieben, präpariert und der wasserlösliche Farbstoff Pyranin $\left(M=524,4 \mathrm{~g} \cdot \mathrm{mol}^{-1}\right)$ in die Poren eingeschlossen. Die porenüberspannenden Membranen sind mit Texas Red DHPE und DOPE, welches an eine Maleimidgruppe gekoppelt ist, dotiert. Nach Kopplung des Nonapeptids $\mathrm{H}_{6}$ WGC kann über die Wechselwirkung zwischen dem Hexhistidin-Tag und Ni-NTA die Kopplung von Cx43 bzw. Cx43-GFP dotierten GUVs erfolgen. Wenn es zur Ausbildung von Gap Junction Kanälen kommt, findet ein Konzentrationsausgleich zwischen den gefüllten Poren und dem Vesikellumen statt. 


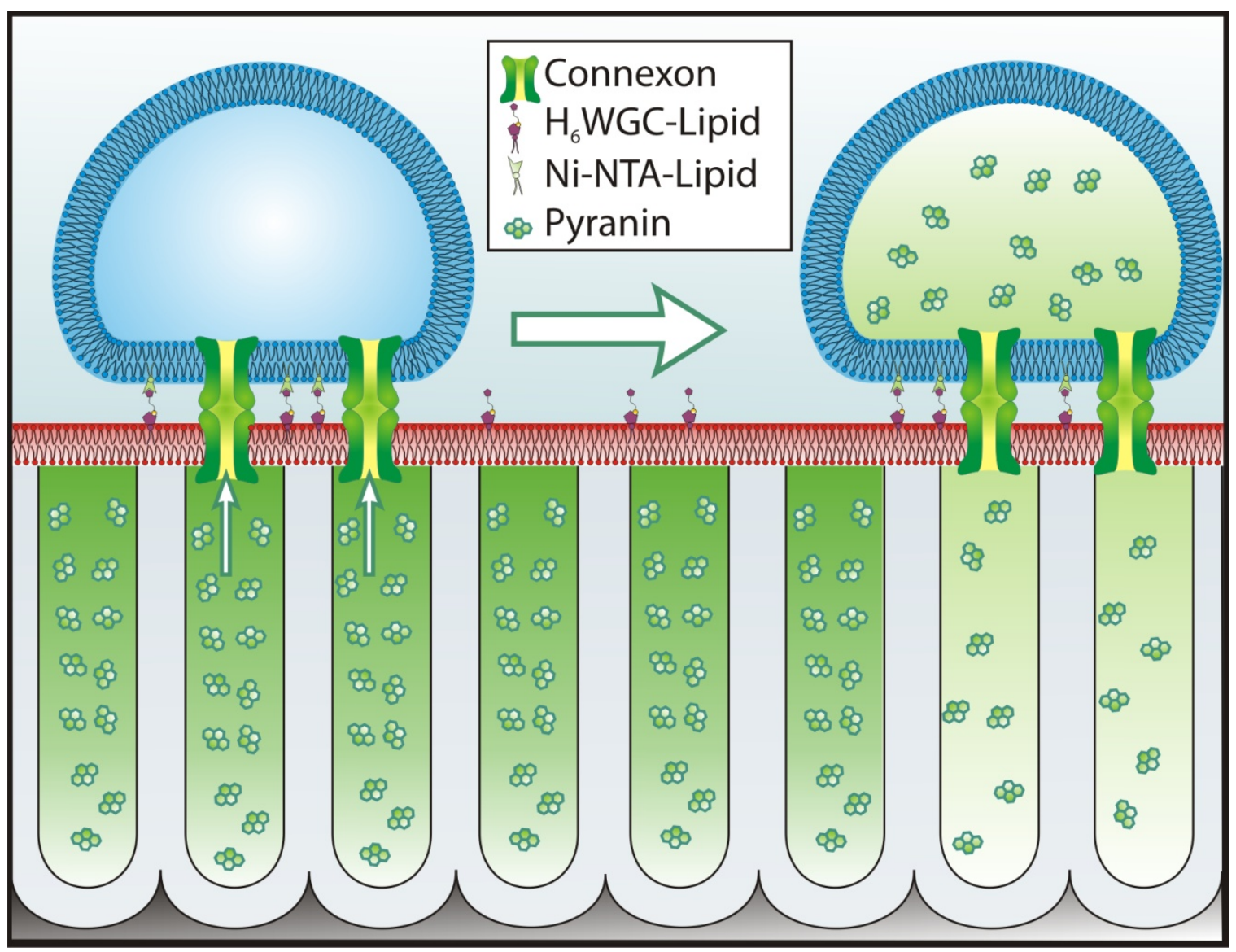

Abb. 4-40: Schematische Darstellung des fluoreszenzbasierten Assays zum Nachweis der Gap Junction Kanalaktivität. Das Größenverhältnis von Pore zu GUV ist nicht maßstabsgerecht dargestellt. Im ersten Schritt wird der wasserlösliche Fluoreszenzfarbstoff Pyranin durch porenüberspannende Membranen, welche mit Texas Red DHPE und MCC-DOPE dotiert sind, eingeschlossen. Nach Funktionalisierung der Lipidmembran mit dem Nonapeptid $\mathrm{H}_{6}$ WGC kommt es zur Anbindung der GUVs, welche mit Perylen dotiert sind, durch die spezifische Interaktion von DOGS-Ni-NTA mit dem $\mathrm{H}_{6}$ WGC. Die Annäherung forciert die Ausbildung von Gap Junction Kanälen, was wiederum den Farbstofftransfer von den Poren in das Vesikel ermöglicht.

Das molekulare Erkennungssystem aus $\mathrm{H}_{6}$ WGC und DOGS-Ni-NTA wurde bereits zur Studie von Membranfusionen von Ines Höfer in der Arbeitsgruppe verwendet. Dabei zeigte sich, dass bei einer Konzentration der Komponenten unter 1 mol\% keine Fusionsereignisse detektiert wurden. ${ }^{[206]}$ Deshalb konnte dieses molekulare Erkennungssystem zur verstärkten Annäherung der Lipidmembranen genutzt werden, ohne das es dabei zur Fusion der Membranen kam, was ebenfalls einen Farbstofftransfer zur Folge hätte. Zunächst wurden zur Visualisierung der Kopplung des Nonapeptids $\mathrm{H}_{6} \mathrm{WGC}$ an die Maleimidgruppe des MCCDOPE festkörperunterstützte Membranen verwendet. Dafür wurden kleine, unilamellare Vesikel (Small Unilamellar Vesicles, SUVs), dotiert mit 0,5 mol\% Perylen und 0, 0,1 oder 0,5 mol\% MCC-DOPE, auf hydrophylisierten Si-Wafern nach Kapitel 3.5.7 gespreitet. 
Zum fluoreszenzmikroskopischen Nachweis der Kopplung des Nonapeptids an die Maleimidgruppe wurde eine mit dem Fluoreszenzfarbstoff 5(6)-TAMRA markierte Variante verwendet (Kapitel 3.3.2). Nach einstündiger Inkubation mit 5(6)-TAMRA-H6WGC wurde die Kopplung des Nonapeptids durch konfokale Laserrastermikroskopie dokumentiert. Abb. 4-41 zeigt, dass mit steigender MCC-DOPE Konzentration auch eine steigende Fluoreszenzintensität an TAMRA-H 6 WGC detektiert werden konnten. Für die nachfolgenden Experimente wurden 0,5 mol\% MCC-DOPE verwendet.
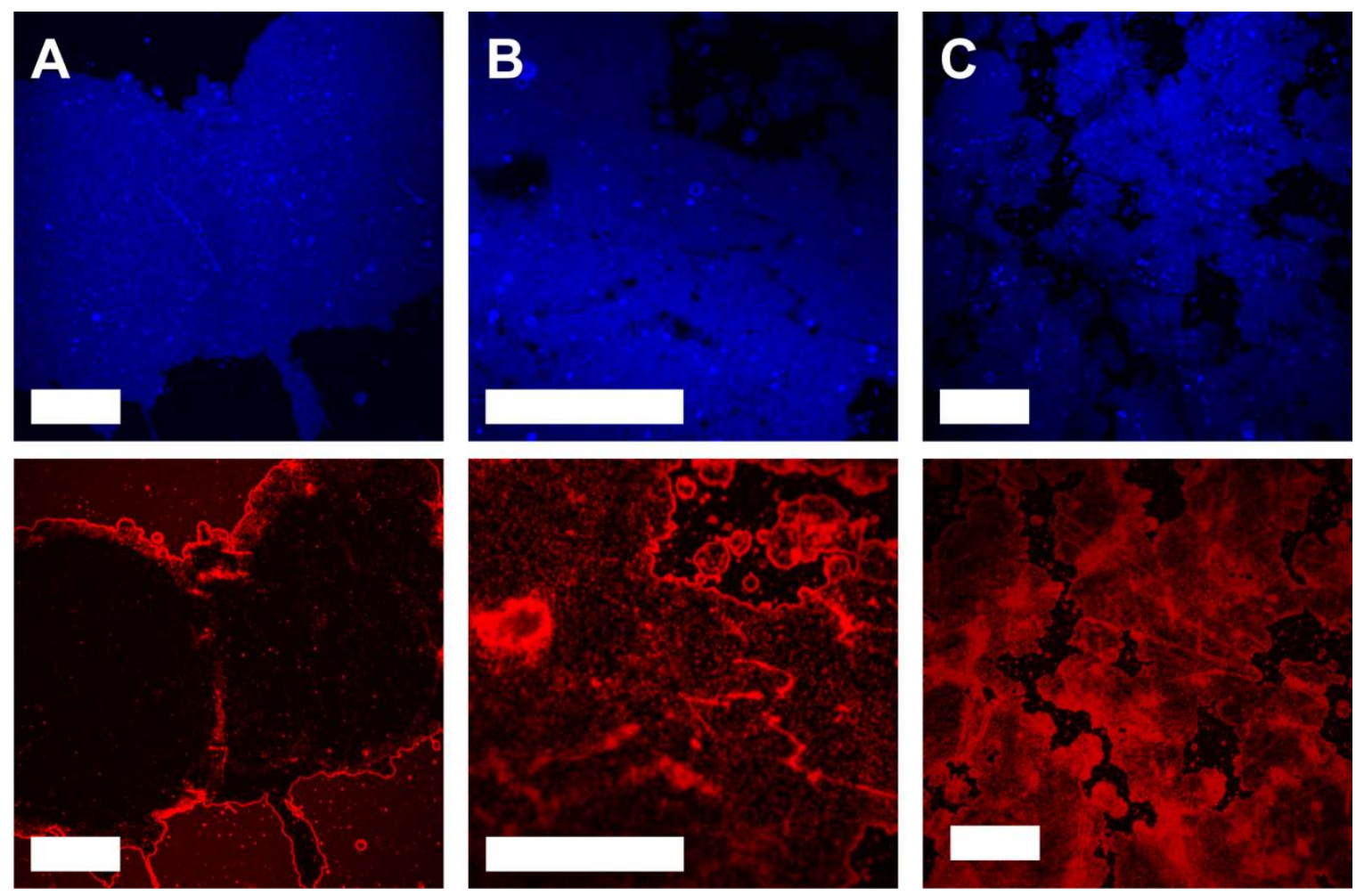

Abb. 4-41: Fluoreszenzmikroskopische Aufnahmen der Kopplung des TAMRA markierten $\mathrm{H}_{6}$ WGC (rot) mit dem Maleimid gekoppelten DOPE integriert in festkörperunterstützte POPC Membranen (0,5 mol\% Perylen, blau). Mit steigender Konzentration von MCC-DOPE wurde mehr Peptid an der Lipidmembran angebunden. $A$, ohne MCC-DOPE. $B, 0,1 \mathrm{~mol} \%$ MCC-DOPE. $C, 0,5 \mathrm{~mol} \%$ MCC-DOPE. Maßstab: $40 \mu \mathrm{m}$ 


\subsubsection{Untersuchung der Gap J unction Kanalaktivität durch einen Farbstofftransferassay basierend auf porenüberspannende Membranen}

Zur Untersuchung der Gap Junction Kanalaktivität wurde ein fluoreszenzbasierter Assay entwickelt, der es ermöglicht, sowohl langsame als auch schnell ablaufende Prozesse in situ zu verfolgen. Da wenig darüber bekannt ist, in welchem Zeitfenster die Gap Junction Kanalbildung in vitro stattfindet, bietet der Assay die ideale Möglichkeit, diesen Prozess zeitaufgelöst mithilfe der Laserrasterfluoreszenzmikroskopie zu verfolgen. Kapitel 4.2 verdeutlicht, dass sich die Methode der fusionsvermittelten Rekonstitution am besten zur Integration von Cx43 und Cx43-GFP eignet. Für die Integration von Cx43 bzw. Cx43-GFP wurde ein Konzentrationsbereich von 8,0 bis $32,0 \mu \mathrm{g} \cdot \mathrm{mL}^{-1}$ bzw. 2,8 bis $9,5 \mu \mathrm{g} \cdot \mathrm{mL}^{-1}$ (2. Fermentationscharge) verwendet. Zunächst wurde der Fluoreszenzfarbstoff Pyranin (10 mM) durch Bildung von porenüberspannenden, POPC-haltigen Membranen, welche mit Texas Red DHPE, MCC-DOPE und Cx43 oder Cx43-GFP dotiert waren, in die Poren eingeschlossen. Anschließend wurde die Maleimidgruppe des Lipids MCC-DOPE mit der $C$-terminalen Thiolgruppe des Peptids $\mathrm{H}_{6} \mathrm{WGC}(23 \mu \mathrm{M})$ in einer einstündigen Inkubation gekoppelt. Nach der Entfernung des überschüssigen Peptids wurden POPC-haltige GUVs, welche mit Perylen, DOGS-Ni-NTA sowie Cx43 oder Cx43-GFP markiert waren, zur präparierten Membran zugegeben. Bei der fluoreszenzmikroskopischen Analyse sind drei Ereignisse denkbar. Im ersten Fall kommt es zur Bildung von Gap Junction Kanälen, wodurch der Farbstoff vom Poreninneren in das Vesikellumen diffundiert. Um diesen Transfer zu visualisieren müssen ausreichend Poren über die gebildeten Transmembrankanäle ihren Inhalt in das Vesikellumen übertragen, da sich der Fluoreszenzfarbstoff im Vesikelvolumen verdünnt. Außerdem könnte es im zweiten Fall zur Hemifusion der Lipidmembranen kommen, da deren Annäherung durch das molekulare Erkennungssystem verstärkt wird. Dies könnte ebenfalls dazu führen, dass es zur Ausschüttung des Farbstoffes durch Membrandefekte ins Vesikelinnere kommt. Als dritter Fall findet kein Farbstofftransfer statt, da Fall 1 und 2 nicht eintreten. Mithilfe der fluoreszenzmikroskopischen Analysen konnten zwei typische Anbindungen von GUVs unterschieden werden. Einerseits wurden POPC-haltige GUVs, welche mit Perylen, DOGS-Ni-NTA und Cx43-GFP dotiert waren, beobachtet, die wahrscheinlich nur über wenige molekulare Rezeptoren wechselwirken, da diese nur eine geringe Deformation zeigten (Abb. 4-42 A). Andererseits wurden POPC-haltige GUVs 
dokumentiert, die durch die Wechselwirkung von $\mathrm{H}_{6}$ WGC, gekoppelt an MCC-DOPE, mit der DOGS-Ni-NTA eine starke Deformation aufwiesen (Abb. 4-42 B). Trotz der forcierten Anbindung von Cx43- bzw Cx43-GFP-haltigen GUVs an Cx43- bzw. Cx43-GFP-haltige porenüberspannende Membranen konnte Fall 1 und 2 nicht beobachtet werden. Die Negativkontrolle ohne molekularen Rezeptor (DOGS-Ni-NTA, $\mathrm{H}_{6}$ WGC gekoppelt mit MCC-DOPE) verdeutlichte nochmals, dass es durch die Wechselwirkung des lipidgekoppelten Hexahistidins mit der lipidgekoppelten Ni-NTA-Gruppe zur verstärkten Interaktion zwischen den beiden Membranen kommt. Nur mit molekularem Rezeptor konnten die POPC-haltigen GUVs mit 0,5 mol\% Perylen bevorzugt auf den porenüberspannenden Membranen gefunden werden (Abb. 4-42 C).

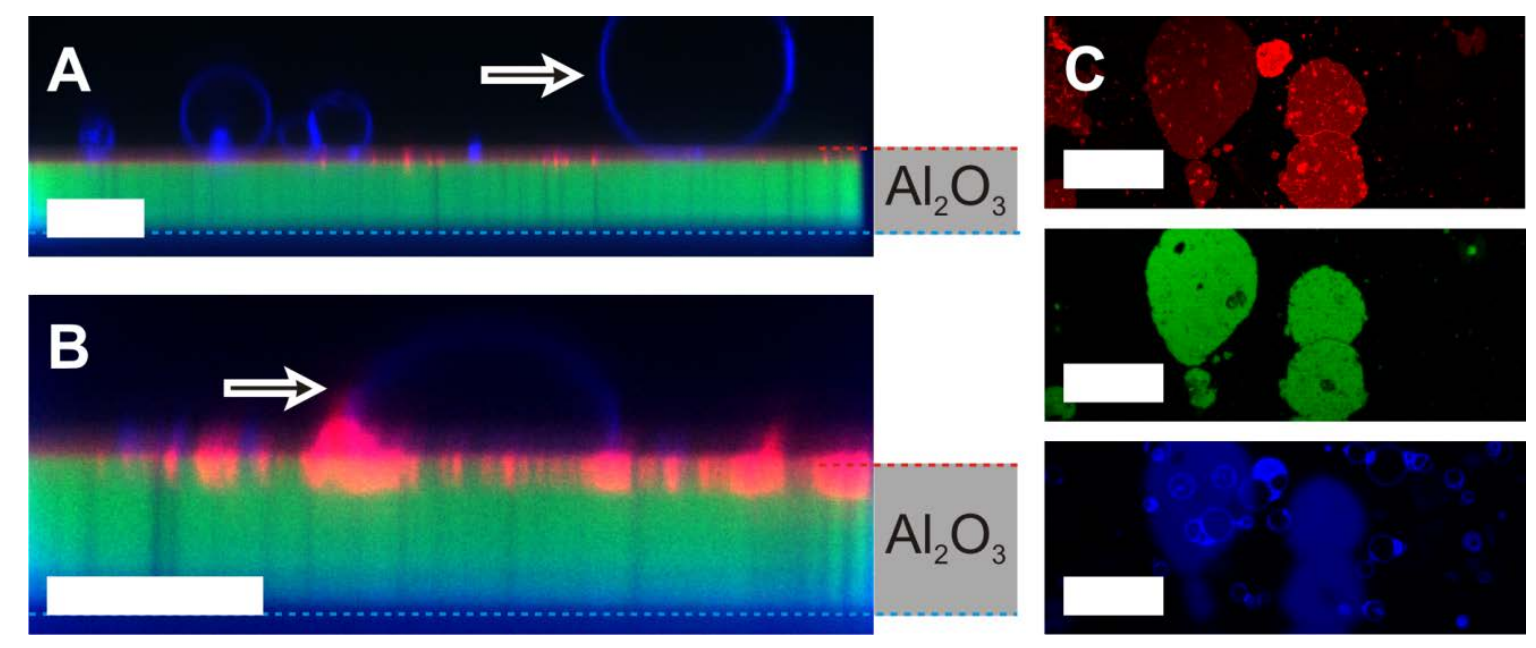

Abb. 4-42: Farbstofftransferassay zum Nachweis der Gap Junction Kanalaktivität. Der Fluoreszenzfarbstoff Pyranin (grün) ist durch die porenüberspannenden, POPC-haltigen Membranen, die mit 0,5 mol\% Texas Red DHPE (rot) und Cx43-GFP dotiert sind, in die Poren eingeschlossen worden. Die Kopplung POPC-haltiger GUVs, welche mit 0,5 mol\% Perylen (blau) und Cx43-GFP dotiert sind, mit porenüberspannenden, POPC-haltigen Membranen durch die Wechselwirkung des MCC-DOPE gekoppelten $\mathrm{H}_{6}$ WGC mit DOGS gekoppelten Ni-NTAGruppen, führt zur verstärkten Annäherung und Interaktion der Lipidmembranen. PBS-Puffer: $136,9 \mathrm{mM} \mathrm{NaCl}, 2,7 \mathrm{mM} \mathrm{KCl}, 8,1 \mathrm{mM} \mathrm{Na} \mathrm{HPO}_{4}, \mathrm{pH}$ 7,4 $\boldsymbol{A} \& \boldsymbol{B}$, Die fluoreszenzmikroskopischen Aufnahmen verdeutlichen, dass die Wechselwirkung zwischen GUVs (Pfeile) und porenüberspannenden Membranen in Abb. B stärker ist als in Abb. A. (Proteo-SUVs: $9,5 \mu \mathrm{g} \cdot \mathrm{mL}^{-1}, 2 \mathrm{mg} \cdot \mathrm{mL}^{-1}$ ); Maßstab: $10 \mu \mathrm{m}$. $C$, Übersicht mehrerer POPC-haltiger Lipidmembranpatches mit 0,5 mol\% Texas Red DHPE (rot), welche Pyranin (grün) einschließen. Durch das molekulare Erkennungssystem wurden die POPC-haltigen GUVs (blau) auf der porenüberspannenden Membran fixiert. (Proteo-SUVs: 6,4 $\mu \mathrm{g} \cdot \mathrm{mL}^{-1}, 2 \mathrm{mg} \cdot \mathrm{mL}^{-1}$ ), Maßstab: $40 \mu \mathrm{m}$.

Durch die Analyse der Experimente zum Funktionsnachweis der Gap Junction Kanalaktivität wurde deutlich, dass es nicht zum Farbstofftransfer kam bzw. dieser nicht visualisiert werden konnte. Wenn es zu einer Gap Junction Bildung kommen würde, wird der Farbstoff 
in das Vesikelinnere transferiert und verdünnt sich. Die Kalkulation des Farbstofftransfers $\left(\sim 10 \mathrm{mM}\right.$ Pyranin) von nur einer Pore $\left(d_{0}=60 \mathrm{~nm}\right)$ in das Vesikellumen eines GUVs mit einem Radius von $10 \mu \mathrm{m}$ ergab, dass es zu einer 24.000-fachen Verdünnung des Fluorophors kommen würde. Im Gegensatz dazu würde die Ausschüttung des Fluorophors von einem GUV, der mit $0,5 \mathrm{mM}$ Pyranin gefüllt ist, in einer Pore $\left(d_{0}=60 \mathrm{~nm}\right) \mathrm{zu}$ einer vernachlässigbaren Verdünnung des Fluorophors führen. Aus diesem Grund wurde ebenfalls ein Farbstofftransferassay getestet, wobei das Prinzip des Transferassays umgekehrt wurde. Hierfür wurde der Fluoreszenzfarbstoff (0,5 mM Pyranin) in die POPC-haltigen GUVs, welche mit Perylen, DOGS-Ni-NTA und Cx43 dotiert waren, eingeschlossen. Für die Präparation der porenüberspannenden, POPC-haltigen Membranen, die mit Texas Red DHPE, MCCDOPE und Cx43 markiert waren, wurde wie zuvor vorgegangen und nach dem Spreiten mit der zuvor verwendeten Konzentration des Peptids $\mathrm{H}_{6}$ WGC inkubiert. Nach der Kopplung der GUVs an die porenüberspannenden Membranen (Abb. 4-43 A) mithilfe des molekularen Erkennungssystems konnten wieder zwei verschiedene Formen der Ankopplung beobachtet werden. Die fluoreszenzmikroskopische Analyse der beobachteten, gekoppelten GUVs in Abb. 4-43 B deutet daraufhin, dass hier eine starke Wechselwirkung stattfindet. Dies wird wieder an der Deformation der gekoppelten Vesikel auf der Membranoberfläche (Pfeil) deutlich, was in Abb. 4-43 C nicht eindeutig zu sehen ist. Mit der fluoreszenzmikroskopischen Analyse zum Farbstofftransfer konnte nicht eindeutig nachgewiesen werden, dass es zum Fluoreszenzfarbstofftransfer vom den Pyranin gefüllten GUVs in die Poren durch Gap Junction Kanalbildung kam. 

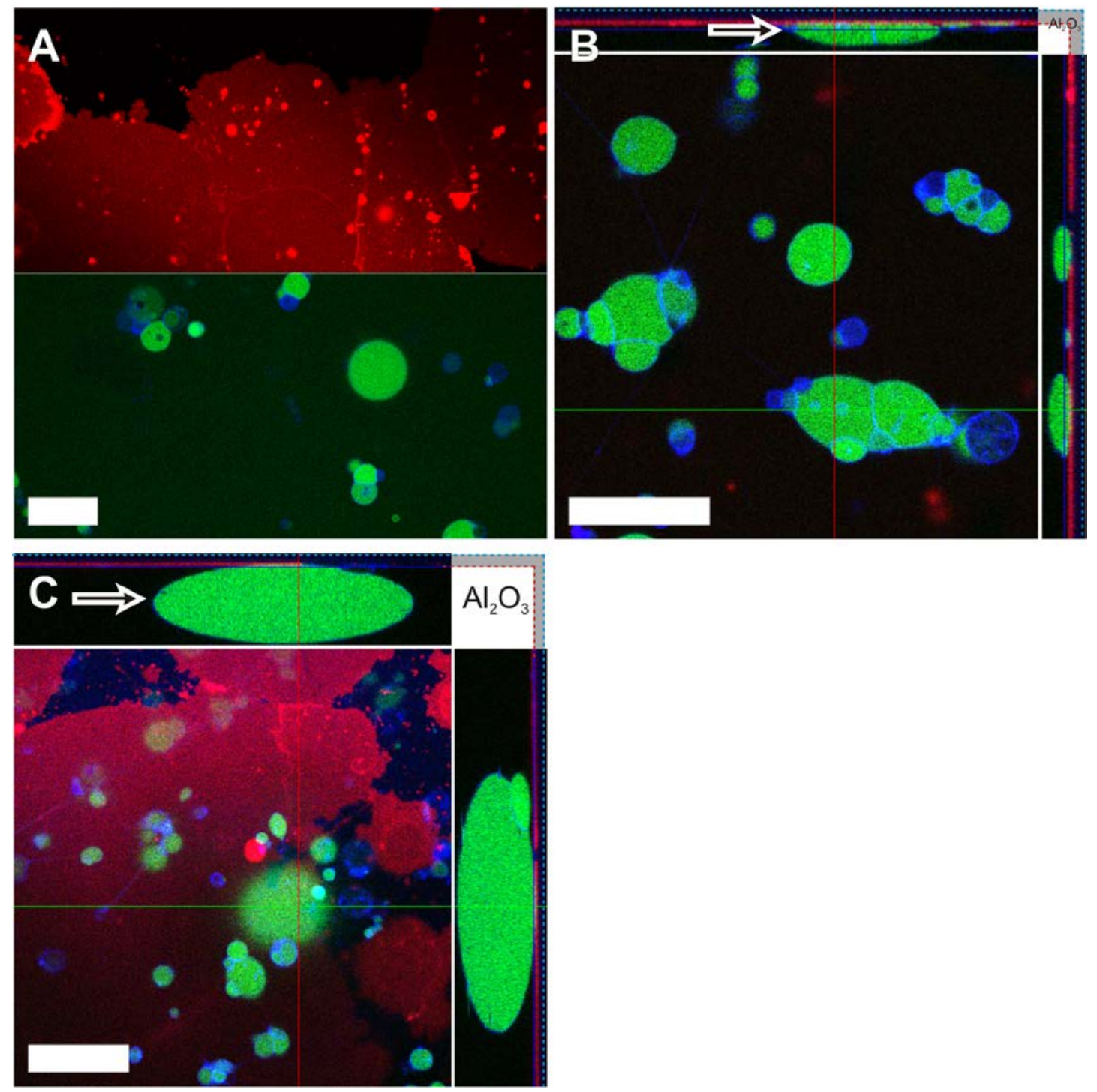

Abb. 4-43: Farbstofftransferassay zum Nachweis der Gap Junction Kanalaktivität. Die fluoreszenzmikroskopischen Aufnahmen zeigen porenüberspannende, POPC-haltige Membranen, welche mit 0,5 mol\% Texas Red DHPE (rot), 0,5 mol\% MCC-DOPE und Cx43 dotiert sind, auf porösen Aluminiumoxidsubstraten. Die POPC-haltigen GUVs, welche mit 0,5 mM Pyranin (grün) gefüllt und mit 0,5 mol\% Perylen (blau), 0,5 mol\% DOGS-Ni-NTA und Cx43 dotiert sind, die über das molekulare Erkennungssystem wechselwirken. PBS-Puffer: 136,9 mM NaCl, 2,7 mM KCl, 8,1 mM $\mathrm{Na}_{2} \mathrm{HPO}_{4}, \mathrm{pH} 7,4$, Maßstab: $80 \mu \mathrm{m} A$, Übersicht des porösen Aluminiumoxidsubstrats mit porenüberspannenden Membranen, an welche GUVs gekoppelt sind. (Proteo-SUVs: $16 \mu \mathrm{g} \cdot \mathrm{mL}^{-1}$, $\left.2 \mathrm{mg} \cdot \mathrm{mL}^{-1}\right) \boldsymbol{B} \& \boldsymbol{C}$, Die fluoreszenzmikroskopischen Aufnahmen zeigen einen z-stack der GUVs angekoppelt an porenüberspannende Membranen. Dabei findet eine unterschiedlich starke Wechselwirkung statt. Das zentrale Bild stellt eine $z$-Ebene dar. Die $z$-Schnitte erfolgen entlang der roten Linie für die rechte Abbildung (y-z-Richtung) und entlang der grünen Linie für die obere Abbildung ( $x$ - $z$-Rinchtung). Der graue Balken veranschaulicht die Position des Aluminiumoxidsubstrates. Die rote gestrichelte Linie markiert die Porenöffnungen, die blaue gestrichelte Linie kennzeichnet die Porenböden. In $z$-Richtung ist kein eindeutiger Farbstofftransfer in die Poren unterhalb der porenüberspannenden Membran erkennbar. 


\section{Diskussion}

\subsection{Gewinnung verschiedener Connexine durch heterologe Proteinexpression}

\subsubsection{Expression von Cx43 und Cx43-eGFP in Dictyostelium discoideum}

D. discoideum konnte für eine Reihe heterolog-exprimierbarer Proteine wie beispielsweise die löslichen Proteine Antithrombin III und den humanen Fas-Liganden sowie die Membranproteine muskarinischer Acetylcholinrezeptor und Glukosetransporter GLUT1 erfolgreich eingesetzt werden ${ }^{[207-210]}$ Die Vorteile der heterologen Proteinexpression in D. discoideum sind, dass es die richtige Faltung eukaryotischer Proteine sowie posttranslationale Modifikationen der höheren Eukaryoten ermöglicht. Obwohl der Schleimpilz auch ein vielzelliges Stadium in seinem Lebenszyklus aufweist, konnten bisher keine Gap Junction Kanäle bei $D$. discoideum nachgewiesen werden. ${ }^{[211]}$

\section{Kultivierung in der Schüttelkultur}

In dieser Arbeit wurde D. discoideum für die Expression von $\mathrm{Cx} 43$ und des Fusionsproteins Cx43-eGFP (enhanced Green Fluorescent Protein) eingesetzt. Dafür wurde der Stamm Ax3-ORF+ sowie das Plasmid pDXA mit dem starken, konstitutiven act15 Promotor benutzt. Zunächst wurde die Kultivierung im Schüttelkolben durchgeführt und die Sauerstoffversorgung variiert. Dazu wurden zwei unterschiedliche Verhältnisse von Medium zu Kolbenvolumen getestet (1:5, 1:10). Die Ergebnisse verdeutlichten, dass mit einem Volumenverhältnis von 1:5 zwar niedrigere Verdopplungszeiten erreicht werden konnten, aber bereits nach etwa $90 \mathrm{~h}$ die Absterbephase der Zellen begann (Abb. 4-2 A, B). Ein Volumenverhältnis von 1:10 ermöglichte mit erhöhten Generationszeiten höhere Zelldichten zu erreichen (Abb. 4-2 C, D). In diesem Kontext ist die Absterbephase der Zellen beider Klone um etwa $40 \mathrm{~h}$ verzögert. Mit Erreichen der stationären Phase produzieren die Zellen wachstumsinhibierende und transkritionsinhibierende Faktoren, welche im Medium akkumulieren. ${ }^{[212,213]}$ 
Auslöser dafür sind eine bestimmte Zelldichte oder der Verbrauch essentieller Mediumsbestandteile. Die Korrelation der Expression von Cx43-eGFP mit der Fluoreszenzmikroskopie verdeutlichte, dass die Expression durch den konstitutiven Promotor über den Zeitraum der Kultivierung zunahm. In der Literatur werden maximal Zelldichten zwischen $1 \cdot 10^{7}$ bis $2 \cdot 10^{7}$ Zellen $\cdot \mathrm{mL}^{-1}$ beschrieben, oft liegen die erreichten Zelldichten weit niedriger. ${ }^{[214]}$ Demzufolge konnten in dieser Arbeit mithilfe der Schüttelkultur die maximalen Zelldichten für das HL5-Medium erreicht werden.

\section{Isolierung und Reinigung von Cx43 und Cx43-eGFP}

Mit der Kultivierung im Schüttelkolben wurde zunächst ausreichend Zellfeuchtmasse für den Nachweis der Proteinexpression mithilfe der Western Blot Analyse gewonnen (Abb. 4-3). Dazu wurde für die Isolierung der Zellmembranen beider Klone ein Protokoll für die Präparation von HeLa Zellmembranfragmenten durch Dichtegradientenzentrifugation nach Hand et al. adaptiert. Die Dichtegradientenzentrifugation ist eine übliche Methode zur Isolierung von Gap Junction Plaques. ${ }^{[39]}$ Dadurch wurde der Nachweis der Expression beider Proteine durch den monoklonalen Antikörper gegen Cx43 ermöglicht. Im nächsten Schritt wurden die Detergenzien $n$-Octylpolyoxyethylen (8-POE) und $n$-Octyl- $\beta$-D-glucopyranosid $(n \mathrm{OG})$ in unterschiedlichen Konzentrationen getestet, um ausreichend Protein aus den isolierten Membranfragmenten zu solubilisieren und diese im nächsten Schritt durch immobilisierte Metallchelataffinitätschromatografie zu reinigen. Die Analyse verdeutlicht, dass Cx43-eGFP mit einer erhöhten Konzentration von $n$ OG (5\%) aus den Membranfragmenten solubilisiert werden konnte (Abb. 4-4 B). Der Nachweis konnte aber nur indirekt über die abfallende Konzentration an Protein im Pellet erbracht werden. Im Gegensatz zu $n$ OG ist für die Solubilisierung von Cx43-eGFP mit 8-POE nur bei einer Konzentration von $1 \%$ eine geringe Abnahme der Cx43-eGFP Konzentration im gesuchten Molmassenbereich zu finden (Abb. 4-4 A). Bei einer Konzentration von $4 \%$ 8-POE ist ebenfalls eine schwache Intensität im gesuchten Molmassenbereich zu sehen, jedoch ist dies eher auf eine schlechte Blot-Effizienz in diesem Bereich zurückzuführen. Außerdem wurden unterhalb des gesuchten Molmassenbereichs weitere Banden identifiziert, die wahrscheinlich auf den proteolytischen Abbau des Proteins hinweisen, was bereits für verschiedene Connexine berichtet wurde. ${ }^{[163,215,216]}$ Die Reinigung von Cx43-eGFP mithilfe der immobilisierten Metallchelataffinitätschromatografie ergab kein positives Ergebnis. Da bisher noch kein Membranprotein aus 
D. discoideum gereinigt wurde, konnte nicht auf etablierte Protokolle zurückgegriffen werden. Es ist anzunehmen, dass zu wenig Biomasse eingesetzt wurde, um ausreichend Protein nach den einzelnen Reinigungsschritten zurückzugewinnen.

\section{Fermentationsversuche von D. discoideum Cx43}

Zu diesem Zweck wurde getestet, ob mithilfe der Kultivierung von D. discoideum Cx43 im Bioreaktor höhere Biomassen erreicht werden können. Dies ermöglicht die Kontrolle von Prozessparametern wie pH-Wert, Temperatur, Begasungsrate, Rührergeschwindigkeit und Nährstoffzufuhr. Dazu wurden drei Versuche mit der satzweisen Kultivierung (BatchKultivierung) durchgeführt. Ein Vergleich der drei Fermentationsversuche macht deutlich, dass die Parameter der zweiten Fermentation für die Kultivierung von D. discoideum am besten geeignet waren, da hier eine Verdopplungszeit von $t_{\mathrm{D}}=24,6 \mathrm{~h}$ erzielt werden konnte (Abb. 4-5 A). Dies könnte ein Ausgangspunkt für weitere Fermentationsversuche zur Optimierung der Wachstumsrate sein. In den Fermentationsversuchen konnten mehrere wichtige Parameter identifiziert werden und diese werden im Folgenden kurz erläutert. Für die Inokulierung der Fermentationskultur muss eine Vorkultur verwendet werden, welche sich in der exponentiellen Wachstumsphase befindet. Die erste Fermentation zeigte, dass die Verwendung einer Vorkultur aus einer späteren Wachstumsphase zu einer schlechten Regulation der Fermentation führt bzw. kein Wachstum mehr stattfindet, da sich schon die Vorkultur in der stationären bzw. Absterbephase befand. In dieser Phase akkumulieren Stoffwechselprodukte sowie Giftstoffe. ${ }^{[212,213]}$ Ein Vergleich der zweiten und dritten Fermentation veranschaulicht, dass die Sauerstoffkonzentration zu Beginn der Fermentation und während der Fermentation ein entscheidender Faktor für das Zellwachstum ist (Abb. 4-5 C, D; Abb. 4-6 C, D). Die Reduktion der Sauerstoffkonzentration zu Beginn der dritten Fermentation führte dazu, dass während der gesamten Kultivierung nicht die Generationszeit der zweiten Fermentation erreicht wurde (Abb. 4-5 A, Abb. 4-6 A). Ähnlich wie für Pichia pastoris ist ebenfalls eine Kultivierung in synthetischen Medien anstelle von komplexen Medien zur Steigerung der Zelldichte bis zu $5 \cdot 10^{7}$ Zellen $\cdot \mathrm{mL}^{-1}$ möglich. ${ }^{[176]}$ In Kombination mit der Zulaufkultivierung könnten dadurch eine einfachere Kultivierung ermöglicht werden, da im Gegensatz zur satzweisen Kultivierung mit komplexen Medien die Zusammensetzung des Mediums bekannt ist und durch die Zufuhr an Medium- bzw. Nährstoffkonzentrat die Wachstumsgeschwindigkeit eingestellt werden kann. Die ersten vollsynthetischen Medien 
(FM-Medium) wurden von Franke und Kession entwickelt und ermöglichten die Kultivierung mit Zelldichten von bis zu 3,6 $10^{7}$ Zellen $\cdot \mathrm{mL}^{-1} \cdot{ }^{[217]}$ Dieses Medium konnte durch Han et al. (SIH-Medium) weiterentwickelt werden und erlaubt die Kultivierung von bis zu $5 \cdot 10^{7}$ Zellen $\cdot \mathrm{mL}^{-1} \cdot{ }^{[218,219]}$ Durch die Immobilisierung der Zellen in einem porösen, anorganischen Material (Keramik, Bimsstein) und Kultivierung in HL5C-Medium lässt sich die Zelldichte über $2 \cdot 10^{8}$ bis $3 \cdot 10^{8}$ Zellen $\cdot \mathrm{mL}^{-1}$ steigern. ${ }^{[214]}$ Die Immobilisierung hat den Vorteil, dass kontinuierlich das Medium erneuert werden kann sowie lösliche, sekretierte Proteine entfernt werden können. Damit wird eine Steigerung der Proteinausbeute ermöglicht. Für den humanen Fas-Liganden konnte auf diese Weise eine Ausbeute zwischen 65 und $70 \mu \mathrm{g} \cdot \mathrm{L}^{-1}$ (15 bis $25 \mu \mathrm{g} \cdot \mathrm{h}^{-1} \cdot \mathrm{L}^{-1}$ Porenvolumen) erreicht werden. Für die Expression von Membranproteinen müssten die Zellen wieder von der porösen Matrix gelöst werden. Da D. discoideum wachstumsinhibierende Faktoren produziert, wäre die kontinuierliche Kultivierung die ideale Methode, um hohe Zelldichten zu erreichen und gleichzeitig Sekundärmetabolite und wachstumsinhibierende Faktoren zu entfernen. Bei der kontinuierlichen Kultivierung können die Zellen beispielsweise durch Membranen zurückgehalten werden. Zusammenfassend kann kein abschließendes Urteil über die Eignung von D. discoideum als heterologes Expressionssystem zum Erreichen von hohen Proteinkonzentrationen gesprochen werden, da die Untersuchungen durch den Wechsel zu P. pastoris nicht abgeschlossen wurden. Kaufmann et al. konnten kürzlich zeigen, dass Cx43 in D. discoideum funktionell exprimiert wird. ${ }^{[220]}$ Dafür wurde der passive Eintritt des wasserlöslichen Fluoreszenzfarbstoffs Carboxyfluorescein in Abwesenheit und Anwesenheit von extrazellulärem $\mathrm{Ca}^{2+}$ untersucht. Calciumionen dienen der chemischen Regulation von Connexin Halbkanälen (Kapitel 1.1.5). Die Ergebnisse verdeutlichen, dass bei $2 \mathrm{mM} \mathrm{Ca}^{2+}$ nur noch eine geringe Aufnahme des Fluorophors in die Zellen beobachtet werden konnte. Zusammen mit den vorgenannten Ergebnissen verdeutlicht dies, dass D. discoideum ein geeignetes System zur Expression von verschiedenen Connexin-Varianten ist. Jedoch sind für das Erreichen hoher Biomasse und die damit verbundenen Proteinkonzentrationen weitere Optimierungsversuche in der Fermentation von D. discoideum notwendig. 


\subsubsection{Expression und Reinigung von Cx43 und Cx43-GFP in Pichia pastoris}

Pichia pastoris wurde als zweites System für die heterologe Proteinexpression von Cx43 und Cx43-GFP (GFP: S65T) verwendet. Ähnlich wie D. discoideum erlaubt es einfache genetische Manipulation, jedoch wurden weit mehr Membranproteine in P.pastoris exprimiert als in D. discoideum. ${ }^{[120,176]}$ Im Gegensatz zum Schleimpilz wird die eingebrachte DNA durch homologe Rekombination dauerhaft ins Genom integriert und nach der Selektion positiver Klone muss kein Antibiotikum zugesetzt werden. Dadurch können hohe Ausbeuten an korrektgefaltetem Protein, welches posttranslationale Modifikationen ähnlich höherer Eukaryoten enthält, gewonnen werden. Die Expression wird durch die Zugabe von Methanol (AOX1-Promotor) induziert.

\section{Fed-Batch-Fermentation von P. pastoris Cx43 und Cx43-GFP}

Für die Gewinnung beider Proteine in hoher Konzentration wurden die P. pastoris Klone, welche Cx43 bzw. Cx43-GFP exprimieren in der Zulauffermentation (Fed-Batch-Fermentation) kultiviert. Zunächst wurde $P$. pastoris Cx43-GFP für die Fermentation verwendet, da nach induzierter Proteinexpression der Erfolg anhand der grünen Färbung der Zellen zu sehen war (Abb. 4-7 B). Es wurde mit einem synthetischen Medium mit Glycerol als Nahrungsquelle begonnen und nach Verbrauch der Nahrungsquelle mit einem Substratkonzentrat zugefüttert (Feeding). Nach insgesamt $25 \mathrm{~h}$ wurde eine Zellfeuchtmasse von $229 \mathrm{~g} \cdot \mathrm{L}^{-1}$ erreicht (Abb. 4-8 A). Für P. pastoris Cx43 wurde das Glycerol-Feeding bis zum Erreichen einer Zellfeuchtmasse von $180 \mathrm{~g} \cdot \mathrm{L}^{-1}$ durchgeführt (Abb. 4-9 A), da es aufgrund der hohen Zelldichte während der ersten Fermentation zu Problemen in der Sauerstoffversorgung kam. Die Generationszeit betrug für $P$. pastoris Cx43-GFP $t_{\mathrm{D}}=4,2 \mathrm{~h}$ und für $\mathrm{Cx} 43 t_{\mathrm{D}}=3,1 \mathrm{~h}$ während des Glycerol-Feedings. Dies entspricht etwa einer Generationszeit $t_{\mathrm{D}} \approx 3 \mathrm{~h}$ wie sie von Cregg et al. für definierte Medien beschrieben wurde. ${ }^{[221]}$ Die erreichten Zelldichten waren ausreichend, damit sich die Zellen im nächsten Schritt an das Methanol-Feeding anpassen konnten. Dies dient gleichzeitig zur Induktion der Proteinsynthese und als Nahrungsquelle. Wenn bei einer zu geringen Zelldichte mit dem Methanol-Feeding begonnen werden würde, könnte dies zu Schwierigkeiten bei der Anpassung der Kultur kommen und die Zellen adaptierten langsamer. Dadurch kann es wiederum dazu kommen, dass Methanol angereichert wird und dies wirkt 
toxisch für die Zellen. Die manuell gesteuerte Zufuhr an Methanol orientierte sich an der Gelöstsauerstoffkonzentration, welche einen Wert von $30 \%$ nicht unterschreiten sollte. Die Zellen benötigten zwischen 4 und 5 h, um sich an das Feeding mit Methanol zu adaptieren. Für ein Standardprotokoll zur Kultivierung der P. pastoris Klone sollten die Startparameter der ersten Fermentation übernommen werden. Jedoch reicht eine Zellfeuchtmasse von $180 \mathrm{~g} \cdot \mathrm{L}^{-1}$ nach dem Glycerol-Feeding aus, um sich effektiv an das Feeding mit Methanol anzupassen und die Regulation der Fermentation wird dadurch erleichtert (Abb. 4-9).

\section{Gewinnung von P. pastoris Cx43 und Cx43-GFP Membranfragmenten}

Zur Gewinnung der Zellmembran wurden verschiedene Methoden wie die Waring Blender-, Grinder-Methode und die French Press getestet. Die Waring Blender- und Grinder-Methode können erfolgreich zum Aufschluss von Saccharomyces cerevisiae eingesetzt werden, jedoch scheint die Zellwand von $P$. pastoris aufgrund ihrer Zusammensetzung widerstandsfähiger zu sein und verlangte eine harschere Methode. ${ }^{[184,222]}$ Mit der French Press konnten ausreichende Scherkräfte appliziert werden, um die P. pastoris Zellen aufzuschließen. Die erhaltene Suspension wurde zwei Mal zentrifugiert. Dabei wurde der Überstand vom Pellet getrennt und mittels Western Blot analysiert. Cx43-GFP war in allen Fraktionen wiederzufinden (Abb. 4-10 A). Im Gegensatz dazu findet man das Cx43 Monomer nur im ersten Pellet (Abb. 4-10 B). Allerdings ist in beiden Überständen eine Dimerbande zu sehen. Dies deutet daraufhin, dass die Zentrifugalkräfte nicht ausreichend waren, um die Membranfragmente vollständig zu pelletieren. Um eine höhere Ausbeute zu erreichen, könnten höhere Zentrifugalkräfte verwendet werden. In der Literatur wird zum Aufschluss geringer Mengen an P.pastoris Glasperlen verwendet, jedoch ist diese Methode nicht für größere Mengen geeignet, da die Effizienz abnimmt. ${ }^{[223]}$

\section{Reinigung von Cx43 und Cx43-GFP durch Affinitätschromatografie}

Nach der Isolierung der Membranfragmente von P. pastoris Cx43 bzw. Cx43-GFP wurden zunächst die Detergenzien $n$-Octyl- $\beta$-D-glucopyranosid ( $n \mathrm{OG}$ ) und $n$-Dodecyl- $\beta$-D-maltosid (DDM) in unterschiedlichen Konzentrationen (2-5\%) getestet und durch die Western Blot Analyse die Effizienz der Solubilisierung getestet. Beide Detergenzien wurden bereits in zahlreichen Studien zur Solubilisierung von Gap Junction Kanälen sowie Connexin Halbkanälen 
verwendet. ${ }^{[37,123,161,163,185]}$ Die Effektivität der Detergenzien für die Solubilisierung von Connexin Halbkanälen schwankt zwischen den verschiedenen Isoformen. Die Ergebnisse verdeutlichen, dass mit höherer DDM-Konzentration mehr Protein solubilisiert werden konnte (Abb. 4-11 B). Stauffer et al. konnten ebenfalls die besten Ergebnisse für die Isolierung von Cx32 Halbkanälen unter Erhalt der Struktur mit DDM erzielen. ${ }^{[185]}$ Für die Isolierung von Cx43 bzw. Cx43-GFP wurde die immobilisierte Metallchelataffinitätschromatografie verwendet. Dafür wurden zwei unterschiedliche Methoden getestet. Einerseits wurde die Reinigung nach Atsu verwendet, die bereits erfolgreich für die Gewinnung von Cx26 aus Sf9 Insektenzellen eingesetzt wurde. ${ }^{[72]}$ Andererseits wurde die Reinigung nach Bao et al. verwendet, welche für die Isolierung von Cx43 und Cx43-eGFP aus Insektenzellen (High Five) hohe Proteinausbeuten (5 bis $10 \mathrm{mg} \cdot \mathrm{L}^{-1}$ Zellen) ermöglichte. Beide Methoden zeigten eine ähnliche Reproduzierbarkeit für die Präparation von Cx43 und Cx43-GFP. Durch die Reinigung nach Atsu wurde trotz Affinitätschromatografie eine Reihe an Verunreinigungen aufkonzentriert (Abb. 4-12 A, B). Mithilfe der Massenspektrometrie konnte die Verunreinigung zwischen 66 und $97 \mathrm{kDa}$ als Alkoholoxidase (AOX) aus P. pastoris identifiziert werden. Diese wird während der Induktion der Proteinsynthese in hohen Konzentrationen in den Peroxisomen von P. pastoris koexprimiert. ${ }^{[224]}$ Peroxisomen sind spezielle Organellen der methylotrophen Hefen wie $P$. pastoris und Hansenula polymorpha, um die Zellen vor $\mathrm{H}_{2} \mathrm{O}_{2}$ zu schützen, was als reaktives Zwischenprodukt während der Metabolisierung von Methanol zu Formaldehyd entsteht (Abb. 5-1 B). ${ }^{[225]}$ In den Peroxisomen liegt AOX in einer kristallinen Struktur vor (Abb. 5-1 A). ${ }^{[188]}$ Es ist bekannt, dass die AOX in Lösung sehr schnell kleine dreidimensionale Kristalle bildet. ${ }^{[187]}$ Dadurch könnte die AOX während der Reinigung zum Teil durch das Säulenmaterial zurückgehalten werden und später die Elutionsfraktion verunreinigen. Andererseits könnte das Oktamer der AOX ein Histidin-Cluster aufweisen, der die spezifische Bindung des Proteins an die Ni-NTA-Gruppe ermöglicht. Durch die Bedingungen der Reinigung nach Bao et al. konnten die Kontamination durch die AOX reduziert werden (Vergleich Abb. 4-12 und Abb. 4-14). ${ }^{[123]}$ Parcej und Eckhardt-Strelau berichten ebenfalls von der Coexpression der AOX, jedoch konnte diese durch die immobilisierte Metallchelataffinitätschromatografie entfernt werden. ${ }^{[226]}$ Die entscheidenden Parameter in der Reinigungsprozedur von Parcej et al. sind schwer zu bestimmen, da die Anreicherung der AOX in dieser Untersuchung kein Problem darstellt. 

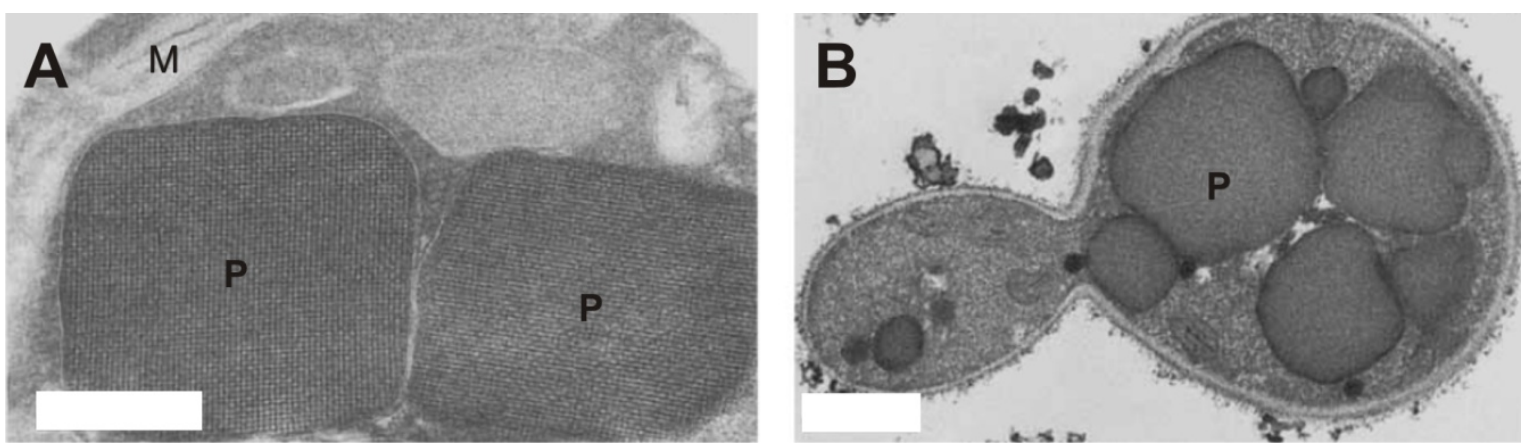

Abb. 5-1: Dünnschliff der methylotrophen Hefe Hansenula polymorpha mit Methanol als Nahrungsquelle kultiviert und mit $\mathrm{CeCl}_{3}$ gefärbt. Maßstab: $0,1 \mu \mathrm{m} A$, Die Abbildung verdeutlicht die kristalline Struktur der Alkoholoxidase in Peroxisomen (P). M-Mitochondrium $\boldsymbol{B}$, Übersicht einer Hefezelle mit mehreren Peroxisomen (P). Abbildung verändert nach Van der Klei et al. ${ }^{[187]}$

In Abb. 4-14 C und D ist für Cx43 sowie Cx43-GFP ein Monomer sowie ein Dimer in dem Western Blot zu erkennen. Connexin Monomere und Dimere wurden ebenfalls für andere Connexine in der SDS-PAGE beobachtet. ${ }^{[72,123,163]}$ Durch die erhöhte Proteinkonzentration, die durch die Reinigung nach Bao et al. erreicht werden konnte, ist es möglich, dass nicht mehr ausreichend SDS vorhanden war, um die Oligomerstuktur des Connexin Halbkanals vollständig aufzulösen und so konnten Monomere und Dimere von Cx43 beobachtet werden.

Der größte Unterschied zwischen den beiden Reinigungsmethoden ist, dass zu Beginn der Reinigung nach Bao et al. die Alkaliextraktion durchgeführt wird. Diese soll Lipide sowie periphere Membranproteine in Lösung überführen und von den Connexin Halbkanälen trennen. ${ }^{[39]}$ Stauffer et al. berichten außerdem von der Notwendigkeit der kombinierten Bedingungen hoher Salzkonzentrationen, alkalischer pH-Wert, reduzierende Verbindungen sowie Detergens, um Connexin Halbkanäle zu isolieren. ${ }^{[185]}$ Nach der Auflösung der lateralen Organisation und dem Vorliegen von Connexin Halbkanälen kann wie in der Reinigung nach Bao et al. die Salzkonzentration, der pH-Wert sowie die DTT- und Detergenskonzentration wieder gesenkt werden. ${ }^{[123]}$ Beiden Methoden ist gemeinsam, dass die Proteine über den Hexahistidin-Tag im Batch-Verfahren an die Nickel-Nitriloessigsäure der Agarosematrix gebunden wurde. Dies wurde vor allem gewählt, weil nicht bekannt war, inwieweit der Hexahistidin-Tag zugänglich ist.

Neben der Isolierung mithilfe eines Affinitätstags wurden in der Literatur hohe Proteinausbeuten durch die Immobilisierung von Antikörpern, die gegen das spezifische Connexin gerichtet sind, an eine Matrix beschrieben. Dies ermöglicht eine sehr spezifische Bindung von Connexin Halbkanälen oder auch Gap Junction Kanälen und Trennung von Fremdproteinen. 
Allerdings erfordert die Elution der Proteine einen pH-Wert zwischen 2 und 4, dies schädigt die Tertiär- sowie Quartärstruktur der Connexine irreversibel und ist deshalb für eine weitere funktionelle sowie strukturelle Untersuchung nicht empfehlenswert. ${ }^{[49,66,163,227]} \mathrm{Kim}$ et al. berichten, dass Cx43 jeweils zur Hälfte als Connexon sowie als Connexin vorlag. ${ }^{[27]}$ Ein Vergleich des Absorptionsspektrums für das isolierte Cx43-GFP beider Reinigungen verdeutlicht, dass durch die Reinigung nach Bao et al. nicht nur Fremdprotein entfernt werden konnte, sondern ebenfalls die Konzentration an Cx43-GFP ansteigt (Vergleich Abb. 4-13, Abb. 4-15). Dies verdeutlicht die Übersicht der erreichten Proteinausbeuten pro Gramm Zellfeuchtmasse in Tab. 4-2. Da die Elutionsfraktionen der Reinigung nach Bao et al. immer noch Kontaminationen mit Fremdprotein aufwiesen, kann nur die Konzentration des GFP für eine quantitative Aussage dienen. Demnach konnten etwa $10 \mu \mathrm{g}$ Protein pro Gramm Zellfeuchtmasse ( $>2 \mathrm{mg} \cdot \mathrm{L}^{-1}$ Fermentationsvolumen) isoliert werden. Im Vergleich zu anderen Studien liegt dies im Mittelfeld für die heterologe Expression von Membranproteinen in P. pastoris. ${ }^{[228-230]}$ Ramón et al. führt einige Vorschläge auf, die die Expression integraler Membranproteine verbessern kann wie die Anpassung der Codon Usage für P. pastoris, die Kultivierung bei tiefen Temperaturen, die Zugabe von Liganden zur Stabilisierung der natürlichen Konformation oder die Verwendung von chemischen Faltungshelfern (Chaperons) wie Dimethylsulfoxid (DMSO). ${ }^{[120]}$ Bei der Ausbeute von Cx43-GFP muss beachtet werden, dass Cx43-GFP ausschließlich aus dem Pellet der ersten Zentrifugation (1. Schicht, siehe Kapitel 4.1.2.2) stammt und durch die Zentrifugationsschritte nicht die gesamten Cx43-GFPenthaltenen Membranfragmente zurückgewonnen werden konnten. Außerdem blieb ebenfalls ein Teil des Proteins in den Membranfragmenten nach der Solubilisierung zurück, was aufgrund der grünen Färbung des Pellets rückgeschlossen werden konnte. Die tatsächliche Ausbeute an Cx43-GFP liegt wahrscheinlich weitaus höher als die Proteinkonzentration, welche in dieser Arbeit erreicht werden konnte. Die Ausbeuten, die für die Isolierung von Cx43 erreicht werden konnten, sind nach der bestimmten Proteinkonzentration bei einer Absorption von $280 \mathrm{~nm}$ niedriger als für Cx43-GFP. Dies lässt vermuten, dass es durch die GFPFusion zu einer erhöhten Expression von Cx43 kommt. Die erhöhte Expression durch GFPFusion wurde auch für andere eukaryotische Membranproteine berichtet und wird zur Überexpression dieser sogar empfohlen. ${ }^{[231,232]}$ Die Gegenüberstellung der Isolierung von Cx43 aus Insektenzellen von Bao et al. verdeutlicht, dass mit diesem Expressionssystem ähnliche Ausbeuten erreicht werden können wie mit dem Baculovirus/Insektenzellen Expressionssystem. ${ }^{[123]}$ Der Vorteil der heterologen Proteinexpression gegenüber den natürlichen Ressour- 
cen ist, dass dadurch höhere Ausbeuten und durch die Verwendung von Affinitätstags eine bessere Reinheit erreicht werden. Durch Massenspektrometrie konnte zusätzlich zur Western Blot Analyse Cx43 und Cx43-GFP nachgewiesen werden. 


\subsection{Funktionelle Rekonstitution in unilamellaren Vesikeln}

Nach der erfolgreichen Expression und Reinigung von Cx43 bzw. Cx43-GFP in Pichia pastoris ist der nächste Schritt die Rekonstitution der Proteine in artifizielle Membranen. Für die elektrophysiologischen Untersuchungen sowie für die Assemblierung von Gap Junction Kanälen in vitro ist es notwendig, die Kanäle wieder in ein System zu überführen, welches seiner natürlichen Umgebung entspricht. Die Detergensmizelle kann dabei, wie in Kapitel 1.2 dargestellt, nur ein transientes System darstellen. Die weiteren Untersuchungen erfordern die Einbringung von Cx43 und Cx43-GFP in unilamellare Riesenvesikel (Giant Unilamellar Vesicles, GUVs). Dafür wurden drei verschiedene Methoden eingesetzt.

\subsubsection{Spontane Integration von Cx43 und Cx43-GFP zur elektrophysio- logischen Charakterisierung}

Für die elektrophysiologischen Untersuchungen in Kapitel 4.3 wurde unter anderem die spontane Integration des Proteins in GUVs verwendet. Dies ermöglicht die schnelle und direkte Integration des Proteins in GUVs aus der Detergensmizelle. Zur elektrophysiologischen Charakterisierung des Proteins werden geringe Proteinkonzentrationen benötigt, da die Untersuchung auf Einzelkanalniveau erfolgt. Nach Rigaud et al. wird die Proteinintegration durch amphipathische Verbindungen wie Cholesterol oder Detergenzien erleichtert und resultiert in einer unidirektionalen Orientierung des Proteins. ${ }^{[162]}$ Für diese Methode wurden GUVs, der Zusammensetzung DPhPC/Cholesterol (9:1), und Cx43 bzw. Cx43-GFP in $n$-Dodecyl- $\beta$-D-maltosid (DDM)-Mizellen verwendet. Cholesterol sowie DDM unterstützen die Integration von Cx43 bzw. Cx43-GFP in die GUVs. Dadurch war es in dieser Arbeit möglich, Cx43 und Cx43-GFP elektrophysiologisch vollständig zu charakterisieren (Kapitel 4.3). Zur Stabilisierung des integrierten Proteins und der Vesikel wurde das Detergens durch Zugabe von BioBeads ${ }^{\text {TM }}$ SM-2 entzogen ${ }^{[233]}$, da das Detergens ebenfalls zur Permeabilisierung der Lipidmembran führt und die elektrophysiologischen Messungen stören würde. 


\subsubsection{Einfluss des Detergens auf die Proteoliposomenbildung}

Desweiteren wurden zwei verschiedene Methoden verwendet, die es ermöglichen, höhere Proteinkonzentrationen in GUVs einzubringen. Zum einen wurde dazu die Bildung von proteinhaltigen Riesenvesikeln nach partieller Dehydratisierung und zum anderen die fusionsvermittelte Rekonstitution verwendet. Für beide Methoden werden zunächst Proteoliposomen mit einem Durchmesser von etwa 100 nm gebildet. Ausgehend von einem Gemisch aus Lipid und Detergens wird durch die Zugabe von Protein ein binäres und ternäres System von gemischten Mizellen erhalten. Das Detergens wird durch eine hydrophobe Matrix, Größenausschlusschromatografie oder Dialyse entzogen. In dieser Arbeit wurde als Detergens $n$-Octyl$\beta$-D-glucopyranosid ( $n \mathrm{OG}$, Kapitel 3.5.4) zur Rekonstitution verwendet. $n \mathrm{OG}$ wurde in zahlreichen Studien zur Reinigung und Rekonstitution von Connexin Halbkanälen und Gap Junction Kanälen verwendet. ${ }^{[34,37,123,160,161,163,227,234,235]}$ Dabei wurde mit den ternären, gemischten Mizellen begonnen und das Detergens durch Dialyse, hydrophobe Matrizes oder Größenausschlusschromatografie entzogen. Detergenzien mit einer relativ hohen kritischen Mizellenbildungskonzentration (Critical Micellar Concentration, CMC) wie $n \mathrm{OG}$ (CMC = $25 \mathrm{mM}$ ) eignen sich am besten zur Rekonstitution, da sie einfach durch die genannten Methoden entzogen werden können. Dagegen besitzt $n$-Dodecyl- $\beta$-D-maltosid (DDM, Kapitel 3.5.4) eine relativ niedrige CMC mit $0,2 \mathrm{mM}$ und lässt sich deshalb nicht durch Dialyse entziehen. Die durchschnittliche Größe der präparierten Proteoliposomen mit Connexonen und $n$ OG schwankt in der Literatur zwischen $45 \mathrm{~nm}$ bis $100 \mathrm{~nm}$, was Rigaud et al. auf die kurze Kohlenwasserstoffkette des nOG zurückführen. ${ }^{[162]}$ Für die Bildung der Proteoliposomen spielt ebenfalls das Tempo des Detergensentzuges eine Rolle. Der schnelle Detergensentzug führt bei der $n$ OG vermittelten Rekonstitution von Bakteriorhodopsin zur Entstehung einer homogenen Fraktion von Proteoliposomen. ${ }^{[236]}$ Dagegen kommt es beim langsamen Entzug des Detergens zur Bildung von Vesikeln mit und ohne Protein. ${ }^{[237]}$ Nach Eytan sind zwei Mechanismen denkbar: Zum einen könnte das integrale Membranprotein direkt am Membranbildungsprozess teilnehmen. Zum anderen findet erst die initiale Vesikelbildung statt und anschließend insertiert das Protein. ${ }^{[238]}$ Für den Entzug des Detergens durch die in dieser Arbeit verwendeten BioBeads SM-2 ist eher der erste Mechanismus anzunehmen. Die hergestellten Proteoliposomen wurden schließlich für die nachfolgenden Methoden eingesetzt. 


\subsubsection{Proteo-GUV-Bildung nach partieller Dehydratisierung}

Die Methode der Bildung von proteinhaltigen GUVs nach partieller Dehydratisierung wurde von Girard et al. adaptiert. ${ }^{[166]}$ Die hergestellten Proteoliposomen mit einer Größe von etwa $100 \mathrm{~nm}$ werden auf einem leitenden Träger partiell dehydratisiert und anschließend werden aus dem hergestellten Protein-Lipid-Film durch Elektroformation Proteo-GUVs hergestellt. Mit dieser Methode konnte Cx43-GFP in GUVs integriert werden. Jedoch könnte der Eintrocknungsprozess eine Aggregation des Proteins zur Folge haben, da sich während der Dehydratisierung mehrere Lipidmembranschichten bilden und dazwischen wahrscheinlich kein Wasser mehr vorhanden ist. Dieser Prozess kann durch die Zugabe von Trehalose oder Saccharose während der Dehydratisierung minimiert werden, da diese Zucker anstelle des Wassers als Wasserstoffbrückendonator dienen können. ${ }^{[239,191]}$ Ein weiterer negativer Effekt war, dass während der Präparation nicht nur unilamellare, sondern auch multilamellare Vesikel entstanden (Abb. 4-16). Dies würde die Bildung von porenüberspannenden Membranen unmöglich machen und deshalb wurde die Bildung von Proteo-GUVs nach partieller Dehydratisierung nicht weiter verfolgt. Erst kürzlich konnte durch Aimon et al. die Rekonstitution des Kaliumkanals KvAP mithilfe dieser Methode gezeigt werden. Dabei wurde sowohl die Lokalisation des Proteins in phasenseparierten GUVs als auch die Funktionalität des Proteins durch Patch Clamp Messungen nachgewiesen. Allerdings handelt es sich um einen Kanal aus einem thermophilen Bakterium, welcher eine hohe Stabilität aufweist. Diese Methode konnte für Cx43-GFP reproduzierbar für die erste Fermentationscharge durchgeführt werden. Für das isolierte Protein aus der zweiten Fermentationscharge konnten keine proteinhaltigen GUVs hergestellt werden. Mögliche Gründe werden in der Diskussion für die letzte Rekonstitutionsmethode erläutert, da sie wahrscheinlich in Zusammenhang mit der Herstellung der Proteoliposomen aus der gemischten, ternären Mizelle stehen.

\subsubsection{Fusionsvermittelte Integration von Cx43 und Cx43-GFP}

Die dritte Methode ist die fusionsvermittelte Rekonstitution und wurde nach Martinac et al. modifiziert. ${ }^{[168]}$ Dabei wurde die hohe Fusionstendenz der hergestellten Proteoliposomen mit einem Durchmesser von etwa $100 \mathrm{~nm}$ genutzt. Es wurde zunächst wie für die Herstellung proteinfreier GUVs Lipidfilme auf einem leitenden Träger eingetrocknet. Während der Elektroformation der POPC GUVs kam es zur Fusion der Proteoliposomen mit den entstehenden GUVs. Ramundo-Orlando et al. berichteten, dass Connexon-haltige Vesikel 
eine höhere Fusionstendenz haben als proteinfreie Vesikel und dies wahrscheinlich die Rekonstitution fördert. ${ }^{[235]}$ Mit der fusionsvermittelten Rekonstitution war es möglich, Cx43 sowie Cx43-GFP in GUVs zu integrieren. Cx43 konnte mithilfe des Affinitätstags, welcher durch einen FITC-gekoppelten Antikörper (Kapitel 3.3.2) erkannt wurde, nachgewiesen werden. Dazu muss ein Teil des integrierten Cx43 in der Orientierung Inside Out in der Lipidmembran integriert sein (Abb. 5-2 A). Die Orientierung Inside Out bedeutet, dass der cytosolische Abschnitt des Proteins außerhalb des Vesikels liegt (Abb. 5-2 A). Dagegen liegt das rekonstituierte Protein in der Outside Out Orientierung wie in der Zelle vor, der cytosolische Bereich ist in das Vesikellumen exponiert. Locke et al. berichten, dass auch Cx32 nach der Rekonstitution in Vesikel in einer Inside Out Orientierung vorlag. In dieser Studie wurde für die Rekonstitution von Cx32 ebenfalls mit der gemischten, ternären Mizelle begonnen und das Detergens durch eine hydrophobe Matrix (Bio-Gel Beads) entzogen. Zur Bestimmung der Orientierung wurde die Protease Thrombin sowohl zur Protein-Detergensmizelle als auch zu den Proteoliposomen zugegeben. Dies führte zur Abspaltung eines Thrombin-Cleaveable Mass Tag $(3,2 \mathrm{kDa})$, welcher am C-Terminus von Cx32 positioniert war. ${ }^{[240]}$ Bao et al. berichten ebenfalls, dass mit der oben genannten Methode überwiegend die Orientierung Inside Out erhalten wird. ${ }^{[123]}$ Dagegen können Ramundo-Orlando et al. interliposomale Gap Junction Kanäle darstellen, wofür die Orientierung Outside Out notwendig ist. ${ }^{[235]}$ In beiden Studien wurde $n$ OG durch Dialyse entzogen. Ramundo-Orlando et al. behandeln die ternären, gemischten Mizellen mehrmals mit Ultraschall, was vermutlich zur Auflösung der lateralen Organisation der Connexone führt. Während des Detergensentzugs würde Cx32 in einer zufälligen Orientierung in die Vesikel integrieren und könnte interliposomale Kanäle bilden. In der fusionsvermittelten Rekonstitution sollte aufgrund des Fusionsmechanismus nach Markin et al. die Orientierung des Proteins erhalten bleiben. ${ }^{[241]}$ Daraus kann für die Rekonstitution von Cx43 geschlossen werden, dass zumindest ein Teil des Proteins in der Orientierung Inside Out vorliegt. Der direkte Nachweis der Membranlokalisation von Cx43 gelang mit einer fluoreszenzmarkierten Variante von Cx43 (Abb. 4-19 B). Dafür wurde Cx43 mit dem Maleimid-gekoppelten Fluorophor Cy3 über freie Cysteinreste markiert.

Für die weitere Analyse der fusionsvermittelten Rekonstitution wurden verschiedene Lipidzusammensetzungen mit DPhPC/Cholesterol (9:1) und POPC/Cholesterol (9:1) getestet. Die Proteo-GUVs bestehend aus POPC/Cholesterol waren kleiner als die POPC Proteo-GUVs und geclustert (Abb. 4-18 C). Dies könnte auf eine stärkere laterale Organisation zurück- 
zuführen sein, in der auch Cholesterol beteiligt ist. ${ }^{[242]}$ Für die Lipidmischung aus DPhPC/Cholesterol konnten nur wenige GUVs mit integriertem Cx43-GFP identifiziert werden (Abb. 4-18 D). DPhPC führt durch seine verzweigten Kohlenwasserstoffketten zu einer stärkeren Rigidität der Lipidmembran. ${ }^{[107]}$ Zusätzlich wird dieses Phänomen der Lipiddoppelschicht durch die Interaktion von Cholesterol mit den Alkylketten von DPhPC noch verstärkt. ${ }^{[243]}$ Die starke Rigidität der Lipidmembran führt wahrscheinlich nur zu wenigen Fusionsereignissen und dementsprechend wenig Protein wird in die GUVs während der Elektroformation integriert.
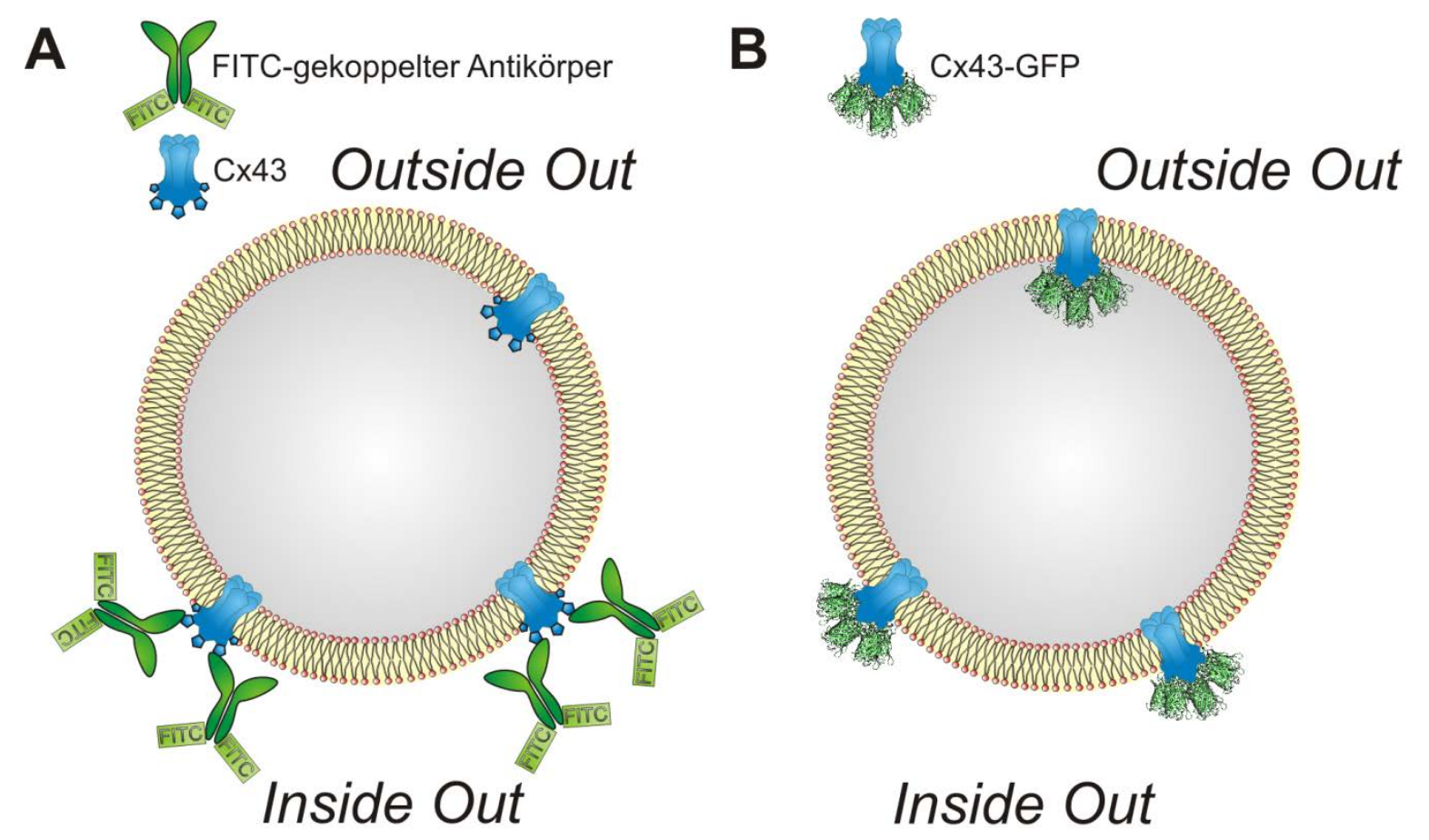

Abb. 5-2: Orientierung von Cx43 bzw. Cx43-GFP in der Vesikelmembran. $A$, Cx43 kann mithilfe eines Antikörpers, welcher gegen den Hexahistidin-Tag gerichtet ist, erkannt werden. Der Antikörper ist wiederum mit dem Fluorophor FITC markiert und ermöglicht die Visualisierung mithilfe der Fluoreszenzmikroskopie. B, Das Fusionsprotein Cx43-GFP kann direkt durch die intrinsische Fluoreszenz des GFP-Chromophors nachgewiesen werden. 


\subsubsection{Reproduzierbarkeit der Proteinintegration für die zweite Fer- mentationscharge}

Die beiden zuletzt genannten Methoden wurden ebenfalls für die Rekonstitution von Cx43 und Cx43-GFP der zweiten Fermentationscharge verwendet. Jedoch war hier eine geringe Reproduzierbarkeit festzustellen und es kam bei der Herstellung der Proteoliposomen aus den gemischten, ternären Mizellen zur Aggregation des Proteins und/oder der Proteoliposomen. Dies könnte auf zwei Phänomene zurückgeführt werden. Einerseits berichteten Kistler et al., dass mit dem Detergens nOG Gap Junction Kanäle bzw. Plaques rekonstituiert werden können. ${ }^{[37]}$ Demzufolge wäre es denkbar, dass sich schon in der Proteoliposomensuspension interliposomale Gap Junction Kanäle ausbilden und es dadurch zur Aggregation der Vesikel untereinander kommt. Andererseits schilderten Stauffer et al., dass die Connexin Halbkanäle sehr schnell aus den Plaques solubilisiert werden können unter der Voraussetzung, dass sie fein verteilt sind (Ultraschall) und diese Prozedur bei $4{ }^{\circ} \mathrm{C}$ durchgeführt wird. Erwärmt man diese Lösung kommt es zur Aggregation der Connexin Halbkanäle. ${ }^{[185]}$ Dies könnte ebenfalls ein Grund sein, warum es zur Aggregation der Connexin Halbkanäle kommt. Die laterale Interaktion der Kanäle in der Elutionsfraktion würde eine Integration verhindern. Jedoch konnten bei der fluoreszenzmikroskopischen Untersuchung der Elutionsfraktion des Cx43-GFPs keine Aggregate in der Größe, wie sie in der Proteoliposomensuspension vorkommen, identifiziert werden. Die Literatur zur Verwendung von $n \mathrm{OG}$ ist sehr gegensätzlich. Zum einen berichten Stauffer et al., dass sich die Detergenzien LDAO, nOG und Nonylglucosid zur Solubilisierung eignen, es aber nach ein paar Tagen zur Auflösung der Halbkanalstruktur kommt. ${ }^{[185]}$ Zum anderen wird $n \mathrm{OG}$ in zahlreichen Studien zur Solubilisierung und Rekonstitution von Connexin Halbkanälen verwendet. Ausschließlich Suga et al. berichten von der Aggregation von Cx26 Halbkanälen, wenn diese mit nOG isoliert werden (Abb. 5-3 B), jedoch aggregierten diese nicht bei der Solubilisierung mit DDM (Abb. 5-3 A). ${ }^{[244]}$ Weiterhin wäre denkbar, dass ausgehend von der gemischten, ternären Mizelle zunächst viel mehr Detergens aus der ternären Mizelle als aus den binären Mizellen entfernt wird, bevor es überhaupt zur Bildung von Vesikeln und damit zur Integration des Proteins kommen kann. Durch die Verminderung des Detergens könnte es zur bevorzugten lateralen Aggregation der Connexin Halbkanäle kommen und die Integration der Kanäle verhindert werden. Abschließend konnte nicht eindeutig geklärt werden, welcher Faktor die Aggregation der Halbkanäle bzw. Proteoliposomen beeinflusst. Wenn man die erste und 
zweite Fermentationscharge vergleicht, müsste die Ausbildung von Gap Junction Kanälen bei beiden Chargen auftreten und dies kann deshalb als Grund ausgeschlossen werden. Für die erste Fermentationscharge wurde die Reinigung nach Bao et al. ohne Alkaliextraktion bei $4{ }^{\circ} \mathrm{C}$ durchgeführt. Da nicht alle Schritte der Reinigung für die zweite Fermentationscharge bei $4{ }^{\circ} \mathrm{C}$ durchgeführt wurden, könnte dies ein möglicher Grund für die Aggregation der Kanäle sein. Prinzipiell ist die fusionsvermittelte Rekonstitution geeignet, um hohe Proteinkonzentrationen in GUVs zu überführen.
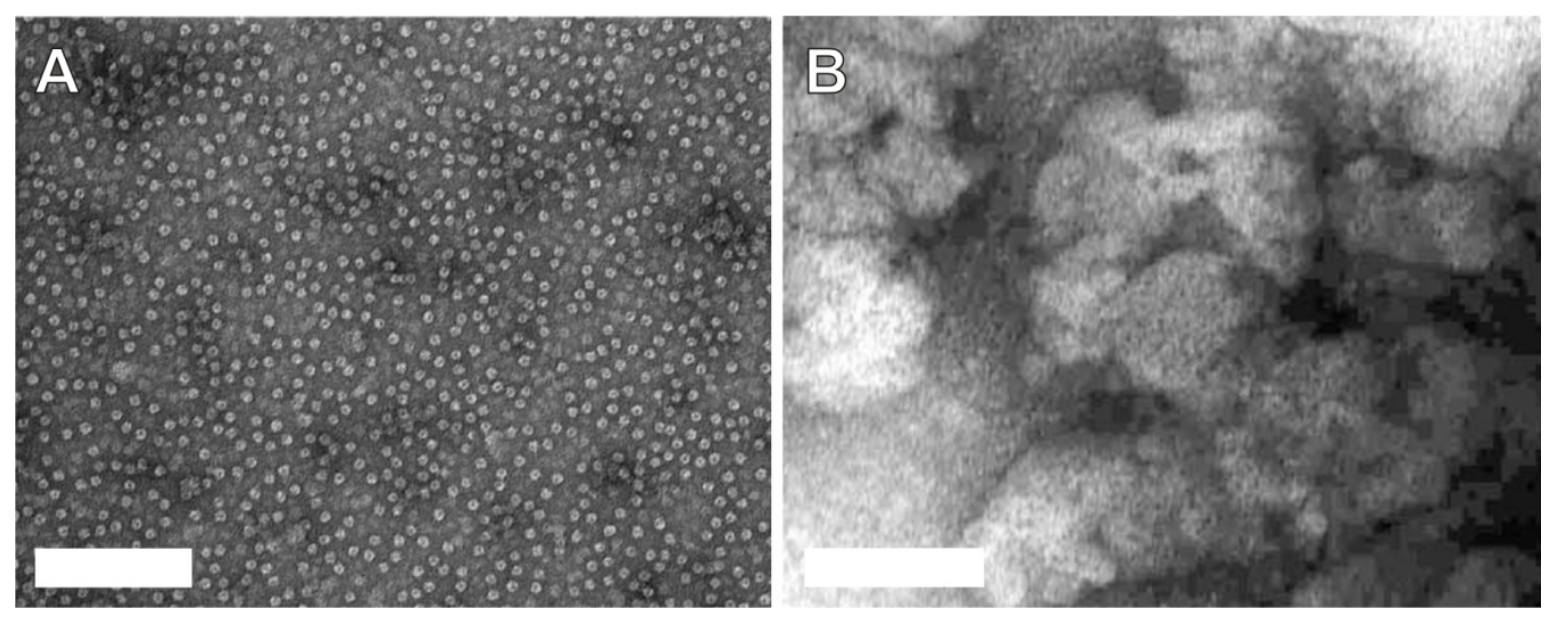

Abb. 5-3: Elektronenmikroskopische Aufnahme von Gap Junction Kanälen. $A$, REM-Aufnahme von Gap Junction Kanälen, die mit DDM solubilisiert wurden. B, REM-Aufnahme von Gap Junction Kanälen, die mit $n$ OG solubilisiert wurden. Die Proben waren aggregiert. Maßstab: $100 \mathrm{~nm}$. Abbildung verändert nach Suga et al. ${ }^{[244]}$ 


\subsection{Einfluss der GFP-Fusion auf die Cx43 Halbkanalaktivität}

In dieser Arbeit wurde Cx43 sowie das Fusionsprotein Cx43-GFP in planare artifizielle Membranen rekonstituiert und vollständig elektrophysiologisch charakterisiert. Dazu wurde das Planar Patch Clamp System Port-a-Patch ${ }^{\oplus}$ (Nanion Technologies GmbH, Abb. 4-21 C) verwendet. Dieses System wurde bereits in zahlreichen elektrophysiologischen Studien erfolgreich eingesetzt. ${ }^{[72,140,189,245-248]}$

Bis Mitte der 1990er Jahre wurde angenommen, dass nach dem Transport von Connexin Halbkanälen (Connexon) zur Plasmamembran die Kanäle inaktiv bzw. geschlossen vorliegen bis diese zum Gap Junction Kanal assemblieren. ${ }^{[55]}$ Erst durch die Kopplung sollten die Kanäle aktiv werden. Die Begründung war, dass sonst der Zellinhalt ungehindert austreten könnte. ${ }^{[12]}$ Erst die Forschung in den letzten zwei Jahrzehnten konnte zeigen, dass Connexone eine Rolle in diversen physiologischen Prozessen haben. ${ }^{[7-15]}$ Für Cx43 Halbkanäle wurden zahlreiche Funktionen nachgewiesen wie ATP-, NAD+- und Glutamat- Freisetzung, Fortpflanzung von Calciumwellen, Regulation des Zellvolumens, Weiterleitung von Signalen zum Zellfortbestand, eine Rolle bei metabolischen Stress sowie dem Zelltod während metabolischen Stresses. ${ }^{[47,249-255]}$ Bis jetzt wurden zur elektrophysiologischen Charakterisierung von Cx43 ausschließlich Patch Clamp Experimente an Cx43-exprimierenden Zelllinien durchgeführt. Außerdem wurde in einer Reihe von zellbasierten Studien das Fusionsprotein aus Cx43 und dem grün fluoreszierenden Protein (GFP) bzw. das enhanced GFP (eGFP) zur Lokalisierung von Cx43 verwendet. ${ }^{[32,196,256,257]}$ Dabei wurde der Einfluss dieses großen Fusionsproteins $\left(M_{\mathrm{GFP}} \approx 27 \mathrm{kDa}\right)$ wenig berücksichtigt. 


\subsubsection{Leitfähigkeiten von Cx43 und Cx43-GFP}

\section{Leitfähigkeiten des Cx43 Halbkanals}

Für die elektrophysiologischen Messungen wurden die Proteine wie in Kapitel 4.2.1 und 4.2.3 beschrieben in GUVs rekonstituiert und diese anschließend auf einem Glaschip mit einer Apertur von etwa $2 \mu \mathrm{m}$ gespreitet. Die Analyse der Einzelkanalaktivität von Cx43 ergab zwei Leitfähigkeitsstufen. Die größte Häufigkeit hatte die Leitfähigkeitsstufe $G_{2}=$ $(224 \pm 26) \mathrm{pS}$ (Abb. 4-23 A). Diese Leitfähigkeit mit $G=(220 \pm 11) \mathrm{pS}$ konnte ebenfalls durch Contreras et al. in Cx43 transfizierten HeLa identifiziert werden. ${ }^{[69]}$ Retamal et al. konnte die Hauptleitfähigkeit von Cx43 Halbkanälen ebenfalls in einem Bereich von 200250 pS einordnen (Tab. 5-1). ${ }^{[258,259]}$ Tab. 5-1 gibt eine Übersicht von Literaturwerten für Cx43 Gap Junction Kanäle und Halbkanäle. Die Hauptleitfähigkeit für Connexin Halbkanäle beträgt ungefähr das Doppelte der Leitfähigkeit von Gap Junction Kanälen und ergibt sich nach Gl. 5-1. ${ }^{[13,40,260,261]}$

$$
G_{\mathrm{GJK}}=\frac{1}{R_{\mathrm{GJK}}}=\frac{1}{R_{\mathrm{HK}}+R_{\mathrm{HK}}}=\frac{1}{2 R_{\mathrm{HK}}}=\frac{1}{2} G_{\mathrm{HK}}
$$

Im Gegensatz zu den Ergebnissen von Contreras et al., welche eine Nebenleitfähigkeit bei $G=(77 \pm 13) \mathrm{pS}$ und $G=145 \mathrm{pS}$ identifizierten, wurde in dieser Arbeit bei $G_{1}=(124 \pm 5) \mathrm{pS}$ nur eine weitere Leitfähigkeitsstufe gefunden. ${ }^{[69]}$ Diese weicht nur wenig von der Leitfähigkeitsstufe bei $145 \mathrm{pS}$ ab.

\section{Leitfähigkeiten des Cx43-GFP Halbkanals}

Im Vergleich dazu konnten für Cx43-GFP zehn verschiedene Leitfähigkeitsstufen unterschieden werden (Abb. 4-23 B). Die Untersuchung von Contreras et al. konnte für Cx43-eGFP in HeLa Zellen nur eine Leitfähigkeitsstufe $G=(223 \pm 9) \mathrm{pS}$ aufzeigen. ${ }^{[69]}$ Allerdings schließt die Studie nur Einzelkanalereignisse bei einer applizierten Spannung von >+60 mV ein. Die beiden GFP-Varianten, welche in beiden Studien verwendet wurden, unterscheiden sich nur in einer Aminosäure (GFP F64, eGFP L64). Eine Übersicht von Leitfähigkeiten, die für Cx43-GFP Halbkanäle und Gap Junction Kanäle in verschiedenen Studien 
ermittelt werden konnten, ist in Tab. 5-1 zusammengefasst. Der größte Unterschied besteht im Expressionssystem, in dem die beiden Halbkanäle assembliert wurden. In den ermittelten Leitfähigkeitsstufen für Cx43-GFP konnten zwei kleine Leitfähigkeiten von $G_{1}=(15 \pm 4) \mathrm{pS}$ und $G_{2}=(31 \pm 4) \mathrm{pS}$ gefunden werden. Diese geringen Leitfähigkeiten konnten ebenfalls durch die Expression von Cx43 in Astrozyten und C6 Zellen durch Kang et al. bestimmt werden (Tab. 5-1). ${ }^{[262]}$ Ferner konnten Kang et al. für Cx43-eGFP nur wenige Einzelkanalereignisse nachweisen, die eine höhere Leitfähigkeit als $15 \mathrm{pS}$ zeigten. Deshalb wurde auch in dieser Studie dem C-Terminus die entscheidende Komponente für die Aktivität von Cx43 Halbkanälen zugeordnet. Die in vitro Expression von Cx43 (Retikulozytenlysat) und die elektrophysiologische Charakterisierung durch Falk et al. ergab eine mittlere Leitfähigkeit von 35,5 pS. ${ }^{[193]}$ Weitere Leitfähigkeitsniveaus wurden ebenfalls für Cx43 und Cx43-GFP, welche in HEK293 Zellen exprimiert wurden, berichtet (Tab. 5-1). ${ }^{[254,263]}$ 
Tab. 5-1: Übersicht der ermittelten Literaturwerte für die Leitfähigkeit von Cx43 Halbkanälen und Gap Junction Kanälen und dem Zelltyp, welcher für die Untersuchung verwendet wurde. Die Leitfähigkeit der Connexin Halbkanäle ist mit HK und die der GapJunction Kanäle mit GJK gekennzeichnet.

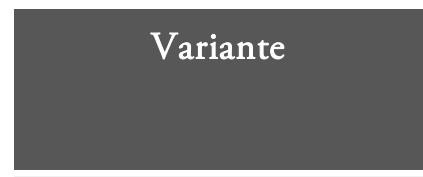

Orellana et al. 2012 $2^{[264]}$

Desplantez et al. $2011^{[265]}$

Schalper et al. 2010 266$]$

Procida et al. $2009^{[70]}$

Kang et al. 2008 $8^{[262]}$

Retamal et al. 2007 259$]$

Contreras et al. 2003 ${ }^{[69]}$

Martinez et al. $2002^{[267]}$

Moreno et al. 2002 268$]$

Bukauskas et al. 2001 [40]

John et al. $1999^{[254]}$

Falk et al. $1997^{[193]}$

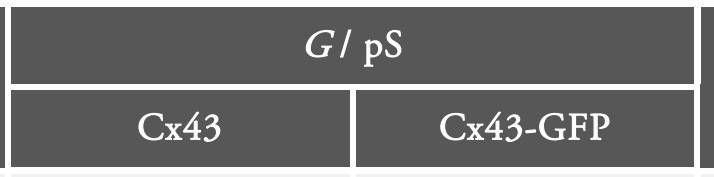

$200(\mathrm{HK})$

$18 / 58(\mathrm{GJK})$

$-220(\mathrm{HK})$

95/119 (GJK)

$15 / 26 / 115 / 165$

(HK)

$228 / 220 / 249(\mathrm{HK})$

77/145/220 (HK)

$36 / 73 / 105 / 126$

(GJK)

102/119 (GJK)

25/85/110 (GJK)

$35,5(\mathrm{HK})$
$110(\mathrm{GJK})$

120 (HK)

\section{Zelltyp}

Tanyzyten (Gliazellen)

HeLa Zellen

HeLa Zellen

HeLa Zellen

C6 Zellen, Astrozyten Aktivität

HeLa Zellen

HeLa Zellen

HeLa Zellen

Xenopus laevis Oocyten

HeLa Zellen

HEK293

Zell-frei exprimiert 


\subsubsection{Untersuchung der Strom-Spannungsabhängigkeit, der Öffnungs- wahrscheinlichkeit und der mittleren Öffnungsdauer}

Zur Untersuchung der Stromspannungsabhängigkeit von Cx43 und Cx43-GFP wurden zwischen $-100 \mathrm{mV}$ und $+100 \mathrm{mV}$ Strom-Spannungskurven (I/V-Traces) aufgenommen. Verhalten sich Cx43 und Cx43-GFP wie ein ohmscher Kanal, so resultiert ein linearer Zusammenhang zwischen der angelegten Spannung und der resultierenden Stromantwort (Abb. 4-24). Dies konnte für Cx43 und Cx43-GFP beobachtet werden. Das ohmsche Verhalten von Cx43 Halbkanälen konnte ebenfalls von Contreras et al. und Kang et al. in HeLa bzw. C6 Zellen beobachtet werden (Abb. 5-4). ${ }^{[69,262]}$
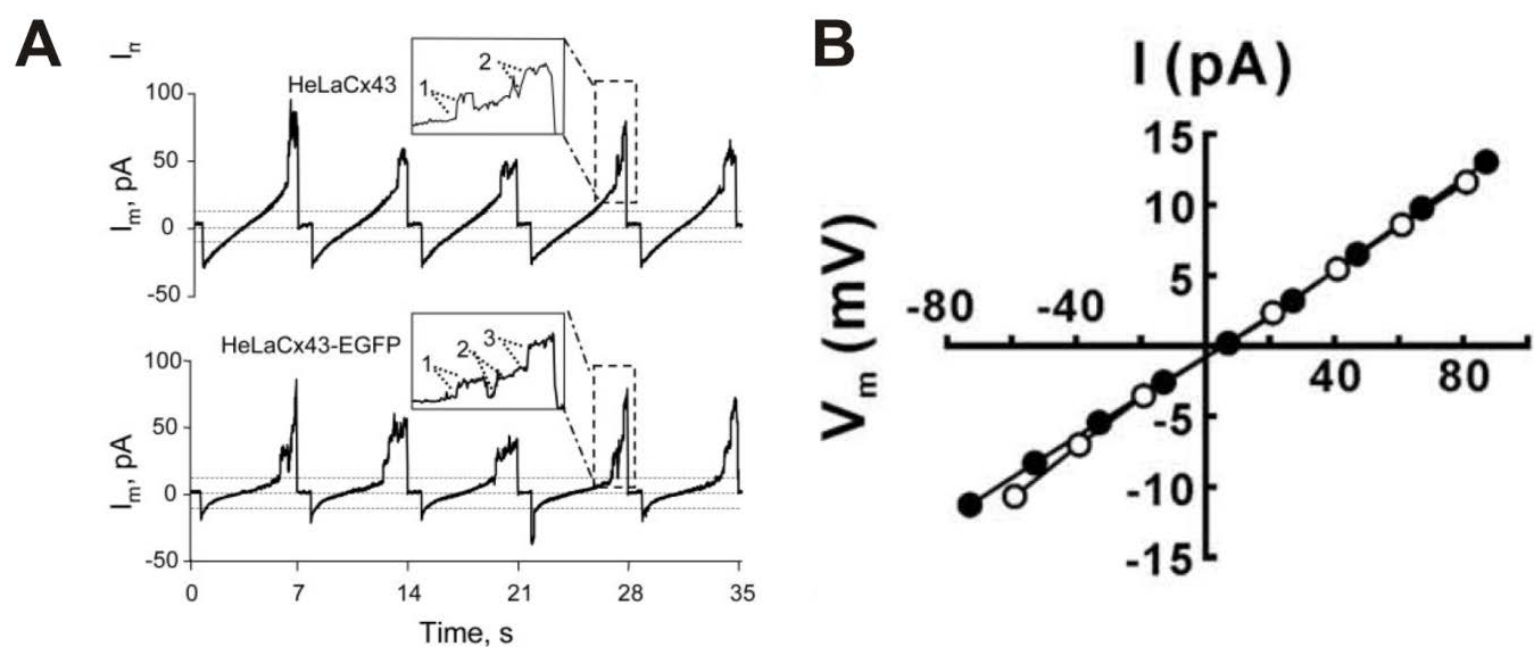

Abb. 5-4: I-V-Traces von Cx43 bzw. Cx43-eGFP Halbkanälen. A, I-V-Traces von Cx43 und Cx43-GFP in HeLa-Zellen in einem Spannungsbereich von $-100 \mathrm{mV}$ bis $+100 \mathrm{mV}$. Erst bei Spannungen >+60 mV konnten Einzelkanalereignisse aufgezeichnet werden. ${ }^{[69]} \boldsymbol{B}$, I-V-Trace für Cx43 Halbkanäle in C6 Zellen (Cell-Attached Patches) mit $130 \mathrm{mM} \mathrm{NaCl}(\bullet)$ oder $\mathrm{Na}_{2} \mathrm{ATP}(\mathrm{\circ}) .{ }^{[262]}$

In dem verwendeten Modellmembransystem zeigen Cx43 und Cx43-GFP eine BoltzmannVerteilung der Öffnungswahrscheinlichkeit von der applizierten Spannung (Abb. 4-26) ähnlich wie sie für Cx32 gefunden werden konnte. ${ }^{[195]}$ Dieser Zusammenhang konnte ebenfalls für die Auftragung der normalisierten Leitfähigkeit $g_{\mathrm{j}, \mathrm{ss}} / g_{\mathrm{j} \text {,inst }}$ von der Transjunctional Voltage $V_{\mathrm{j}}$ für Cx43 beobachtet werden (Abb. 5-5 A). Die maximale Öffnungswahrscheinlichkeit beträgt für Cx43-GFP bei $0 \mathrm{mV} 71 \%$ und ist damit etwas höher als für Cx43 mit 54\%. Dies könnte ebenfalls wieder auf die sterische Hinderung des GFPs zurückgeführt werden. In zellbasierten Studien wird ebenfalls von einer niedrigen Öffnungswahrscheinlichkeit von Cx43 Halbkanälen berichtet. ${ }^{[69]}$ 
Ein Vergleich der mittleren Öffnungsdauern von Cx43 und Cx43-GFP verdeutlicht, dass diese mit $\tau_{1}=(15 \pm 3) \mathrm{ms}$ und $(10 \pm 1) \mathrm{ms}$ bzw. $\tau_{2}=(75 \pm 5) \mathrm{ms}$ und $(80 \pm 26) \mathrm{ms}$ annähernd übereinstimmen. Dies deckt sich mit der mittleren Öffnungsdauer von $\tau=(10,4 \pm 0,8) \mathrm{ms}$, welche für Cx43 in C6 Zellen ermittelt werden konnte. ${ }^{[262]}$ Diese Öffnungsdauern spiegeln vermutlich das in der Einleitung beschriebene Fast und Slow Gating von Connexin Halbkanälen und Gap Junction Kanälen wieder. Der Übergang zum vollständig geöffneten Zustand, wie er von Contreras et al. für Cx43-eGFP beschrieben wurde, konnte in dieser Arbeit nur für $1,5 \%$ der ermittelten Leitfähigkeiten beobachtet werden. Allerdings konnte auch Kang et al. für Cx43-eGFP Halbkanäle in C6 Zellen und Astrozyten eine geringe Aktivität nachweisen.

\section{Einfluss eines Hexahistidin-Tags auf die Cx43 Kanalaktivität}

Ferner untersuchten Desplantez etal. den Effekt eines Hexahistidin-Tags auf die Leitfähigkeit von Cx43 Gap Junction Kanälen. Dazu wurde der Cx43 Wildtyp (WT-Cx43) $C$-terminal mit einem Hexahistidin-Tag über ein V5 Epitop (V5/His - -Tag) fusioniert (Cx43-Tag). Das V5 Epitop wird häufig zum spezifischen Nachweis des exprimierten Proteins in der Western Blot Analyse oder der Immunofluoreszenz verwendet. Die Studie an HeLa Zellen verdeutlicht, dass sich die Abhängigkeit der Leitfähigkeit vom Transjunctional Voltage $V_{\mathrm{j}}$ durch den Hexahistidin-Tag von einer Glockenform zu einem sigmoidalen Verlauf verschiebt (Abb. 5-5 A). ${ }^{[265]}$ Die weitere Untersuchung verdeutlichte, dass sich die Hauptleitfähigkeit von WT-Cx43 von $G_{2, \text { WT-Cх43 }}=(58,4 \pm 1,8) \mathrm{pS}$ auf $G_{2, \text {, } 443-\mathrm{Tag}}=$ $(28,9 \pm 1,6) \mathrm{pS}$ des Cx43-Tag Gap Junction Kanals reduziert (Abb. 5-5 B, C). Dies konnte ebenfalls für die ermittelte Nebenleitfähigkeit beobachtet werden $\left(G_{1, \text { Сх43-WT }}=(17,6 \pm 1,4) \mathrm{pS}\right.$, $\left.G_{1, \text { Cx43-Tag }}=(7,9 \pm 0,9) \mathrm{pS}\right)$. Dieser Vergleich veranschaulicht, dass Cx43-Tag GapJunction Kanäle eine geringere Abhängigkeit von der Spannung $V_{\mathrm{j}}$ haben. Die Autoren schlossen aus den Ergebnissen, dass der Hexahistidin-Tag zusammen mit dem V5 Epitop einen Einfluss auf die Konformation des Kanals hat und somit indirekt die Eigenschaften des Kanals verändert. Außerdem wird eine verlängerte Öffnungsdauer durch V5/His 6 -Tag angenommen. Die Analyse umfasste ebenfalls Cx40 und Cx45 Gap Junction Kanäle. Hier hatte der V5/His6-Tag einen weitaus geringeren Einfluss auf die Funktion der Gap Junction Kanäle. Die Studie von Desplantez et al. verdeutlicht, dass bereits kleine Veränderungen wie ein Affinitätstag einen Einfluss auf die Struktur und Funktion eines Proteins haben können. Schließlich führen 
Desplantez et al. die beobachteten Effekte auf die gestörte molekulare Interaktion des $C$-Terminus mit dem $N$-Terminus oder der cytoplasmatischen Schleife von Cx43 zurück. Dies könnte durch die erhöhte positive Ladung des Hexahistidin-Tags verursacht worden sein. ${ }^{[265]}$ In dieser Arbeit wurde ein Hexahistidin-Tag über das c-myc Epitop mit Cx43 fusioniert. Jedoch ist für die Hauptleitfähigkeit im Vergleich mit Literaturwerten keine Veränderung zu beobachten. In den nachfolgenden Kapiteln wird noch detailierter auf die Ursachen der veränderten Elektrophysiologie der Cx43-GFP Halbkanäle eingegangen.
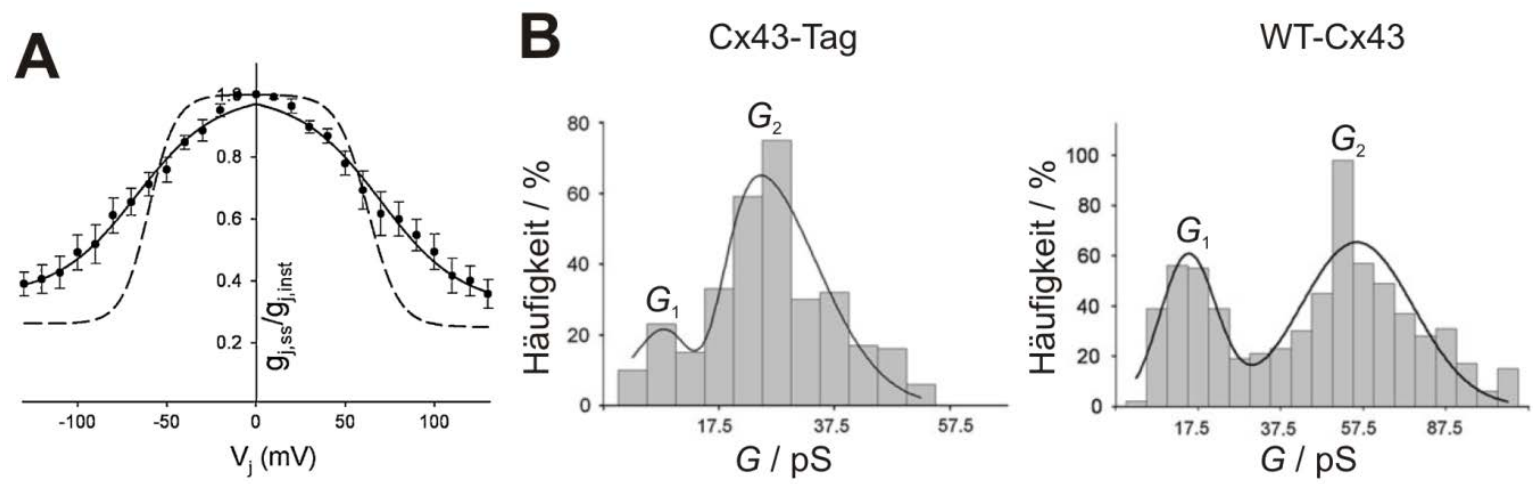

Abb. 5-5: Untersuchung des Einflusses eines Hexahistidin-Tags auf die Leitfähigkeit von WT-Cx43 durch Desplantez et al. A, Auftragung der normalisierten Leitfähigkeit im Gleichgewicht (Steady State, ss), $g_{\mathrm{j}, \mathrm{ss}} / g_{\mathrm{j}, \text { inst }}$ gegen die Tranjunctional Voltage $V_{\mathrm{j}}$. Die durchgezogene Linie zeigt die BoltzmannAnpassung (-). Die gestrichelte Linie zeigt die Boltzmannanpassung von Desplantez et al. (2004) der Abhängigkeit von $g_{\text {j,ss }} / g_{\text {,inst }}$ gegen $V_{\mathrm{j}}$ des WT-Cx43 (---). ${ }^{[269]} \boldsymbol{B}$, Punktamplitudenhistogramme der ermittelten Leitfähigkeiten der Gap Junction Kanäle von WT-Cx43 und Cx43-Tag (Intervallbreite 5 pS). Die durchgezogene Linie zeigt die Anpassung von zwei Normalverteilungen an die Daten (-). Dabei konnte jeweils eine Hauptleitfähigkeit und eine Nebenleitfähigkeit unterschieden werden. ${ }^{[265]}$

\subsubsection{Chemische Regulation von Cx43 und Cx43-GFP Halbkanälen}

Die Aktivität von Connexin Halbkanälen und Gap Junction Kanälen kann durch Phosphorylierungen, den intrazellulären $\mathrm{pH}$-Wert sowie niedermolekulare Verbindungen moduliert werden. Außerdem konnten eine Reihe an verschiedenen Blockern für Cx43 identifiziert werden wie Flufenaminsäure, 5-Nitro-2-(3-phenylpropylamino)benzoesäure, Nifluminsäure, 18- $\alpha$-Glycyrrhetinsäure, 18- $\beta$-Glycyrrhetinsäure, Carbenoxolon, Oktanol, Heptanol, $\mathrm{Gd}^{3+}, \mathrm{La}^{3+}, \mathrm{Ba}^{2+}, \mathrm{Sr}^{2+}, \mathrm{Mg}^{2+}$, Oleamide, Halothan sowie verschiedene Aminosulfonsäurederivate. ${ }^{[13]}$ In dieser Arbeit wurden die Blocker Taurin und Lanthanchlorid eingesetzt, um die Aktivität von Cx43 sowie Cx43-GFP zu modulieren bzw. blockieren. Taurin gehört mit zu den Aminosulfonaten, die in ihrer protonierten Form (Taurin, 
pKa $=9,1$ bei $25^{\circ} \mathrm{C}$ ) direkt die Aktivität von Connexin Halbkanälen sowie Gap Junction Kanälen modulieren können. ${ }^{[26,66,234]}$ Sowohl die Aktivität von Cx43 als auch von Cx43-GFP Halbkanälen konnte durch die Zugabe von Taurin reduziert werden (Abb. 4-27). Allerdings erforderte die Inhibierung von Cx43-GFP Halbkanälen die fünffache Menge an Taurin im Vergleich zu Cx43 Halbkanälen. Dies könnte ebenfalls auf eine veränderte Struktur des $C$-Terminus durch die GFP-Fusion zurückgeführt werden. Erst kürzlich konnten Locke et al. die strukturellen Bereiche, welche für die Modulation der Kanalaktivität von Cx26 verantwortlich sind, eingrenzen. In dieser Studie wurde verdeutlicht, dass Taurin an die cytoplasmatische Schleife bindet und die Interaktion zwischen $C$-Terminus und cytoplasmatischer Schleife unterbindet. ${ }^{[26]}$ Dies führt zum Verschluss des Connexin Halbkanals. Vermutlich wird durch die GFP-Fusion eine höhere Konzentration an Taurin benötigt, da es die cytoplasmatische Schleife abschirmt.

\subsubsection{Ursachen für den Einfluss der GFP-Fusion auf die Cx43 Halbkanal- aktivität}

GFP ist am C-Terminus jedes Connexin Monomers lokalisiert und sechs Connexin Monomere bilden einen Connexin Halbkanal. Die Quasi-Zweidimensionalität der Membran bedingt zusammen mit der erhöhten Konzentration von GFP in einem Halbkanal eine lokal gesteigerte Konzentration von GFP. Dies könnte die Dimerbildung von GFP vermittelt durch den hydrophoben Patch (Aminosäuren: Ala206, Leu221 und Phe223) forcieren, welche bei hohen Proteinkonzentrationen $(>100 \mu \mathrm{M})$ und hohen Ionenstärken (>100 mM) auftritt. ${ }^{[270,271]}$ Die Interaktion bzw. das Auftreten von inter- oder intramolekularen Dimeren könnte die Konformationsänderung vom geschlossenen in den geöffneten Zustand von Cx43 behindern und damit die beobachteten Leitfähigkeitsstufen verursachen.

Die Berechnung der lokalen GFP-Konzentration an einem Connexin Halbkanal basierend auf den Abmessungen von Falk (Abb. 5-6 A) ergab, dass sechs GFP Moleküle in einem Zylinder mit einer Länge von $42 \AA$ und einem Radius von $32,5 \AA$ eine Konzentration von 0,71 mol.L $\mathrm{L}^{-1}$ aufweisen (Abb. 5-6 B). ${ }^{[272]}$ Natürlich kann dies nur eine Abschätzung sein, da der Zylinder wahrscheinlich etwas zu klein ist und GFP etwas mehr Freiraum hat als in Abb. 5-6 A dargestellt ist. Daraus lässt sich schlußfolgern, dass die Konzentration von GFP am Cx43 Halbkanal relativ hoch ist und eine Dimerisierung begünstigt. Bei einer näheren Betrachtung der Leitfähigkeiten von Cx43-GFP von $G_{1}$ bis $G_{6}$ fällt auf, dass jede Leitfähigkeit 
ein Vielfaches von 15 pS darstellt. Einerseits könnte dies die konformationelle Änderung der einzelnen Connexin Untereinheiten darstellen, die durch die GFP-Fusion gestört ist. Andererseits könnte dies die Wechselwirkung der einzelnen GFP-Untereinheiten miteinander darstellen. Dies hat ebenfalls Auswirkung auf die Wechselwirkung des $C$-Terminus mit der cytoplasmatischen Schleife, worauf im Folgenden kurz eingegangen werden soll.

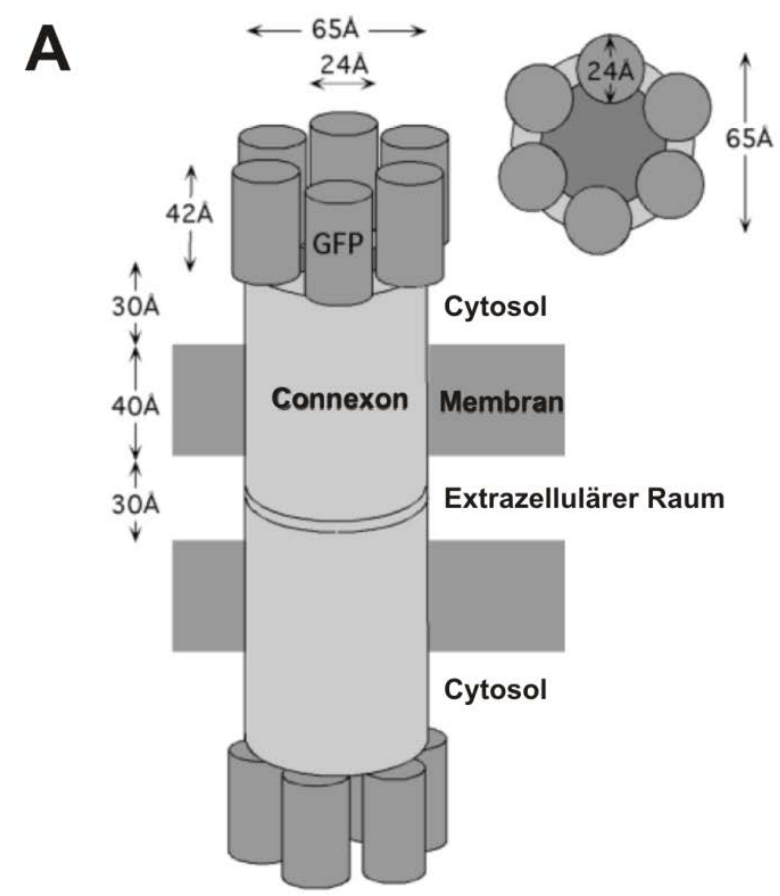

B

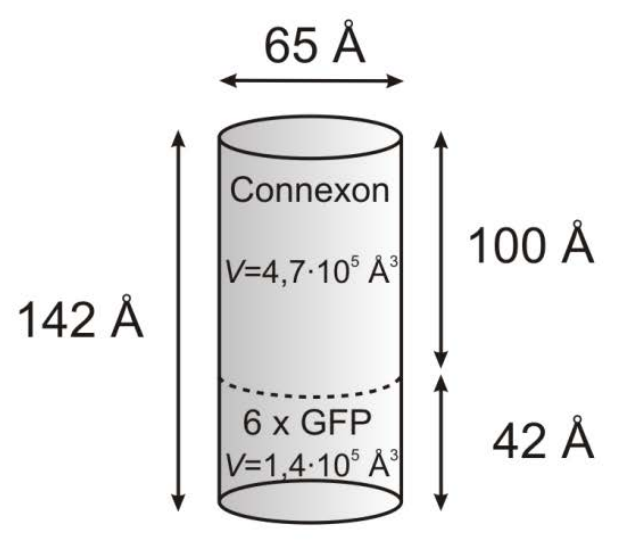

Abb. 5-6: Berechnung der lokalen Konzentration von GFP am Connexin Halbkanal. $A$, Schematische Darstellung eines Gap Junction Kanals mit der GFP Fusion pro Untereinheit. Dies soll den beanspruchten Raum der sechs GFP-Moleküle pro Connexin Halbkanal veranschaulichen. ${ }^{[272]} \boldsymbol{B}$, Basierend auf den Abmessungen in $A$ wurde die Konzentration der sechs GFP Moleküle am Connexin Halbkanal berechnet.

Vorherige Studien haben gezeigt, dass es sich beim $C$-Terminus (CT) um eine regulatorische Domäne sowohl von Cx43 GapJunction Kanälen als auch von den jeweiligen Halbkanälen handelt. ${ }^{[33,44,65,70,268,273-276]}$ Moreno et al. zeigten, dass die Abhängigkeit des Transjunctional Currents $I_{\mathrm{j}}$ von der Transjunctional Voltage $V_{\mathrm{j}}$ in $\mathrm{N} 2 \mathrm{a}$ Zellen verringert wird. ${ }^{[268]}$ Hier konnten drei Leitfähigkeiten für Cx43 Gap Junction Kanäle bestimmt werden $G=(35 \pm 5) \mathrm{pS},(102 \pm 18) \mathrm{pS}$ und $(118 \pm 14) \mathrm{pS}$ (Abb. 5-7 A). Für die $C$-terminal verkürzte Variante Cx43M257 konnte nur eine Leitfähigkeit mit $G=(110 \pm 10)$ pS bestimmt werden (Abb. 5-7 B). Die Coexpression von Cx43M257 und Cx43CT führte dazu, dass sechs verschiedene Leitfähigkeitsstufen für die untersuchten Gap Junction Kanäle beobachtet werden konnten, $\quad G=(36 \pm 4) \mathrm{pS}, \quad(50 \pm 7) \mathrm{pS}, \quad(61 \pm 17) \mathrm{pS}, \quad(84 \pm 8) \mathrm{pS}, \quad(100 \pm 16) \mathrm{pS}$ und 
$(117 \pm 7) \mathrm{pS}$ (Abb. 5-7 C). Diese Multiplizität der Leitfähigkeit konnte in dieser Arbeit ebenfalls für Cx43-GFP Halbkanäle beobachtet werden. Beides zeigt, dass sowohl die Coexpression des Cx43CT als auch die Fusion mit GFP zu einer veränderten Regulation durch den $C$-Terminus führt. Die $C$-terminal verkürzte Variante von Cx43 zeigt ebenfalls eine veränderte Abhängigkeit der Leitfähigkeit von der Transjunctional Voltage $V_{\mathrm{j}}$ (Abb. 5-7 D). Die Autoren spekulieren, dass die Multiplizität der Leitfähigkeit auf die Interaktion des coexpremierten Cx43CT mit einer bestimmten Region, die als Rezeptor für den CT dient, zurückzuführen ist. Weiter wird vermutet, dass ein kovalent gebundener CT wahrscheinlich eine stabilere Interaktion ermöglicht und dadurch keine weiteren Leitfähigkeitsstufen auftreten. Ferner wäre denkbar, dass Cx43CT höhere Freiheitsgrade in der Struktur hat und damit verschiedene Interaktionen ermöglicht werden, die die unterschiedlichen Leitfähigkeiten verursachen. ${ }^{[268]}$ In diesem Zusammenhang konnten Seki et al. zeigen, dass die L2 Region der cytoplasmatischen Schleife als Rezeptor dient. Nach Zugabe bindet das synthetische L2 Peptid an der cytoplasmatischen Schleife und blockiert die Interaktion. ${ }^{[277]}$ Dadurch sind die ähnlichen Effekte wie für das $C$-terminal verkürzte $\mathrm{Cx} 43$ zu beobachten. Mit den genannten Ursachen lässt sich für die Cx43-GFP Halbkanalaktivität ein Modell entwickeln, worauf im nächsten Kapitel eingegangen werden soll. 
A $\quad$ Cx43

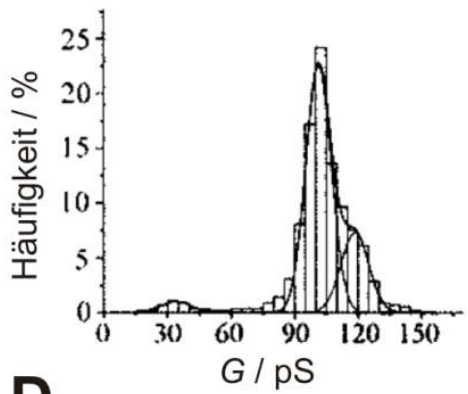

D

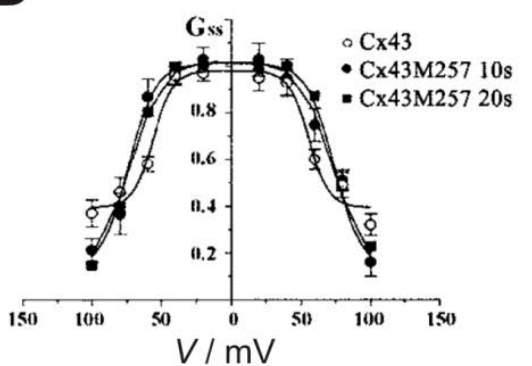

B $\quad$ Cx43M257 C $\mathrm{Cx} 43 \mathrm{M} 257+$

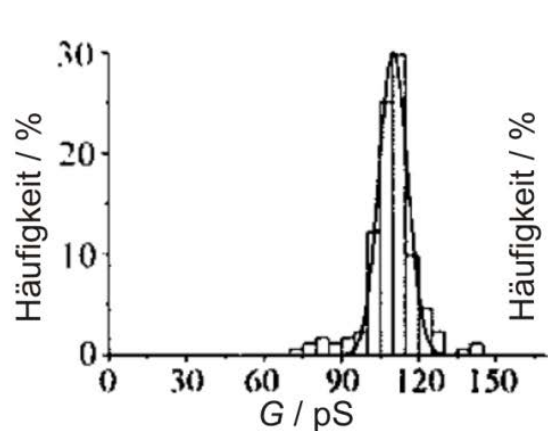
CX43CT

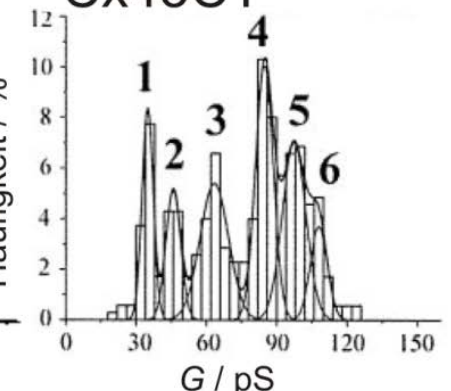

$\mathrm{G} / \mathrm{pS}$

Abb. 5-7: Elektrophysiologische Untersuchung von Cx43 und Cx43M257 ( $C$-terminal verkürzt) Gap Junction Kanälen durch Moreno et al. $A-C$, Punktamplitudendiagramme der Einzekanalereignisse der Gap Junction Kanäle von Cx43, Cx43M257 und Cx43M257 mit Cx43CT. D, Abhängigkeit der Leitfähigkeit im Gleichgewicht (Steady State, ss) $G_{s s}$ von der Transjunction Voltage $V_{\mathrm{j} .}{ }^{[268]}$ 


\subsubsection{Modell für die Cx43-GFP Halbkanalaktivität}

Allgemein wird für die Interaktion zwischen $C$-Terminus und der cytoplasmatischen Schleife von einem Ball-and-Chain Modell ausgegangen (Abb. 5-8 A), wobei der C-Terminus die Pore des Gap Junction Kanals direkt oder indirekt blockiert. Dieses Modell wurde hauptsächlich von Delmar et al. im Zusammenhang mit dem Chemical Gating formuliert und erstmalig durch Zagotta et al. für verschiedene Ionenkanäle postuliert (Abb. 5-8 A). ${ }^{[273,278]}$ In diesem Modell ist der C-Terminus der Modulator, der für das Öffnen und Schließen des Gap Junction Kanals verantwortlich ist. Bei physiologischem $\mathrm{pH}-$ Wert findet keine Interaktion des $C$-Terminus mit der Pore des Kanals statt. Kommt es zur Absenkung des pH-Wertes, bindet der $C$-Terminus an einen Rezeptor, vermutlich die L2-Region der cytoplasmatischen Schleife, was zum Verschluss der Pore führt. Die L2-Region umfasst die Aminosäurereste 119-144 von Cx43 (Abb. 1-6). ${ }^{[275]}$ In diesem Zusammenhang stehen die Ergebnisse von Ponsaerts et al. ${ }^{[275]}$ Die Autoren konnten zeigen, dass Cx43 in Xenopus laevis Oocyten inaktiv vorliegt. Erst die Zugabe des $C$-Terminus von $\mathrm{Cx} 43$ als Fusion mit dem membrangängigen Tat-Peptid konnte die Aktivität des Cx43 Halbkanals wiederherstellen. Außerdem zeigten sie, dass die Aktivität der Cx43 Halbkanäle in HeLa Zellen bei einer hohen Calciumionenkonzentration durch die Zugabe von Tat-Cx43CT wiederhergestellt werden kann. Im Gegensatz dazu konnten die Cx43 Halbkanäle durch die Zugabe von Tat-L2, welches mit einem Teil der cytoplasmatischen Schleife übereinstimmt, inhibiert werden. Die Ergebnisse verdeutlichen, dass die Interaktion zwischen $C$-Terminus und cytoplasmatischer Schleife essentiell für die Aktivität des Cx43 Halbkanals ist.

Zusammen mit den vorgenannten Ergebnissen und Untersuchungen lässt sich ein Modell für die Aktivität des Cx43 Halbkanals erstellen. Für Cx43 Halbkanäle führt die Interaktion zwischen C-Terminus und cytoplasmatischer Schleife zum Öffnen des Kanals (Abb. 5-8 B). Wenn diese Interaktion durch GFP gestört wird oder die Assoziation bzw. Dissoziation der beiden Domänen verlangsamt ist, beeinflusst dieser Prozess das Öffnen und Schließen des Cx43 Halbkanals (Abb. 5-8 C). Die Dimerisierung von GFP würde in diesem Modell dazu führen, dass die Interaktion der beiden Domänen weiter eingeschränkt wird. Revilla et al. berichten ebenfalls, dass durch ein größeres Fusionsprotein die Beweglichkeit des $C$-Terminus eingeschränkt wird oder alternativ die Konformation geändert werden könnte. ${ }^{[279]}$ Die in Abb. 5-8 dargestellten Modelle können nur einen Teil der Funktion von Gap Junction Kanäle 
bzw. Connexin Halbkanäle erklären und bieten kein ganzheitliches Modell für das Voltage und Chemical Gating.

A

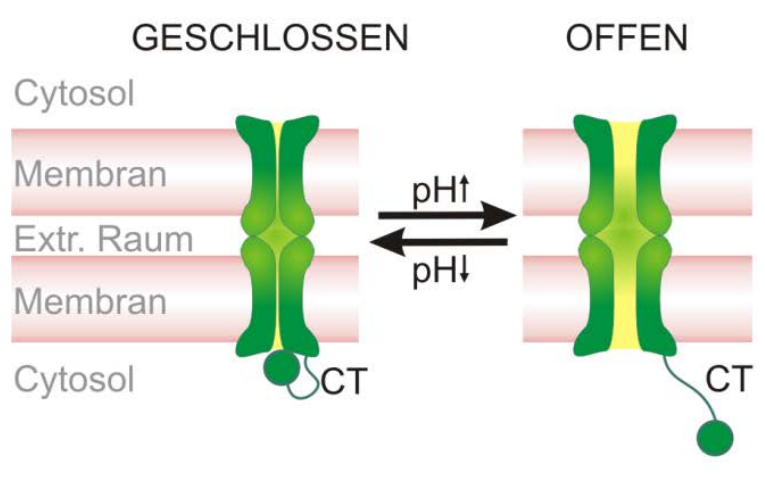

B

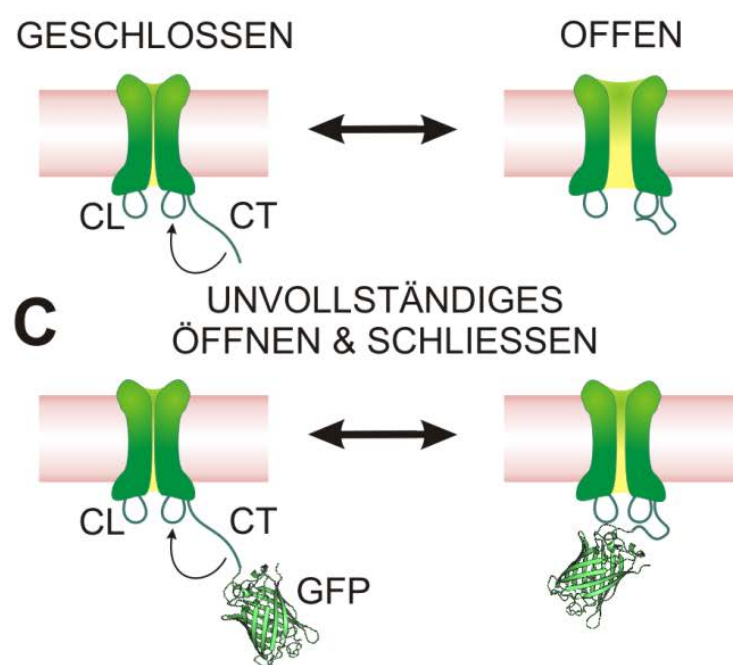

Abb. 5-8: Modelle zum Einfluss des C-Terminus für Cx43 Gap Junction Kanäle und Cx43 Halbkanäle. A, Ball-and-Chain Modell nach Delmar et al. Bei physiologischen $\mathrm{pH}$-Wert ist der Gap Junction Kanal geöffnet. ${ }^{[279]}$ Kommt es zur Senkung des $\mathrm{pH}$-Wertes interagiert der $C$-Terminus mit dem Rezeptor und vermittelt das Schließen des Kanals. $B$, Die Interaktion des $C$-Terminus mit der L2 Region der cytoplasmatischen Schleife führt zum Öffnen des Cx43 Halbkanals. $C$, Die Fusion des $C$-Terminus von Cx43 mit GFP beeinflusst die Assoziation und Dissoziation mit der cytoplasmatischen Schleife. Dies führt zu einer Reihe von Nebenleitfähigkeiten, da der Kanal unvollständig öffnet und schließt.

Zusammenfassend zeigen die Ergebnisse, dass sowohl Cx43 als auch Cx43-GFP Halbkanäle funktionell in Pichia pastoris exprimiert werden konnten. Die Untersuchung mithilfe des Planar Patch Clamp Systems erlaubt eine schnelle Untersuchung von Ionenkanälen. Zusammen mit den aufgeführten Studien wird deutlich, dass der $C$-Terminus eine regulatorische Funktion für die Halbkanalaktivität hat. Sowohl das Voltage als auch das Chemical Gating werden durch die GFP-Fusion beeinflusst. Die Ergebnisse der elektrophysiologischen Charakterisierung von Cx43-GFP unterscheiden sich von den Ergebnissen von Bukauskas et al. und Contreras et al., da überwiegend Nebenleitfähigkeiten aufgezeichnet wurden und die Hauptleitfähigkeit nur in 1,5\% der aufgezeichneten Ereignisse erreicht wurde. 


\subsection{Porenüberspannende Membranen als Basis für einen Farb- stofftransferassay}

Nach der erfolgreichen Expression, Reinigung und elektrophysiologischen Charakterisierung von Cx43 und Cx43-GFP war das nächste Ziel ein geeignetes System zum Nachweis der Gap Junction Kanalaktivität basierend auf porenüberspannenden Membranen aufzubauen. Mithilfe dieses fluoreszenzbasierten Assays soll der Transfer von Farbstoff zwischen zwei geschlossenen Kompartimenten via Gap Junction Kanäle visualisiert werden. Dies erfordert zum einen die Visualisierung des wasserlöslichen Farbstoffs, welcher durch die porenüberspannende Membran eingeschlossen ist, und zum anderen die Abbildung der porenüberspannenden Membran, welche mithilfe eines Farbstoff-gekoppelten Lipids markiert ist.

\subsubsection{Präparation von artifiziellen Membranen auf porösen Aluminium- oxidsubstraten}

Zu diesem Zweck wurden poröse, hochgeordnete Aluminiumoxidsubstrate eingesetzt, da sie bis zu einer Schichtdicke von $10 \mu \mathrm{m}$ optisch transparent sind. Die Aluminiumoxidsubstrate besitzen eine Porosität von $10^{10}$ Poren $\cdot \mathrm{cm}^{-2}\left(d_{0}=70 \mathrm{~nm}\right)$ und eine Oberfläche von 180 bis $250 \mathrm{~m}^{2} \cdot \mathrm{g}^{-1} \cdot{ }^{[280,281]}$ Ein Vorteil ist, dass mit einer geringen Porengröße von etwa $60 \mathrm{~nm}$ auch eine hohe Stabilität der porenüberspannenden Membranen verbunden ist. ${ }^{[93]}$ Die Aluminiumoxidsubstrate konnten reproduzierbar in einem zweistufigen Anodisierungsprozess hergestellt werden (Kapitel 4.4.1). Der Porendurchmesser wurde mithilfe von 5 \%iger Phosphorsäure bis zu $70 \mathrm{~nm}$ erweitert. Zum Spreiten von unilamellaren Vesikeln reicht die Adhäsionsenergie auf Aluminiumoxid nicht aus, um die Lipidmembran soweit zu verformen, dass es zum Aufreißen der Vesikel kommt. ${ }^{[201]}$ Das Spreiten der Vesikel ist abhängig von der Oberflächenladung sowie von den van-der-Waals-Kräften. ${ }^{[98]}$ Hohe Adhäsionsenergien führen zwar zum Spreiten, jedoch geht die laterale Mobilität dabei verloren. ${ }^{[282]}$ Ist die Adhäsionsenergie zu schwach, adsorbieren die Vesikel in einer Schicht auf dem Substrat. ${ }^{[201]}$ Um die Adhäsion zwischen der Oberfläche und den Vesikeln zu verstärken wurde in dieser Arbeit die Oberflächen mithilfe des Silans 3-Mercaptotriethoxypropylsilan funktionalisiert. Das Silan wurde durch eine dünne Goldschicht auf den Porenstegen geschützt und nach der Entfernung der Funktionalisierung aus dem Poreninneren durch die Applikation von Sauerstoffplasma eine hydrophile Silanoloberfläche erzeugt (Abb. 3-19). Thomas D. Lazzara (AK Steinem) entwickelte im Rahmen 
seiner Dissertation unterschiedliche Arten der Oberflächenfunktionalisierungen zur Präparation von porenüberspannenden Membranen auf porösen, hochgeordneten Aluminiumoxid. Mit dieser Art der Präparation konnten die stabilsten, porenüberspannenden Membranen gebildet werden.

\section{Alternative Techniken zur Präparation von Lipiddoppelschichten auf Aluminiumoxid}

Für die Oberflächenfunktionalisierung von Aluminiumoxid bzw. Präparation von Lipidmembranen auf Aluminiumoxid wurden in den letzten Jahren noch alternative Methoden, unter anderem von Mager et al., Venkatesan et al., Mutalib Md Jani et al., Bhattacharya et al. und Roskamp et al. entwickelt. ${ }^{[97,98,201,283,284]}$ Mager et al. entwickelten eine Methode der Bubble Collapse Deposition, um auf nicht-funktionalisiertem Aluminiumoxid Vesikel zu spreiten. ${ }^{[201,285]}$ Für die Präparation wird zunächst eine Luftblase mit einer Lipidmonoschicht überzogen und anschließend mit der Oberfläche kontaktiert (Abb. 5-9 A). Durch langsames Zurückziehen der Luft entsteht durch Zurückfalten der Lipidmonoschicht eine Lipiddoppelschicht auf der Oberfläche. Dabei konnte für POPC Lipidmembranen mithilfe des Fluorescence Recovery After Photobleaching (FRAP) ein Diffusionskoeffizient von $D=0,6 \mu \mathrm{m}^{2} \cdot \mathrm{s}^{-1}$ ermittelt werden. Im Vergleich mit dem Diffusionskoeffizient für die silanisierten Aluminiumoxidsubstrate $\left(D=4 \pm 1 \mu \mathrm{m}^{2} \cdot \mathrm{s}^{-1}\right)$ und Silikasubstrate $\left(D=1\right.$ bis $\left.3 \mu \mathrm{m}^{2} \cdot \mathrm{s}^{-1}\right)$ ist dieser niedriger. ${ }^{[155,201]}$ Der reduzierte Diffusionskoeffizient von Mager et al. könnte auf eine veränderte Viskosität der vermittelnden Wasserschicht oder an der stärkeren Interaktion von Aluminiumoxid mit Wasser zurückgeführt werden. ${ }^{[201]}$ Dagegen konnten Venkatesan et al. einen Diffusionskoeffizient von $2,7 \mu \mathrm{m}^{2} \cdot \mathrm{s}^{-1}$ mittels FRAP für DOPC Lipidmembranen auf Aluminiumoxid ermitteln, was auf eine dickere Wasserschicht zurückgeführt wird. ${ }^{[98]}$

Der Vorteil der funktionalisierten Oberfläche in dieser Arbeit ist, dass durch das Spreiten von Vesikeln eine Lipidmembran mit einer hohen Mobilität präpariert werden kann, die dem zellulären System ähnelt. ${ }^{[155]}$ Die Methode der Bubble Collapse Deposition könnte ebenfalls für das Spreiten auf den funktionalisierten Aluminiumoxidsubstraten verwendet werden, um eine vollständige Belegung zu erreichen. Damit können Lipidmembranpatches von etwa $500 \mu \mathrm{m}$ erzeugt werden. ${ }^{[201]}$ Ähnlich wie Lazzara et al. konnten Mutalib Md Jani et al. eine doppelte Funktionalisierungsstrategie (Janus-like Anodic Aluminium Oxide) entwickeln, bei der die Porenstege und der -innenraum mit einem unterschiedlichen Silan funktionalisiert sind 
(Abb. 5-9 B). ${ }^{[283]}$ Allerdings wird die erste Silanisierung nach der ersten Anodisierung und dem Ablösen des Aluminiumoxids durchgeführt (siehe Kapitel 3.5.1), dadurch ist diese Funktionalisierung auf die Porenstege beschränkt und das Poreninnere kann nach der zweiten Anodisierung chemisch modifiziert werden. Bhattacharya et al. haben einen Aufbau realisiert, indem die Anodisierung, die Silanisierung sowie das Spreiten in einem System stattfindet (Abb. 5-9 C). Allerdings wird nur ein einstufiger Anodisierungsprozess durchgeführt, dementsprechend ist die Ordnung des erzeugten Aluminiumoxidsubstrates niedrig. Nach der Funktionalisierung des Substrates wird das Spreiten von unilamellaren Vesikeln unter Durchflussbedingungen impedanzspektroskopisch verfolgt.
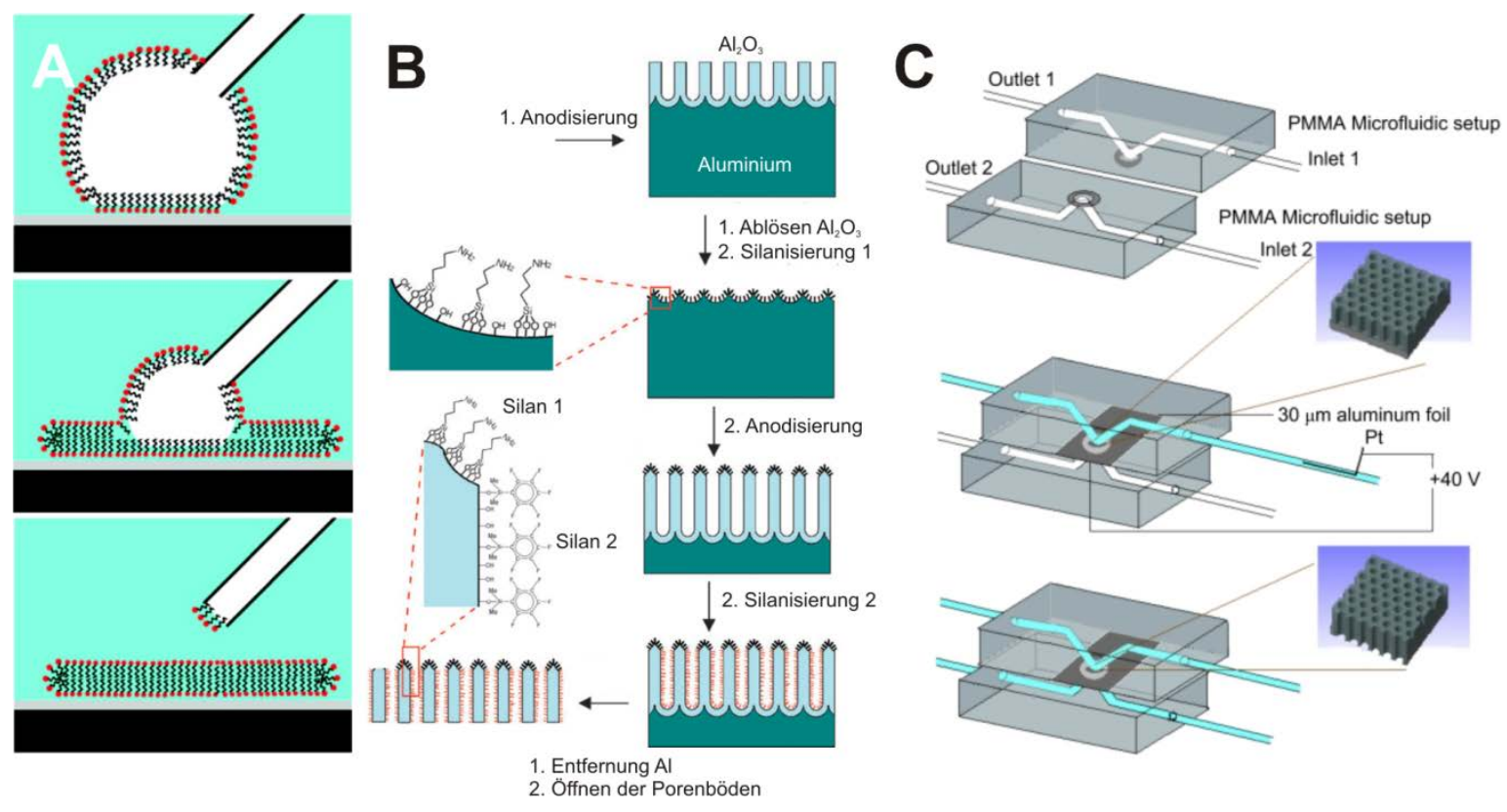

Abb. 5-9: $A$, Schematische Darstellung der Bubble Collapse Deposition. Luftblase mit Lipidmonoschicht wird an Substrat angenähert. Das langsame Zurückziehen der Luft führt zur Rückfaltung der Lipidmonoschicht, so dass eine Lipiddoppelschicht entsteht. Schließlich entsteht ein Lipidmembranpatch, dessen Größe von der Größe der Luftblase und Adhäsionfläche abhängt. $B$; Herstellung der doppelten Oberflächenfunktionalisierung von Aluminiumoxidsubstraten. $C$, Aufbau der Durchflusszelle, welche die Anodisierung, Funktionalisierung und das Spreiten in einem System ermöglicht. Die Anodisierung wurde bei $40 \mathrm{~V}$ unter einem konstanten Fluss von Oxalsäure durchgeführt, um poröses Aluminiumoxid zu bilden. Im letzten Schritt werden die Porenböden durch Phosphorsäure geöffnet. 


\title{
5.4.2 Validierung der porenüberspannenden Membranen mit Melittin
}

\author{
Einschluss des wasserlöslichen Fluoreszenzfarbstoffs Pyranin
}

Zum Nachweis der Gap Junction Kanalaktivität mithilfe der Fluoreszenzmikroskopie werden zwei abgeschlossene Kompartimente benötigt. Deshalb wurde im nächsten Schritt der Einschluss des wasserlöslichen Farbstoffs Pyranin durch porenüberspannende Membranen getestet. Dabei wären zwei verschiedene Szenarien nach der Gap Junction Kanalbildung denkbar. Einerseits kann der Farbstofftransfer von den Poren in die angekoppelten GUVs stattfinden. Andererseits ist der Transfer von Farbstoff aus GUVs in die Poren möglich. Mithilfe von porenüberspannenden Membranen war es in dieser Arbeit möglich, Pyranin einzuschließen (Abb. 4-34). Zum Nachweis, dass der Farbstoff auf die Poren beschränkt ist und jede Pore ein unabhängiges Kompartiment darstellt, wurde ein definierter Bereich gebleicht und die Fluoreszenzintensität in der betrachteten Region aufgezeichnet. Innerhalb von 5 min wurde nur ein geringfügiger Anstieg in der betrachteten Region beobachtet. Dieser kann auf die Diffusion von Farbstoff, welcher sich nicht in der fokalen Ebene befand, zurückgeführt werden.

\section{Gezielte Freisetzung von Pyranin durch Melittin}

Die Gap Junction Kanalaktivität soll durch den Transfer von Farbstoff zwischen zwei geschlossenen Kompartimenten visualisiert werden. Für die gezielte Freisetzung des wasserlöslichen Fluoreszenzfarbstoffs aus den membranüberspannten Poren wurde das lytische Peptid Melittin verwendet. Das kationische Peptid Melittin, welches ein Hauptbestandteil des Bienengifts ist, wird häufig zur Untersuchung des Mechanismus der Membranpenetration durch antimikrobielle Peptide als Modell eingesetzt. ${ }^{[286]}$ Es besteht aus 26 Aminosäuren mit einem eher hydrophoben $N$-Terminus und einem überwiegend hydrophilen $C$-Terminus. Mit verschiedenen Melittinkonzentrationen war es möglich, den eingeschlossenen Farbstoff aus dem porösen Bereich freizusetzen (Abb. 4-36). Die Freisetzung des Farbstoffs zeigt auch, dass am Rand jedes Lipidmembranpatches wahrscheinlich die Membran aufgefaltet vorliegt (Multistacks), da hier keine Farbstofffreisetzung stattfand. Außerdem konnte ebenfalls der konzentrationsabhängige Eintritt des Farbstoffs für porenüberspannende POPC-haltige Membranen gezeigt werden (Abb. 4-37 A-C). Die unterschiedliche Geschwindigkeit des Farbstoff- 
eintritts kann darauf zurückgeführt werden, dass mit steigender Peptidkonzentration der Porendurchmesser ansteigt. ${ }^{[287]}$ Ferner ist bei niedrigeren Peptidkonzentrationen die Anordnung des Peptids parallel zur Membran bevorzugt, erst bei höheren Peptidkonzentrationen kommt es zur Insertion in die Lipidmembran. ${ }^{[288,289]}$ Nach dem Carpet Modell für lytische Peptide kommt es neben der Porenbildung auch zur Entstehung von Mizellen. Dadurch könnte es zum Transport von Lipidmaterial in die Poren kommen, wie es in Abb. 4-37 B zu sehen ist. Desweiteren wurde die Lipidmischung DPhPC/Cholesterol (9:1) mit gleichen Melittinkonzentrationen getestet und die Freisetzung des Farbstoffes findet zeitlich verzögert statt. Die verzweigten Fettsäureketten des DPhPC-Lipids sowie Cholesterol bedingen eine starke Rigidität der Lipidmembran und dies könnte die Bindung als auch die Insertion von Melittin in die Membran stören bzw. verhindern. ${ }^{[243,290-292]}$ Dies ist ein möglicher Grund, dass antimikrobielle Peptide selektiv bakterielle Plasmamembranen zerstören und nicht die eukaryotische Zellmembran. ${ }^{[293]}$ Die Melittinkonzentration, welche für die Penetration der porenüberspannenden Lipidmembranen verwendet wurde, entsprechen eher Konzentrationen, die in zell-basierten Studien eingesetzt wurden als den Konzentrationen, die für Vesikelassays eingesetzt wurden. ${ }^{[294]}$ Der sigmoidale Verlauf der Freisetzung von Pyranin aus den porenüberspannenden Membranen (Abb. 4-37 C, D) konnte ebenfalls für die Freisetzung von Hämoglobin aus Erythrozyten in einem Konzentrationsbereich von 0,3 bis 1,2 $\mu \mathrm{M}$ Melittin beobachtet werden. ${ }^{[294]}$ Dies bestätigt noch einmal, dass dieses Modellmembransystem als zellmimetisches System eingesetzt werden kann.

\subsubsection{Validierung der Gap J unction Kanalaktivität}

Zum Nachweis der Gap Junction Kanalaktivität wurden Connexon-dotierte porenüberspannende Membranen und Connexon-dotierte GUVs verwendet. Die Ergebnisse der Transferassays in dieser Arbeit, bei denen zwei unterschiedliche GUV-Populationen eingesetzt wurden (Kapitel 4.5.1), und von Gaßmann verdeutlichten, dass die Anzahl der Ereignisse, die auf eine Gap Junction Kanalaktivität hinweisen, gering war. ${ }^{[186]}$ Deshalb wurde die Anzahl der Ereignisse durch ein molekulares Erkennungssystem erhöht. Dafür wurde die spezifische Wechselwirkung der Imidazolreste eines Hexahistidin-Tags und der Nickel-Nitrilotriessigsäure, gekoppelt an DOPE bzw. DOGS, verwendet. Dies ermöglicht die Annäherung der beiden Membransysteme auf etwa 3 bis $4 \mathrm{~nm}$. Der Abstand zwischen den Plasmamembranen zweier benachbarter Zellen beträgt für Cx43 Gap Junction Kanäle ungefähr $4 \mathrm{~nm}$ 
(Kapitel 1.1.2). ${ }^{[20]}$ Durch die Abstandsverringerung wird es den Connexin Halbkanälen ermöglicht, Gap Junction Kanäle auszubilden. Bei der Durchführung des Transferassays ohne das molekulare Erkennungssystem müsste die Annäherung der Lipidmembranen sowie die Gap Junction Kanalbildung gleichzeitig stattfinden.

\section{Passierbarkeit des Cx43 Halbkanals für niedermolekulare Verbindungen}

In dieser Arbeit verdeutlichte der Einschluss von Carboxyfluorescein bzw. Pyranin in unilamellare Vesikel für die verschiedenen Transferassays (Kapitel 4.5), dass der Farbstoff nicht den Cx43 Halbkanal passieren kann. Zum gleichen Schluss kommen auch Kaneda et al. In dieser Studie wurde Cx43 während der zellfreien Expression mit Retikulozytenlysat (in vitro Expression) in PC-haltige (Egg Yolk) Vesikel rekonstituiert. ${ }^{[203]}$ Dabei wird das Protein zufällig in der Inside Out sowie Outside Out Orientierung integriert (Abb. 5-2). Während der in vitro Expression konnte der Fluoreszenzfarbstoff Calcein eingeschlossen werden. Die fluoreszenzmikroskopische Untersuchung der Fluoreszenzintensität des eingeschlossenen Farbstoffs über vier Stunden zeigte, dass die Fluoreszenz im Vergleich zu Vesikeln ohne Cx43 nicht signifikant abnahm (Abb. 5-10 A). Ferner konnten Kaneda et al. den Calceintransfer von Cx43-haltigen Vesikeln in Cx43 exprimierenden Zellen über Gap Junction Kanälen zeigen (Abb. 5-10 B). Der Einschluss von Calcein in die Vesikel und die Unpassierbarkeit für den Cx43 Halbkanal kann aber auch darauf zurückgeführt werden, dass sich der Durchmesser der Pore mit der Gap Junction Kanalbildung vergrößert und damit nicht im vollständig geschlossenen Zustand vorliegt. ${ }^{[18]}$ 

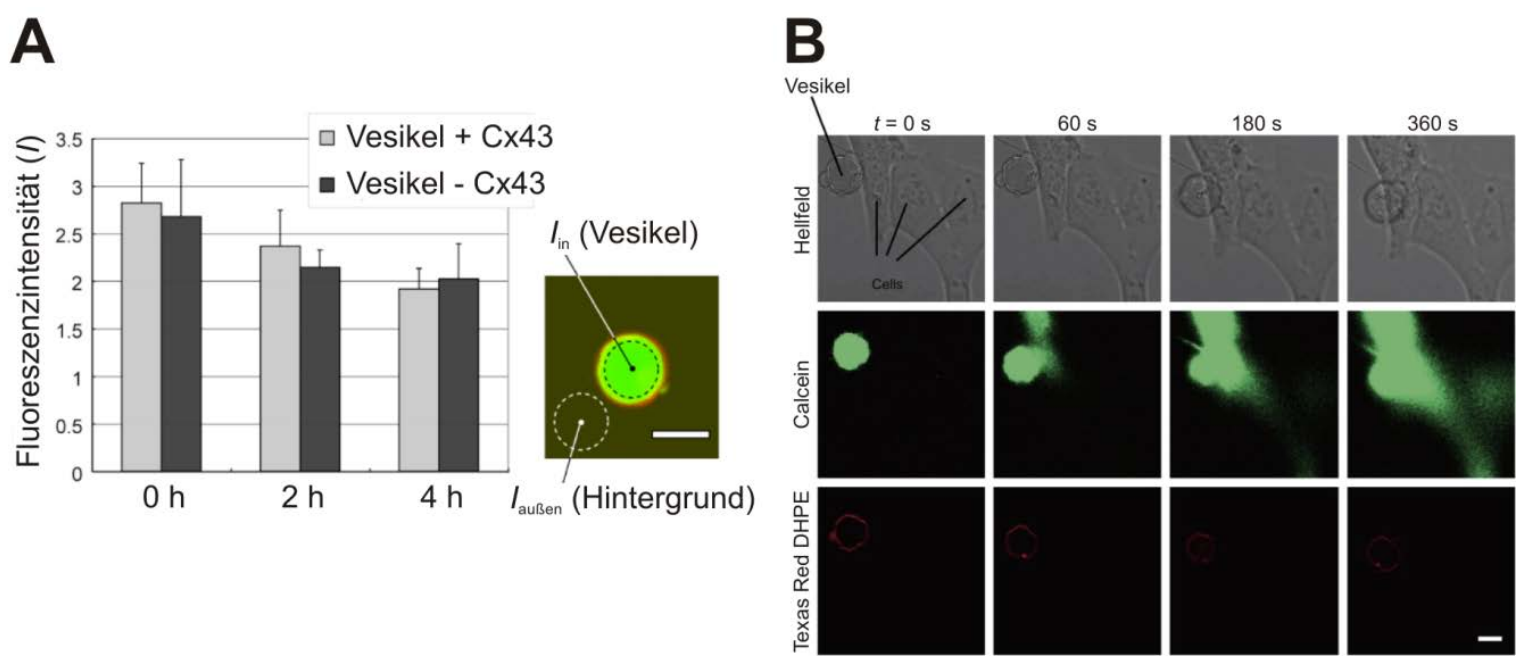

Abb. 5-10: Zellfreie Expression von Cx43 in Vesikel. $A$, Die zeitabhängige Untersuchung des Fluoreszenzintensitätsverlaufs innerhalb der Riesenvesikel mit und ohne integriertem $\mathrm{Cx} 43$ zeigen, dass es keine signifikante Abnahme gibt und der Farbstoff in den Vesikeln eingeschlossen bleibt. Maßstab: $5 \mu \mathrm{m}$. B, Farbstofftransfer von Cx43-dotierten Vesikeln, welche Calcein enthalten, zu Cx43 exprimierenden Zellen. Konfokalmikroskopische Aufnahmen des zeitlichen Verlaufs von der Anlagerung des Vesikels an die Cx43-U2OS Zellen. Das Vesikel ist außerdem mit Texas Red-DHPE dotiert. Maßstab: $10 \mu \mathrm{m}$. Abbildung modifiziert nach Kaneda et al. ${ }^{[203]}$

Moritani et al. exprimierten Cx43 bzw. Cx43-eGFP mit den minimalen Proteinsynthesefaktoren aus Escherichia coli (The PURE System) in unilamellare DOPC-haltige Vesikel. Ähnlich wie in dieser Arbeit konnte die Membranlokalisation von Cx43-eGFP und von Cx43 durch die konfokale Laserrastermikroskopie nachgewiesen werden (Abb. 5-11 A, B). Zum Nachweis der Connexin Halbkanalaktivität des zellfrei-exprimierten Cx43 wurde der Fluorophor 8-Aminonaphathalen-1,3,6-trisulfonsäure (ANTS) in die Vesikel eingeschlossen und durch die Zugabe des Quenchers p-Xylen-bis-pyridiniumbromid (DPX) wurde die Fluoreszenzlöschung spektrometrisch verfolgt. Dabei sind zwei Ereignisse möglich (Abb. 5-11 C), zum einen könnte ANTS über Cx43 Halbkanäle aus den Vesikeln heraus- oder DPX in die Vesikel hineindiffundieren. Beides würde zur Fluoreszenzlöschung von ANTS führen. Abb. 5-11 D zeigt die Fluoreszenzabnahme nach DPX Zugabe, wenn Cx43 in den Vesikeln integriert ist. Demzufolge lag Cx43 als funktioneller Halbkanal vor. Dem verwendeten PURE System fehlen die Faktoren, die Cx43 phosphorylieren können. Phosphorylierungen von Cx43 durch die Proteinkinase $\mathrm{C}$ führen zu einem reduzierten Porendurchmesser des Cx43 Halbkanals. ${ }^{[123,295]}$ Dagegen führt die Expression von Cx43 im Baculovirus/Insektenzellen (High Five) zur Phosphorylierung von Cx43. 
Die Phosphorylierung von Cx43 könnte das Verhalten, dass die rekonstituierten Cx43 Halbkanäle in dieser Arbeit nicht für Carboxyfluorescein und Pyranin passierbar waren, erklären. Allerdings wurde in dieser Arbeit nicht ermittelt, ob Cx43 bzw. Cx43-GFP in Pichia pastoris phosphoryliert wurden. Bao et al. berichten, dass durch die Phosphorylierung von Cx43 der Halbkanal zwar noch für anorganische Ionen passierbar bleibt, aber das Moleküle in der Größe von Saccharose $\left(M=342 \mathrm{~g} \cdot \mathrm{mol}^{-1}\right)$ nicht mehr transportiert werden. ${ }^{[295,296]}$ Dies verdeutlicht, dass das phosphorylierte Cx43 zwar Ionenleitfähigkeit zeigt, jedoch der Transport von größeren Molekülen $>62 \mathrm{~g} \cdot \mathrm{mol}^{-1}$ nicht mehr möglich ist.
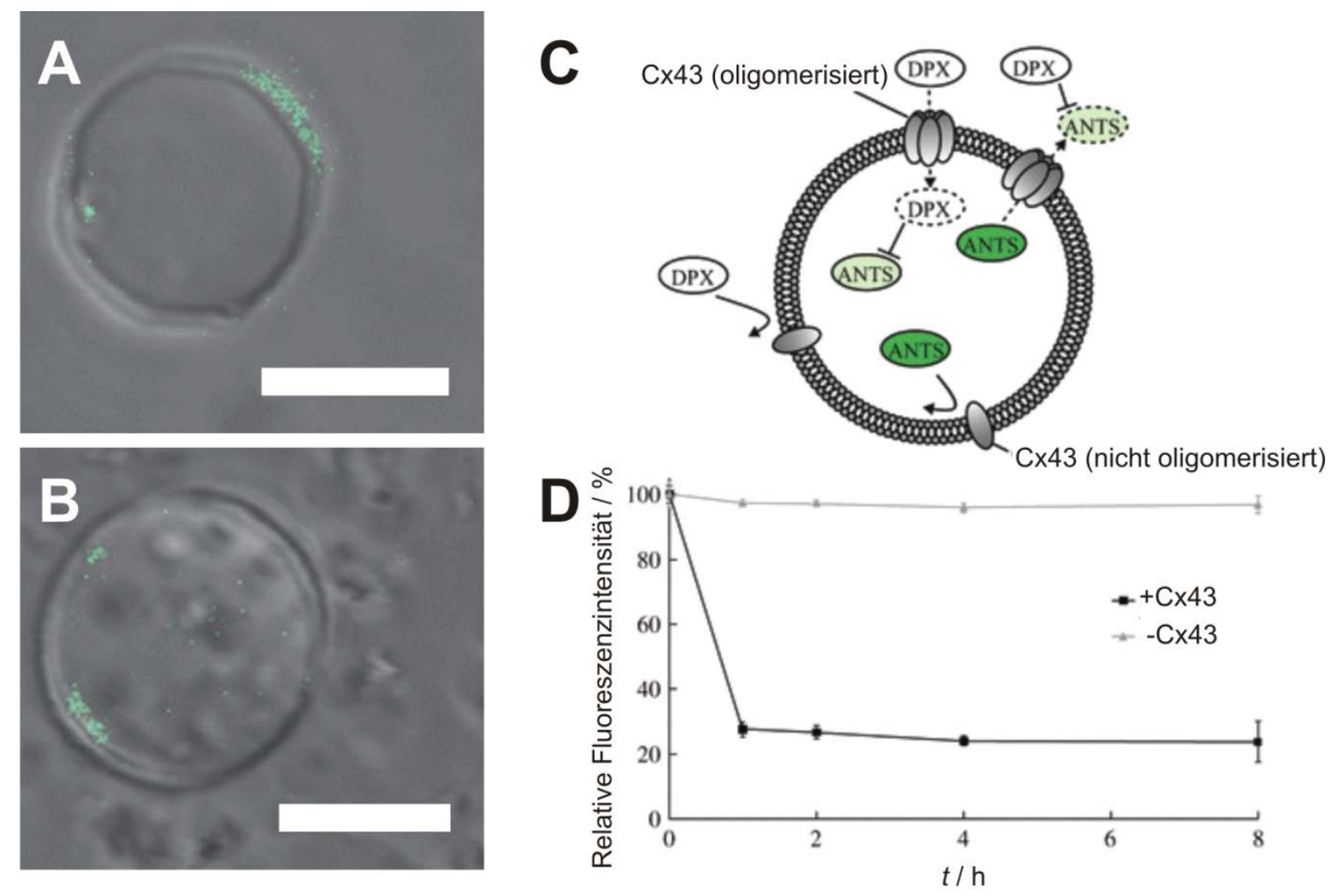

Abb. 5-11: Zellfreie Expression von Cx43 und Cx43-eGFP in unilamellare Vesikel und Untersuchung der Halbkanalaktivität. $\boldsymbol{A}-\boldsymbol{B}$, Konfokalmikroskopische Fluoreszenzaufnahme von Cx43-eGFP in GUVs sowie Cx43, das durch einen fluoreszenzmarkierten Antikörper, welcher gegen den $C$-Terminus von Cx43 gerichtet ist, nachgewiesen werden konnte. Die Fluoreszenzaufnahmen sind mit Bildern der differentiellen Interferenzkontrastmikroskopie überlagert. Maßstab: $10 \mu \mathrm{m} C$, Schematischer Aufbau des Fluoreszenzlöschungsassays zur Verifizierung von Cx43 Halbkanälen. D, Zeitlicher Verlauf der ANTS Fluoreszenz mit und ohne integrierte Cx43 Halbkanäle nach der Zugabe des Fluoreszenzlöschers DPX. Abbildung geändert nach Moritani et al. ${ }^{[27]}$

Ferner konnte durch Kamiya et al. eine sehr interessante Methode für die Rekonstitution von Cx43 sowie Cx43-eGFP in Riesenvesikel präsentiert werden. ${ }^{[298]}$ Diese Methode wurde bereits für zwei verschiedene G-Protein gekoppelte Rezeptoren erfolgreich eingesetzt. ${ }^{[299,300]}$ 
Dazu werden rekombinante Baculoviren, welche Cx43 bzw. Cx43-eGFP exprimieren, mit Riesenvesikeln bei einem pH-Wert von 4,5 miteinander fusioniert. Das Protein behält dabei seine ursprüngliche Outside Out Orientierung bei. Die Autoren konnten zeigen, dass mithilfe von Cx43 Gap Junction Kanälen Farbstoff von Cx43-haltigen Riesenvesikeln in Cx43-exprimierende Sf9 Zellen übertragen werden kann.

Alle drei Studien konnten die Cx43 Halbkanal- oder die Gap Junction Kanalaktivität zeigen. Im Unterschied zu den Experimenten in dieser Arbeit wurde das Protein direkt in die artifizielle Lipidmembran synthetisiert bzw. mit Vesikeln fusioniert. Die direkte Integration ohne die Schritte der Isolierung und Rekonstitution scheinen förderlich zu sein, um schließlich Gap Junction Kanalaktivität nachzuweisen.

\section{Untersuchung der Gap Junction Kanalaktivität}

Zur Visualisierung der Gap Junction Kanalaktivität wurde zunächst der Farbstoff Pyranin durch porenüberspannende Membranen in die geschlossenen Poren des Aluminiumoxidsubstrates eingeschlossen oder es wurden GUVs mit Farbstoff gefüllt. Der Transfer sollte auch mit diesem Farbstoff möglich sein, da dessen Ladung und Molekülgröße mit Farbstoffen und sekundären Botenstoffen, die bereits erfolgreich für die Untersuchung von Cx43 Halbkanälen sowie Gap Junction Kanälen eingesetzt wurden, ähnlich ist (Tab. 5-2). Zur Visualisierung des transferierten Pyranins im Vesikellumen ist es von Vorteil, dass ausreichend Transmembrankanäle verteilt auf die Poren im Interaktionsbereich zur Verfügung stehen, um wiederum ausreichend Fluoreszenzfarbstoff in das Innere des Vesikels zu transportieren. Wenn sich nur der Inhalt einer einzigen Pore $\left(d_{0}=60 \mathrm{~nm}, h=6 \mu \mathrm{m}\right)$ in einem Vesikel entleert, kommt es zur 24.000-fachen Verdünnung. Bei Umkehr des Assays ist von einer vernachlässigbaren Verdünnung auszugehen. Die Aktivität von Cx43 Gap Junction Kanälen hätte nur visualisiert werden können, wenn ausreichend Cx43 Halbkanäle bzw. Gap Junction Kanäle zur Verfügung gestanden hätten. 
Tab. 5-2: Fluorophore sowie sekundäre Botenstoffe, welche in Uptake Assays über Cx43 Halbkanäle und Gap Junction Kanäle in Zellen aufgenommen wurden. ${ }^{[13,18]}$

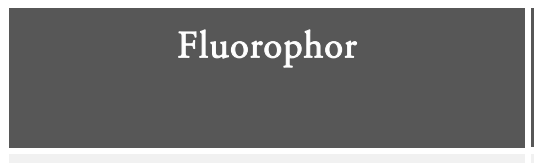

Ethidiumbromid

Lucifer Yellow

Carboxyfluorescein

Calcein

(Pyranin)

$\mathrm{NAD}^{+}$

ATP

Glutamat

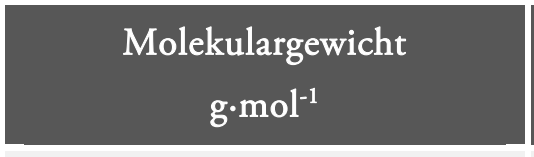

314

443

376

147

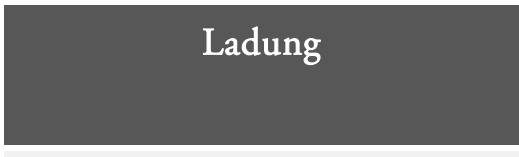

$+1$

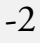

$-2$

$-4$

$-3$

$-1$

$-4$

$-1$

Für beide Varianten des Farbstofftransferassays konnten keine positiven Ergebnisse erhalten werden. Dies kann einerseits auf die geringe Rekonstitutionseffizienz für die fusionsvermittelte Rekonstitution für die Proteine der zweiten Fermentationscharge zurückgeführt werden (Kapitel 4.2). Andererseits ist die Orientierung des Cx43 Halbkanals in der Lipidmembran dafür verantwortlich, ob die Gap Junction Kanalbildung überhaupt stattfinden kann. Ausgehend von der gemischten, ternären Mizelle sollte es bei der Proteoliposomenbildung durch den Entzug des Detergens zur zufälligen Orientierung des Proteins in der Membran kommen. ${ }^{[162]}$ In Kapitel 5.2 wurde bereits erwähnt, dass Locke et al. und Bao et al. für Proteoliposomen, die ausgehend von der gemischten, ternären Mizelle hergestellt wurden, überwiegend eine Inside Out Proteinorientierung aufzeigen (Abb. 5-2). ${ }^{[240,296]}$ Nach dem Fusionsmechanismus nach Markin etal. würde die Orientierung rekonstitutierter Proteine der Proteoliposomen in den Proteo-GUVs beibehalten. Dabei wären für den Transferassay zwei Szenarien denkbar. Durch das Spreiten von GUVs auf den porösen, hochgeordneten Aluminiumoxidsubstraten werden porenüberspannende Membranen präpariert, die entweder Cx43 Halbkanäle mit einer Inside Out oder mit einer zufälligen Orientierung beinhalten (Abb. 5-12). Im nächsten Schritt wird über das molekulare Erkennungssystem eine weitere GUV-Population angebunden. Im Fall der Inside Out Orientierung kommt es nicht zur Gap Junction Bildung, da nur die Interaktion der extrazellulären Bereiche die Ausbildung von Gap 
Junction Kanälen erlaubt (Abb. 5-12 A). Dagegen ist bei einer zufälligen Orientierung die Gap Junction Kanalbildung möglich (Abb. 5-12 B).
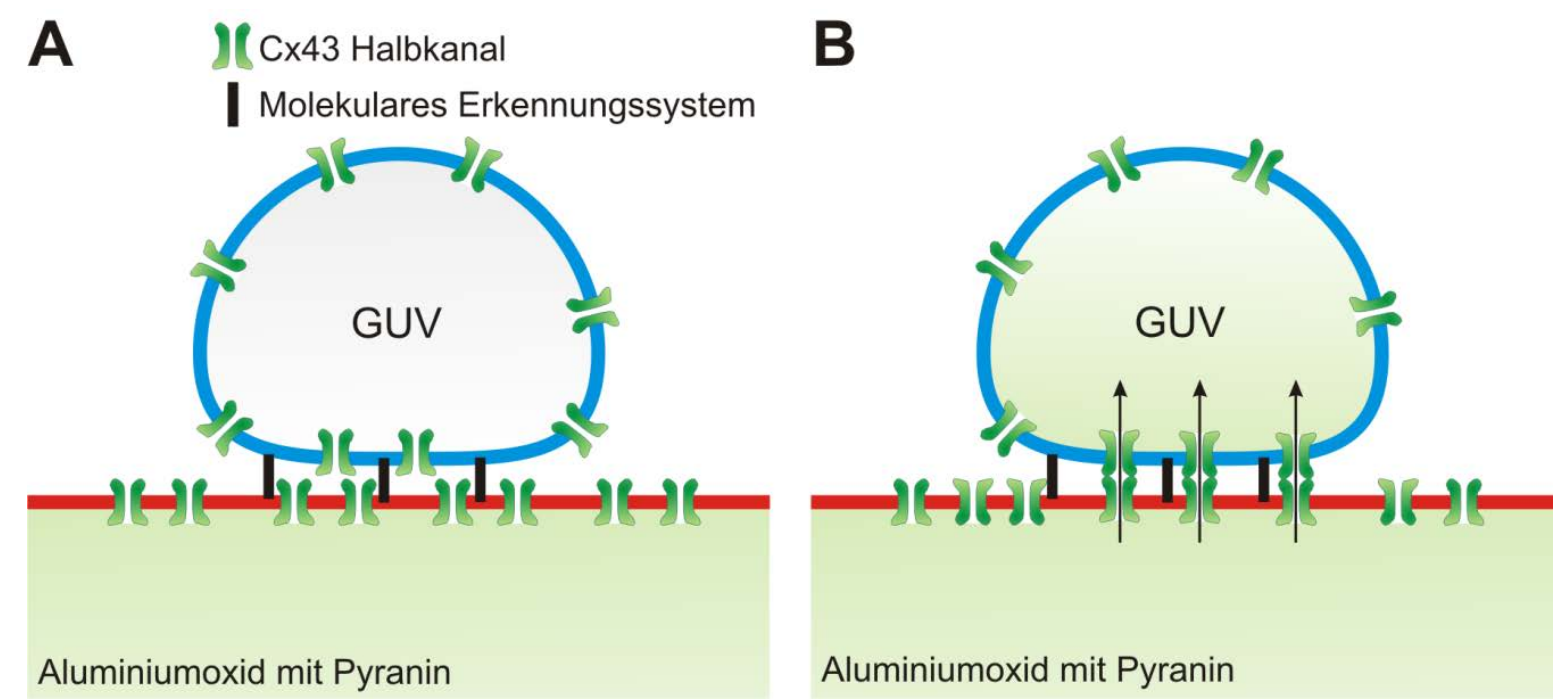

Abb. 5-12: Schematische Darstellung der Abhängigkeit der Gap Junction Kanalbildung von der Orientierung der Cx43 bzw. Cx43-GFP Halbkanäle. A, Inside Out Orientierung der Cx43 Halbkanäle nach Rekonstiution in GUVs. Aufgrund des Spreitmechanismuses ist der $C$ - und $N$-Terminus in das Innere der Poren gerichtet. Die Orientierung der Kanäle verhindert eine Gap Junction Kanalbildung. $B$, Die zufällige Orientierung der Cx43 Halbkanäle in der Lipidmembran ermöglicht die Ausbildung von Gap Junction Kanälen. Schwarze Linien stellen das molekulare Erkennungssystem vereinfacht dar.

Außerdem verdeutlicht die Untersuchung von Bukauskas et al. zur Funktionalität von Gap Junction Kanälen in Gap Junction Plaques, dass wahrscheinlich eine gewisse Anzahl an Gap Junction Kanälen (>300) notwendig sind, damit auch funktionelle Kanäle darin enthalten sind. ${ }^{[40]}$ In eine Pore des Aluminiumoxids mit einem Durchmesser $d_{0}=60 \mathrm{~nm}$ passen weniger als 44 Connexin Halbkanäle $(d \approx 9 \mathrm{~nm})$. Wenn eine laterale Interaktion zwischen wenigstens 300 Gap Junction Kanälen notwendig ist, dann ist die Darstellung von Gap Junction Kanälen mit diesem System nicht möglich. Bukauskas und Verselis postulieren, dass Halbkanäle ähnlich wie Gap Junction Kanäle in relativ großen Aggregaten vorliegen müssen, bevor sich nur ein Kanal öffnet. ${ }^{[53]}$ Desweiteren betonen Locke et al. die Bedeutung der Membranzusammensetzung, im besonderen negativ geladene Lipide sowie Cholesterol, für die Funktionalität der Connexin Halbkanäle sowie der Gap Junction Kanäle. ${ }^{[301]}$ Leider wurde dieser Einfluss bis jetzt nur unzureichend untersucht, jedoch verdeutlichen unter anderem die Studien von Shen et al., Ramundo-Orlando et al., Kaneda et al. und Moritani et al., dass auch in artifiziellen Lipidmembranen basierend auf Phosphatidylcholin Connexin Halbkanal- sowie Gap Junction Kanalaktivität nachgewiesen werden können. ${ }^{[160,203,235,297]}$ Demnach sollte es mit 
dem aufgebauten Transferassay möglich sein Gap Junction Kanalaktivität zu zeigen, wenn die lokale Connexin Halbkanal Konzentration in vitro keine Rolle spielt.

Die fluoreszenzmikroskopischen Untersuchungen zur Penetration der porenüberspannenden Membran durch Melittin in Kapitel 4.4.4 verdeutlichen (Abb. 4-37 A, B), dass die Intensität von Pyranin in Lösung oberhalb des porösen Substrats höher ist im Vergleich zur Fluoreszenzintensität des Farbstoffs innerhalb der Aluminiumoxidporen. Unter Berücksichtigung dieser Beobachtung konnten auch aufgrund der Hintergrundfluoreszenz und der Auflösungsgrenze (siehe Gl. 3-5) des Konfokalmikroskops keine eindeutige Aussage bezüglich eines Farbstoffstransfers vom Vesikellumen in die Poren des Aluminiumoxids unterhalb der porenüberspannenden Membranen getroffen werden. Dies schließt nicht aus, dass Einzelereignisse auftraten, welche aber nicht visualisiert werden konnten. 


\section{Ausblick}

Die Einzelkanalstudien von Cx43 und Cx43-GFP Halbkanälen mithilfe des Port-a-Patch ${ }^{\circledast}$ verdeutlichen, dass die Connexin Halbkanäle funktionell in artifizielle Membranen rekonstituiert wurden. Für das weitere Verständnis der Gap Junction Kanalbildung ist eine Untersuchung sogenannter Formation Plaques notwendig, welche die laterale Organisation der Connexin Halbkanäle darstellt als Vorstufe zum Gap Junction Plaque. Dabei wäre eine Untersuchung denkbar, wie sich die Porengröße auf die Bildung der Formation Plaques auswirken würde und ob es nur ab einer Minimumanzahl von 300 Kanälen $\left(A_{\min }=3 \cdot 10^{4} \mathrm{~nm}^{2}\right)$ zur Ausbildung von Gap Junction Kanälen kommt. ${ }^{[40]}$ Diese minimale Fläche kann nur mit Substraten gewährleistet werden, die eine Porengröße $d>200 \mathrm{~nm}$ aufweisen. Ferner ist eine Untersuchung zur Orientierung des Proteins in der Lipidmembran notwendig, da nur mit einer ausreichend großen Anzahl an Kanälen die Ausbildung von Gap Junction Kanälen ermöglicht wird. Zur Feststellung der Cx43 Halbkanal-Orientierung in der Lipidmembran von Vesikeln kann ein proteolytischer Assay eingesetzt werden. ${ }^{[302]}$ Dafür wird Cx43 rekonstituiert in Vesikeln mit der unspezifischen Serinprotease Proteinase K inkubiert. Integriert in die Lipidmembran sind nur die extrazellulären Schleifen sowie intrazelluläre Schleifen und der $C$ - und $N$-Terminus zugänglich, wodurch definierte Fragmente abhängig von der Orientierung des Proteins entstehen. Anschließend werden die Fragmente durch SDSPAGE ihrer Größe nach aufgetrennt und weiter mithilfe der Massenspektrometrie identifiziert. Eine andere Möglichkeit ist der Einsatz spezifischer, Fluorophor-gekoppelter Antikörper gegen die extra- bzw. intrazellulären Anteile des Proteins, wodurch die Orientierung des Proteins in der Lipidmembran quantifiziert werden kann. Desweiteren könnte die Phosphorylierung für die Aktivität von Cx43 Halbkanälen und Gap Junction Kanälen eine Rolle spielen und den Transport von Fluoreszenzfarbstoff verhindert haben. Eine Möglichkeit bietet die Massenspektrometrie, um zu klären, ob Cx43 bzw. Cx43-GFP während der Expression in P. pastoris phosphoryliert wird. Diese Parameter sind entscheidende Parameter für das Projekt, um im nächsten Schritt Gap Junction Kanäle in vitro zu bilden. 


\section{Zusammenfassung}

In dieser Arbeit war es das Ziel Cx43 bzw. Cx43-GFP nach erfolgreicher, heterologer Proteinexpression in artifizielle Membranen zu integrieren und die Gap Junction Kanalbildung in vitro durch einen fluoreszenz-basierten Transferassay zu visualisieren. In Abschnitt I der Arbeit wurden die zwei Expressionssysteme Pichia pastoris und Dictyostelium discoideum für die Herstellung von Cx43 und dem Fusionsprotein aus $\mathrm{Cx}_{43}$ und dem grün fluoreszierenden Protein (Green Fluorescent Protein, GFP) bzw. dem enhanced GFP kultiviert (Abb. 7-1 I). Dabei gelang es mit dem Expressionssystem Pichia pastoris hohe Zellfeuchtmassen in der Fermentation zu erreichen und mit der Etablierung verschiedener Reinigungsprotokolle eine Proteinkonzentration von bis zu $10 \mu \mathrm{g} \cdot \mathrm{g}^{-1}$ Zellfeuchtmasse zu erreichen. Die Entwicklung verschiedener Rekonstitutionsprozeduren in Abschnitt II ermöglichte die Integration von Cx43 und Cx43-GFP in hohen Konzentrationen (Fusionsvermittelte Rekonstitution, Abb. 7-1 II). Basierend auf den verschiedenen Rekonstitutionsprozeduren konnten in Abschnitt III porenüberspannende Membranen auf mikroporösen Substraten mit Cx43-GFP präpariert werden (Abb. 7-1 III). In der gleichen Phase war es außerdem möglich, in Zusammenarbeit mit Nanion Technologies GmbH, Cx43 und Cx43-GFP mithilfe des Planar Patch Clamp Systems umfassend elektrophysiologisch zu charakterisieren. Dabei verdeutlichten die Messungen, dass die Fusion von GFP mit Cx43 ein verändertes Öffnungs- und Schließungsverhalten des Connexin Halbkanals zur Folge hatte und zehn unterschliedliche Leitfähigkeiten im Bereich von 15 bis 250 pS für Cx43-GFP identifiziert werden konnten. Darauf aufbauend wurde in Abschnitt IV ein Farbstofftransferassay zur Validierung der Gap Junction Kanalaktivität basierend auf porenüberspannenden Membranen entwickelt (Abb. 7-1 IV). Dazu wurde ein wasserlöslicher Farbstoff, welcher durch porenüberspannende Membran auf porösem, hochgeordneten Aluminiumoxid eingeschlossen wurde, durch das lytische Peptid Melittin entlassen. Dies verdeutlichte, dass der Farbstoff in geschlossenen Poren mithilfe von Lipidmembranen eingeschlossen und gezielt wieder entlassen werden kann. Außerdem wurde das System hinsichtlich unterschiedlicher Membranzusammensetzungen untersucht. In Abschnitt $V$ wurden die Connexon-dotierten porenüberspannenden Membranen mit Connexon-haltigen GUVs über ein molekulares Erkennungssystem gekoppelt (Abb. 7-1 V). 
Dies sollte die Ausbildung von Gap Junction Kanälen forcieren, wobei die Gap Junction Kanalbildung nicht eindeutig nachgewiesen werden konnte.
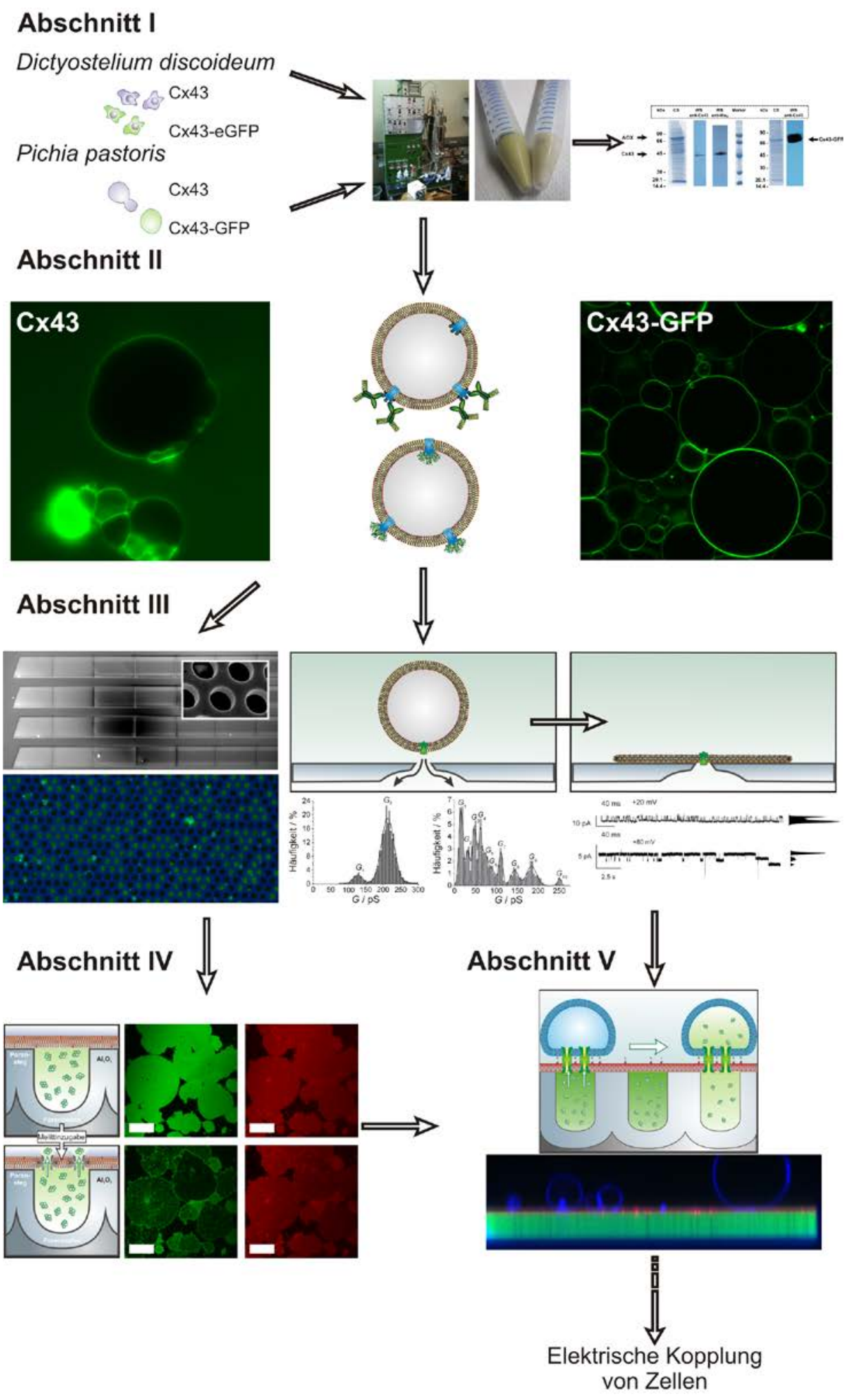

Abb. 7-1: Schematische Darstellung der Meilensteine, die im Rahmen dieser Doktorarbeit erreicht werden konnten. 


\section{Literaturverzeichnis}

[1] Sagan, C., (1980), Cosmos, 1. Auflage, Random House, New York

[2] Eiberger, J., Degen, J., Romualdi, A., Deutsch, U., Willecke, K., and Söhl, G., (2001), Connexin genes in the mouse and human genome, Cell Commun. Adhes., 8, 163-165

[3] Phelan, P., and Starich, T. A., (2001), Innexins get into the gap, Bioessays, 23, 388396

[4] Danesh-Meyer, H. V., and Green, C. R., (2008), Focus on molecules: connexin 43mind the gap, Exp. Eye Res., 87, 494-495

[5] Maeda, S., and Tsukihara, T., (2011), Structure of the gap junction channel and its implications for its biological functions, Cell. Mol. Life Sci., 68, 1115-1129

[6] Nakagawa, S., Maeda, S., and Tsukihara, T., (2010), Structural and functional studies of gap junction channels, Curr. Opin. Struct. Biol., 20, 423-430

[7] Verselis, V. K., Trexler, E. B., and Bukauskas, F. F., (2000), Connexin hemichannels and cell-cell channels: comparison of properties, Braz. J. Med. Biol. Res., 33, 379-389

[8] Bennett, M. V. L., Contreras, J. E., Bukauskas, F. F., and Sáez, J. C., (2003), New roles for astrocytes: gap junction hemichannels have something to communicate, Trends Neurosci., 26, 610-617

[9] John, S., Cesario, D., and Weiss, J. N., (2003), Gap junctional hemichannels in the heart, Acta Physiol. Scand., 179, 23-31

[10] Goodenough, D. A., and Paul, D. L., (2003), Beyond the gap: functions of unpaired connexon channels, Nat. Rev. Mol. Cell Biol., 4, 285-294

[11] Stout, C., Goodenough, D. A., and Paul, D. L., (2004), Connexins: functions without junctions, Curr. Opin. Cell Biol., 16, 507-512

[12] Sáez, J. C., Contreras, J. E., Bukauskas, F. F., Retamal, M. A., and Bennett, M. V. L., (2003), Gap junction hemichannels in astrocytes of the CNS, Acta Physiol. Scand, 179, $9-22$

[13] Sáez, J. C., Retamal, M. A., Basilio, D., Bukauskas, F. F., and Bennett, M. V. L., (2005), Connexin-based gap junction hemichannels: Gating mechanisms, Biochim. Biophys. Acta-Biomembranes, 1711, 215-224 
[14] Spray, D. C., Ye, Z.-C., and Ransom, B. R., (2006), Functional connexin "hemichannels": a critical appraisal, Glia, 54, 758-773

[15] Scemes, E., (2011), Nature of plasmalemmal functional "hemichannels", Biochim. Biophys. Acta

[16] Sosinsky, G. E., and Nicholson, B. J., (2005), Structural organization of gap junction channels, Biochim. Biophys. Acta, 1711, 99-125

[17] Beyer, E. C., Paul, D. L., and Goodenough, D. A., (1987), Connexin43: a protein from rat heart homologous to a gap junction protein from liver, J. Cell Biol., 105, 2621-2629

[18] Harris, A. L., (2001), Emerging issues of connexin channels: biophysics fills the gap, Q. Rev. Biophys., 34, 325-472

[19] Elfgang, C., Eckert, R., Lichtenberg-Fraté, H., Butterweck, A., Traub, O., Klein, R. A., Hülser, D. F., and Willecke, K., (1995), Specific permeability and selective formation of gap junction channels in connexin-transfected HeLa cells, J. Cell Biol., $129,805-817$

[20] Maeda, S., Nakagawa, S., Suga, M., Yamashita, E., Oshima, A., Fujiyoshi, Y., and Tsukihara, T., (2009), Structure of the connexin 26 gap junction channel at $3.5 \AA$ resolution, Nature, 458, 597-602

[21] Unger, V. M., (1999), Three-Dimensional Structure of a Recombinant Gap Junction Membrane Channel, Science, 283, 1176-1180

[22] Hawat, G., and Baroudi, G., (2008), Differential modulation of unapposed connexin 43 hemichannel electrical conductance by protein kinase C isoforms, Pflugers Arch. Eur. J. Physiol., 456, 519-527

[23] Warren L. DeLano Scientific LLC, S., (2006), PyMOL, The Molecular Graphics System, San Francisco

[24] Perkins, G. A., Goodenough, D. A., and Sosinsky, G. E., (1998), Formation of the gap junction intercellular channel requires a $30^{\circ}$ rotation for interdigitating two apposing connexons, J. Mol. Biol., 277, 171-177

[25] Kwon, T., Harris, A. L., Rossi, A., and Bargiello, T. A., (2011), Molecular dynamics simulations of the Cx26 hemichannel: evaluation of structural models with Brownian dynamics, J. Gen. Physiol., 138, 475-493 
[26] Locke, D., Kieken, F., Tao, L., Sorgen, P. L., and Harris, A. L., (2011), Mechanism for modulation of gating of connexin26-containing channels by taurine, J. Gen. Physiol., 138, 321-339

[27] Fleishman, S. J., Harrington, S., Friesner, R. A., Honig, B., Ben-Tal, N., Unger, V. M., and Yeager, M., (2004), An Automatic Method for Predicting Transmembrane Protein Structures Using Cryo-EM and Evolutionary Data // A $\mathrm{C}^{\alpha}$ model for the transmembrane $\alpha$ helices of gap junction intercellular channels, Biophys. J., 87, 34483459

[28] Yeager, M., and Harris, A. L., (2007), Gap junction channel structure in the early $21^{\text {st }}$ century: facts and fantasies, Curr. Opin. Cell Biol., 19, 521-528

[29] Unger, V. M., Kumar, N. M., Gilula, N. B., and Yeager, M., (1997), Projection structure of a gap junction membrane channel at $7 \AA$ resolution, Nat. Struct. Biol., 4, $39-43$

[30] Oshima, A., Tani, K., Hiroaki, Y., Fujiyoshi, Y., and Sosinsky, G. E., (2007), Threedimensional structure of a human connexin26 gap junction channel reveals a plug in the vestibule, Proc. Natl. Acad. Sci. U.S.A., 104, 10034-10039

[31] Braun, J., Abney, J. R., and Owicki, J. C., How a gap junction maintains its structure, Nature, 310, 316-318

[32] Jordan, K., Solan, J. L., Dominguez, M., Sia, M., Hand, A., Lampe, P. D., and Laird, D. W., (1999), Trafficking, assembly, and function of a connexin43-green fluorescent protein chimera in live mammalian cells, Mol. Biol. Cell, 10, 2033-2050

[33] Johnson, R. G., Reynhout, J. K., TenBroek, E. M., Quade, B. J., Yasumura, T., Davidson, K. G. V., Sheridan, J. D., and Rash, J. E., (2012), Gap junction assembly: roles for the formation plaque and regulation by the C-terminus of connexin43, Mol. Biol. Cell, 23, 71-86

[34] Mazet, F., and Mazet, J. L., (1990), Restoration of gap junction-like structure after detergent solubilization of the proteins from liver gap junctions, Exp. Cell Res., 188, 312-315

[35] Lampe, P. D., Kistler, J., Hefti, A., Bond, J., Müller, S., Johnson, R. G., and Engel, A., (1991), In vitro assembly of gap junctions, J. Struct. Biol., 107, 281-290

[36] Kistler, J., Bond, J., Donaldson, P., and Engel, A., Two distinct levels of gap junction assembly in vitro, J. Struct. Biol., 110, 28-38 
[37] Kistler, J., Goldie, K., Donaldson, P., and Engel, A., (1994), Reconstitution of nativetype noncrystalline lens fiber gap junctions from isolated hemichannels, J. Cell Biol., $126,1047-1058$

[38] Hand, G. M., Müller, D. J., Nicholson, B. J., Engel, A., and Sosinsky, G. E., (2002), Isolation and characterization of gap junctions from tissue culture cells, J. Mol. Biol., $315,587-600$

[39] Hertzberg, E. L., (1984), A detergent-independent procedure for the isolation of gap junctions from rat liver, J. Biol. Chem., 259, 9936-9943

[40] Bukauskas, F. F., Bukauskiene, A., Bennett, M. V., and Verselis, V. K., (2001), Gating properties of gap junction channels assembled from connexin 43 and connexin43 fused with green fluorescent protein, Biophys. J., 81, 137-152

[41] Laird, D. W., (2006), Life cycle of connexins in health and disease, Biochem. J., 394, 527

[42] Yeager, M., and Gilula, N. B., (1992), Membrane topology and quaternary structure of cardiac gap junction ion channels, J. Mol. Biol., 223, 929-948

[43] Hervé, J.-C., Bourmeyster, N., and Sarrouilhe, D., (2004), Diversity in proteinprotein interactions of connexins: emerging roles, Biochim. Biophys. Acta Biomembranes, 1662, 22-41

[44] Solan, J. L., and Lampe, P. D., (2009), Connexin43 phosphorylation: structural changes and biological effects, Biochem. J., 419, 261-272

[45] Song, Y.-N., Zhang, H., Zhao, J.-Y., and Guo, X.-L., (2009), Connexin 43, a new therapeutic target for cardiovascular diseases, Pharmazie, 64, 291-295

[46] Rochefort, G. Y., Pallu, S., and Benhamou, C. L., (2010), Osteocyte: the unrecognized side of bone tissue, Osteoporos Int, 21, 1457-1469

[47] Plotkin, L. I., Manolagas, S. C., and Bellido, T., (2002), Transduction of cell survival signals by connexin-43 hemichannels, J. Biol. Chem., 277, 8648-8657

[48] Paznekas, W. A., Karczeski, B., Vermeer, S., Lowry, R. B., Delatycki, M., Laurence, F., Koivisto, P. A., van Maldergem, L., Boyadjiev, S. A., Bodurtha, J. N., and Jabs, E. W., (2009), GJA1 mutations, variants, and connexin 43 dysfunction as it relates to the oculodentodigital dysplasia phenotype, Hum. Mutat., 30, 724-733

[49] Loo, L. W., Berestecky, J. M., Kanemitsu, M. Y., and Lau, A. F., (1995), pp60srcmediated phosphorylation of connexin 43, a gap junction protein, J. Biol. Chem., 270, $12751-12761$ 
[50] Yeager, M., (1998), Structure of cardiac gap junction intercellular channels, J. Struct. Biol., 121, 231-245

[51] Duffy, H. S., (2002), pH-Dependent Intramolecular Binding and Structure Involving Cx43 Cytoplasmic Domains, J. Biol. Chem., 277, 36706-36714

[52] Sorgen, P. L., Duffy, H. S., Sahoo, P., Coombs, W., Delmar, M., and Spray, D. C., (2004), Structural changes in the carboxyl terminus of the gap junction protein connexin43 indicates signaling between binding domains for $\mathrm{c}-\mathrm{Src}$ and zonula occludens-1, J. Biol. Chem., 279, 54695-54701

[53] Bukauskas, F. F., and Verselis, V. K., (2004), Gap junction channel gating, Biochim. Biophys. Acta, 1662, 42-60

[54] Bargiello, T. A., Tang, Q., Oh, S., and Kwon, T., (2011), Voltage-dependent conformational changes in connexin channels, Biochim. Biophys. Acta

[55] Trexler, E. B., Bennett, M. V., Bargiello, T. A., and Verselis, V. K., (1996), Voltage gating and permeation in a gap junction hemichannel, Proc. Natl. Acad. Sci. U.S.A, 93, $5836-5841$

[56] Oh, S., Rivkin, S., Tang, Q., Verselis, V. K., and Bargiello, T. A., (2004), Determinants of gating polarity of a connexin 32 hemichannel, Biophys. J., 87, 912-928

[57] Shibayama, J., Gutiérrez, C., González, D., Kieken, F., Seki, A., Carrión, J. R., Sorgen, P. L., Taffet, S. M., Barrio, L. C., and Delmar, M., (2006), Effect of charge substitutions at residue his-142 on voltage gating of connexin 43 channels, Biophys. J., $91,4054-4063$

[58] Revilla, A., Bennett, M. V., and Barrio, L. C., (2000), Molecular determinants of membrane potential dependence in vertebrate gap junction channels, Proc. Natl. Acad. Sci. U.S.A., 97, 14760-14765

[59] Anumonwo, J. M., Taffet, S. M., Gu, H., Chanson, M., Moreno, A. P., and Delmar, M., (2001), The carboxyl terminal domain regulates the unitary conductance and voltage dependence of connexin40 gap junction channels, Circ. Res., 88, 666-673

[60] Oshima, A., Tani, K., Toloue, M. M., Hiroaki, Y., Smock, A., Inukai, S., Cone, A., Nicholson, B. J., Sosinsky, G. E., and Fujiyoshi, Y., (2011), Asymmetric configuretions and $\mathrm{N}$-terminal rearrangements in connexin26 gap junction channels, J. Mol. Biol., 405, 724-735 
[61] Suchyna, T. M., Xu, L. X., Gao, F., Fourtner, C. R., and Nicholson, B. J., (1993), Identification of a proline residue as a transduction element involved in voltage gating of gap junctions, Nature, 365, 847-849

[62] Ri, Y., Ballesteros, J. A., Abrams, C. K., Oh, S., Verselis, V. K., Weinstein, H., and Bargiello, T. A., (1999), The role of a conserved proline residue in mediating conformational changes associated with voltage gating of Cx32 gap junctions, Biophys. J., 76, 2887-2898

[63] Gómez-Hernández, J. M., Miguel, M. de, Larrosa, B., González, D., and Barrio, L. C., (2003), Molecular basis of calcium regulation in connexin-32 hemichannels, Proc. Natl. Acad. Sci. U.S.A., 100, 16030-16035

[64] Spray, D. C., Harris, A. L., and Bennett, M. V., (1981), Gap junctional conductance is a simple and sensitive function of intracellular $\mathrm{pH}$, Science, 211, 712-715

[65] Morley, G. E., Taffet, S. M., and Delmar, M., (1996), Intramolecular interactions mediate $\mathrm{pH}$ regulation of connexin43 channels, Biophys. J., 70, 1294-1302

[66] Bevans, C. G., and Harris, A. L., (1999), Regulation of connexin channels by pH. Direct action of the protonated form of taurine and other aminosulfonates, J. Biol. Chem., 274, 3711-3719

[67] Müller, D. J., Hand, G. M., Engel, A., and Sosinsky, G. E., (2002), Conformational changes in surface structures of isolated connexin 26 gap junctions, $E M B O$ J., 21, 3598-3607

[68] Thimm, J., (2005), Calcium-dependent Open/Closed Conformations and Interfacial Energy Maps of Reconstituted Hemichannels, J. Biol. Chem., 280, 10646-10654

[69] Contreras, J. E., Sáez, J. C., Bukauskas, F. F., and Bennett, M. V. L., (2003), Gating and regulation of connexin 43 (Cx43) hemichannels, Proc. Natl. Acad. Sci. U.S.A, 100, 11388-11393

[70] Procida, K., Jørgensen, L., Schmitt, N., Delmar, M., Taffet, S. M., Holstein-Rathlou, N.-H., Nielsen, M. S., and Braunstein, T. H., (2009), Phosphorylation of connexin43 on serine 306 regulates electrical coupling, Heart Rhythm., 6, 1632-1638

[71] Zhou, X. W., Pfahnl, A., Werner, R., Hudder, A., Llanes, A., Luebke, A., and Dahl, G., (1997), Identification of a pore lining segment in gap junction hemichannels, Biophys. J., 72, 1946-1953

[72] Gaßmann, O., Kreir, M., Ambrosi, C., Pranskevich, J., Oshima, A., Röling, C., Sosinsky, G., Fertig, N., and Steinem, C., (2009), The M34A mutant of Connexin26 
reveals active conductance states in pore-suspending membranes, J. Struct. Biol, 168, $168-176$

[73] Phillips, R., Ursell, T., Wiggins, P., and Sens, P., (2009), Emerging roles for lipids in shaping membrane-protein function, Nature, 459, 379-385

[74] Andersen, O. S., and Koeppe, R. E., (2007), Bilayer thickness and membrane protein function: an energetic perspective, Annu. Rev. Biophys. Biomol. Struct., 36, 107-130

[75] Seddon, A. M., Curnow, P., and Booth, P. J., (2004), Membrane proteins, lipids and detergents: not just a soap opera, Biochim. Biophys. Acta, 1666, 105-117

[76] Denisov, I. G., Grinkova, Y. V., Lazarides, A. A., and Sligar, S. G., (2004), Directed self-assembly of monodisperse phospholipid bilayer Nanodiscs with controlled size, $J$. Am. Chem. Soc., 126, 3477-3487

[77] Sanders, C. R., and Prosser, R. S., (1998), Bicelles: a model membrane system for all seasons?, Structure, 6, 1227-1234

[78] Nath, A., Atkins, W. M., and Sligar, S. G., (2007), Applications of phospholipid bilayer nanodiscs in the study of membranes and membrane proteins, Biochem., 46, 2059-2069

[79] Kahya, N., (2010), Protein-protein and protein-lipid interactions in domain-assembly: lessons from giant unilamellar vesicles, Biochim. Biophys. Acta, 1798, 1392-1398

[80] Bangham, A. D., Standish, M. M., and Watkins, J. C., (1965), Diffusion of univalent ions across the lamellae of swollen phospholipids, J. Mol. Biol., 13, 238-252

[81] Angelova, M. I., and Dimitrov, D. S., (1986), Liposome electroformation, Faraday Discuss. Chem. Soc, 81, 303-311

[82] Helm, C., Lösche, M., and Möhwald, H., Eds., (1992), Progress in Colloid and Polymer Science, Trends Coll. \& Interf. Sci. VI, Steinkopff; Springer-Verlag, Darmstadt

[83] Bagatolli, L. A., Parasassi, T., and Gratton, E., (2000), Giant phospholipid vesicles: comparison among the whole lipid sample characteristics using different preparation methods: a two photon fluorescence microscopy study, Chem. Phys. Lipids, 105, 135147

[84] Mueller, P., Rudin, D. O., Tien, H. T., and Wescott, W. C., (1962), Reconstitution of cell membrane structure in vitro and its transformation into an excitable system, Nature, 194, 979-980

[85] Cremer, P. S., and Boxer, S. G., (1999), Formation and Spreading of Lipid Bilayers on Planar Glass Supports, J. Phys. Chem. B, 103, 2554-2559 
[86] Lingler, S., Rubinstein, I., Knoll, W., and Offenhäusser, A., (1997), Fusion of Small Unilamellar Lipid Vesicles to Alkanethiol and Thiolipid Self-Assembled Monolayers on Gold, Langmuir, 13, 7085-7091

[87] Florin, E. L., and Gaub, H. E., (1993), Painted supported lipid membranes, Biophys. J., 64, 375-383

[88] Blodgett, K. B., (1935), Films Built by Depositing Successive Monomolecular Layers on a Solid Surface, J. Am. Chem. Soc., 57, 1007-1022

[89] Langmuir, I., and Schaefer, V. J., (1938), Activities of Urease and Pepsin Monolayers, J. Am. Chem. Soc., 60, 1351-1360

[90] Boxer, S. G., (2000), Molecular transport and organization in supported lipid membranes, Curr. Opin. Chem. Biol., 4, 704-709

[91] Richter, R. P., Bérat, R., and Brisson, A. R., (2006), Formation of solid-supported lipid bilayers: an integrated view, Langmuir, 22, 3497-3505

[92] Montal, M., and Mueller, P., (1972), Formation of bimolecular membranes from lipid monolayers and a study of their electrical properties, Proc. Natl. Acad. Sci. U.S.A., 69, 3561-3566

[93] Mager, M. D., and Melosh, N. A., (2008), Nanopore-Spanning Lipid Bilayers for Controlled Chemical Release, Adv. Mater., 20, 4423-4427

[94] Kresák, S., Hianik, T., and Naumann, R. L. C., (2009), Giga-seal solvent-free bilayer lipid membranes: from single nanopores to nanopore arrays, Soft Matter, 5, 4021

[95] Im, H., Wittenberg, N. J., Lesuffleur, A., Lindquist, N. C., and Oh, S.-H., (2010), Membrane protein biosensing with plasmonic nanopore arrays and pore-spanning lipid membranes, Chem. Sci., 1, 688-696

[96] Im, H., Lee, S. H., Wittenberg, N. J., Johnson, T. W., Lindquist, N. C., Nagpal, P., Norris, D. J., and Oh, S.-H., (2011), Template-stripped smooth Ag nanohole arrays with silica shells for surface plasmon resonance biosensing, ACS Nano, 5, 6244-6253

[97] Bhattacharya, J., Kisner, A., Offenhäusser, A., and Wolfrum, B., (2011), Microfluidic anodization of aluminum films for the fabrication of nanoporous lipid bilayer support structures, Beilstein J. Nanotechnol., 2, 104-109

[98] Venkatesan, B. M., Polans, J., Comer, J., Sridhar, S., Wendell, D., Aksimentiev, A., and Bashir, R., (2011), Lipid bilayer coated $\mathrm{Al}_{2} \mathrm{O}_{3}$ nanopore sensors: towards a hybrid biological solid-state nanopore, Biomed. Microdevices, 13, 671-682 
[99] Nikolelis, D. P., and Siontorou, C. G., (1995), Bilayer lipid membranes for flow injection monitoring of acetylcholine, urea, and penicillin, Anal. Chem., 67, 936-944

[100] Nikolelis, D. P., and Siontorou, C. G., (1997), Stabilized filter-supported bilayer lipid membranes (BLMs) for automated flow monitoring of compounds of clinical, pharmaceutical, environmental and industrial interest, J. Automat. Chem., 19, 1-8

[101] White, R. J., Ervin, E. N., Yang, T., Chen, X., Daniel, S., Cremer, P. S., and White, H. S., (2007), Single ion-channel recordings using glass nanopore membranes, J. Am. Chem. Soc., 129, 11766-11775

[102] Baaken, G., Ankri, N., Schuler, A.-K., Rühe, J., and Behrends, J. C., (2011), Nanopore-based single-molecule mass spectrometry on a lipid membrane microarray, ACS Nano, 5, 8080-8088

[103] Römer, W., Lam, Y. H., Fischer, D., Watts, A., Fischer, W. B., Göring, P., Wehrspohn, R. B., Gösele, U., and Steinem, C., (2004), Channel activity of a viral transmembrane peptide in micro-BLMs: Vpu(1-32) from HIV-1, J. Am. Chem. Soc., $126,16267-16274$

[104] Schmitt, E. K., Vrouenraets, M., and Steinem, C., (2006), Channel activity of OmpF monitored in nano-BLMs, Biophys. J., 91, 2163-2171

[105] Pilz, C. S., and Steinem, C., (2008), Modulation of the conductance of a 2,2'-bipyridine-functionalized peptidic ion channel by $\mathrm{Ni}^{2+}$, Eur. Biophys. J., 37, 1065-1071

[106] Römer, W., and Steinem, C., (2004), Impedance analysis and single-channel recordings on nano-black lipid membranes based on porous alumina, Biophys. J., 86, $955-$ 965

[107] Mey, I., Stephan, M., Schmitt, E. K., Müller, M. M., Ben Amar, M., Steinem, C., and Janshoff, A., (2009), Local membrane mechanics of pore-spanning bilayers, J. Am. Chem. Soc., 131, 7031-7039

[108] Schmitt, E. K., Weichbrodt, C., and Steinem, C., (2009), Impedance analysis of gramicidin D in pore-suspending membranes, Soft Matter, 5, 3347

[109] Orth, A., Johannes, L., Römer, W., and Steinem, C., (2012), Creating and modulating microdomains in pore-spanning membranes, ChemPhysChem., 13, 108-114

[110] Höfer, I., and Steinem, C., (2011), A membrane fusion assay based on pore-spanning lipid bilayers, Soft Matter, 7, 1644

[111] Hübner, C. A., and Jentsch, T. J., (2002), Ion channel diseases, Hum. Mol. Genet., 11, $2435-2445$ 
[112] Manahan, C. L., Iglesias, P. A., Long, Y., and Devreotes, P. N., (2004), Chemoattractant signaling in Dictyostelium discoideum, Annu. Rev. Cell Dev. Biol, 20, 223-253

[113] Shaulsky, G., and Kessin, R. H., (2007), The cold war of the social amoebae, Curr. Biol., 17, R684-92

[114] Van Haastert, P. J. M., and Devreotes, P. N., (2004), Chemotaxis: signalling the way forward, Nat. Rev. Mol. Cell. Biol., 5, 626-634

[115] Chisholm, R. L., and Firtel, R. A., (2004), Insights into morphogenesis from a simple developmental system, Nat. Rev. Mol. Cell. Biol., 5, 531-541

[116] Cocucci, S. M., and Sussman, M., (1970), RNA in cytoplasmic and nuclear fractions of cellular slime mold amebas, J. Cell. Biol., 45, 399-407

[117] Manstein, D. J., Schuster, H. P., Morandini, P., and Hunt, D. M., (1995), Cloning vectors for the production of proteins in Dictyostelium discoideum, Gene, 162, 129-134

[118] Wildt, S., and Gerngross, T. U., (2005), The humanization of N-glycosylation pathways in yeast, Nat. Rev. Microbiol, 3, 119-128

[119] Freigassner, M., Pichler, H., and Glieder, A., (2009), Tuning microbial hosts for membrane protein production, Microb. Cell Fact., 8, 69

[120] Ramón, A., and Marín, M., (2011), Advances in the production of membrane proteins in Pichia pastoris, Biotechnol. J., 6, 700-706

[121] Porath, J., Carlsson, J., Olsson, I., and Belfrage, G., (1975), Metal chelate affinity chromatography, a new approach to protein fractionation, Nature, 258, 598-599

[122] Porath, J., (1992), Immobilized metal ion affinity chromatography, Protein Expr. Purif., 3, 263-281

[123] Bao, X., Reuss, L., and Altenberg, G. A., (2004), Regulation of purified and reconstituted connexin 43 hemichannels by protein kinase C-mediated phosphorylation of Serine 368, J. Biol. Chem., 279, 20058-20066

[124] Laemmli, U. K., (1970), Cleavage of structural proteins during the assembly of the head of bacteriophage T4, Nature, 227, 680-685

[125] Lottspeich, F. Z. H., (1998), Bioanalytik, Spektrum Akademischer Verlag GmbH, Heidelberg, Berlin

[126] Dyballa, N., and Metzger, S., (2009), Fast and sensitive colloidal coomassie G-250 staining for proteins in polyacrylamide gels, J. Vis. Exp., 30, 1431 
[127] Kang, D., Gho, Y. S., Suh, M., and Kang, C., (2002), Highly Sensitive and Fast Protein Detection with Coomassie Brilliant Blue in Sodium Dodecyl Sulfate-Polyacrylamide Gel Electrophoresis, Bulletin of the Korean Chemical Society, 23, 1511-1512

[128] Candiano, G., Bruschi, M., Musante, L., Santucci, L., Ghiggeri, G. M., Carnemolla, B., Orecchia, P., Zardi, L., and Righetti, P. G., (2004), Blue silver: a very sensitive colloidal Coomassie G-250 staining for proteome analysis, Electrophoresis, 25, 13271333

[129] Renart, J., Reiser, J., and Stark, G. R., (1979), Transfer of proteins from gels to diazobenzyloxymethyl-paper and detection with antisera: a method for studying antibody specificity and antigen structure, Proc. Natl. Acad. Sci. U.S.A, 76, 3116-3120

[130] Towbin, H., Staehelin, T., and Gordon, J., (1979), Electrophoretic transfer of proteins from polyacrylamide gels to nitrocellulose sheets: procedure and some applications, Proc. Natl. Acad. Sci. U.S.A, 76, 4350-4354

[131] BioRad, (09.02.12), http://www.bio-rad.com/webroot/web/images/lsr/products/ electrophoresis/product_overlay_content/global/lsr_trans_blot_sd_assembly.jpg

[132] Gill, S. C., and Hippel, P. H. von, (1989), Calculation of protein extinction coefficients from amino acid sequence data, Anal. Biochem., 182, 319-326

[133] Gasteiger, E., Gattiker, A., Hoogland, C., Ivanyi, I., Appel, R. D., and Bairoch, A., (2003), ExPASy: The proteomics server for in-depth protein knowledge and analysis, Nucleic Acids Res., 31, 3784-3788

[134] Patterson, G. H., Knobel, S. M., Sharif, W. D., Kain, S. R., and Piston, D. W., (1997), Use of the green fluorescent protein and its mutants in quantitative fluorescence microscopy, Biophys. J, 73, 2782-2790

[135] (09.02.2012), http://www.nist.gov/ncnr/upload/E136uvvis.pdf

[136] Shevchenko, A., Wilm, M., Vorm, O., and Mann, M., (1996), Mass spectrometric sequencing of proteins silver-stained polyacrylamide gels, Anal. Chem., 68, 850-858

[137] Berg, J. M., Tymoczko, J. L., and Stryer, L., (2003), Biochemie, 5. Auflage, Spektrum Akad. Verl., Heidelberg [u.a.]

[138] Cole KS, (1949), Dynamic electrical characteristics of squid axon membrane, Archives des Sciences Physiologiques, 2, 253-258

[139] Hodgkin, A. L., and Huxley, A. F., (1952), A quantitative description of membrane current and its application to conduction and excitation in nerve, J. Physiol., 117, 500544 
[140] Schmidt, Mayer, and Vogel, (2000), A Chip-Based Biosensor for the Functional Analysis of Single Ion Channels, Angew. Chem. Int. Ed. Engl., 39, 3137-3140

[141] Ole Mathis Schütte, (2011), Untersuchung der Membran-Peptid-Interaktion am Beispiel von modifiziertem Gramicidin A, Masterarbeit, Göttingen

[142] Walter, P. L., (2002), Shock and Blast Measurement - Rise Time Capability of Measurement Systems?, Sound and Vibration

[143] Galla, H.-J., (1988), Spektroskopische Methoden in der Biochemie, Thieme, Stuttgart

[144] Georg G. Stokes, On the change of refrangibility of light, Abstracts of the Papers Communicated to the Royal Society of London, 1850-54, 195-200

[145] Skaug, M. J., Longo, M. L., and Faller, R., (2009), Computational studies of Texas Red-1,2-dihexadecanoyl-sn-glycero-3-phosphoethanolamine-model building and applications, J. Phys. Chem. B., 113, 8758-8766

[146] Marvin Minsky, (07.02.1957), Microscopy apparatus, Patentnummer: 3013467

[147] Carl Zeiss NTS GmbH, Ed., (2004), Handbuch für die Rasterelektronenmikroskope SUPRA (VP) und ULTRA, SmartSEM V 05.00

[148] Riedel, E., (2004), Anorganische Chemie, 6. Auflage, W. de Gruyter, Berlin ;, New York

[149] Masuda, H., and Fukuda, K., (1995), Ordered metal nanohole arrays made by a twostep replication of honeycomb structures of anodic alumina, Science, 268, 1466-1468

[150] O'Sullivan, J. P., and Wood, G. C., (1970), The Morphology and Mechanism of Formation of Porous Anodic Films on Aluminium, Proc. of the R. Soc. A: Mathematical, Physical and Engineering Sciences, 317, 511-543

[151] Jessensky, O., Müller, F., and Gösele, U., (1998), Self-organized formation of hexagonal pore arrays in anodic alumina, Appl. Phys. Lett., 72, 1173

[152] Nielsch, K., Choi, J., Schwirn, K., Wehrspohn, R. B., and Gösele, U., (2002), Selfordering Regimes of Porous Alumina: The 10 \% Porosity Rule, Nano Lett., 2, 677680

[153] Ghicov, A., and Schmuki, P., (2009), Self-ordering electrochemistry: a review on growth and functionality of $\mathrm{TiO}_{2}$ nanotubes and other self-aligned $\mathrm{MO}_{x}$ structures, Chem. Commun., 2791-2808

[154] Thomas Dominic Lazzara, (2011), Directing macromolecular assemblies by tailored surface functionalizations of nanoporous alumina, Dissertation, Göttingen 
[155] Lazzara, T. D., Carnarius, C., Kocun, M., Janshoff, A., and Steinem, C., (2011), Separating attoliter-sized compartments using fluid pore-spanning lipid bilayers, $A C S$ Nano, 5, 6935-6944

[156] Walde, P., Cosentino, K., Engel, H., and Stano, P., (2010), Giant vesicles: preparations and applications, ChemBioChem, 11, 848-865

[157] Pott, T., Bouvrais, H., and Méléard, P., (2008), Giant unilamellar vesicle formation under physiologically relevant conditions, Chemistry and Physics of Lipids, 154, 115119

[158] Casey, J. R., and Reithmeier, R. A., (1993), Detergent interaction with band 3, a model polytopic membrane protein, Biochem., 32, 1172-1179

[159] Abel, S., Dupradeau, F.-Y., Raman, E. P., MacKerell, A. D., and Marchi, M., (2011), Molecular simulations of dodecyl- $\beta$-maltoside micelles in water: influence of the headgroup conformation and force field parameters, J. Phys. Chem. B., 115, 487-499

[160] Shen, L., Shrager, P., Girsch, S. J., Donaldson, P. J., and Peracchia, C., (1991), Channel reconstitution in liposomes and planar bilayers with HPLC-purified MIP26 of bovine lens, J. Membr. Biol., 124, 21-32

[161] Harris, A. L., Walter, A., Paul, D., Goodenough, D. A., and Zimmerberg, J., (1992), Ion channels in single bilayers induced by rat connexin32, Brain Res. Mol. Brain Res., $15,269-280$

[162] Rigaud, J. L., Pitard, B., and Levy, D., (1995), Reconstitution of membrane proteins into liposomes: application to energy-transducing membrane proteins, Biochim. Biophys. Acta, 1231, 223-246

[163] Rhee, S. K., Bevans, C. G., and Harris, A. L., (1996), Channel-forming activity of immunoaffinity-purified connexin32 in single phospholipid membranes, Biochem., 35, 9212-9223

[164] Arlt, B., Datta, S., Sottmann, T., and Wiegand, S., (2010), Soret effect of $n$-octyl beta-D-glucopyranoside $\left(\mathrm{C}_{8} \mathrm{G}_{1}\right)$ in water around the critical micelle concentration, $J$. Phys. Chem. B., 114, 2118-2123

[165] Rehm, H., (2006), Der Experimentator: Proteinbiochemie, Proteomics, 5. Auflage, Elsevier, Spektrum, Akad. Verl, München, Heidelberg

[166] Girard, P., Pécréaux, J., Lenoir, G., Falson, P., Rigaud, J.-L., and Bassereau, P., (2004), A New Method for the Reconstitution of Membrane Proteins into Giant Unilamellar Vesicles, Biophys. J., 87, 419-429 
[167] Streicher, P., Nassoy, P., Bärmann, M., Dif, A., Marchi-Artzner, V., Brochard-Wyart, F., Spatz, J., and Bassereau, P., (2009), Integrin reconstituted in GUVs: a biomimetic system to study initial steps of cell spreading, Biochim. Biophys. Acta, 1788, 2291-2300

[168] Martinac, B., Rohde, P. R., Battle, A. R., Petrov, E., Pal, P., Foo, A. F., Vásquez, V., Huynh, T., and Kloda, A., (2010), Studying mechanosensitive ion channels using liposomes, Methods Mol. Biol., 606, 31-53

[169] Gerisch, G., (1982), Chemotaxis in Dictyostelium, Annu. Rev. Physiol, 44, 535-552

[170] Watts, D. J., and Ashworth, J. M., (1970), Growth of myxameobae of the cellular slime mould Dictyostelium discoideum in axenic culture, Biochem. J, 119, 171-174

[171] Lu, Y., (2002), Technische Massnahmen zur Verbesserung der Züchtung von Dictyostelium discoideum, Shaker, Aachen

[172] Fey, P., Kowal, A. S., Gaudet, P., Pilcher, K. E., and Chisholm, R. L., (2007), Protocols for growth and development of Dictyostelium discoideum, Nat. Protoc., 2, $1307-1316$

[173] Howard, P. K., Ahern, K. G., and Firtel, R. A., (1988), Establishment of a transient expression system for Dictyostelium discoideum, Nucleic Acids Res., 16, 2613-2623

[174] Nellen, W., Silan, C., and Firtel, R. A., (1984), DNA-mediated transformation in Dictyostelium discoideum: regulated expression of an actin gene fusion, Mol. Cell. Biol., 4, 2890-2898

[175] Hadfield, C., Jordan, B. E., Mount, R. C., Pretorius, G. H., and Burak, E., (1990), G418-resistance as a dominant marker and reporter for gene expression in Saccharomyces cerevisiae, Curr. Genet., 18, 303-313

[176] Arya, R., Bhattacharya, A., and Saini, K. S., (2008), Dictyostelium discoideum-a promising expression system for the production of eukaryotic proteins, FASEB J, 22, 4055-4066

[177] Ellis, S. B., Brust, P. F., Koutz, P. J., Waters, A. F., Harpold, M. M., and Gingeras, T. R., (1985), Isolation of alcohol oxidase and two other methanol regulatable genes from the yeast Pichia pastoris, Mol. Cell. Biol., 5, 1111-1121

[178] Heim, R., Cubitt, A. B., and Tsien, R. Y., (1995), Improved green fluorescence, Nature, 373, 663-664

[179] Evan, G. I., Lewis, G. K., Ramsay, G., and Bishop, J. M., (1985), Isolation of monoclonal antibodies specific for human $c-m y c$ proto-oncogene product, Mol. Cell. Biol., 5, 3610-3616 
[180] Cregg, J. M., Barringer, K. J., Hessler, A. Y., and Madden, K. R., (1985), Pichia pastoris as a host system for transformations, Mol. Cell. Biol., 5, 3376-3385

[181] Cregg, J. M., Madden, K. R., Barringer, K. J., Thill, G. P., and Stillman, C. A., (1989), Functional characterization of the two alcohol oxidase genes from the yeast Pichia pastoris, Mol. Cell. Biol., 9, 1316-1323

[182] Gatignol, A., Durand, H., and Tiraby, G., (1988), Bleomycin resistance conferred by a drug-binding protein, FEBS Lett., 230, 171-175

[183] Cereghino, G. P. L., Cereghino, J. L., Ilgen, C., Cregg, J. M., and Cereghino, G. P., (2002), Production of recombinant proteins in fermenter cultures of the yeast Pichia pastoris, Curr. Opin. Biotechnol, 13, 329-332

[184] Walker, G. M., (1998), Yeast physiology and biotechnology, John Wiley \& Sons, Chichester

[185] Stauffer, K. A., Kumar, N. M., Gilula, N. B., and Unwin, N., (1991), Isolation and purification of gap junction channels, J. Cell Biol., 115, 141-150

[186] Gaßmann, O., (2010), Integration von Connexonen in Lipidmembranen auf porösen Oberflächen, Dissertation, Göttingen

[187] Van der Klei, I. J., Harder, W., and Veenhuis, M., (1991), Biosynthesis and assembly of alcohol oxidase, a peroxisomal matrix protein in methylotrophic yeasts: a review, Yeast, 7, 195-209

[188] Vonck, J., and van Bruggen, E. F., (1990), Electron microscopy and image analysis of two-dimensional crystals and single molecules of alcohol oxidase from Hansenula polymorpha, Biochim. Biophys. Acta, 1038, 74-79

[189] Kreir, M., Farre, C., Beckler, M., George, M., and Fertig, N., (2008), Rapid screening of membrane protein activity: electrophysiological analysis of OmpF reconstituted in proteoliposomes, Lab Chip, 8, 587-595

[190] Lasic, D. D., (1988), The mechanism of vesicle formation, Biochem. J, 256, 1-11

[191] Aimon, S., Manzi, J., Schmidt, D., Poveda Larrosa, J. A., Bassereau, P., and Toombes, G. E. S., (2011), Functional reconstitution of a voltage-gated potassium channel in giant unilamellar vesicles, PLoS ONE, 6, e25529

[192] Allen, T. M., Romans, A. Y., Kercret, H., and Segrest, J. P., (1980), Detergent removal during membrane reconstitution, Biochim. Biophys. Acta, 601, 328-342 
[193] Falk, M. M., Buehler, L. K., Kumar, N. M., and Gilula, N. B., (1997), Cell-free synthesis and assembly of connexins into functional gap junction membrane channels, EMBO J., 16, 2703-2716

[194] Fertig, N., Klau, M., George, M., Blick, R. H., and Behrends, J. C., (2002), Activity of single ion channel proteins detected with a planar microstructure, Appl. Phys. Lett., 81,4865

[195] Mazet, J. L., Jarry, T., Gros, D., and Mazet, F., (1992), Voltage dependence of liver gap-junction channels reconstituted into liposomes and incorporated into planar bilayers, Eur. J. Biochem., 210, 249-256

[196] Bukauskas, F. F., Jordan, K., Bukauskiene, A., Bennett, M. V., Lampe, P. D., Laird, D. W., and Verselis, V. K., (2000), Clustering of connexin 43-enhanced green fluorescent protein gap junction channels and functional coupling in living cells, Proc. Natl. Acad. Sci. U.S.A, 97, 2556-2561

[197] Thompson, R. J., Zhou, N., and MacVicar, B. A., (2006), Ischemia opens neuronal gap junction hemichannels, Science, 312, 924-927

[198] Masuda, H., and Fukuda, K., (1995), Ordered metal nanohole arrays made by a twostep replication of honeycomb structures of anodic alumina, Science, 268, 1466-1468

[199] Naumann, R., Schiller, S. M., Giess, F., Grohe, B., Hartman, K. B., Kärcher, I., Köper, I., Lübben, J., Vasilev, K., and Knoll, W., (2003), Tethered Lipid Bilayers on Ultraflat Gold Surfaces, Langmuir, 19, 5435-5443

[200] Eva Katharina Schmitt, (2009), Hochohmige porenüberspannende Lipidmembranen: Elektrochemische Untersuchungen zur Aktivität von Gramicidin und Bacteriorhodopsin, Dissertation, Göttingen

[201] Mager, M. D., Almquist, B., and Melosh, N. A., (2008), Formation and characterization of fluid lipid bilayers on alumina, Langmuir, 24, 12734-12737

[202] Lazzara, T. D., Kliesch, T.-T., Janshoff, A., and Steinem, C., (2011), Orthogonal functionalization of nanoporous substrates: control of $3 \mathrm{D}$ surface functionality, $A C S$ Appl. Mater Interfaces, 3, 1068-1076

[203] Kaneda, M., Nomura, S.-i. M., Ichinose, S., Kondo, S., Nakahama, K.-i., Akiyoshi, K., and Morita, I., (2009), Direct formation of proteo-liposomes by in vitro synthesis and cellular cytosolic delivery with connexin-expressing liposomes, Biomaterials, 30, 3971-3977 
[204] Schuy, S., Treutlein, B., Pietuch, A., and Janshoff, A., (2008), In situ synthesis of lipopeptides as versatile receptors for the specific binding of nanoparticles and liposomes to solid-supported membranes, Small, 4, 970-981

[205] Stephanie Voß, (2010), Einfluss molekularer Erkennungsreaktionen auf die Fusion von Vesikeln mit porenüberspannenden Membranen, Diplomarbeit, Göttingen

[206] Ines Höfer, (2011), Entwicklung eines Fusionsassays basierend auf porenüberspannenden Membranen, Dissertation, Göttingen

[207] Dingermann, T., Troidl, E. M., Bröker, M., and Nerke, K., (1991), Expression of human antithrombin III in the cellular slime mould Dictyostelium discoideum, Appl. Microbiol. Biotechnol., 35, 496-503

[208] Lu, Y., Knol, J. C., Linskens, M. H. K., Friehs, K., van Haastert, P. J. M., and Flaschel, E., (2004), Cultivation of immobilized Dictyostelium discoideum for the production of soluble human Fas ligand, Appl. Microbiol. Biotechnol., 65, 547-552

[209] Voith, G., and Dingermann, T., (1995), Expression of the human muscarinic receptor gene $\mathrm{m} 2$ in Dictyostelium discoideum, Biotechn., 13, 1225-1229

[210] Cohen, N. R., Knecht, D. A., and Lodish, H. F., (1996), Functional expression of rat GLUT 1 glucose transporter in Dictyostelium discoideum, Biochem. J., 315, 971-975

[211] Barbe, M. T., Monyer, H., and Bruzzone, R., (2006), Cell-cell communication beyond connexins: the pannexin channels, Physiology, 21, 103-114

[212] Yarger, J., Stults, K., and Soll, D. R., (1974), Observations on the growth of Dictyostelium discoideum in axenic medium: evidence for an extracellular growth inhibitor synthesized by stationary phase cells, J. Cell. Sci., 14, 681-690

[213] Yarger, J., and Soll, D. R., (1975), Transcription and division inhibitors in the medium of stationary phase cultures of the slime mold Dictyostelium discoideum, Biochim. Biophys. Acta, 390, 45-55

[214] Lu, Y., Lu, Y., Knol, J. C., Linskens, M. H. K., Friehs, K., van Haastert, P. J. M., and Flaschel, E., (2004), Production of the soluble human Fas ligand by Dictyostelium discoideum cultivated on a synthetic medium, J. Biotechn., 108, 243-251

[215] Hertzberg, E. L., and Skibbens, R. V., (1984), A protein homologous to the 27,000 dalton liver gap junction protein is present in a wide variety of species and tissues, Cell, 39, 61-69

[216] Paul, D. L., (1986), Molecular cloning of cDNA for rat liver gap junction protein, J. Cell Biol., 103, 123-134 
[217] Franke, J., and Kessin, R., (1977), A defined minimal medium for axenic strains of Dictyostelium discoideum, Proc. Natl. Acad. Sci. U.S.A., 74, 2157-2161

[218] Han, S.-I., Friehs, K., and Flaschel, E., (2004), Improvement of a synthetic medium for Dictyostelium discoideum, Process Biochem., 39, 925-930

[219] Han, S.-I., Friehs, K., and Flaschel, E., (2004), Cultivation of Dictyostelium discoideum on an improved synthetic medium in a conventional bioreactor, Process Biochem., 39, 585-589

[220] Kaufmann, S., Weiss, I. M., Eckstein, V., and Tanaka, M., (2012), Functional expression of $\mathrm{Ca}^{2+}$ dependent mammalian transmembrane gap junction protein $\mathrm{Cx} 43$ in slime mold Dictyostelium discoideum, Biochem. Biophys. Res. Commun., 419, 165-169

[221] Cregg, J. M., Tolstorukov, I., Kusari, A., Sunga, J., Madden, K., and Chappell, T., (2009), Expression in the yeast Pichia pastoris, Meth. Enzymol., 463, 169-189

[222] Li, P., Anumanthan, A., Gao, X.-G., Ilangovan, K., Suzara, V. V., Düzgüneş, N., and Renugopalakrishnan, V., (2007), Expression of Recombinant Proteins in Pichia pastoris, Appl. Biochem. Biotechnol., 142, 105-124

[223] Feng, W., Cai, J., Pierce, W. M., and Song, Z.-H., (2002), Expression of CB2 cannabinoid receptor in Pichia pastoris, Protein Expr. Purif., 26, 496-505

[224] Kobayashi, K., Kuwae, S., Ohya, T., Ohda, T., Ohyama, M., and Tomomitsu, K., (2000), High level secretion of recombinant human serum albumin by fed-batch fermentation of the methylotrophic yeast, Pichia pastoris, based on optimal methanol feeding strategy, J. Biosci. Bioeng., 90, 280-288

[225] Ozimek, P., Veenhuis, M., and van der Klei, I. J., (2005), Alcohol oxidase: a complex peroxisomal, oligomeric flavoprotein, FEMS Yeast Res., 5, 975-983

[226] Parcej, D. N., and Eckhardt-Strelau, L., (2003), Structural characterisation of neuronal voltage-sensitive $\mathrm{K}+$ channels heterologously expressed in Pichia pastoris, J. Mol. Biol., 333, 103-116

[227] Kim, D. Y., Kam, Y., Koo, S. K., and Joe, C. O., (1999), Gating connexin 43 channels reconstituted in lipid vesicles by mitogen-activated protein kinase phosphorylation, J. Biol. Chem., 274, 5581-5587

[228] Sarramegna, V., Muller, I., Mousseau, G., Froment, C., Monsarrat, B., Milon, A., and Talmont, F., (2005), Solubilization, purification, and mass spectrometry analysis of the human mu-opioid receptor expressed in Pichia pastoris, Protein Expr. Purif., 43, 85-93 
[229] Yurugi-Kobayashi, T., Asada, H., Shiroishi, M., Shimamura, T., Funamoto, S., Katsuta, N., Ito, K., Sugawara, T., Tokuda, N., Tsujimoto, H., Murata, T., Nomura, N., Haga, K., Haga, T., Iwata, S., and Kobayashi, T., (2009), Comparison of functional non-glycosylated GPCRs expression in Pichia pastoris, Biochem. Biophys. Res. Commun., 380, 271-276

[230] Oberg, F., Ekvall, M., Nyblom, M., Backmark, A., Neutze, R., and Hedfalk, K., (2009), Insight into factors directing high production of eukaryotic membrane proteins; production of 13 human AQPs in Pichia pastoris, Mol. Membr. Biol., 26, 215227

[231] Newstead, S., Kim, H., Heijne, G. von, Iwata, S., and Drew, D., (2007), Highthroughput fluorescent-based optimization of eukaryotic membrane protein overexpression and purification in Saccharomyces cerevisiae, Proc. Natl. Acad. Sci. U.S.A., 104, 13936-13941

[232] Drew, D., Newstead, S., Sonoda, Y., Kim, H., Heijne, G. von, and Iwata, S., (2008), GFP-based optimization scheme for the overexpression and purification of eukaryotic membrane proteins in Saccharomyces cerevisiae, Nat. Protoc., 3, 784-798

[233] Rigaud, J. L. e. a., Rigaud, J. L., Mosser, G., Lacapere, J. J., Olofsson, A., Levy, D., and Ranck, J. L., (1997), Bio-Beads: An Efficient Strategy for Two-Dimensional Crystallization of Membrane Proteins, J. Struct. Biol., 118, 226-235

[234] Tao, L., and Harris, A. L., (2004), Biochemical requirements for inhibition of Connexin26-containing channels by natural and synthetic taurine analogs, J. Biol. Chem., 279, 38544-38554

[235] Ramundo-Orlando, A., Serafino, A., and Villalobo, A., (2005), Gap junction channels reconstituted in two closely apposed lipid bilayers, Arch. Biochem.Biophys., 436, 128 135

[236] Jackson, M. L., and Litman, B. J., (1985), Rhodopsin-egg phosphatidylcholine reconstitution by an octyl glucoside dilution procedure, Biochim. Biophys. Acta, 812, 369-376

[237] Jackson, M. L., and Litman, B. J., (1982), Rhodopsin-phospholipid reconstitution by dialysis removal of octyl glucoside, Biochem., 21, 5601-5608

[238] Eytan, G. D., (1982), Use of liposomes for reconstitution of biological functions, Biochim. Biophys. Acta - Reviews on Biomembranes, 694, 185-202 
[239] Geertsma, E. R., Nik Mahmood, N. A. B., Schuurman-Wolters, G. K., and Poolman, B., (2008), Membrane reconstitution of ABC transporters and assays of translocator function, Nat. Protoc., 3, 256-266

[240] Locke, D., (2004), Reversible Pore Block of Connexin Channels by Cyclodextrins, J. Biol. Chem., 279, 22883-22892

[241] Markin, V. S., Kozlov, M. M., and Borovjagin, V. L., (1984), On the theory of membrane fusion. The stalk mechanism, Gen. Physiol. Biophys., 3, 361-377

[242] Cascio, M., (2005), Connexins and their environment: effects of lipids composition on ion channels, Biochim. Biophys. Acta, 1711, 142-153

[243] Arcisio-Miranda, M., dos Santos Cabrera, M. P., Konno, K., Rangel, M., and Procopio, J., (2008), Effects of the cationic antimicrobial peptide eumenitin from the venom of solitary wasp Eumenes rubronotatus in planar lipid bilayers: surface charge and pore formation activity, Toxicon, 51, 736-745

[244] Suga, M., Maeda, S., Nakagawa, S., Yamashita, E., and Tsukihara, T., (2009), A description of the structural determination procedures of a gap junction channel at 3.5 Å resolution, Acta Crystallogr. D. Biol. Crystallogr., 65, 758-766

[245] Pantoja, R., Sigg, D., Blunck, R., Bezanilla, F., and Heath, J. R., (2001), Bilayer reconstitution of voltage-dependent ion channels using a microfabricated silicon chip, Biophys. J., 81, 2389-2394

[246] Fertig, N., Blick, R. H., and Behrends, J. C., (2002), Whole cell patch clamp recording performed on a planar glass chip, Biophys. J., 82, 3056-3062

[247] Fertig, N., George, M., Klau, M., Meyer, C., Tilke, A., Sobotta, C., Blick, R. H., and Behrends, J. C., (2003), Microstructured apertures in planar glass substrates for ion channel research, Recept. Channels, 9, 29-40

[248] Sondermann, M., George, M., Fertig, N., and Behrends, J. C., (2006), High-resolution electrophysiology on a chip: Transient dynamics of alamethicin channel formation, Biochim. Biophys. Acta, 1758, 545-551

[249] Stout, C. E., Costantin, J. L., Naus, C. C. G., and Charles, A. C., (2002), Intercellular calcium signaling in astrocytes via ATP release through connexin hemichannels, J. Biol. Chem., 277, 10482-10488

[250] Bruzzone, S., Guida, L., Zocchi, E., Franco, L., and De Flora A, (2001), Connexin 43 hemi channels mediate $\mathrm{Ca} 2+$-regulated transmembrane $\mathrm{NAD}+$ fluxes in intact cells, FASEB J, 15, 10-12 
[251] Ye, Z.-C., Wyeth, M. S., Baltan-Tekkok, S., and Ransom, B. R., (2003), Functional hemichannels in astrocytes: a novel mechanism of glutamate release, J. Neurosci., 23, $3588-3596$

[252] Romanello, M., and D'Andrea, P., (2001), Dual mechanism of intercellular communication in HOBIT osteoblastic cells: a role for gap-junctional hemichannels, J. Bone Miner. Res., 16, 1465-1476

[253] Quist, A. P., Rhee, S. K., Lin, H., and Lal, R., (2000), Physiological role of gapjunctional hemichannels. Extracellular calcium-dependent isosmotic volume regulation, J. Cell Biol., 148, 1063-1074

[254] John, S. A., Kondo, R., Wang, S. Y., Goldhaber, J. I., and Weiss, J. N., (1999), Connexin-43 hemichannels opened by metabolic inhibition, J. Biol. Chem., 274, 236240

[255] Contreras, J. E., Sánchez, H. A., Eugenin, E. A., Speidel, D., Theis, M., Willecke, K., Bukauskas, F. F., Bennett, M. V. L., and Sáez, J. C., (2002), Metabolic inhibition induces opening of unapposed connexin 43 gap junction hemichannels and reduces gap junctional communication in cortical astrocytes in culture, Proc. Natl. Acad. Sci. U.S.A., 99, 495-500

[256] Hunter, A. W., Jourdan, J., and Gourdie, R. G., (2003), Fusion of GFP to the carboxyl terminus of connexin43 increases gap junction size in HeLa cells, Cell Commun. Adhes, 10, 211-214

[257] Hunter, A. W., Barker, R. J., Zhu, C., and Gourdie, R. G., (2005), Zonula occludens-1 alters connexin43 gap junction size and organization by influencing channel accretion, Mol. Biol. Cell, 16, 5686-5698

[258] Retamal, M. A., Froger, N., Palacios-Prado, N., Ezan, P., Sáez, P. J., Sáez, J. C., and Giaume, C., (2007), Cx43 hemichannels and gap junction channels in astrocytes are regulated oppositely by proinflammatory cytokines released from activated microglia, $J$. Neurosci., 27, 13781-13792

[259] Retamal, M. A., Schalper, K. A., Shoji, K. F., Bennett, M. V. L., and Sáez, J. C., (2007), Opening of connexin 43 hemichannels is increased by lowering intracellular redox potential, Proc. Natl. Acad. Sci. U.S.A, 104, 8322-8327

[260] Cottrell, G. T., and Burt, J. M., (2001), Heterotypic gap junction channel formation between heteromeric and homomeric $\mathrm{Cx} 40$ and Cx43 connexons, Am. J. Physiol., Cell. Physiol., 281, C1559-67 
[261] Cottrell, G. T., Wu, Y., and Burt, J. M., (2002), Cx40 and Cx43 expression ratio influences heteromeric/ heterotypic gap junction channel properties, Am. J. Physiol., Cell. Physiol., 282, C1469-82

[262] Kang, J., Kang, N., Lovatt, D., Torres, A., Zhao, Z., Lin, J., and Nedergaard, M., (2008), Connexin 43 hemichannels are permeable to ATP, J. Neurosci., 28, 47024711

[263] Kondo, R. P., Wang, S. Y., John, S. A., Weiss, J. N., and Goldhaber, J. I., (2000), Metabolic inhibition activates a non-selective current through connexin hemichannels in isolated ventricular myocytes, J. Mol. Cell. Cardiol., 32, 1859-1872

[264] Orellana, J. A., Sáez, P. J., Cortés-Campos, C., Elizondo, R. J., Shoji, K. F., Contreras-Duarte, S., Figueroa, V., Velarde, V., Jiang, J. X., Nualart, F., Sáez, J. C., and García, M. A., (2012), Glucose increases intracellular free $\mathrm{Ca}^{2+}$ in tanycytes via ATP released through connexin 43 hemichannels, Glia, 60, 53-68

[265] Desplantez, T., Halliday, D., Dupont, E., Severs, N. J., and Weingart, R., (2011), Influence of $\mathrm{v} 5 / 6-\mathrm{His}$ tag on the properties of gap junction channels composed of connexin43, connexin40 or connexin45, J. Membr. Biol., 240, 139-150

[266] Schalper, K. A., Sánchez, H. A., Lee, S. C., Altenberg, G. A., Nathanson, M. H., and Sáez, J. C., (2010), Connexin 43 hemichannels mediate the $\mathrm{Ca}^{2+}$ influx induced by extracellular alkalinization, Am. J. Physiol., Cell. Physiol., 299, C1504-15

[267] Martinez, A. D., Hayrapetyan, V., Moreno, A. P., and Beyer, E. C., (2002), Connexin43 and connexin45 form heteromeric gap junction channels in which individual components determine permeability and regulation, Circ. Res., 90, 11001107

[268] Moreno, A. P., Chanson, M., Elenes, S., Anumonwo, J., Scerri, I., Gu, H., Taffet, S. M., and Delmar, M., (2002), Role of the carboxyl terminal of connexin43 in transjunctional fast voltage gating, Circ. Res., 90, 450-457

[269] Desplantez, T., Halliday, D., Dupont, E., and Weingart, R., (2004), Cardiac connexins $\mathrm{Cx} 43$ and $\mathrm{Cx} 45$ : formation of diverse gap junction channels with diverse electrical properties, Pflugers Arch., 448, 363-375

[270] Phillips, G. N., (1997), Structure and dynamics of green fluorescent protein, Curr. Opin. Struct. Biol., 7, 821-827

[271] Chalfie, M., and Kain, S., (2006), Green fluorescent protein, Properties, applications, and protocols, 2. Auflage, Wiley-Interscience, Hoboken, N.J 
[272] Falk, M. M., (2000), Connexin-specific distribution within gap junctions revealed in living cells, J. Cell. Sci., 113, 4109-4120

[273] Delmar, M., (2004), Structural bases for the chemical regulation of Connexin43 channels, Cardiovasc. Res., 62, 268-275

[274] Bouvier, D., Spagnol, G., Chenavas, S., Kieken, F., Vitrac, H., Brownell, S., Kellezi, A., Forge, V., and Sorgen, P. L., (2009), Characterization of the structure and intermolecular interactions between the connexin 40 and connexin 43 carboxyl-terminal and cytoplasmic loop domains, J. Biol. Chem., 284, 34257-34271

[275] Ponsaerts, R., Vuyst, E. de, Retamal, M., D'hondt, C., Vermeire, D., Wang, N., Smedt, H. de, Zimmermann, P., Himpens, B., Vereecke, J., Leybaert, L., and Bultynck, G., (2010), Intramolecular loop/tail interactions are essential for connexin 43-hemichannel activity, FASEB J., 24, 4378-4395

[276] Wayakanon, P., Bhattacharjee, R., Nakahama, K.-i., and Morita, I., (2012), The role of the Cx43 C-terminus in GJ plaque formation and internalization, Biochem. Biophys. Res. Commun., 420, 456-461

[277] Seki, A., (2004), Modifications in the Biophysical Properties of Connexin43 Channels by a Peptide of the Cytoplasmic Loop Region, Circ. Res., 95, 22

[278] Zagotta, W. N., Hoshi, T., and Aldrich, R. W., (1990), Restoration of inactivation in mutants of Shaker potassium channels by a peptide derived from ShB, Science, 250, $568-571$

[279] Revilla, A., Castro, C., and Barrio, L. C., (1999), Molecular dissection of transjunctional voltage dependence in the connexin-32 and connexin-43 junctions, Biophys. J, 77, 1374-1383

[280] La Flamme, K. E., Popat, K. C., Leoni, L., Markiewicz, E., La Tempa, T. J., Roman, B. B., Grimes, C. A., and Desai, T. A., (2007), Biocompatibility of nanoporous alumina membranes for immunoisolation, Biomaterials, 28, 2638-2645

[281] Masuda, H., Yamada, H., Satoh, M., Asoh, H., Nakao, M., and Tamamura, T., (1997), Highly ordered nanochannel-array architecture in anodic alumina, Appl. Phys. Lett., 71, 2770

[282] Groves, J. T., Ulman, N., Cremer, P. S., and Boxer, S. G., (1998), Substrate-Membrane Interactions: Mechanisms for Imposing Patterns on a Fluid Bilayer Membrane, Langmuir, 14, 3347-3350 
[283] Mutalib Md Jani, A., Anglin, E. J., McInnes, S. J. P., Losic, D., Shapter, J. G., and Voelcker, N. H., (2009), Nanoporous anodic aluminium oxide membranes with layered surface chemistry, Chem. Commun., 3062-3064

[284] Roskamp, R. F., Vockenroth, I. K., Eisenmenger, N., Braunagel, J., and Köper, I., (2008), Functional tethered bilayer lipid membranes on aluminum oxide, ChemPhysChem, 9, 1920-1924

[285] Mager, M. D., and Melosh, N. A., (2007), Lipid bilayer deposition and patterning via air bubble collapse, Langmuir, 23, 9369-9377

[286] Raghuraman, H., and Chattopadhyay, A., (2007), Melittin: a membrane-active peptide with diverse functions, Biosci. Rep., 27, 189-223

[287] Matsuzaki, K., Yoneyama, S., and Miyajima, K., (1997), Pore formation and translocation of melittin, Biophys. J., 73, 831-838

[288] Van den Bogaart, G., Guzmán, J. V., Mika, J. T., and Poolman, B., (2008), On the mechanism of pore formation by melittin, J. Biol. Chem., 283, 33854-33857

[289] Yang, L., Harroun, T. A., Weiss, T. M., Ding, L., and Huang, H. W., (2001), Barrelstave model or toroidal model? A case study on melittin pores, Biophys. J., 81, 14751485

[290] Needham, D., and Nunn, R. S., (1990), Elastic deformation and failure of lipid bilayer membranes containing cholesterol, Biophys. J., 58, 997-1009

[291] Chen, L.-Y., Cheng, C.-W., Lin, J.-J., and Chen, W.-Y., (2007), Exploring the effect of cholesterol in lipid bilayer membrane on the melittin penetration mechanism, Anal. Biochem., 367, 49-55

[292] Allende, D., and McIntosh, T. J., (2003), Lipopolysaccharides in bacterial membranes act like cholesterol in eukaryotic plasma membranes in providing protection against melittin-induced bilayer lysis, Biochem., 42, 1101-1108

[293] Zasloff, M., (2002), Antimicrobial peptides of multicellular organisms, Nature, 415, 389-395

[294] Dempsey, C. E., (1990), The actions of melittin on membranes, Biochim. Biophys. Acta, 1031, 143-161

[295] Bao, X., Lee, S. C., Reuss, L., and Altenberg, G. A., (2007), Change in permeant size selectivity by phosphorylation of connexin 43 gap-junctional hemichannels by PKC, Proc. Natl. Acad. Sci. U.S.A, 104, 4919-4924 
[296] Bao, X., Chen, Y., Reuss, L., and Altenberg, G. A., (2004), Functional expression in Xenopus oocytes of gap-junctional hemichannels formed by a cysteine-less connexin 43, J. Biol. Chem, 279, 9689-9692

[297] Moritani, Y., Nomura, S.-i. M., Morita, I., and Akiyoshi, K., (2010), Direct integration of cell-free-synthesized connexin-43 into liposomes and hemichannel formation, FEBS J, 277, 3343-3352

[298] Kamiya, K., Tsumoto, K., Arakawa, S., Shimizu, S., Morita, I., Yoshimura, T., and Akiyoshi, K., (2010), Preparation of connexin43-integrated giant Liposomes by a baculovirus expression-liposome fusion method, Biotechnol. Bioeng., 107, 836-843

[299] Fukushima, H., Mizutani, M., Imamura, K., Morino, K., Kobayashi, J., Okumura, K., Tsumoto, K., and Yoshimura, T., (2008), Development of a novel preparation method of recombinant proteoliposomes using baculovirus gene expression systems, J. Biochem., 144, 763-770

[300] Fukushima, H., Matsuo, H., Imamura, K., Morino, K., Okumura, K., Tsumoto, K., and Yoshimura, T., (2009), Diagnosis and discrimination of autoimmune Graves' disease and Hashimoto's disease using thyroid-stimulating hormone receptorcontaining recombinant proteoliposomes, J. Biosci. Bioeng., 108, 551-556

[301] Locke, D., and Harris, A. L., (2009), Connexin channels and phospholipids: association and modulation, BMC Biol., 7, 52

[302] Kalmbach, R., Chizhov, I., Schumacher, M. C., Friedrich, T., Bamberg, E., and Engelhard, M., (2007), Functional cell-free synthesis of a seven helix membrane protein: in situ insertion of bacteriorhodopsin into liposomes, J. Mol. Biol., 371, 639648 


\section{Anhang}

\subsection{Abkürzungsverzeichnis}

$\mathrm{A} / \mathrm{D}$

AOX

Bio-Cap-PE

Bodipy-PC

cAMP

CL

CLSM

$\mathrm{CMC}$

CT

$\mathrm{Cx}$

DDM

DMSO

DNA

DTT

DOGS-Ni-

NTA

DPhPC

E

ECL

EDTA

EGTA
Analog/Digital

Alkoholoxidase

1,2-Dipalmitoyl-sn-glycero-3-phosphoethanolamin- $N$-capronsäurebiotinNatriumsalz

2-(4,4-Difluoro-5-methyl-4-bora-3a,4a-diaza-s-diaza-indazen-3-dodecanoyl)-1hexadecanoyl-sn-glycero-3-phosphocholin

Zyklisches Adenosinmonophosphat (Cyclic Adenosine Monophosphate)

Cytoplasmatische Schleife (Cytoplasmatic Loop)

Konfokale Laserrastermikroskopie (Confocal Laser Scanning Microscopy)

Kritische Mizellenbildungskonzentration (Critical Micellar Concentration)

C-Terminus

Connexin

$n$-Dodecyl- $\beta$-D-maltosid

Dimethylsulfoxid

Desoxyribonukleinsäure (Desoxyribonucleic Acid)

Dithiotreitol

1,2-Dioleoyl-sn-glycero-3-[(N-(5-amino-1-carboxypentyl)iminodiessigsäure)succinyl]

1,2-Diphytanoyl-sn-glycero-3-phosphocholin

Extrazelluläre Schleife

Enhanced Chemiluminescence

Ethylendiamintetraessigsäure (Ethylendiaminetetraacetic Acid)

Ethylenglycol-bis(aminoethylenether)- $N, N, N^{\prime}, N^{\prime}$-tetraessigsäure

(Ethyleneglycoltetraacetic Acid) 
ESI

Elektrosprayionisation

FITC Fluoresceinisothiocyanat

FRAP Fluorescence Recovery After Photobleaching

GFP Grün fluoreszierendes Protein (Green Fluorescent Protein)

eGFP Enhanced Green Fluorescent Protein

GUVs Riesige unilamellare Vesikel (Giant Unilamellar Vesicles)

G418 Geneticin

HRP Meerrettichperoxidase (Horseradish Peroxidase)

$\mathrm{H}_{6}$ WGC Hexa-L-histidyl-L-tryptophanyl-L-glycyl-L-cysteinamid

IMAC Immobilisierte Metallionenaffinitätschromatographie

ITO Indiumzinnoxid (Indium Tin Oxide)

LC/MS Liquid Chromatography / Mass Spectrometry

LUVs Große unilamellare Vesikel (Large Unilamellar Vesicles)

MCC-DOPE 1,2-Dioleoyl-sn-glycero-3-phosphoethanolamin- $N$-[4-( $p$-maleimidomethyl)cyclohexan-carboxamid]-Natriumsalz

MLV Multilamellare Vesikel

Ni-NTA Nickel-Nitrilotriessigsäure (Nickel Nitrilotriacetic Acid)

NT N-Terminus

$n$ OG $\quad n$-Octyl- $\beta$-D-glucopyranosid

OD Optische Dichte

PCR Polymerasekettenreaktion (Polymerase Chain Reaction)

PMSF Phenylmethylsulfonylfluorid

POPC 1-Palmitoyl-2-oleoyl-sn-glycero-3-phosphocholin

PVC Polyvinylchlorid

8-POE n-Octylpolyoxyethylen

ROI Region of Interest

RT Raumtemperatur

SEM Scanning Electron Microscopy

SDS-PAGE Sodiumdodecylsulfat-Polyacrylamidgelelektrophorese 
Slpm Standard-Liter pro Minute

SSMs $\quad$ Festkörperunterstützte Membranen (Solid Supported Membranes)

SUVs $\quad$ Kleine unilamellare Vesikel (Small Unilamellar Vesicles)

5(6)-TAMRA 5(6)-Carboxytetramethylrhodamin

TEMED $\quad N, N, N^{\prime}, N^{\prime}$-Tetramethylethylendiamin

Texas Red- Sulforhodamine 101 1,2-dihexyadecanoyl-sn-glycero-3-phosphoethanol-L-amin-

DHPE Triethylammoniumsalz

THF Tetrahydrofuran

TM Transmembranständige $\alpha$-Helices

WT Wildtyp

\subsection{Symbolverzeichnis}

$\begin{array}{ll}A & \text { Absorption } \\ c & \text { Lichtgeschwindigkeit } \\ d & \text { Durchmesser } \\ D & \text { Diffusionskoeffizient } \\ E & \text { Energie } \\ f & \text { Frequenz } \\ G & \text { Leitfähigkeit } \\ b & \text { Plancksche Wirkungsquantum } \\ I & \text { Stromstärke, Intensität } \\ m & \text { Steigung } \\ M & \text { Molekulargewicht } \\ N A & \text { Numerische Apertur } \\ P_{\mathrm{o}} & \text { Öffnungswahrscheinlichkeit } \\ p\left(\mathrm{O}_{2}\right) & \text { Sauerstoffpartialdruck } \\ R & \text { Widerstand } \\ t & \text { Zeit }\end{array}$




$\begin{array}{ll}t_{\mathrm{o}} & \text { Verweildauer des geöffneten und geschlossenen Zustandes } \\ T & \text { Temperatur } \\ t_{\mathrm{D}} & \text { Verdopplungszeit } \\ U & \text { Spannung } \\ V_{\mathrm{j}} & \text { Transjunctional Voltage } \\ X(\mathrm{t}) & \text { Zellzahl zum Zeitpunkt } t \\ \varepsilon & \text { Molarer Absorptionskoeffizient } \\ \lambda & \text { Wellenlänge } \\ \lambda-\lambda & \text { Gitterkonstante } \\ \mu & \text { Charakteristische Wachstumsrate } \\ \tau & \text { Mittlere Öffnungsdauer, halbmaximale Diffusionszeit } \\ \omega & \text { Durchmesser Bleichfleck }\end{array}$

\subsection{Chemikalien}

\begin{tabular}{|c|c|}
\hline Acrylamid-Bisacrylamid & Carl Roth GmbH (Karlsruhe) \\
\hline Agar-Agar & Carl Roth GmbH (Karlsruhe) \\
\hline $\mathrm{Al}_{2}\left(\mathrm{SO}_{4}\right)_{3} \cdot 18 \mathrm{H}_{2} \mathrm{O}$ & Fluka (Steinheim) \\
\hline $\mathrm{NH}_{3}$ & Sigma-Aldrich (Taufkirchen) \\
\hline APS & Sigma-Aldrich (Taufkirchen) \\
\hline Argon & Air Liquide Deutschland GmbH (Düsseldorf) \\
\hline Bio-Cap-PE & Avanti Polar Lipids (Alabaster, USA) \\
\hline Biotin & Sigma-Aldrich (Taufkirchen) \\
\hline Bodipy-PC & Life Technologies GmbH (Darmstadt) \\
\hline Borsäure & Merck (Darmstadt) \\
\hline Brilliant Blue G250 & Carl Roth GmbH (Karlsruhe) \\
\hline Bromphenolblau Na-Salz & Carl Roth GmbH (Karlsruhe) \\
\hline 5(6)-Carboxyfluorescein & Sigma-Aldrich (Taufkirchen) \\
\hline $\mathrm{CaSO}_{4}$ & Riedel-deHaën (Seelze) \\
\hline
\end{tabular}




\begin{tabular}{|c|c|}
\hline Cholesterin & Sigma-Aldrich (Taufkirchen) \\
\hline Chrom & Umicore Materials AG (Balzers, Liechtenstein) \\
\hline Chloroform & VWR International (Darmstadt) \\
\hline $\mathrm{CoCl}_{2}$ & Carl Roth GmbH (Karlsruhe) \\
\hline Cumarinsäure & Sigma-Aldrich (Taufkirchen) \\
\hline DDM & Carl Roth GmbH (Karlsruhe) \\
\hline DOGS-Ni-NTA & Avanti Polar Lipids (Alabaster, USA) \\
\hline $\mathrm{DPhPC}$ & Avanti Polar Lipids (Alabaster, USA) \\
\hline EDTA & Sigma-Aldrich (Taufkirchen) \\
\hline EGTA & Carl Roth GmbH (Karlsruhe) \\
\hline Ethanol & Sigma-Aldrich (Taufkirchen) \\
\hline $\mathrm{FeSO}_{4} \cdot 7 \mathrm{H}_{2} \mathrm{O}$ & Fluka (Steinheim) \\
\hline Glucose & Carl Roth GmbH (Karlsruhe) \\
\hline Glycerol & Riedel-deHaën (Seelze) \\
\hline Glycin & AppliChem GmbH (Darmstadt) \\
\hline \multicolumn{2}{|l|}{ Gold } \\
\hline Hefeextrakt & Carl Roth GmbH (Karlsruhe) \\
\hline Hellmanex & Hellmanex GmbH (Müllheim) \\
\hline HEPES & Carl Roth GmbH (Karlsruhe) \\
\hline HL5-Medium & Formedium (Norfolk, UK) \\
\hline Imidazol & Merck (Darmstadt) \\
\hline Iodid & Carl Roth GmbH (Karlsruhe) \\
\hline $\mathrm{KCl}$ & Merck (Darmstadt), Carl Roth GmbH (Karlsruhe) \\
\hline KI & Carl Roth GmbH (Karlsruhe) \\
\hline $\mathrm{CuCl}_{2}$ & Acros Organics (New Jersey, USA) \\
\hline $\mathrm{KH}_{2} \mathrm{PO}_{4}$ & Merck (Darmstadt) \\
\hline $\mathrm{K}_{2} \mathrm{SO}_{4}$ & Janssen Chimica (Geel, Belgien) \\
\hline Luminol & Fluka (Steinheim) \\
\hline Magermilchpulver & Merck (Darmstadt) \\
\hline
\end{tabular}




\begin{tabular}{|c|c|}
\hline $\mathrm{MnSO}_{4} \cdot \mathrm{H}_{2} \mathrm{O}$ & Merck (Darmstadt) \\
\hline MCC-DOPE & Avanti Polar Lipids (Alabaster, USA) \\
\hline Melittin & Sigma-Aldrich (Taufkirchen) \\
\hline Mercaptoethanol & Sigma-Aldrich (Taufkirchen) \\
\hline Methanol & Sigma-Aldrich (Taufkirchen) \\
\hline MOPS & Carl Roth GmbH (Karlsruhe) \\
\hline Mucasol & Merck (Darmstadt) \\
\hline $\mathrm{NaN}_{3}$ & Fluka (Steinheim) \\
\hline $\mathrm{NaCl}$ & Merck (Darmstadt), Acros Organics (NY, USA) \\
\hline $\mathrm{Na}_{2} \mathrm{HPO}_{4}$ & Merck (Darmstadt) \\
\hline $\mathrm{Na}_{2} \mathrm{HPO}_{4} \cdot \mathrm{H}_{2} \mathrm{O}$ & VWR International (Darmstadt) \\
\hline $\mathrm{NaI}$ & Carl Roth GmbH (Karlsruhe) \\
\hline $\mathrm{Na}_{2} \mathrm{MoO}_{4} \cdot 2 \mathrm{H}_{2} \mathrm{O}$ & AppliChem GmbH (Darmstadt) \\
\hline $\mathrm{NiSO}_{4}$ & Riedel-deHaën (Seelze) \\
\hline ortho-Phosphorsäure & Merck (Darmstadt) \\
\hline Oxalsäure-Dihydrat & AppliChem GmbH (Darmstadt) \\
\hline Pepton & Sigma-Aldrich (Taufkirchen) \\
\hline Perylen & Sigma-Aldrich (Taufkirchen) \\
\hline PMSF & Sigma-Aldrich (Taufkirchen) \\
\hline 8-POE & Bachem (Bubendorf) \\
\hline PonceauS & Sigma-Aldrich (Taufkirchen) \\
\hline$n$-Propanol & Carl Roth GmbH (Karlsruhe) \\
\hline Pyranin & Acros Organics (New Jersey, USA) \\
\hline Saccharose & Carl Roth GmbH (Karlsruhe) \\
\hline Salzsäure & Merck (Darmstadt) \\
\hline Sauerstoff & Air Liquide Deutschland GmbH (Düsseldorf) \\
\hline Schwefelsäure, 95-97 \% & Merck (Darmstadt) \\
\hline SDS & AppliChem GmbH (Darmstadt) \\
\hline Sorbit & Carl Roth GmbH (Karlsruhe) \\
\hline
\end{tabular}




$\begin{array}{ll}\text { Taurin } & \text { Sigma-Aldrich (Taufkirchen) } \\ \text { TEMED } & \text { Sigma-Aldrich (Taufkirchen) } \\ \text { Tetrahydrofuran } & \text { VWR International (Darmstadt) } \\ \text { Texas Red DHPE } & \text { Sigma-Aldrich (Taufkirchen) } \\ \text { Trifluoressigsäure } & \text { Carl Roth GmbH (Karlsruhe) } \\ \text { TRIS } & \text { Carl Roth GmbH (Karlsruhe) } \\ \text { Trypton } & \text { Carl Roth GmbH (Karlsruhe) } \\ \mathrm{Tween}^{\odot} 20 & \text { Carl Roth GmbH (Karlsruhe) } \\ \mathrm{H}_{2} \mathrm{O}_{2}(30 \%) & \text { Carl Roth GmbH (Karlsruhe) } \\ \mathrm{Zeocin} & \text { InvivoGen (San Diego, USA) } \\ \mathrm{ZiCl}_{2} & \text { AppliChem GmbH (Darmstadt) }\end{array}$

\subsection{Materialien}

$\begin{array}{ll}\text { Aluminium }(99,999 \%) & \text { Goodfellow (Bad Nauheim) } \\ \text { BioBeads }{ }^{\text {TM }} \text { SM-2 } & \text { BioRad (München) } \\ \text { Braungläschen } & \text { OCHS GmbH (Göttingen) } \\ \text { 3M Electrical Tap 102087 } & \text { Scotch }^{\text {TM }} \text { (St. Paul, USA) } \\ 1,5 \text { mL Reaktionsgefäße } & \text { Sarstedt (Nürnbrecht) } \\ \text { Eppendorfpipetten } & \text { Eppendorf (Hamburg) } \\ \text { His-Bind Resin } & \text { Novagen (Darmstadt) } \\ \text { ITO-Gläser } & \text { Präzisions Glas \& Optik GmbH (Iserlohn) } \\ \text { Kalrez O-Ringe } & \text { Dupont Dow Elast (Newark, USA) } \\ \text { Klemmen } & \text { ALCO (Arnsberg) } \\ \text { Kupferband } & \text { Präzisions Glas \& Optik GmbH (Iserlohn) } \\ \text { Norland Optical Adhesive } 83 \mathrm{H} & \text { Norland Products (Cranbury, USA) } \\ \text { NPC-1 Chips, 3-5 M } \Omega & \text { Nanion Technologies GmbH (München) } \\ \text { Objektträgergläschen } & \text { Menzel Gläser, ThermoScientific (Braunschweig) }\end{array}$


Parafilm

Petrischalen

Pipettenspitzen

PRIMARIA Tissue Culture Dish

Silberdraht

Schwingquarz-Kristall

UHU plus sofort fest - 2

Komponentenkleber
Pechiney Plastik Packaging (Chicago, USA)

Sarstedt (Nümbrecht)

Sarstedt (Nümbrecht)

Falcon (San Jose, USA)

Goodfellow (Bad Nauheim)

Elektronen Optik Service GmbH (Dortmund)

UHU GmbH \& Co KG (Bühl/Baden)

\subsection{Geräte}

\section{Ätzapparatur}

2400 Source Meter

Temperaturregler

\section{Einzelkanalmessung}

A/D-Wandler DIGIDATA 1322A

Axopatch 200 B Amplifier

Port-a-Patch
Keithley Instruments (Cleveland, USA)

Greisinger Elektronik GmbH (Regenstauf)
Axon Instruments (Union City, USA)

Axon Instruments (Union City, USA)

Nanion Technologies GmbH (München)

Kofokales Laserrastermikroskop (CLSM)

LSM 710 Examiner

Objektiv WPlan APOChromat 63x/1.0
Carl Zeiss (Jena)

Carl Zeiss (Jena)

\section{Kathodenzerstäuber/Bedampfung}


Sputter Coater 108 auto

Thickness Controller MTM20

Plasma Cleaner PDC 32 G-2

\section{Plasmacleaner}

Cleaner PDC 32 G-2

\section{Rasterelektronenmikroskop}

Supra $^{\text {TM }} 55 \mathrm{VP}$

\section{Reinstwasseranlage}

Milli-Q Gradient A10

Milli-Q Elix 5

\section{Sonstige Geräte}

Feinwaage

Frequenzgenerator Agilent 33220A

Magentrührer MR $3001 \mathrm{~K}$

pH-Meter Calimatic 766

Schwenker CAT ST5

Spannungsquelle DC Power Supply PS 280

Tip-Sonifier Sonoplus HD2070

Überkopfschüttler

Ultraschallbad Sonorex RK 255 H

Umluftofen N30/65HA

Vakuumtrockenschrank VD 23

Varian Cary Scan 50
Cressington Scientific Instruments (Watford, UK)

Cressington Scientific Instruments (Watford, UK)

Harrick (Ithaka, USA)

Harrick Plasma (Ithaca, USA)

Carl Zeiss (Jena)

Millipore (Eschborn)

Millipore (Eschborn)

Avesin (Ottawa, Kanada)

Agilent Technologies (Santa Clara, USA)

Heidolph (Schwabach)

Knick (Berlin)

Zipperer GmbH (Staufen)

Textronics (Beaverton, USA)

Bandelin (Berlin)

VWR International (Darmstadt)

Bandelin (Berlin)

Nabertherm (Lilienthal/Bremen)

Binder (Tuttlingen)

Agilent Technologies (Santa Clara, USA) 
Zellkultivierung und Proteinanalytik
Biostat E Typ E 5
B. Braun (Melsungen)
Biostat E Typ ES
B. Braun (Melsungen)
PerfectBlue ${ }^{\text {"m }}$ Vertikale Doppelgelsysteme
PEQLAB Biotechnologie GmbH, Erlangen
Trans-Blot ${ }^{\oplus}$ SD Semi-Dry
Bio-Rad Laboratories GmbH, München
Electrophoretic Transfer Cell
Schüttelschrank
Edmund Bühler GmbH (Hechingen)

\subsection{Software}

ZEN 2008

Carl Zeiss (Jena)

Origin $7 \mathrm{G}$

OriginLab Corporation

Clampfit 10.2

Axon Intruments (Union City, USA)

pClamp 10

Axon Intruments (Union City, USA)

\subsection{Nukleotidsequenzen}

\subsubsection{Connexin 43}

Connexin 43 (Expression in D. discoideum)

Struktur: HindIII Cx43 XbaI

5'-AAAATCAGATCCCAAGCTTAAAAAATGGGTGATTGGTCAGCATTAGGTAAA TTACTGGACAAGGTCCAAGCCTACTCCACGGCCGGAGGGAAGGTGTGGCTGT CGGTGCTCTTCATTTTCAGAATCCTGCTCCTGGGGACAGCGGTTGAGTCAGCT 
TGGGGTGATGAACAGTCTGCCTTTCGCTGTAACACTCAACAACCCGGTTGTGA AAATGTCTGCTATGACAAGTCCTTCCCCATCTCTCACGTGCGCTTCTGGGTCC TTCAGATCATATTCGTGTCTGTGCCCACACTCCTGTACTTGGCTCACGTGTTC TATGTGATGAGAAAGGAAGAGAAGCTGAACAAGAAAGAAGAGGAGCTCAAAGTG GCGCAGACCGACGGGGTCAACGTGGAGATGCACCTGAAGCAGATTGAAATCAA GAAGTTCAAGTATGGGATTGAAGAACACGGCAAGGTGAAGATGAGAGGTGGCC TGCTGAGAACCTACATCATCAGCATCCTCTTCAAGTCTGTCTTCGAGGTGGCC TTCCTGCTGATCCAGTGGTACATCTATGGGTTCAGCCTGAGTGCGGTCTACAC CTGCAAGAGAGATCCCTGCCCCCACCAGGTGGACTGCTTCCTCTCACGTCCCA CGGAGAAAACCATCTTCATCATCTTCATGCTGGTGGTGTCCTTGGTGTCTCTC GCTCTGAATATCATTGAGCTCTTCTATGTCTTCTTCAAGGGCGTTAAGGATCG CGTGAAGGGAAGAAGCGATCCTTACCACGCCACCACCGGCCCACTGAGCCCAT CCAAAGACTGCGGATCTCCAAAATATGCTTACTTCAATGGCTGCTCCTCACCAA CGGCCCCACTCTCACCTATGTCTCCTCCTGGGTACAAGCTGGTCACTGGTGAC AGAAACAATTCCTCCTGCCGCAATTACAACAAGCAAGCCAGCGAGCAAAACTGG GCGAATTACAGCGCAGAGCAAAATCGAATGGGGCAGGCCGGAAGCACCATCTC CAACTCCCACGCCCAGCCGTTTGATTTCCCTGACGACAGCCAAAATGCCAAAAA AGTTGCTGCTGGACACGAACTCCAGCCCTTAGCTATCGTGGATCAGCGACCTT CCAGCAGAGCCAGCAGCCGCGCCAGCAGCAGACCTCGGCCTGATGACCTGGA GATTGCAGGATCCACTCGAGATGCATTACATCATCATCATCATCATCACCACTA AGTCTAGAGGATCAATTCAAGTTTTACCAT-3'

Connexin 43 (Expression in P. pastoris)

Struktur: EcoRI Cx43 XbaI

5'-AATAATGAATTCGAAACGATGGGTGACTGGAGCGCCTTGGGGAAGCTGCT GGACAAGGTCCAAGCCTACTCCACGGCCGGAGGGAAGGTGTGGCTGTCGGTG CTCTTCATTTTCAGAATCCTGCTCCTGGGGACAGCGGTTGAGTCAGCTTGGGG TGATGAACAGTCTGCCTTTCGCTGTAACACTCAACAACCCGGTTGTGAAAATGT CTGCTATGACAAGTCCTTCCCCATCTCTCACGTGCGCTTCTGGGTCCTTCAGA TCATATTCGTGTCTGTGCCCACACTCCTGTACTTGGCTCACGTGTTCTATGTG ATGAGAAAGGAAGAGAAGCTGAACAAGAAAGAAGAGGAGCTCAAAGTGGCGCAG ACCGACGGGGTCAACGTGGAGATGCACCTGAAGCAGATTGAAATCAAGAAGTT CAAGTATGGGATTGAAGAACACGGCAAGGTGAAGATGAGAGGTGGCCTGCTGA GAACCTACATCATCAGCATCCTCTTCAAGTCTGTCTTCGAGGTGGCCTTCCTG CTGATCCAGTGGTACATCTATGGGTTCAGCCTGAGTGCGGTCTACACCTGCAA GAGAGATCCCTGCCCCCACCAGGTGGACTGCTTCCTCTCACGTCCCACGGAGA AAACCATCTTCATCATCTTCATGCTGGTGGTGTCCTTGGTGTCTCTCGCTCTG AATATCATTGAGCTCTTCTATGTCTTCTTCAAGGGCGTTAAGGATCGCGTGAA GGGAAGAAGCGATCCTTACCACGCCACCACCGGCCCACTGAGCCCATCCAAAG ACTGCGGATCTCCAAAATATGCTTACTTCAATGGCTGCTCCTCACCAACGGCC CCACTCTCACCTATGTCTCCTCCTGGGTACAAGCTGGTCACTGGTGACAGAAA CAATTCCTCCTGCCGCAATTACAACAAGCAAGCCAGCGAGCAAAACTGGGCGAA 
TTACAGCGCAGAGCAAAATCGAATGGGGCAGGCCGGAAGCACCATCTCCAACT CCCACGCCCAGCCGTTTGATTTCCCTGACGACAGCCAAAATGCCAAAAAAGTTG CTGCTGGACACGAACTCCAGCCCTTAGCTATCGTGGATCAGCGACCTTCCAGC AGAGCCAGCAGCCGCGCCAGCAGCAGACCTCGGCCTGATGACCTGGAGATTCT AGAATATAT-3،

\subsubsection{Connexin 43-Grün fluoreszierendes Protein}

Cx43-eGFP (Expression in D. discoideum)

Struktur: HindIII Cx43 eGFP

5'-TTAAATTAAATAAAAAATAAAAATCAGATCCCAAGCTTAAAAAATGGGTGAT TGGTCAGCATTAGGTAAATTACTGGACAAGGTCCAAGCCTACTCCACGGCCGG AGGGAAGGTGTGGCTGTCGGTGCTCTTCATTTTCAGAATCCTGCTCCTGGGG ACAGCGGTTGAGTCAGCTTGGGGTGATGAACAGTCTGCCTTTCGCTGTAACAC TCAACAACCCGGTTGTGAAAATGTCTGCTATGACAAGTCCTTCCCCATCTCTCA CGTGCGCTTCTGGGTCCTTCAGATCATATTCGTGTCTGTGCCCACACTCCTGT ACTTGGCTCACGTGTTCTATGTGATGAGAAAGGAAGAGAAGCTGAACAAGAAAG AAGAGGAGCTCAAAGTGGCGCAGACCGACGGGGTCAACGTGGAGATGCACCTG AAGCAGATTGAAATCAAGAAGTTCAAGTATGGGATTGAAGAACACGGCAAGGTG AAGATGAGAGGTGGCCTGCTGAGAACCTACATCATCAGCATCCTCTTCAAGTC TGTCTTCGAGGTGGCCTTCCTGCTGATCCAGTGGTACATCTATGGGTTCAGCC TGAGTGCGGTCTACACCTGCAAGAGAGATCCCTGCCCCCACCAGGTGGACTGC TTCCTCTCACGTCCCACGGAGAAAACCATCTTCATCATCTTCATGCTGGTGGT GTCCTTGGTGTCTCTCGCTCTGAATATCATTGAGCTCTTCTATGTCTTCTTCA AGGGCGTTAAGGATCGCGTGAAGGGAAGAAGCGATCCTTACCACGCCACCACC GGCCCACTGAGCCCATCCAAAGACTGCGGATCTCCAAAATATGCTTACTTCAAT GGCTGCTCCTCACCAACGGCCCCACTCTCACCTATGTCTCCTCCTGGGTACAA GCTGGTCACTGGTGACAGAAACAATTCCTCCTGCCGCAATTACAACAAGCAAGC CAGCGAGCAAAACTGGGCGAATTACAGCGCAGAGCAAAATCGAATGGGGCAGG 
CCGGAAGCACCATCTCCAACTCCCACGCCCAGCCGTTTGATTTCCCTGACGAC AGCCAAAATGCCAAAAAAGTTGCTGCTGGACACGAACTCCAGCCCTTAGCTATC GTGGATCAGCGACCTTCCAGCAGAGCCAGCAGCCGCGCCAGCAGCAGACCTC GGCCTGATGACCTGGAGATTGCAGGATCCGTCGCCACCCCGGTGAGCAAGGG CGAGGAGCTGTTCACCGGGGTGGTGCCCATCCTGGTCGAGCTGGACGGCGAC GTAAACGGCCACAAGTTCAGCGTGTCCGGCGAGGGCGAGGGCGATGCCACCT ACGGCAAGCTGACCCTGAAGTTCATCTGCACCACCGGCAAGCTGCCCGTGCCC TGGCCCACCCTCGTGACCACCCTGACCTACGGCGTGCAGTGCTTCAGCCGCTA CCCCGACCACATGAAGCAGCACGACTTCTTCAAGTCCGCCATGCCCGAAGGCT ACGTCCAGGAGCGCACCATCTTCTTCAAGGACGACGGCAACTACAAGACCCGC GCCGAGGTGAAGTTCGAGGGCGACACCCTGGTGAACCGCATCGAGCTGAAGG GCATCGACTTCAAGGAGGACGGCAACATCCTGGGGCACAAGCTGGAGTACAAC TACAACAGCCACAACGTCTATATCATGGCCGACAAGCAGAAGAACGGCATCAAG GTGAACTTCAAGATCCGCCACAACATCGAGGACGGCAGCGTGCAGCTCGCCGA CCACTACCAGCAGAACACCCCCATCGGCGACGGCCCCGTGCTGCTGCCCGACA ACCACTACCTGAGCACCCAGTCCGCCCTGAGCAAAGACCCCAACGAGAAGCGC GATCACATGGTCCTGCTGGAGTTCGTGACCGCCGCCGGGATCACTCTCGGCA TGGACGAGCTGTACAAGGCTCGAGATGCATTACATCATCATCATCATCATCACC ACTAAGTCT-3'

Cx43-GFP (Expression in P. pastoris)

Struktur: EcoRI Cx43 GFP(S65T) SalI

5'-AATAATGAATTCGAAACGATGGGTGACTGGAGCGCCTTGGGGAAGCTGCT GGACAAGGTCCAAGCCTACTCCACGGCCGGAGGGAAGGTGTGGCTGTCGGTG CTCTTCATTTTCAGAATCCTGCTCCTGGGGACAGCGGTTGAGTCAGCTTGGGG TGATGAACAGTCTGCCTTTCGCTGTAACACTCAACAACCCGGTTGTGAAAATGT CTGCTATGACAAGTCCTTCCCCATCTCTCACGTGCGCTTCTGGGTCCTTCAGA TCATATTCGTGTCTGTGCCCACACTCCTGTACTTGGCTCACGTGTTCTATGTG ATGAGAAAGGAAGAGAAGCTGAACAAGAAAGAAGAGGAGCTCAAAGTGGCGCAG ACCGACGGGGTCAACGTGGAGATGCACCTGAAGCAGATTGAAATCAAGAAGTT CAAGTATGGGATTGAAGAACACGGCAAGGTGAAGATGAGAGGTGGCCTGCTGA GAACCTACATCATCAGCATCCTCTTCAAGTCTGTCTTCGAGGTGGCCTTCCTG CTGATCCAGTGGTACATCTATGGGTTCAGCCTGAGTGCGGTCTACACCTGCAA GAGAGATCCCTGCCCCCACCAGGTGGACTGCTTCCTCTCACGTCCCACGGAGA AAACCATCTTCATCATCTTCATGCTGGTGGTGTCCTTGGTGTCTCTCGCTCTG AATATCATTGAGCTCTTCTATGTCTTCTTCAAGGGCGTTAAGGATCGCGTGAA GGGAAGAAGCGATCCTTACCACGCCACCACCGGCCCACTGAGCCCATCCAAAG ACTGCGGATCTCCAAAATATGCTTACTTCAATGGCTGCTCCTCACCAACGGCC CCACTCTCACCTATGTCTCCTCCTGGGTACAAGCTGGTCACTGGTGACAGAAA CAATTCCTCCTGCCGCAATTACAACAAGCAAGCCAGCGAGCAAAACTGGGCGAA TTACAGCGCAGAGCAAAATCGAATGGGGCAGGCCGGAAGCACCATCTCCAACT CCCACGCCCAGCCGTTTGATTTCCCTGACGACAGCCAAAATGCCAAAAAAGTTG 
CTGCTGGACACGAACTCCAGCCCTTAGCTATCGTGGATCAGCGACCTTCCAGC AGAGCCAGCAGCCGCGCCAGCAGCAGACCTCGGCCTGATGACCTGGAGATTCT AGCCGCCACCATGAGCAAGGGCGAGGAACTGTTCACTGGCGTGGTCCCAATTC TCGTGGAACTGGATGGCGATGTGAATGGGCACAAATTTTCTGTCAGCGGAGAG GGTGAAGGTGATGCCACATACGGAAAGCTCACCCTGAAATTCATCTGCACCAC TGGAAAGCTCCCTGTGCCATGGCCAACACTGGTCACTACCTTCACCTATGGCG TGCAGTGCTTTTCCAGATACCCAGACCATATGAAGCAGCATGACTTTTTCAAGA GCGCCATGCCCGAGGGCTATGTGCAGGAGAGAACCATCTTTTTCAAAGATGAC GGGAACTACAAGACCCGCGCTGAAGTCAAGTTCGAAGGTGACACCCTGGTGAA TAGAATCGAGTTGAAGGGCATTGACTTTAAGGAAGATGGAAACATTCTCGGCCA CAAGCTGGAATACAACTATAACTCCCACAATGTGTACATCATGGCCGACAAGCA AAAGAATGGCATCAAGGTCAACTTCAAGATCAGACACAACATTGAGGATGGATC CGTGCAGCTGGCCGACCATTATCAACAGAACACTCCAATCGGCGACGGCCCTG TGCTCCTCCCAGACAACCATTACCTGTCCACCCAGTCTGCCCTGTCTAAAGATC CCAACGAAAAGAGAGACCACATGGTCCTGCTGGAGTTTGTGACCGCTGCTGGG ATCACACATGGCATGGACGAGCTGTACAAGGGTGTCGACGGTCTAGAATGG-3“

\subsection{Aminosäuresequenzen}

\subsubsection{Connexin 43}

Expression in D. discoideum

MGDWSALGKLLDKVQAYSTAGGKVWLSVLFIFRILLLGTAVESAWGDEQSAFRC NTQQPGCENVCYDKSFPISHVRFWVLQIIFVSVPTLLYLAHVFYVMRKEEKLNKKEE ELKVAQTDGVNVEMHLKQIEIKKFKYGIEEHGKVKMRGGLLRTYIISILFKSVFEVAF LLIQWYIYGFSLSAVYTCKRDPCPHQVDCFLSRPTEKTIFIIFMLVVSLVSLALNIIELFY VFFKGVKDRVKGRSDPYHATTGPLSPSKDCGSPKYAYFNGCSSPTAPLSPMSPPGYKL VTGDRNNSSCRNYNKQASEQNWANYSAEQNRMGQAGSTISNSHAQPFDFPDDSQ NAKKVAAGHELQPLAIVDQRPSSRASSRASSRPRPDDLEIAGSTRDALHHHHHHHH

Expression in P. pastoris

MGDWSALGKLLDKVQAYSTAGGKVWLSVLFIFRILLLGTAVESAWGDEQSAFRC NTQQPGCENVCYDKSFPISHVRFWVLQIIFVSVPTLLYLAHVFYVMRKEEKLNKKEE ELKVAQTDGVNVEMHLKQIEIKKFKYGIEEHGKVKMRGGLLRTYIISILFKSVFEVAF LLIQWYIYGFSLSAVYTCKRDPCPHQVDCFLSRPTEKTIFIIFMLVVSLVSLALNIIELFY VFFKGVKDRVKGRSDPYHATTGPLSPSKDCGSPKYAYFNGCSSPTAPLSPMSPPGYKL VTGDRNNSSCRNYNKQASEQNWANYSAEQNRMGQAGSTISNSHAQPFDFPDDSQ NAKKVAAGHELQPLAIVDQRPSSRASSRASSRPRPDDLEILEQKLISEEDLNSAVDHH $\mathrm{HHHH}$ 


\title{
9.8.2 Connexin 43-Grün fluoreszierendes Protein
}

\author{
Expression in D. discoideum
}

MGDWSALGKLLDKVQAYSTAGGKVWLSVLFIFRILLLGTAVESAWGDEQSAFRC NTQQPGCENVCYDKSFPISHVRFWVLQIIFVSVPTLLYLAHVFYVMRKEEKLNKKEE ELKVAQTGVNVEMHLKQIEIKKFKYGIEEHGKVKMRGGLLRTYIISILFKSVFEVAFLL IQWYIYGFSLSAVYTCKRDPCPHQVDCFLSRPTEKTIFIIFMLVVSLVSLALNIIELFYVF FKGVKDRVKGRSDPYHATTGPLSPSKDCGSPKYAYFNGCSSPTAPLSPMSPPGYKLVT GDRNNSSCRNYNKQASEQNWANYSAEQNRMGQAGSTISNSHAQPFDFPDDSQNA KKVAAGHELQPLAIVDQRPSSRASSRASSRPRPDDLEIAGSVATPVSKGEELFTGVVPIL VELDGDVNGHKFSVSGEGEGDATYGKLTLKFICTTGKLPVPWPTLVTTLTYGVQCF SRYPDHMKQHDFFKSAMPEGYVQERTIFFKDDGNYKTRAEVKFEGDTLVNRIELKG IDFKEDGNILGHKLEYNYNSHNVYIMADKQKNGIKVNFKIRHNIEDGSVQLADHY QQNTPIGDGPVLLPDNHYLSTQSALSKDPNEKRDHMVLLEFVTAAGITLGMDELYK ARDALHHHHHHHH

Expression in P. pastoris

MGDWSALGKLLDKVQAYSTAGGKVWLSVLFIFRILLLGTAVESAWGDEQSAFRC NTQQPGCENVCYDKSFPISHVRFWVLQIIFVSVPTLLYLAHVFYVMRKEEKLNKKEE ELKVAQTDGVNVEMHLKQIEIKKFKYGIEEHGKVKMRGGLLRTYIISILFKSVFEVAF LLIQWYIYGFSLSAVYTCKRDPCPHQVDCFLSRPTEKTIFIIFMLVVSLVSLALNIIELFY VFFKGVKDRVKGRSDPYHATTGPLSPSKDCGSPKYAYFNGCSSPTAPLSPMSPPGYKL VTGDRNNSSCRNYNKQASEQNWANYSAEQNRMGQAGSTISNSHAQPFDFPDDSQ NAKKVAAGHELQPLAIVDQRPSSRASSRASSRPRPDDLEILAATMSKGEELFTGVVPIL VELDGDVNGHKFSVSGEGEGDATYGKLTLKFICTTGKLPVPWPTLVTTFTYGVQCF SRYPDHMKQHDFFKSAMPEGYVQERTIFFKDDGNYKTRAEVKFEGDTLVNRIELKG IDFKEDGNILGHKLEYNYNSHNVYIMADKQKNGIKVNFKIRHNIEDGSVQLADHY QQNTPIGDGPVLLPDNHYLSTQSALSKDPNEKRDHMVLLEFVTAAGITHGMDELY KGVDHHHHHH 


\subsection{Vektoren}

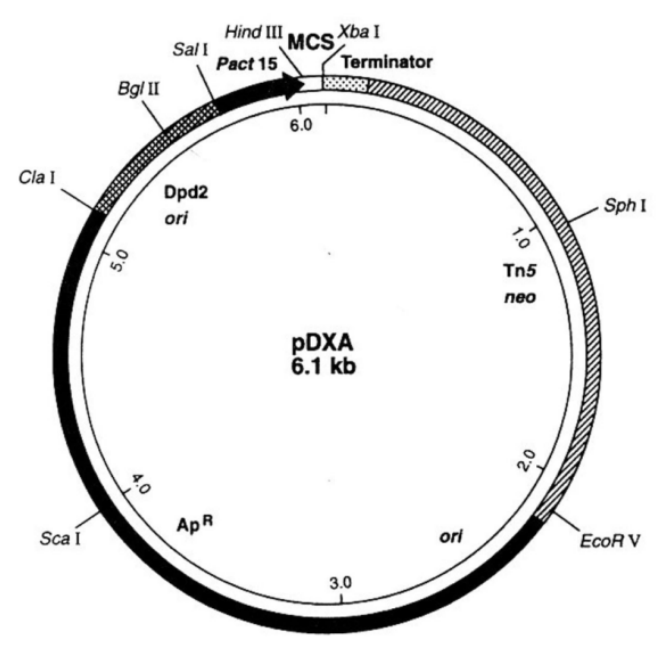

DDXA-3H:

KPnI SaCl BOMHI Xhol Ns/I

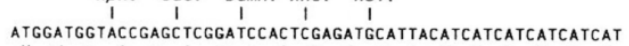

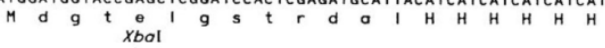
$\underset{H}{\text { CACCACIAAGTCIAGA }}$

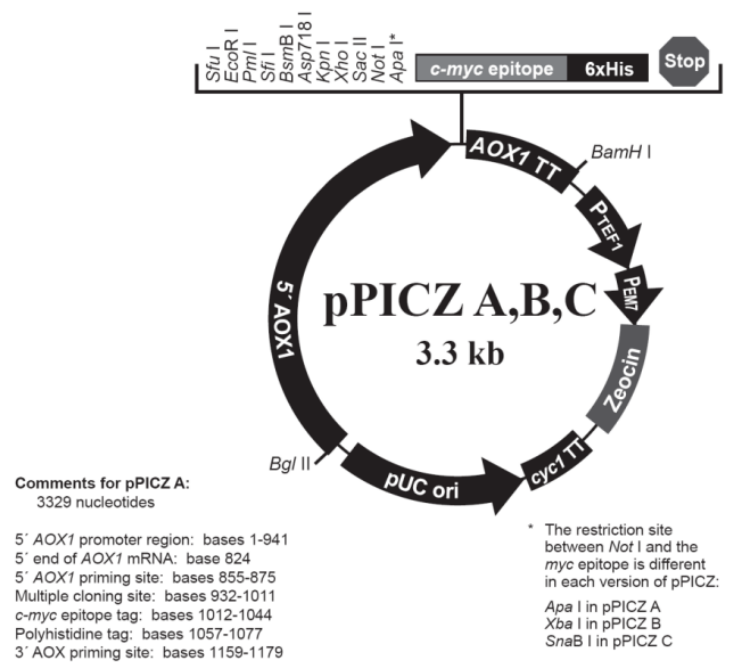

bases 1057-1077

3 ' end of mRNA: base 1250

AOX1 transcription termination region: bases $1078-1418$

Fragment containing TeF 1 promoter: bases $1419-1830$

EM7 promoter: bases $1831-1898$

CYC1 transcription termination region: bases 2274-2591

pUC origin: bases 2602-3275 (complementary strand) 


\section{Danksagung}

Zunächst möchte ich Prof. Dr. Claudia Steinem für das entgegengebrachte Vertrauen, dieses aktuelle und vielseitige Thema gemeinsam anzugehen, danken. Die Atmosphäre der Arbeitsgruppe erlaubt es stets, neue Ideen zu entwickeln und umzusetzen.

Prof. Dr. Christian Griesinger gilt mein Dank für die Übernahme des Korreferats.

Dr. Christoph Methfessel und Dr. Volker Möhrle danke ich für die Bereitstellung der P. pastoris Klone sowie sehr viele gute Ratschläge für die Umsetzung der Kultivierung in Göttingen.

Bei Dr. Niels Fertig und Dr. Mohammed Kreir von Nanion Technologies GmbH möchte ich mich für die ausgezeichnete Zusammenarbeit in der elektrophysiologischen Charakterisierung von $\mathrm{Cx} 43$ und $\mathrm{Cx} 43-\mathrm{GFP}$ bedanken.

Außerdem bedanke ich mich bei der Arbeitsgruppe von Prof. Dr. Motumo Tanaka für die Bereitstellung der D. discoideum Klone.

Prof. Dr. Gina E. Sosinsky und Cinzia Ambrosi von der UCSD danke ich für die Bereitstellung von Cx26 und für die Durchführung der Transmissionselektronenmikroskopie.

Außerdem bedanke ich mich bei der Arbeitsgruppe Prof. Dr. Ficner (GZMB) und der Arbeitsgruppe Prof. Dr. Lührmann (MPI für biophysikalische Chemie) für die Bereitstellung und Hilfestellung bei den Aufschlussversuchen von P. pastoris. Ferner möchte ich mich beim Institut für Biochemie und Biotechnologie der Martin-Luther-Universität Halle-Wittenberg für die Nutzung der French Press bzw. der Hilfestellung von Dr. Nils Drechsler beim Aufschluss von P. pastoris bedanken. Desweiteren danke ich Dr. Oliver Valerius (Institut für Mikrobiologie und Genetik) für die exzellente Zusammenarbeit zum Nachweis von Cx43 und Cx43-GFP durch ESI-MS.

Weiter möchte ich mich bei Dany, Ole, Daniel, Conrad, Julia und Thomas für das schnelle und sorgfältige Korrekturlesen meiner Arbeit bedanken.

Bei meinem Diplomanden Lando und meinen Bachelorstudenten Marcel und Andrea möchte ich mich für die ergiebige Arbeit bedanken. Es hat mir große Freude bereitet, mit euch 
im Labor zu arbeiten. Durch eure Arbeit habt ihr einen wesentlichen Beitrag zu meiner Arbeit geleistet.

Bei Thomas bedanke ich mich für die erfolgreiche Zusammenarbeit bei der Entwicklung der hydrophilen Funktionalisierung der AAOs und dem GUV Spreiten. Es war wirklich schön, mit dir zusammenzuarbeiten und unsere Deutsch- und Englischkenntnisse zu erweitern.

Jutta, Hans-Jörg und Micha danke ich für die Unterstützung bei der Kultivierung der verschiedenen Organismen sowie der täglichen Laborarbeit, wodurch viele Ideen bzw. Experimente sehr viel schneller umsetzbar waren. Bei Frau Dr. Schubert, Anja und Angela möchte ich mich für die Hilfestellung in der Zellkultur bedanken. Weiterhin möchte ich mich bei den Sekretärinnen für Ihre Hilfestellung in organisatorischen Fragestellungen bedanken.

Bei den Werkstätten der OC und PC möchte ich mich für die schnelle Umsetzung von Ideen bedanken, vor allem für die Hilfsbereitschaft von Herrn Thao.

Ferner möchte ich mich bei der gesamten Arbeitsgruppe für die freundliche Aufnahme bedanken. Es war wirklich eine sehr schöne Zeit mit euch zusammen. Danke für die lustigen Kaffeepausen, Messzeiten und Spaziergänge.

Meinem Freund Olli danke ich für die schöne gemeinsame Zeit in Labor 37, die oft mit viel Spaß und Freude an der Arbeit einherging. Es war eine tolle Zeit, gemeinsam dieses Projekt zu stämmen.

Weiter möchte ich mich bei allen Freunden aus Göttingen und denen, die über ganz Deutschland verteilt sind, bedanken. Ihr seid für uns da, wenn wir Unterstützung brauchen.

Meiner Familie danke ich für die Unterstützung auf meinem Lebensweg. Es war großartig, alle vereint auf unserer Hochzeit zu sehen.

Schließlich möchte ich mich besonders bei meiner Frau Anika bedanken. Wir haben uns entschieden, diese Reise des Lebens gemeinsam miteinander zu gehen und konnten auch nur zusammen soweit kommen. Nur mit dir kann ich meine alltäglichen Träume und Ideen umsetzen, die andere in den Wahnsinn treiben würden. Du gibst mir die Energie, mehr zu geben als ich eigentlich leisten kann. Nur gemeinsam ist das Erlebte etwas wert und ich freue mich auf das, was da noch kommt. 


\section{Lebenslauf}

Christian Carnarius

Geboren am 15.12.1982 in Magdeburg

Deutsch

\section{SCHULAUSBILDUNG}

09/1989-07/1993 Grundschule „Weitlingstraße“, Magdeburg

09/1993-07/2002 Allgemeine Hochschulreife (Gesamtnote: 1,9)

Integrierte Gesamtschule „Willy Brandt“, Magdeburg

\section{ZIVILDIENST}

10/2002-07/2003 Bahnhofsmission Magdeburg

\section{STUDIUM}

10/2003 Beginn des Studiums der Biochemie an der Martin-Luther-Universität Halle-Wittenberg

07/2006-09/2006 Forschungsgruppenpraktikum am Institut für Biochemie und Biotechnologie an der Martin-Luther-Universität Halle-Wittenberg

Thema: „Überexpression des humanen Peptidtransporters PEPT1 in verschiedenen Escherichia coli-Stämmen"

10/2007 - 07/2008 Diplomarbeit am Institut für Biochemie und Biotechnologie an der MartinLuther-Universität Halle-Wittenberg

Thema: "Funktionelle Rekonstitution des Neuropeptid $Y Y_{I}$ Rezeptors in Nanodiscs"

08/2008 Diplom Biochemie (Gesamtnote: Sehr Gut)

\section{DISSERTATION}

Seit 09/2008

Promotion am Institut für Organische und Biomolekulare Chemie an der Georg-August-Universität in Göttingen

Thema: „Funktionelle Rekonstitution von Connexonen in artifizielle Membranen: Expression, Reinigung und Charakterisierung von Connexin 43" 
Lazzara T. D., Carnarius C., Kocun M., Janshoff A., Steinem C., (2011), Separating attoliter-sized compartments using fluid pore-spanning lipid-bilayers, ACS Nano 5, 6935-6944.

Carnarius C., Kreir M., Krick M., Methfessel C., Moehrle V., Valerius O., Brüggemann A., Steinem C., Fertig N., (2012), Green fluorescent protein changes the conductance of Connexin 43 (Cx43) hemichannels reconstituted in planar lipid bilayers, J. Biol. Chem. 287, 2877-2886.

\section{TAGUNGSBEITRÄGE/KONFERENZEN}

07/2009 Poster: "Expression and reconstitution of connexin 43 in pore-suspending membranes", $7^{\text {th }}$ European Biophysics Congress, Genua, Italien

03/2010 Poster: "Expression and reconstitution of connexin 43 and connexin 43GFP in pore-suspending membranes”, International Workshop: „The role of heterogeneity and asymmetry of membranes for their biological function", Gomadingen, Deutschland

04/2010 Poster: "Expression and reconstitution of connexin 43 and connexin 43GFP in pore-suspending membranes", Frühjahrssymposium des JungChemikerForums, Göttingen, Deutschland

10/2010 Poster: "Analysis of gap junction formation in vitro: A case study of connexin 43", Annual Meeting of the German Biophysical Society, Bochum, Deutschland

$11 / 2010$

Optical Imaging Workshop, Göttingen, Deutschland

$02 / 2011$

$07 / 2011$

$4^{\text {th }}$ Halle Conference on Recombinant Protein Production, Halle/Saale, Deutschland

Poster: "Expression, reconstitution and electrophysiological analysis of connexin 43", JungChemikerForum, Göttingen, Deutschland

\section{LEHRTÄTIGKEIT}

04/2009-04/2012 Assistent im Praktikum „Biomolekulare Chemie“ im Diplom- und Masterstudiengang

Übungsassistent der Vorlesung „Einführung in die Biomolekulare Chemie“ im Bachelorstudiengang Chemie

03/2010 - 02/2012 Einführung und Betreuung von Diplom- und Bachelorkandidaten 

